\title{
IMPROVING INTEGRATION OF SEISMIC RETROFIT AND ARCHITECTURE IN UNREINFORCED MASONRY BUILDINGS
}

BY

NABIL ALLAF

A thesis submitted to the Victoria University of Wellington

in fulfilment of the requirements for the degree of

Doctor of Philosophy

in Architecture

Victoria University of Wellington

2018 



\begin{abstract}
This thesis bridges architecture and seismic engineering. These two disciplines, despite being closely interrelated especially in earthquake-prone countries like New Zealand, often operate separately. This observation is particularly relevant when examining the integration of seismic retrofit and architecture. While technical solutions along with design methodologies and legislation have been continuously improved over the last decades, the relationship between architecture and seismic retrofit remains overlooked.
\end{abstract}

An acknowledgment that architecture is a legitimate component of seismic retrofit design introduces the potential for retrofitted buildings to reach both adequate earthquake resistance and even have enhanced architecture quality. Some retrofit guidance documents draw attention to architecture, yet their approaches, commonly taking the form of guidelines or recommendations, focus on maintaining buildings' existing features. Little reflection on the integration of seismic retrofit and the architectural qualities of existing buildings is given. This leaves an unexplored area regarding the architectural impact seismic structure may have on existing buildings, whether negative, neutral, or positive.

In this context, the thesis investigates the following question: How can the integration of seismic retrofit and architecture be improved?

Such an inquiry requires an understanding of the practice of seismic retrofit through both structural engineering and architectural perspectives. To respond to the research question, the study utilises a qualitative research methodology using a multiple case study strategy. This includes the collection of building documentation, visits to selected seismically retrofitted unreinforced masonry buildings, and interviews with their architects and structural engineers.

The thesis starts by reviewing the literature on the relationship between structure and architecture. Several authors emphasise how a structure's capacity to exceed its technical tasks by engaging with architecture can result in enriched projects. Following the transposition of generic relationships between structure and architecture into the context of seismic retrofit, the study explores the issue of integration in a 'real-life context' through five case studies. Each is investigated through the perspectives of architecture, seismic structure and design practice. The conditions and factors influencing integration are identified so awareness and recommendations can be made to introduce designers to new ways of approaching seismic retrofit design. 
The main conclusion of this research is that while integration between seismic retrofit and architecture can be improved, no standard solution applicable to all retrofit projects exists. Indeed, the thesis highlights the complexity of integration which is a combination of many variables. These variables include among others, time of involvement of the architect, type of seismic structure, and extent of interior refurbishment. Designers need to be aware of certain conditions and positive factors they can draw upon for successful integration as well as negative ones they should avoid. 
I dedicate this thesis to my beloved family.

My parents, Karim and Vicenta,

My brother Raoul,

And my sister, Tamara. 
PAGE LEFT INTENTIONALLY BLANK 


\section{ACKNOWLEDGMENTS}

First and foremost, I would like to express my deepest gratitude to my first supervisor and mentor, Associate Professor Andrew Charleson. A few years ago, he offered me an exceptional opportunity to work with him as a research assistant, and this inspiring collaboration motivated me to start a $\mathrm{PhD}$. His expertise, guidance, patience, trust and ongoing encouragements have made the achievement of this thesis possible. For all this, I consider myself very fortunate and would like to truly thank him.

I also thank my co-supervisor Professor Regan Potangaroa, whose knowledge and experience on seismic and disasters provided helpful advices to the thesis. To my former secondary supervisor, Senior Lecturer Mark Southcombe, and administrative supervisor, Associate Professor Michael Donn, thank you for the help during the refinement of the Research Proposal.

I want to thank the Victoria University of Wellington (VUW) and the School of Architecture and Design, in particular their administration and technical staff for their assistance and availability, especially Selena Shaw, Philippe Campays, Allison Kay, Asmaa Bouhalba, Karena Ring, Hillary Reid, and computer specialists Stuart Milne and Eric Camplin.

I am extremely grateful to all the architects and structural engineers who participated in my study as well as the clients and building owners who allowed their buildings to serve as case studies.

I would like to express my gratitude to Senior Lecturer Guy Marriage and Dr Remy Leblanc who assisted me in proofreading and commenting upon my thesis.

I wish to mention my wonderful fellow PhD colleagues, Anastasia Globa, Maryam Lesan, Esther Van Dijk, Birgit Bachler, Ensiyeh Ghavampour, and Karen Henning-Hansen. Their support and friendship throughout these years made this journey unique and memorable. Thanks also to all my friends, in New Zealand and overseas.

Finally, and most importantly, to my dear family, your love and support helped me face the most difficult times. This thesis would never have been achieved without you. I love you so much. 
PAGE LEFT INTENTIONALLY BLANK 


\section{TABLE OF CONTENTS}

ABSTRACT i

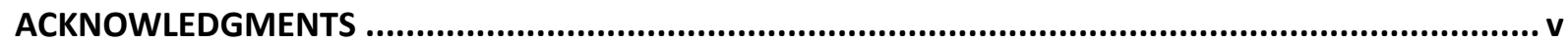

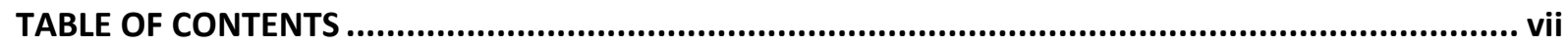

LIST OF FIGURES

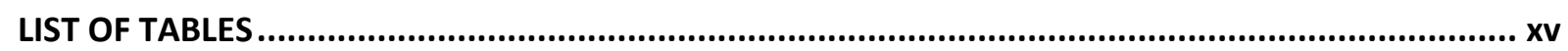

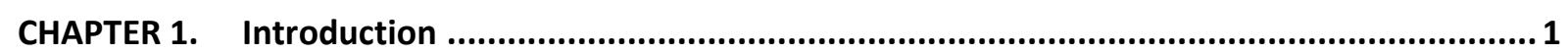

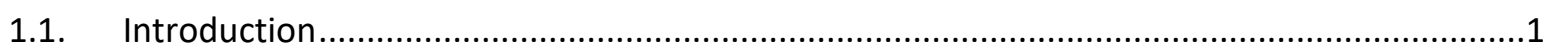

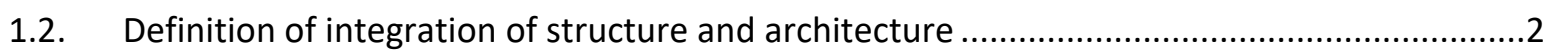

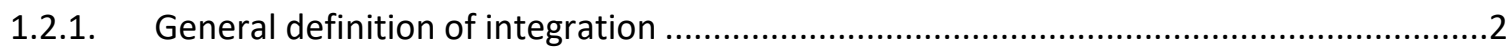

1.2.2. Implications of integration in a seismic retrofit context................................................

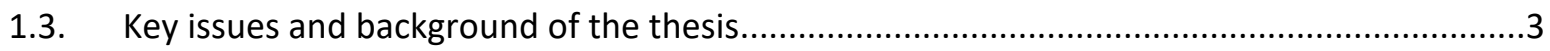

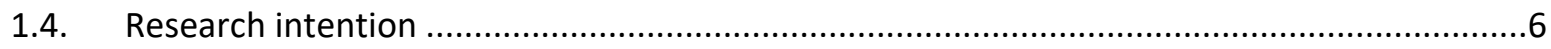

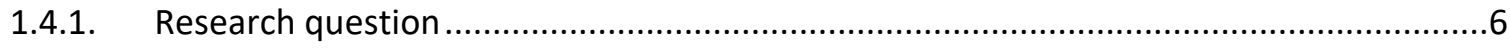

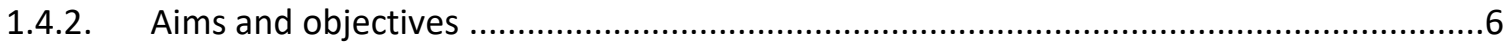

1.5. Overall data collection strategy and research settings ....................................................

1.5.1. Exploring integration through seismically retrofitted buildings and seismic retrofit

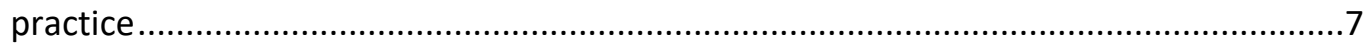

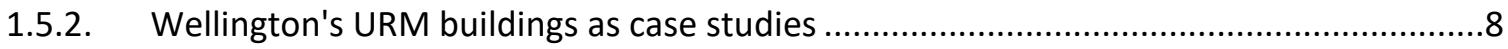

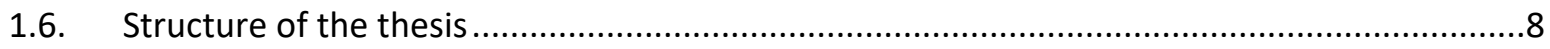

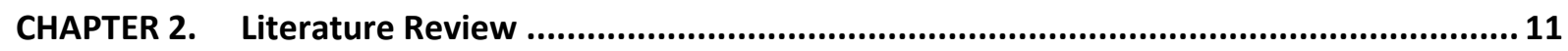

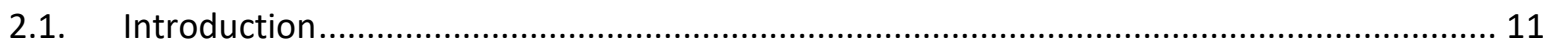

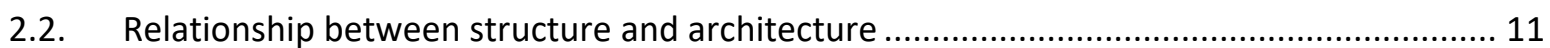

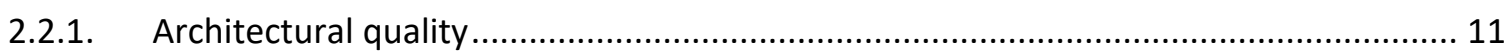

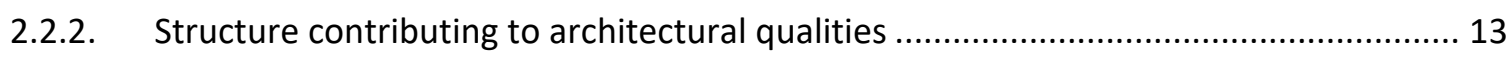

2.2.3. Collaboration between architects and structural engineers .......................................... 15

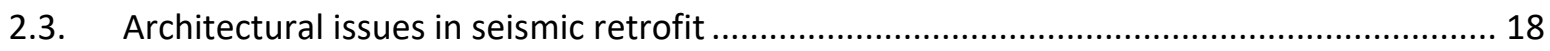

2.3.1. Architectural considerations in non-heritage buildings ............................................ 18

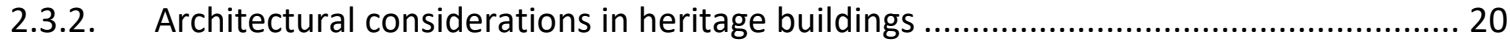

2.3.3. Issues regarding architectural considerations in seismic retrofit .................................. 24

2.4. Interaction between seismic retrofit structure and architectural quality ........................... 25

2.4.1. Seismic retrofit structure contributing to existing architecture .................................. 25

2.4.2. Impact of seismic retrofit on the architecture of a building .......................................... 28 


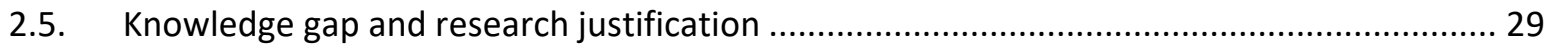

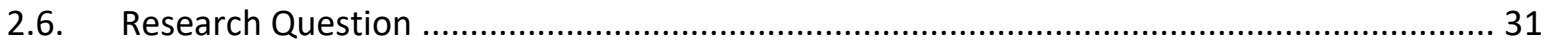

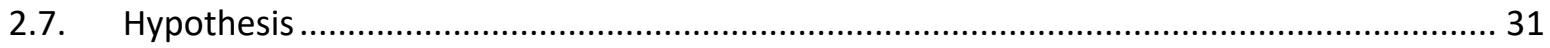

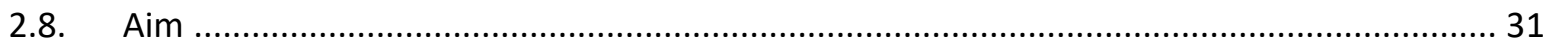

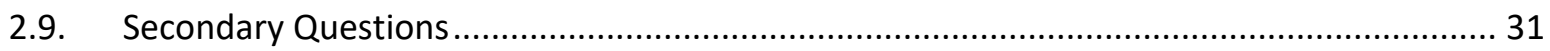

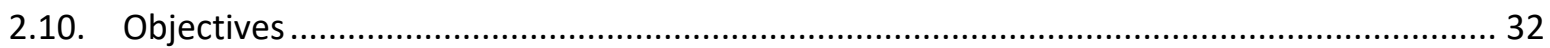

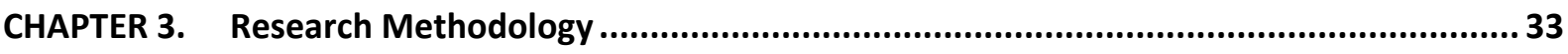

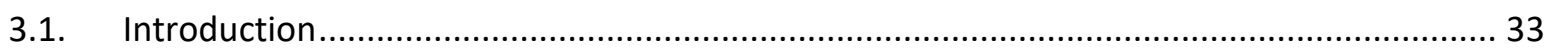

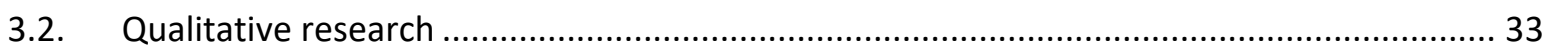

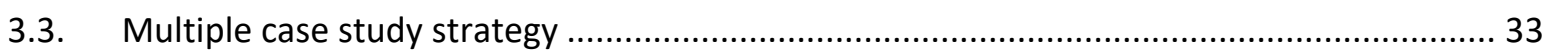

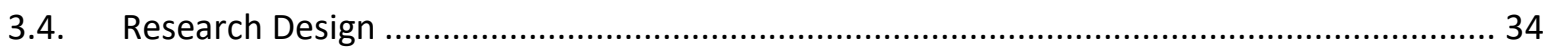

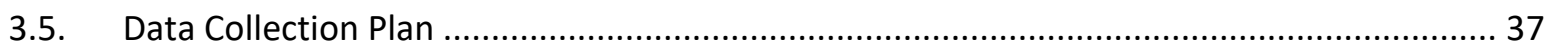

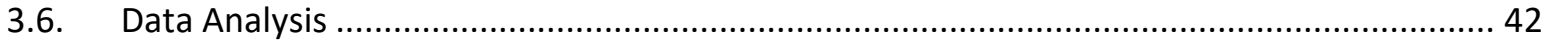

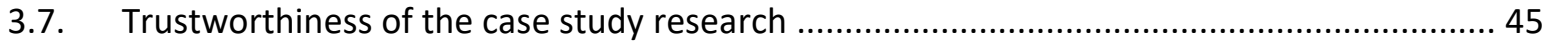

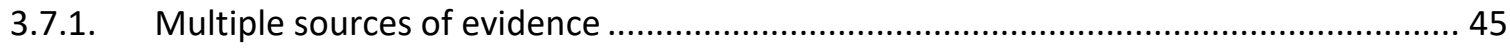

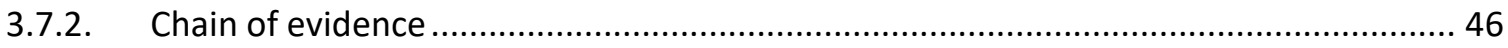

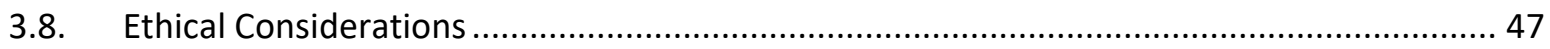

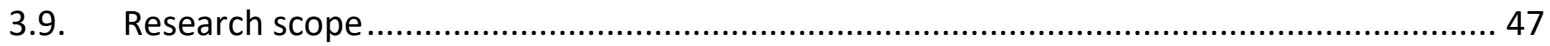

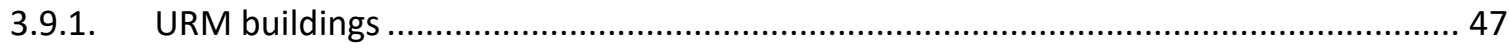

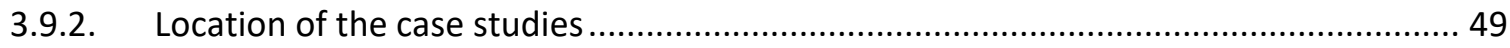

3.9.3. Selection and characteristics of the case studies...................................................... 52

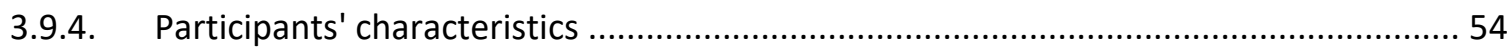

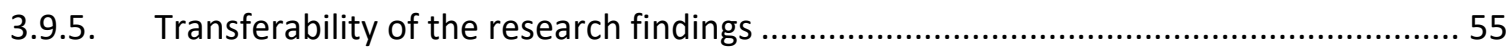

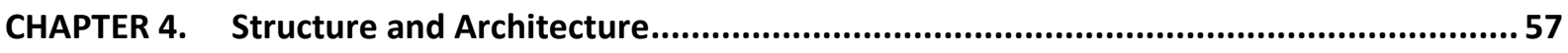

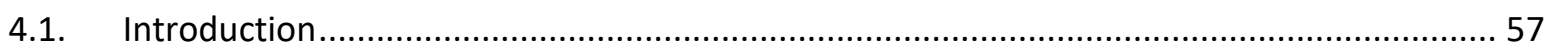

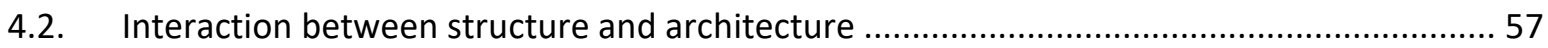

4.2.1. Selecting the appropriate approach in identifying architectural qualities related to

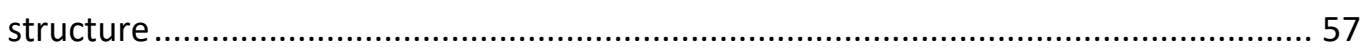

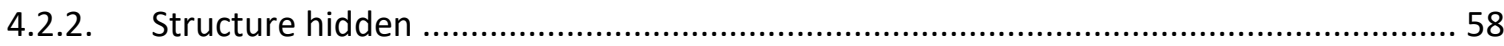

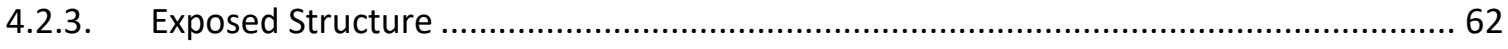

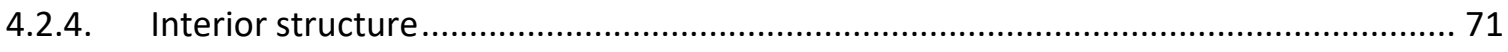

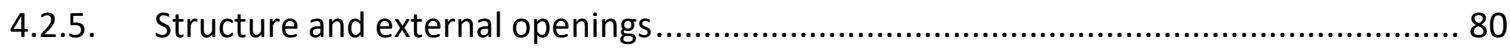

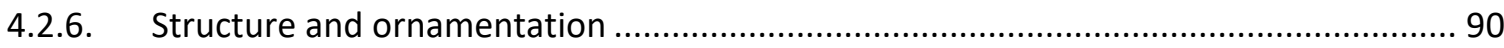

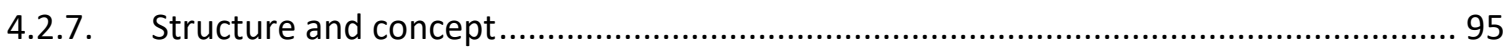


4.2.8. Summary

4.3. Integration of seismic retrofit and existing architecture ............................................... 100

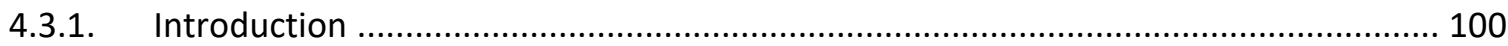

4.3.2. Architectural considerations of seismic structure .................................................. 100

4.3.3. Main relationships between seismic structure and existing architecture ................... 102

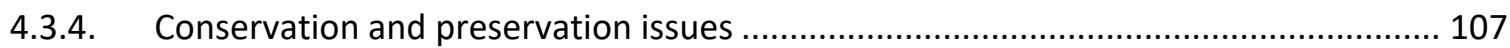

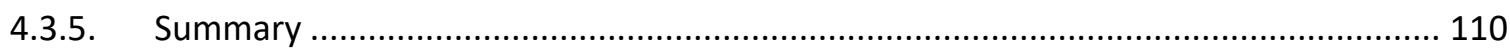

4.4. List of architectural qualities relevant to the seismic retrofit context............................... 111

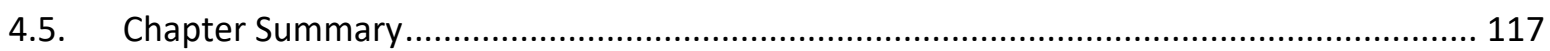

CHAPTER 5. Analysis of the Seismic Systems in the Five Retrofitted URM Buildings (\#1-\#5)...... 119

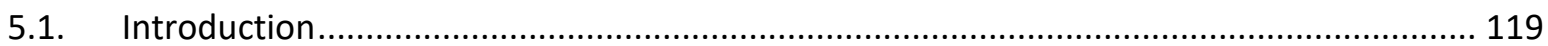

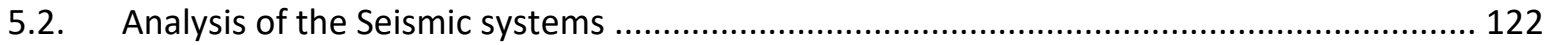

5.2.1. Shear wall (Buildings \#1, \#2, \#3, \#4) ...................................................................... 122

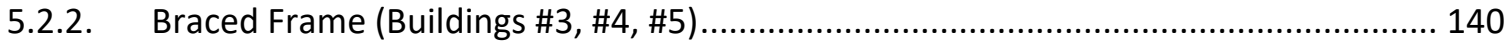

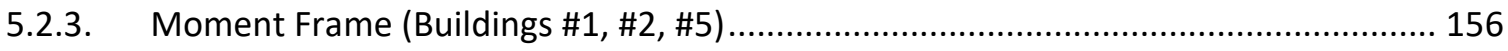

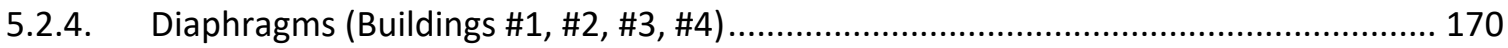

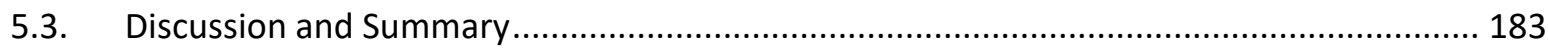

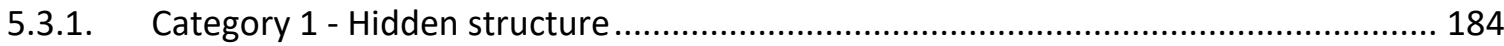

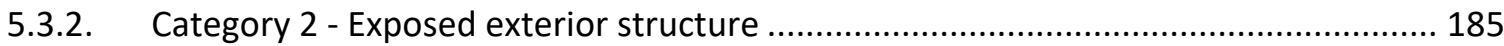

5.3.3. Category 3 - Exposed interior structure ….............................................................. 185

5.3.4. Category 4 - Interaction with external openings ….................................................. 186

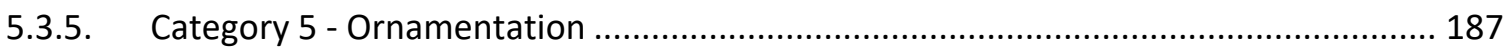

5.3.6. Category 6 - Expression of an architectural concept ................................................ 187

5.3.7. Category 7 - Conservation and preservation principles .............................................. 188

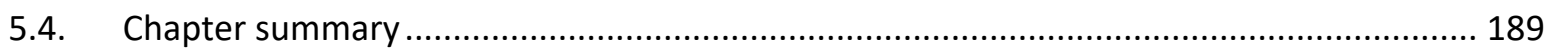

CHAPTER 6. Interviews of the Architect and Structural Engineer of the Five Case Studies......... 191

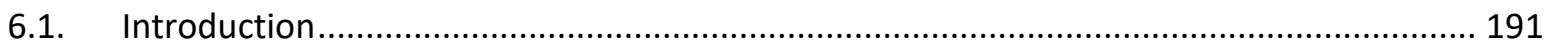

6.2. Designers' opinions on integration of seismic retrofit and architecture ............................ 192

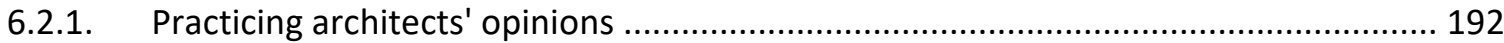

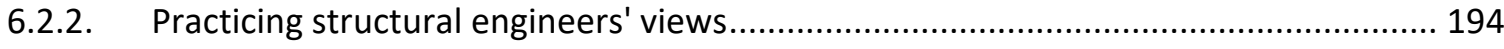

6.2.3. Summary of the designers' definitions of integration ............................................... 197

6.2.4. Designers' suggestions to improve integration.......................................................... 198

6.2.5. Summary of the designers' solutions for successful integration ................................ 201

6.3. Designers' reflections on their seismic retrofit projects and their design processes ......... 202 
6.3.1. Integration in the seismically retrofitted buildings - Building \#1 …........................... 203

6.3.2. Integration in the seismically retrofitted buildings - Building \#2 .............................. 215

6.3.3. Integration in the seismically retrofitted buildings - Building \#3 .............................. 227

6.3.4. Integration in the seismically retrofitted buildings - Building \#4 ............................... 239

6.3.5. Integration in the seismically retrofitted buildings - Building \#5 .................................. 252

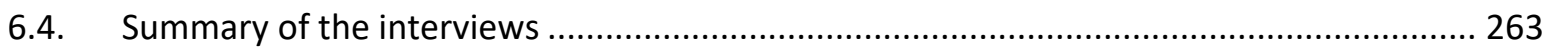

6.4.1. General factors influencing integration and designers' recommendations for

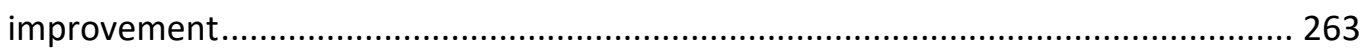

6.4.2. Factors influencing integration in the five URM buildings........................................ 265

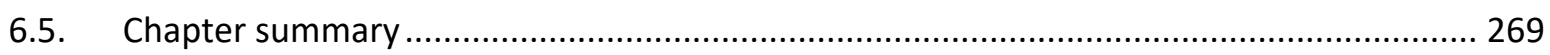

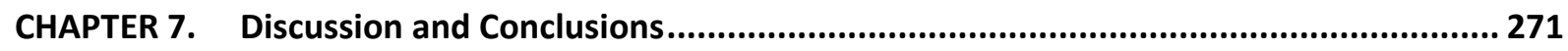

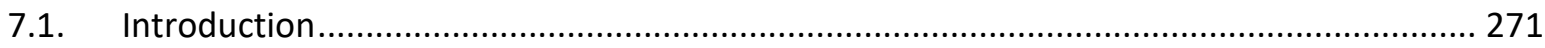

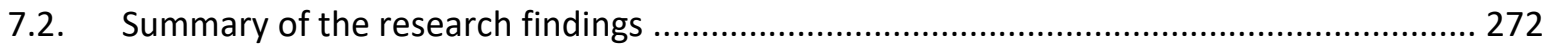

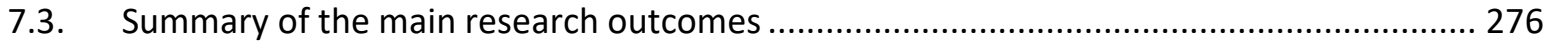

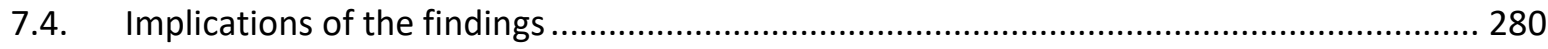

7.4.1. Architectural awareness regarding seismic retrofit structure .................................... 280

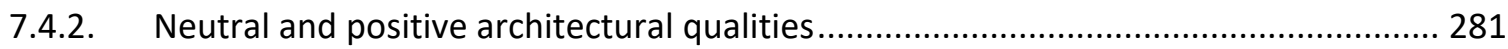

7.4.3. Reconsideration of conservation and preservation principles .................................. 282

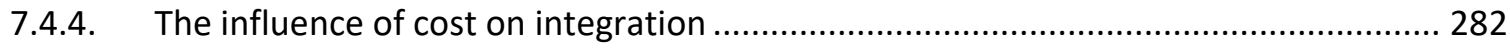

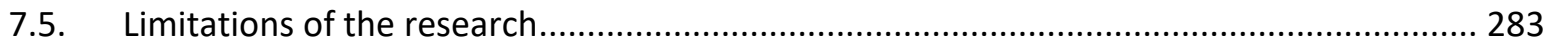

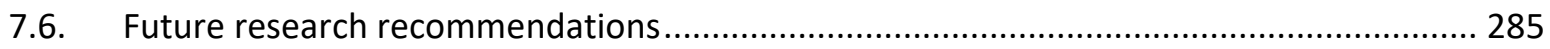

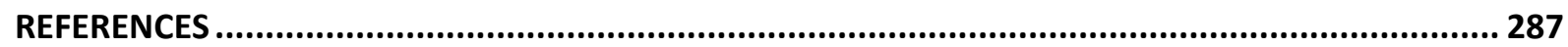

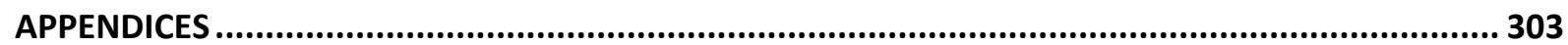

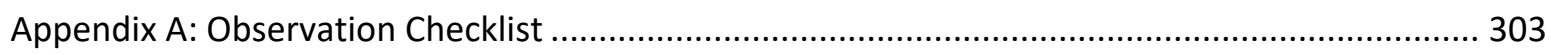

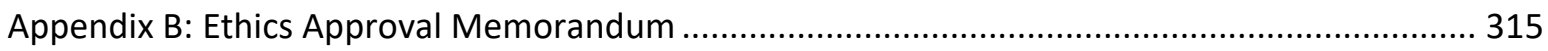

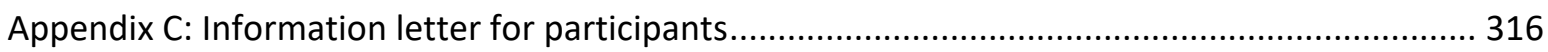

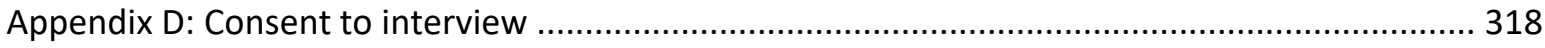

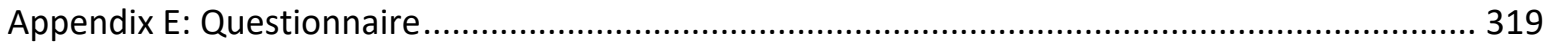




\section{LIST OF FIGURES}

Figure 1. Diagram illustrating the four stages of the research study

Figure 2. Capacity chain presenting a hierarchy of vulnerability among URM building components (Source: NZSEE et al., 2017) ...

Figure 3. Different in-plane failure modes of a laterally loaded URM wall.....

Figure 4. Map of New Zealand with the seismic risk areas based on the seismic hazard factor ' $Z$ ' (Source: MBIE, 2016, p. 52).

Figure 5. Guggenheim Museum (Source: http://wordpress.com, accessed April 2015)..... 59

Figure 6. Patrick Autocare (Source: http://dna-architects.com.au, accessed April 2018) 60

Figure 7. Cube Houses (Sources: https://www.archdaily.com and http://www.hiddenarchitecture.net, accessed April 2018).....

Figure 8. Bus station of Cáceres (Sources: http://www.spainisculture.com and http://www.justogarcia.com, accessed April 2018).

Figure 9. Lake Shore Drive (Source: https://www.e-architect.co.uk, accessed May 2015)

Figure 10. Lloyds headquarters (Source: http://www.londonarchitectureblog.com, accessed May 2015)

Figure 11. Exhibition hall (Source: https://structurae.net, accessed June 2017)

Figure 12. Macquarie Bank building (Source: https://www.fitzpatrickpartners.com, accessed April 2018)

Figure 13. House of Cedar (Source: https://divisare.com, accessed April 2018).....

Figure 14. Palace of Labour (Source: Cresciani \& Forth, 2014, p. 60) 68

Figure 15. Entrance of the 30 St Mary Axe building (Source: http://miesarch.com, accessed April 2018).

Figure 16. Hong Kong and Shanghai Bank (Source: http://keywordsuggest.org, accessed April 2018).......

Figure 17. Model of the Sendai Mediatheque (Source: http://www.harvarddesignmagazine.org, accessed April 2018).....

Figure 18. From implicit to explicit space (Source: Von Meiss, 1990, p. 102)......

Figure 19. Variation of spatial enclosure created by vertical structures (Source: Ching, 2007, p.

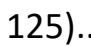

Figure 20. Structural layouts and their impacts on space (Source: Ogg, 1987, p. 49)

Figure 21. Solomon R. Guggenheim Museum (Sources: Weston, 2004, p. 89 and https://wsimag.com, accessed April 2008).

Figure 22. Baroque Museum (Source: https://www.dezeen.com, accessed April 2018) 
Figure 24. 15th floor plan of the 30 St Mary Axe building (Source:

http://www.harvarddesignmagazine.org, accessed April 2018)

Figure 25. Entrance of the Ufan Museum (Source: https://a2.cdn.japantravel.com, accessed April 2018).

Figure 26. North Colonnade of the Stabian Baths (Source: http://www.pompeiiinpictures.com, accessed April 2018).

Figure 27. Crystal Palace Sports Centre (Sources: http://www.justinnichollsarchitect.com and http://thetrianglese19.blogspot.co.nz, accessed April 2018)

Figure 28. Castelvecchio Museum (Sources: https://rivaspring2016.wordpress.com and https://www.flickr.com/photos/yeh-tom, accessed April 2018)....

Figure 29. Structure housing vertical circulation routes (Sources: http://leonamade.com and https://moreaedesign.wordpress.com, accessed April 2018).

Figure 30. Exterior of the Nelson-Atkins Museum of Art (Source: http://www.stevenholl.com, accessed April 2018).

Figure 31. Detail of the structural T-shape walls of the Nelson-Atkins Museum of Art (Source: http://www.stevenholl.com, accessed April 2018)

Figure 32. Interior of the Joe and Rika Mansueto Library (Source:

http://featuresblogs.chicagotribune.com, April 2018)

Figure 33. Genoa Subway Station (Source: http://www.rpbw.com, accessed May 2015).....

Figure 34. Castellón Auditorium and Conference Centre (Source:

http://www.sanahujapartners.com, accessed April 2018). 84

Figure 35. Termitary House (Source: https://www.archdaily.com, accessed April 2018)

Figure 36. Ito House (Source: Plummer, 2009, p. 225) 85

Figure 37. Locking Piece, Henry Moore, 1963-1964 (Source: Von Meiss, 1990, p. 125) 86

Figure 38. Rookery building (Sources: http://www.meganhurford.com and https://www.metalocus.es, accessed April 2018)

Figure 39. Skylight of the Solomon R. Guggenheim Museum (Sources:

http://www.romanovgrave.com, accessed April 2018)....

Figure 40. Interior of the Church of light with natural light visually emerging from the gap

between the ceiling and diagonal wall (Source: http://capsula.arq.br, accessed April 2018) 88

Figure 41. Diagonal walls intersecting the transversal wall of the Church of light (left) and Sunday School (right) (Sources: http://figure-ground.com and http://iwasky.blog.so-net.ne.jp, accessed April 2018).

Figure 42. Udden 6-7 house (Source: http://skalso.se, accessed April 2018)..... 90

Figure 43. Guaranty Building (Sources: http://www.bluffton.edu and http://www.skyscrapercity.com, accessed May 2015). 
Figure 44. Goldman and Salatsch building (Source: https://en.wikiarquitectura.com, accessed June 2017)

Figure 45. Waterloo International Terminal (Source: https://changehere.wordpress.com, accessed May 2015)

Figure 46. Lake Shore Drive Apartments (Source: http://www.archdata.org, accessed May 2015).... 95

Figure 47. Simmons Hall Residence (Sources: https://www.archute.com and https://en.wikiarquitectura.com, accessed April 2018).

Figure 48. Turning Torso sketch (left) and completed building (centre and right) (Sources: https://inhabitat.com and http://www.skyscrapercenter.com, accessed April 2018)

Figure 49. Veterans Affairs San Diego Medical centre with braced frames expressing an ornamental pattern (Sources: http://surgery.ucsd.edu and http://www.nyase.com, accessed July 2015).

Figure 50. California College of Arts and Crafts (Source: http://www.Imsarch.com, accessed July 2015).

Figure 51. Seismically retrofitted buildings (Left: Student apartments, Tokyo; Centre: Skinner Building, Seattle; Right: Office building, San Francisco) (Sources: Andrew Charleson, http://www.djc.com, accessed July 2015, and Charleson, 2008, p. 188)

Figure 52. Turnbull House - Reception Room (Left: transverse wall and its panelling that references the installation of the new seismic structure; Right: developed surface of the retrofitted room) (Source: Taylor et al., 2002, p. 46 \& 64).

Figure 53. Shed 13 with new concrete columns connected to existing trusses but separated from the URM walls (Sources: Cattanach, 2008, p. 8 and Author)

Figure 54. Turnbull House - Entrance Hall (Left: existing timber panel; centre: seismic system combining two layers of steel work; right: timber mouldings covering the ovoid perforations) (Source: Taylor et al., 2002, p. 19 \& 61)

Figure 55. Wallace F. Bennett Federal Building (Right: before retrofit; Left: After retrofit)

(Sources: http://www.reaveley.com and http://forum.skyscraperpage.com, accessed July 2015) .. 110

Figure 56. Installation of the braced frames in the Wallace F. Bennett Federal Building (Source:

Symans et al., 2008)

Figure 57. Colour code of the influence of seismic system on architectural quality

Figure 58. Ground floor plan of Building \#4 with shear walls (blue).

Figure 59. Front façade of Building \#4 with the shear wall visually matching the existing façade wall

Figure 60. Ground floor plans with the interior shear walls (blue) located at the entrance of Building \#2 (left) and in the car park of Building \#4 (right).

Figure 61. Ground floor plans with the interior shear walls (blue) exposed and contributing to the new interior elevations of Building \#1 (left) and of the bar of Building \#3 (right) 
Figure 62. Rear (top) and front (bottom) façades of Building \#4 with the shear walls masking existing windows at the ground floor

Figure 63. Ornamental exposed shotcreted shear wall running along the entire length of the bar of Building \#3.

Figure 64. Interior shear walls of Building \#4 displaying an ornamental pattern

Figure 65. Ground floor plan of Building \#1 with distinctive interior and exterior characters

Figure 66. Second-floor plan of Building \#4 with two braced frames (red)

Figure 67. Half of an eccentric braced frame located in a bedroom in Building \#3

Figure 68. Elevation of the V-braced frame creating a new motif in front of the existing pattern of the glazed wall in Building \#5

Figure 69. Eccentric braced frame emphasising the passage by framing the door

Figure 70. Extract of the ground floor plan of Building \#5 with the V-braced frame (red)

reinforcing the enclosure of the interior space

Figure 71. Extract of the first-floor plan of Building \#3 with half of an eccentric braced frame located in a bedroom in Building \#3

Figure 72. Ground floor plan of Building \#5 with the hidden moment frames (orange) delimiting different areas

Figure 73. Simplified elevation of the moment frame replicating the existing front façade.

Figure 74. Ground floor plan of Building \#1 with the moment frame (orange) emphasising the building's entrance and interior circulation

Figure 75. Exposed raw concrete moment frames and shear walls

Figure 76. Ground floor plans of Building \#1 before (left) and after (right) the seismic retrofit showing the interior spatial division

Figure 77. Second-floor ceiling plan of Building \#2 showing the location of the diagonal members of the cross-braces (green)

Figure 78. Second-floor plan of Building \#2 showing the location of the plywood panels (brown) ... 174

Figure 79. Detailing of the composite diaphragm used in Building \#1

Figure 80. Detailing of the cross-bracing connections in Building \#2

Figure 81. Section of Building \#1 showing the moment frames (orange), diaphragms (purple), and castellated beams located at the ground and first-floor 


\section{LIST OF TABLES}

Table 1. New Zealand URM Building Typologies (Source: Russell \& Ingham, 2010, p. 189).

Table 2. Characteristics of the five selected URM buildings

Table 3. Experience of the participants in terms of years of practice and number of seismic retrofit buildings

Table 4. Blank template of a Table of Analysis.

Table 5. Example of a summary table of architectural quality 2.1 Elevation with enhanced and neutral influences from two shear walls.

Table 6. Tables of Analysis representing the influences of the shear wall system on each architectural quality of Buildings \#1, \#2, \#3 and \#4

Table 7. Tables of Analysis representing the influences of the braced frame system on each architectural quality of Buildings \#3, \#4 and \#5

Table 8. Tables of Analysis representing the influences of the moment frame system on each architectural quality of Buildings \#1, \#2, and \#5

Table 9. Tables of Analysis representing the influences of the diaphragm systems on each architectural quality of Buildings \#1, \#2, \#3 and \#4

Table 10. Tables of Analysis representing the influences of the seismic systems of Building \#1 on architectural qualities.

Table 11. Table of Design Process: Main stakeholders and their time of involvement in Building $\# 1$.

Table 12. Tables of Analysis representing the influences of the seismic systems of Building \#2 on architectural qualities.

Table 13. Table of Design Process: Main stakeholders and their time of involvement in Building \#2.

Table 14. Tables of Analysis representing the influences of the seismic systems of Building \#3 on architectural qualities.

Table 15. Table of Design Process: Main stakeholders and their time of involvement in Building \#3.

Table 16. Tables of Analysis representing the influences of the seismic systems of Building \#4 on architectural qualities.

Table 17. Table of Design Process: Main stakeholders and their time of involvement in Building \#4.

Table 18. Tables of Analysis representing the influences of the seismic systems of Building \#5 on architectural qualities.

Table 19. Table of Design Process: Main stakeholders and their time of involvement in Building \#5. 
PAGE LEFT INTENTIONALLY BLANK 


\section{CHAPTER 1. INTRODUCTION}

\subsection{Introduction}

In New Zealand, existing buildings lacking appropriate seismic resistance require an upgrade to the building standards through seismic retrofit. Seismic retrofit is defined as "either structural strengthening or providing the means necessary to modify the seismic response that would otherwise be expected by an existing building during an earthquake, to significantly reduce hazards to life and safety while also providing for the substantial safe ingress and egress of the building occupants immediately after an earthquake" (CHSC, 2013).

Commonly, seismic retrofit requires the installation of one or several new structural systems in a building in order to enhance its capacity to withstand earthquakes. The presence of a seismic retrofit structure in an existing building usually introduces changes to the architecture. More generally, seismic retrofit questions the relationship and compatibility between the retrofit structure and the building's existing architecture. Indeed, many ill-fitting examples of seismic retrofit structure and existing architecture are found in the literature and are also directly observable in the city of Wellington. In many of these buildings, the seismic structure seems simply attached to the façade, with no relationship to the existing architecture. Often the structure passes in front of windows, or is offset from the axial symmetry of the existing façade, therefore disrupting the architectural elevation. This situation highlights a key issue: in wanting to help a building withstand damage or destruction from earthquakes, seismic retrofit might endanger the building's architecture. This observation raises the following questions: is there a better way to combine both seismic retrofit structure and existing architecture, and how?

Such an issue leads this research to undertake critical reflection on the integration of seismic retrofit and architecture, and explore the different factors that influence this relationship. This work will be undertaken in the context of unreinforced masonry buildings (URM). By understanding which factors reduce integration and which contribute to it, the research intends to help designers achieve a stronger and more coherent retrofit design in respect of both seismic retrofit and architecture. 


\subsection{Definition of integration of structure and architecture}

\subsubsection{General definition of integration}

As integration is a key component of the current research, it is necessary to ensure that its meaning is plainly understood and adapted to the research. The Oxford English Dictionary (n.d.) provides the following definition of integration:

"The making up or composition of a whole by adding together or combining the separate parts or elements; combination into an integral whole: a making whole or entire."

According to this definition, integration implies associating elements together so as their combination forms a sense of completeness. In other words, an entity can be fully appreciated as a whole through the composition of the different elements constituting it.

As integration implies the association of several elements together, it is often linked to the idea of coherence. The association of these two ideas is not fortuitous. Firstly, when looking at their synonyms we realise that they share some characteristics in common such as unity, unification, union, integrity or harmony. Secondly, if no coherence is noticeable between the elements composing an entity then they may hardly express its entirety. The following definition of coherence provided by the Oxford English Dictionary (n.d.) stresses this characteristic:

"Consistency in reasoning, or relating, so that one part of the discourse does not destroy or contradict the rest' (Johnson); harmonious connection of the several parts, so that the whole 'hangs together'."

Ensuring that coherence exists between integrated elements helps assist the message conveyed by the whole. In contrast, avoiding coherence in a design might lead to confusion or a misleading understanding of the message an entity seeks to express.

Transposed to the architectural context and the issue of the current research, integration relates to the combination of architecture and structure where both aspects are used to achieve, if not a finite object, at least an object expressing a whole. Both architectural and structural components relate to one another toward the expression of a single entity. This idea of a single entity relates to Fay Jones' (1999) recommendation for the need of an architecture in which the relationship between the parts and the whole is clearly expressed. This type of relationship aims at ensuring coherence through different scales between the components participating in the expression of the 
architectural concept. Jones' position is that integration alone does not necessarily lead to the achievement of a successful architectural project. A project is commonly driven by a design concept which expresses a message through the building's architecture. It is therefore essential to establish not only the integration of architectural and structural components but also to ensure that this integration makes sense - is coherent, regarding the intended architectural message.

\subsubsection{Implications of integration in a seismic retrofit context}

The idea of a 'whole' in the seismic retrofit context highlights a particular issue. When seismically retrofitting a building, new seismic structure is added in order to ensure appropriate resistance to earthquakes. The newly added structure joins a series of existing components including the actual load-bearing structure and architectural features that most likely already form a completed and finished building. This addition has therefore to be undertaken through an integration that ensures coherence between the new and existing components. The risk of adding seismic structure without reflecting on the integration issue is for the new structure not to be considered as part of the 'whole' building, but also to affect the possibly already established coherency between the existing architecture and structure. As a result, the architectural message carried by the existing building might be disrupted.

\subsection{Key issues and background of the thesis}

Integration of seismic retrofit and architecture is therefore an issue relevant in any earthquakeprone countries, including New Zealand. In order for the research to explore this topic in depth, a series of questions need to be addressed.

How to talk about architectural quality?

As the integration of seismic retrofit and architecture can redefine the building as a whole, it might also affect the building's architectural quality. Architectural quality represents the combination of several architectural criteria also known as architectural qualities (Rönn, 2011a). There is however no definitive definition of architectural quality and therefore no exhaustive list of qualities. Such a situation appears to be problematic as the investigation of integration of seismic retrofit structure and architecture requires understanding and communicating any changes to the existing architecture. It is therefore necessary to establish a list of architectural qualities that can be described and reviewed in the context of seismic retrofit. 
How are structure and architecture related?

Various authors have investigated the relationship between structure and architecture. While structure is primarily considered as a physical necessity to provide support to a building (Sandaker, Eggen, \& Cruvellier, 2011), it is also presented as a component capable of interacting with architecture. This interaction possesses multiple facets: from various combinations of structural and architectural forms (Macdonald, 2001) to the creation and expression of architectural qualities (Clark \& Pause, 2005). Thus when approached architecturally, structure can be understood as integrating with a building's architecture. This capacity appears as a great asset for designers to convey and enhance their architectural ideas (Charleson, 2014). Structure can be therefore considered as a valuable component to reinforce and enrich a building's architecture. In this way, structure extends beyond its technical requirements and becomes part of a building's architectural language. This role of architecture has been however mainly investigated through the perspective of new buildings and remains to be explored in the context of seismic retrofit.

How do architects and structural engineers collaborate in seismic retrofit projects?

Integration of structure and architecture relies greatly on the collaboration of the structural engineer and architect as pointed out in two studies (Charleson \& Pirie, 2009; Uihlein, 2013). The studies reveal that each designer acknowledges the value of the other and their contribution to an architectural project. However, architects and engineers also mention a series of personal concerns potentially leading to issues when not addressed and accepted by the other designer. It appears that, throughout the design process of a project, these concerns may influence the achievement of the successful integration. These two studies focused on collaboration during the design process of new buildings. It is therefore necessary to investigate if similar or new issues appear in the context of seismic retrofit.

How is architecture considered in seismic retrofit practice in New Zealand?

The addition of seismic structure to an existing building is mainly perceived in the current literature through the perspective of the impact and resulting changes it might bring to the architecture of an already completed building. In New Zealand, this notion of impact is considered differently between non-heritage and heritage buildings. In the case of non-heritage buildings, due to little consideration of the architectural issue until recently (Cattanach, Alley, \& Thornton, 2008; Goodwin, Tonks, \& Ingham, 2009) the consequences of the presence of structure on architecture are rarely properly addressed in the literature. In the case of heritage buildings, a series of conservation and preservation principles encourage designers to maintain the building's heritage values (Look, Wong, 
\& Augustus, 1997; NZHPT, 2007f; Robinson \& Bowman, 2000). The recommendations based upon these principles aim to maintain the existing architecture and limit detrimental impacts. In both cases, consideration of interaction between structure and architecture is limited and narrow. Structure is primarily perceived as a potential risk of negative impacts its presence might bring to existing architectural features. This single perspective does not allow an exploration of the potential for structure to integrate with architecture and its capacity to contribute to the architectural qualities of a building.

Has there been any research on the integration of seismic retrofit and architecture? If yes, how have the related approaches and recommendations been implemented?

There is an increasing interest from scholars and professionals to cast new light on the role of structure in seismic retrofit. Several authors point out the architectural nature of seismic structure and encourage exploration of this aspect when retrofitting a building (Charleson, Preston, \& Taylor, 2001; Goodwin et al., 2009; McClean, 2010). Through this approach, the seismic retrofit structure is seen as able to add further architectural interest to a building. Such a use of structure does not however disregard respect for conservation and preservation principles. On the contrary, both aspects are considered to be compatible (Cattanach et al., 2008; McClean, 2010) as retrofit structure can be used to correct a building's existing flaws as well as improving its architectural qualities (Charleson \& Southcombe, 2014, 2017; Taylor, Preston, \& Charleson, 2002). So far, the use of seismic structure for architectural purposes has been developed through a specific type of design approach named Earthquake Architecture which corresponds to architectural expression inspired by the earthquake threat (Charleson \& Taylor, 2000; Slak \& Kilar, 2012).

What type of buildings is the most relevant when examining the integration of seismic retrofit and architecture?

The relationship between seismic retrofit structural systems and existing architecture can be analysed in any earthquake-prone building. However, among the various type of buildings potentially requiring seismic retrofit, URM buildings stand as some of the most relevant. URM buildings are acknowledged by several authors as the most vulnerable type of construction under seismic loads (Beyer \& Lucca, 2016; Bruneau, 1994; FEMA, 2009). This vulnerability results from the different types of failures directly related to the materiality and construction characteristics of these buildings (Tomaževič, 1999). Various works can be undertaken to respond to these deficiencies, such as providing adequate ties between the masonry walls and floor diaphragms, bracing parapets to roofs, using steel tie rods to improve the connections between orthogonal walls (Reid Middleton, 
2007; Senaldi, Magenes, \& Ingham, 2011). To a larger extent, the building would require the use of vertical seismic structural systems to help existing structure resist in-plane failure. As a consequence, and as pointed out by Goodwin (2008, p. 12), "Seismic strengthening of unreinforced masonry (URM) buildings is likely to require invasive work and additional structure which could fundamentally change the character of a building". Therefore, seismically retrofitting a building and ensuring successful integration with its existing architecture appears to require exceptionally sensitive work in the case of URM buildings.

\subsection{Research intention}

The answers to the above questions clarified the background of this research. They pointed out that previous studies discussed the ability of structure to contribute to architectural qualities and therefore to integrate with architecture. Such use of structure enriches a building's architecture as the expression of its architectural qualities is reinforced. Similar possibilities could be expected from seismic retrofit structure, resulting in buildings with enhanced architectural qualities. However, despite some authors encouraging an architectural use of structure, so far very few studies have explored this topic.

This research will investigate the contemporary situation of seismic retrofit in New Zealand, and explore how the notion of integration is considered and approached in current practice. It will investigate how seismic structure and architecture can be integrated, but moreover identify factors and conditions that influence their integration. Such work aims to identify the various aspects contributing positively rather than negatively to integration. In doing to, recommendations are made on how to improve integration in future seismic retrofit projects.

\subsubsection{Research question}

How can the integration of seismic retrofit and architecture in URM buildings be improved?

\subsubsection{Aims and objectives}

\section{Aim}

- Aim 1: Raise awareness of the architectural opportunities that seismic retrofit can bring to existing URM buildings.

- Aim 2: Contribute to improved seismic retrofit practice in regard to integration in existing URM buildings. 


\section{Objectives}

The objectives of the research directly arise from the above aims and help reaching them:

- Objective 1a: Establish a list of architectural qualities against which to review integration of seismic retrofit and architecture.

- Objective $1 \mathrm{~b}$ : Identify potential predisposition of seismic retrofit structural systems to engage with existing architectural qualities in URM buildings.

- Objective 2: Examine how designers in New Zealand define and approach integration of seismic retrofit and architecture in order to identify the key factors affecting integration in URM buildings within and outside the design process.

\subsection{Overall data collection strategy and research settings}

\subsubsection{Exploring integration through seismically retrofitted buildings and seismic retrofit practice}

The topic of this research is related to a real-life problem that designers face when seismically retrofitting existing buildings. To identify the different factors and conditions influencing integration, it is necessary to investigate the current situation of seismic retrofit and understand how integration between seismic retrofit structure and architecture is considered and approached by practicing designers.

This research thus uses seismically retrofitted buildings as case studies and reviews their degree of integration through direct observations. As integration is directly related to the architectural use of structure, it is possible to review it through the contribution or lack of contribution of seismic retrofit structure to architectural qualities. Due to the nature of integration and its review, implying a form of personal judgment, this study is undertaken as qualitative research. The use of several case studies allows a comparison of the similarities and differences between different buildings. As a result, the range of factors and conditions affecting integration is widened.

In addition, as mentioned earlier, some differences of expectations exist between architects and structural engineers which might therefore influence the achievement of effective integration. An investigation into the designers' collaboration, and to wider extent on the design process of each of the case studies, is analysed. This is undertaken by interviewing the architects and structural engineers. Such work provides complementary information to the observation and review of the retrofitted buildings. 


\subsubsection{Wellington's URM buildings as case studies}

The research focuses on URM buildings in Wellington. Two main reasons justify this decision. First, URM buildings whether heritage or not are part of New Zealand's history (Cooper, Carter, \& Fenwick, 2012a). Yet, their particularly small number, approximately 3750 buildings (Russell \& Ingham, 2010) including 677 in Wellington, increases the risk of society losing their values due to earthquakes and poor seismic retrofit design. Secondly, New Zealand is categorised into three seismic risk areas: high, medium, and low. Wellington, like Christchurch, is located in the high-risk area in comparison to Auckland who is situated in a low-risk zone (MBIE, n.d.-a). This difference results in the seismic retrofit of buildings in high-risk zones having more stringent design requirements than for those located in low-risk zones (BRANZ, n.d.). Seismically retrofitting existing buildings in Wellington can also be more challenging than in Christchurch as the seismic factor ' $Z$ ', used to determine the required design strength for an existing building, is notably higher in the first city (MBIE, n.d.-b). As a result, buildings in Wellington need to be retrofitted for significant high seismic loads in comparison to other cities possessing URM buildings. This commonly leads to the addition of seismic structural systems to avoid existing building from collapsing. The physical characteristics of these new systems, commonly shear walls, braced frames, and moment frames, would have a stronger impact on the architecture of these buildings in comparison to the retrofit work of secondary components such as parapets and chimneys.

\subsection{Structure of the thesis}

The thesis is divided into seven chapters. Following this first chapter (Chapter 1 ) which provides an introduction and overview of the research, Chapter 2 presents a critical review of the literature of the various fields investigated in this research. The review starts with the overall relationship between structure and architecture, continues with a consideration of architectural issues in seismic retrofit, and finishes with the interaction between seismic retrofit structure and architectural quality. The issues identified explain and justify the knowledge gap investigated in this research.

Chapter 3 then introduces the research methodology developed for the current study. It is based on a qualitative method using multiple case studies. The different stages of the research are also presented, in particular the processes of data collection and analysis. The chapter also includes sections on the trustworthiness of the case study research, ethical considerations, and research scope. 
The thesis then establishes the research framework in Chapter 4. It starts with examining the concept of integration between structure and architecture. This part allows the exploration of how structural components can serve architectural purposes and contribute to the expression of architectural qualities. This characteristic is then discussed in the context of seismic retrofit. From this work, architectural qualities directly related to seismic structure can be established.

The architectural qualities defined in Chapter 4 are used in an Observation Checklist to examine the integration of seismic retrofit and architecture in the buildings used as case studies. This review is undertaken through direct observation, and the data collected is then analysed and presented in Chapter 5 . The findings provide a first understanding of the factors affecting integration between seismic retrofit and existing architecture. In addition, the architectural qualities most receptive to improvement by the retrofit solutions are also identified.

Chapter 6 complements the findings of the previous chapter by focusing on seismic retrofit practice and more precisely on the design processes of the case studies. The architect and structural engineer of each building are interviewed and several themes are addressed. They include the definition of both successful and poor integration, recommendations for future improvement, integration in regard to the architectural qualities of each building, and the design process. This chapter explains the various influences and factors designers face during seismic retrofit, therefore clarifying why some seismically retrofitted buildings are better designed than others.

Finally, Chapter 7 concludes the research. It summarises the main findings of the study, emphasises their implications, points out limitations, and discusses future research recommendations. 
PAGE LEFT INTENTIONALLY BLANK 


\section{CHAPTER 2. LITERATURE REVIEW}

\subsection{Introduction}

The topic of this research incorporates two disciplines that are closely interrelated, yet often separately explored: seismic retrofit and architecture. This literature review starts with (1) a description of the relationship between structure and architecture. In order to do so, the notion of architectural qualities is first explored. This allows understanding and considering architecture through the qualities it carries. From there, the issue of structure is introduced and its interaction with architectural qualities explored. Then, the collaboration between structural engineer and architect is addressed which allows drawing attention to current issues both types of designers face when working together. These three aspects address contemporary views on the relationship between structure and architecture and set the ground for the following two parts regarding seismic retrofit. The literature review thus continues by (2) revealing the current situation of architectural consideration in the context of seismic retrofit. This part examines heritage and non-heritage buildings and compares how seismic retrofit is approached in relation to architecture in both cases. Current architectural considerations can thus be identified. The chapter then moves to (3), the interaction between seismic structure and architectural quality. This part is treated as a response to the issues identified previously. It highlights new perspectives on how to approach the design of seismic retrofit, gradually leading to the capacity of seismic structure to contribute to existing architecture. In addition, the writings of professionals from the building industry regarding of the impact of seismic retrofit on existing architecture are investigated. This allows appreciating how stakeholders in the building industry consider this issue and what approaches they undertake to deal with it. Progressively, these three parts lead to identifying the knowledge gap and the opportunity to explore the integration of seismic structure and architecture.

\subsection{Relationship between structure and architecture}

\subsubsection{Architectural quality}

Architecture is perceived by many authors as an interdisciplinary field that encompasses art, science, technology, human and social issues (Chakraborty, 2014; Siem, Braaten, \& Gilberg, 2016; Wraber, Kirkegaard, \& Fisker, 2008). This unique combination of issues makes the identification and judgment of architectural quality a complex task that remains a continual matter of debate among 
academics. As stated by Volker (2010, p. 16) "architectural quality embraces all the aspects by which a building is judged" and therefore allows for a broad series of interpretations and definitions.

This situation leads Rönn (2011b, p. 238) to mention architectural quality as an "essentially contested concept". This term, created by Gallie (1955), a British philosopher and social and political theorist, refers to a concept that leads to endless disputes about its correct and definitive meaning. With no single answer, Rönn focuses on the study of European architectural policy programmes in the European Forum for Architectural Policies (Ferreira Bento, 2012), to determine several characteristics of architectural quality. He believes architectural quality is a concept specific to each person and built on knowledge gained through education and experience therefore promoting debate as to its meaning. Rönn (2011b, p. 240), just like Nelson (2006) before him, perceives architectural quality as something positive, enhancing values rather than simply describing an object with zero defects. Architectural quality can be assessed using criteria including "opinions, values, ideals and impressions of desirable characteristics" which therefore avoid any right or wrong answers. Architectural quality represents the combination of several qualities forming a whole. Finally, architectural history and more specifically Vitruvius' description of architecture serve as a basis of ageless values for architects to refer to when determining architectural quality.

This last aspect is accepted by several authors and professionals who stress that architectural quality is a combination of Vitruvius' three principles of 'firmitas', 'utilitas' and 'venustas' which can respectively be understood as construction/structure/strength, function/utility/commodity and form/aesthetics/delight (Brophy \& Lewis, 2011; Emmitt, Prins, \& den Otter, 2009; Slak \& Kilar, 2008a; Vitruvius \& Morgan, 1960; Wraber et al., 2008). As noted by Volker (2010, p. 17), these principles can be characterised as either tangible or intangible architectural characteristics. Tangible refers to "technical, physical hard, functional, and objective" characteristics, identified through measurable and objective approaches, and intangible to "perceptual, soft, subjective, and judgemental" ones which are appreciated in sensitive and subjective ways. Rönn (2011a) indicates that architects commonly include an emotional aspect in their own professional judgements when appraising the architectural quality of any project. In contrast, he also stresses that engineers appreciate architectural quality through technical and measurable aspects. Rönn (2011b, p. 239) emphasises the importance of unification of both of these aspects to achieve architectural quality. He therefore encourages the creation of "conceptual bridges" between architects and structural engineers to enhance such achievement.

For Volker (2010), the framework established by Vitruvius has been and still remains a basis for the development of architectural theories and movements, some of which have broadened our 
understanding of architecture. Wraber et al. (2008) stress, for example, how the Modernist movement included issues focusing on the society, the context, and the user's place in the design of architectural projects. Then, over time, additional issues relevant to designers have been raised such as the building's morphology and its relationship with the surroundings, the concept driving the architectural design, and the harmony of composition in terms of geometrical ratios and relations between the components. It is the synthesis of all these considerations that architects bring to bear upon an architectural proposal (Slak \& Kilar, 2008b). The constant addition of architectural considerations also reveals that qualities are scalable and their forms and contents are not frozen in time (Rönn, 2011a). New understandings of quality appear over time but even in the same period this concept can be defined differently from one person to another.

Establishing a definitive list of architectural qualities is therefore hardly feasible and would not be systematically accepted. Wraber et al. $(2008$, p. 1$)$ suggest instead that the architectural qualities of a building should be "[established] in relation to a specific working field with fixed contextual values" and "as many relevant theories as possible [should be used] in the uncovering of the issues of the defined working field". This approach simplifies the identification of architectural qualities as only the qualities specific to a certain context are considered. This implies knowing which working field to refer to and what contextual values are related to it.

The approach suggested by Wraber et al. (2008) appears to be particularly relevant in regard to the research topic. Indeed, as the study explores the integration between seismic structure and architecture within the specific context of seismic retrofit, the latter can be identified as the working field. Concerning the contextual values and theories, they can be established through the contribution of structure to architecture, and through the various principles framing seismic retrofit design. Each of these aspects is presented within the following sections of the literature review.

\subsubsection{Structure contributing to architectural qualities}

As mentioned in the previous section, structure primarily relates to the principle of 'firmitas' established by Vitruvius (Vitruvius \& Morgan, 1960). MacDonald (2001, p. xi) explains that based on that principle, the role of structure is to ensure a building's physical integrity and stability. He further stresses the importance of structure by linking it to the other two principles as "without structure there is no building and therefore no 'commodity'. Without well-designed structure there can be no 'delight'". This position is promoted by Sandaker et al. (2011) who indicate that while it is possible to conceive structure without architecture, the opposite is impossible. Structure is therefore a response to an architectural need and cannot be dissociated from it. 
Christopher Alexander (1977) shares a similar attitude regarding the relationship between structure and architecture. For him, structure should always follow the completion of the architectural design. The location, dimension and geometry of the structure must then create physical spaces that are "congruent" with the social spaces defined by the architectural scheme. This attitude is justified as a response to the modern construction of the mid-twentieth century, in which social spaces are commonly forced to fit within structural spaces created by engineering requirements. On the other hand, Alexander (1977, p. 943) warns about any architecture in which the structure would be independent from the architectural spaces as this would result in "a fundamental and disturbing incoherence in the fabric of the building". For Alexander, structure is such a crucial component both technically and socially that it should always remain massive, exposed and be used as a space creator.

MacDonald, in his book "Structure and Architecture" (2001), continues and refines his thinking started in "Structural Design for Architecture" (1997) regarding the interaction between structural and architectural forms. He establishes six types of relationships ranging from total domination of structure over architecture to the complete disregard of architecture of structural requirements. The relationships are either described through case studies or presented as considerations driving the design process. An example of one particular consideration, labelled 'structure as architecture', is when structure becomes the sole generator of a building's architecture. Macdonald's desire is to widen both architects' and engineers' perceptions of the interconnection of architecture and structure and emphasise how their boundaries can, to various degrees, be blurred. However, he acknowledges that his reflection on the topic solely focuses on two aspects of a building; namely its form and its aesthetics.

In addition to MacDonald's work, other authors have written of the capacity of structure to engage with architecture from a more detailed perspective. Clark \& Pause $(2005$, p. 3) for instance, point out how structure through its different types and members can engage with specific architectural qualities. They state, "At the basic level, structure is synonymous with support, and therefore exists in all building. At a more germane level, structure is columnar, planar, or a combination of these which a designer can intentionally use to reinforce or realize ideas. In this context, columns, walls and beams can be thought of in terms of concepts of frequency, pattern, simplicity, regularity, randomness and complexity. As such, structure can be used to define space, create units, articulate circulation, suggest movement, or develop composition and modulations. In this way, it becomes inextricably linked to the very elements which create architecture, its quality and excitement". This 
statement makes two key points. First, that structure can possess and create architectural qualities; and secondly, that it can, through its qualities, contribute to and enliven a building's architecture.

These two characteristics are elaborated on and further demonstrated by Charleson (2014). His view of the role of structure in architecture is based on the action of architects and engineers to voluntarily make use of the architectural capacity of structure. This attitude appears to be more 'positive' than those of other authors reflecting on the role of structure in architecture. Simitch \& Warke (2014, pp. 72-81) for instance, identify structure as a "physical substance" which takes part in the architectural language of a building. Yet, its interaction with architecture is primarily presented as a consequence of the constant battle to accommodate loads which inevitably affects the architectural form and shapes architectural spaces. Its interaction with architecture is described more as a consequence of the structure's presence than a desire to have structure enhance architectural quality.

Charleson's position (2014) results from a detailed study on the relationship between structure and architectural qualities. Based on a large number of case studies, he presents the vision of structure as an architectural element that creates opportunities rather than constraints to a design. By considering the structure architecturally, he highlights its ability to reinforce architectural concepts and qualities. In doing so, structure becomes an integral part of a building's architecture, thus enriching it. To strengthen his arguments, the author presents a wide diversity of architectural qualities structure may help achieve. As a result, a large range of options for designers to explore and use to best serve their design concepts are presented.

\subsubsection{Collaboration between architects and structural engineers}

Despite sharing a common ancestor known as 'Master Builder', architects and structural engineers are now the representatives of two distinctive disciplines. For Saint $(2008$, p. 487), this distinction leads each type of designer to consider the design of structures through a unique approach: "the one emphasizing the engineering aspect, i.e. structural analysis and calculation, and the other stressing the architectural aspects, i.e. the aesthetic appearance". For Saint, these approaches are not contradictory. They represent two forms of knowledge who, when combined together, manages to achieve state-of-the-art buildings.

Charleson (2014) supports that point of view and further warns that the enrichment of architecture by structure can only be achieved through an extensive and intensive collaboration between architects and structural engineers. As structure is identified as a component relevant to both 
groups of designers, a shared architectural view must be present to successfully achieve both architectural and technical requirements.

Sharing an architectural view does not however ensures shared input to the project's design. As explained by Yeomans (2013) two types of collaborations exist between architects and engineers. The first one, 'passive', assigns the engineers to the sole calculation and sizing of structural members. Engineers would therefore not take part in the design determining the building's aspect. In contrast, an 'active' collaboration considers the architect and engineer as part of a same team where each one can contribute to the overall form and aspect of the building as well as its structure. Bernabeu Larena (2006) thus justifies the success of the structural engineer Ove Arup by its capacity to combine his own aesthetic and structural knowledge with the architects' aesthetic intentions. The contribution made by an engineer may vary from one design team to another. For Newby (1962), each type of designer has a specific purpose to fulfil. While an engineer can provide relevant contribution from an aesthetic point of view, it is up to the architect to make good use of such a 'gift' by understanding the architectural features the structural propositions could bring. Newby's point of view concerning the relationship between architects and structural engineers is clear about this issue. He states: "The architect's tools are his consultants - the all-important thing the architect has to do is to learn how to use them without allowing them to make their own particular mark.... It is important that the engineer explain each proposed scheme so that the architect really understands the principles and possible developments of the structural design" (Yeomans, 2013, p. 444).

While the 'active' approach is highly encouraged by authors like Özmen \& Ünay (2011) and Yeomans (2013), the reality of current design practice appears more complex. Indeed, two key research findings provide information on the difficulties both designers face when working together. The first, undertaken by Charleson \& Pirie (2009), focuses on the issue of collaboration between architects and structural engineers. The second comes from Uihlein (2013) who reflects on the issue of structural integration as a combination of architecture and structural engineering work. The research methods used by the authors are similar as they both interview practicing architects and engineers in order to unveil current issues and make recommendations for improvement. Despite that each piece of research possesses its own perspective and focuses on professionals from its own country, New Zealand for Charleson \& Pirie (2009) and The United States of America for Uihlein (2013), the results are remarkably similar. This not only stresses the strong correlation between designers' collaboration and their integration of structure and architecture, but also suggests that the issues faced by designers are universal. 
In both studies, one of the most noticeable issues is the engineer's contribution to an architectural project. Architects stress their desire to have engineers engage with their design by following their architectural intent or even enhancing it. When engineers contribute to an architectural design, they want the value of their input to be acknowledged and not be restrained by the architects' requirements. They do not want to be at the service of the architects but instead to be treated as partners. Uihlein (2013, p. 510) also indicates that architects, aiming for successful integration between structure and architecture, want engineers to be "creative and innovative".

To properly contribute to the design, engineers require being involved the very early stages of a project (Charleson \& Pirie, 2009; Uihlein, 2013). This aspect is also supported by architects although they remain cautious on the importance of engineering input early in the design process. Charleson \& Pirie (2009) comment that architects want to have flexibility in designing a project and involve engineers once their design is settled. Engineers, on the other hand, want to contribute to the architectural decisions. With no definitive solution to this problem, Charleson \& Pirie (2009) require from both designers high communication qualities and respectful attitudes regarding their respective skills.

Following the 2010 and 2011 Canterbury earthquakes, the Canterbury Earthquakes Royal Commission (Cooper, Carter, \& Fenwick, 2012b, p. 13 \& 17) responded to concerns regarding deficient collaboration between architects and engineers by making two recommendations:

"163 A structural Chartered Professional Engineer should be engaged at the same time as the architect for the design of a complex building.

The Institution of Professional Engineers New Zealand, the New Zealand Institute of Architects, and the New Zealand Registered Architects Board, supported by the Ministry of Business, Innovation and Employment, should work together to ensure greater collaboration and information sharing between architects and structural engineers".

Both of these recommendations have been taken into account by the IPENZ, NZAI, SESOC, NZRAB, MBIE, and NZSEE working group (2014) which addressed the issue of collaboration between architects and structural engineers. The result is a conjointly written document entitled "Improving Collaboration between Architects and Engineers". The document stresses the importance of a change in the attitudes and approaches of architects and structural engineers regarding their responsibilities and tasks when designing a project. It provides several forms of guidance, including comments regarding the design process, construction stages, times of involvement of architects and 
engineers, guidelines to achieve effective collaboration, and a range of actions and tools for designers to refer to.

Throughout the document, engineers are encouraged to interact with architects and their designs. Engineers are thus recommended to "understand the desired architectural concepts and qualities before suggesting solutions", "contribute to the development of the primary architectural design ideas", and develop elegant technical solutions that would integrate with the overall architecture (IPENZ et al., 2014, pp. 5-7). These recommendations emphasise the combination of architecture and structure and 'Integration Quality' is listed among several benefits of effective collaboration. An example of this quality is provided, "Functional and aesthetic goals are better met when there is a seamless meshing of structural layout and services components with architectural planning requirements" (IPENZ et al., 2014, p. 3). Unfortunately, this unique example falls short at describing the architectural enrichment structure can provide to a building. The architectural potential of integration between structure and architecture is therefore not stressed. While structure should not disrupt a building's architecture, the document does not suggest an architecture enlivened by structure as the greatest goal of collaboration.

\subsection{Architectural issues in seismic retrofit}

\subsubsection{Architectural considerations in non-heritage buildings}

When considering the seismic retrofit of an existing building, a series of initial considerations, whether imposed on the design team or based on the designers' concerns, influence the owner's decision making. These considerations are identified by the American Society of Civil Engineers (ASCE, 2007, p. 5) as: "structural characteristics", "site seismic hazards", "results from prior seismic evaluations", "occupancy", "historic status", "economic considerations", "societal issues" and "local jurisdictional requirements". Most of these factors are also found in New Zealand (Egbelakin \& Wilkinson, 2008; Egbelakin, Wilkinson, Potangaroa, \& Ingham, 2011; Solberg, Rossetto, \& Joffe, 2010). Following the design of one or several seismic schemes, another series of considerations are used to select the preferred structural seismic solution. The Federal Emergency Management Agency (FEMA, 2006a, p. 299) indicates that the selection of the seismic solution is essentially based on the building owner's or user's concerns which are identified as: "seismic performance, construction cost, disruption to the building users during construction (often translating to a cost), long-term affect on building space planning, and aesthetics, including consideration of historic preservation". 
As seismic retrofit commonly implies the physical insertion of new structure, interaction with existing fabric, and to a larger extent, architectural features could be expected. It is therefore surprising to not find 'architecture' as a decision-making criterion. Only two aspects - "building space planning" and "aesthetics" - can be identified as architectural concerns. Arnold (2001) confirms the owner's awareness of these two issues but, as indicated by the FEMA (2006a), they are not considered deeply. Concern for a retrofit structure's "long-term effect on building space planning" is regularly thought of by building owners as having lesser importance than other considerations and is usually sacrificed in favour of the latter. Concerning "aesthetics", despite being usually agreed upon as a criterion for judging a retrofit solution, it is also often sacrificed in the interest of cost and disruption to building users when retrofitting non-heritage buildings (FEMA, 2006a). Therefore, it appears that the different criteria, especially architectural, considered by building owners do not have the same level of importance compared to others such as seismic performance or cost.

Research undertaken by Egbelakin et al. (2011) reveals that the small amount of interest in architectural concerns regarding non-heritage seismic retrofit projects is not restricted to building owners. The researchers conducted 35 interviews in four geographic regions spanning low to very high levels of earthquake risk. The participants included building owners as well as property valuers, structural engineers, architects, managers of insurance companies, financial and governmental organizations, all involved in the seismic rehabilitation of earthquake-prone buildings. Across the four regions, $73 \%$ to $81 \%$ of the participants emphasised the importance of retrofitting heritage listed buildings as they were considered "important cultural artefacts" thanks to the heritage values they possess including their architecture (Egbelakin et al., 2011, p. 295). This incorporation of architecture as a value in heritage buildings is found in the ICOMOS New Zealand Charter (2010). In contrast, the same group of participants believed that non-heritage buildings lacked of values worth justifying their seismic retrofit.

Architectural considerations in seismic retrofit projects of non-heritage buildings thus appear to be disregarded or at least not given priority by current stakeholders. Such a situation can be understood by the fact that raising architectural issues is relatively recent in the context of seismic design. As explained by Cattanach et al. (2008), from 1960 to the end of the 20th century the main concerns around seismic retrofit related to maximising life-preservation performance and cost savings. Seismic retrofit was therefore undertaken with little consideration regarding its impact on architectural features and the fabric of buildings (Cattanach et al., 2008; Goodwin et al., 2009). The 
consideration of existing architecture in the context of seismic retrofit is therefore recent and likely to be improved.

Nowadays, several documents helping architects and engineers to develop a retrofit design with reference to architecture do exist. These documents either aim at 'teaching' designers, and particularly architects, to better understand seismic engineering (Charleson, 2008; FEMA, 2006a; Zacek, 2004), or at providing more technical and structural information for engineers (ASCE, 2007; FEMA, 2006b). In both kinds of sources architectural issues are treated in two different ways. The first focuses on how architectural components might affect the behaviour of the seismic responding structure, while the second addresses the repercussions of seismic retrofit on architectural characteristics. However, this second aspect remains of little concern, particularly when the building to be retrofitted is not listed as heritage. The FEMA 547 document (FEMA, 2006b) is one example. The strength of this publication is that for a large range of existing structural types (wood light frames, steel moment frames, steel braced frames, steel frames with concrete shear walls, etc.) it indicates the technical, economic and architectural issues that may arise during the design, detailing and construction phases. Yet, despite the fact that it constantly analyses the effects of different seismic techniques on structural and economic issues, the architectural consequences are barely mentioned in some of the examples, and only then in broad terms.

\subsubsection{Architectural considerations in heritage buildings}

The notion of 'heritage' relates to the concepts of inheritance and transmission of valued things that are passed down from previous generations (Oxford English Dictionary, n.d.). Heritage can represent single or several items, physical or immaterial, carrying individual or group histories (Aplin, 2002). The cultural values of heritage are numerous and include "aesthetic, archaeological, architectural, commemorative, functional, historical, landscape, monumental, scientific, social, spiritual, symbolic, technological or traditional" (ICOMOS, 2010, p. 9). Heritage New Zealand lists architecture as a physical value that can be appreciated through "its design, form, scale, materials, ornamentation, style, period, craftsmanship or other architectural elements" (NZHPT, 2007c, p. 11). It is the combination of the different values that gives a building its specific significance which requires any alteration of heritage buildings, including seismic retrofit, to be based on the conservation and preservation of these values. Therefore, the importance of maintaining a building's heritage values responds first and foremost to a cultural requirement. However, the related economical issue should not be neglected. In earthquake-prone countries where tourism represents a significant source of wealth, such as Italy or Turkey, ensuring that the maintenance of heritage buildings and 
their related features are taken into account when designing a retrofit solution is paramount (Betti \& Galano, 2012).

Several legislative acts frame the management of heritage buildings in New Zealand. These include the Resource Management Act 1991 (RMA), Heritage New Zealand Pouhere Taonga Act 2014 (replacing the Historic Places Act 1993), and the Building Act 2004. The RMA promotes the sustainable management of natural and physical resources by ensuring their use, development, and protection. It aims at balancing development and changes with the need to protect the values and resources of the environment (New Zealand Parliament, 1991). This is principally regulated through district plans of Territorial Authorities providing provisions for heritage buildings and areas (New Zealand Parliament, 1991; Wellington City Council, 2000). Territorial Authorities require a Resource Consent alongside a Building Consent for any changes to the fabric of a heritage building. As an affected party, Heritage New Zealand (formerly the New Zealand Historic Places Trust) has some influence on development proposals. It may support or disapprove of them (Heritage New Zealand, 2014; New Zealand Parliament, 2004; NZHPT, 2007d). This participation of Heritage New Zealand results from the Heritage New Zealand Pouhere Taonga Act 2014 which allocates a series of functions to this agency including maintaining a register of heritage listed buildings and advocating their conservation and protection (New Zealand Parliament, 2014). Finally, the Building Act 2004 sets expectations and requirements regarding the modification of existing buildings and their levels of performance (New Zealand Parliament, 2004). Modifications, such as a change of use or significant alteration, require complying as reasonably practicable with provisions of the building code in regard to structural performance, access for disabled people and fire safety (New Zealand Parliament, 2004).

Heritage New Zealand relies on several international and national documents to manage and conserve heritage buildings and their related values when significant alterations are proposed. When focusing on architecture and seismic retrofit, it is possible to distinguish two categories of recommendations provided by the different guideline documents. The first helps designers to identify the different architectural features prior to any retrofit scheme, whereas the second provides guidance during the design process.

In the first category, the aim is to make designers aware of the existing visual features constituting the architectural character of a heritage building. Heritage New Zealand asks a simple question with respect to architectural value for designers to consider: "Is the place significant because of its design, form, scale, materials, ornamentation, style, period, craftsmanship or other architectural element?" (NZHPT, 2007a, p. 23). The National Park Service of the U.S Department of Interior provides greater 
guidance through a three-step process (L. H. Nelson \& FAIA, 1988). The process consists of a series of questions to identify pre-listed features starting with the overall external visual aspects of the building, then moving closer to determine surface qualities of the materials and craftsmanship, and finally focusing on interior characteristics. This approach contributes to the development of a Conservation Plan document recommended by Heritage New Zealand (NZHPT, 2007d) and the ICOMOS New Zealand Charter (2010). The document aims to point out the significance of the heritage values of a building, establish conservation policies, and make recommendations to safeguard those values (Heritage New Zealand, n.d.).

The second category of guidelines gives a certain number of recommendations for designers to follow during the design process. This guidance comes in three formats:

- The first format consists of a series of principles. They are mainly established by the ICOMOS New Zealand Charter (2010) as it represents the most extensive document specifically adapted to the conservation of heritage places in New Zealand. It presents a series of conservation principles to protect places of cultural heritage including, among others, minimising change, ensuring compatible use, respecting previous alterations, and respecting the patina of age (NZHPT, 2007a). Drawing upon the Charter, Heritage New Zealand developed the Sustainable Management of Historic Heritage Guidance Series (NZHPT, 2007f). This series of documents intends first to provide an overview of heritage matters in relation to legislation but also aims to help designers maintain and preserve heritage buildings. To do so, the documents provide a series of principles for "Assessing appropriate or inappropriate Subdivision, Use and Development on Historic Heritage Values" (NZHPT, 2007a, pp. 12-13) and for the "Alterations and Additions to Historic Buildings" (NZHPT, 2007e, p. 1). More specifically, the issue of seismic retrofit incorporates three main principles. They were first defined by Look et al. (1997) and repeated by Robinson \& Bowman (2000) as key objectives for structural engineers to consider. They are: minimum intervention, respect for the character of the heritage building, and reversibility of the seismic work. All these conservation principles are to guide designers undertaking modifications on heritage buildings but are purposefully not strict rules. Designers thus have consequent flexibility in terms of interpreting and achieving these principles.

- The second format aims to encourage designers to reflect on their design proposal and its consequences on the existing architecture by answering a series of questions. The questions ask whether alternatives to the use and location of structural components have been considered. Aguilar (2016) justifies this method as a way for the stakeholders to achieve a 
seismic retrofit solution with the lowest visual impact on existing features. This approach allows designers to not simply follow established principles but also, to some degree, critique their proposed solution.

- The third format appears as a series of assessment checklists developed by Heritage New Zealand as part of the Sustainable Management of Historic Heritage Guidance Series (NZHPT, 2007f). Their aim is to assess impact on historic heritage. In the case of seismic retrofit, two main checklists appear to be relevant (NZHPT, 2007b). They relate to internal and external alterations and addition to buildings. Unlike the previous two formats, the checklists do not guide the designers through their proposed seismic retrofit solution, but instead test the proposal against a series of statements. This is how the completed design is evaluated. Based on the principle of 'tick the box', designers indicate if they did or did not follow the alteration principles.

A final point to address is the seismic assessment of heritage buildings in order to determine the amount of work required to seismically retrofit them. Most engineers are aware of the three principles established by Look et al. (1997) and Robinson \& Bowman (2000), and aim at respecting them. However, they are often confronted to the difficulty of properly assessing the existing building's seismic performance, in particular with URM buildings. This difficulty comes from both the amount of uncertainties regarding the characteristics of an existing building's structure, materiality, and constructability (Ceroni, Pecce, Sica, \& Garofano, 2012; Quattrone, 2012), as well as simplistic methods analysing the seismic resistance of the building (Beyer et al., 2017). As a result, some retrofit solutions provide dispensable strengthening measures, such as oversized or redundant seismic structures. This outcome contradicts the conservation principles as it creates a strong and unnecessary impact on the building's appearance and potentially on any of the architectural qualities it carries. Some engineers and researchers are currently exploring and developing different approaches to optimise the intervention schemes.

A first example is a collaborative project between the Swiss Federal Institute of Technology (EPFL) and the University of Pavia in Italy (Beyer et al., 2017). The authors point out that current linear models used to determine a building's seismic response are only relevant to new buildings. Their use on existing buildings is not adapted as, to compensate for the variation between expected and actual behaviour, they are calibrated to generate conservative results. The project being currently investigated consists in a series of advanced nonlinear simulations related to the seismic response of URM. The aim is to help designers develop retrofit strategies more adapted to the building's seismic performance and with limited interventions and being reversible. Such project is however limited 
according to the authors as its resulting models would only be effective in countries with low to moderate seismicity, therefore excluding countries like New Zealand and Japan.

A second example is the PERPETUATE project which intends to establish a series of European guidelines for the evaluation and preservation of buildings with cultural heritage value (Lagomarsino et al., 2011; Lagomarsino \& Cattari, 2015). With particular interest towards the minimum intervention principle, the project aims at defining target performance levels not solely related to the use and safety of building's users but also to the conservation of architectonic and artistic assets. The project thus classifies each group of assets. Regarding the architectonic assets, the various types of historic buildings constituting them are divided based on the damage or failures they are most subjected to. Concerning the artistic assets, they are organised based on whether they are structural, nonstructural but connected to structure, or non-structural with their own seismic response. Based on this classification, a series of different mechanical models are listed and their relevance when assessing an existing building is indicated for each asset (Lagomarsino, Cattari, \& Calderini, 2012). Structural engineers can then select the most appropriate model strategy in accordance. The guidelines of the project do not provide specific recommendations in regard to the architectural value of a heritage building. However, the use of different performance levels and targets in relation to architectonic and artistic assets give the opportunity for designers to design more refined retrofit solutions in regard to the minimum intervention principle.

\subsubsection{Issues regarding architectural considerations in seismic retrofit}

The two previous sections reveal an imbalance in the considerations of non-heritage and heritage buildings. The architectural issues and their relationships to seismic retrofit are less considered in the first type of buildings. This situation is considered inappropriate by several authors for two reasons.

First, heritage buildings do not have a monopoly of architectural value and any buildings whether listed or not possess different degrees of architectural interest (Goodwin, Tonks, \& Ingham, 2011; Volker, 2010). Cattanach et al. (2008) further note that although not listed as heritage, a building may still have cultural value worth considering, including its architecture. Some buildings lack of architectural interest, nevertheless, such a situation might lead to them having their architecture detrimentally affected by a careless seismic retrofit (ASCE, 2007; Charleson et al., 2001).

Secondly, Goodwin et al. (2011, p. 30) reject the distinction between heritage and non-heritage buildings. The authors explain "Old buildings can become 'heritage', where they become important 
to the public rather than just to the owner and occupants;... There is no line on one side of which lies 'heritage', and on the other 'not heritage'; all old buildings will have some heritage value". This position is evident in some seismic retrofit examples published in the New Zealand Society of Earthquake Engineering (NZSEE) Bulletin, which reveal a lack of architectural consideration by the structural engineers in the last decades. A relevant example is the Wellington Opera house which had all the windows in the auditorium walls filled up with bricks in order to "remove unnecessary weaknesses" (Christianson, 1983, p. 177). This negative impact of the seismic retrofit on the existing architecture occurred only four years before the building was listed as heritage in 1985.

Although not all buildings might end up being listed as heritage, the two arguments above stress the importance of considering existing architecture of any building when undertaking seismic retrofit. To help designers seismically retrofit non-heritage buildings, one solution would be for them to refer to the guidelines and recommendations mentioned above for listed buildings. However, despite the need for more consideration of architectural issues, the various guiding documents have two main limitations:

- First, the list of features defining the architectural character of a building is incomplete in terms of architectural qualities as it is only based on visual features. Other architectural qualities that might be affected by seismic retrofit are missing. For example, the quality of interaction between natural light and interior spaces indicated by Volker (2010) is not addressed.

- Secondly, the guiding documents focus on the conservation of existing architectural features by encouraging precautionary approaches. They recommend the lowest impact, minimum disruption and limited visual presence of the structural components. All these principles intend to maintain the building's existing appearance and avoid any negative impact. However, such an approach of restraint disregards any possible positive architectural contribution a seismic retrofit may bring to a building's architecture.

\subsection{Interaction between seismic retrofit structure and architectural quality}

\subsubsection{Seismic retrofit structure contributing to existing architecture}

Although acknowledging the importance of the conservation principles (ICOMOS, 2010) and accepting them, some authors question the common assumption that seismic retrofit should be hidden or resemble as closely as possible the historic character of a building. 
Cattanach et al. (2008, p. 6) suggest an approach based on the notion of 'Transparency' in which the seismic structure is read distinctively from the existing architectural character. It is presented as follows: "Transparency in the detailing (separating material, technique, or form) aids the reading of a heritage structure after strengthening. Even if the addition is "in keeping" with the original style it should be discernible to the educated eye without destructive investigation. It allows the building to be seen in the future as a history built up in layers without relying on retained documentation to describe the picture". The new seismic structure therefore becomes an integral part of the building's historic evolution. Such a distinction however does not reject the importance of visual and physical compatibilities between the existing building and its seismic retrofit.

In addition to Cattanach et al., Goodwin et al. (2009, p. 27) challenge passive conservation approaches. They state: "The most important attribute that a designer can have is creativity. Conservation principles exist to inform the type of action that will result in a good solution from the perspective of conservation of heritage. Stringent adherence to these principles will not necessarily result in a solution that is good from an architectural or usability perspective. Sound judgment and design skill are required to deploy conservation principles with imagination and artfulness. The best strengthening solution will work with the existing material to complement the architectural character with a minimum of impact. There may never be a perfect solution or a single right answer; however, a solution that significantly works towards achieving the above goals can be considered to be a successful and effective intervention". This statement acknowledges seismic structure as an architectural component. Moreover, it encourages the development of more active retrofit solutions, in which retrofit designs engage with existing architecture and enhance it.

A new guide (McClean, 2010), yet to be included in the Sustainable Management of Historic Heritage Guidance Series (NZHPT, 2007f), supports the position of the above authors. McClean further reinforces the idea of an architectural contribution by the seismic retrofit and specifically seismic structure by referring to the Earthquake Architecture movement.

Earthquake Architecture is described by Arnold (1996, p. 10) as "an architecture [that] might expose the elements necessary to provide seismic resistance in ways that would be of aesthetic interest and have meaning beyond decoration". Charleson \& Taylor (2000, p. 1) draw upon this definition and further complement it by noting that it "describes a degree of architectural expression of some aspect of earthquake action or resistance. The wide breadth of expressive possibilities ranges from metaphorical uses of seismic issues, to the more straightforward exposure of seismic technology". This movement fully embraces seismic structure and technology as architectural components, thus becoming an integral part of a building's architecture. It specifically aims toward a specific 
architectural language stimulated by the seismic risk (Charleson \& Taylor, 2000; Llunji, 2016; Slak \& Kilar, 2008a). Slak \& Kilar (2008a, 2008b, 2011, 2012) have based their recent works on this particular type of architecture. A significant part of their work is the development of a method evaluating and classifying the degree to which a building expresses a creative response to the seismic risk. The method combines two series of evaluation parameters: one related to earthquake engineering and another related to the architectural response to the seismic threats. The evaluation of a building is undertaken through the use and analysis of its architectural and engineering detailed drawings, general concept, formal aspect and location. The goal of the authors' work is to encourage designers to develop a particular architectural design in seismic areas. The method, through the use of earthquake engineering and architectural criteria, evaluates the degree to which a building expresses Earthquake Architecture. This research is one of the very few based on the interdisciplinary area of study combining architecture and seismic engineering but is restrained to this specific type of architecture.

McClean (2010) does not however refer to Earthquake Architecture to persuade designers to follow this specific type of architectural intervention. Instead, through several retrofit examples, he primarily tries to encourage architects and engineers to design seismic solutions that are compatible with the existing heritage fabric while simultaneously enhancing architectural qualities.

The idea of enhancement of existing architectural qualities is also addressed by Michael Ostwald (2002) and further developed by Charleson \& Southcombe $(2014,2017)$. It corresponds to the 'Dialogue' approach, in which the seismic retrofit solution is used as an opportunity to reflect on a building's existing flaws and qualities in order to improve them. Several strategies can be used, such as partially hiding or exposing the seismic structure, juxtaposing or interweaving it with the existing architectural layers. This approach aims at being more critical of the existing architectural quality of a building in comparison to the three other approaches listed by the authors; namely 'Indifference', 'Invisibility', and 'Separation'. The first one corresponds to the treatment of the seismic solution as solely an engineering problem. No architectural reflection is undertaken, leading to the risk of structure negatively impacting on existing architecture. The second approach corresponds to the hiddenness of the seismic solution as recommended by the conservation principles and commonly accepted by designers. The third approach is similar to the concept of 'Transparency' defined by Cattanach. 


\subsubsection{Impact of seismic retrofit on the architecture of a building}

The implementation of seismic retrofit techniques has a greater or lesser impact on a building's architecture (ASCE, 2007; Charleson, 2008; FEMA, 2006b; Goodwin et al., 2011; Wenk, 2008). As it is the designers' task to consider such an impact, some professionals in the building industry have started to reflect on the consequences of seismic retrofit on architectural qualities.

Nishizawa (2008) presents in his paper a table evaluating and comparing a series of seismic solutions against six criteria. The table is based on a combination of written observations, describing how the criteria and sub-criteria are being affected by each solution, and scores are assigned to each criterion. This approach aims at facilitating decision making. Out of these six criteria, only two are related to the building's architecture. The first criterion focuses on the impact of the seismic work on the building's operations. The second refers to the impact of the retrofit on the cultural asset. Two sub-criteria comprise this last consideration: "Changes to the exterior of the building" and "Degree of effects on the registered cultural asset" (Nishizawa, 2008, p. 4). Although the mentioned criteria and sub-criteria are related to architectural concerns, they remain basic and limited. They actually fail to help designers to effectively analyse the consequences of their seismic schemes on architectural qualities.

Cattanach et al. (2008, p. 1) propose an "appraisal framework", quite similar to Nishizawa's evaluation and comparison table, to assess retrofit methods. The most noticeable differences are the use of additional architectural criteria and the absence of scores attributed to each criterion. Despite providing more consideration to architectural qualities, and particularly on how seismic structure affects them, the framework also remains limited. First, the listed architectural parameters are very general and need be further developed and detailed. Secondly, additional architectural qualities impacted by the presence of seismic structure remain to be taken into account.

Drawing upon Cattanach's framework, Pattinson \& Egbelakin (2016, p. 1) propose an assessment tool to "examine the effectiveness of seismic strengthening designs for heritage buildings". The tool, known as Heritage Evaluation Framework (HEF) (Partington, Dizhur, Ingham, \& Egbelakin, 2017), aims to be multidisciplinary and collaborative. It therefore possesses six main categories; namely, Seismic Engineering, Heritage, Feasibility, Architecture, Services and Fire Protection, and Buildability. Each category possesses sub-categories to which the client establishes priorities. The designers then indicate for each proposed seismic solution whether it meets the client's requirements and to what level falls short, achieves minimum requirements, exceeds them, or 
greatly exceeds them. The result is a spider-diagram superposing the client's consideration for each of the six main categories on the designers' proposal in order to compare the appropriateness of the seismic retrofit solution. Although this tool is the most exhaustive of the three assessment instruments, some comments can be made regarding its approach to architecture. First, many of the sub-categories of the 'Architecture' criterion relate to building science concerns, such as acoustic performance, thermal insulation and weather-tightness of the envelope, and could therefore be gathered into a distinct category. This would then allow for a greater development of the remaining sub-categories, which are in common with Cattanach's list and therefore possess similar issues as the ones described in the previous paragraph. Secondly, Architecture and Heritage are listed as two different categories. Such a decision is surprising as architecture is considered as being part of a building's heritage values (ICOMOS, 2010). It appears that this distinction aims to encourage designers to focus more greatly on the conservation principles. However, when examining the two sets of sub-categories, many of them actually relate to each other and become redundant.

Nishizawa (2008), Cattanach et al. (2008), and Pattinson \& Egbelakin (2016) have considered, through to various degrees, the impact of seismic retrofit on architectural quality. The tools' purposes are particularly relevant as they allow members of a same design team to evaluate and appreciate the strengths and weaknesses of their retrofit designs. However, two main issues can be noticed:

- The first is the lack of architectural criteria and related qualities. This includes criteria such as structural expressiveness (Charleson, 2014; Macdonald, 2001) and architectural concept (Slak \& Kilar, 2008b; Svensson, 2009). As a consequence, the review of the impact of seismic retrofit on a building's architecture remains incomplete.

- Secondly, the capacity of seismic retrofit to enrich architecture through structure, as indicated in the previous section, is not addressed. In the first two tools, architectural issues are only approached through minimum alterations and maintenance of original features. Regarding the last tool, the assessment of the impact of the retrofit on architecture remains unclear. For example, the tiered ranking option simply indicates whether the client's expectations have been met or not. This approach remains vague when intending to assess the potential contribution of seismic structure on architecture.

\subsection{Knowledge gap and research justification}

Structure is revealed throughout the literature review as a special component with a unique relationship to a building. While its technical role is fundamental to the physical integrity of a 
building, structure is also, potentially, a formidable architectural component. Its variety of forms and materiality allows it to contribute to various architectural qualities, and on a broader scale to architectural concepts. Approached architecturally, structure thus provides opportunities to enrich architecture.

As structure is both a technical and architectural component, the achievement of its successful integration with architecture is directly related to the collaboration between architects and engineers, particularly during the design process. Such collaboration is affected by several difficulties architects and engineers need to overcome. In New Zealand, the most recent document helping designers to collaborate, "Improving Collaboration between Architects and Engineers" (IPENZ et al., 2014), does not explore the potential for collaboration to enrich architecture.

The issue of integration between structure and architecture is acknowledged and supported by several authors, yet their work and arguments are almost exclusively based on the design of new buildings. Reflection on integration and therefore architectural enrichment by structure has been, so far, barely approached in the context of seismic retrofit. Yet, this issue should be of concern to designers and clients when planning to seismically retrofit buildings. Indeed, the addition of new seismic structure in a building is never a trivial act and it is the role of designers to ensure that its presence is appropriate to the actual architecture. Numerous publications emphasise the importance of respecting the existing architecture and provide guidance to architects and engineers throughout the design process. While these documents encourage designers to be vigilant regarding their proposals and to reflect on their decisions, they barely address the issue of integration. Critical reflection on this issue is a necessity for architects and structural engineers, and both should be ready to review their own seismic retrofit approaches.

Some academics and professionals have begun such a reflection. They emphasise how seismic retrofit should be both respectful of the existing architecture while also introducing a new architectural layer. However, so far, such work has only been explored through the concept of Earthquake Architecture. This type of architecture takes inspiration from seismic engineering design issues and aims toward the expression of seismic risk or its mitigation. It is therefore a very narrow and specific type of integration of seismic structure and architecture. Moreover, Earthquake Architecture does not aim at the enrichment of existing architecture by structure. Regarding current design practice, professionals are developing tools to better consider architectural issues in their seismic retrofit designs, but the tools do not provide enough detail to comprehensively consider the architectural contribution of seismic structure. 
There is therefore a gap in knowledge and practice regarding how seismic retrofit can be used as an opportunity to enliven existing architecture, and how architects and structural engineers collaborate to achieve successful integration of seismic retrofit and architecture. To act in answer to this gap, the research aims at raising awareness of the architectural opportunities that seismic retrofit can bring to existing URM buildings, and improving seismic retrofit practice in regard to integration in existing URM buildings. To achieve the first aim, it is necessary to question: what are the architectural qualities potentially affected by seismic retrofit? To answer this question two objectives are considered. First, identify the architectural qualities specific to the context of seismic retrofit and with which seismic structure can engage. This would allow the researcher to appreciate and review integration of seismic retrofit and architecture. Secondly, the relationship between seismic retrofit structures and architectural qualities, and more specifically their predisposition to engage with one another, needs to be examined. This helps appreciating the capacity of architectural enrichment of seismic structural systems. To achieve the second aim, it is imperative to question what factors and influences affect the integration of seismic retrofit and architecture in URM buildings. This information can be obtained by exploring how practicing architects and structural engineers consider and approach the integration of architecture and structure when seismically retrofitting a building. The outcome is the identification of factors affecting integration in URM buildings within and outside the design process.

\subsection{Research Question}

How can the integration of seismic retrofit and architecture in URM buildings be improved?

\subsection{Hypothesis}

The integration of seismic retrofit and architecture in URM buildings can be improved.

\subsection{Aim}

- Aim 1: Raise awareness of the architectural opportunities that seismic retrofit can bring to existing URM buildings.

- Aim 2: Contribute to improved seismic retrofit practice in regard to integration in existing URM buildings.

\subsection{Secondary Questions}

The aims of the research raise two secondary research questions; 
- Secondary question 1: What are the architectural qualities potentially affected by seismic retrofit?

- Secondary question 2: What factors and influences affect the integration of seismic retrofit and architecture in URM buildings?

\subsection{Objectives}

To respond to the secondary questions, the following objectives must be achieved:

- Objective 1a: Establish a list of architectural qualities against which to review integration of seismic retrofit and architecture.

- Objective 1b: Identify potential predisposition of seismic retrofit structural systems to engage with existing architectural qualities in URM buildings.

- Objective 2: Examine how designers in New Zealand define and approach integration of seismic retrofit and architecture in order to identify the key factors affecting integration in URM buildings within and outside the design process. 


\section{CHAPTER 3. RESEARCH METHODOLOGY}

\subsection{Introduction}

This chapter discusses the research methodology adopted for this study, including the methods and tactics employed to investigate the research question. The chapter starts with the justification of the selected methods and continues by presenting the overall research design and its various stages. It also touches on the data collection and analysis, as well as on the reliability of the research, ethical considerations, and the research scope.

\subsection{Qualitative research}

A qualitative research methodology is selected to explore and understand the issue of architectural integration in the context of seismic retrofit. With this method, the thesis examines the integration of completed retrofitted projects and analyses this issue in the context of real-life architectural and engineering practice. Qualitative research appears as the most suitable strategy for several reasons explained by Groat \& Wang (2002). First, this strategy involves analysis of the objects of inquiry within their natural settings which is essential for this particular research study. Secondly, the researcher takes part in interpreting and making sense of the collected information. Thirdly, the way the respondents perceive and understand the phenomenon being studied is taken into account. Fourthly, multiple tactics can be combined to collect data.

These four characteristics are considered as follows in this research:

- the study is set in the context of the seismic retrofit of buildings and designers' practices,

- the information gained is interpreted through the perspective of integration of seismic retrofit and architecture as discussed,

- in-depth interviews allow taking into account how architects and structural engineers comprehend integration, and

- complementary tactics including direct observations of completed buildings and interviews of designers are used to gain data from multiple sources

\subsection{Multiple case study strategy}

This qualitative research adopts a case study strategy of which a most useful and frequently accepted definition is provided by Yin (1984, p. 23): "A case study is an empirical inquiry that 
investigates a contemporary phenomenon within its real-life context; when the boundaries between phenomenon and context are not clearly evident; and in which multiple sources of evidence are used".

Such a strategy appears particularly relevant when examining the issue of integration in the context of seismic retrofit. This is because the research aims for an in-depth yet multi-faceted exploration of the factors and issues influencing the integration of seismic retrofit and existing architecture. The use of case studies allows exploration of both completed retrofitted buildings and the design processes that resulted in their construction. This possibility of undertaking several observations is a characteristic of the case study approach, as pointed out by Blatter (2008). The use of "multiple sources of evidence" mentioned by Yin (1984, p. 23) facilitates the development of various observations and also strengthens the credibility of the research findings as stated by Rothbauer (2008). The sources of evidence or data are thus collected through architectural and engineering plans, archival documents, photographs, direct observations, and interviews.

As a seismic retrofit project is expected to have a specific design process and resulting levels of integration, a decision was taken to use multiple case studies for this research. Authors recommend using multiple case studies when each case, thanks to its characteristics and settings (Groat \& Wang, 2002), "[serves] a specific purpose within the overall scope of inquiry" (Yin, 1994, p. 46). A multiple case study strategy allows the researcher to analyse the data within each case but also across cases (Yin, 2009). This characteristic facilitates understanding the differences and similarities between the different cases (Baxter \& Jack, 2008). The evidence resulting from multiple case studies are commonly considered compelling and reliable, therefore making the research study more robust (Baxter \& Jack, 2008; Yin, 2009).

\subsection{Research Design}

The research process began with a literature review in Chapter 2 which identifies the knowledge gap and the area of research to be followed. The four subsequent stages are summarised in the flowchart below (Figure 1) and elaborated upon on the following pages. 


\section{Stage 1}

\section{Step A}

Exploring integration of structure and architecture and the architectural qualities related to it

\section{Step B}

Reframing the notion of integration to the seismic retrofit context and exploring its specificities
Step C

Establishing the architectural qualities related to the integration of seismic retrofit and architecture

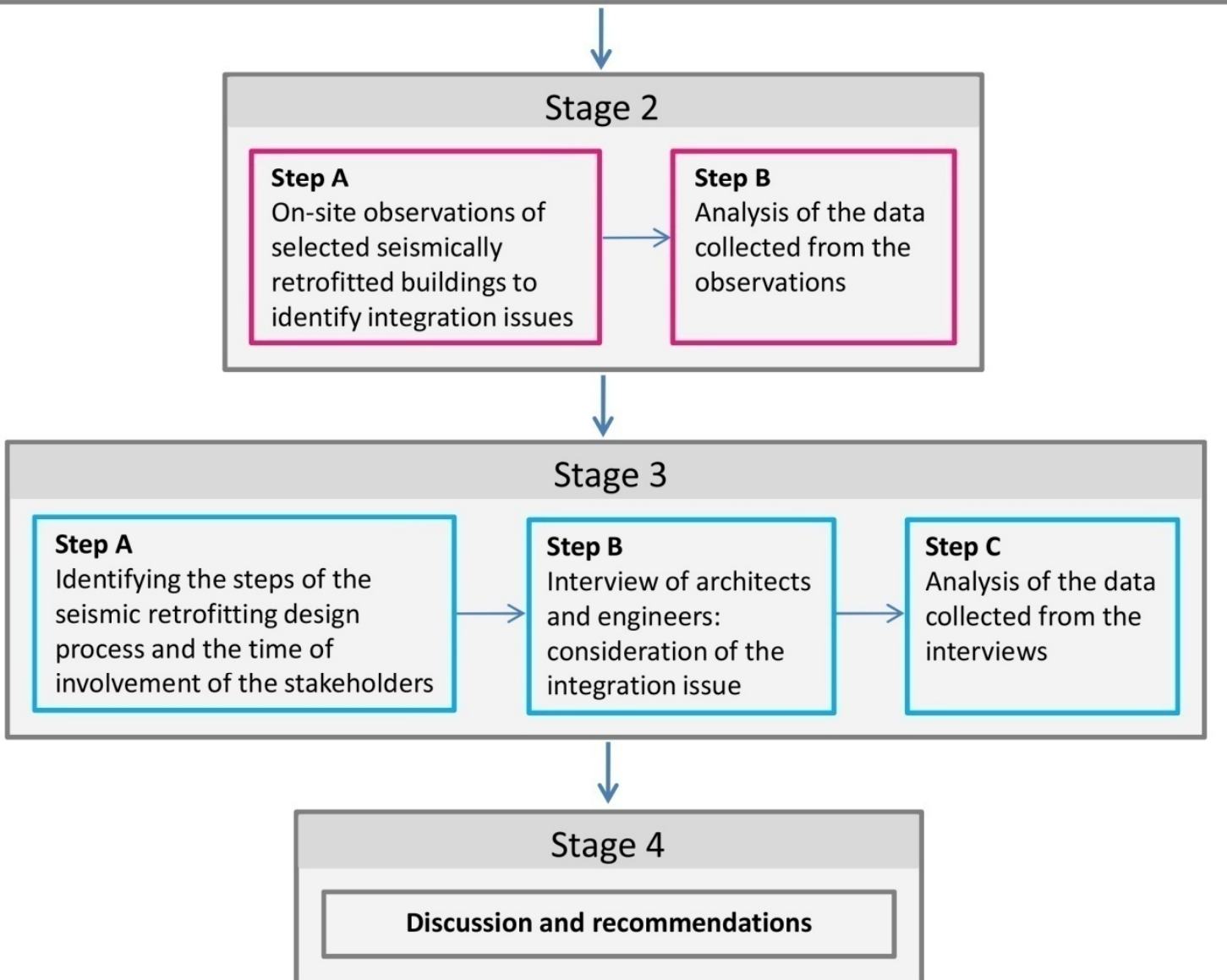

Literature

Site visits \&

documentation

Interviews

Figure 1. Diagram illustrating the four stages of the research study

\section{Stage 1: Creation of the theoretical framework by contextualizing the issue of integration of}

\section{seismic retrofit and architecture}

- Step A: The first step explores the issue of integration of structure and architecture. This is undertaken by identifying from different sources how structural components may serve architectural purposes and contribute to the expression of architectural qualities.

- Step B: The findings of the steps above are transposed to the seismic retrofit context. The notion of integration is reframed to the specific scenario of existing buildings being 
seismically retrofitted. This task is undertaken through three complementary ways. First, the importance of integration in this particular context is explained and justified. Second, key categories of relationships between seismic retrofit structure and existing architecture are analysed. Third, conservation and preservation issues in regard to seismic retrofit projects are discussed.

- Step C: The outcomes of Steps A and B led to the establishment of 16 architectural qualities related to the integration of seismic retrofit and architecture. Drawing upon these findings an Observation Checklist displaying a series of architectural qualities that can be affected by retrofit structure is designed. This table is used to collect data from five seismically retrofitted unreinforced masonry buildings in Wellington.

Stage 1 and its related steps achieve Objective 1a of the research: establish a list of architectural qualities against which to review integration of seismic retrofit and architecture.

Stage 2: Observation of the selected seismically retrofitted buildings and review of their integration

- Step A: Using the Observation Checklist, direct and focused observations are made on the five case studies. This step is further explained in Phase 1 of the Data Collection section.

- Step B: Once collected, the data from the observation is analysed and presented through a combination of Tables of Analysis and written explanations. This allows factors affecting integration of seismic retrofit and architecture to be identified. The findings also identify which architectural qualities are more susceptible to be influenced by retrofit solutions. This step is further explained in Phase 1 of the Data Analysis section.

Stage 2 and its related steps contribute to the achievement of research objectives $1 \mathrm{~b}$ and 2 . It highlights potential predisposition of seismic structural systems to engage with existing architectural qualities, and some factors affecting integration.

Stage 3: Interview of the designers in charge of the seismic retrofit of the case studies to explore their approach of integration in the real-life context

The information obtained from Stage 2 is complemented and contrasted by additional material that provides a holistic understanding of the seismic retrofit design process. Stage 3 thus focuses on the architects' and structural engineers' practice in regard to seismic retrofit. 
- Step A: A holistic understanding of integration in real life implies the identification of the most common steps of the seismic retrofit design process and the time of involvement of the various stakeholders in the design process, from the beginning to the end. This information is obtained and summarised using a Table of Design Process as described in the Data Collection section.

- Step B: A semi-structured interview is undertaken with the architect and engineer of each case study. It investigates how these designers define integration and approach it when retrofitting existing buildings.

- Step C: Once gathered, information of the previous steps is analysed in order to identify factors during the design process that influence integration, what these factors are based on or caused by, and which stakeholders they relate to. This step is presented in Phase 2 of the Data Analysis section.

Stage 3 and its steps complete the research objectives $1 \mathrm{~b}$ and 2 initiated in Stage 2 . It identifies factors affecting integration outside and within the design process, and also refines some of the results from the previous chapter by considering the designers' reflection on the level of integration of their retrofit work.

\section{Stage 4: Reflection on how to improve current practice}

This last stage reflects on and discusses the identified issues from stage 2 and 3 . As a result, recommendations to improve integration and therefore the relationship between seismic retrofit and architecture are provided. The nature of the issues affecting integration, the sources giving rise to them, and the time of their appearance in the design process lead to different types of recommendations.

\subsection{Data Collection Plan}

The data collection plan was designed to ensure that the researcher would gather sufficient relevant information to respond to the main research question as well as the secondary questions and reach their related objectives. As indicated in the previous chapter, the main research question How can the integration of seismic retrofit and architecture in URM buildings be improved? implies answering two related queries: what are the architectural qualities potentially affected by seismic retrofit?, and what factors and influences affect the integration of seismic retrofit and architecture in URM buildings? 
To collect the data related to these questions, the qualitative research used a combination of different tactics which allowed investigating various sources of information (Groat \& Wang, 2002). The findings from these different sources could then be compared with one another. In doing so, different perspectives and dimensions of a same case study were explored and understood. This approach is identified as 'Triangulation' and allows reducing the biases resulting from the application of a single method of inquiry and from a single source of information (Rothbauer, 2008).

Two research tactics were selected for their complementarity in obtaining information related to the two secondary research questions. Each tactic corresponded to one phase of data collection:

- Phase 1: on-site direct observations of buildings following the collection of building documentation, including architectural and engineering construction drawings, archival documents, and photographs.

- Phase 2: semi-structured interviews of the main designers of the retrofitted buildings; namely, the structural engineers and the architects.

The observation tactic gave the opportunity for the researcher to observe directly on-site how the seismic retrofit structures integrate with the existing architectural qualities. This allowed gathering information useful to the achievement of two objectives: identification of factors affecting integration, and appreciation of potential predisposition of seismic structural systems to engage with existing architectural qualities. The information collected from on-site observations alone could not be considered as complete. It required a second phase, aiming for the same objectives yet gaining data from other participants. Additional information was thus obtained from the architects and structural engineers in charge of the seismic retrofit of the case studies. Through interviews, different point of views could be explored thus balancing and completing the work undertaken in the first phase.

The following paragraphs provide further detail about the two phases:

Phase 1 corresponded to the visit to the five buildings with the aim of collecting data regarding the integration of seismic retrofit and architecture for each one of them. More specifically, through the visits, the researcher examined how the three main seismic structures (shear wall, braced frame, and moment frame) and the diaphragms were integrated with the buildings' architectural qualities. The phase started by contacting the structural engineers and architects by e-mails, presenting the research project, and soliciting their participation. Following their acceptance and the selection of potential case studies, the designers then sought agreement from the buildings' owners and former 
clients to provide documentation and allow on-site visits. Once permission had been obtained, the designers provided architectural and structural documents, as well as archival records. These documents were either sent by e-mail or delivered by hand during brief meetings with the designers. These documents enabled identification of the seismic retrofit works and the location of the various structural systems. This also allowed for a check if any changes were undertaken in between the end of the retrofit work and the on-site visit. In doing so, the risk of potential new refurbishments affecting the examination of integration between seismic retrofit and architecture was avoided.

In parallel to the collection of documents and prior to the on-site visits, an "observational instrument", as defined by Yin (2009, p. 109), was created as part of the case study protocol. This instrument, the Observation Checklist, drew upon seven architectural and heritage categories that had been previously identified which comprised a total of 16 architectural qualities. These categories and their related architectural qualities resulted from the literature review undertaken in Stage 1, in which various contributions of structure to architecture were identified. The table comprised a series of questions with the purpose of directing the researcher to examine how the seismic structural elements were interacting with the various architectural qualities. The Observation Checklist was therefore a way to help the researcher construct his review of the integration of the seismic retrofit solution with existing architecture.

The on-site observations were initiated in October 2015 and finished in April 2016. They were undertaken by the researcher alone, with the exception of one building in which the building manager provided guidance during the entire visit. The observation of each building was undertaken on site, by answering the questions from the Observation Checklist. Each visit took between one to two hours depending on the number of architectural qualities to be examined and the accessibility of each space in the building.

The approach of selecting criteria, i.e. architectural qualities, and questions to help examine integration drew upon two studies exploring contemporary architectural design competitions and assessment of architectural quality (Kazemian, Rönn, \& Svensson, 2005, 2007). Rönn (2011a) and Volker (2010) explain that a competition is widely accepted by professionals and lay people as a way to assess the architectural qualities of entries in order to choose the most successful one. To do so, one common approach is the use of assessment criteria to help the jury members form their respective opinions on each criterion for each of the entries (AIA, 2010; Kazemian \& Rönn, 2009; Svensson, 2009). The criteria first indicate to the jurors what are the key aspects for them to judge, and secondly, how to assess them by answering a series of questions. The "Coherence and surroundings" criterion (Rönn, 2011a, p. 108) for instance implies three questions: "How well does 
the proposal fit the site? Is the scale appropriate? How does the design blend in with the neighbouring buildings and the surrounding landscape?". As indicated by Rönn, this process does not lead to one particular outcome but allows each jury member to develop his or her own opinion and then express it to the other members.

In Phase 1, the results of the observations were directly related to the researcher's judgment. This aspect of the research was in accordance with the nature of qualitative research. As indicated by Groat \& Wang (2002, p. 71), "Qualitative research ... assumes a subjective reality and a view of the researcher as interactive with the subject of inquiry". Referring to John Creswell (1994), Groat \& Wang further point out that "reality is subjective and multiple as seen by participants in a study". As a result, while the researcher took into account his reality of the subject of inquiry in Phase 1 , the research study also addressed the reality of each of the participants in Phase 2. Like the researcher, the architects and structural engineers were required to review the level of integration of their own seismic retrofit solution with the 16 selected architectural qualities. This approach ensured that a total of three participants would be given the opportunity to provide a personal opinion regarding the level of integration of the seismic retrofit work with each architectural quality.

In between Phases 1 and 2, a Table of Design Process was given to the structural engineer of each case study for him or her to complete. The table indicated the different stages of the seismic retrofit design process and the timing of stakeholders' involvement in the project. The aim was to identify the timing of involvement of each stakeholder at the different stages of the design process. The table was organised around the main design process stages, as indicated in the Design Documentation Guidelines (NZCIC, 2004), and included all likely stakeholders. The engineers, however, had the opportunity to add any additional design stages or modify others if needed. Similar adjustment was allowed regarding the stakeholders. Once completed by the engineer, the document was verified and completed by the architect in case of it lacking any information. The aim of the table was to support and complement the interviews in Phase 2. It thus facilitated the researcher's understanding of the project's evolution.

Phase 2 was a series of semi-structured interviews conducted with the five architects and five structural engineers of the selected case study projects. The interviews followed the visits and reviews of the five buildings, and were undertaken between April and July 2016.

The interview was designed in three sections: 
- The first section was general in order to appreciate how the interviewee perceived and defined the issue of integration based on his or her professional experience. The questions were therefore not focused on the retrofitted building but instead on issues regularly experienced in seismic retrofit practice.

- Moving to a more specific level, the second section asked the interviewee about the completed seismically retrofitted building serving as a case study. The interviewee explained how the relationship between the seismic systems and architectural qualities was considered. The questions were organised based on the 16 architectural qualities used to review each building in Phase 1. This approach had two advantages. First, it allowed gathering of information on specific architectural qualities while maintaining open-ended questions. Secondly, it allowed the interviewee to provide new perspectives, additional those obtained by the researcher in Phase 1, regarding the issue of integration. This section of the interviews was therefore the equivalent of Phase 1 with the difference that opportunity was given now to the designers to reflect on the integration of their own design. The equivalent of the Observation Checklist - relevant during on-site visits but not usable for interviews - was a series of a series of questions related to the same 16 architectural qualities that allowed appreciating the level of integration in each case study.

- Finally, as the issue of integration was clarified from a general as well as detailed perspective, the interview then focused on the retrofit design process. The questions aimed to understand how the issue of integration was approached through the development of the retrofit solution.

The questionnaire was thus ordered so the interviewee would first define integration and have a basis to then respond to the second section of the interview treating the 16 architectural qualities. This second section would then also serve as a basis for the interviewee to answer more efficiently the last section regarding integration during the design process. The interview also used openended questions in order to provide flexibility to the interviewee and obtain comprehensive information unique to each designer.

Each interview was organised as a face-to-face meeting between the researcher and the interviewee. This approach maintained the interviewee's concentration regarding the questions asked, in contrast to a phone or email interview that would have been less effective. Also, ensuring that the designer of each case study was interviewed separately avoided any potential interruption or influence of one interviewee on another. Each interview followed an identical procedure, meaning that it took place at the interviewee's office and at a time he or she found adequate. The 
interview was also audio-recorded in agreement with the interviewee. The time of each meeting varied between one hour and a half and two hours. For each case study, the first designer to be interviewed was always the structural engineer. This was justified by the fact that, due to the nature of seismic retrofit projects, the structural engineer was almost constantly the first stakeholder of the design team to be commissioned by the client. He or she would thus provide information from the very start of the retrofit project and give the researcher a wide understanding of the case study for the rest of the research. Once the interview with the engineer was completed, the researcher then met the architect and asked the same questions. This method was used for all five case studies and a total of 10 interviewees.

Although identical questions were asked to the architect and structural engineer of the same case study, some questions from Section 2 of the interview could vary from one case study to another. Depending on the treatment of the seismic retrofit - for instance, whether the seismic structure was located externally or internally, or hidden instead of exposed - the affected architectural qualities would be different and therefore some questions would become irrelevant. These changes were not detrimental to the collection of data. On the contrary, they ensured that all the architectural qualities influenced by the seismic structure were taken into account.

By the end of the data collection, complementary information was gathered using two different research tactics. This method aimed at limiting potential biases that the qualitative research may carry. Indeed, the researcher, architects, and structural engineers had the opportunity to provide information regarding their own understanding and appreciation of the integration of the seismic retrofit solutions with the 16 identified architectural qualities. The tool used to collect the data was adapted to the type of participant - Observation Checklist for the researcher and list of questions for the designers. Yet, all participants addressed the same issue of the level of integration of the seismic retrofit structure and architectural quality. As a result, and similar to contemporary architectural design competitions, every participant had the opportunity to express their own point of view in regard to identical criteria (AIA, 2010; Kazemian \& Rönn, 2009; Svensson, 2009). Any difference of opinion between the researcher, architects, and structural engineers was then reported in the thesis.

\subsection{Data Analysis}

The data analysis was divided in two phases similar to those of the data collection:

- Phase 1: analysis of the on-site observations. 
- Phase 2: analysis of the transcripts of the interviews.

In Phase 1, the analysis of the on-site visit observations relied on the answers gathered by the researcher using the Observation Checklist. The answers were analysed in relation to the architectural quality they related to. The analysis took support from the various type of influences seismic retrofit structural systems may have on architectural qualities. This allowed the researcher to determine, from his point of view and experience as a practicing architect, how each seismic structure and diaphragm integrated with individual architectural qualities.

This information was then translated into a Table of Analysis. For each seismic system, this table displayed all 16 architectural qualities, using colour codes to indicate how the seismic system influenced each specific architectural quality. Four colours were used: green where structure enhanced quality, blue where a quality remained neutral, orange where quality was detracted from, and grey for not applicable. This representation of the influences structure has on architectural qualities allowed for a simple and quick appreciation of their impacts. This process was repeated for each seismic system of each case study.

The Tables of Analysis were then organised per structural system: shear wall, braced frame, moment frame, and diaphragm. This organisation was established to purposefully address and contribute to two objectives ( $1 \mathrm{~b}$ and 2 ) of the research:

- Explore if and how integration was related to or dependent on the type of system and its characteristics such as geometry and form, and to

- Identify factors affecting the integration between a system and each architectural quality.

The objectives were achieved by supplementing the tables with written explanations. These explanations compared the reasons for the various influences a seismic system had on each architectural quality.

The presentation of the analysis of the on-site observations organised per seismic structural systems rather than per building, as normally done for a qualitative research with multiple case studies, was carefully considered by the researcher. It was justified by its effectiveness in extracting common patterns from the results of the Tables of Analysis, as well as identifying the potential redundancy of reasons and factors influencing integration. Such a work would have been considerably more difficult to achieve if undertaken per building. Due to the substantial amount of seismic retrofit structural systems to examine, their individual analysis in each building would have weakened the 
identification of potential predisposition from a type of structure to integrate with existing architectural qualities.

To fully complete the objectives started in Phase 1, it was necessary to focus on the analysis of the designers' interviews in Phase 2. This allowed appreciating different point of views regarding integration of seismic retrofit and architecture, and more specifically to refine the findings associated with the objectives.

In Phase 2, the coding of the interview transcripts was undertaken through the QSR International's NVivo 11 qualitative data analysis Software. NVivo helped manage and analyse the collected data through the three sections of the interview questionnaire. The coding system was as follows:

- In the first section, the data was framed and analysed through three topics: successful integration, poor integration, and possible solutions. These topics rose from Charleson \& Pirie's (2009) and Uihlein's (2013) research on collaboration between architects and engineers, and structural integration respectively. The data was analysed separately between architects and engineers in order to appreciate how each type of professional considered integration. Only for the analysis of the possible solutions were the answers examined together as they transcended the interviewees' disciplines.

- For the second section, the data was coded based on the 16 architectural qualities examined in Phase 1. For each quality, the answers of the architect and engineer of a same building were analysed and compared. This allowed comparing how the professionals of each case study approached and reviewed the integration of their seismic retrofit with the architectural qualities. This approach was repeated for each case study. This process identified common factors influencing integration through the five case studies.

- In the last section, three topics focussed the analysis of the data: design steps and time of involvement, leadership, and constraints to integration. These topics were previously determined from the literature as being important and they explored the evolution of a seismic retrofit design process, the collaboration between the architect and engineer, and any difficulties affecting the retrofit design. Like the previous section, the data was analysed per case study by comparing the answers of the architect and engineer of the same building. In repeating the process, unique and recurring issues could thus be identified between the various case studies.

The transition from Phase 1 to Phase 2 allowed to gradually move from a smaller scale, the structural systems, to a wider scale, the entire building and it design process. To maintain the link between 
both phases, the Tables of Analysis of Phase 1 were included in Phase 2 and organised per building. This approach ensured that the findings obtained from the on-site observations were put in contrast with those of the interviews. This also gave the opportunity to present individual case reports. These reports allowed appreciating how the researcher, architects, and engineers determined the levels of integration of the seismic retrofit with the 16 architectural qualities in each building. A second series of case reports focusing on the design process of each building was also established based on the answers of the interviews. Finally, a cross case report drawing upon the findings of every single case study was provided at the end of Phase 2 .

Overall, the two phases aimed at being complementary in achieving two objectives of the current study. These objectives then allowed responding to the secondary questions. Thus, to answer the question 'What are the architectural qualities potentially affected by seismic retrofit?', the study identified potential predisposition of seismic retrofit structural systems to engage with existing architectural qualities in URM buildings. Regarding the second question, 'What factors and influences affect the integration of seismic retrofit and architecture in URM buildings?', the analysis in Phase 1 and 2 established a series of key factors affecting integration in URM buildings within and outside the design process.

\subsection{Trustworthiness of the case study research}

The trustworthiness of data collection and analysis of qualitative research is considered a challenging issue (Groat \& Wang, 2002). To help establish reliability and construct the validity of a case study strategy, Yin (2009) lists three principles to follow; namely, use multiple sources of evidence, create a case study database, and maintain a chain of evidence. Two of these principles were followed but the case study database was not created as the anonymity of the buildings and related stakeholders would have been lost.

\subsubsection{Multiple sources of evidence}

Multiple sources were used to collect data. This included architectural and engineering plans of the five buildings, photographs of the retrofit construction processes, archival documents, direct observations made by the researcher, and finally, a series of interviews. The diverse types of sources were complementary thus providing comprehensive data, and reducing mistakes and misinterpretations throughout the research. The plans, photographs, and archival documents provided guidance and references for the researcher during the on-site observations and also allowed corroboration or contradiction of the interviewees' information. 


\subsubsection{Chain of evidence}

The chain of evidence aimed at ensuring that any reader could trace back the steps of the study from its beginning to its end and vice versa. This meant maintaining a link through the research between the initial questions, buildings' documentation, on-site observations, participants' interviews, and research conclusions. As indicated by Yin (2009), four links are required to create and maintain a chain of evidence. First, the research reports, whether resulting from directobservations or interviews, should indicate the data from which the findings are based. According to Whitley, Kite \& Adams (2013, p. 375), this can be achieved by "[quoting] excerpts from interviews and documents or provide detailed descriptions of observations in support of a conclusion". To achieve this first link, the chapter examining the data collected during on-site observations would provide both sketches and highly detailed descriptions of the seismic retrofit structural systems and their levels of integration with architectural qualities. In addition, the chapter analysing of the transcripts of the interviews would regularly provide quotes from the participants to support the findings. The second link requires the case study data base to provide a copy of all the gathered and recorded data so that any evidence could be read in context. In the case of the current research, the data base would include the entire collection of building documentation as well as the full transcripts of the interviews. As explained at the beginning of section 3.7, such a data base would imperil the anonymity of the buildings and stakeholders who participated in their seismic retrofit and could not be provided. Moreover, based on the Victoria University's Human Ethics and Consent to Interview (Appendix D), the collected information is to remain confidential to the researcher and the supervisor, and is to be destroyed three years after the research. Finally, the transcription of the interviews would have resulted in an addition of 62000 words to the thesis, which is disproportionate in regard to the thesis' length. To compensate with the lack of data base, the current research methodology gives the opportunity to cross-check information gathered in each phase of the data collection and analysis. This implies that the information and findings of the onsite observations can be directly compared with the data gathered from the interviews. Reciprocally, the responses of the designers in the interviews can be connected with the sketches and Tables of analysis obtained from the on-site visits. As a result, connections between the data is created, thus limiting personal interpretation of the gathered information. The third link mentioned by Yin (2009), corresponds to the respect of the case study protocol meaning that the information gathered for each case study has to be undertaken following a similar procedure and under similar circumstances. As described in section3.5, the gathering of information was carefully undertaken so that its procedure and circumstances were respected and identical for each case study, during both the on-site observations and interviews. The last link requires the data collection plan to indicate 
the link between the data collected and the initial study questions and objectives. Such a relationship is explained in sections 3.4 and 3.5 of the thesis. The sections explain which data is intended to answer which question and achieve which objective.

\subsection{Ethical Considerations}

The research was highly dependent on the acceptance of clients, building owners, structural engineers, and architects to allow the researcher to study the selected seismically retrofitted buildings. While most of the architects and structural engineers who were approached were inclined to participate in the research, several clients refused to allow their buildings to be part of the study. To reduce future reluctance and encourage participants, the researcher ensured anonymity to any stakeholders involved in the design and construction of the buildings. As a result:

- The five buildings and their related architects and engineers are identified using numbers. For example, the first case study is identified as Building \#1 and is designed by Architect \#1 and Engineer \#1,

- No reproduction of documentation related to the buildings is provided in the thesis,

- No photos of the buildings' interior or exterior are presented in the thesis, and

- Simplified sketches are used to support the written analysis.

Regarding ethical research standards, the researcher submitted an Ethics Approval application in order to undertake interviews. It was reviewed and approved by the Victoria University's Human Ethics Committee (Issued Number 22566) (Appendix B). The application includes an Information Letter for participants (Appendix C), a Consent to Interview (Appendix D), and the Interview Questionnaire form (Appendix E). Prior to the interview, the Consent to Interview statement was provided to the participants and each of them signed the document.

\subsection{Research scope}

\subsubsection{URM buildings}

While the subject of integration of seismic retrofit and existing architecture can be explored in any building regardless of its materiality, the researcher decided to focus on URM buildings. In 2010, around 3750 URM buildings remained in New Zealand and represented approximately $8 \%$ of the commercial building stock in terms of floor area (Russell \& Ingham, 2010). To understand the importance of this information, these numbers must be put in perspective with two other aspects. First, despite the small number, the total URM building stock represents an approximate value of 
\$NZ1.5 billion (Russell \& Ingham, 2010) which is a significant sum for the country. Secondly, the URM buildings are considered an important part of the heritage and character of New Zealand (Cooper et al., 2012a). The impact of damaging or losing part of New Zealand's architectural identity is thus particularly great with such a limited number of URM buildings. In addition, any alterations to these buildings may have a direct impact on their economic, cultural and heritage values. Therefore, analysing seismic retrofit and more particularly its integration in these unique buildings is particularly relevant.

In New Zealand, URM buildings are typically composed of exterior URM walls arranged in orthogonal directions, timber floors taking on the structural role of diaphragms, and a wooden lightweight roof (Russell, 2010). While these buildings generally possess regular plan configurations allowing their URM walls to be part of the in-plane resisting system, they commonly possess several failures. These failures can be hierarchised depending on the vulnerability of the building's components they are related to. The "capacity chain" (NZSEE, SESOC, NZGS, MBIE, \& EQC, 2017) below displays a decreasing vulnerability from left to right among the URM building components (Figure 2).

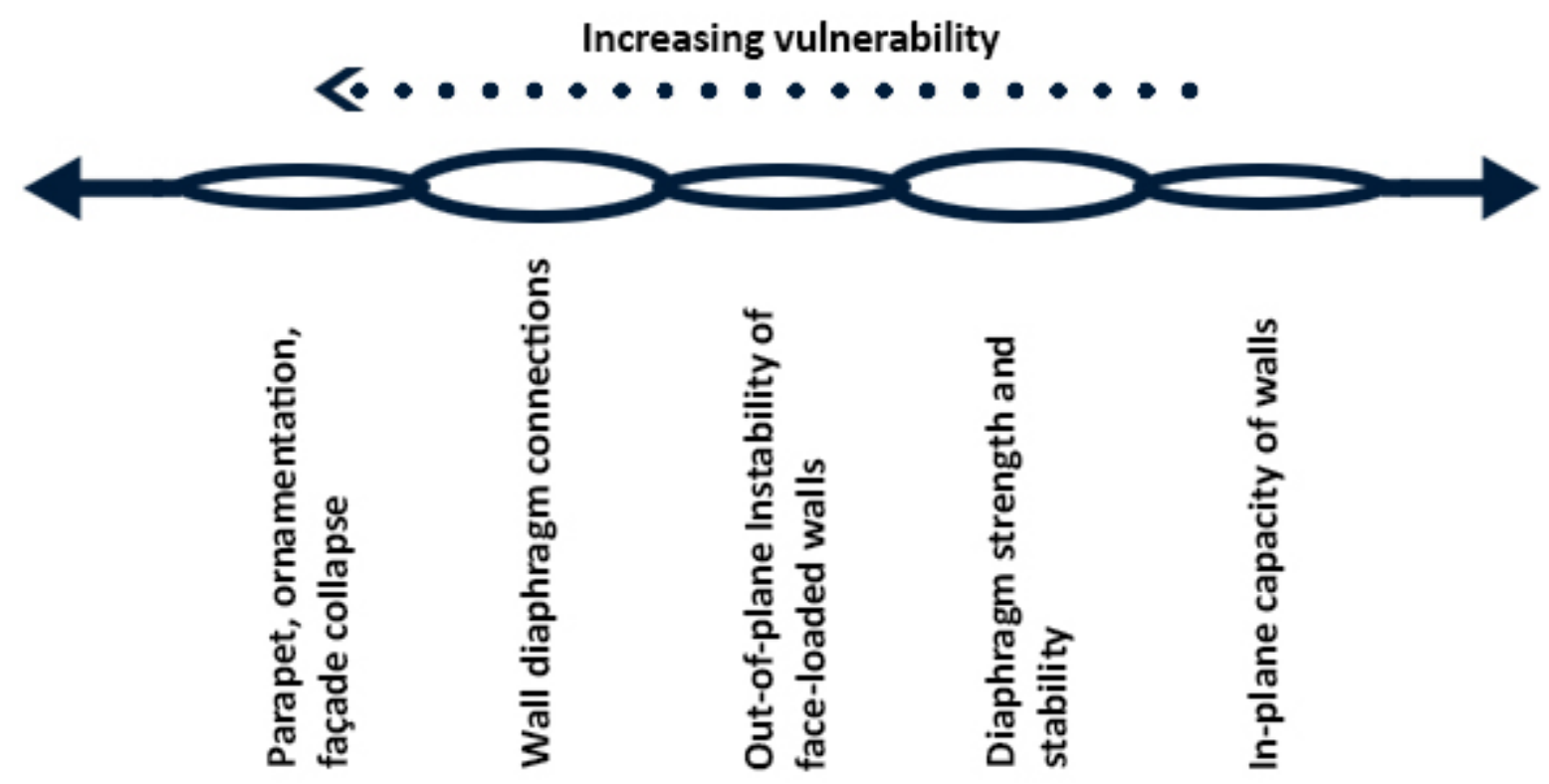

Figure 2. Capacity chain presenting a hierarchy of vulnerability among URM building components (Source: NZSEE et al., 2017)

The first two most vulnerable groups of components may suffer from inadequate connections. They include poorly restrained elements located at height such as parapets and chimneys. They also relate to the lack of strong connections between diaphragms and walls (Charleson, 2008).

Regarding the out-of-plane failures, they can occur when the ceiling joist-to-wall anchors are insufficient. As a result, URM walls perpendicular to the motion of the earthquakes are unable to 
resist seismic loads. In addition, due to the multi-directional nature of earthquakes, the combination of in-plane and out-of-plane loads further affects URM walls. A crack from an in-plane failure, would create "triangular cantilever wedges" (Bruneau, 1994) thus considerably reducing the out-of-plane strength of the walls.

Another deficiency comes from the flexibility of timber diaphragms in contrast with the stiffness of exterior URM walls. While moving in-plane, the diaphragms exert significant forces on the walls leading in some cases to their collapse (Bruneau, 1994; Koliou, Lawson, Filiatrault, \& Kelly, 2017).

Finally, the in-plane failures include different issues summarised by Magenes \& Calvi (1997) and represented below (Figure 3).

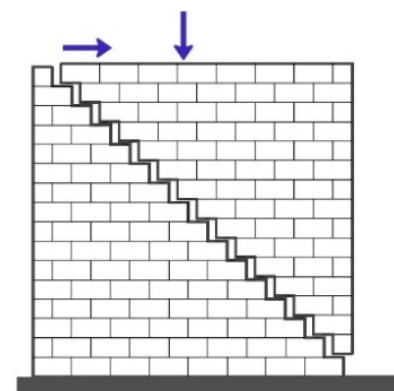

a) Shear failure

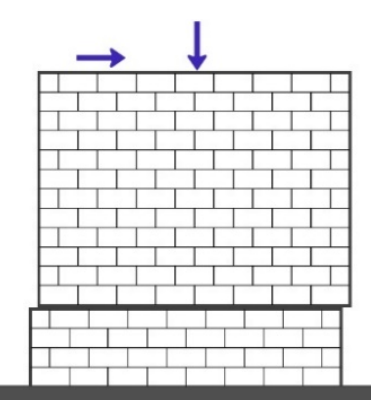

b) Sliding failure

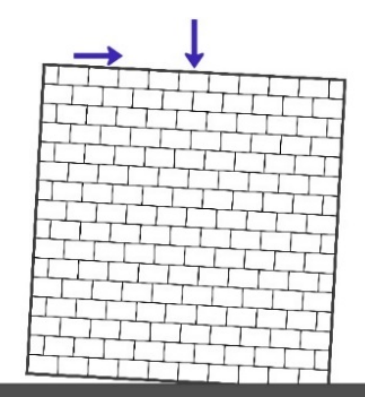

c) Rocking failure

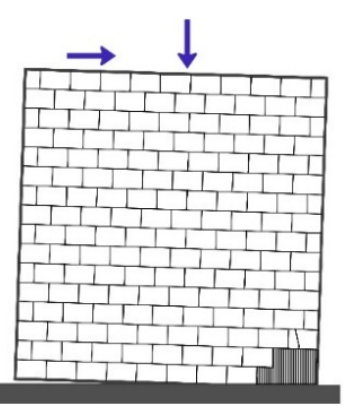

d) Toe crushing

Figure 3. Different in-plane failure modes of a laterally loaded URM wall

A seismic assessment of a URM building would therefore start from the most vulnerable components and gradually move towards those less vulnerable. Elements like parapets would require relatively minimal work, such as the installation of steel angle braces to restrain them from falling. At the other end of the capacity chain, in-plane failure of walls would require more consequent work. Additional vertical seismic systems, such as shear walls, braced frames, or moment frames would commonly be used resulting in a greater impact on the building's architecture.

\subsubsection{Location of the case studies}

The research is conducted in the city of Wellington, New Zealand, which possesses an estimated 677 URM buildings. Wellington has the second largest number of URM buildings in the North Island after Auckland (Russell \& Ingham, 2010). In 2010, around 92\% of these buildings were considered as potentially earthquake-prone (Russell, 2010). While this percentage is very high, the researcher's conversations with various structural engineering firms based in Wellington revealed a reasonable number of URM buildings had been retrofitted since 2012. This situation could have resulted from the Earthquake-prone Buildings Policy of the Wellington City Council encouraging building owners 
to retrofit their buildings within 10 to 20 years depending on the level of priority (Wellington City Council, 2013). On average, each of the dozen consulting engineering firms approached by the researcher has seismically retrofitted four seismically retrofitted URM buildings. A sufficient number of potential case studies was therefore available.

A second reason for choosing URM buildings from Wellington comes from the categorisation of New Zealand by the Building (Earthquake-prone Buildings) Amendment Act 2016 (New Zealand Parliament, 2016) into three seismic risk areas: high, medium, and low. Wellington, as well as Christchurch, are located in high-risk areas in comparison to Auckland who is situated in a low-risk zone (MBIE, n.d.-a). The difference between these areas depends on the seismic hazard factor ' $Z$ ' (Figure 4). A high factor $Z$ results in the seismic retrofit of buildings having more stringent design requirements than for those situated in low-risk zones (BRANZ, n.d.). As factor $Z$ is used to determine the required design strength for an existing building, its difference of level within a same seismic risk area can increase the difficulty for designers to seismically retrofit a building. As Wellington possesses a factor $Z$ (0.40), greater than Christchurch (0.30), its URM buildings need to be to retrofitted for the utmost earthquake scenario. Their seismic retrofit would encompass not only the requirements for buildings located in low risk areas like Auckland or Dunedin, but would also be potentially confronted to the entire types of failures presented in the capacity chain and introduced in the previous section. Selecting Wellington therefore increases the number of options and variations of seismic solutions. As a result, greater amount of information can be gained. 


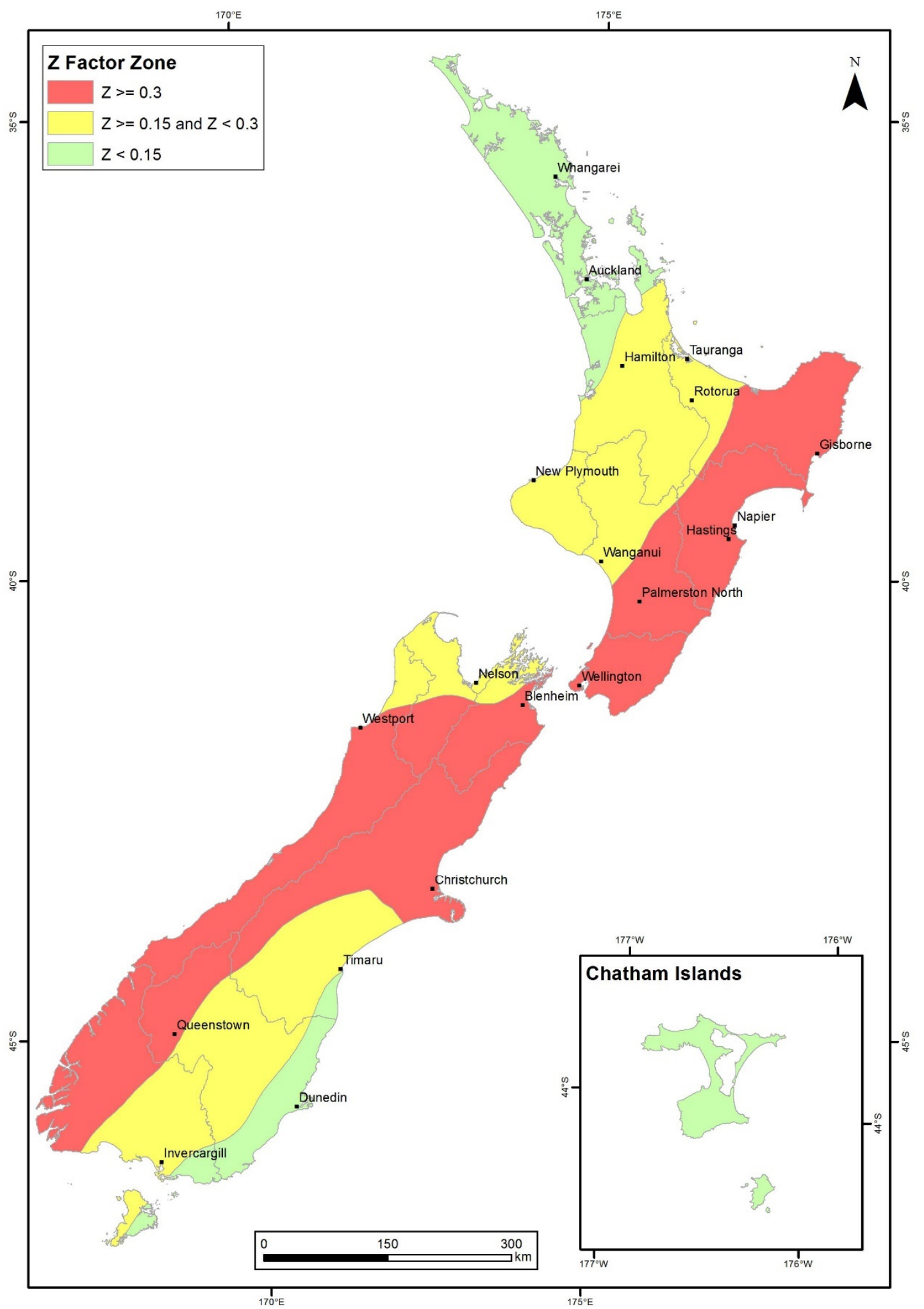

Figure 4. Map of New Zealand with the seismic risk areas based on the seismic hazard factor ' $Z$ ' (Source: MBIE, 2016, p. 52)

Another advantage of choosing Wellington buildings is that seismic retrofit work undertaken in Wellington since the '70s-'80s is particularly respectful of the buildings' roles in the city's history (L.T. McGuinness, n.d.; Thornton, 2010). With several decades of experience in a city with a high 
seismicity, the local professionals appear to be particularly relevant subjects regarding the issue of integration of seismic structure and architecture. The decision to work with Wellington architects and structural engineers is further comforted by the acknowledgement of the NZSEE of the stateof-the-art seismic retrofit works undertaken in the capital. From 2013 to 2015, the NZSEE (n.d.) launched a series of national competitions for designers to present their finest seismic retrofit projects. Over these three years, the projects undertaken in Wellington by local designers has been repeatedly awarded in various categories, including those related to this research. The 'Overall winner and Best adaptive re-use' award was granted every single year to Wellingtonian buildings and designers, and the 'Heritage' and 'Best engineering solution' awards twice. Architectural and structural engineering firms therefore appear to be among the most qualitative and exemplar professionals in regard to seismic retrofit. The information to gain from them and the URM buildings they have retrofitted would therefore be of great value for the research and, to further extent, inspiring and relevant to the rest of New Zealand.

Finally, undertaking the research in Wellington was also appropriate as it provided greater flexibility to set meetings with the architects and structural engineers in order to collect documentation and conduct the interviews. This allowed saving a considerable amount of time and facilitated access to the various buildings selected as case studies.

\subsubsection{Selection and characteristics of the case studies}

In New Zealand, URM buildings have been classified into seven typologies (Russell \& Ingham, 2010) as indicated in Table 1.

Table 1. New Zealand URM Building Typologies (Source: Russell \& Ingham, 2010, p. 189)

\begin{tabular}{|c|c|c|l|}
\hline Type & Description & $\begin{array}{c}\text { Importance level } \\
\text { (from NZS 1170.0) }\end{array}$ & \multicolumn{1}{c|}{ Details } \\
\hline A & One storey, isolated & 2,4 & $\begin{array}{l}\text { One storey URM buildings. Examples include convenience stores in } \\
\text { suburban areas, and small offices in a rural town. }\end{array}$ \\
\hline B & One storey, row & 2,4 & $\begin{array}{l}\text { One storey URM buildings with multiple occupancies, joined with common } \\
\text { walls in a row. Typical in main commercial districts, especially along the } \\
\text { main street in a small town. }\end{array}$ \\
\hline C & Two storey, isolated & 2,4 & $\begin{array}{l}\text { Two storey URM buildings, often with an open front. Examples include } \\
\text { small cinemas, a professional office in a rural town and post offices. }\end{array}$ \\
\hline D & Two storey, row & 2,4 & $\begin{array}{l}\text { Two storey URM buildings with multiple occupancies, joined with common } \\
\text { walls in a row. Typical in commercial districts. }\end{array}$ \\
\hline E & Three+ storey, isolated & 2,4 & $\begin{array}{l}\text { Three + storey URM buildings, for example office buildings in older parts of } \\
\text { Auckland and Wellington. }\end{array}$ \\
\hline F & Three+ storey, row & $\begin{array}{l}\text { Three + storey URM buildings with multiple occupancies, joined with } \\
\text { common walls in a row. Typical in industrial districts, especially close to a } \\
\text { port (or historic port). }\end{array}$ \\
\hline G & Institutional, Religious, \\
Industrial
\end{tabular}

From this starting point, a series of criteria were considered when selecting potential case studies: 
- The seismic retrofit had to be undertaken after the implementation of the Building Act 2004. This ensured that all the designers were assessing and designing their seismic retrofit design based on similar legislative requirements. In addition, this constraint reduced the risk of having the integration of seismic retrofit and architecture of a building modified through its life time;

- Each building had to possess at least two storeys in order to take into account the potential retrofit of a floor diaphragm. This criterion automatically excluded the consideration of URM buildings Types A and B;

- Each building had to be retrofitted using a combination of two of the three most commonly used seismic systems; namely, shear wall, braced frame, and moment frame. This allowed maximising the number of seismic structures to be analysed per case study; and

- An architect and a structural engineer had to be involved in the seismic retrofit design. This condition was necessary to analyse the collaboration between both types of designers and examine how each of them approached integration.

These criteria shortened the lists of URM buildings available from the structural engineering and architecture firms contacted. Among the dozen remaining buildings, a total of five case studies were selected. The selected buildings varied in many aspects, including their typology, heritage listing, exposure or hiddenness of their seismic components, function, and percentage of NBS. NBS refers to the New Building Standards and is defined as "the minimum structural performance standard that must be met by a new building based on present day design codes" (Wellington City Council, 2013, p. 31). The case studies also possessed similarities such as types of seismic structures. This situation allowed the examination of different approaches to seismic retrofit while also being able to compare the results for similar seismic systems.

The decision to use five case studies was also driven by the numbers of seismic structural systems able to be compared. A decision was made to have each structural system feature at least three times among the selected buildings. While a minimum of two similar structures were sufficient to make a comparison of their related integration, a third example allowed refinement and further elaboration of the findings. As a result, the selected five case studies provided a total of four shear wall systems, three braced frame systems, and three moment frame systems.

The researcher acknowledges that the selection of the case studies was also dependent on unpredictable factors. A first one was the refusal of some clients to use their buildings as case studies. This reduced the flexibility of the researcher to choose case studies among the pre-selected buildings. A second issue was the accessibility of some buildings. In some cases, direct observations 
would not have been possible due to physical restrictions to enter the buildings or explore key spaces.

The case studies all fell into the Importance Level 2 category defined by AS/NZS 1170.0:2002 (Standards New Zealand, 2002). This situation allowed working with case studies that represented the bulk of Wellington's built environment (Wellington City Council, 2013).

The characteristics of the selected buildings are summarised in Table 2 .

Table 2. Characteristics of the five selected URM buildings

\begin{tabular}{|c|c|c|c|c|c|c|c|c|c|}
\hline Building & $\begin{array}{c}\text { Type (see } \\
\text { Table 1) }\end{array}$ & Materials & Heritage & $\begin{array}{c}\text { Occupancy } \\
\text { Type }\end{array}$ & $\begin{array}{c}\text { Seismic structural } \\
\text { systems }\end{array}$ & $\begin{array}{c}\text { Building } \\
\text { height }\end{array}$ & Year of build & $\begin{array}{l}\text { Year of } \\
\text { retrofit }\end{array}$ & $\%$ NBS \\
\hline$\# 1$ & $\mathrm{~F}$ & $\begin{array}{l}\text { Solid unreinforced } \\
\text { masonry walls, } \\
\text { timber floors, steel } \\
\text { beams, and cast iron } \\
\text { columns }\end{array}$ & $\begin{array}{l}\text { Building } \\
\text { listed as } \\
\text { Historic } \\
\text { Place } \\
\text { Category } 2\end{array}$ & $\begin{array}{l}\text { Retail trade } \\
\text { and offices }\end{array}$ & $\begin{array}{l}\text { Concrete shear } \\
\text { walls } \\
+ \\
\text { Concrete moment } \\
\text { frames }\end{array}$ & 4-storey & $\begin{array}{c}\text { Original } \\
\text { building 1908; } \\
\text { 'infill' building } \\
\text { behind in } 1985\end{array}$ & 2013 & $100 \%$ \\
\hline$\# 2$ & $\mathrm{~F}$ & $\begin{array}{l}\text { Solid unreinforced } \\
\text { masonry brick walls, } \\
\text { timber floors, steel } \\
\text { beams, and cast iron } \\
\text { columns }\end{array}$ & $\begin{array}{l}\text { Non heritage } \\
\text { building but } \\
\text { located in a } \\
\text { heritage area }\end{array}$ & $\begin{array}{l}\text { Restaurant } \\
\text { and offices }\end{array}$ & $\begin{array}{l}\text { Concrete shear } \\
\text { walls } \\
+ \\
\text { Concrete moment } \\
\text { frames }\end{array}$ & $\begin{array}{l}\text { 3-storey+ } \\
\text { lightweight } \\
\text { additional } \\
\text { floor }\end{array}$ & 1908 & 2014 & $70 \%$ \\
\hline \#3 & $\mathrm{F}$ & $\begin{array}{l}\text { Solid unreinforced } \\
\text { masonry brick walls } \\
\text { timber floors, and } \\
\text { steel columns and } \\
\text { girders }\end{array}$ & $\begin{array}{l}\text { Non heritage } \\
\text { building but } \\
\text { located in a } \\
\text { heritage area }\end{array}$ & $\begin{array}{l}\text { Hotel and } \\
\text { restaurant }\end{array}$ & $\begin{array}{l}\text { Concrete shear } \\
\text { walls } \\
+ \\
\text { Steel K braced } \\
\text { frames }\end{array}$ & 4-storey & 1903 & 2004 & $100 \%$ \\
\hline$\# 4$ & $\mathrm{E}$ & $\begin{array}{l}\text { Solid unreinforced } \\
\text { masonry brick walls, } \\
\text { timber floors, steel } \\
\text { columns }\end{array}$ & $\begin{array}{l}\text { Non heritage } \\
\text { building and } \\
\text { not located } \\
\text { in a heritage } \\
\text { area }\end{array}$ & $\begin{array}{l}\text { Offices and } \\
\text { residential }\end{array}$ & $\begin{array}{l}\text { Concrete shear } \\
\text { walls } \\
+ \\
\text { Steel X braced } \\
\text { frames }\end{array}$ & 4-storey & \begin{tabular}{|} 
1930's. \\
Refurbished \\
and \\
seismically \\
retrofitted in \\
1995
\end{tabular} & 2016 & $45 \%$ \\
\hline$\# 5$ & D & $\begin{array}{l}\text { Solid unreinforced } \\
\text { masonry brick walls, } \\
\text { and concrete frames } \\
\text { and floors }\end{array}$ & $\begin{array}{l}\text { Non heritage } \\
\text { building and } \\
\text { not located } \\
\text { in a heritage } \\
\text { area }\end{array}$ & $\begin{array}{l}\text { Restaurant } \\
\text { and leisure }\end{array}$ & $\begin{array}{l}\text { Steel moment } \\
\text { frames } \\
+ \\
\text { Steel V braced } \\
\text { frames }\end{array}$ & 2-storey & $\begin{array}{c}1919 . \\
\text { Refurbished } \\
\text { and initially } \\
\text { seismically } \\
\text { retrofitted in } \\
\text { late 90's }\end{array}$ & 2012 & $75 \%$ \\
\hline
\end{tabular}

\subsubsection{Participants' characteristics}

Each architect and engineer contributed only once to the interviews. In addition, each participant worked in a different firm with the exception of Architect \#5 and Engineer \#5 who practiced in the same company. The experience of each participant is indicated in Table 3 below. With the exception of Architect \#4, the participants can be considered as experienced in seismic retrofit. 
Table 3. Experience of the participants in terms of years of practice and number of seismic retrofit buildings

\begin{tabular}{|c|c|c|}
\hline & $\begin{array}{l}\text { Years of practicing } \\
\text { experience }\end{array}$ & $\begin{array}{l}\text { Number of seismic retrofit } \\
\text { projects designed }\end{array}$ \\
\hline Architect \#1 & 22 & 6 \\
\hline Structural engineer \#1 & 5 & 10 \\
\hline Architect \#2 & 25 & 12 \\
\hline Structural engineer \#2 & 17 & 20 \\
\hline Architect \#3 & 20 & 5 \\
\hline Structural engineer \#3 & 40 & 30 \\
\hline Architect \#4 & 14 & 2 \\
\hline Structural engineer \#4 & 4 & 8 \\
\hline Architect \#5 & 35 & 20 \\
\hline Structural engineer \#5 & 44 & 80 \\
\hline
\end{tabular}

\subsubsection{Transferability of the research findings}

The purpose of a qualitative research study is to undertake an intensive and rich investigation on a precise phenomenon related to human experience, within a specific locality and in a particular context (Leung, 2015; Polit \& Beck, 2010). However, such a work does not restrict a qualitative research from providing results that may be relevant and applicable to other situations or settings (Mayring, 2007). To extrapolate qualitative research findings, a form of generalisability is required. Three models are presented by Firestone (1993) and commonly referred to when undertaking quantitative and qualitative studies. The first, 'Statistical Generalisation', is embedded to qualitative research and is therefore not applicable to the current study. The second, 'Analytic Generalisation', compares the research findings to a previously developed theory in order to support or challenge it. While effective when evidences supporting the theory can be undisputedly confirmed, the difficulty of making constant and unanimously causal inferences can weaken the generalisability of the research (Ercikan \& Roth, 2014). Thorne \& Darbyshire (2005) and Polit \& Beck (2010) thus warn about the problematics of this model of generalisability, which often leads the researcher to premature closure, enthusiasm for artificial coherence, overgeneralisation, and stopping when favourable rather than when attaining saturation. Unlike the two previous models of generalisation, the last one, 'Transferability' avoids any broad claims. Instead, transferability or case-to-casetransfer, is considered as a collaborative process between the researcher and the reader. The researcher's task is to provide extensive information about the context of the research, the phenomenon being examined, settings, participants, and case studies in order for the readers to make assumptions about extrapolating the findings to other conditions (Polit \& Beck, 2010). With this form of generalisability, it is the reader who is requested to appreciate and determine the extent to which the findings of the research can be applied to the situation and context being examined (Firestone, 1993). This approach has close ties with the principle of "proximal similarity" as defined by Campbell (1986, p. 76). This principle implies for the reader to determine a causal validity based 
on the similarities between the referring research and the one examined by the reader. Through the spectrum of similarities and differences including the date of the phenomenon, the type of participants involved, settings, and context, the transferability of the findings can be undertaken by the reader (Lincoln \& Guba, 1985).

The model of transferability is particularly relevant in the current research. Indeed, the methodology developed in this research to analyse the integration of seismic retrofit and architecture in URM buildings can be reiterated by future researchers to analyse the same phenomenon but in different situations. As little work has been undertaken on the topic explored in this research, it is through the replication of the current methodology in different earthquake-prone cities and countries, that the current research findings can be confirmed, refined, deviated, or negated. For example, employing the current methodology to analyse URM buildings in California would be a particularly relevant way to use the model of transferability on the findings of this study. Indeed, California shares several traits in common with New Zealand which allows determining common settings for a future research. Both are considered as a young state and young country respectively, with a notably low number of URM buildings - around 25000 for California and around 3750 for New Zealand - in regard to their population. Despite this small number the URM buildings are considered in both places as being particularly important in regard to their cultural and heritage values (Chalana \& Wiser, 2013; Cooper et al., 2012a). In addition, both countries have stopped the construction of new URM buildings around the same time, 1931 for New Zealand and 1933 for California (Blaikie \& Spurr, 1992). The remaining buildings presents similar vulnerabilities including among others the risk of collapsing parapets, weak diaphragm to wall connections, out-of-plane and in-plane failures (FEMA, 2009). As a result, seismic retrofit solutions identical to the ones used in New Zealand are being applied to these overseas URM buildings (Forell/Elsesser Engineers, n.d.; NEHRP, 1997). Comparing the findings of the analysis of integration of seismic retrofit and architecture in both countries through transferability would be extremely significant for the generalisability of this research findings and to further extent for the overall knowledge on the issue of integration. 


\section{CHAPTER 4. STRUCTURE AND ARCHITECTURE}

\subsection{Introduction}

In this chapter, the researcher explores the various forms integration of structure and architecture can take and the architectural qualities related to it. The benefits of integration are examined as well as the unique aspects of the seismic retrofit context that can frame it. This chapter thus aims at establishing a theoretical framework which will then be used when analysing the research case studies.

The first section addresses the uses and roles of structure in the design of new architectural projects. More specifically, it concentrates on the capacity for structure to integrate with architecture, either by generating or reinforcing specific architectural qualities. A series of architectural qualities directly related to structure can thus be determined.

The second section explores integration in the specific context of seismic retrofit. The challenges inherent to this context as well as the architectural opportunities brought by seismic retrofit structure are examined. The legitimacy of seismic retrofit structure to contribute to existing architecture is thus established.

The findings of the two sections allow determining a series of architectural qualities specific to the seismic retrofit context. In addition, the different influences that a seismic retrofit structure may have on these architectural qualities are also established. The first objective of the thesis is therefore achieved as the identified architectural qualities can be used to review integration of seismic retrofit and architecture.

\subsection{Interaction between structure and architecture}

\subsubsection{Selecting the appropriate approach in identifying architectural qualities related to structure}

The literature review reported that no definitive list of architectural qualities exists. Consequently, and in order to create a theoretical framework allowing to review integration of seismic retrofit and architecture, it is necessary to constitute a list of architectural qualities relevant to the research topic. 
A first approach considered is to look at various architectural movements throughout time and list down every one of their architectural qualities. Then, in a second time, relate structure to these qualities. However, this approach raises three issues. Firstly, the problematic decision to determine which movements to examine as, over the last hundred years, fifteen to thirty architectural movements can be considered. Secondly, the laborious identification of the entire architectural qualities related to these movements. Thirdly, the difficulty to determine whether structure interacts with these qualities and how. These last two points are particularly difficult to undertake. For instance, where the relationship between structure and open plan related to Modernist movement can be easily understood and eventually reviewed, this task becomes particularly challenging with ambiguous aspects such as thermal insulation or resource efficiency associated with Sustainable Architecture.

The second, and selected, approach is based on a reversed method. Wraber et al. (2008) explains that each working field possesses its own architectural qualities that can be established. Therefore, rather than trying fruitlessly to define an exhaustive list of architectural qualities and then reflect on the different approaches for structure to interact with them, decision is taken to proceed in the reversed way. Structure is addressed as the primary source of common architectural qualities. Different uses of structure are then analysed in relation to architectural qualities they interact with. This approach draws upon two types of literature. The first corresponds to a series of reflections primarily undertaken by key architects and structural engineers who explore and analyse the architectural roles of structure. The second type of literature provides further reasoning and understanding regarding these qualities and their characteristics.

Based on this approach, the current section starts by exploring the characteristics of hidden structure and its implications in regard to architecture. It is followed by the contrasting notion of visually expressed structure which refers to a series of qualities identifiable outside and inside a building. The section then addresses the relationship between structure and external openings. The last part appears as the sum of these qualities as it focuses on the notion of architectural concept.

\subsubsection{Structure hidden}

It might appear at first sight, that the decision to hide the structure reveals a desire to limit or even to reject its interaction with the architecture. Indeed, a hidden structure has a more limited visual expression than an exposed one. Such a decision of concealing structure may arise for instance from a lack of aesthetic value in a structural element or be related to necessity, such as the 
undergrounding of foundation systems for structural effectiveness. However, the hiddenness of structure may also be the most appropriate approach to best serve an architectural concept.

\section{Structure Ignored}

A design approach often related to hidden structure is the one defined by Macdonald (2001, pp. 109-114) as "Structure Ignored". It aims at designing the architectural form of a building without reflecting on the structural implications. This approach provides a sense of freedom in the exploration of the architectural form. The architectural requirements take precedence over structural considerations and confine structure to its technical role. This attitude relates to Semper's opinion on the purpose of structural components: structure is used only to provide stability to the desired architectural form and support to the exposed architectural features (Semper, 2011). The architecture of the Guggenheim Museum (Bilbao, Spain, Frank Gehry, 1997) is one example of this design approach (Figure 12). Yet, even if structure is totally hidden, its interaction with architecture remains present. Structure generates a volume that, whether visually expressed or hidden, influences the visual perception of a building (Macdonald, 1997). As a result, structure participates in the overall architectural form and, depending on the concealing technique and its degrees of hiddenness, influences the visual architectural character.

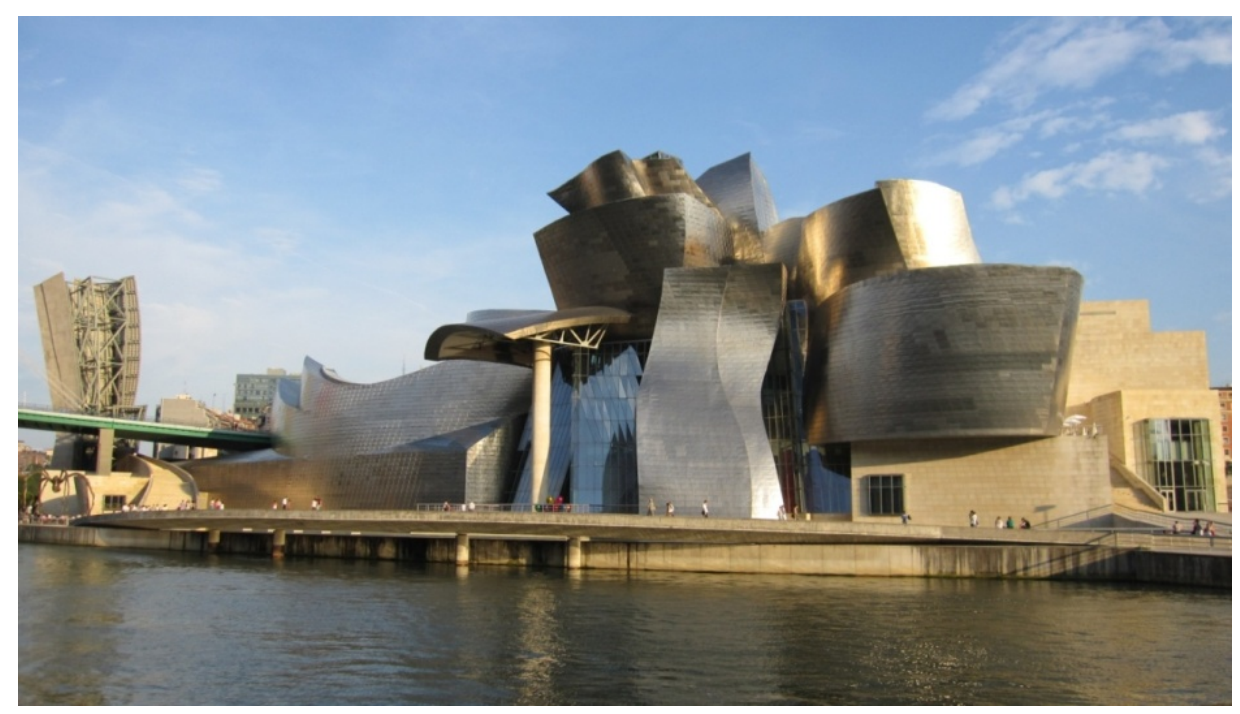

Figure 5. Guggenheim Museum (Source: http://wordpress.com, accessed April 2015)

\section{Concealment approaches}

The hiddenness of structure may serve a variety of architectural purposes. In some cases, a building's programme may be achieved more efficiently when structure remains unnoticed. For instance, when designing the exhibition space of a museum, an architect might conceal structural components, such as columns, behind planar surfaces. The set-up of artwork and their display would 
be visually and physically less disturbed without any expressed structure. This use of concealment is consistent with the 'utilitas' principle defined by Vitruvius as it aims at fulfilling the purpose of a space.

The concealment of structure may also be used to create a certain aesthetic, influence the perceptions of building users, or transform structure into an ornament. Screening, by using cladding or panelling, represents a common way of hiding structure. This technique is used in both the interior and exterior of the building. The former is usually undertaken using plasterboards; the latter tends to be more variable as it has at its disposal a large range of materials. For Wigley $(2002$, p. 90), this technique directly refers to Semper's perception of architecture as it focuses on reading the "sensuous surface" of a building. This technique is therefore primarily driven by aesthetic goals which vary depending on the materiality of the cladding and its degree of opacity.

The Guggenheim Museum (Bilbao, Spain, Frank Gehry, 1997) displays a completely opaque cladding, making the structural system invisible, and creating large continuous curved volumes with titanium panels (Figure 5). The concealment of the structure allows the forms, surface, and materiality of the volumes to act in correspondence with the Nervión river.

The industrial facility designed by DnA Architects (Perth, Australia, 2010) achieves a different aesthetic using a translucence polycarbonate cladding. This approach provides a diffuse appearance of the internal structure (Figure 6). The external cladding thus influences the perception of the human eye. The boundaries of the structure are perceivable but slightly blurry, creating a sense of evanescence as some parts of the structure are more highlighted than others by the internal lights.

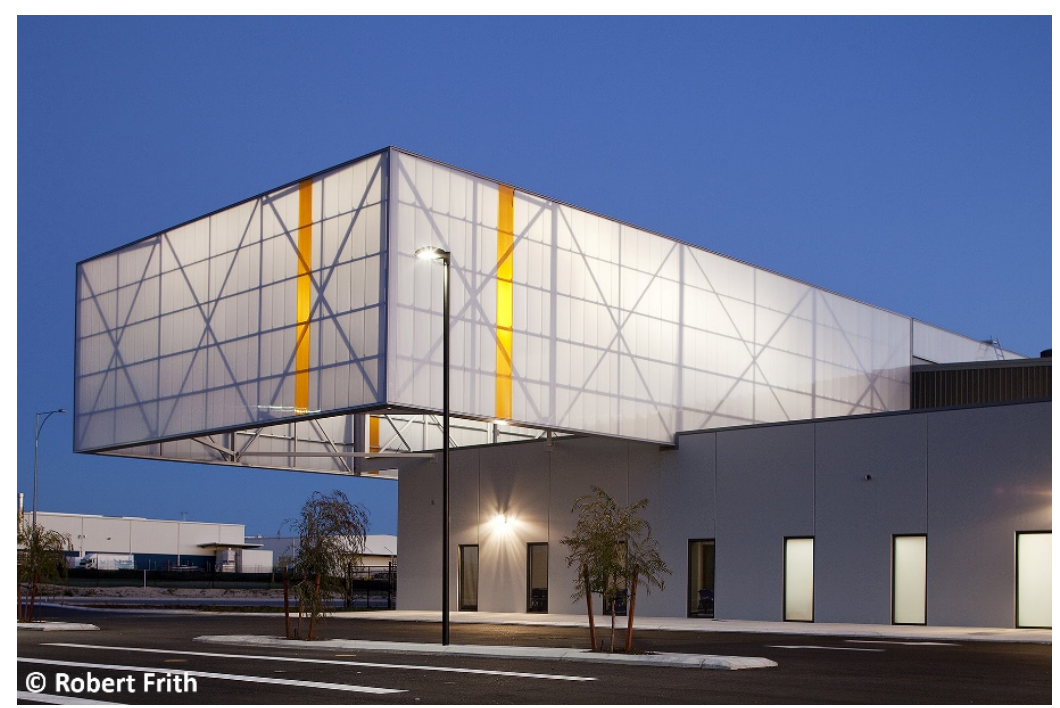

Figure 6. Patrick Autocare (Source: http://dna-architects.com.au, accessed April 2018) 
Hiding the structure behind cladding may also achieve a unique architectural character and challenge the human perception of a building. This approach can be appreciated in the Cube Houses (Rotterdam, The Netherlands, Piet Blom, 1977). Each house is composed of a cube inclined 45 degrees and positioned on hexagon-shaped pylon (Figure 7). The wood cladding leaves wondering how the interior is organised as well as how the structure is designed to ensure stability. This lack of understanding is reinforced by the presence of windows on every sides of the cube and the deceiving coloured pattern of the cladding. Only when entering the house does one understand that the building is composed of three concrete pillars supporting three concrete floors (Pascucci, 2014).
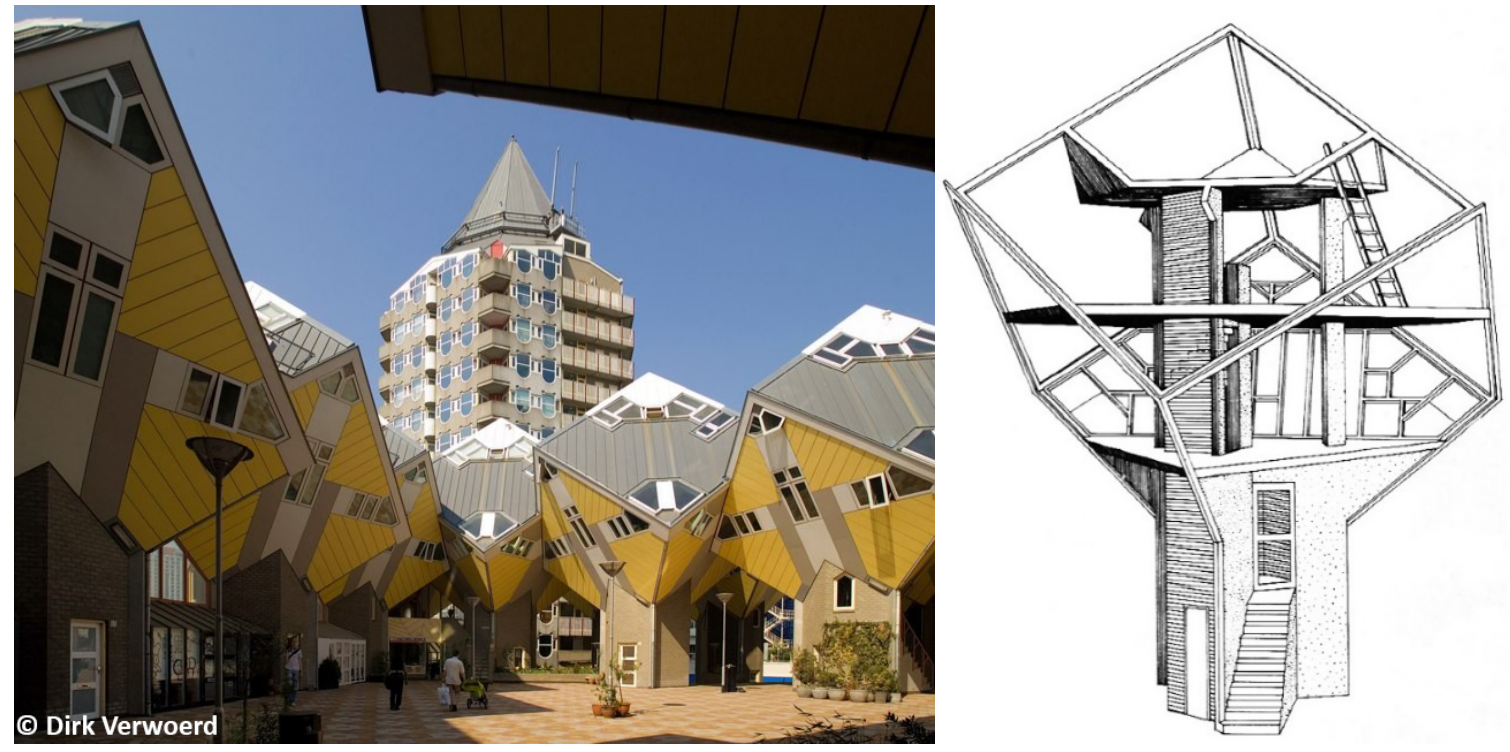

Figure 7. Cube Houses (Sources: https://www.archdaily.com and http://www.hiddenarchitecture.net, accessed April 2018)

Another approach consists in detailing structure so its supporting task is not or barely perceivable. This approach does not imply hiddenness by cladding but rather by mind concealment: users do not perceive the structure as a technical component but rather as an ornamental or sculptural feature. The role of the structure becomes twofold: it assures the stability of the building, albeit disguised; and also provides a sense of beauty, adding aesthetic quality to the architectural character.

The bus station of Cáceres (Spain, Justo García Rubio, 2004) uses reinforced concrete shell structures (Figure 8). Responding to both structural and architectural requirements, the building is considered a "functional sculpture" (Ayuntamiento de Caceres, n.d., p. 13). Variations of thickness respond to the technical requirements while also creating unique sculptural geometry (Eguiluz, 2015; Mendoza, n.d.). Structural form merges with architectural form, making its identification as a technical component difficult to perceive. 

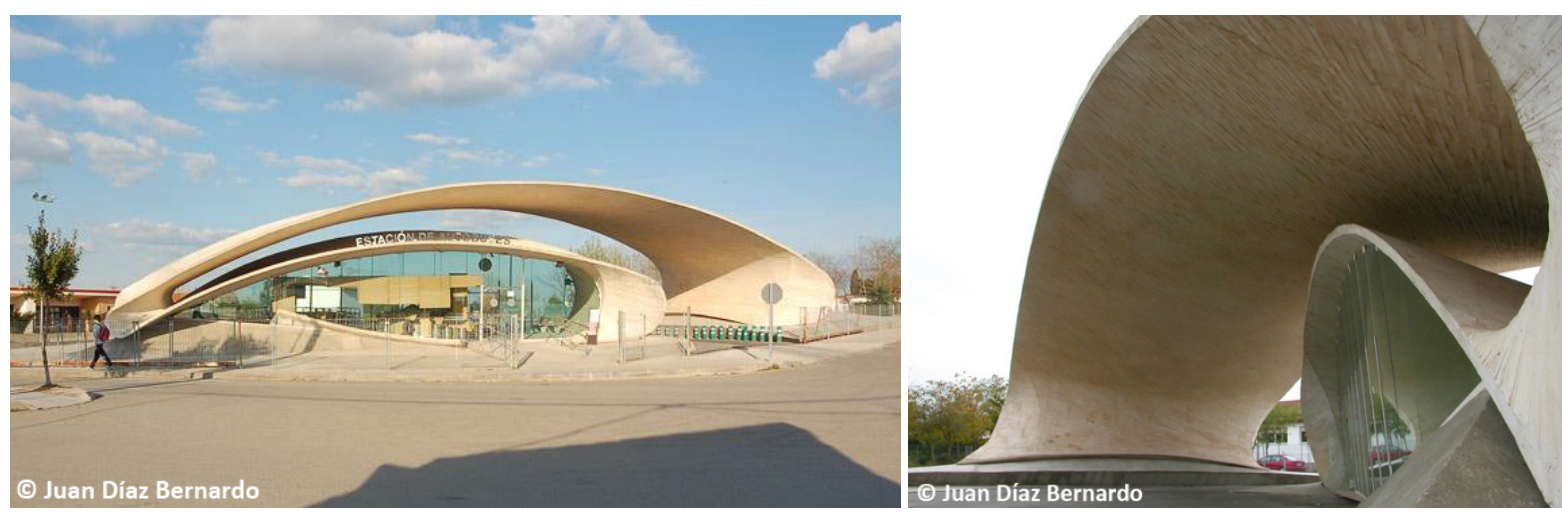

Figure 8. Bus station of Cáceres (Sources: http://www.spainisculture.com and http://www.justogarcia.com, accessed April 2018)

\subsubsection{Exposed Structure}

In contrast to hidden structure, exposed structure refers to any visible structural component. Whether installed internally or externally, exposed structure inevitably interacts with the architecture of a building, if only visually. Its exposure is rarely arbitrary and deliberately aims at enhancing architectural interaction.

Modern architecture, and particularly the International Style, has led to breakthroughs in expressiveness and structural exposure. A sense of simplicity was brought, relating the building form to its function, excluding use of ornament and respecting the true nature of materials used. Mies van der Rohe, while in the United States, regularly used steel-skeleton as the primary structure for many of his projects. He said "what I tried to do in architecture is to develop a clear structure ... [and that] we just should call it [my kind of architecture] a structural approach" (Peter, 1994, p. 161). He thus developed a steel and glass-based architecture. The glass allows the constructive principle to be revealed (Van der Rohe, 1922). The exposure of structure was driven by Mies' desire to develop a "structural architecture" (Spaeth, 1985, p. 16). Architect Robin Evans (1990) remains however perplexed with Mies' work, especially the Lake Shore Drive Apartments (Chicago, USA, Mies van der Rohe, 1949) (Figure 9). Evans notes the skeleton structure and lightweight cladding remove any sense of a load-bearing system. He queries: "How, then, have his buildings maintained their reputation as expressions of structural truth and structural rationality?" (Evans, 1990, pp. 59-60). For Evans, structure, as used by Mies, does not represent its true role. This raises the issue of the representation of visually expressed structure. 


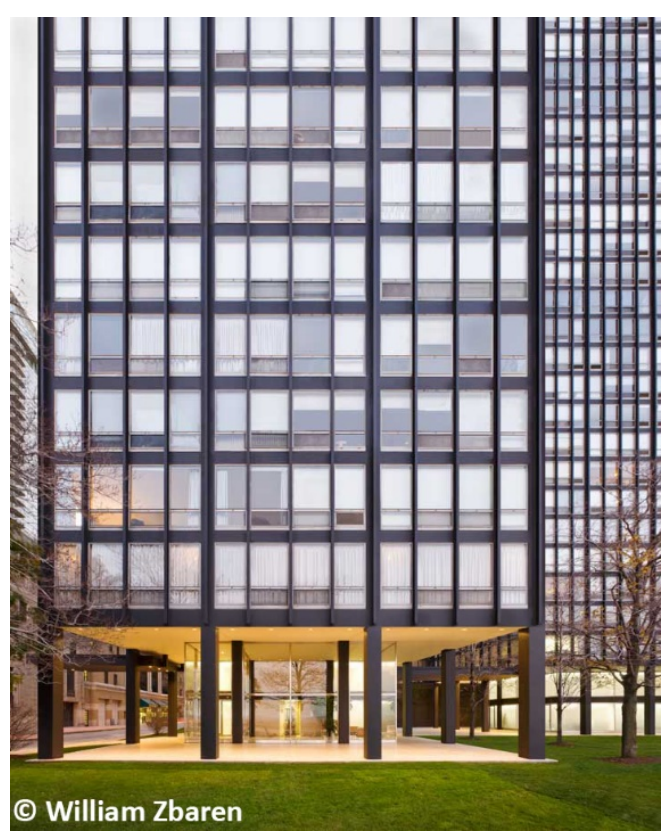

Figure 9. Lake Shore Drive (Source: https://www.e-architect.co.uk, accessed May 2015)

\section{Comparing two main uses of exposed structure}

Expressing structure, internally or externally, often relates to an architectural attitude regarding truth. Von Meiss (1990, p. 167) relates the issue of "truthful" and "untruthful" attitudes "to the relationship between the form and construction", i.e., to the ways form expresses the structural technique. He stresses the difficulty in identifying any one specific approach as truthful in opposition to others. High-Tech architecture illustrates this issue, displaying both structural and technical elements, using them as the key visual expression of the building. Macdonald identifies two approaches based on the expressiveness of the structure: "True structural High-Tech" (Macdonald, 1997, pp. 32-33) later renamed "Structure as architecture" (Macdonald, 2001, pp. 86-101), and "Structure symbolised" (Macdonald, 1997, pp. 30-32).

In the first approach, the main priority is given to the design of the structure, fully defining the building's form and architectural vocabulary (Macdonald, 1997, 2001). This approach engineering driven. The building is designed to the technically feasible limits. Architectural issues such as aesthetics and space-planning become secondary. Relationship between the structure and the architecture is straightforward: very few structural adaptations are made to comply with architectural requirements. An exposed structure is fully technical and provides its technical vocabulary to the architectural aesthetic.

In the second approach, structure mainly has a symbolic role. The image of technicality and stateof-the-art technology is sought: the technical performance and suitability of the structure remain 
secondary. Structure is dictated by aesthetic purposes and representing an image of technical progress and prowess. The sizes, forms and arrangements of the structural components are determined by visual decisions. Macdonald (1997, p. 32) uses the word "dishonest" regarding this approach, pointing out that High-Tech, while celebrating and praising technology and technical excellence, actually generates buildings with poor structural efficiency. He stresses that this approach frequently compromises the structural design and that it is an "inevitable consequence of this method" (Macdonald, 1997, p. 30). He notes the entrance canopy of Lloyds (London, UK, Richard Rogers and Partners, 1986) (Figure 10) and stresses that the architectural perforation of the curved steel increases the risk of the canopy being blown away by the wind (Macdonald, 2001).

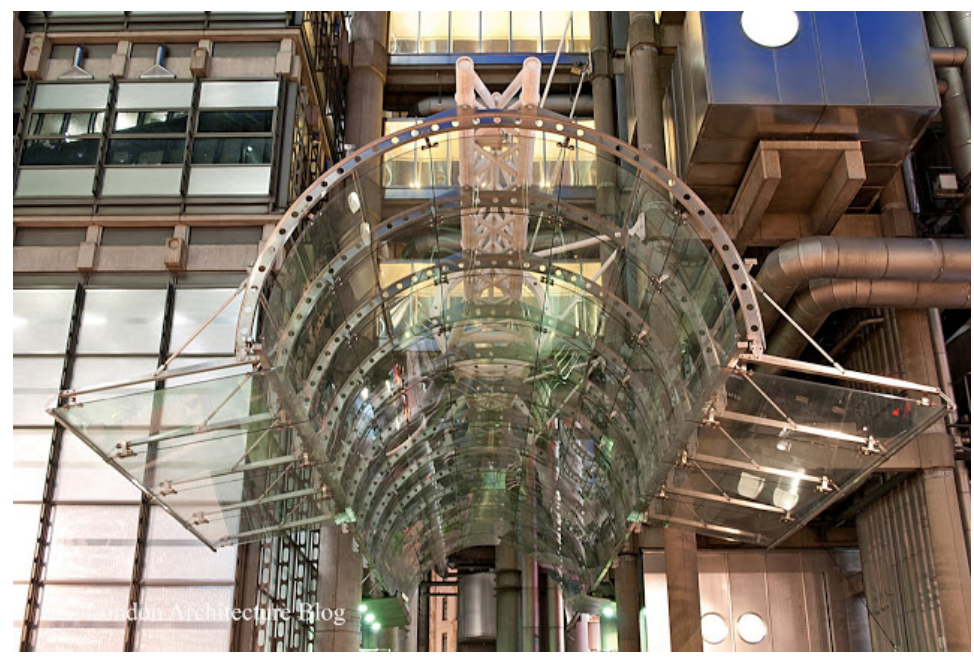

Figure 10. Lloyds headquarters (Source: http://www.londonarchitectureblog.com, accessed May 2015)

Macdonald criticises the weakening of the structural design due to this symbolic approach. The use of the structure primarily for aesthetics, and secondary for engineering purposes reduces its technical efficiency, impacts on economy of means and leads to structural deficiencies. Nonetheless, the degree of optimisation of structure may be balanced between the architect, engineer and client.

Macdonald distinguishes both approaches very clearly. "Structure as architecture" is driven by structural necessities, where "Structure symbolised" is based on architectural purposes. Von Meiss, while acknowledging this distinction, softens these boundaries. Where Macdonald refers to the buildings based on the first approach as "little other than a structure, the form of which was determined by purely technical criteria" adding that "the inherent architectural delight therefore consisted of an appreciation of 'pure' structural form" (Macdonald, 2001, p. 101), Von Meiss (1990, pp. 168-169) relativises such structural purity. He accepts the condition of "logical construction" and the emergent aesthetic value, yet also gives credit to the "intuition and artistic sensitivity" of the engineers. He states that "calculation is only one means of control, after intuition and invention". With these sensible factors comes the risk of "styling" (Von Meiss, 1990, p. 170) which implies the 
alteration of structure for visual purposes. The stronger the styling of pure structural components, the less the difference between "Structure as architecture" and "Structure symbolised". Von Meiss even acknowledges that examples he refers to as structurally truthful, such as the Exhibition hall Giovanni Agnelli (Turin, Italy, Nervi, 1949) (Figure 11), are not only technical necessities.

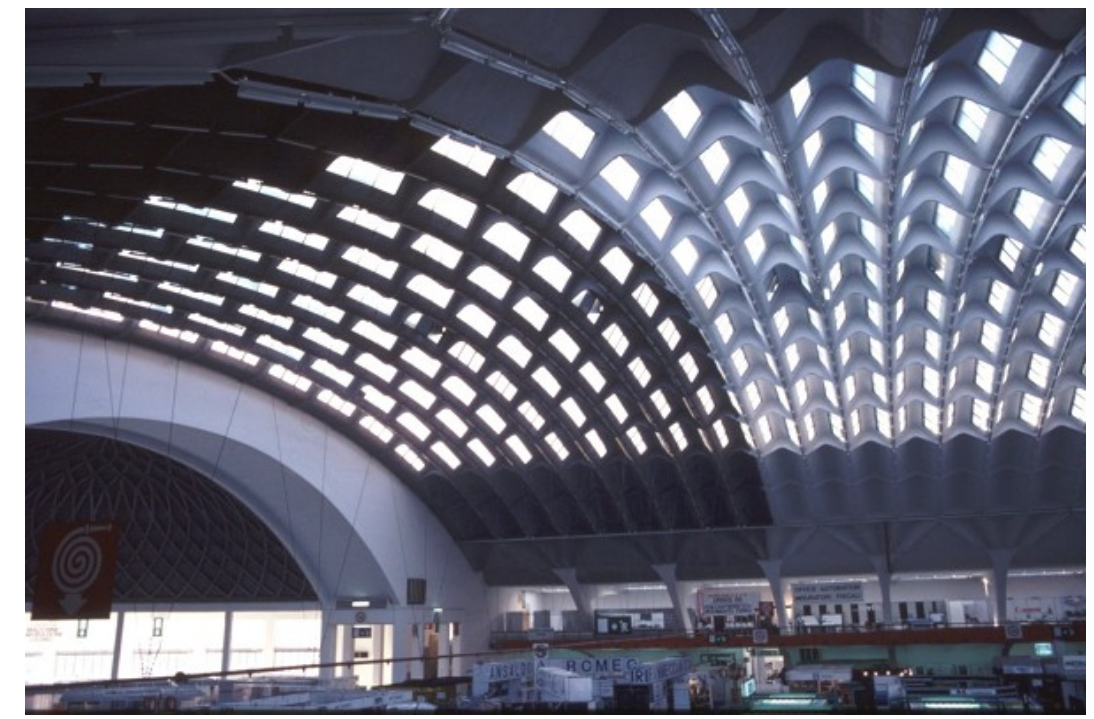

Figure 11. Exhibition hall (Source: https://structurae.net, accessed June 2017)

\section{Surface as a surface composer}

Architectural composition is inextricably linked to ordering principles including axis, symmetry, rhythm (Arnheim, 1977; Ching, 2007; Rasmussen, 1964). These principles often guide the composition of a building, whether through plan, volume, or façade. Arnheim (1977) notes order is a necessity to achieve any architectural work: without it, only confusion results. He is critical towards Venturi (1977) who considers the use of order in Modern architecture as cold and austere, and therefore praises the use of a form of disorder. Venturi (1977, p. 41) further justifies the breaking of order by "the recognition of variety and confusion inside and outside, in program and environment, indeed, at all levels of experience; and the ultimate limitation of all orders composed by man. When circumstances defy order, order should bend or break: anomalies and uncertainties give validity to architecture". This Post-modern approach promotes richness over simplicity (Owens, 1986). Venturi is however clear: while complexity and contradiction are sought, incoherence and arbitrariness are not. The logic behind Venturi's compositional approach is further examined by Von Meiss (2013). He identifies a range of compositions between order and chaos, including Homogeneity and texture, Alignment and series, Gradation, Hierarchy, Contrast, Complexity, Contradiction, and finally Chaos. Except for Chaos, every form of composition possesses a sense of coherence (Von Meiss, 2013). The key aspect of architectural composition is the capacity of grouping components together, whether their visual and physical relationships are easily 
identifiable, or more complex. The maintenance of coherence can be achieved using different factors (Von Meiss, 2013).

The first, 'Repetition and Resemblance', considers that structural resemblance of components dominates their differences. Partially common features between different components foster links and heterogenous components can thus be grouped through similar dimensions, materiality, form and scale. Similarity of features includes form, materiality, texture and dimensions. The second factor, 'Proximity', is based on grouping elements close to each other and distinguishing those which are further apart. This approach allows clustering of disparate features while maintaining cohesion. The third factor is 'Enclosure or common background'. Enclosure groups heterogeneous or homogeneous components and distinguishes them from elements outside the boundaries. The fourth factor, 'Orientation of elements', is based on the natural reading of the human eye to identify patterns by organising heterogeneous elements, orienting them vertically, horizontally, parallel, or converging them.

Among the various elements that contribute to architectural composition, structure appears highly significant. When a structure is located adjacent to a vertical plane, whether internal or external, it can influence the composition of the plane. Referring to buildings façades, Hanlon (2009, p. 259) explains "many buildings are suited to a standard plan of their type, while their exteriors often offer greatest latitude for design. The principal opportunity to shape the architectural character of such a building is in its articulated skin, most often its façade". Externally expressed, structure influences the architectural character, becoming a component of its visual identity, alongside other components such as the building's shape, openings, roof, projections, recesses, and materials (L. H. Nelson \& FAIA, 1988). Curtis (2011) defines two types of façades: uniform facades, with the wall surface as primary component; and varied or broken façades, modulated by projections and recesses. In both cases, architectural composition of the exterior elevation may generate a pattern determined by the combination of components such as openings, mullions, types of cladding, and in some cases, structure. From barely noticeable presence to highly expressive, structure can therefore contribute widely to façade compositions.

The Macquarie Bank building (Sydney, Australia, Fitzpatrick + partners, 2009) presents an external structural diagrid system (Figure 12). The location of the steel structure is primarily justified by the opportunity to avoid perimeter columns and maximise internal space (Yudelson \& Meyer, 2013). The architect also refers to the design as a structural play permitting a unique external visual character (Mcdonald, 2008). The structure, through colour and geometry, creates a simple diamond pattern highlighted by its visual and physical distance with the sleek glazed envelope behind. 


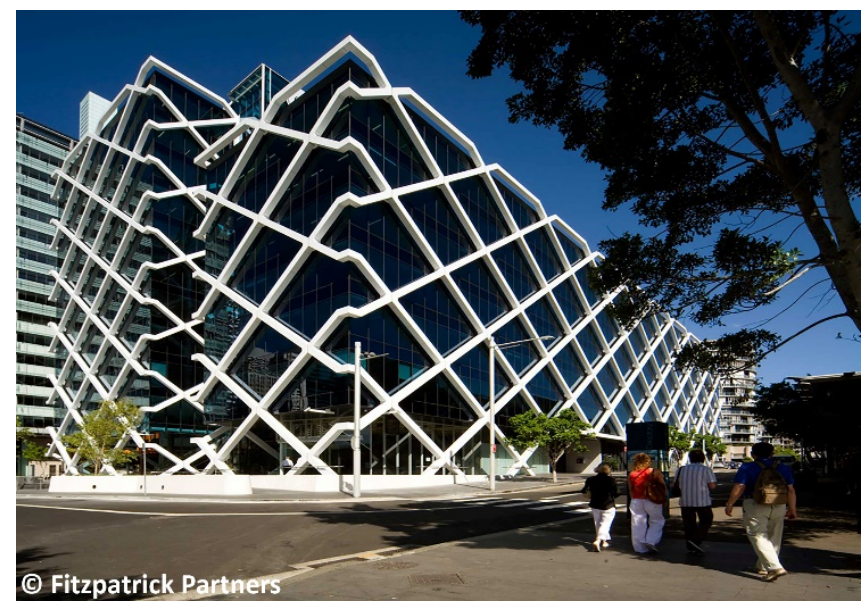

Figure 12. Macquarie Bank building (Source: https://www.fitzpatrickpartners.com, accessed April 2018)

Interior expressed structure also has the ability to participate in composition of surfaces. For Michel (1995), such use is twofold. The composition of internal structural surfaces allows creating aesthetic patterns while also accentuating spatial boundaries. These characteristics are noticeable in the House of Cedar (Osaka, Japan, Suga Atelier, 2012). An internally exposed wooden frame structural system of nine transverse structural frames is purposefully detailed using small timber components (Figure 13). The structure recalls tree trunks and branches, creating a unique interior aesthetic (Parafianowicz, 2012). No panels cover the perimeter walls and ceilings, leaving the struts and joist fully exposed and allowing them to contribute to the composition of the interior surfaces.
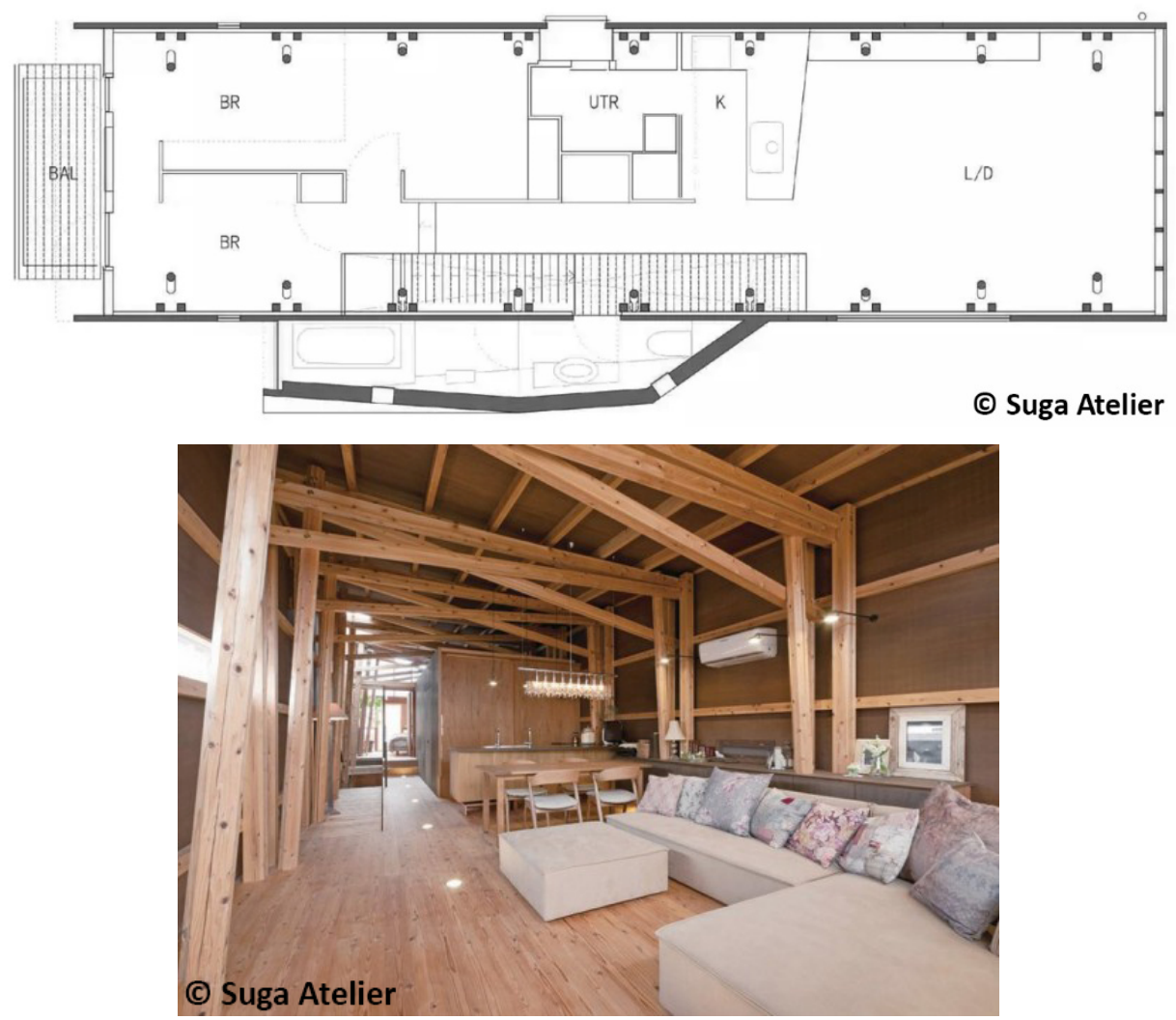

Figure 13. House of Cedar (Source: https://divisare.com, accessed April 2018) 


\section{Structural expressiveness}

Sandaker (2007) notes structure is commonly expected to respond to loads. Two options can be considered. Designers might decide to maintain constant shape and cross-section of components forming the structural system. Conversely, structure may express the forces and variations of stresses that it is confronted to, to "attract architectural attention" (Sandaker, 2007, p. 70).

This second option is found in the Palace of Labour (Milan, Italy, Pier Luigi Nervi, 1961), where an isostatic mezzanine slab runs along the building perimeter wall (Figure 14). The structure displays ribs representing strain-lines of the principal bending moments within the ferroconcrete slab (Cresciani \& Forth, 2014). For Sharp (2002, p. 245), such "energetic exhibition" of the structure defines Nervi's architectural aesthetic.

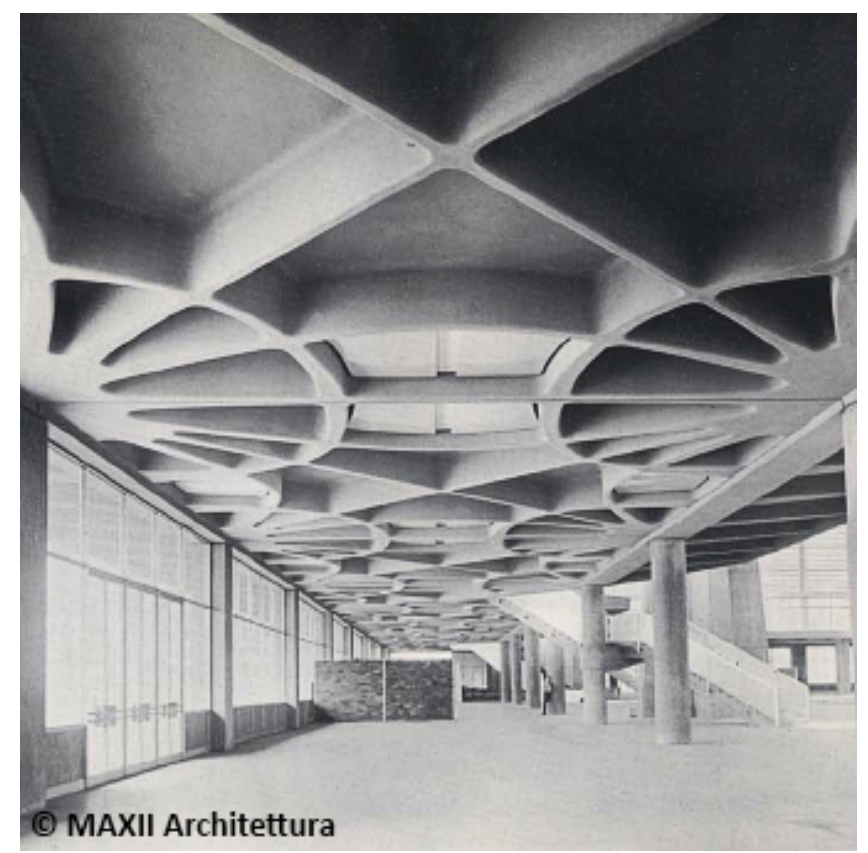

Figure 14. Palace of Labour (Source: Cresciani \& Forth, 2014, p. 60)

For Balmond (2002), even dull structure can be expressive if its detailing is celebrated. Balmond warns however that the risk of over-detailing is to turn such ambition into a fetish. This outcome is not considered an issue for those who acknowledge detailing as an aesthetic opportunity (Benedetti \& Charleson, 2000; Brainov, 1980; Calderon, Schimek, \& Wiltsche, 2011).

Structural expressiveness is not solely limited to expression of physical representation of structural load paths. Structure can be used to express and enhance different aspects. Al-Kodmany \& Ali (2016) indicate how the 30 St Mary Axe building (London, UK, Foster and Partners, 2003) features a cutout allowing exposure of the diagrid structure (Figure 15). This treatment of the façade combined 
with the expressiveness of the structure emphasises both the entrance and the threshold between exterior and interior.

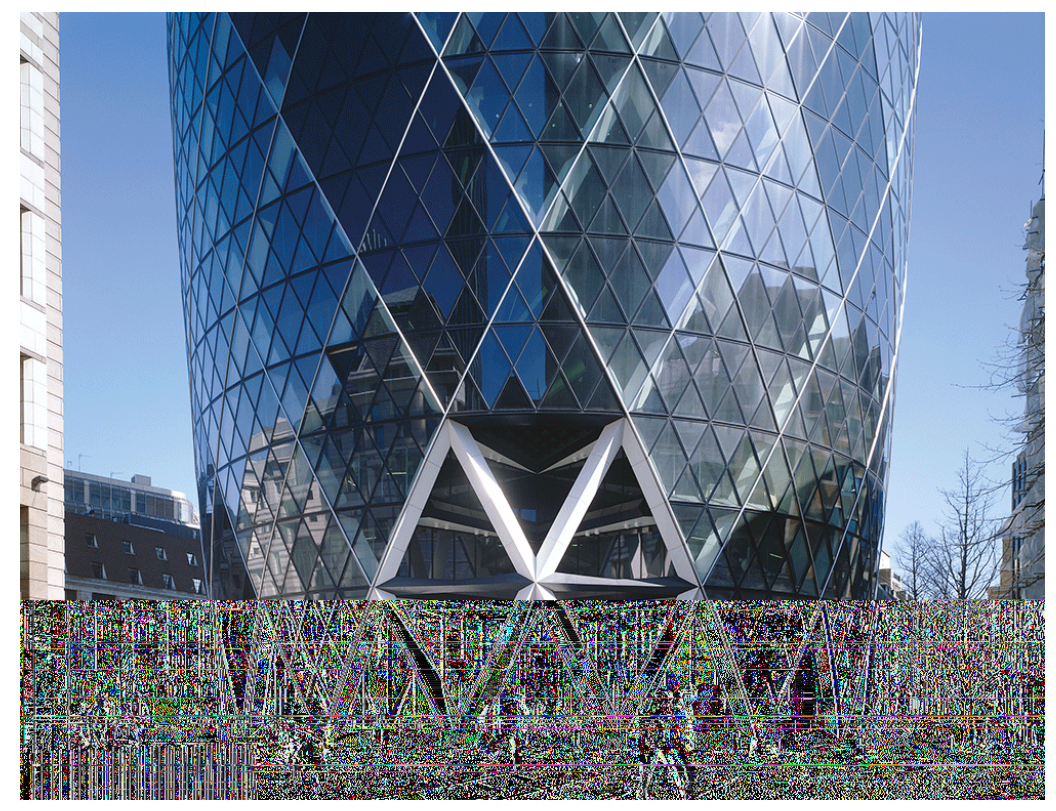

Figure 15. Entrance of the 30 St Mary Axe building (Source: http://miesarch.com, accessed April 2018)

Al-Kodmany \& Ali (2016) also appreciate structural expressiveness as an opportunity to highlight the iconic identity of a building. Externally, expressed structure defines the exterior architectural character. Like Macdonald (1997), the authors are aware that some structures may not be the result of sole technical requirements, taking the Hong Kong and Shanghai Bank (Hong Kong, China, Foster Associates, 1986) as an example (Figure 16). The mega-frame, while defining the external character, is not representative of the building's structural necessities. Nevertheless, Al-Kodmany \& Ali (2016) acknowledge the aesthetic expressiveness of the external frame. Charleson (2014) explores this expressive purpose of the external structure, explaining how the mega-frame expresses inner functions and organisation within the building. The masts separate the offices and main hall at the centre from the service areas at the ends. Vertically, the spacing between trusses reflects the five distinct corporate banking divisions, expressing the functional inner program. 


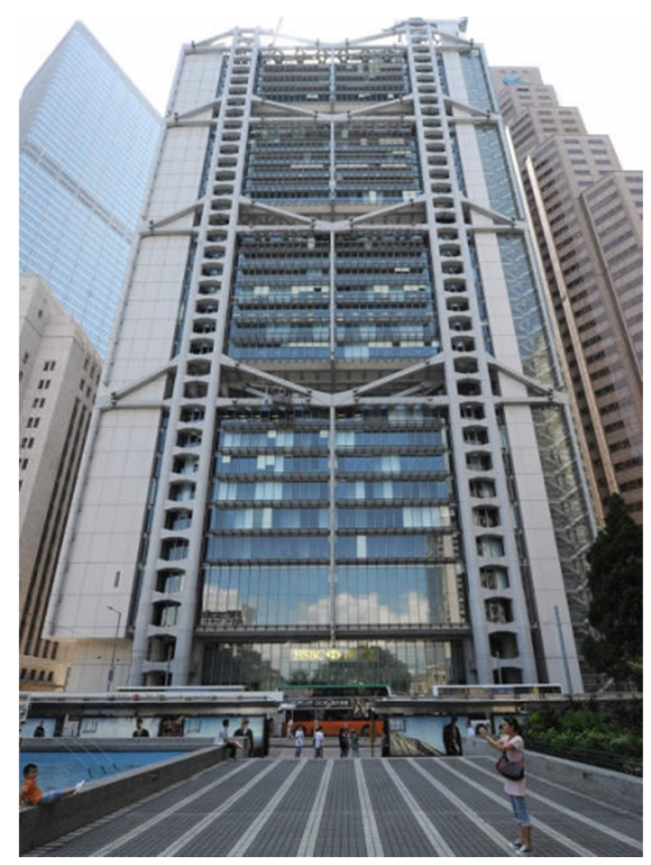

Figure 16. Hong Kong and Shanghai Bank (Source: http://keywordsuggest.org, accessed April 2018)

The expressiveness of a structure can also serve metaphorical purposes. The Sendai Mediatheque (Sendai, Japan, Toyo Ito, 2001) is based on a metaphorical aquarium (Witte, 2002) primarily represented by the transparent skin and structural system of 13 distinct steel-ribbed shafts (Figure 17). The shafts, or columns, are composed of a series of steel tubes varying from two to nine meters in diameter. Sandaker (2007) explains the shafts are characterised by gradual width changes along their height similar to a series of trees. This organic origin is further explained by Ito. The architect describes the shafts as "seaweed-like columns ... softly swaying in the virtual water that fills the tank" (Ito, 1997, p. 126). Structural expressiveness is thus used to achieve a symbolic function.

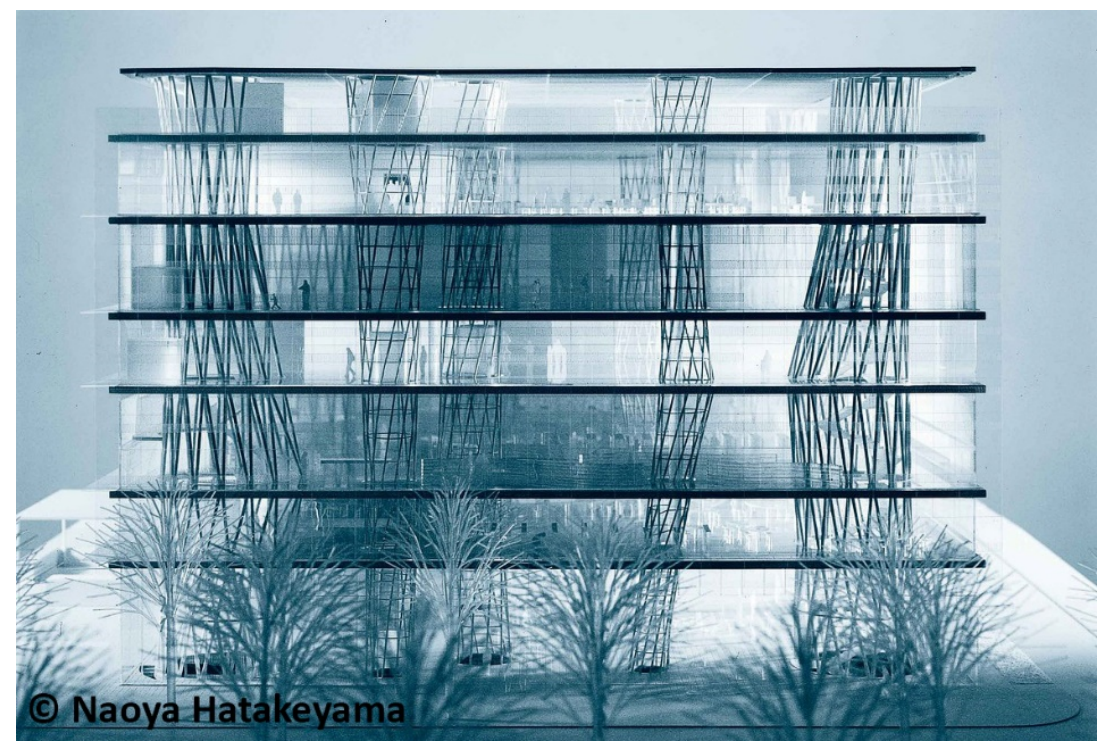

Figure 17. Model of the Sendai Mediatheque (Source: http://www.harvarddesignmagazine.org, accessed April 2018) 


\subsubsection{Interior structure}

In addition to modulation of surfaces and expressiveness qualities, interior structure can interact with spatial; functional; and circulation qualities.

\section{Structure and space}

Salvadori \& Heller (1986, p. 12) explain the main goal of a structure is to "enclose and define a space" to serve a particular function. The idea of 'enclosure' may be defined as "a space included within or marked off by boundaries" (Oxford English Dictionary, n.d.). In architecture, this definition relates to the physical enclosure of a space, commonly achieved by walls. Yet, for many authors physical enclosure is not a necessary condition for defining a space. Von Meiss (1990, p. 101) explains: "Architectural space is born from the relationship between objects or boundaries and from planes which do not themselves have the character of object, but which define limits. These limits may be more or less explicit, constitute continuous surfaces forming an uninterrupted boundary, or, on the contrary, constitute only a few cues (for examples four columns) between which the observer establishes relationships, enabling him to interpret an implicit limit". A space may therefore be defined using different types of structures, from the most 'open' to the most 'enclosed' ones (Figure 18). The more physical presence the structure has, the more explicit the space.
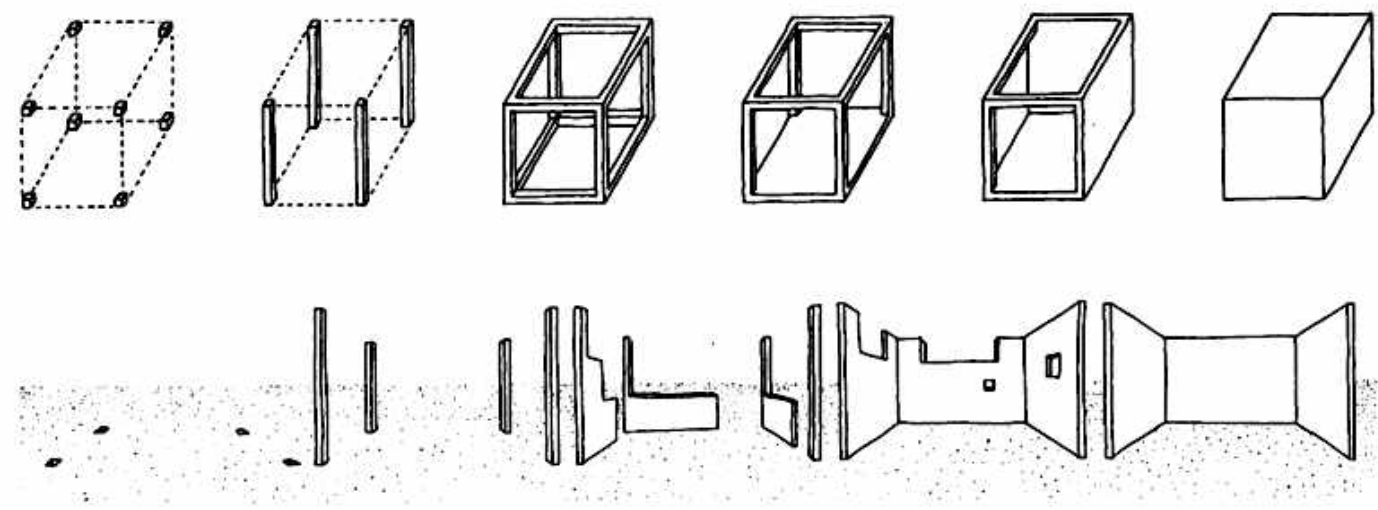

Figure 18. From implicit to explicit space (Source: Von Meiss, 1990, p. 102)

Holgate (1986) explores the idea of non-physical boundaries. He stresses the capability for tiling patterns and steps to help generate spatial boundaries, thus avoiding structural components as space definers. In contrast, Ching (2014, p. 184) points out the risks of reducing or losing structural components when defining a space. He explains "the space loses its sense of enclosure, becomes more diffuse, and begins to merge with adjacent spaces". This consequence may however not necessarily be negative as long as it serves architectural purposes. 
Ching (2007), like Von Meiss, explores the variety of structural enclosures and how they affects the user's experience of a space. He identifies six configurations (Figure 19).

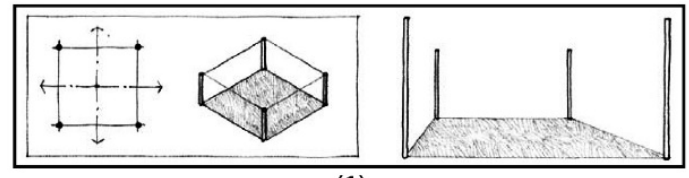

(1)

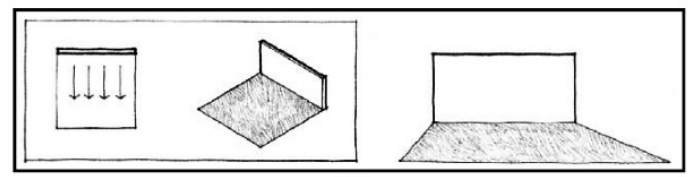

(2)

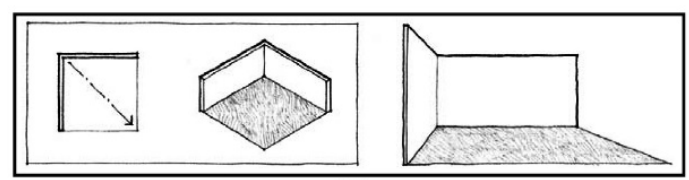

(3)

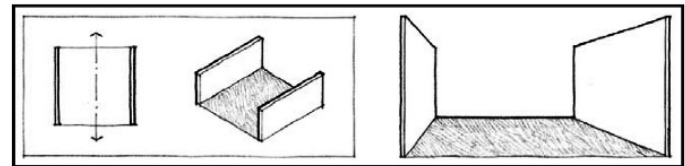

(4)

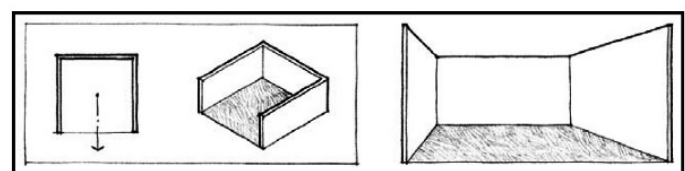

(5)

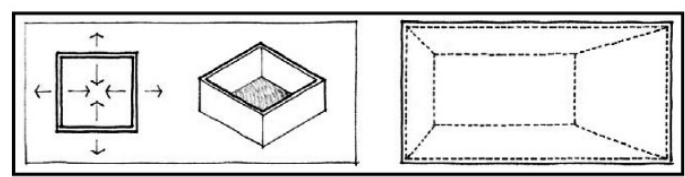

(6)

Figure 19. Variation of spatial enclosure created by vertical structures (Source: Ching, 2007, p. 125)

For each configuration, Ching highlights the influences structure may have on the user's sightline, visual spatial representation, and movement within and outside the space. Designers can thus articulate a space with the appropriate structural layout to achieve their intended architectural goal.

Similarly, Ogg's diagram presents five different structural layouts, each providing distinct spatial qualities within a same building envelope (Figure 20). As analysed by Charleson (2014), the whole inner volume may be appreciated as one single space in the first two options despite minor differences. In contrast, the next two layouts due to structural changes, divide the volume in two separated spatial zones. Finally, the last structural layout creates a relationship between exterior and interior spaces, where the four previous ones were related to the inner spaces.

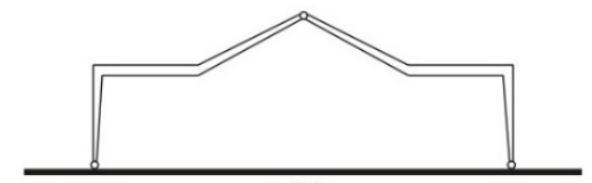

(a)

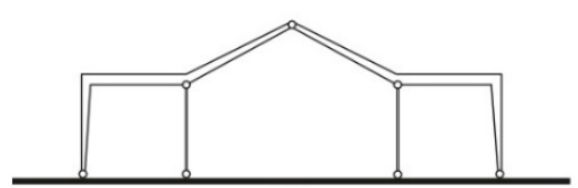

(b)

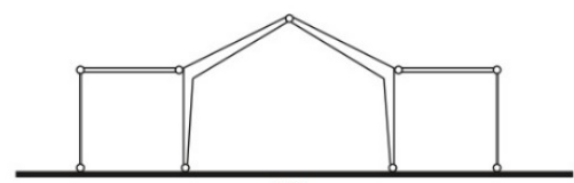

(d)

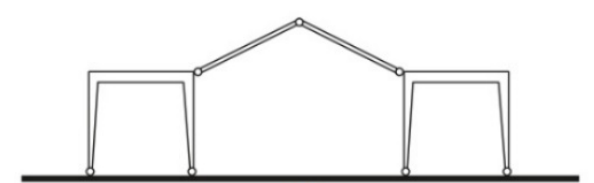

(c)

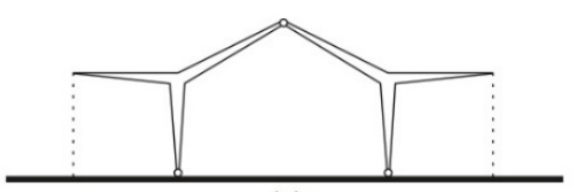

(e)

Figure 20. Structural layouts and their impacts on space (Source: Ogg, 1987, p. 49) 
The spatial configurations presented by Von Meiss (1990), Ching (2007), and Ogg (1987) represent primary scenarios. Designers have the opportunity to create hybrid spatial layouts depending on their architectural concept and selected structure.

The Solomon R. Guggenheim Museum (New York, USA, Frank Lloyd Wright, 1959) provides an example of structure gradually emphasising spatial enclosure (Figure 21). The museum's main gallery is composed of a spiral ramp and twelve equally spaced concrete slanted walls. The walls, similar to ribs, appear as columns at the bottom levels. Their presence barely impacts on the circulation area, letting users to freely walk along the ramp. As users reach the upper levels, the walls become more prominent, creating a range of exhibition alcoves (Breiner, 1990). Each Ushaped alcove creates a three-sided volume resulting in an inward focus as well as an outward opening maintaining a visual and physical connection with the ramp.
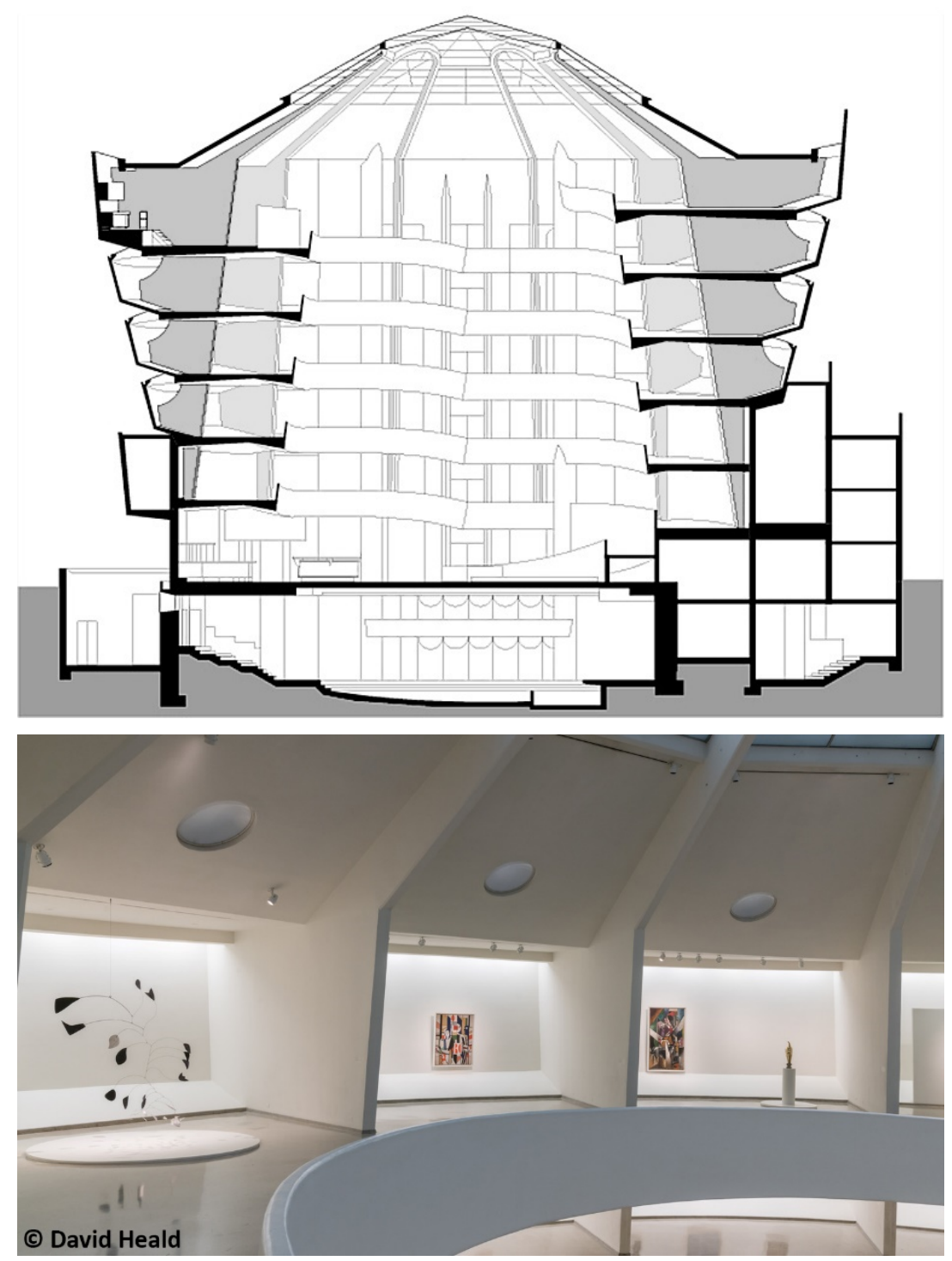

Figure 21. Solomon R. Guggenheim Museum (Sources: Weston, 2004, p. 89 and https://wsimag.com, accessed April 2008) 


\section{Structure and function}

A building is commonly designed to serve a purpose, whether it relates to utilitarian, religious, or symbolic functions (Jensen, 2004). As structure ensures stability and takes part in the building's volume, it shelters the building's function. More specifically, structure has the capacity to define space and influence how users experience it. As spaces are commonly designed to respond to the building's programme, they serve specific functions and activities (Van der Voordt \& Wegen, 2005). How then can structure be used to contribute to the functions carried by spaces and articulate them?

For Krier (1988, p. 27), structure and function are strongly linked, and require their relationship to work harmoniously to achieve an "architectonic end product". Unwin (2013, p. 177) supports this position as "an important aspect of the art of architecture is to choose a structural strategy that will be in some sort of accord with the intended spatial organisation". For both authors, structure is a spatial organiser which, depending on the functions carried by the spaces, can make use of a variety of structural systems.

The Baroque Museum (Puebla, Mexico, Toyo Ito, 2016) uses its structure as a space and function organiser. The building is composed of several square units varying in size but characterised by massive sculptural concrete walls defining their boundaries (Figure 22). The building's programme is thus distributed through the various spaces created by the structure, with openings in the walls connecting the units to one another.

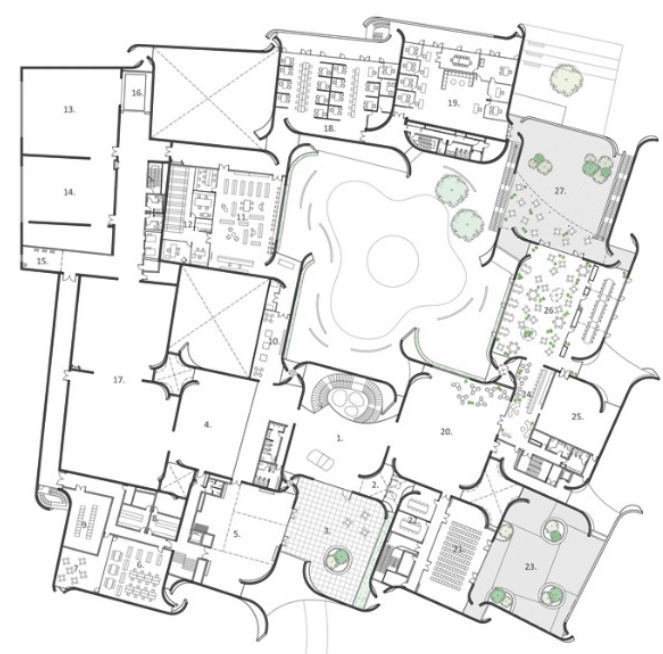

(C) Toyo Ito \& Associates

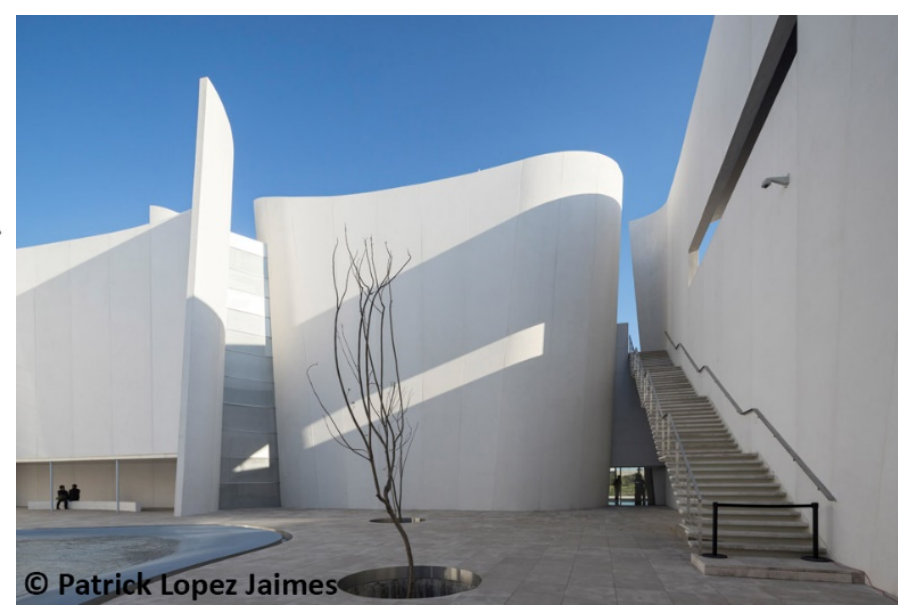

Figure 22. Baroque Museum (Source: https://www.dezeen.com, accessed April 2018) 
Structure can divide a space into smaller ones with individual functions, but also provide flexible spatial organisation (Sinclair, 2015). Several architects have reflected on approaches to organise interior layout with minimum restriction from the structure. One approach is based on the principle of 'free plan' set in the Dom-ino concept by Le Corbusier. It consists in preventing structural restriction by using thin columns to support concrete slabs (Figure 23). Located around the edges, the columns provide great freedom to design the interior layout. Several buildings are designed based on this concept, organising their columns into a structural grid. For Unwin (2013), this approach possesses a double advantage: it allows defining spaces with distinct functions inside the grid, while the columns settles the boundaries of each space. The grid system is however not free of defaults as pointed out by Krier (1988). Each column is a physical component and generates a footprint. As the number of columns increases and the type of grid becomes more complex, the functional and spatial limitations and restrictions escalate.

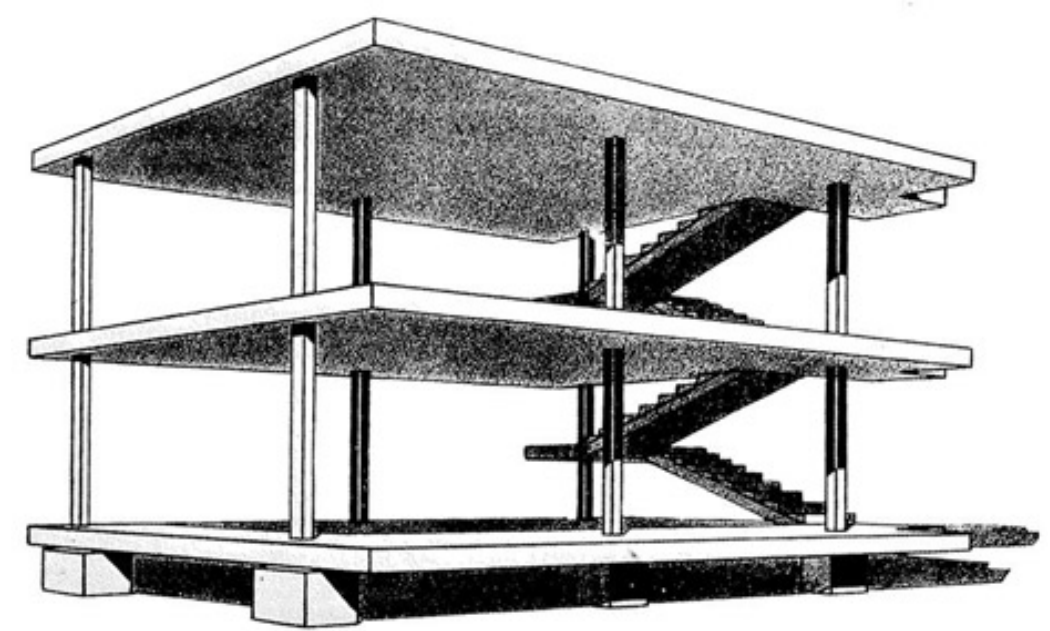

Figure 23. Dom-ino system (Source: https://www.dezeen.com, accessed April 2018)

According to Sev \& Özgen (2009) and Wells (2005), great spatial flexibility can be achieved when vertical structure is located at the perimeter while beams or trusses span from one edge to the other. Interior floor slab is therefore free of columns that would reduce the flexibility of the usable interior space. For Wells (2005), optimum use of perimeter structure is achieved when it is located outside the building's envelope as its footprint has no repercussion on the internal spatial organisation. The 30 St Mary Axe building (London, UK, Foster and Partners,2003) uses a perimeter diagrid structure located within the double layered envelope. This ensures that the interior floor plan is free of columns (Figure 24) allowing internal office spaces to be organised with maximum freedom. 


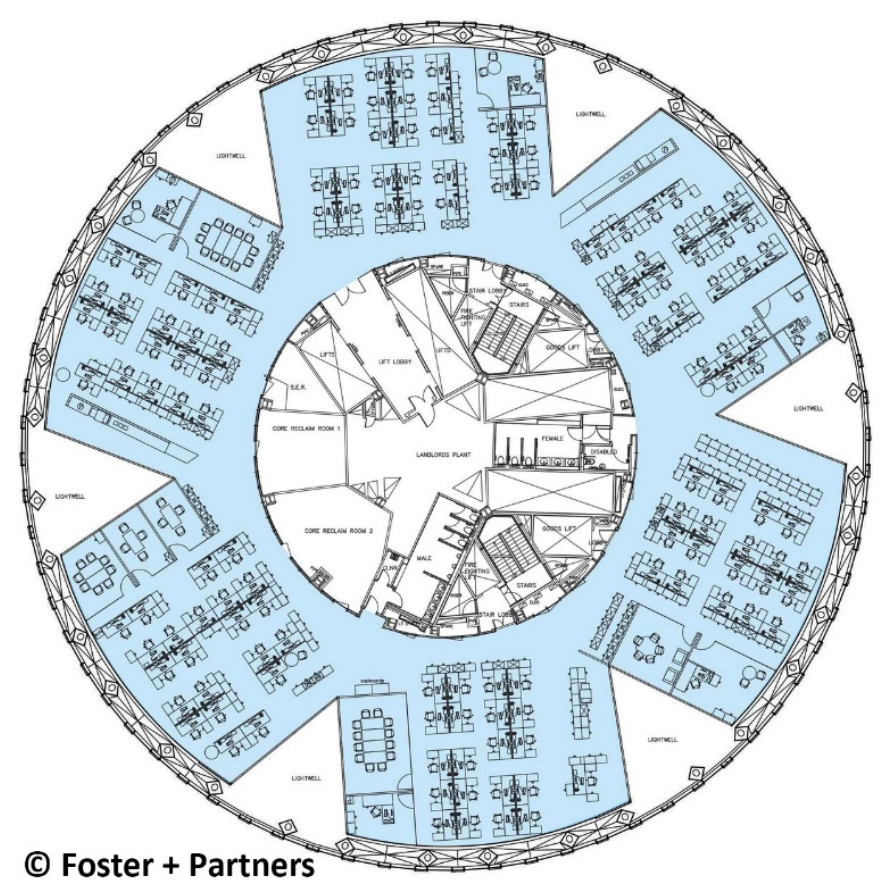

Figure 24. 15th floor plan of the 30 St Mary Axe building (Source: http://www.harvarddesignmagazine.org, accessed April 2018)

\section{Articulating circulation}

Ching (2007, p. 240) defines circulation as "the path of our movement [which] can be conceived as the perceptual thread that links the spaces of a building, or any series of interior or exterior spaces, together". This statement conveys two key ideas: circulation creates a link between spaces and implies a sense of movement. Natapov et al. $(2015$, p. 2) further emphasise that an efficient circulation system depends on its capacity to "[make] the destination evident to the user (groups), so that users can easily direct their movement towards their goals". The purpose of a circulation system is therefore to guide the user to reach the intended termination. This goal can be achieving by composing with the location and form of the entrance, the length of the path, its configuration, and the nodes composing it, in order to create a unique experience serving architectural purposes (Ching, 2007).

Where does structure stand in regard to circulation? As for any other space, circulation area may then be delimited by structure. Yet, circulation implies a sense of movement. How may structure, commonly a static element, articulate circulation in order to suggest direction and movement? To answer this question, it is worth looking at three types of circulation spaces identified by Ching (2007) and understand how structure might relate to each one of them. 
The first corresponds to 'enclosed' circulation space and is defined by a corridor created by side walls. This circulation area is connected to the spaces of the building through openings in the wall plane or at end of the corridor. The Lee Ufan Museum (Naoshima, Japan, Tado Ando, 2010) displays a path flanked by two massive raw concrete walls leading to the building's entrance (Figure 25). The width of the path can be justified by Salvan (1999, p. 298) who explains "[a] narrow, enclosed path will encourage movement" therefore further inviting the visitor to enter the building. In contrast, corridors can be widened to create "pausing, resting, or viewing" areas.

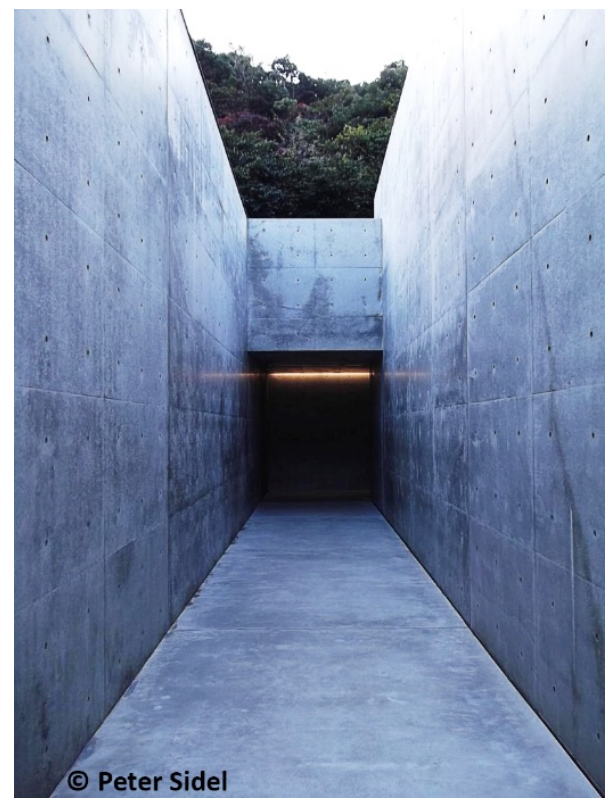

Figure 25. Entrance of the Ufan Museum (Source: https://a2.cdn.japantravel.com, accessed April 2018)

The second type of space is 'open on one side' and, while defining a path for users to follow, also ensures visual and physical link with the adjacent space. The Stabian Baths in Pompeii, Italy, is one example (Figure 26). Inside the building, the colonnade facing north forms a gallery along with the side wall, while allowing views and accesses to the central court.

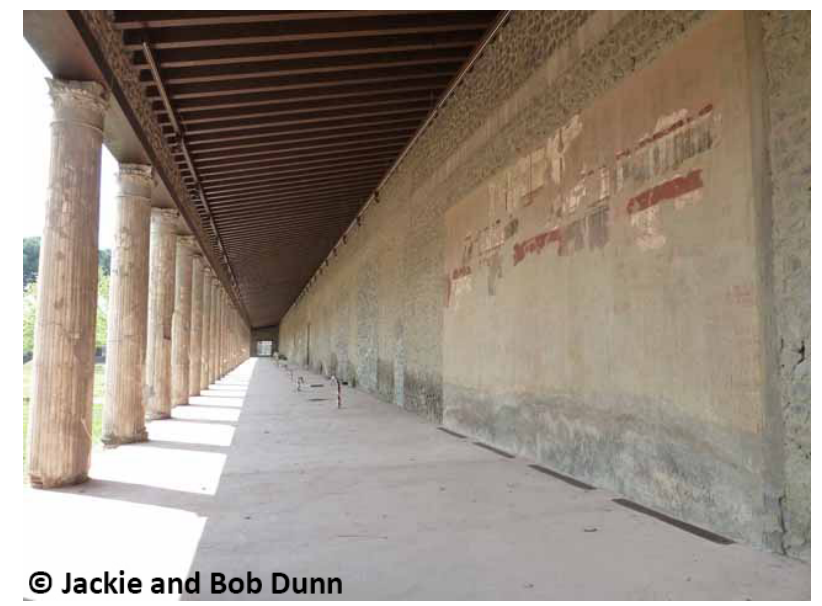

Figure 26. North Colonnade of the Stabian Baths (Source: http://www.pompeiiinpictures.com, accessed April 2018) 
The last type, 'open on both sides', is characterised by a circulation space which, while fully part of the space it passes through, maintains a sense of path and direction. When considering the role of structure in this scenario, two options can be examined. In the first option, structure directs movement but does not restrain users from taking another route. The Crystal Palace Sports Centre (London, UK, LCC Architects Department, 1964) for instance, possesses a colonnade of concrete struts running through the entire building and distributing the swimming pool on one side and the gymnasium on the other (Figure 27). The structure defines the direction of circulation thanks to the repetitive rhythm of the ranking struts establishing a strong perspective along the axis. This is reinforced by the struts physically and visually representing the building's spine (Nicholls, 2012; Thyer, 2011). For Cook (1996), a structure functioning as a spine becomes a forceful generator of a primary circulation route. Indeed, the structure delimits the central gallery but remains open on its sides allowing users to move to secondary routes.
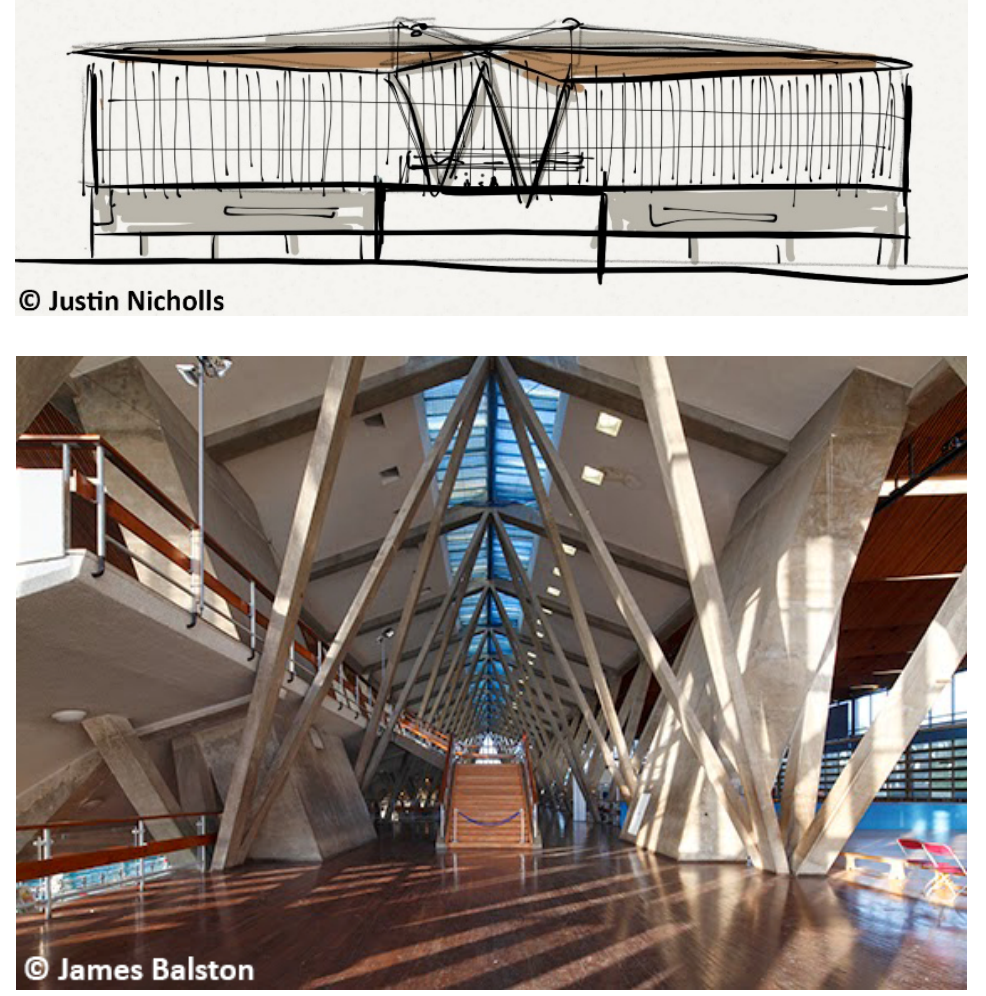

Figure 27. Crystal Palace Sports Centre (Sources: http://www.justinnichollsarchitect.com and http://thetrianglese19.blogspot.co.nz, accessed April 2018)

The second option corresponds to structure simply suggesting the route for users to take. Users have entire freedom of movement yet, structure acts as a visual signal emphasising the direction of movement. In the Carserma wing of the Castelvecchio Museum (Verona, Italy, Carlo Scapa, 1964), five identical galleries are successively aligned and arched openings allow circulation between them. In addition, an $\mathrm{H}$ steel beam supporting the ceiling and perfectly aligned with the openings runs 
through the entire wing (Figure 28). The beam is characterised by its singular materiality and colour, as well as by its detailing which includes carefully located supports and steel bearings giving the impression that the beam is floating. Thanks to its unique presence, the beam emphasises the path for users to take (Onniboni, 2014; Scarpa, Olsberg, \& Guidi, 1999).
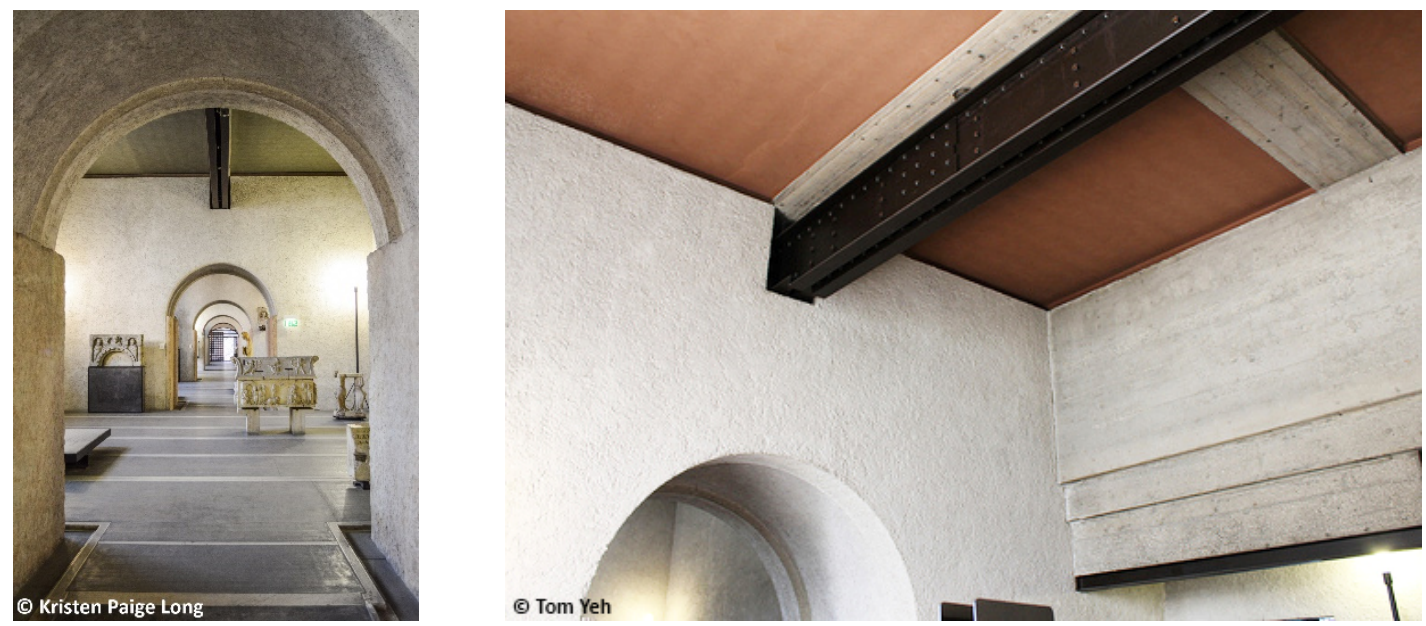

Figure 28. Castelvecchio Museum (Sources: https://rivaspring2016.wordpress.com and https://www.flickr.com/photos/yehtom, accessed April 2018)

A final approach, not mentioned by Ching yet identifiable in several buildings, corresponds to the circulation components being bounded by structure. This is achieved in the Sendai Mediatheque (Sendai, Japan, Toyo Ito, 2001) where the 13 hollow columns provide 'vertical circulation routes' (Witte, 2002). The structure ensures the distribution of air, electricity, water as well as people. Indeed, out of the four largest columns placed at the corners of the building, two house passengers and goods elevators, and two others stairs (Figure 29). Structure is thus used to physically define circulation area, while the vertical circulation components housed by it express direction and movement.
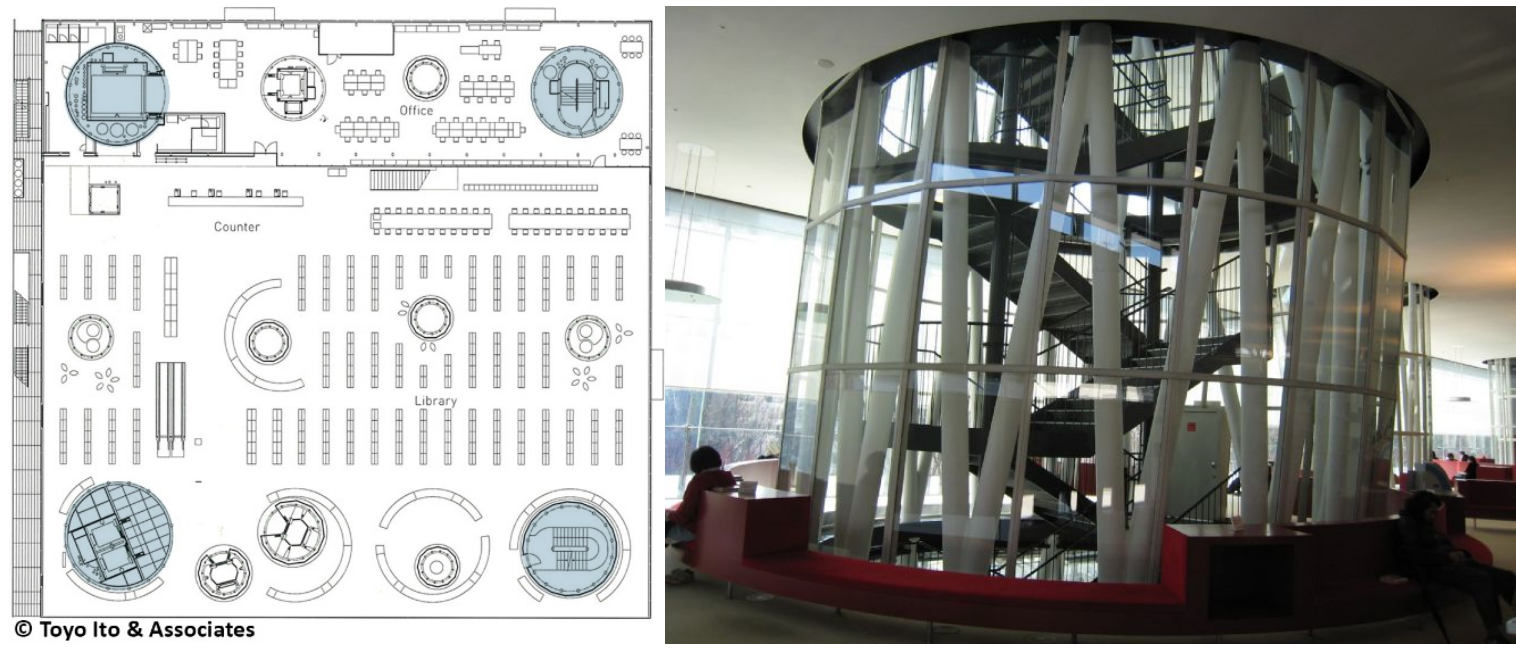

Figure 29. Structure housing vertical circulation routes (Sources: $h t t p: / / l e o n a m a d e . c o m$ and https://moreaedesign.wordpress.com, accessed April 2018) 


\subsubsection{Structure and external openings}

This sub-section starts by pointing out different relationships between structure and light. The second part of the sub-section focuses on the modulation of light by structure. Then, the capacity of light to influence the perception of structure is addressed. Finally, the relationship between structure and outdoor views is examined.

\section{Relationships between structure and light}

Light, and its relationship with structure, is perceived in many different ways by designers. A first approach may be based on Kahn's pre-1967 point of view. For him, light is defined as a natural phenomenon, compulsory for architectural spaces (Kahn, 1991e). For a space to exist, "life-giving light" is needed (Kahn, 1991f, p. 228). He brings the notion of "structure [as] the maker of the light" and justifies: "When I choose an order of structure that calls for column alongside column, it presents a rhythm of no light, light, no light, light, no light, light. A vault, a dome, is also a choice of a character of light. To make a square room is to give it the light which reveals the square of its infinite moods" (Kahn, 1991f, p. 227). Light refers to the choice of a structure which defines the image of a space (Kahn, 1991b). In this approach, the structure shapes the light to suit the appropriate space.

A second approach relates to Kahn's new definition of light since 1967. No longer a natural phenomenon, light becomes "the giver of all presences" and is referred to "the means to express" (Kahn, 1991a, p. 248). He defines it by relating it to materials and indicating that "material is spent light" (Kahn, 1991d, p. 309). He further explains that material is "utilized light... I mean to say that the light has burnt itself out in order to become a material... everything is utilized light" (Kahn, 1991c, p. 339). In this approach light has been 'used' to reveal a material which implies that, to a large extent, light exposes the presence of components such as structure.

Arnheim (1974) provides a third approach and attributes to lit objects the value of light sources. The focus is therefore not solely on a single source of natural light coming from the sun but also on the objects as sources of light. Von Meiss (1990, p. 121) applies this approach to architectural design which he considers as "the art of placing and controlling light sources in space". In this scenario, structure may be attributed the role of light source as much as any other architectural component. It is the structure being illuminated but also its capacity to block or facilitate the introduction of light that makes it a source of light. Steven Holl takes this approach to an extreme level with the NelsonAtkins Museum of Art (Kansas City, USA, Steven Holl Architects, 2007). In this project, the five pavilions do not rely on conventional lighting to display their volumes. Instead, each one of them 
glows from within and emit their own light to the outside (Figure 30). Each pavilion becomes literally sources of light, with Holl explaining that the "building seems to be completely constructed out of luminous material" (Descottes \& Ramos, 2011, p. 121). The load-bearing structure, along with other architectural components, contribute to that effect. Chris McVoy states that a series of T-shaped walls forming the structural spine of each building ensures that not only internal galleries gain natural light but also that each building projects light at night (Donoff, 2007) (Figure 31).

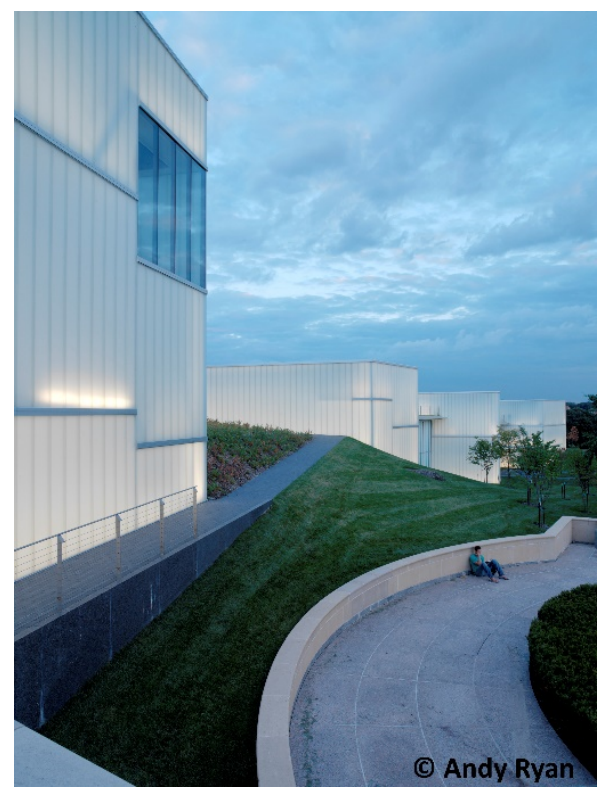

Figure 30. Exterior of the Nelson-Atkins Museum of Art (Source: http://www.stevenholl.com, accessed April 2018)

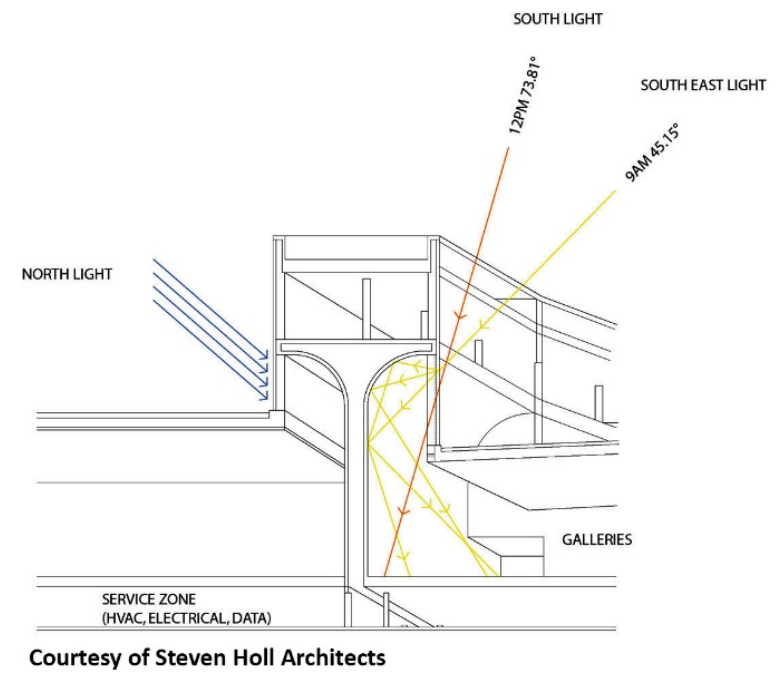

Figure 31. Detail of the structural T-shape walls of the Nelson-Atkins Museum of Art (Source: http://www.stevenholl.com, accessed April 2018)

The three presented approaches offer a range of different interpretations regarding light: light may be defined by structure, light may expose structure, and finally, structure may be a source of light. These aspects are actually complementary. Structure has the capacity to control light by facilitating or inhibiting its introduction within a space, or projecting it outside a building. Through its form, 
configuration and materiality, structure may also shape light according to the architectural design (Chernyshov, 2008; Kutlu, 2000; Michel, 1995). On the other hand, light may influence the perception of a structure, enhancing its presence or on the contrary, masking it (Kutlu, 2000; Millet \& Barrett, 1996; Von Meiss, 1990).

\section{Structure modulating light}

Sandaker (2007, p. 147) notes "structure is a tool for designing the rhythm and 'shape' of the light, for choosing its quantity, direction and colour". Michel (1995) further emphasises that structure, through the variety of its designs, can dictate the location, dimension, and shape of penetrations. When designing a building, modulating light using structural members appear therefore as a relevant approach to achieve intended architectural purposes. The outcome depends on the use and requirements, whether aesthetic or functional, of the space being illuminated (Descottes \& Ramos, 2011; Jaglarz, 2011). For Phillips (2004) using structure to control light is in tune with a 'passive architecture' as it allows reducing the need for mechanical devices to achieve the same purpose. A certain form of control is therefore used where structure can give maximum freedom to light or instead restrict its presence.

The Joe and Rika Mansueto Library (Chicago, USA, Helmut Jahn, 2011) provides maximum freedom to natural light. The building is an elliptical glass dome supported by a grid shell structure (Figure 32). The structure is composed of $150 \mathrm{~mm}$ diameter steel tubes parallel to the ellipse axis and spaced about $1800 \mathrm{~mm}$ in each direction. The thin section of the structure combined with its grid pattern allowed to minimise the structural silhouette. Lighting designer Michael Rohde explains that with little interference, natural daylight was maximised within the building thus avoiding the use of artificial light (Madsen, 2012).

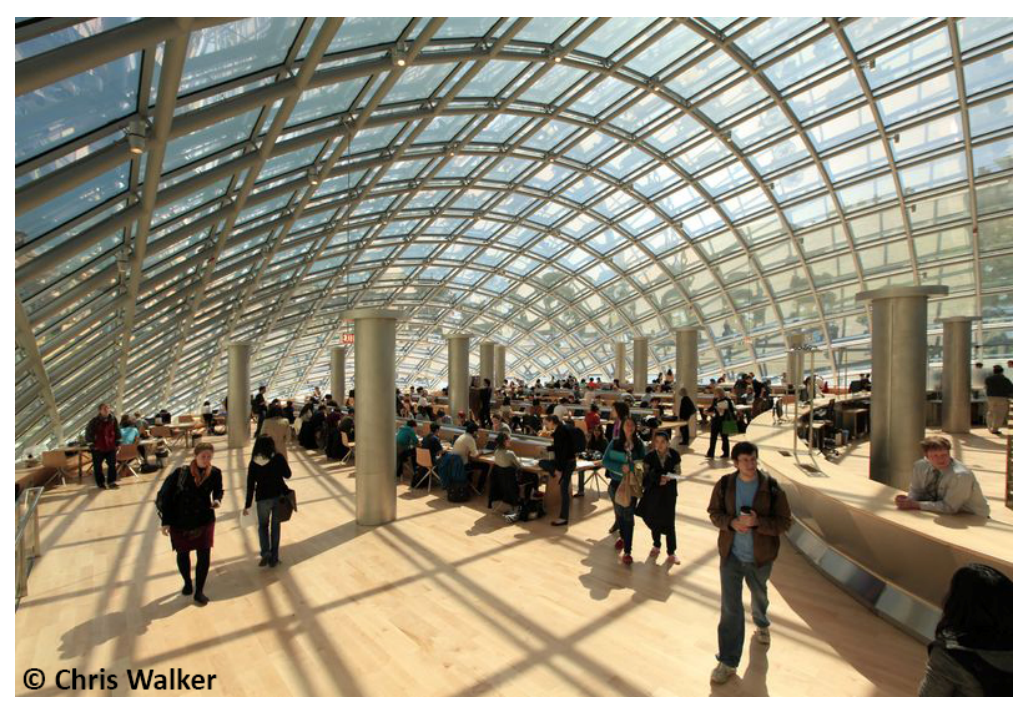

Figure 32. Interior of the Joe and Rika Mansueto Library (Source: http://featuresblogs.chicagotribune.com, April 2018) 
While minimising the dimensions of structural members allows maximising the entrance of light, another approach consists in penetrating the structure (Charleson, 2014). Wiendahl, Reichardt, \& Nyhuis (2015) thus highlight the capacity of castellated beams and truss girders to spread natural light in a space. This approach is used by Renzo Piano when designing a five subway stations project (1983-2003) in Genoa, Italy. Some of these stations are designed using perforated curved steel beams which, despite structural constraints let the light flow largely uninterrupted (Figure 33). Combined with glazing over the structure, the overall design creates a light-filled space.

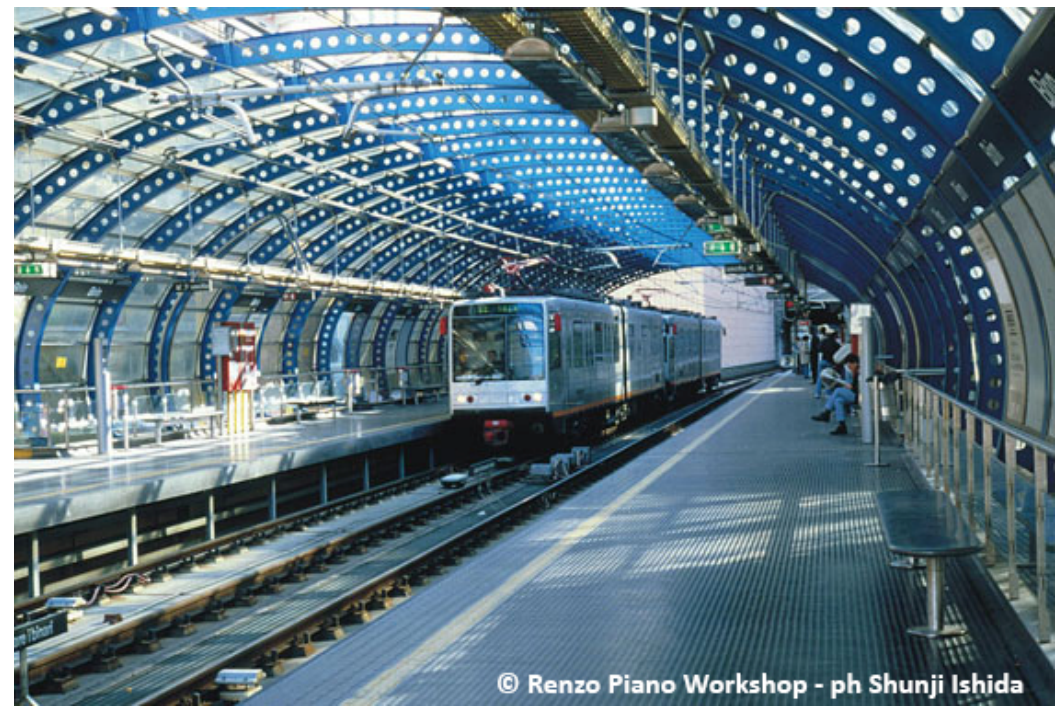

Figure 33. Genoa Subway Station (Source: http://www.rpbw.com, accessed May 2015)

While maximising the entrance of light can be acknowledged as a significant asset for most architectural projects, Plummer (2009) considers it a conventional solution. For Plummer, greater interest should be given to architectures capable of directing and channelling natural light within a building. Referring to works from architects like Le Corbusier, Alvar Alto and Frank Lloyd Wright, where paths for lights are carved out in the building, Plummer (2009, p. 150) explains: "In such excavated structures, daylight absorbed around the perimeter is directed through a network of channels to where it is needed inside. The ingeniousness of these previous forms was paralleled by an equal fascination with the quality of light being allocated, shaped by collecting radiation from specific portions of sky, and then sculpting that energy with the same vessels used to conduct its flow, thereby giving formless light a memorable character". An example using structure as a 'vessel' and 'sculptor' of light is the Castellón Auditorium and Conference Centre (Castellón de la Plana, Spain, Carlos Ferrater, 2004). In this building, the architect explains conveying and shaping light using 'folded skylights'. This term corresponds to an interstitial zone where the concrete slab appears to move back from the vertical wall, as if the 'the ceiling folds back over itself' (Plummer, 2009). As a result, natural light is controlled and sculpted, using cast-in-place walls to diffuse it (Figure 34). 

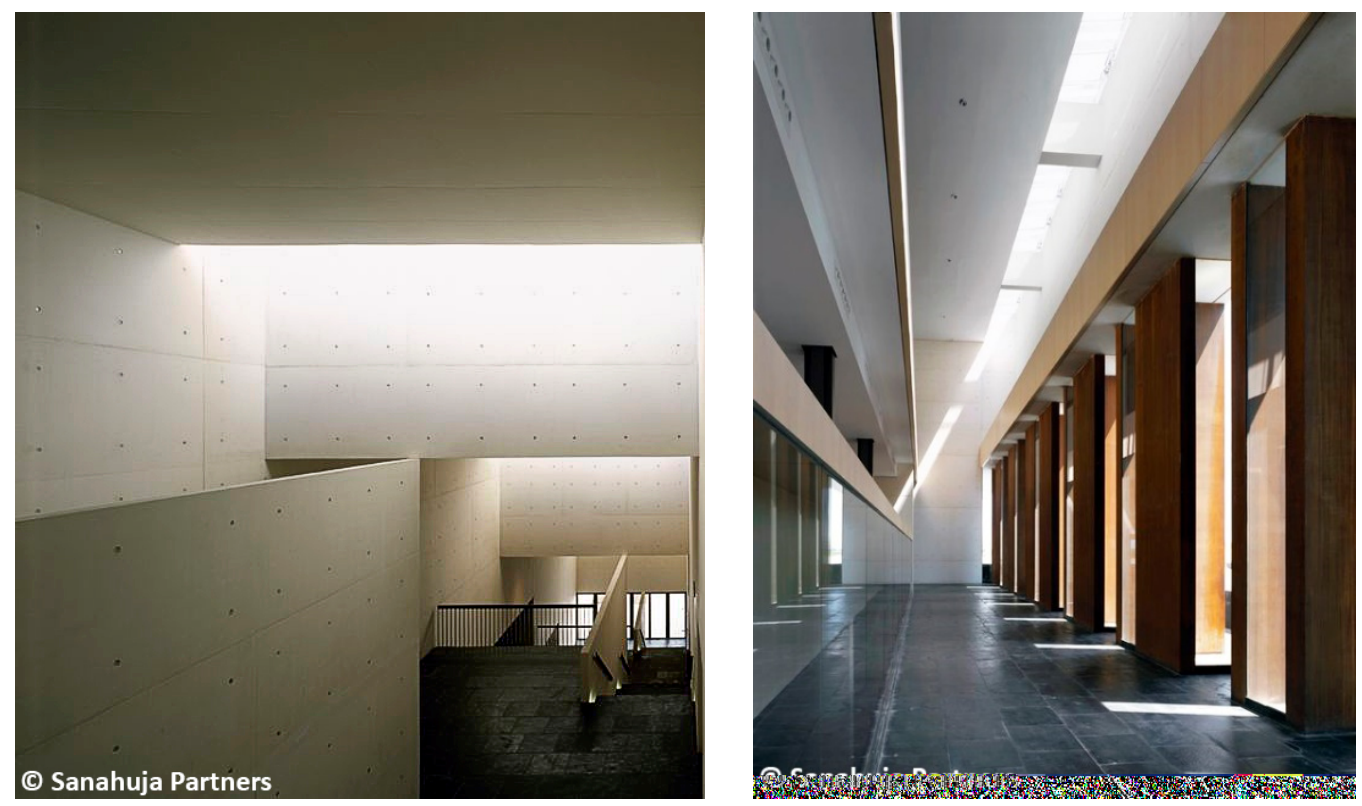

Figure 34. Castellón Auditorium and Conference Centre (Source: http://www.sanahujapartners.com, accessed April 2018)

The capacity of structure to control light and its outcomes can be further explored through the notion of filtering. The importance of filtering light can be appreciated in the essay "In Praise of Shadows" by Jun'ichirō Tanizaki (1977). The author explores the opposition between the western and Japanese aesthetics, in particular their contrast through the use of light. In support of the traditional Japanese aesthetic, Tanizaki praises the delicate use of shadows and dim light, in particular through the use of panels of Shoji paper shifting daylight. Undertaking a similar reflection on filtered light, Pawson (2015) emphasises that "the effect of the subdued light suffusing spaces is both to calm the spirit and sharpen the senses, heightening the way one experiences the texture of a tatami mat, the grain of a length of timber or the junction between surfaces, as well as fostering an intensity of atmosphere". Filtering natural light therefore implies more than simply reducing the amount of sunlight within a building; it allows emphasising various architectural features. The Termitary House (Da Nang, Vietnam, Tropical Space, 2014) uses its main structure, perforated brick walls, as a filtering device. The walls act as porous screens, fracturing natural light yet not obstructing it (Figure 35). Throughout the day, patterned shadows are cast inside the house while the intensity of light changes. The result is a constant changing atmosphere creating a unique interior character (Ngo, 2015). 


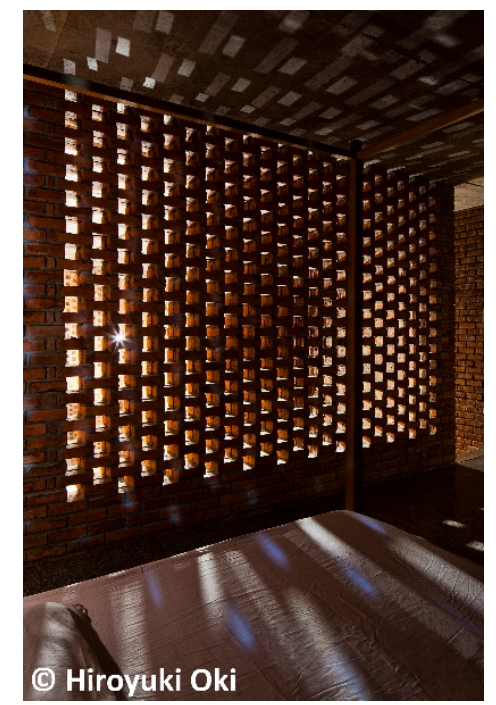

Figure 35. Termitary House (Source: https://www.archdaily.com, accessed April 2018)

At the end of the spectrum of structure modulating light, designers may decide to materialise light, making it become an object. Antonakaki (2007) explains such a use of light is often aimed for symbolic purposes, as in several religions natural light is "treated as the materialised representation of the divine". Transforming light into an object therefore appears as a 'mystical' achievement. Peter Zumthor (2006, p. 61) supports this value given to natural light as he states: "I feel [light] almost as a spiritual quality. ... It gives me the feeling there is something beyond me, something beyond all understanding". Light can be materialised by taking the form of the object it illuminates. This can be achieved by having the object radiating light applied on it. Such an achievement depends on the materiality and surface of the object as well as the intensity of light (Millet \& Barrett, 1996). In the Ito House (Tokyo, Japan, Tadao Ando, 1990), Plummer (2009) notes how an interior curved cast-inplace concrete wall becomes a luminous entity when natural light strikes it (Figure 36). This is largely due to the combination of cement and aggregate composing the concrete wall producing a light grey surface able to radiate light.

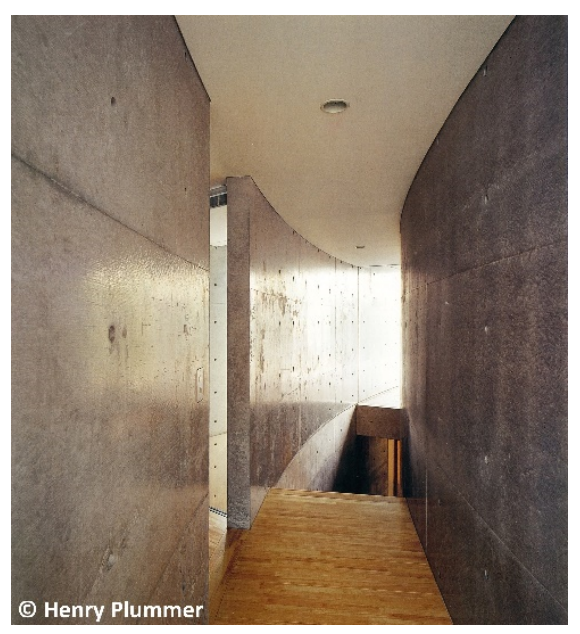

Figure 36. Ito House (Source: Plummer, 2009, p. 225) 


\section{Light affecting structure}

Light may influence the perception of structure. Von Meiss (1990, p. 125) explains how the same structure is affected by the type of light projected on it and is therefore read differently. He refers to the Locking Piece sculpture of Henry Moore to exemplify his statement (Figure 37). In the first situation, the selected object is illuminated by a "parallel and directed light" which leads to a limited appreciation of the three-dimensional form of the object. The second situation uses multiple light sources as well as reflections which result in a play of shadows on the object increasing the threedimensionality of the object. The last situation refers to a "uniform light" leading to an absence of shadows therefore complicating the reading of the object.
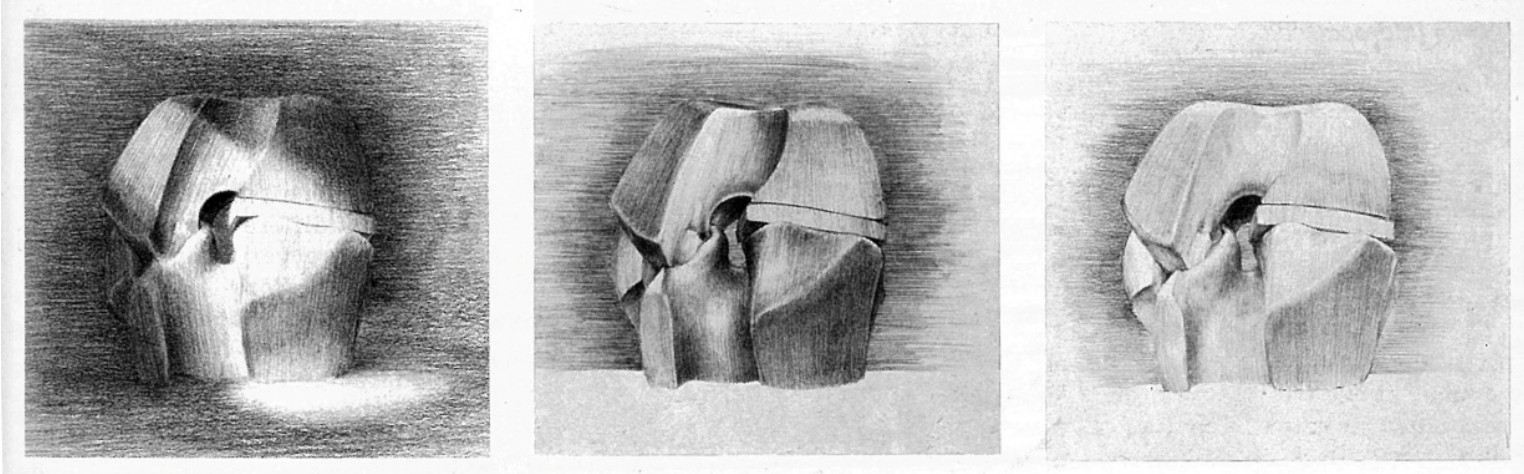

Figure 37. Locking Piece, Henry Moore, 1963-1964 (Source: Von Meiss, 1990, p. 125)

Depending on the architectural intention, light might then be used to reveal or, on the contrary, conceal structure (Clark \& Pause, 2005). An example is the Rookery building (Chicago, USA, Root \& Burnham, 1888) and its eleven-storey light well supported by a skeleton steel frame. The building's structure allows the creation of wide windows granting the upper floors access to both air and light. The two bottom floors display a central light court (Figure 38). While the perforated steel beams of the skeleton frame allow natural light to easily flow throughout the court (Achilles, 2013), the structure is equally revealed by the entering light. Light celebrates structural performance, in particular the capacity of steel structure to support glass while permitting the entry of large amounts of daylight (Kutlu, 2000; Millet \& Barrett, 1996). 

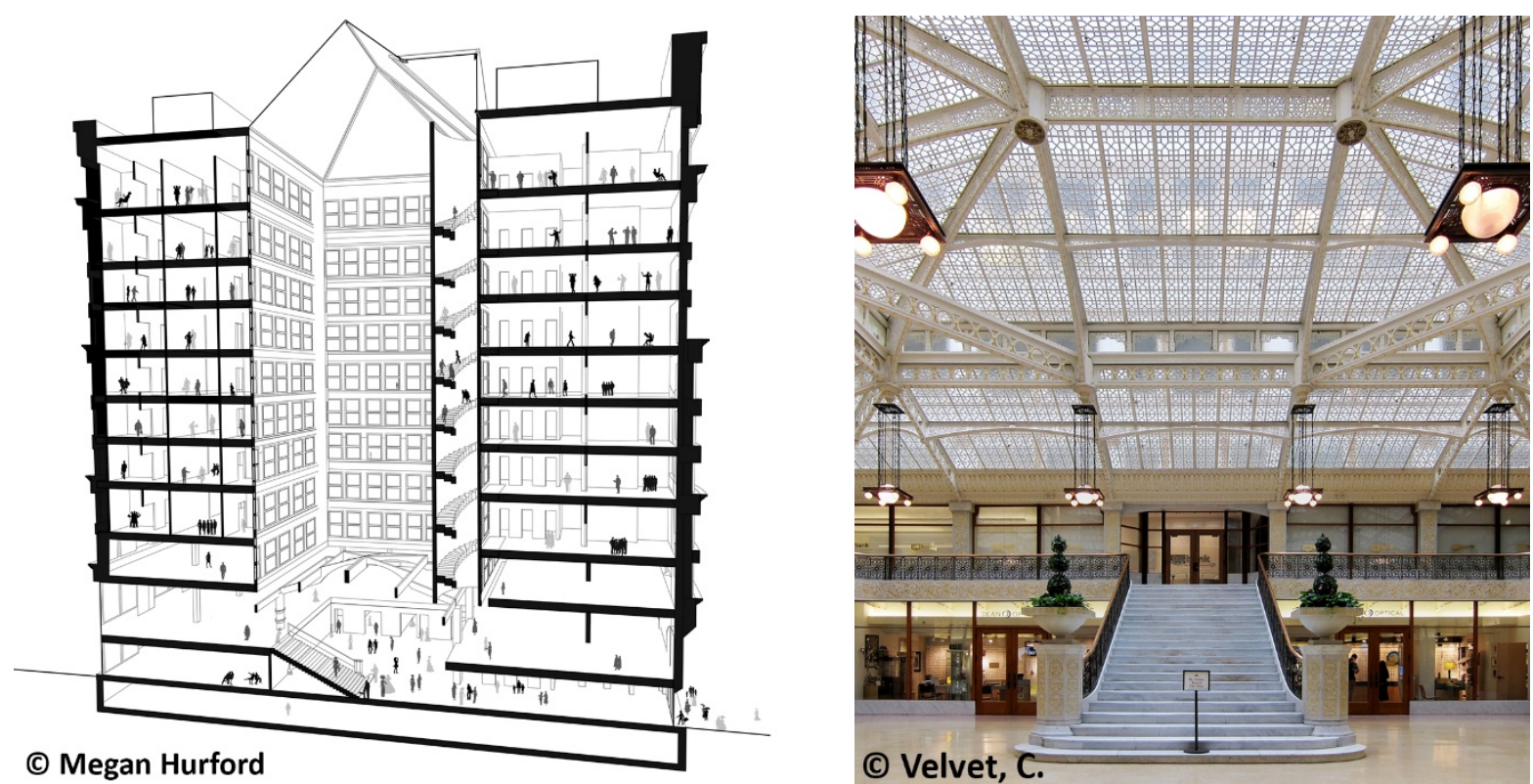

Figure 38. Rookery building (Sources: http://www.meganhurford.com and https://www.metalocus.es, accessed April 2018)

This mutual benefit for structure and natural light is also noticeable in the Solomon R. Guggenheim Museum (New York, USA, Frank Lloyd Wright, 1959). On the last floor, a skylight is composed of structural members arising from the uppermost walls and meeting at their ends to form a series of hairpin like shapes (Figure 39). The structure is an integral part of the skylight both supporting it and composing with the steel and glass components of the roof to create a unique pattern (Michel, 1995). The resulting skylight provides an abundant amount of light which then highlights the pattern created by the structural components (Kutlu, 2000).

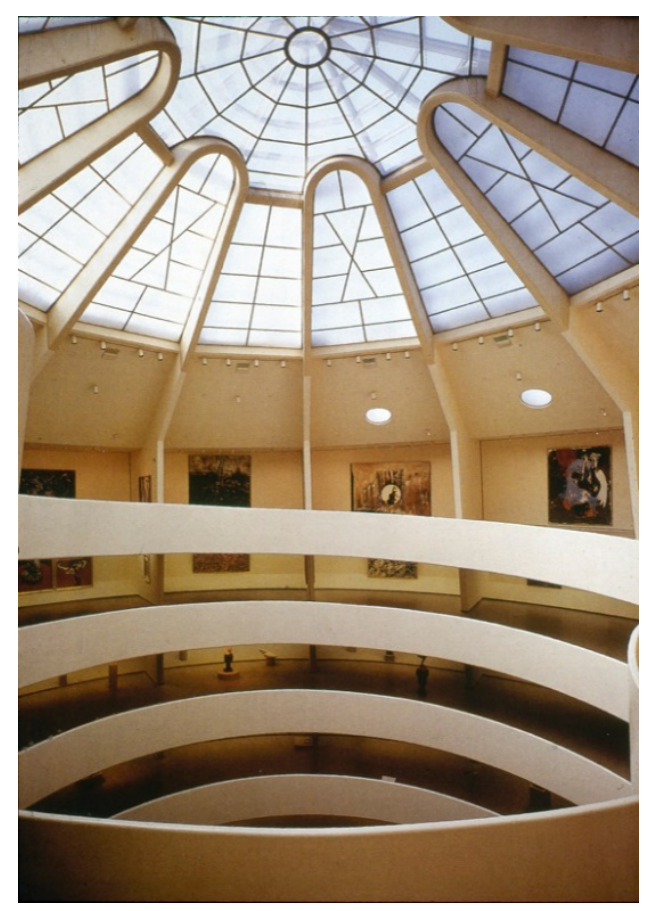

Figure 39. Skylight of the Solomon R. Guggenheim Museum (Sources: http://www.romanovgrave.com, accessed April 2018) 
In contrast to the two examples above, a designer might aim at concealing the presence of structural systems by manipulating light. An intense glare for instance can dematerialise a structure. This effect can even be enhanced if the structure possesses a reflective surface resulting into a secondary source of light obscuring the clear perception of the structural form (Gill, 2006). An example is the use of natural light in the Church of Light (Ibaraki, Japan, Tadao Ando, 1989). Ando (n.d.) characterises his work as an architecture of enclosed spaces mainly through the use of massive exposed concrete walls. The aim is first and foremost to "create a space for the individual" which would then allow light to penetrate in order to reconnect the building with nature (Ando, n.d.). The Church, and its 1999 extension Sunday school, are each composed of a rectangular volume cut through by a 15 degree angle free standing concrete wall. In both buildings, natural light is used in contrast with the solid walls and affects the perception of the load-bearing structure. For instance, the intensity of natural light passing through the gap created between the ceiling and the diagonal wall in the Church results in the roof seemingly floating without any support (Figure 40). Also, the strong sunlight illuminates so brightly the extremities of the diagonal walls that their materiality fades almost completely (Kroll, 2011) (Figure 41). The wall in the Church is then perceived as if it stops right at the window opening. In the Sunday school, the structural connection between both parts of the walls appears as an endless cantilever beam.

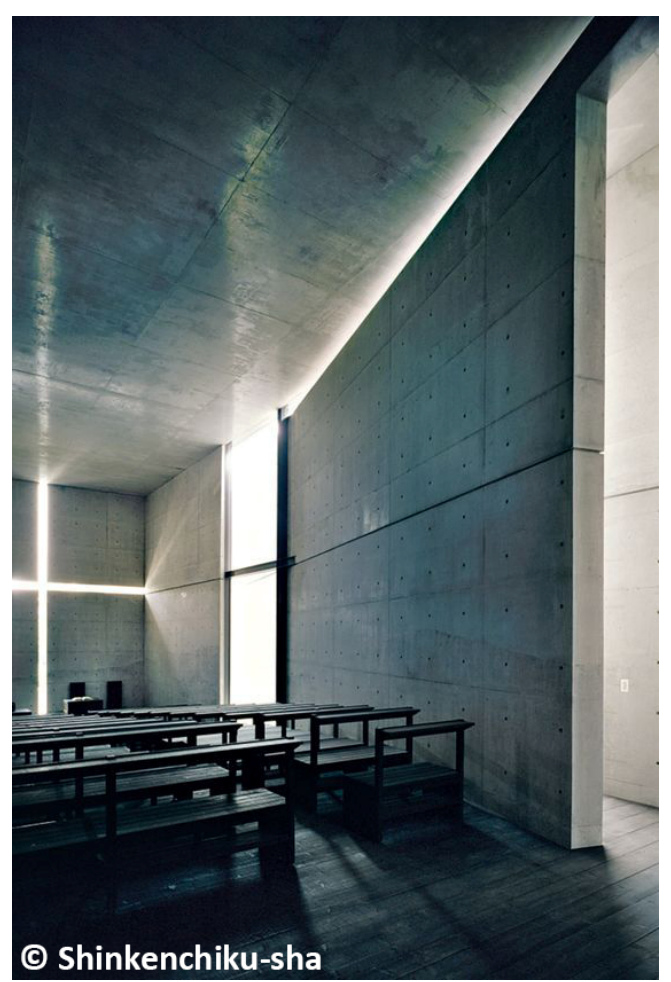

Figure 40. Interior of the Church of light with natural light visually emerging from the gap between the ceiling and diagonal wall (Source: $h t t p: / / c a p s u l a . a r q . b r$, accessed April 2018) 

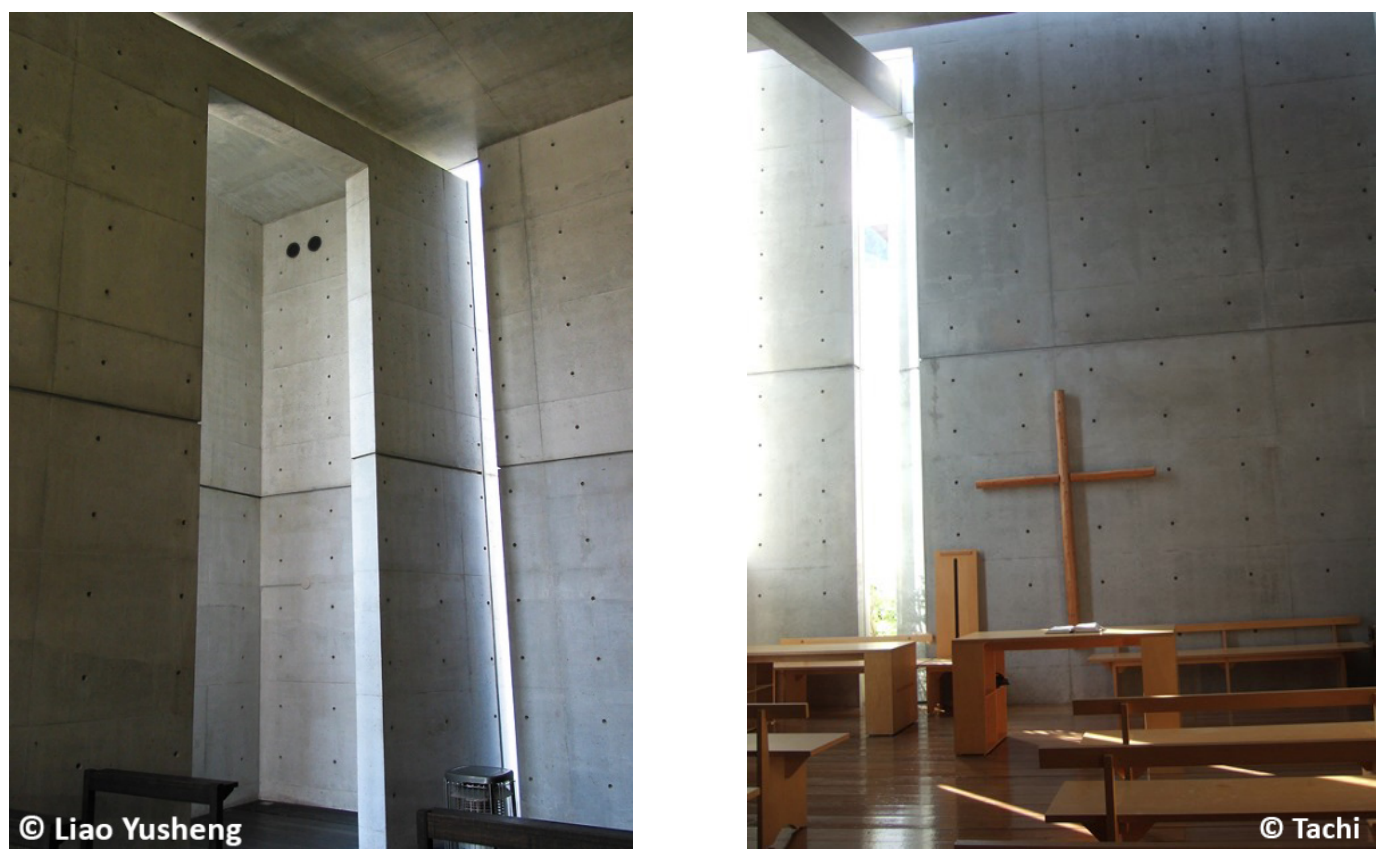

Figure 41. Diagonal walls intersecting the transversal wall of the Church of light (left) and Sunday School (right) (Sources: http://figure-ground.com and http://iwasky.blog.so-net.ne.jp, accessed April 2018)

\section{Outside views and sightlines}

External openings also raise the issue of the relationship between structure and outside views. Millet \& Barrett (1996) consider exterior openings as key architectural features providing views to the outdoors and creating visual relationship between a space and its surroundings. This position is supported by Ching (2007) and Phillips (2004, p. 15) who further indicates that "where a view is available it should be exploited". The two authors also link the dimensions and locations of openings to the building's programme and architectural intentions. A small opening would direct the view to a specific detail, where a large one projects the viewer into a scene. The variety of structural designs allows great freedom in achieving specific external openings. The Udden 6-7 house (Bungenäs, Sweden, Skilsö Arkitekter, 2016) is an old bunker refurbished into a private residence. The project consists in slicing the concrete block, resulting in a variation of vertical openings (Figure 42). Their arrangement also creates a range of narrow walls of different widths, similar to the trees surrounding the building. The sequence of the openings creates a range of different views toward the outside, similar to the views one would have if standing in a forest. 


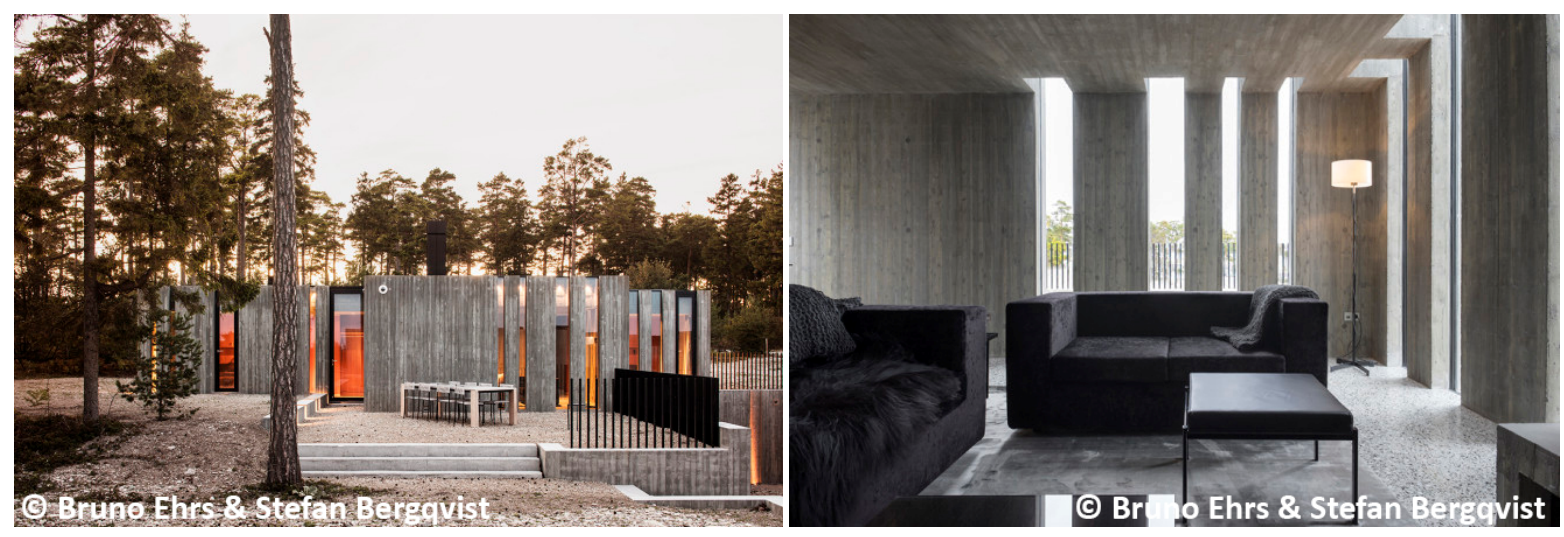

Figure 42. Udden 6-7 house (Source: http://skalso.se, accessed April 2018)

\subsubsection{Structure and ornamentation}

In several previous sub-sections, the capacity for structure to participate in architectural aesthetics has been addressed. Aesthetics relates to the creation and appreciation of beauty, and corresponds to Vitruvius' principle of 'venustas'. In this sense, the participation of structure in the aesthetics of a building aims at enhancing the qualities of beauty and delight carried by architecture. Several architectural components may serve aesthetic purposes, but ornament is perhaps the one that most divides architects regarding its usefulness in architecture.

This sub-section analyses the relationship between structure and ornament, starting with the definition of the latter and its categorisations. Distinct attitudes toward ornament and their respective explanations are then briefly discussed. Finally, the different ways structure takes on the role of ornament is discussed.

\section{Definition and categorisation of ornament}

The Oxford English Dictionary (n.d.) defines ornament as "an accessory or adjunct, primarily functional, but often also fancy or decorative" and as "something used to adorn, beautify, or embellish, or that naturally does this". Ornament may then be considered as a medium to concretely manifest beauty. The artist Tom Phillips (2002) adds the following interpretation: "Ornament serves strength with strength. It is not an afterthought as is decoration. It is not merely applied but becomes one with the object it helps to create". In his opinion, ornament is an inherent feature of an object, while some describe it as an 'add-on', a superfluous addition with the purpose of embellishing a completed and fully functional object.

James Eyre (2002) considers that this division of opinion regarding ornament results from different points of view on aesthetics between architects and engineers. He explains: "the very essence of the 
misunderstanding between civil engineers and architects is revealed in terms of their diverging attitudes to aesthetics. Historically, aesthetics was generally viewed as an 'add-on': the so-called engineering structures that we admire today (principally stations and bridges) were often subjected to aesthetic add-ons merely to make them acceptable for society. Such additions were usually undertaken by architects". This quote can be related to Andrew Saint's description of the Eiffel Tower in which he indicated how the architect Stephen Sauvestre added great arches to the base of the building as aesthetic add-ons: "Structurally they do nothing, they are decorative, or rhetorical ... they were put there to help sell the tower, to make it acceptable" (Saint, 2008, p. 6).

\section{Different attitudes toward ornament}

In the early twentieth century, with the rise of modernist architecture, the legitimacy of ornament was questioned among architects. Some supporters relied on Owen Jones' thoughts to justify its use: "[Ornament] is the best measure of the care and refinement bestowed upon the work" (Jones, 2001, p. 472). In other words, the use of ornament acknowledges the hard work undertaken by the architect and craftsman on a building. Louis Sullivan justified ornament differently. For him, it expressed the building's identity and individuality (Sherman, 1962). He proposed a relationship between structure and ornament, where both are expressed as a single idea. Indeed, Sullivan (2012) expressed ornament as a natural extension of structure and not as an added component . He also specified that "the ornament should appear, not as something receiving the spirit of the structure, but as a thing expressing that spirit by virtue of differential growth" (Sullivan, 2012, p. 189). In this scenario, structure and ornament enhance each other and the removal of ornament would inevitably destroy the building's individuality. The result is not identified as tectonic structure but instead an "organic system of ornamentation" (Sullivan, 2012, p. 189): an object defining and communicating the specific and individual character of the building.

An example of Sullivan's approach may be seen in the Guaranty Building (New York, USA, Sullivan \& Adler, 1914) in which the steel-frame structure is covered by highly ornamented terra cotta cladding (Figure 43). The building expresses on its façades the division of a classical column with a base, shaft, and capital (Whiffen \& Koeper, 1983). At its ground and first floor, the large spans between structural piers display delicate ornamentation, more highly expressed at the junctions of the steel members. On the shaft, or upper levels, ornamentation is more richly detailed and expressed. The vertical lines of the steel columns are thus more accentuated. Finally, the capital is expressed by a highly elaborated cornice composed of a row of round windows. Despite the fact that some aspects of the building express the association of ornament and structure, it appears that their 
interdependence may not be as strong as Sullivan states. The role of the structure, apart from its load bearing purpose, appears to mainly be a physical support for ornament.

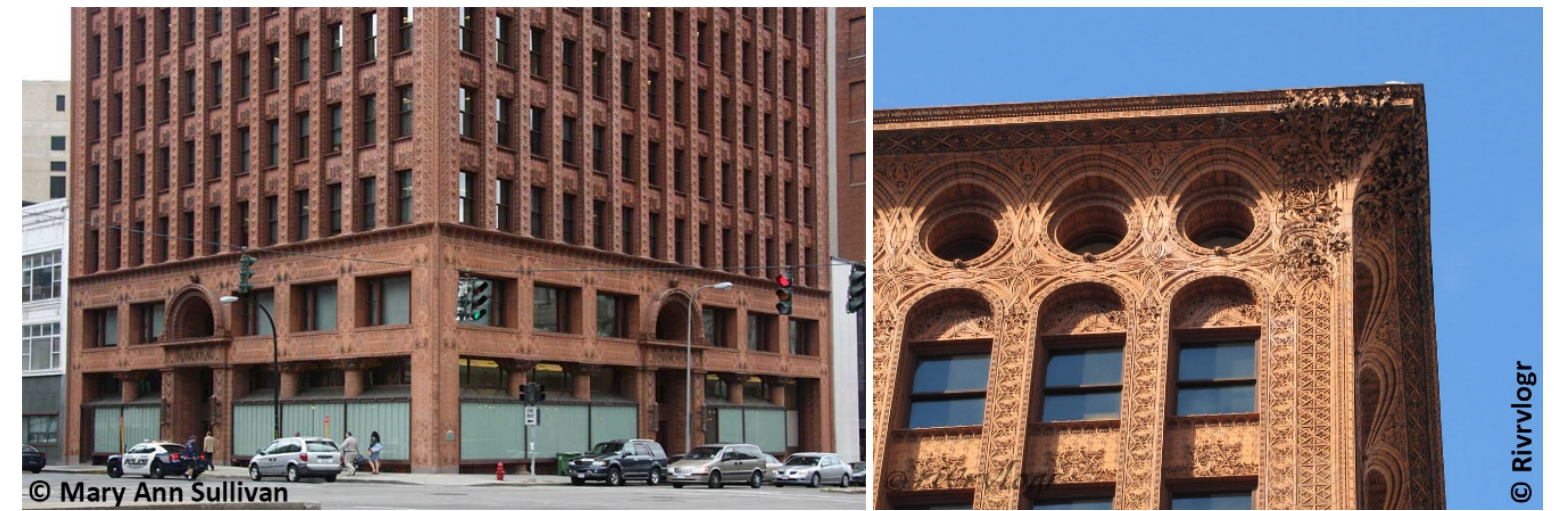

Figure 43. Guaranty Building (Sources: http://www.bluffton.edu and http://www.skyscrapercity.com, accessed May 2015)

In contrast to the supporters of ornament, Adolf Loos, published in 1908 a long essay called "Ornament and Crime". He wrote that "the evolution of culture is synonymous with the removal of ornamentation from objects of everyday use" and considers people trying to perpetuate the use of ornaments on any modern object as "criminals" who "are slowing down the cultural development of the nations and of humanity" (Loos \& Opel, 1998, pp. 167-170). He justified his position by stressing the unstable nature of ornament, as it changes through time, making past ornament outdated and inviting constant renewal. He also strongly criticised the adverse consequences that ornament brings in terms of economy. According to him, it only contributed to the "waste of human labour, money, and material" (Loos \& Opel, 1998, p. 169). Sandra Alfoldy (2012) explains that Loos' thoughts have to be understood in the socio-political context of Austria in 1908. His aim was to force consumers and craftspeople to appreciate the "dangers of nationalistic decoration" that involves " $a$ waste of time and labour, and obscures larger political and social issues through the demanding focus on detailed work" (Alfoldy, 2012, p. 107). However, as emphasised by Christopher Long (2011), Loos was not calling for an unconditional eradication of ornament. The critique of the Austrian architect was directed toward the use of ornament as an add-on. Loos held in great esteem "organic ornament" (Long, 2011, p. 30) which refers to the use of inherent features of materials to express beauty. The Goldman and Salatsch building (Vienna, Austria, Adolf Loos, 1912) provides example of this type of ornament. In this building, ornament is expressed by the marble cladding at the bottom floors and the veins resulting from its materiality (Figure 44). The ornament role of the Cipolino marble and its natural pattern is emphasised by the symmetrical treatment of the material on the façade. The only other sources of ornament are the bronze shields and the name and street lamps that have been added afterwards and were not part of Loos' design. 


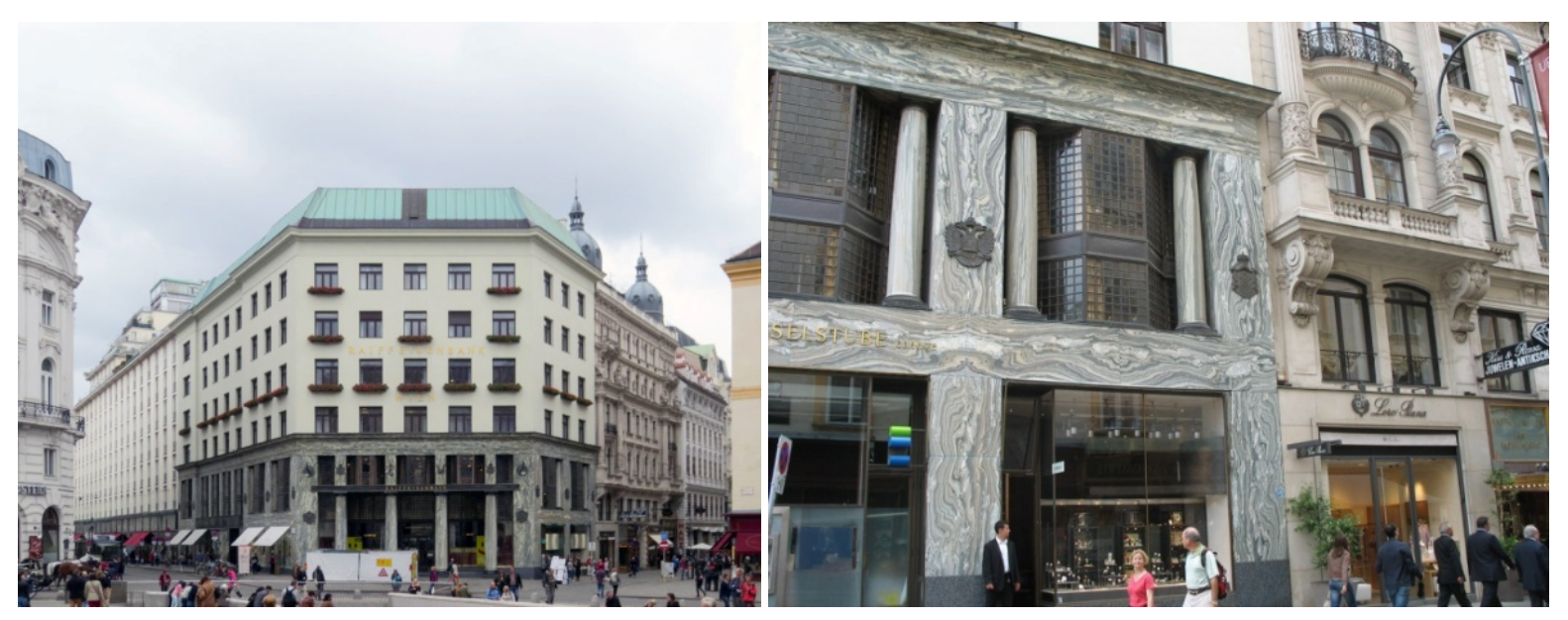

Figure 44. Goldman and Salatsch building (Source: https://en.wikiarquitectura.com, accessed June 2017)

\section{Structure assuming ornament roles through different approaches}

After defining and analysing the distinct attitudes toward ornament, some of the different relationships existing between ornament and structure are presented.

The first relationship is defined by Macdonald (2001, pp. 73-77) as "Ornamentation of structure". In this scenario, structure is fully justified from a technical point of view and expresses the structural engineering state-of-the-art. This goal is different from Sullivan's desire to ensure that the exceptional work undertaken by the designers is fully acknowledged (Jones, 2001). First, "Ornamentation of structure" exposes the structural component instead of hiding it behind an added layer of ornamented cladding. Second, unlike Sullivan's approach in which structure is ornamented to express a specific character of the building, here, structure is tectonic and reveals the techniques of construction. It is also conceivable some structural components would be considered as 'organic ornament' thanks to their materiality. Stainless steel structures would mostly likely fall in this category. The structure of the Waterloo Station (London, UK, Nicholas Grimshaw, 1993), while being technically fully justified, contributes aesthetic value through its technical vocabulary (Figure 45). The arches of the train shed roof are composed of two dissimilar curved trusses, triangular in section. Arches are attached to each other by a secondary tubular steel structure cross-braced by steel tension rods (Waterloo International Terminal, 1993). The ornamental quality displayed by the structure may be read in two ways. First, the structural hierarchy between the components and their repetition establishes an ornamental pattern all along the roof. Second, the refined detailing of some components such as the pin jointed connections at the base of each truss enhances the elegance of the engineering work. 


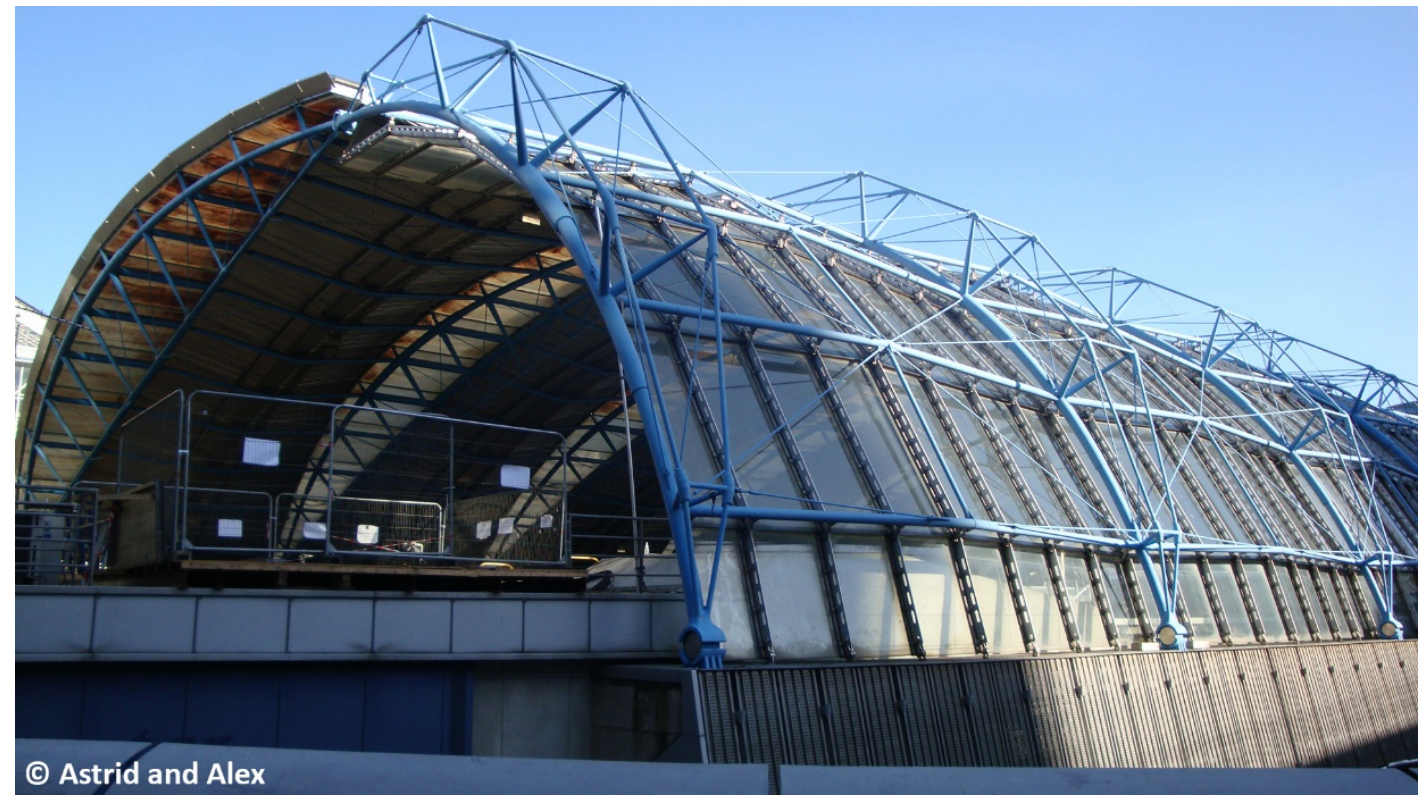

Figure 45. Waterloo International Terminal (Source: https://changehere.wordpress.com, accessed May 2015)

A second relationship is defined by Robert Kerr as "Structure Ornamented" (Beeby, 1977; Bothireddy, 2007, p. 23; Collins, 1998, p. 125) and describes applied or surface ornamentation. Structural components and ornament are in this situation clearly distinct. This approach was strongly criticised by Loos but fully applied by Sullivan in many of his projects such as the Guaranty building (New York, USA, Sullivan \& Adler, 1914).

In a third relationship, structure is mainly designed for its aesthetic and therefore ornamental qualities. The primary consideration is for structure to be more visual than technical. This approach corresponds to Kerr's description of "Structure Ornamentalized" (Beeby, 1977; Bothireddy, 2007, p. 23; Collins, 1998, p. 125). In many cases, the aim is to express technical progress even if the structural performance is not necessarily achieved. This is the case in the "Structure symbolised" approach described in the 'Structure Expressed' sub-section. This relationship may be described as structural component being shaped as ornament. The Lake Shore Drive Apartments (Chicago, USA, Mies van der Rohe, 1949) provides an example of "Structure Ornamentalized". Each façade displays a series of exposed vertical I-beams welded to the columns of the main structure and to the mullions (860-880 Lake Shore Apartments, n.d.) (Figure 46). From a structural point of view, the I-beams do little apart from slightly stiffening the mullions. Their main purpose remains aesthetic. First, each Ibeam is ornamental, expressing a technical vocabulary. Second, taking a broader approach, the combined ornaments develop a specific rhythm to the façades (Weston, 2010) as well as emphasizing the building's height, and adding depth and texture to the exterior skin (Innovations and Influence, n.d.). 


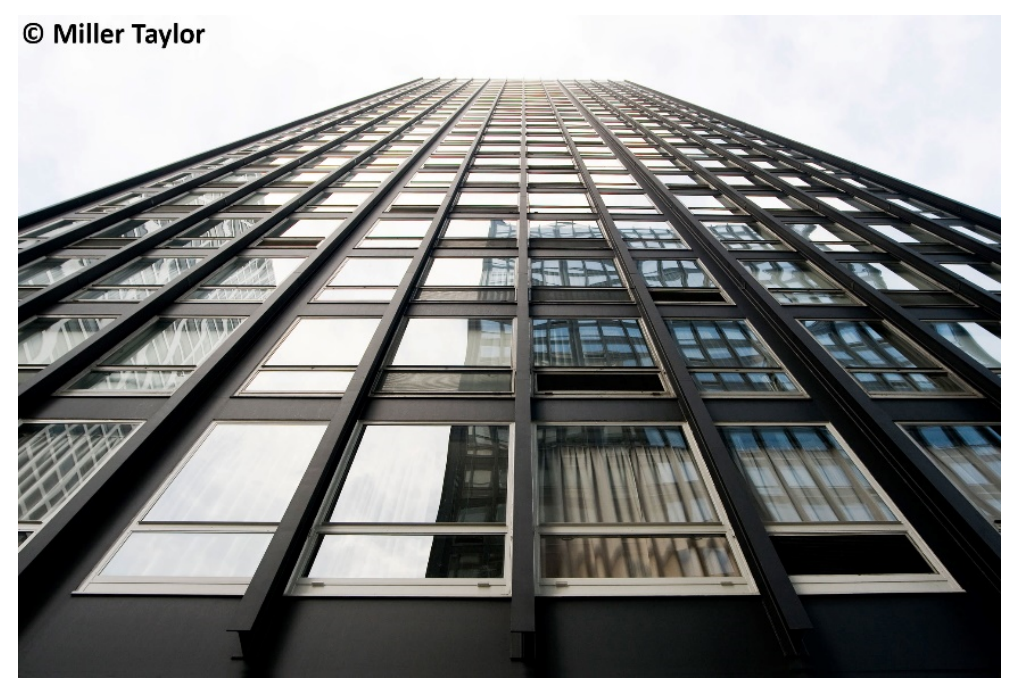

Figure 46. Lake Shore Drive Apartments (Source: http://www.archdata.org, accessed May 2015)

\subsubsection{Structure and concept}

The notion of design concept has been briefly referred to in previous sub-sections. The design concept of the Guggenheim Museum (Bilbao, Spain, Frank Gehry, 1997) justifies the hiddenness of structure. Similarly, the symbolic expressiveness of the vertical structure in the Sendai Mediatheque (Sendai, Japan, Toyo Ito, 2001) as 'seaweed-like columns' support the concept of giant aquarium. As this sub-section explores in greater details the relationship of structure and architectural concept, a definition of design concept is necessary before going further.

\section{Definition of architectural concept}

Pressman (2012, p. 23) proposes the following definition of architectural concept and continues by emphasising its relevance in a project: "[Concept] refers to the essential formative scheme, idea, or basic organizing principle of a building design ... A strong initial idea is valuable because design decisions can be imprinted by it and then relate to it (or even express it), thereby ensuring coherence among all elements of a project ... When design decisions are less arbitrary, i.e., they are informed by the concept, the architecture becomes greater, more powerful, and meaningful". The use of a concept as a 'strong formative idea' is therefore of paramount importance as it supports and enhances the architectural relevance of a project.

Other architects also emphasise how essential the use of a concept is to develop a project. For Louis Kahn (Frampton, 1985), the concept is the starting point to any architectural project. Only when the conceptual form is achieved can it be adjusted to shelter the functions of the programme. Steven Holl $(2002$, p. 73) is less adamant than Kahn yet acknowledges his reliance on this type of design approach as he states: "I depend entirely on concept diagrams, I consider them my secret weapon. 
They allow me to move afresh from one project to the next, from one site to the next. ... Finding an initial concept for each project that captures the essence of the architectural opportunities unique to that project is, for me, a way into it, the door through which new ideas enter architecture". Similar to Pressman, Holl points out that a concept allows designers relying on formative idea. In addition, it provides confidence to the architect that the project being designed possesses its own identity.

Overall, an architectural concept fulfils two requirements. First, beyond its role as an initial idea, concept is used to drive the design through the entire project and to ensure that a building expresses the desired message. Secondly, it aims at giving sense of meaning to a project and justifying some of the architectural decisions.

\section{Structure as a conceptual component}

As a formative idea, a concept may refer to a range of different notions, from the most explicit to the vaguest. The entire challenge for a designer is then to transform this mental idea into a physical object expressing the intended architectural message. Achieving a concept therefore corresponds to the physical construction of a thought formed in the designer's mind.

Structure can participate in the communication of concepts. For several authors, this contribution is in fact compulsory to the successful achievement of a concept. A first assertion is given by Charleson (2014) for whom the combination of architectural and structural forms should always serve the architectural concept and contribute to the intended achievement of architectural qualities. Macdonald (1997, pp. 1-2) further emphasises that "the contribution of the structure to the achievement of higher architectural objectives is always crucial". Following similar reflections, Michel (1995) stresses the importance for designers to carefully consider the appropriateness and correctness of the selected structure in regard to the building's programme and concept. For him, such a consideration is imperative for the accomplishment of quality architectural design.

Careful reflection and consideration regarding the selection and design of structure to best serve a concept can be appreciated in several architectural projects. A first example of structure expressing a concept is the Simmons Hall student residence (Cambridge, USA, Steven Holl, 2002). The building is based on the concept of 'porosity' which relates to the quality of an object "[to contain] minute interstices through which water, air, etc., may pass" (Oxford English Dictionary, n.d.). The translation of this notion into a physical object is obtained by developing a volume composed of five large openings, with its facades consisting of external perforated wall panels (Figure 47). These structural walls are the result of a type of precast concrete system and act as vierendeel trusses (Sokol, 2002). As a result, the structure supports gravity load and resists lateral loads (Simpson Gumpertz \& Heger 
Inc., n.d.). The 'pores' in the panels therefore serve technical requirements as well as transcribe the architectural concept by letting air and light pass through its facades (Kotsopoulos, 2008).

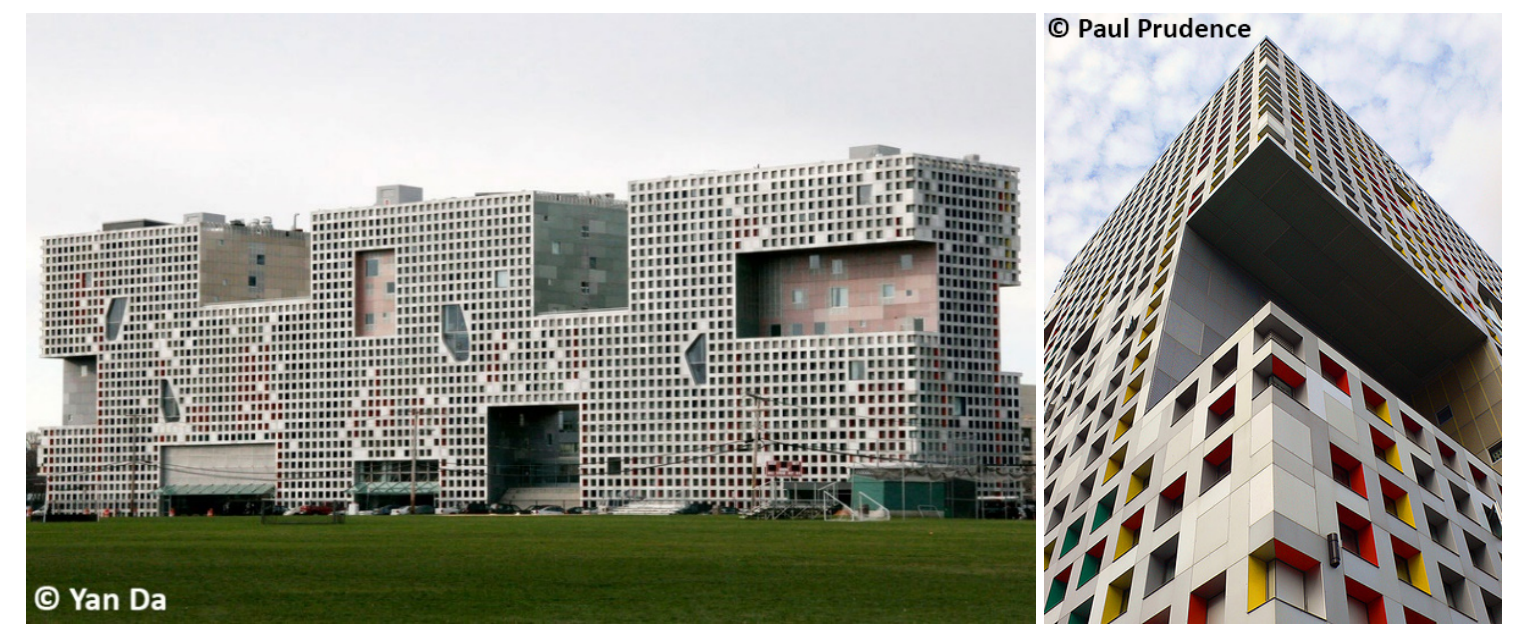

Figure 47. Simmons Hall Residence (Sources: https://www.archute.com and https://en. wikiarquitectura.com, accessed April 2018)

Santiago Calatrava develops his architecture through concepts, often taking inspiration from birds, plants, and human body. As both an architect and an engineer, Calatrava is particularly efficient in using structure in the expression of his architectural design. The Turning Torso (Malmö, Sweden, Calatrava, 2005) tower is a simple yet elegant physical representation of the concept of a human body in a twisting motion (Figure 48). The building is divided into nine cubes turning around a vertical axis and braced by a steel-tube exoskeleton. This external structure is composed of a single upright attached to the tower between each cube using a combination of horizontal and diagonal tubes. While the cubes represent the main body, the exoskeleton represents, both metaphorically and physically, its spine and ribs (Calatrava, Kausel, \& Julian, 2002; Nordenson, 2003; Tryggestad, 2006).
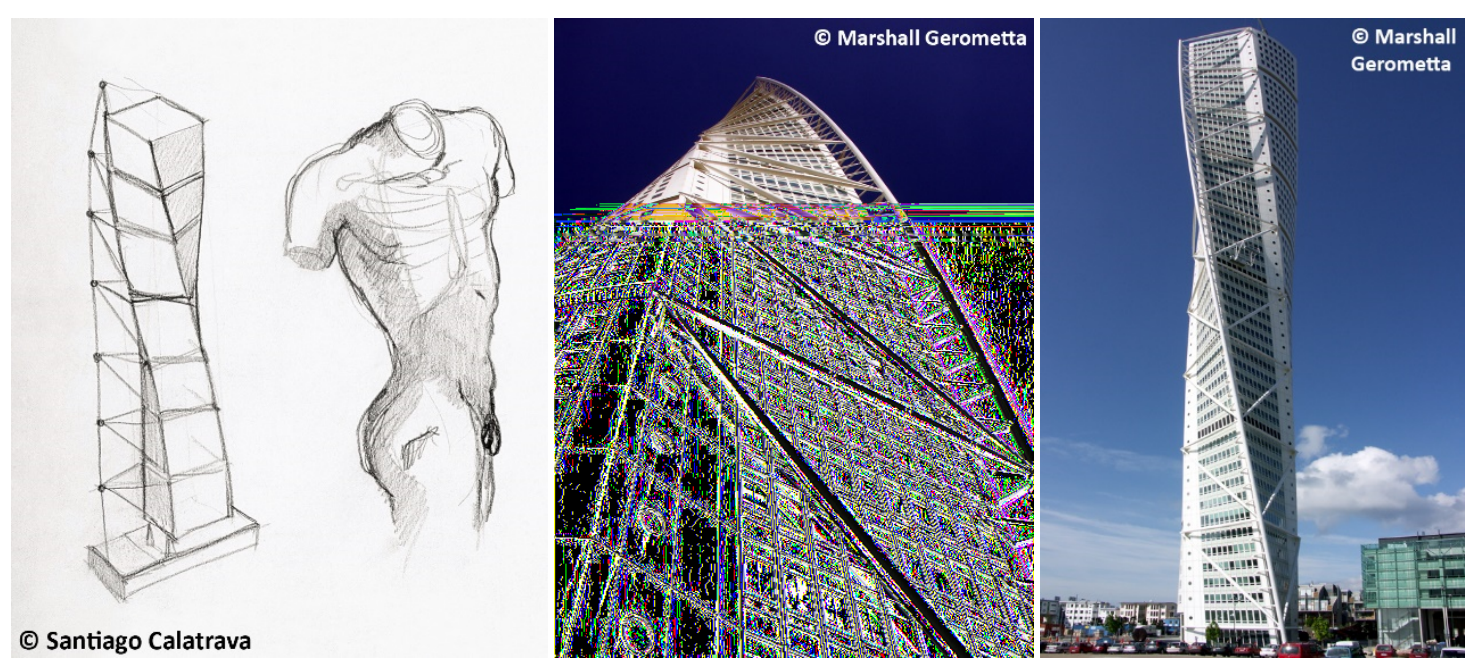

Figure 48. Turning Torso sketch (left) and completed building (centre and right) (Sources: https://inhabitat.com and http://www.skyscrapercenter.com, accessed April 2018) 
The above examples have indicated some ways for structure to participate in the expression and reinforcement of an architectural concept. These buildings result from a strong will to engage structure to express the architectural concept and to ensure that the structural components serve the intended message. For such a result to be achieved, Sabrina Leon $(2012$, p. 54) stresses the importance of considering the role of the structure throughout the design process and ensure both architecture and structure aim at the same goal: "When the structure is approached at the same time and in the same manner as the architecture and is motivated by the same design intentions, ... the result is unequivocally stronger because the design concept is universally legible, profoundly integrated, and consistently applied".

\section{Reinforcing the concept}

For a concept to be understood and appreciated, structure needs to be coherent with the intended architectural message and with the other components expressing the concept (Pressman, 2012, p. 23). The notion of coherence implies a "harmonious connection of the several parts, so that the whole 'hangs together"' (Oxford English Dictionary, n.d.).

One strategy enhancing conceptual coherence is structural detailing. For Sandaker (2007, p. 54), structural detailing should concentrate the sum of the building's features, meaning that it should represent the metaphor of the building's architectural message. His consideration for this issue is particularly delicate as he states: "The detail ... will be like a small poem. In the detail, as in the poem, information and aesthetic experience are completely condensed. The detail is all about giving form to certain functions in a very compressed space, where many different aspects of a building are brought together and resolved by a single idea". Structural detailing can thus take reference from the building's architectural form, structural actions, materiality and construction, or function (Charleson, 2014). Visual connections may thus be created between structural members and architectural elements, allowing their combination to express more strongly the intended concept and to establish coherence between them. The architect Fay Jones (1999, p. $48 \& 54)$ is particularly concerned by the importance of detailing and promotes an architecture where the relationship between the parts and the whole is obvious: "Organic architecture has a central generating idea; as in most organisms every part and every piece has a relationship. Each should benefit the other; there should be a family of form, and pattern. You should feel the relationship to the parts and the whole ... The generating idea establishes the central characteristics, or the essence, or the nucleus, or the core; it's the seed idea that grows and generates the complete design, where it manifests itself from the large details down to the small subdivision of the details". Two main outcomes may be extracted from Jones' statement. The first is to establish coherence between the smaller parts of the building 
and the whole. The second refers to the expression of a common message, i.e. concept, through different scales.

Jones' opinion is reinforced by Edward White's (1975, p. 25) reflection on the need to reinforce architectural concepts. The author writes: "Reinforcement involves the statement of the principal messages of the form in as many ways as possible. There are several ways that the building conveys messages to those using it. Scale, extent of entry invitation, type and amount of fenestration, the way the building meets the ground and the functional access between the departments are a few ways the building communicates to its users. The more ways that the designer can mobilize his vocabulary of forms to convey the message he intends, the more clearly and strongly his building will communicate the desired information. A design message said in five ways with form has a better chance to be perceived and understood than if only said one way". Like Jones, White suggests expressing the intended concept several times through different features of the building. However, where Jones promotes the establishment of a 'family of form, and pattern' being used at different scales, White recommends a broader approach.

\subsubsection{Summary}

This section reflects on the integration of structure and architecture as well as potential approaches to achieve it. Structure may be perceived at first solely as a technical component providing stability and ensuring building's integrity. However, this section emphasises the capacity of structure to exceed this limited characterisation and become a primary architectural component. It is through this understanding of structure that its integration with architecture can be appreciated. Indeed, in considering structure architecturally, the current section analyses its capacity to interact with architecture, in particular by supporting and enhancing of architectural qualities and concepts.

As a result of the analysis undertaken in this section, 13 architectural qualities are identified. They can be divided in six categories:

- Hidden structure: Architectural reasons, Hiding technique's effect upon architecture

- Exposed exterior structure: Elevation, Expressive roles of the structure

- Exposed interior structure: Elevation, Expressive roles of the structure, Structure and space, Structure and function, Structure and circulation

- Interaction with external openings: Modulation of light, Outside views/sightlines

- Ornamentation: Use of structure for ornamental purposes

- Expression of an architectural concept: Development of an architectural concept 


\subsection{Integration of seismic retrofit and existing architecture}

\subsubsection{Introduction}

The previous section stresses the capacity for structure to integrate with architecture in newly designed buildings. Various architectural qualities related to structure are thus explored. This provides a first step in establishing a list of architectural qualities related to seismic retrofit. However, where the previous section focuses on the combination of new architecture and new structure, seismic retrofit involves existing architecture with new seismic structure. Therefore, to finalise and refine the list of architectural qualities, this section explores the characteristics and challenges inherent to the seismic retrofit context. Through these issues, the architectural qualities treated previously are appreciated through new perspectives.

This section starts by justifying seismic retrofit structure from an architectural perspective. The benefits existing buildings gain from greater integration of seismic retrofit structure and architectural qualities are emphasised. Secondly, key categories of relationships between seismic retrofit structure and existing architecture are analysed. Thirdly, conservation and preservation issues in relation to seismic retrofit are discussed. As outlined in the research methodology chapter, these three steps complete the establishment of architectural qualities related to seismic retrofit. This creates the framework from which seismic retrofit and its integration with the architecture of the case studies will be analysed.

\subsubsection{Architectural considerations of seismic structure}

This sub-section explains the architectural role of seismic structure in the context of its technical purpose. This approach cast new light on the relevance of seismic structure as an architectural element. Two examples illustrate how seismic retrofit contributes to an existing building's architecture through its integration with various architectural qualities.

As already emphasised, integration between structure and architecture is strengthened when the former is considered architecturally and not exclusively technically and economically. Architectural consideration of structure may be equally or even more justified in the context of seismic retrofit than it is in the design of new buildings. In the book "Moments of Resistance" (Taylor et al., 2002, pp. 17-18), the authors propose a seismic retrofit solution using a series of external braced props surrounding an existing building in Wellington and justify the architectural aspect of their work with the following quote: "since earthquake strengthening only takes on a structural relation to the 
building during a quake, it must function ornamentally at other times". This statement can be appreciated in buildings such as the Veterans Affairs San Diego Medical centre, in which new braced frames installed on the building's four sides provide ornamentation to the otherwise bland façades (Figure 49).

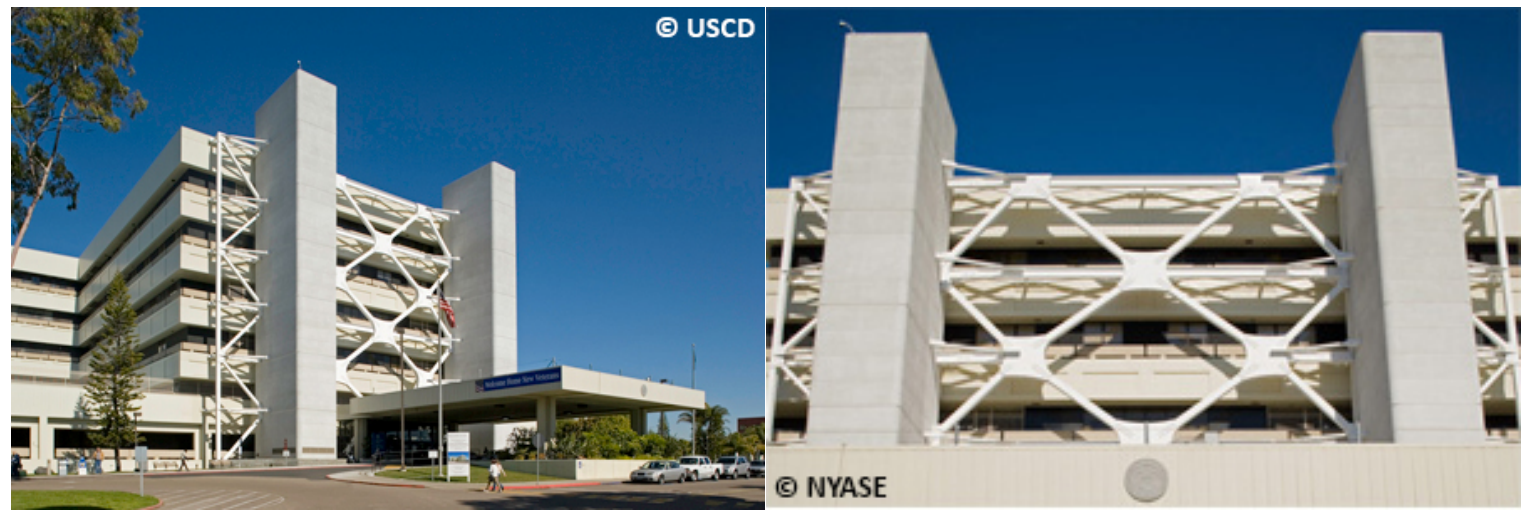

Figure 49. Veterans Affairs San Diego Medical centre with braced frames expressing an ornamental pattern (Sources:

http://surgery.ucsd.edu and http://www.nyase.com, accessed July 2015)

Taylor et al.'s statement also leads to a comparison between existing load-bearing and seismic retrofit structures within a same building. In the first case, the primary role of structure is to provide continuous stability and rigidity to the construction. In addition, approaching this very same structure architecturally allows enriching the building's architecture. A load-bearing structure may therefore permanently carry both technical and architectural purposes as demonstrated in the first section. In contrast, the primary and technical role of a seismic structure only 'activates' during an earthquake which actually corresponds to very short and limited moments, if at all, in the life-span of a building. As the technical purpose of the seismic structure may not be required, the structural presence might be considered, relatively speaking, as unnecessary during non-earthquake periods. It is therefore legitimate and necessary to reflect on the other role seismic structure may play. Most of the time, it is an architectural component potentially contributing to existing architectural features.

The California College of Arts and Crafts (San Francisco, USA, Leddy Maytum Stacy Architects, Merrill, 1998), formerly a bus maintenance garage, demonstrates a careful architectural reflection on the seismic structure used in its retrofit. The building possesses inverted $\mathrm{V}$ braces in both orthogonal directions (Figure 50). Those oriented transversally interact with the existing architecture so that several architectural qualities are enhanced. Aligned with the entrance, the braces represent the building's spine both figuratively and physically. First, the seismic structure symbolically appears as a series of vertebrae and this impression is reinforced by the light and skeletal nature of the steel braces. Secondly, the alignment and repetition of the structural 
components articulate circulation by establishing the main direction of movement. The structural layout also divides the main space into smaller ones which helps highlight the distinction of functions. The interior character is strongly defined by the contrast between the existing structure composed of portal frames and the new steel structure. Apart from their difference of materiality their contrast may be appreciated through several other features such as: curved against angular geometries, dark versus light, and raw in opposition to smooth. Finally, the existing skylights are preserved by using a diaphragm system composed of steel bracing similar to the vertical braces. Their thin structural members offer little obstruction to natural light.

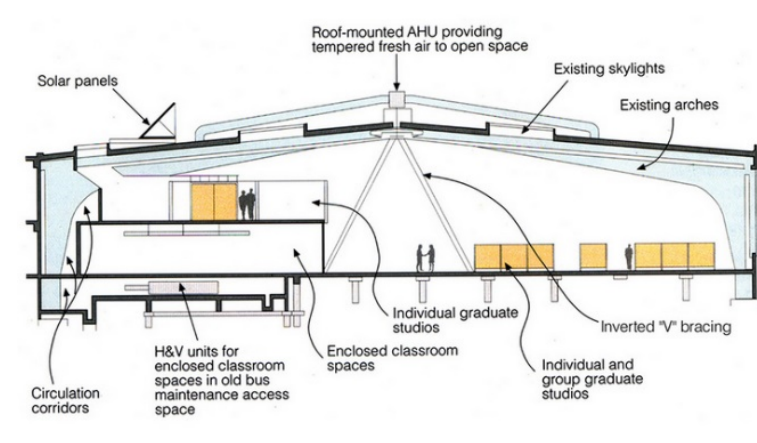

() Imsarch

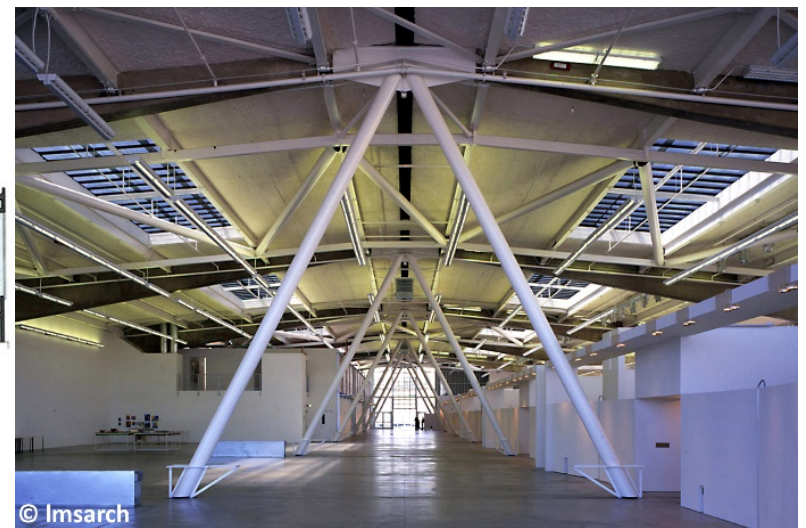

(c) Imsarch

Figure 50. California College of Arts and Crafts (Source: http://www.Imsarch.com, accessed July 2015)

\subsubsection{Main relationships between seismic structure and existing architecture}

In the context of seismic retrofit, a review of the literature reveals four key relationships between seismic structure and existing architecture. In the real-life situation, a retrofit design might however combine several of these approaches within the same building depending on the architectural intentions and initial constraints. The exploration of these relationships allows an appreciation of the various influences a seismic retrofit solution may have on architectural qualities.

\section{Indifference}

The indifferent relationship is regularly witnessed when new structure provides sound seismic resistance but poor architectural integration. It usually results from an approach based on the common assumption that seismic retrofit is solely a structural engineering issue. This attitude is understandable in some way as the seismic strengthening of an existing building is a response to a lack of the current structure to withstand earthquake loads. Seismic retrofit appears therefore as a technical response to an engineering problem. However, this approach causes an imbalance between new structure and existing architecture as the former impacts freely on the architectural qualities the latter may possess. The consequences vary from a confusing and misleading 
understanding of the building's architecture to the damage and loss of architectural features and qualities (Cattanach et al., 2008; Goodwin et al., 2009). Examples of buildings with inadequate integration of seismic retrofit structure and existing architecture may be found in all earthquakeprone countries (Figure 51). Often, these retrofitted buildings suffer from functional, circulation and aesthetic disturbances causing problems to the building and its users.

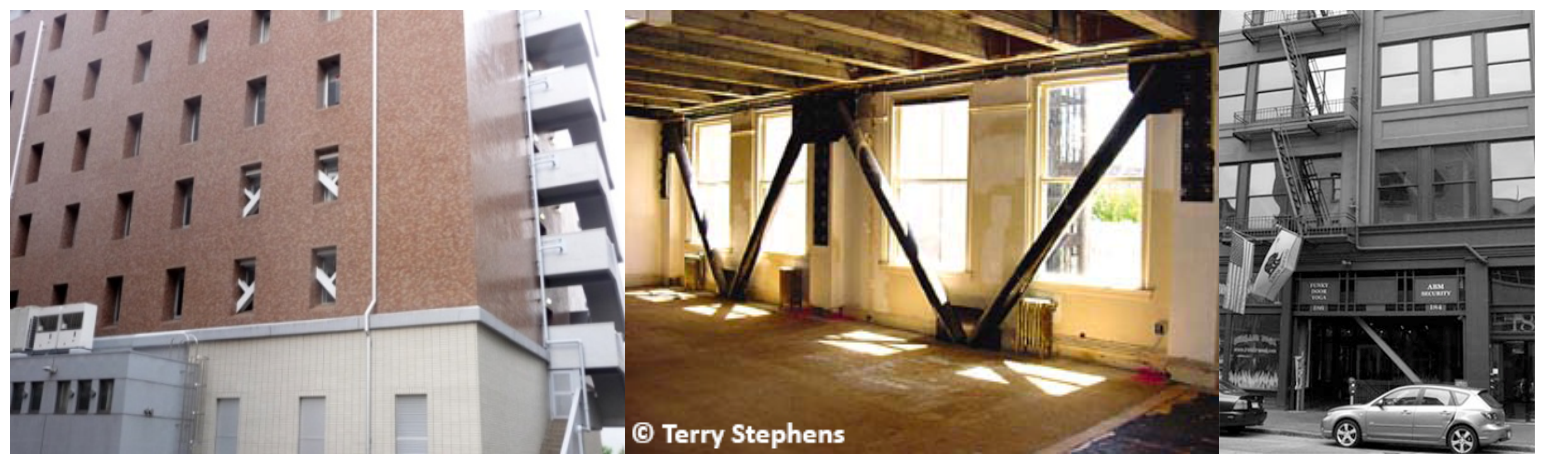

Figure 51. Seismically retrofitted buildings (Left: Student apartments, Tokyo; Centre: Skinner Building, Seattle; Right: Office building, San Francisco) (Sources: Andrew Charleson, http://www.djc.com, accessed July 2015, and Charleson, 2008, p. 188)

In the case of the above examples, it appears that neither the potential architectural characteristics of the structures nor their impacts have been considered. As a result, the seismic structures fail to enrich existing architecture and actually disturb already established architectural features. Overall and in each example, the added seismic structure fails to be considered as one of the building's legitimate and coherent components. These are examples of poor or a lack of integration of seismic structure and architecture.

This problem might be justified by the difficulty of accommodating the seismic structure with the architectural morphology and structural configuration of the existing building. These two aspects influence the type of retrofit structure to use and its dimensions (Goodwin et al., 2011; Mezzi, Parducci, \& Verducci, 2004). However, for each existing building, several seismic solutions may be designed (Charleson, 2008; Nishizawa, 2008). Examples presented in the 'Interaction between structure and architecture' section revealed how some types of structures integrate well with intended architectural qualities, and a similar situation may also occur with seismic structures. Depending on the architectural qualities designers aim at preserving or enhancing, a variety of seismic structures may be used.

\section{Hidden/Invisibility}

Seismic strengthening structure is often hidden to preserve a building's original architectural and eventually historic character (Goodwin et al., 2011; Look et al., 1997). In such a case, invisibility of the seismic structure is sought by designers. However, the reality of retrofit work implies that some 
parts of the existing building need to be modified or removed in order to install the newly added structure (Charleson, 2008). Most commonly, designers will seek for structural components to be masked by materials and coverings providing a sense of visual continuity with existing architectural features and minimal physical alterations. For some authors (Goodwin et al., 2011; Taylor et al., 2002), this design approach might be considered to some extent self-contradictory. Indeed, on one hand designers and clients seek to preserve and express the authenticity of the building, yet on the other hand they use newly added materials and components that are intended to be considered as original ones.

As indicated with the design of new projects, hidden structure may still engage with architectural qualities and therefore be considered well integrated. This statement may also be applied to seismic structure as demonstrated by the retrofit proposition (Taylor et al., 2002) for the Turnbull House (Wellington, New Zealand, William Turbnbull, 1914). A distinct set of seismic retrofit techniques are presented for each main space in the building. Focusing on the 'Reception Room' (Figure 52), the authors propose to seismically strengthen the longitudinal walls using a series of steel rib mullions. The implementation implies the removal of existing joinery from the walls except for the panelling of the transverse wall used "to set datums and rhythms" (Taylor et al., 2002, p. 63) for the new steel mullions. Once installed on the bare longitudinal walls, the new structural components are then clad with timber moulding. As a result, the hidden seismic structure participates in the expression of an ornamental pattern and to a larger extent to the architectural character of the room.
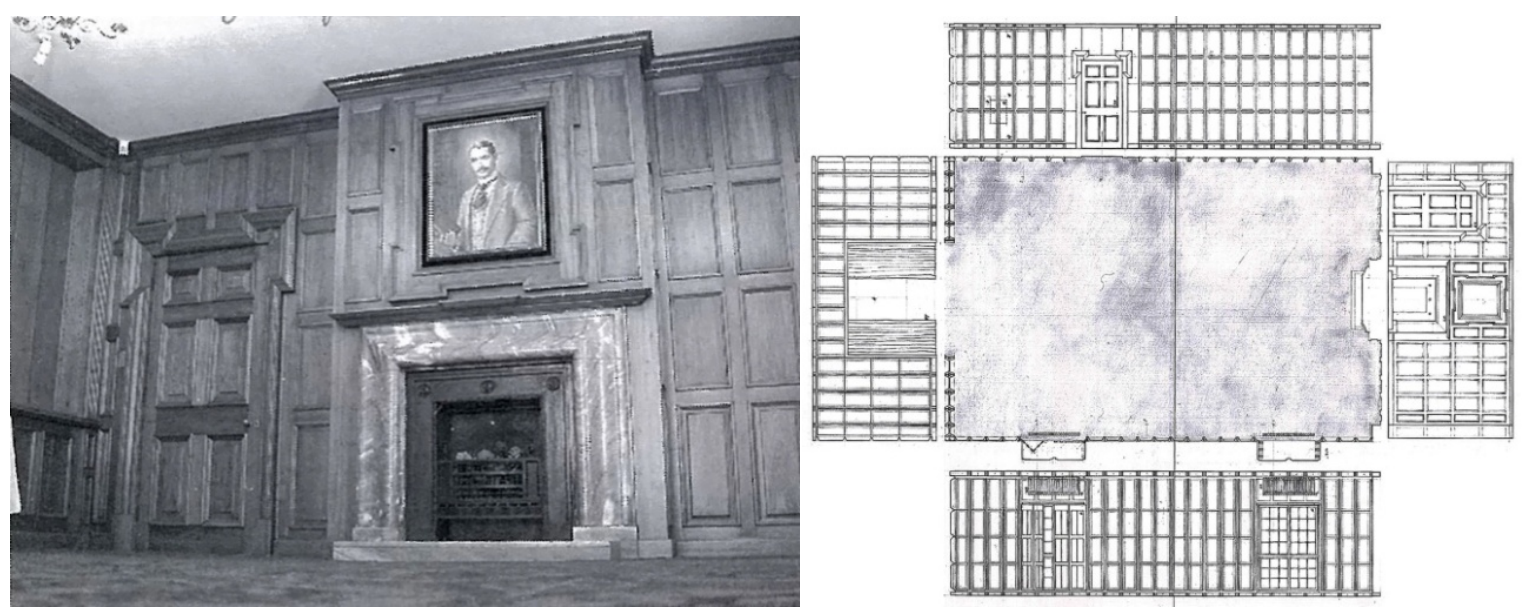

Figure 52. Turnbull House - Reception Room (Left: transverse wall and its panelling that references the installation of the new seismic structure; Right: developed surface of the retrofitted room) (Source: Taylor et al., 2002, p. 46 \& 64)

\section{Separation}

In contrast to the 'Hidden' strategy, Michael J. Ostwald (2002), in his essay "Binding issues and critical strengthening", explains a seismic retrofit approach based on the separation and distinction 
between existing architectural and structural components, and new structure. In this scenario, the newly added structure is visually expressed. Distance is set between existing and new components, whether physically, historically or materially. The idea is to help visitors and building users distinguishing the new layer of work from the original elements. A sense of neutrality is sought in order to limit the impact of the seismic retrofit work and to read separately new and old components.

The seismic retrofit of Shed 13 (Wellington, New Zealand, CCM Architects, 2007) illustrates 'Separation'. This former industrial warehouse is single storey with long and narrow dimensions. The existing structure is composed of URM perimeter walls and 14 timber trusses spanning the width of the building. The seismic retrofit work was mainly carried out internally and consists of vertically post-tensioning the existing walls with rods and installing six post-tensioned cantilevered concrete columns (CCM Architects, n.d.). The columns are then connected to the existing trusses using a ductile yielding plate to absorb seismic energy, thus resulting in six frames resisting transverse loads (Cattanach et al., 2008) (Figure 53). The seismic retrofit is respectful of the existing architecture and greatly preserves its architectural character. This outcome mainly results from the position of the new concrete columns spaced off the existing walls. This gap, combined with the slender dimensions of the new structure, and its distinct materiality, allows a distinct reading of the new and existing layers.

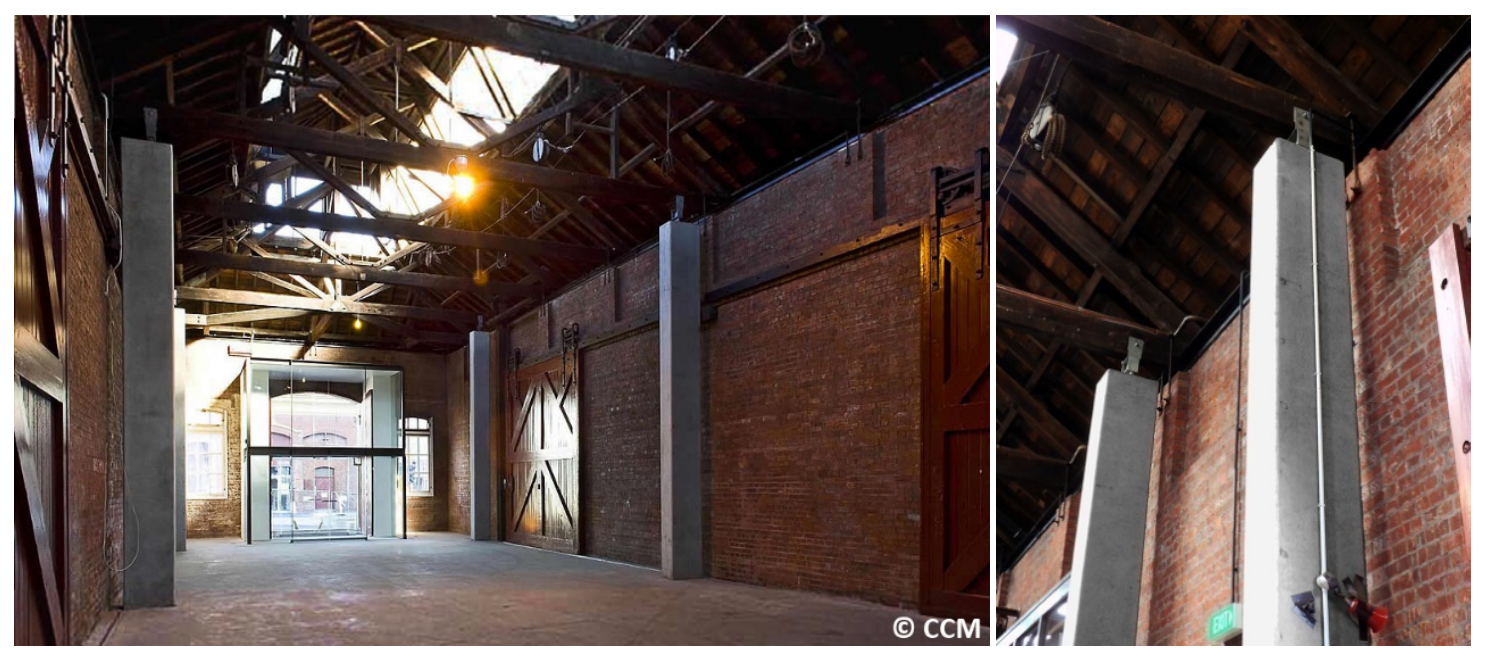

Figure 53. Shed 13 with new concrete columns connected to existing trusses but separated from the URM walls (Sources: Cattanach, 2008, p. 8 and Author)

\section{Dialogue}

Unlike the passive use of seismic retrofit in the 'Separation' strategy, the 'Dialogue' approach aims for an active relationship between newly added structure and existing architecture. Ostwald (2002) justifies this approach as a means for seismic structure to critically illuminate existing architecture. 
The author defends his statement by citing Alberti (1988, p. 362) stressing that strengthening should not "neglect the elegance of work. If a wall happens to be unsightly because it is too high, insert a cornice or paint on lines where appropriate to articulate height". Strengthening structure thus appears as a possible way to improve potential flaws a building may possess and to enhance some of its weakest aspects.

In this scenario, both the technical and architectural capacities of the structure critique and engage in a dialogue with the building's history. From the technical point of view, the structural deficiency of the existing structure is acknowledged and the need for a seismic retrofit may be more or less highlighted depending on the selected solution. Historic deficiencies in terms of construction may then be exposed to the building's users. Using the seismic structure architecturally might therefore improve the reading of the former layer of the building and understanding its potential historic flaws.

The 'Dialogue' relationship allows reading existing architecture through the lens of retrofit structure and vice versa. As the seismic retrofit is developed responding to the flaws and qualities of the existing building, the resulting architecture becomes a combination of old and new features. The richness of this relationship comes from the multiple modes of expression. The duality of the added structure and the old components might, for instance, be treated through a hierarchical approach. Depending on the intended architectural outcome, existing features might be over or less emphasised than those newly added. The degree of visual expression or the hiddenness of the seismic structure may also vary to best serve the architectural intentions.

Taylor et al. (2002) propose a seismic retrofit solution for the 'Entrance Hall' of Turnbull House (Figure 54) based on a 'Dialogue' approach. The seismic retrofit focuses on the main longitudinal wall from which the existing plain modulated panels are removed and replaced by a steel surface "cut, bolted, welded and screwed onto the interior wall" (Taylor et al., 2002, p. 60). Panels of watercut steel plates are then placed over the steel surface and bolted to the wall. These exposed steel plates visually express the intensity of forces the wall will face during an earthquake through the pattern of diagonal lines. This strong expressive element is softened by a series of timber mouldings covering the ovoid perforations of the plates. This approach generates a contrast between the new material, steel, and the timber which not only includes the added mouldings but also the remaining panels of the entrance hall. The contrast is also emphasised by the seismic resistance expressed by the structural steel plates and the rounded and delicate mouldings added in between. The authors justify this solution as an echo of the original panel framing (Taylor et al., 2002). They refer to Barry's "Lecture on Architecture" (1881, p. 94). He states that during the Jacobean era carpenters, along 
with masons and plasterers, were in charge of covering walls with "constructed decoration" and that this form of decoration gives "dignity and beauty to the forms of construction". The proposed seismic solution follows this approach and thus refers to the building's history to create a similar achievement.
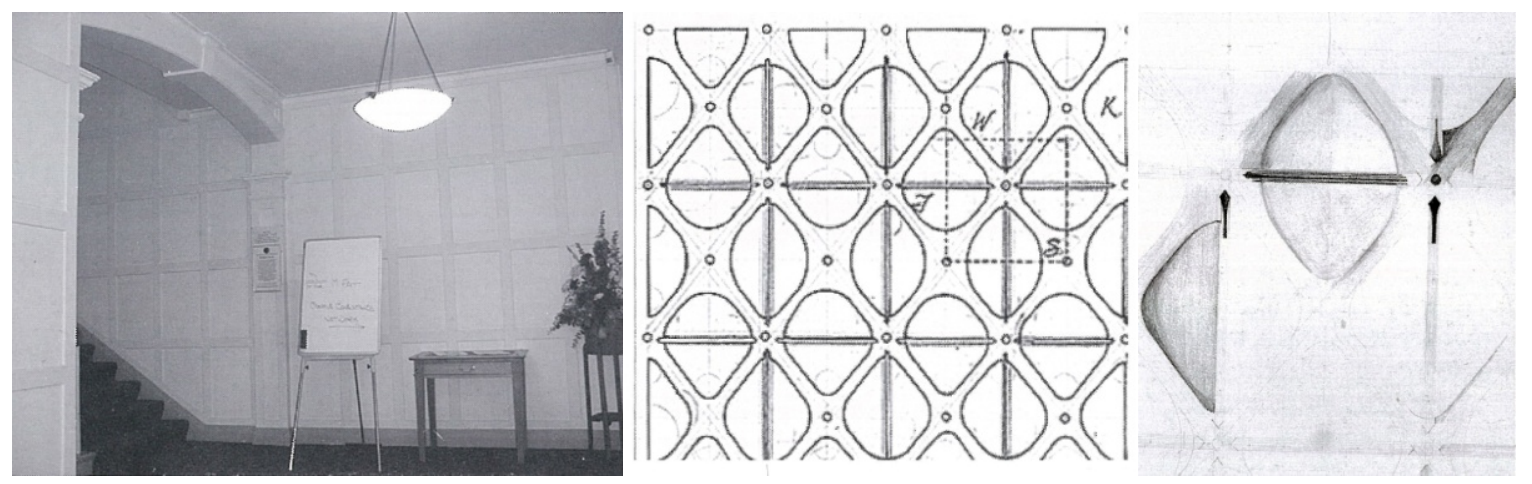

Figure 54. Turnbull House - Entrance Hall (Left: existing timber panel; centre: seismic system combining two layers of steel work; right: timber mouldings covering the ovoid perforations) (Source: Taylor et al., 2002, p. 19 \& 61)

\subsubsection{Conservation and preservation issues}

The four relationships between seismic structure and existing architecture presented above might be potentially applied to any earthquake-prone buildings whether listed as heritage or not. The key difference between the two types of buildings mainly arises from the degree of conservation and preservation of their existing values, whether cultural, historic, or architectural. Where the seismic retrofit of heritage buildings is usually based on the preservation of existing architectural features, non-heritage buildings provide greater freedom for potential modifications. However, it is necessary to consider two facts. First, a non-heritage building might be, one day, listed as heritage (Goodwin et al., 2011). Second, some existing features of a non-heritage building might be deemed worthy of preservation by the designers and client. These two observations justify to some extent the application of heritage conservation and preservation guidelines to the seismic retrofit of nonheritage buildings.

Several earthquake-prone countries such as the United States of America, Italy and New Zealand refer to similar conservation and preservation principles. They may result from international associations including the International Council on Monuments and Sites (ICOMOS) and the International Centre for the Study of the Preservation and the Restoration of Cultural property (ICCROM), but also from national standards used as references by other countries (NZHPT, 2009). Despite not being strict rules, and therefore allowing a certain degree of flexibility and compromise by designers (Goodwin et al., 2009), these principles provide guidance in the respect of existing architectural features. 


\section{Three key preservation principles}

A set of three principles commonly accepted by designers in earthquake-prone countries are provided by the National Park Service of the US Department of Interior (Look et al., 1997, p. 2). The authors first emphasise that "historic materials should be preserved and retained to the greatest extent possible and not replaced wholesale in the process of seismic strengthening". This statement relates to the concept of "minimum intervention" recommended by ICOMOS New Zealand Charter $(2010$, p. 3) and Lou Robinson \& Ian Bowman (2000, p. 4) which encourages seismic strengthening work with the least degree of intervention in order to retain existing values. This principle is to limit the changes to an existing building and the history it carries, but also help in controlling the economic impact of the seismic retrofit work. However, as pointed out by Goodwin et al. (2011, p. 31) "this guideline has some degree of flexibility in that extra work may sometimes result in a better overall solution, so sound judgement is necessary".

The second principle states that "new seismic retrofit systems, whether hidden or exposed, should respect the character and integrity of the historic building and be visually compatible with it in design" (Look et al., 1997, p. 2). This principle raises the issue of the authenticity and integrity of historic buildings. Designers should be careful not to alter or damage a building to the extent that its heritage values and its architectural character diminish.

The final principle points out that "seismic work should be "reversible" to the greatest extent possible to allow removal for future use of improved systems and traditional repair of remaining historic materials" (Look et al., 1997, p. 2). The reversibility idea acknowledges the limitations of current seismic retrofit systems and the evolution of strengthening techniques as well as the possible changes of standards and requirements in terms of earthquake-resistance (Robinson \& Bowman, 2000 , p. 4). An additional argument justifying this principle is provided by Cattanach et al. (2008) who stress that the reversibility of structure provides greater planning flexibility for future use and re-use of a building.

\section{Adaptation (alteration \& addition)}

According to the ICOMOS New Zealand Charter (2010), the conservation of a building is facilitated when the building serves a useful purpose. In some cases, whether the building maintains or changes its current use, some adaptations need to be undertaken to ensure its function. This may require some alterations and eventually additions but always in respect of the building's cultural heritage value. The NZHPT provides a checklist of recommendations for designers to refer to 
(NZHPT, 2007e, p. 1) based on the ICOMOS New Zealand Charter guidelines. They are divided in three categories: internal alterations, external alterations, and additions to buildings and structures. Their main recommendations are summed up as follow:

- $\quad$ "Retain surviving internal and external heritage fabric as far as possible and disturb, distort or obscure it as little as possible."

- "Respect the design, form, scale, materials, workmanship, patina of age, colours, contents, location, curtilage and setting, including alterations that have heritage value."

- "Avoid work that will compromise or obscure fabric of heritage value."

- "Ensure any new work is of a scale and location that it does not dominate the heritage place and respects its setting."

In some cases, alteration and addition might be undertaken conjointly with seismic retrofit. The integration issue between seismic retrofit and architecture may then become slightly more complex due to additional architectural elements independent of the seismic system.

The Wallace F. Bennett Federal Building (Salt Lake City, USA, 1963) is an eight-storey structure made of reinforced concrete. In 2001, the building was seismically retrofitted in conjunction with a renovation design (GSBS Architects) (Figure 55). Its seismic retrofit structure consists of a series of steel braced frames installed on the building perimeter and placed in front of existing reinforced concrete columns (Figure 56). The seismic retrofit could have been completed as such, leading to an interaction between the newly added structure and some existing architectural features. However, designers decided to take advantage of the seismic strengthening to "replace the existing pre-cast exterior cladding with a modern, attractive and energy-efficient curtain wall system" (Brown, Aiken, \& Jafarzadeh, 2001, p. 32). This new architectural element does not participate structurally in the seismic solution but rather architecturally in the building's renovation. It brings new architectural qualities to the building such as a maximising natural light thanks to larger windows. This aspect might at first sight be seen as an additional quality unrelated to the seismic retrofit design. Yet, this new façade and its rhythm are modulated by the presence of slabs and the new structural frames. They redefine the new exterior architectural character of the building. This building highlights the fact that the integration between seismic retrofit and architecture should not only be considered with respect to existing architectural qualities but also, in some cases, to new ones as well. 


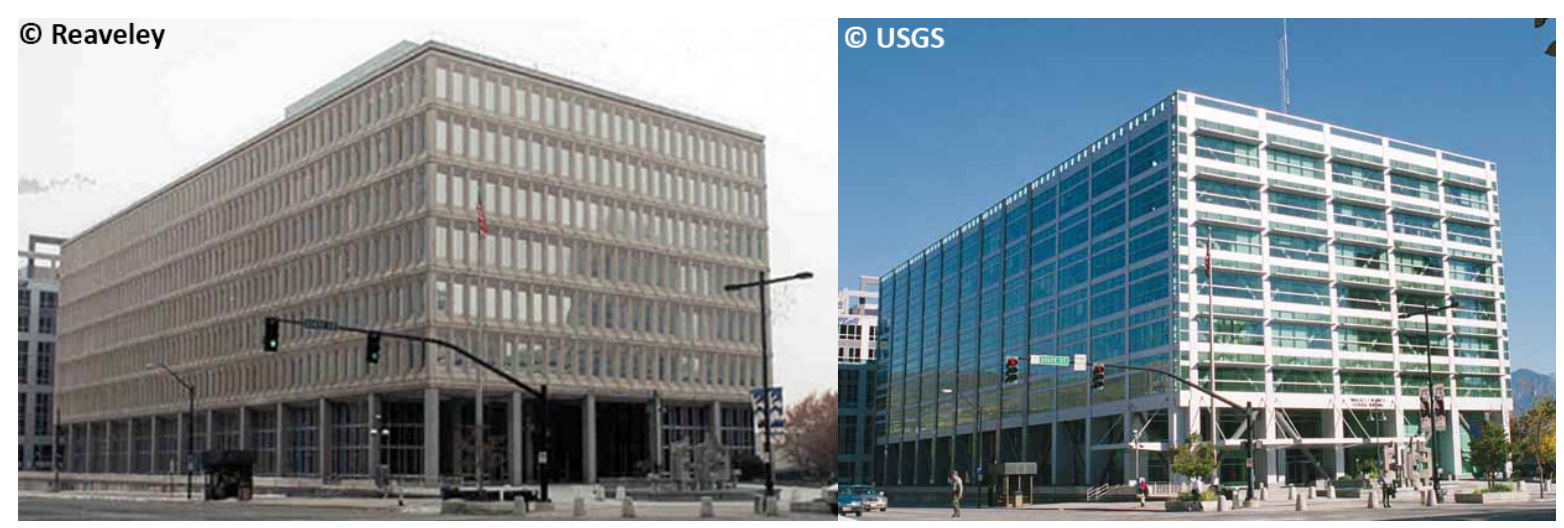

Figure 55. Wallace F. Bennett Federal Building (Right: before retrofit; Left: After retrofit) (Sources: http://www.reaveley.com and http://forum.skyscraperpage.com, accessed July 2015)

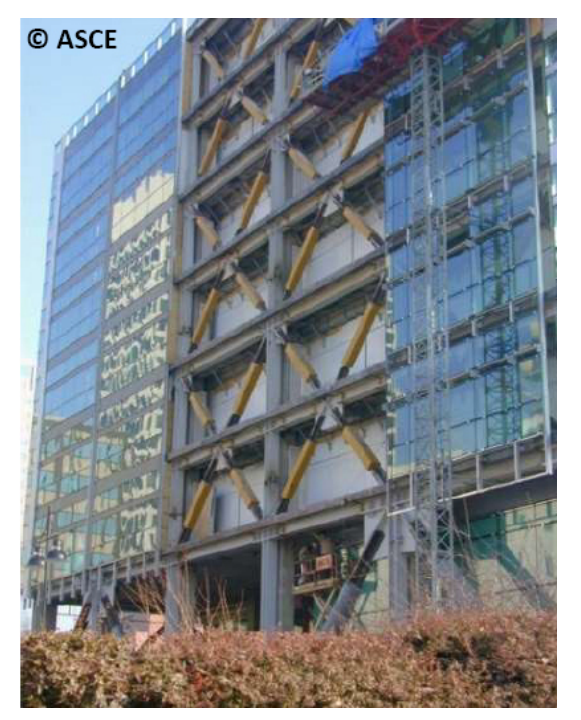

Figure 56. Installation of the braced frames in the Wallace F. Bennett Federal Building (Source: Symans et al., 2008)

When designing possible additions to a building, three main integration options present themselves. First, seismic retrofit only interacts with the existing architectural qualities of the earthquake-prone building and does not participate in the design of any extension. Second, the seismic system is integrated with both the existing building and its extension. In this case, integration of seismic structure and architecture might occur with both the existing architecture as well as that of the additional extension. Third, the seismic solution is mainly located in the new addition with very limited interaction with the existing building. In this scenario, the structure of the extension resists earthquake-loads and structural tie members installed in the existing building would drag back forces to the seismic system.

\subsubsection{Summary}

This section explores the characteristics of the integration of seismic retrofit and existing architecture. It highlights how relevant and important the architectural role of seismic structure is 
to an existing building. Like load bearing structure, seismic structure can integrate with architectural qualities and emphasise them thus resulting in a building with enriched architecture.

Different relationships between seismic structure and existing architecture are also identified. They cover a variety of considerations of seismic retrofit, from its poorest to its most thoughtful. The variety of relationships implies that seismic structure can influence existing architectural qualities in different ways, by enhancing, maintaining, or detracting from them.

The section also presents a series of principles that, although established for heritage buildings, are also relevant to the seismic retrofit of non-heritage buildings. The three key principles specific to seismic retrofit are Minimum Intervention, Architectural Character, and Reversibility. They are to help designers maintain the heritage value of an existing building. Their intentional flexible nature allows for interpretation, thus giving designers a certain freedom in applying these principles. As a result, the affect of the seismic structure on these principles might vary. The design of the seismic structure can cautiously follow the principles, disregard them, or even exceed their recommendations.

The chapter also stresses that seismic retrofit might be undertaken alongside a building's Change of Use and various forms of Adaptation, including alterations and additions. These aspects also relate to some preservation principles in regard to a building's cultural heritage value and provide additional recommendations for designers to consider. As the recommendations seek to maintain and ensure compatibility of the seismic retrofit with the building's heritage value, Change of Use and Adaptation can be addressed through the three main preservation principles.

Finally, Change of Use and Adaptation raise an important issue regarding integration of seismic retrofit structure and architecture as seismic retrofit can be undertaken alongside refurbishment and potential extensions. The combination of these two works with seismic retrofit provides opportunity for the seismic structure to not simply integrate with the existing architecture but also contribute to the expression of new architecture.

\subsection{List of architectural qualities relevant to the seismic retrofit context}

This section combines the outcomes of the 'Interaction between structure and architecture' and 'Integration of seismic retrofit and existing architecture' sections. This combination establishes a list of architectural qualities that structure can integrate with in the specific seismic retrofit context. 
In the 'Interaction between structure and architecture' section, a series of architectural qualities directly related to structure are identified. These qualities can be categorised in six groups: Hidden structure, Exposed exterior structure, Exposed interior structure, Interaction with external openings, Ornamentation, and Expression of an architectural concept. The section 'Integration of seismic retrofit and existing architecture' confirms that these architectural qualities are also relevant to seismic retrofit structure. In addition, further issues specific to seismic retrofit are presented. First, designers should consider the three preservation and conservation principles in regard to integration. Secondly, the presence of the seismic retrofit structure can affect architectural qualities in different ways. Seismic retrofit structure can have a neutral influence and therefore maintain architectural qualities, enhance them thus enriching the building's architecture, or detract them due to a negative impact.

In summary, the first section defines 13 architectural qualities divided in the six categories mentioned above. The second section adds a new category which includes the minimum intervention, compatibility with existing architectural character, and reversibility. As a result, a total of 16 architectural qualities directly related to the seismic retrofit context and divided in seven categories are identified:

\section{CATEGORY 1: HIDDEN STRUCTURE}

\subsection{ARCHITECTURAL REASONS}

- $\quad$ Enhance: The hiddenness of the retrofit structure enhances the existing functionality of a space and/or its architectural character; or develops new qualities such as spatial and circulation qualities.

- $\quad$ Neutral: The hiddenness of the retrofit structure preserves the existing functionality of a space and/or its architectural or historic character; and does not participate in the development of new architectural qualities.

- Detract: The hiddenness of the retrofit structure affects the functionality (ex: reducing the usability) of a space and/or its architectural or historic character (ex: masking architectural or historic features).

\subsection{HIDING TECHNIQUE'S EFFECT UPON ARCHITECTURE}

- Enhance: The selected technique of hiding the structure contributes to the enhancement of an existing architectural quality such as architectural character, concept, or ornamental quality; or to the creation of a new quality. 
- $\quad$ Neutral: The selected technique does not engage with the function of a space and/or its architectural or historic character; nor does it contribute to any additional architectural quality.

- Detract: The selected hiding technique removes or modifies key architectural or historic features therefore reducing architectural or historic character.

\section{CATEGORY 2: EXPOSED EXTERIOR STRUCTURE}

\subsection{ELEVATION}

- Enhance: The retrofit structure modifies the façade by adding a new architectural layer that complements the existing one. For example, a new rhythm of the façade is created by the new retrofit structure which complements that which exists.

- Neutral: The retrofit structure replicates or maintains the existing structural or architectural articulation of the façade.

- Detract: The retrofit structure disrupts the existing pattern, rhythm, or ornament.

\subsection{EXPRESSIVE ROLES OF THE STRUCTURE}

- Enhance: The retrofit structure highlights specific aspects of the building, whether tangible (ex: the entrance) or non-tangible (ex: building's functionality). The retrofit structure may also accentuate its technical vocabulary via its detailing.

- $\quad$ Neutral: The retrofit structure replicates or maintains existing expressed elevational features without adding any that are new.

- Detract: The location and detailing of the retrofit structure lessen the expressiveness of other architectural qualities carried by the façade.

\section{CATEGORY 3: EXPOSED INTERIOR STRUCTURE}

\subsection{ELEVATION / FLOOR AND CEILING SURFACE}

- Enhance: The retrofit structure modifies the existing interior surfaces by adding a new and complementary architectural layer. For example, a new rhythm on the interior surface is created by the retrofit structure.

- Neutral: The retrofit structure replicates or maintains the existing structural or architectural interior surfaces. Also, the new structural elevation could be bland and uninteresting with no architectural justification.

- Detract: The retrofit structure disrupts or causes a loss of the existing pattern, rhythm, or ornament of the existing interior surfaces. 


\subsection{EXPRESSIVE ROLES OF THE STRUCTURE}

- Enhance: The retrofit structure highlights specific aspects of the building, whether tangible (ex: the exit) or non-tangible (ex: building's functionality). The retrofit structure may also accentuate its technical vocabulary via its detailing.

- $\quad$ Neutral: The retrofit structure replicates or follows existing expressed features without adding any that are new.

- Detract: The location and detailing of the retrofit structure lessen the expressiveness of other architectural qualities.

\subsection{STRUCTURE AND SPACE}

- Enhance: The retrofit structure reinforces the existing perception of the space by further opening the space up or enclosing it. The retrofit structure may also create a new delimitation of space for architectural purposes.

- $\quad$ Neutral: The retrofit structure preserves the existing perception and delineation of space.

- Detract: The retrofit structure, through its location and orientation, detracts from the existing perception and delineation of space.

\subsection{STRUCTURE AND FUNCTION}

- Enhance: The structure and its position provides greater flexibility to existing interior planning. The retrofit structure may also contribute to the interior organisation and function of the building by creating new spaces.

- $\quad$ Neutral: The retrofit structure retains the original function by replicating or following existing layout and structure.

- Detract: The functionality of the space is disrupted by the location or detailing of the retrofit structure.

\subsection{STRUCTURE AND CIRCULATION}

- Enhance: The retrofit structure enhances circulation by housing circulation components (ex: corridors, stairs, lift), imposing or suggesting a direction of movement.

- $\quad$ Neutral: The retrofit structure preserves the existing circulation areas.

- Detract: The retrofit structure reduces the effectiveness of circulation in the area it is installed. 


\section{CATEGORY 4: INTERACTION WITH EXTERNAL OPENINGS}

\subsection{MODULATION OF LIGHT}

- Enhance: The retrofit structure modulates natural light, enhancing an existing architectural quality or generating a new quality. Aspects such as diffusion, reflection, and shadow pattern are considered.

- $\quad$ Neutral: The retrofit structure does not affect the existing entry of natural light.

- Detract: The retrofit structure negatively affects natural light inside the building with no architectural benefits.

\subsection{OUTSIDE VIEWS/SIGHTLINES}

- $\quad$ Enhance: The retrofit structure provides new views outside.

- $\quad$ Neutral: The view outside is unaffected by the retrofit structure.

- Detract: The retrofit structure reduces the view outside.

\section{CATEGORY 5: ORNAMENTATION}

\subsection{USE OF STRUCTURE FOR ORNAMENTAL PURPOSES}

- Enhance: The retrofit structure provides additional ornamentation to the building either by inherent physical characteristics, by supporting applied ornamentation, or by being detailed for aesthetic purposes.

- $\quad$ Neutral: The structure replicates existing ornament. The structure may also provide no ornamental feature.

- Detract: The retrofit structure reduces the reading of the building's existing ornament. Ornamental features may also be lost or damaged by the structure.

\section{CATEGORY 6: EXPRESSION OF AN ARCHITECTURAL CONCEPT}

\subsection{REINFORCEMENT OF AN EXISTING ARCHITECTURAL CONCEPT OR DEVELOPMENT OF A NEW} CONCEPT

- Enhance: The retrofit structure expresses an existing or new architectural concept.

- $\quad$ Neutral: The retrofit structure replicates or follows existing features that convey the architectural concept of the building without providing a new or enhanced concept.

- $\quad$ Detract: The retrofit structure detracts from the existing architectural concept of the building. 


\section{CATEGORY 7: CONSERVATION AND PRESERVATION PRINCIPLES}

\subsection{MINIMUM INTERVENTION}

- Enhance: No intervention such as removal or modification is undertaken on the key architectural or historic features of the building.

- $\quad$ Neutral: The modification or removal of key architectural and historic features and spaces is kept to a minimum.

- Detract: Key architectural or historic features and spaces have been modified or lost by the implementation of the retrofit structure.

\subsection{COMPATIBILITY WITH EXISTING ARCHITECTURAL CHARACTER}

- Enhance: The retrofit structure contributes to the existing architectural and historic features of the building by adding a new architectural layer compatible with the architectural character.

- $\quad$ Neutral: The retrofit structure does not dominate the existing architectural features defining the existing architectural character and is visually compatible.

- Detract: The retrofit structure alters or reduces the building's architectural character and detracts from its historic values.

\subsection{REVERSIBILITY}

- Enhance: The retrofit structure is easily removed without damaging any existing key architectural and historic features, and should not affect future upgrades.

- Neutral: The retrofit structure can be removed without affecting existing key architectural and historic features. For example, the retrofit structure is located in secondary spaces.

- $\quad$ Detract: The retrofit structure cannot be removed without damaging irredeemably existing key architectural and historic features.

The establishment of this list of architectural qualities and the influences seismic structure may have on them serves as a basis for the next step of the research which reviews the integration of seismic retrofit structure and architecture in the five case studies.

Integration of seismic retrofit and architecture should be assessed based on the competency of seismic retrofit structure to serve an architectural design through the communication of the concept and the enhancement of the architectural qualities. The question to be asked then is, to what extent has structure been used architecturally? The above listed architectural qualities and different influences seismic retrofit structure may have on them help to provide an answer. 
Drawing upon these findings, an Observation Checklist (Appendix A) is created. The Observational Checklist allows the researcher to collect data on the integration of seismic retrofit structure and architecture in the five case studies. This is undertaken by using a comprehensive series of questions related to each of the identified architectural qualities. This approach of relating a series of questions to an architectural criterion in order to assess is based on contemporary architectural design competitions (Kazemian et al., 2005, 2007).

\subsection{Chapter Summary}

This chapter explores the notion of integration of structure and architecture and analyses the different architectural qualities related to it. It emphasises the capacity of structure to integrate with architectural qualities and therefore to enrich a building's architecture. Integration is also addressed in the specific context of seismic retrofit which allows identifying new challenges and opportunities brought by the installation of new structure to an existing building. Combined together, the findings allow 16 architectural qualities that seismic structure can integrate with to be determined.

This chapter thus achieves the first objective of the thesis, meaning the establishment of a list of architectural qualities against which to review integration of seismic retrofit and architecture. These identified architectural qualities led to the creation of an Observation Checklist to review the integration of seismic retrofit structure and architecture in the five URM buildings used as case studies. The collected data is then analysed in the following chapter. The influences seismic retrofit structures have on the architectural qualities are thus examined, and factors weakening and strengthening integration are investigated. 
PAGE LEFT INTENTIONALLY BLANK 


\section{CHAPTER 5. ANALYSIS OF THE SEISMIC SYSTEMS IN THE FIVE RETROFITTED URM BUILDINGS (\#1-\#5)}

\subsection{Introduction}

This chapter analyses the data collected from direct observations made during visits to the five URM buildings. The analysis examines integration of seismic retrofit and architecture from the perspective of the main types of retrofit systems: shear wall, braced frame, moment frame, and diaphragms. It identifies the influences that different retrofit structures have on the architectural Categories defined in the previous chapter. The reasons justifying these influences are examined below and help identify factors affecting integration. The analyses also identify trends on the influences of retrofit on Categories and sub-categories. This ascertains if some architectural qualities are more susceptible than others to be influenced by retrofit systems. This chapter contributes to the achievement of two research objectives: the identification of factors affecting integration, and potential predisposition of seismic structural systems to engage with existing architectural qualities.

The analysis is divided in four sections, each focusing on one seismic system. Each section is presented in an identical way. First, Tables of Analysis are used; each of them displays the number of the building being examined, the characteristics of the seismic system used, and the Categories and sub-categories being analysed (Table 4).

Table 4. Blank template of a Table of Analysis

\begin{tabular}{|c|c|c|c|c|c|c|c|}
\hline BUILDING \#... & $\begin{array}{l}\text { CAT 1. HIIDDEN } \\
\text { STRUCTURE }\end{array}$ & $\begin{array}{l}\text { CAT 2. EXPOSED } \\
\text { EXTERIOR STRUCTURE }\end{array}$ & \begin{tabular}{|l} 
CAT 3. EXPOSED INTERIOR \\
STRUCTURE
\end{tabular} & $\begin{array}{l}\text { CAT 4. INTERACTION WITH } \\
\text { EXTERNAL OPENINGS }\end{array}$ & CAT 5. ORNAMENTATION & $\begin{array}{l}\text { CAT 6. EXPRESSION OF } \\
\text { AN ARCHITECTURAL } \\
\text { CONCEPT } \\
\end{array}$ & $\begin{array}{l}\text { CAT 7. CONSERVATION } \\
\text { AND PRESERVATION } \\
\text { PRINCIPLES } \\
\end{array}$ \\
\hline \multirow{5}{*}{$\begin{array}{l}\text { SEISMIC SYSTEM - } \\
\text { DIRECTION }\end{array}$} & $\begin{array}{l}1.1 \text { ARCHITECTURAL } \\
\text { REASONS }\end{array}$ & 2.1. ELEVATION & 3.1. ELEVATION & 4.1 MODULATION OF LIGHT & $\begin{array}{l}5.1 \text {.1 USE OF STRUCTURE FOR } \\
\text { ORNAMENTAL PURP OSES }\end{array}$ & $\begin{array}{l}\text { 6.1 EXXISTING OR NEW } \\
\text { ARCHITECTURAL CONCEPT }\end{array}$ & $\begin{array}{l}7.1 \text { MINIMUM } \\
\text { INTERVENTION }\end{array}$ \\
\hline & $\begin{array}{l}\text { 1.2 THE EFFECT OF THE } \\
\text { HIDING TECHNIQUE UPON } \\
\text { ARCHITECTURE }\end{array}$ & $\begin{array}{l}\text { 2.2 EXPRESSIVE ROLES OF } \\
\text { THE STRUCTURE }\end{array}$ & $\begin{array}{l}\text { 3.2 EXPRESSIVE ROLES OF } \\
\text { THE STRUCTURE }\end{array}$ & $\begin{array}{l}4.2 \text { OUTSIDE } \\
\text { VIEWS/SIGHTLNES }\end{array}$ & & & \multirow{2}{*}{$\begin{array}{l}\text { 7.2 COMPATIBILTY WITH } \\
\text { ELISTING ARCHITECTURAL } \\
\text { CAARAATER } \\
7.3 \text { REVERSIBLITY }\end{array}$} \\
\hline & & & 3.3 STRUCTURE AND SPACE & & & & \\
\hline & & & $\begin{array}{l}\text { 3.4 STRUCTURE AND } \\
\text { EUNCTION }\end{array}$ & & & & \\
\hline & & & \begin{tabular}{|l} 
3.5 STRUCTURE AND \\
CIRCULATION
\end{tabular} & & & & \\
\hline
\end{tabular}

The Tables of Analysis communicate the data collected from the direct observations through the use of colour codes indicating the influence of the seismic system on each architectural quality (Figure 57). 


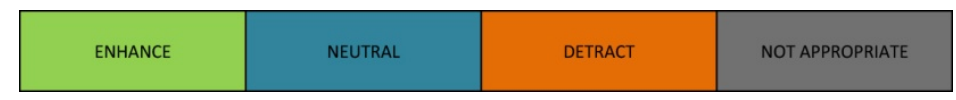

Figure 57. Colour code of the influence of seismic system on architectural quality

In each section, the Tables of Analysis for the same seismic system from different case studies are gathered, starting with Table 6 and the analysis of shear walls. This provides a simple yet quick overall appreciation of the impacts of retrofit on architectural qualities.

Secondly, each influenced architectural quality is extracted from the Tables of Analysis and analysed independently from the other qualities. This is undertaken by having summary tables (Table 5) combined with written explanations justifying the identified influence of the seismic system on the architectural quality.

Table 5. Example of a summary table of architectural quality 2.1 Elevation with enhanced and neutral influences from two shear walls

\begin{tabular}{|c|c|}
\hline \multicolumn{2}{|c|}{2.1 ELEVATION } \\
\hline $\begin{array}{c}\text { BUILDING \#... } \\
\text { External Shear } \\
\text { Wall } \\
\text { - Transverse } \\
\text { Direction }\end{array}$ & $\begin{array}{c}\text { BUILDING \#... } \\
\text { External Shear } \\
\text { Wall } \\
\text { - Longitudinal } \\
\text { Direction }\end{array}$ \\
\hline ENHANCE & NEUTRAL \\
\hline
\end{tabular}

To respect the anonymity of the stakeholders involved in the design and construction of the URM buildings used as case studies, photographs are replaced by sketches in the current chapter. Further information on each building is presented in Table 2 (Chapter 3 ). 
PAGE LEFT INTENTIONALLY BLANK 


\subsection{Analysis of the Seismic systems}

\subsubsection{Shear wall (Buildings \#1, \#2, \#3, \#4)}

Table 6. Tables of Analysis representing the influences of the shear wall system on each architectural quality of Buildings \#1, \#2, \#3 and \#4

\begin{tabular}{|c|c|c|c|c|c|c|c|}
\hline BUILDING \#1 & $\begin{array}{l}\text { CAT 1. HIDDEN } \\
\text { STRUCTURE }\end{array}$ & $\begin{array}{l}\text { CAT 2. EXPOSED } \\
\text { EXTERIOR STRUCTURE }\end{array}$ & $\begin{array}{l}\text { CAT 3. EXPOSED INTERIOR } \\
\text { STRUCTURE }\end{array}$ & $\begin{array}{l}\text { CAT 4. INTERACTION WITH } \\
\text { EXTERNAL OPENINGS }\end{array}$ & CAT 5. ORNAMENTATION & $\begin{array}{l}\text { CAT 6. EXPRESSION OF } \\
\text { AN ARCHITECTURAL } \\
\text { CONCEPT }\end{array}$ & $\begin{array}{l}\text { CAT 7. CONSERVATION } \\
\text { AND PRESERVATION } \\
\text { PRINCIPLES }\end{array}$ \\
\hline \multirow{5}{*}{$\begin{array}{l}\text { INTERNAL CONCRETE } \\
\text { SHEAR WALL- } \\
\text { LONGITUDINAL DIRECTION }\end{array}$} & $\begin{array}{l}\overline{1.1 \text { ARCHITECTURAL }} \\
\text { REASONS }\end{array}$ & 2.1. ELEVATION & 3.1. ELEVATION & 4.1 MODULATION OF LIGHT & $\begin{array}{l}\text { 5.1 USE OF STRUCTURE FOR } \\
\text { ORNAMENTAL PURPOSES }\end{array}$ & \begin{tabular}{|l}
6.1 EXISTING OR NEW \\
ARCHITECTURAL CONCEPT
\end{tabular} & $\begin{array}{l}7.1 \text { MINIMUM } \\
\text { INTERVENTION }\end{array}$ \\
\hline & $\begin{array}{l}1.2 \text { THE EFFECT OF THE } \\
\text { HDING TECHNIQUE UPON } \\
\text { ARCHITECTURE }\end{array}$ & $\begin{array}{l}\text { 2.2 EXPRESSIVE ROLES OF } \\
\text { THE STRUCTURE }\end{array}$ & $\begin{array}{l}\text { 3.2 EXPRESSIVE ROLES OF } \\
\text { THE STRUCTURE }\end{array}$ & $\begin{array}{l}4.2 \text { OUTSIDE } \\
\text { VIEWS/SIGHTLNES }\end{array}$ & & & $\begin{array}{l}\text { 7.2 COMPATIBILTY WITH } \\
\text { EXISTING ARCHITECTURAL } \\
\text { CHARACTER }\end{array}$ \\
\hline & & & 3.3 STRUCTURE AND SPACE & & & & 7.3 REVERSIBILTY \\
\hline & & & $\begin{array}{l}3.4 \text { STRUCTURE AND } \\
\text { FUNCTION }\end{array}$ & & & & \\
\hline & & & $\begin{array}{l}\text { 3.5 STRUCTURE AND } \\
\text { CIRCULATION }\end{array}$ & & & & \\
\hline
\end{tabular}

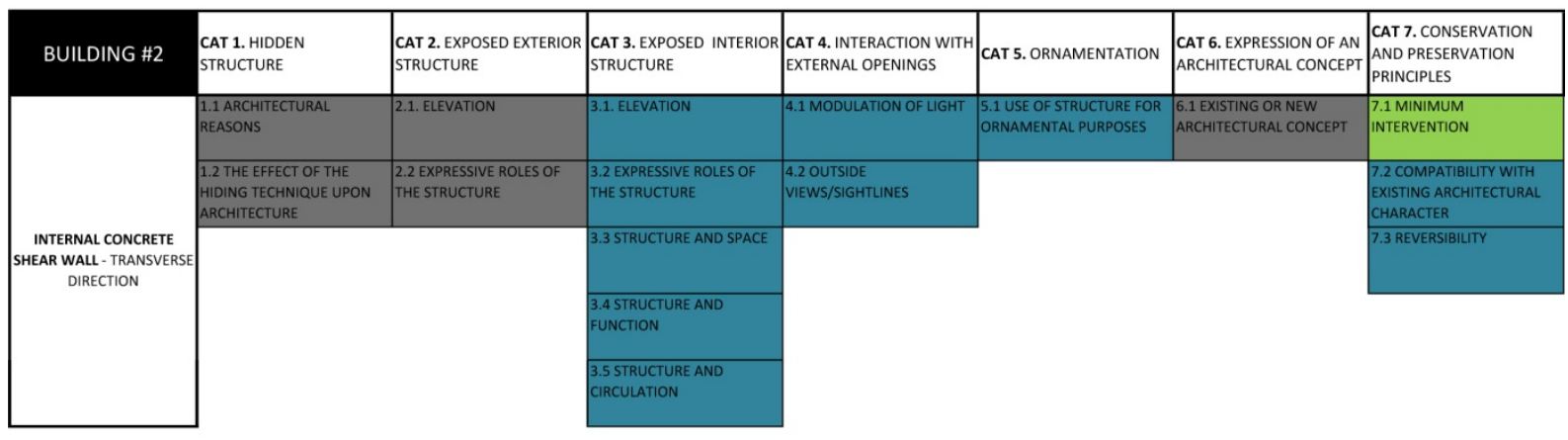

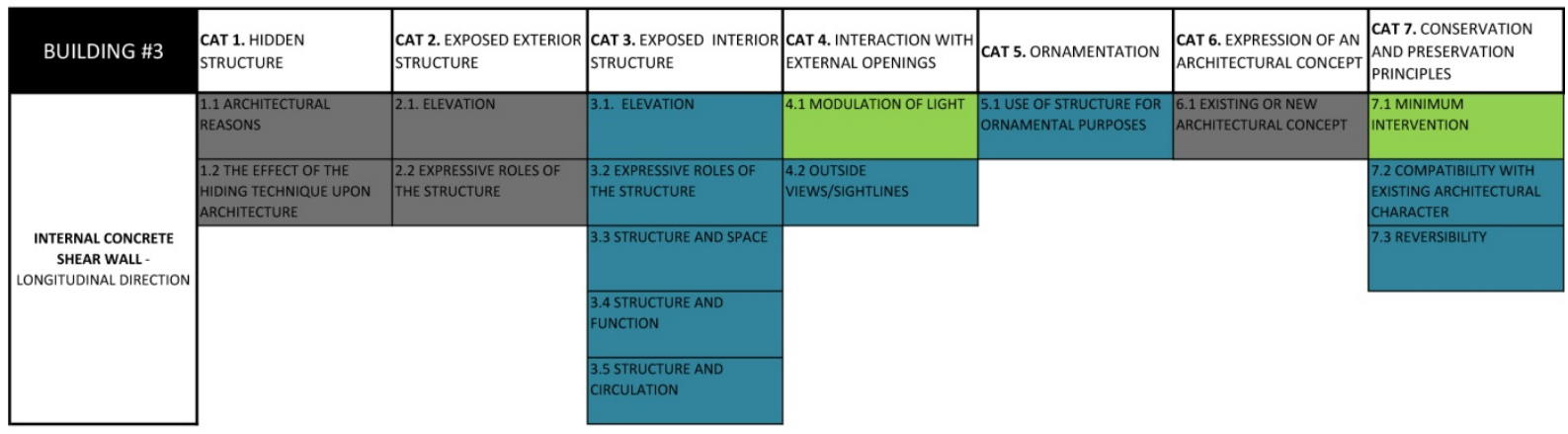

\begin{tabular}{|c|c|c|c|c|c|c|c|}
\hline $\begin{array}{c}\text { BUILDING \#3 } \\
\text { BAR/RESTAURANT }\end{array}$ & $\begin{array}{l}\text { CAT 1. HIDDEN } \\
\text { STRUCTURE }\end{array}$ & $\begin{array}{l}\text { CAT 2. EXPOSED EXTERIOR } \\
\text { STRUCTURE }\end{array}$ & $\begin{array}{l}\text { CAT 3. EXPOSED INTERIOF } \\
\text { STRUCTURE }\end{array}$ & $\begin{array}{l}\text { CAT 4. INTERACTION WITH } \\
\text { EXTERNAL OPENINGS }\end{array}$ & CAT 5. ORNAMENTATION & $\begin{array}{l}\text { CAT 6. EXPRESSION OF AN } \\
\text { ARCHITECTURAL CONCEPP }\end{array}$ & \begin{tabular}{|l|} 
CAT 7. CONSERVATION \\
$\begin{array}{l}\text { AND PRESERVATION } \\
\text { PRINCIPLES }\end{array}$
\end{tabular} \\
\hline \multirow{5}{*}{$\begin{array}{l}\text { INTERNAL CONCRETE } \\
\text { SHEAR WAL- } \\
\text { LONGITUDINAL DIRECTION }\end{array}$} & $\begin{array}{l}1.1 \text { ARCHIT } \\
\text { REASONS }\end{array}$ & 2.1. ELEVATION & 3.1. ELEVATION & & $\begin{array}{l}5.1 \text { USE OF STRUCTURE FOR } \\
\text { ORNAMENTAL PURPOSES }\end{array}$ & $\begin{array}{l}\text { 6.1 EXISTING OR NEW } \\
\text { ARCHTECTURAL CONCEPT }\end{array}$ & $\begin{array}{l}7.1 \text { MINIMUM } \\
\text { INTERVENTION }\end{array}$ \\
\hline & $\begin{array}{l}\text { 1.2 THE EFFECT OF THE } \\
\text { HIDING TECHNIQUE UPON } \\
\text { ARCHITECTURE }\end{array}$ & $\begin{array}{l}\text { 2.2 EXPRESSIVE ROLES OF } \\
\text { THE STRUCTURE }\end{array}$ & $\begin{array}{l}\text { 3.2 EXPRESIIVE ROLES OF } \\
\text { THE STRUCTURE }\end{array}$ & $\begin{array}{l}4.2 \text { OUTSIDE } \\
\text { VIEW/SIGGHUINES }\end{array}$ & & & $\begin{array}{l}7.2 \text { COMPATIBILTYY WITH } \\
\text { EXISTING ARCHITECTURAL } \\
\text { CHARACTER }\end{array}$ \\
\hline & & & 3.35TRUCIURE ANU SPACE & & & & P. \\
\hline & & & $\begin{array}{l}\text { 3.4STRUCTURE AND } \\
\text { FUNCTION }\end{array}$ & & & & \\
\hline & & & $\begin{array}{l}3.5 \text { STRUCTURE AND } \\
\text { CIRCULATION }\end{array}$ & & & & \\
\hline
\end{tabular}



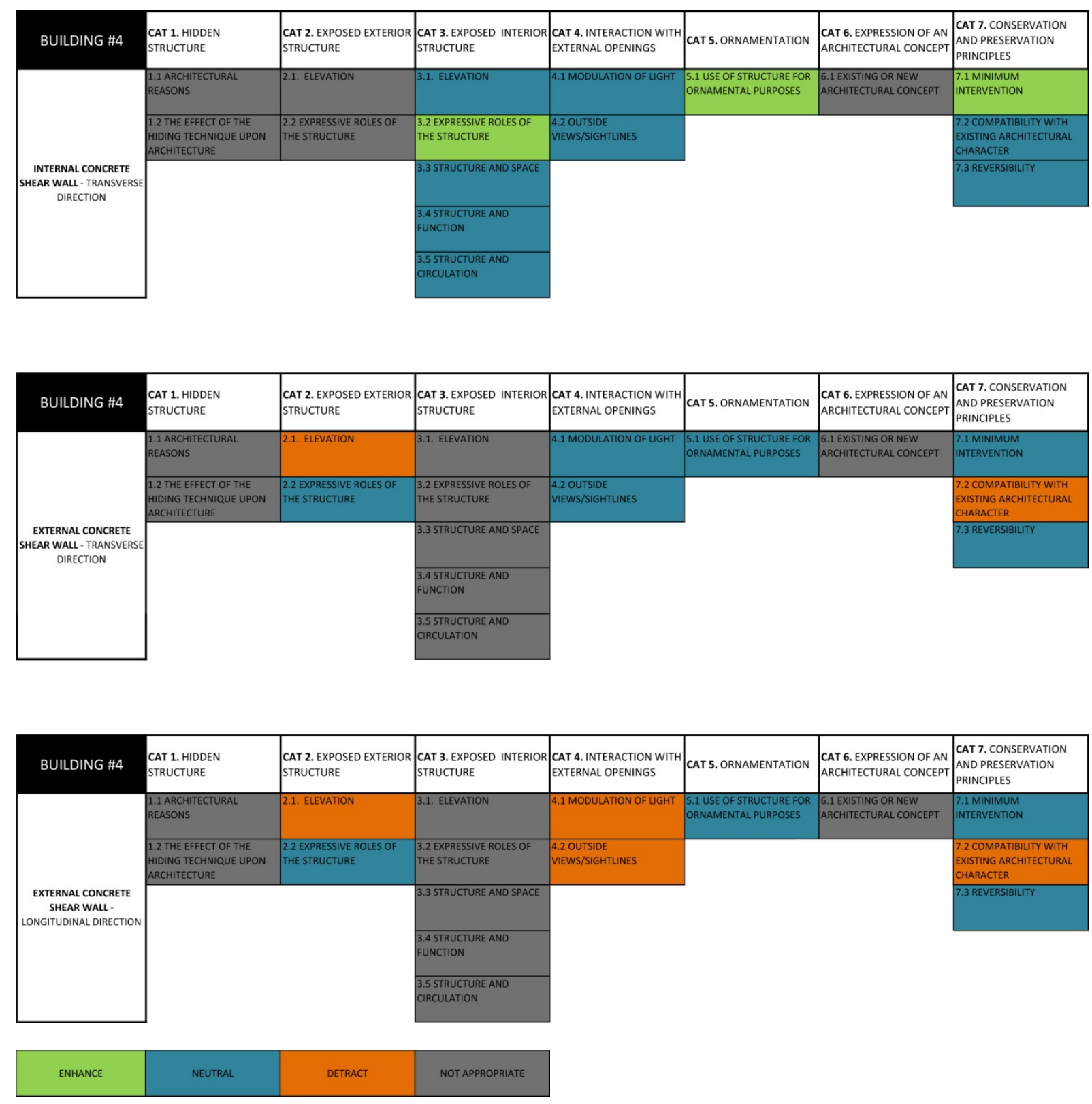

○ Category 1 - Hidden structure

N/A: all the shear walls are exposed.

\section{$\circ$ Category 2 - Exposed exterior structure}

\section{- 2.1: Elevation}

\begin{tabular}{|c|c|}
\hline $\begin{array}{c}\text { BUILDING \#4 } \\
\text { External Shear } \\
\text { Wall } \\
\text { - Transverse } \\
\text { Direction }\end{array}$ & $\begin{array}{c}\text { BUILDING \#4 } \\
\text { External Shear } \\
\text { Wall } \\
\text { - Longitudinal } \\
\text { Direction }\end{array}$ \\
\hline DETRACT & DETRACT \\
\hline
\end{tabular}


Building \#4 has external shear walls built against its four façades. These exterior concrete shear walls have a plastered texture and are painted similar to the existing walls, therefore lessening their visual presence. However, the relationship between the retrofit structure and the existing façades is not clearly defined. The retrofit structure neither fully merges with the existing façades nor does it clearly distinguish itself from them. Several aspects weaken the complete merging:

- the shear walls are not continuous. Horizontally, they are located close to, but not exactly on, the centre of each façade (Figure 58). Vertically, they don't run the full height of the existing façades but stop before the existing frieze at the top of the façades,

- as the shear walls are constructed against a portion of the existing walls, their depth inevitably indicates their presence,

- the shear walls disrupt the linearity of the façades without providing new rhythm or pattern.

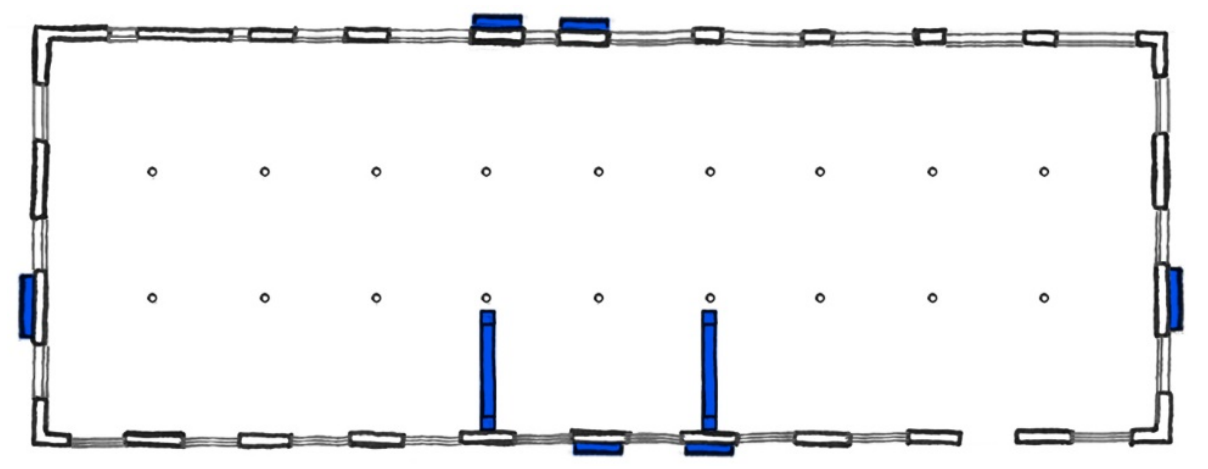

Figure 58. Ground floor plan of Building \#4 with shear walls (blue)

Due to the lack of a clear relationship between the old architectural layer and the new structure, the disruption of the existing linear façades and the absence of an aesthetic contribution, the seismic solution detracts from the former external architectural character.

- 2.2: Expressive role of the structure

\begin{tabular}{|c|c|}
\hline $\begin{array}{c}\text { BUILDING \#4 } \\
\text { External Shear } \\
\text { Wall } \\
\text { - Transverse } \\
\text { Direction }\end{array}$ & $\begin{array}{c}\text { BUILDING \#4 } \\
\text { External Shear } \\
\text { Wall } \\
\text { - Longitudinal } \\
\text { Direction }\end{array}$ \\
\hline NEUTRAL & NEUTRAL \\
\hline
\end{tabular}

The structural detailing of the external shear walls in Building \#4 visually matches the existing façade walls; therefore, the shear walls are not expressive of anything. The intention appears to maintain the building's existing aesthetic and as a result: 
- existing red metal anchors covered by the installation of the shear walls are reinstalled over them,

- the shear walls are dowelled into the existing façade and no connections between the two elements are visible,

- the tops of the shear walls are slightly angled. Such detailing softens the connection of the shear wall with the existing façade.

By maintaining the existing visual pattern of the red anchors and limiting the presence of the shear walls, the expressiveness of the retrofit structure is considered neutral (Figure 59).

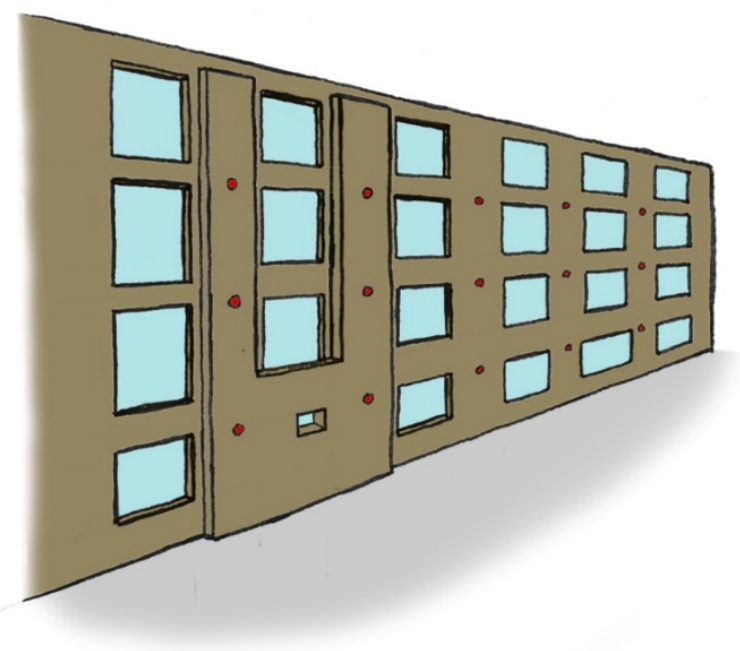

Figure 59. Front façade of Building \#4 with the shear wall visually matching the existing façade wall

\section{○ Category 3 - Exposed interior structure}

- 3.1: Elevation

\begin{tabular}{|c|c|c|c|c|}
\hline $\begin{array}{c}\text { BUILDING \#1 } \\
\text { Internal Shear } \\
\text { Wall } \\
\text { - Longitudinal } \\
\text { Direction }\end{array}$ & $\begin{array}{c}\text { BUILDING \#2 } \\
\text { Internal Shear } \\
\text { Wall } \\
\text { - Transverse } \\
\text { Direction }\end{array}$ & $\begin{array}{c}\text { BUILDING \#3 } \\
\text { Internal Shear } \\
\text { Wall } \\
\text { (Bar/restaurant) } \\
\text { - Longitudinal } \\
\text { Direction }\end{array}$ & $\begin{array}{c}\text { BUILDING \#3 } \\
\text { Internal Shear } \\
\text { Wall } \\
\text { - Transverse } \\
\text { Direction }\end{array}$ & $\begin{array}{c}\text { BUILDING \#4 } \\
\text { Internal Shear } \\
\text { Wall } \\
\text { - Transverse } \\
\text { Direction }\end{array}$ \\
\hline ENHANCE & NEUTRAL & ENHANCE & NEUTRAL & NEUTRAL \\
\hline
\end{tabular}

The three neutral effects can be explained by several reasons. The main one is the use of plaster and white paint on the shear walls in Buildings \#2 and \#3. Such treatment leads to a bland interior surface elevation. The shear walls are therefore visually neutralised. The second reason, found in Buildings \#2 and \#4, is the maintaining of the existing architectural interior elevation. This is achieved by the visual and physical replacement of an existing component with identical characteristics. The third reason, is the location of the shear wall, either installed on such a small 
portion of the building that it becomes a negligibly sized element, or located in a secondary space lacking architectural interest (Figure 60).
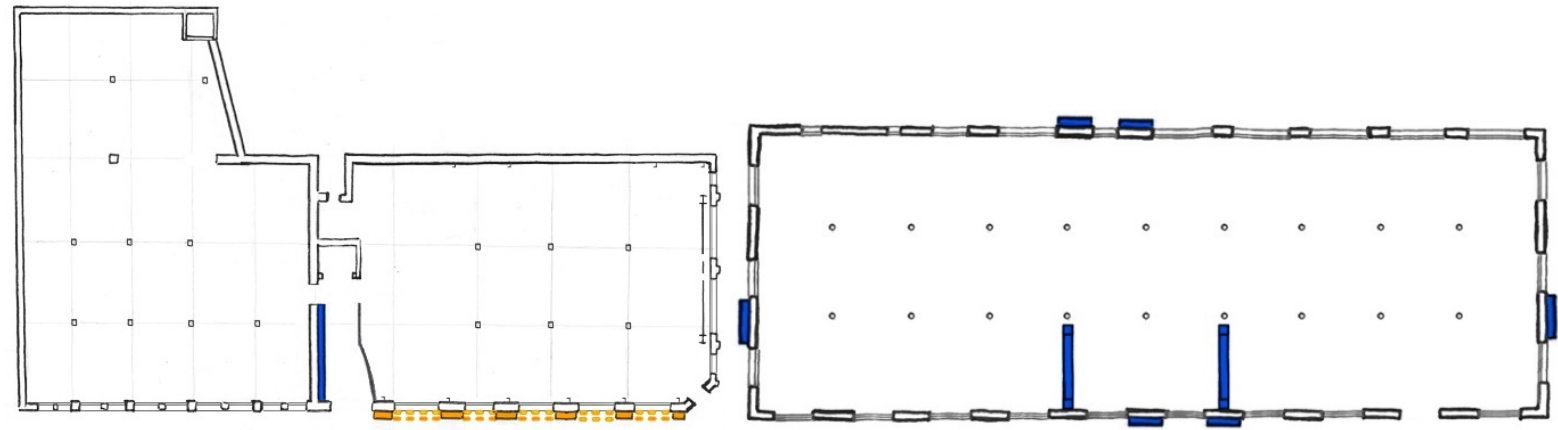

Figure 60. Ground floor plans with the interior shear walls (blue) located at the entrance of Building \#2 (left) and in the car park of Building \#4 (right)

In Building \#1 and in a specific space of Building \#3, a bar, the current sub-category is enhanced by the shear wall system (Figure 61). Both buildings can be considered as particular cases as their seismic retrofit involved the removal of previous fit-outs in order to undertake a complete internal refurbishment. New interior elevations are achieved by two approaches found in both buildings. The first is the expression of raw concrete materiality and detailing of the retrofit structure which creates new interior surfaces, and to a larger extent defines a new industrial architectural character. The second approach enhances the first due to the large dimensions of the shear walls. Indeed, in both buildings the retrofit structure is installed along the full length of the longitudinal walls and within a single space. Such a large scale highlights the presence of the retrofit structure and redefines the interior elevations.

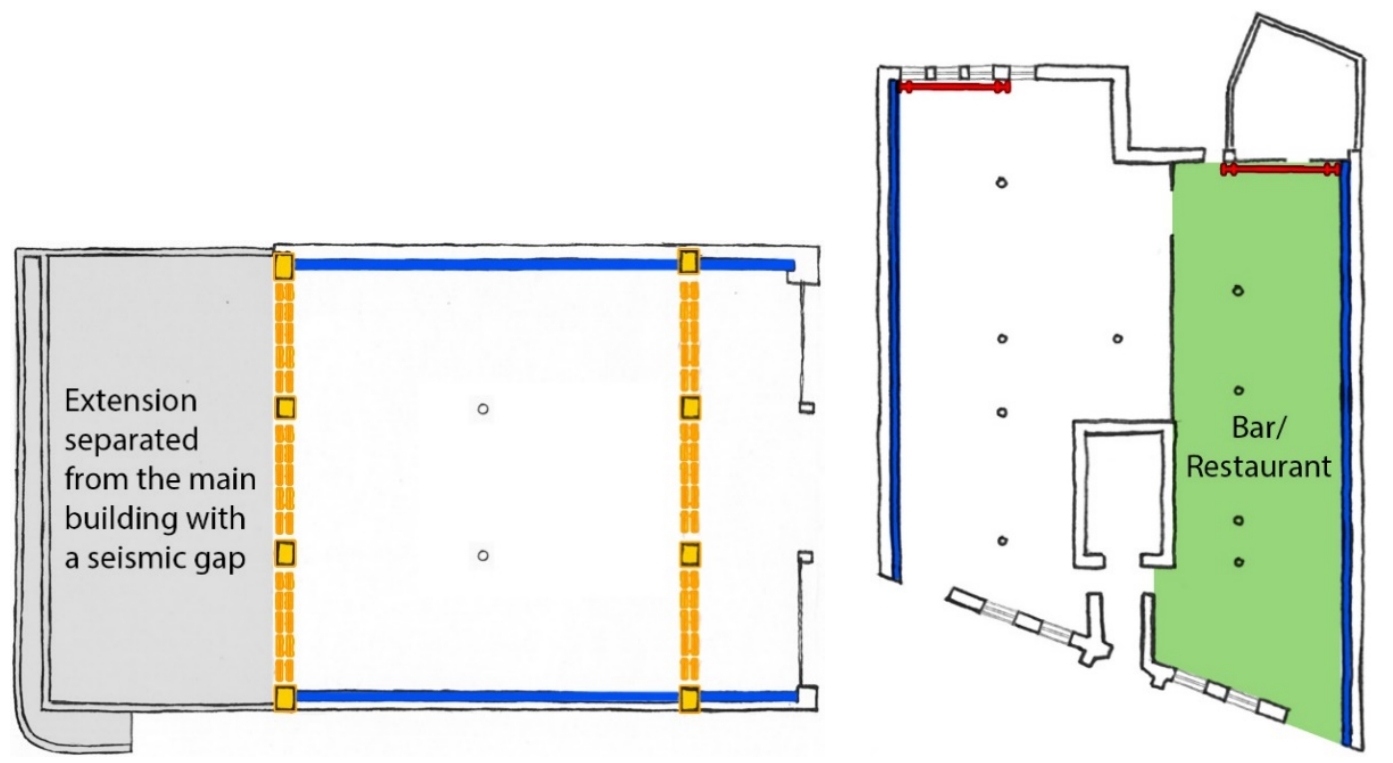

Figure 61. Ground floor plans with the interior shear walls (blue) exposed and contributing to the new interior elevations of Building \#1 (left) and of the bar of Building \#3 (right) 


\section{- 3.2: Expressive roles of the structure}

\begin{tabular}{|c|c|c|c|c|}
\hline $\begin{array}{c}\text { BUILDING \#1 } \\
\text { Internal Shear } \\
\text { Wall } \\
\begin{array}{c}\text { Longitudinal } \\
\text { Direction }\end{array}\end{array}$ & $\begin{array}{c}\text { BUILDING \#2 } \\
\text { Internal Shear } \\
\text { Wall } \\
\text { - Transverse } \\
\text { Direction }\end{array}$ & $\begin{array}{c}\text { BUILDING \#3 } \\
\text { Internal Shear } \\
\text { Wall } \\
\text { (Bar/restaurant) } \\
\text { - Longitudinal } \\
\text { Direction }\end{array}$ & $\begin{array}{c}\text { BUILDING \#3 } \\
\text { Internal Shear } \\
\text { Wall } \\
\text { - Transverse } \\
\text { Direction }\end{array}$ & $\begin{array}{c}\text { BUILDING \#4 } \\
\text { Internal Shear } \\
\text { Wall } \\
\text { - Transverse } \\
\text { Direction }\end{array}$ \\
\hline NEUTRAL & ENHANCE & NEUTRAL & ENHANCE \\
\hline
\end{tabular}

The two neutral effects on the current sub-category result from the treatment of the shear wall surfaces. In both Buildings \#2 and \#3, the shear walls are plastered. Smooth rendering and white paint deliver a plain and simple surface with no expressive features. The lack of visible connections between the shear walls and the existing URM walls also contribute to the simplicity of the structure's appearance.

In Buildings \#1, \#4, and in the bar of Building \#3, the shear walls express their materiality and construction techniques. Although their concrete materiality is exposed in each building, their surface treatments are different and result from their respective construction techniques. Two buildings, \#1 and \#3, possess sprayed concrete (shotcrete) walls with roughened surfaces. In contrast, the cast-in-place shear walls in Building \#4 express smoother finishing with the expression of a grid of tie-bolt holes specific to this technique. The shear walls in these three buildings express technical aspects of their construction with raw detailing. Such designs define, in combination with other structural and non-structural components, an industrial architectural character in Buildings $\# 1$ and \#3.

\section{- 3.3: Structure and space}

\begin{tabular}{|c|c|c|c|c|}
\hline $\begin{array}{c}\text { BUILDING \#1 } \\
\text { Internal Shear } \\
\text { Wall } \\
\text { - Longitudinal } \\
\text { Direction }\end{array}$ & $\begin{array}{c}\text { BUILDING \#2 } \\
\text { Internal Shear } \\
\text { Wall } \\
\text { - Transverse } \\
\text { Direction }\end{array}$ & $\begin{array}{c}\text { BUILDING \#3 } \\
\text { Internal Shear } \\
\text { Wall } \\
\text { (Bar/restaurant) } \\
\text { - Longitudinal } \\
\text { Direction }\end{array}$ & $\begin{array}{c}\text { BUILDING \#3 } \\
\text { Internal Shear } \\
\text { Wall } \\
\text { - Transverse } \\
\text { Direction }\end{array}$ & $\begin{array}{c}\text { BUILDING \#4 } \\
\text { Internal Shear } \\
\text { Wall } \\
\text { - Transverse } \\
\text { Direction }\end{array}$ \\
\hline NEUTRAL & NEUTRAL & NEUTRAL & NEUTRAL & NEUTRAL \\
\hline
\end{tabular}

In Buildings \#1,\#2,\#3, new retrofit structure is placed against the existing exterior URM walls. As a result, and although the texture may differ from those walls, the spatial characteristics of the spaces are preserved. No further openness or enclosure is provided by the new retrofit structure. Also, by installing the shear walls against the existing URM walls, the existing delineations of internal spaces are maintained. 
Building \#4 possesses internal shear walls installed perpendicular to existing walls. The new walls replace two X-braced frames from previous seismic retrofit done a decade ago and that delineate spaces for two cars to park. Despite creating a more enclosed space, the retrofit structure has little influence over the spatial characteristics of the whole interior car park. Indeed, due to their small dimensions and number in comparison with the large dimensions of the open-space, the shear walls appear as minor components. In this case, the difference of scales neutralises the influence of the retrofit structure in the interior space.

- 3.4: Structure and function

\begin{tabular}{|c|c|c|c|c|}
\hline $\begin{array}{c}\text { BUILDING \#1 } \\
\text { Internal Shear } \\
\text { Wall } \\
\begin{array}{c}\text { - Longitudinal } \\
\text { Direction }\end{array}\end{array}$ & $\begin{array}{c}\text { BUILDING \#2 } \\
\text { Internal Shear } \\
\text { Wall }\end{array}$ & $\begin{array}{c}\text { BUILDING \#3 } \\
\text { Internal Shear } \\
\text { Wall } \\
\text { Diransverse } \\
\text { (Bar/restaurant) } \\
\text { - Longitudinal } \\
\text { Direction }\end{array}$ & $\begin{array}{c}\text { BUILDING \#3 } \\
\text { Internal Shear } \\
\text { Wall } \\
\text { - Transverse } \\
\text { Direction }\end{array}$ & $\begin{array}{c}\text { BUILDING \#4 } \\
\text { Internal Shear } \\
\text { Wall } \\
\text { - Transverse } \\
\text { Direction }\end{array}$ \\
\hline NEUTRAL & NEUTRAL & NEUTRAL & NEUTRAL & NEUTRAL \\
\hline
\end{tabular}

The shear walls in Buildings \#1, \#2, \#3 are against the existing URM walls, visually replacing them, but preserving their spatial boundaries (Figure 60 and Figure 61). As a result, internal planning and the functionality of interior spaces remain untouched by the new retrofit structure.

In Building \#4, the two shear walls with similar dimensions replacing the two steel X-braced frames take the role of the previous structure in terms of interior planning and organisation of the interior space (Figure 60). Despite the change of materiality, functionality remains similar before and after seismic retrofit.

- 3.5: Structure and circulation

\begin{tabular}{|c|c|c|c|c|}
\hline $\begin{array}{c}\text { BUILDING \#1 } \\
\text { Internal Shear } \\
\text { Wall } \\
\begin{array}{c}\text { - Longitudinal } \\
\text { Direction }\end{array}\end{array}$ & $\begin{array}{c}\text { BUILDING \#2 } \\
\text { Internal Shear } \\
\text { Wall } \\
\text { - Transverse } \\
\text { Direction }\end{array}$ & $\begin{array}{c}\text { BUILDING \#3 } \\
\text { Internal Shear } \\
\text { Wall } \\
\text { (Bar/restaurant) } \\
\text { - Longitudinal } \\
\text { Direction }\end{array}$ & $\begin{array}{c}\text { BUILDING \#3 } \\
\text { Internal Shear } \\
\text { Wall } \\
\text { - Transverse } \\
\text { Direction }\end{array}$ & $\begin{array}{c}\text { BUILDING \#4 } \\
\text { Internal Shear } \\
\text { Wall } \\
\text { - Transverse } \\
\text { Direction }\end{array}$ \\
\hline NEUTRAL & NEUTRAL & NEUTRAL & NEUTRAL \\
\hline
\end{tabular}

The existing URM walls in Buildings \#1 and \#3, and the existing X-braced frames in Building \#4, did not define any circulation areas. The reason results from the location of the structure which solely delineates usable spaces. As a result, the shear walls supplementing the existing structure, visually and physically, also avoid any impact on circulation. 
In Building \#2, the existing URM wall frames a circulation area in combination with a partition wall in front of it. The shear wall is cast against the existing structure and replicates its dimensions. Due to its thickness, the shear wall slightly reduces the width of the circulation area but such impact is negligible. The circulation quality is therefore maintained.

\section{○ Category 4 - Interaction with external openings}

\section{- 4.1: Modulation of light}

\begin{tabular}{|c|c|c|c|c|c|c|}
\hline BUILDING \#1 & BUILDING \#2 & BUILDING \#3 & BUILDING \#3 & BUILDING \#4 & BUILDING \#4 & BUILDING \#4 \\
\hline
\end{tabular}

It is helpful to distinguish shear walls located internally from those installed externally as the reasons for the neutrality of structure are different. Regarding interior shear walls, it is worth noticing that they are all installed perpendicular to openings. Two main reasons explain the lack of light modulation. The first is the small dimensions of the shear walls, as is the case in Buildings \#2 and \#4. With little surface for the natural light to be impacted by, no modulation is observed. In Building \#4, the lack of modulation is furthermore absent by the small amount of light coming from the window and the large dimensions of the open-space car park compared to the new structure. Both of these reasons explain why although shear walls replace the $\mathrm{X}$-braced frames and prevent light from passing through them, such a change of treatment is negligible. The second reason, found in Building \#1 and in the bar of Building \#3, is the expression of raw concrete surfaces. The shotcreting process used on the shear walls leads to roughened surfaces which do not reflect light.

In Building \#4, each external transverse wall is installed in between two sets of windows therefore avoiding any obstruction to light. To further minimise the impact on the entry of light, the shear walls stop $200 \mathrm{~mm}$ before the window frames. In doing so, the existing frames maintain their depth therefore avoiding greater shadowing.

Apart from its 'neutral' shear wall discussed above, most shear walls in Building \#3 actually modulate natural light. As the shear walls have flat smooth plastered surfaces with satin paint, the natural light entering from the openings is softly diffused inside various spaces. In addition, the shear walls always run along the longest side of each space they are located in, therefore spreading the light further inside the building. 
Building \#4 displays on each of its longitudinal façades two shear walls installed in between two sets of windows and joining at the ground floor. The joined shear walls at the base of the main façade reduce the entry of light by reducing the dimensions of the existing opening (Figure 62). The shear walls on the rear façade completely cover the other existing window. Natural light is therefore reduced from entering the building at the ground floor, partially on one façade and fully on the other. This negative impact is however minimised by two aspects. First the function of the space, as a car park necessitates less natural light. Secondly, the large open-space allows the car park to rely on other openings in the façades to provide light.
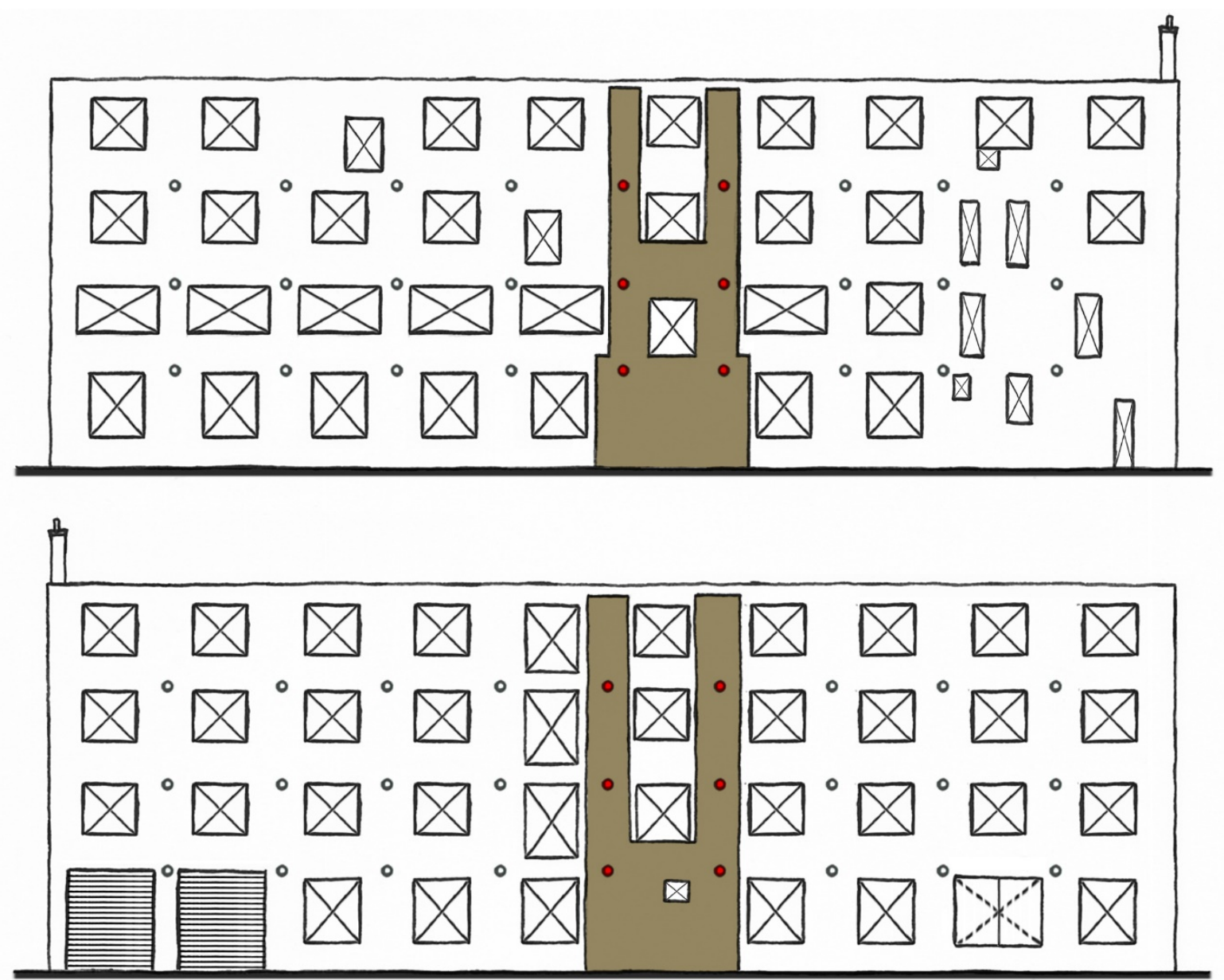

Figure 62. Rear (top) and front (bottom) façades of Building \#4 with the shear walls masking existing windows at the ground floor

- 4.2: Outside views/sightlines

\begin{tabular}{|c|c|c|c|c|c|c|}
\hline $\begin{array}{c}\text { BUILDING \#1 } \\
\text { Internal Shear } \\
\text { Wall } \\
\text { - Longitudinal } \\
\text { Direction }\end{array}$ & $\begin{array}{c}\text { BUILDING \#2 } \\
\text { Internal Shear } \\
\text { Wall } \\
\text { - Transverse } \\
\text { Direction }\end{array}$ & $\begin{array}{c}\text { BUILDING \#3 } \\
\text { Internal Shear } \\
\text { Wall } \\
\text { (Bar/restaurant) } \\
\text { - Longitudinal } \\
\text { Direction }\end{array}$ & $\begin{array}{c}\text { BUILDING \#3 } \\
\text { Internal Shear } \\
\text { Wall } \\
- \text { Transverse } \\
\text { Direction }\end{array}$ & $\begin{array}{c}\text { BUILDING \#4 } \\
\text { Internal Shear } \\
\text { Wall } \\
- \text { Transverse } \\
\text { Direction }\end{array}$ & $\begin{array}{c}\text { BUILDING \#4 } \\
\text { External Shear } \\
\text { Wall } \\
\text { - Transverse } \\
\text { Direction }\end{array}$ & $\begin{array}{c}\text { BUILDING \#4 } \\
\text { External Shear } \\
\text { Wall } \\
\text { - Longitudinal } \\
\text { Direction }\end{array}$ \\
\hline NEUTRAL & NEUTRAL & NEUTRAL & NEUTRAL & NEUTRAL & NEUTRAL & DETRACT \\
\hline
\end{tabular}


In all buildings, the interior shear walls are installed at $90^{\circ}$ to the openings and their depth does not reduce the dimensions of the windows. The original outside views are therefore maintained.

The transverse external shear walls of Building \#4 stop before the window frames and do not restrict the outside views. The longitudinal external shear walls have however a negative impact on the outside views. At ground floor, they reduce the dimensions of the existing opening on the main façade and cover the other window on the rear façade. The consequence is a smaller view on one side and a completely lost view on the other. Such a negative impact needs however to be balanced by the fact that the area affected is the building car park - a secondary space.

\section{○ Category 5 - Ornamentation}

- 5.1: Use of structure for ornamental purposes

\begin{tabular}{|c|c|c|c|c|c|c|}
\hline $\begin{array}{c}\text { BUILDING \#1 } \\
\text { Internal Shear } \\
\text { Wall } \\
\text { - Longitudinal } \\
\text { Direction }\end{array}$ & $\begin{array}{c}\text { BUILDING \#2 } \\
\text { Internal Shear } \\
\text { Wall } \\
\text { - Transverse } \\
\text { Direction }\end{array}$ & $\begin{array}{c}\text { BUILDING \#3 } \\
\text { Internal Shear } \\
\text { Wall } \\
\text { (Bar/restaurant) } \\
\text { - Longitudinal } \\
\text { Direction }\end{array}$ & $\begin{array}{c}\text { BUILDING \#3 } \\
\text { Internal Shear } \\
\text { Wall } \\
- \text { Transverse } \\
\text { Direction }\end{array}$ & $\begin{array}{c}\text { BUILDING \#4 } \\
\text { Internal Shear } \\
\text { Wall } \\
- \text { Transverse } \\
\text { Direction }\end{array}$ & $\begin{array}{c}\text { BUILDING \#4 } \\
\text { External Shear } \\
\text { Wall } \\
- \text { Transverse } \\
\text { Direction }\end{array}$ & $\begin{array}{c}\text { BUILDING \#4 } \\
\text { External Shear } \\
\text { Wall } \\
\text { - Longitudinal } \\
\text { Direction }\end{array}$ \\
\hline NEUTRAL & NEUTRAL & ENHANCE & NEUTRAL & ENHANCE & NEUTRAL & NEUTRAL \\
\hline
\end{tabular}

Most shear walls have no influence over the ornamental quality of the buildings. In Buildings \#1, \#2 and \#3, the first aspect to take into account is the lack of ornamental features of the existing walls behind the new retrofit structures. There is therefore no loss or damage of any existing ornamental quality. In addition, the retrofit structures, with the exception of one raw concrete shear wall in Building \#3 and two others in Building \#1, possess simple plain surfaces, either plastered and painted, or simply painted. The result is a series of shear walls with no ornamental patterns, no detailing expressing a technical vocabulary, no applied ornamentation, and no ornamental shapes.

A similar lack of additional ornamentation is noticeable in the external retrofit structure of Building \#4. The new external shear walls have been plastered and painted in accordance with the visual treatment of the existing façades. These façades however display a series of red metal anchors generating an ornamental pattern. In this case, the neutral effect of the retrofit structure results from the re-instalment of the red anchor plates over the shear walls. The existing ornamental pattern is therefore maintained.

Building \#3 possesses one sprayed concrete shear wall with a roughened surface which contributes to a raw, technical and industrial character. A similar comment can be made about the shear walls in Building \#1, however only the retrofit structure in the Building \#3 is identifiable as ornament 
(Figure 63). Two reasons explain this difference. First, the fact that the shear wall in Building \#3 is a unique element highlights it as the main feature of the space. It is the largest and longest element when compared to other structural elements whether existing or new. The shear wall therefore displays the naturally roughened concrete texture. The shear walls in Building \#1, on the other hand, share their exposed concrete materiality with the transverse retrofit structure, i.e. massive concrete moment frames, and new steel and concrete floors. The finishing of both vertical structures is also very similar. This omnipresence of exposed concrete materiality reduces the potential for the shear walls to appear as ornamental objects. The second reason comes from the linear and continuous treatment of the shear wall in Building \#3. Here the retrofit structure runs along the whole length of the interior space and remains as an untouched and pure architectural feature. In contrast, the shear walls in Building \#1 are visually affected by new columns and moment frames that stop their appearance of linearity. In addition, the discontinuity caused by the columns and moment frames does not generate any pattern or rhythm on the walls.

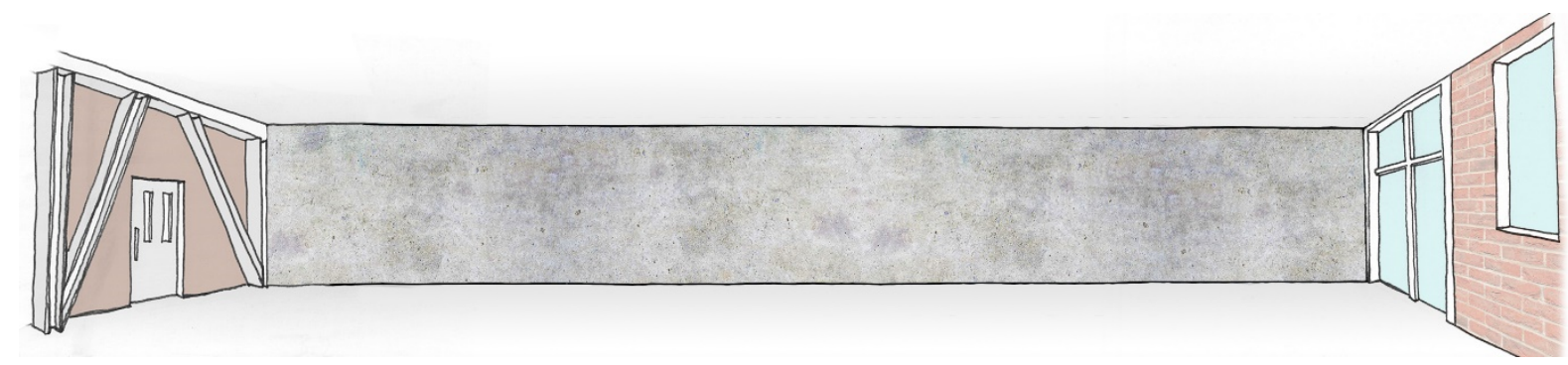

Figure 63. Ornamental exposed shotcreted shear wall running along the entire length of the bar of Building \#3

In Building \#4, the shear walls display on their surfaces a series of holes arranged in a grid pattern resulting from the cast-in-place technique (Figure 64). The result is an ornamental pattern expressed on the surfaces of each wall. This ornamental quality however barely serves the building as the shear walls are located in the car-park.

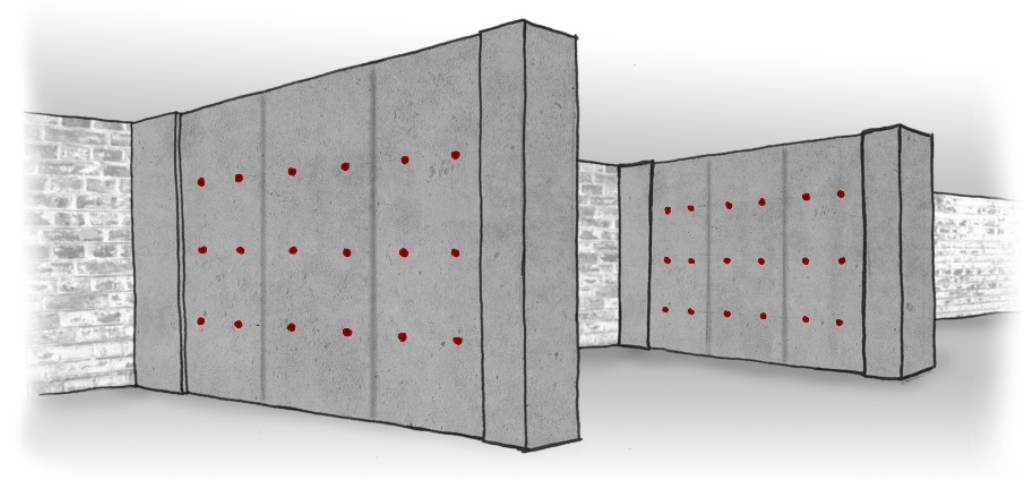

Figure 64. Interior shear walls of Building \#4 displaying an ornamental pattern 


\section{○ Category 6 - Expression of an architectural concept}

- 6.1: Reinforcement of an existing architectural concept or development of a new one

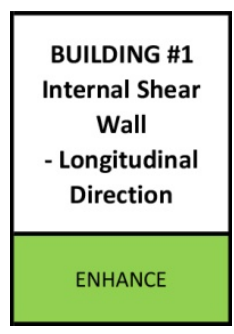

None of the buildings possess a clear identifiable existing design concept but rather a main architectural character. Such an architectural character usually results from a key element in the building that by its dimensions, location and geometry outweighs secondary components. For most of the buildings, this key element corresponds to their front façade, often carrying heritage value.

Although existing buildings may not possess obvious architectural concept, a new concept generated by retrofit structure can be found in Building \#1. This building had its existing fit-out removed and its seismic retrofit solution participates in a full internal refurbishment. The shear walls located along the existing longitudinal interior URM walls show their raw concrete materiality and detailing. Their large dimensions, covering the full height of each floor and the entire length of the building, also reinforce their presence. With these characteristics, a contrasting concept emerges based on the distinct reading of the existing highly refined Edwardian Baroque front façade, and the raw industrial character of the shotcrete shear walls (Figure 65).

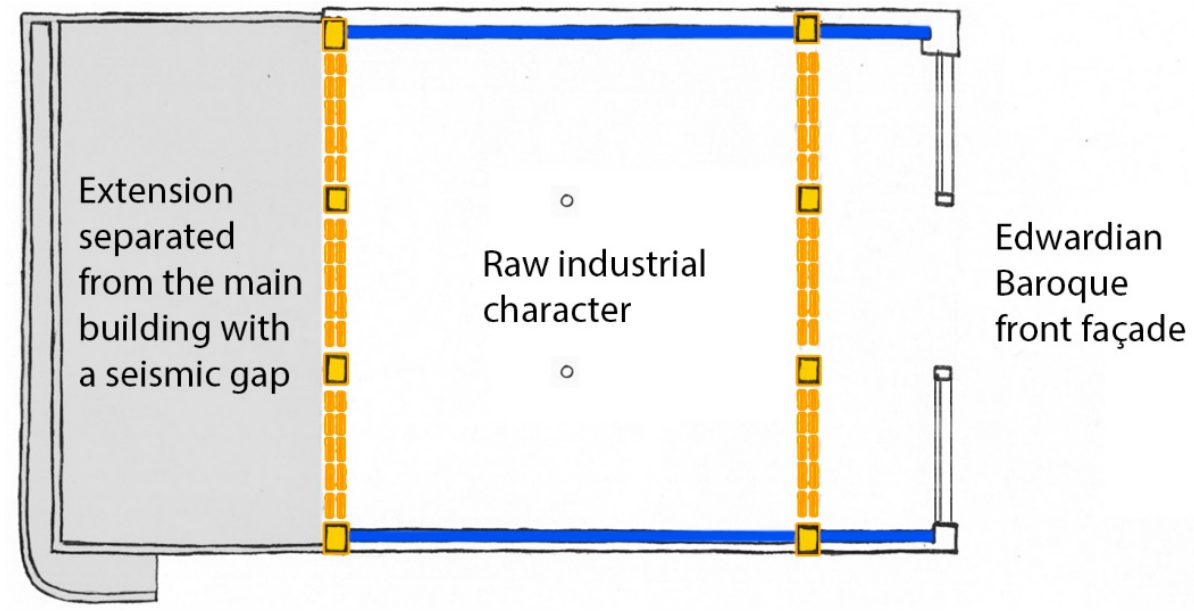

Figure 65. Ground floor plan of Building \#1 with distinctive interior and exterior characters

In addition, moment frames and composite steel and concrete floors also express raw concrete materiality and detailing. This similarity between the shear walls and these structures ensures 
coherency between them and reinforce the expression of the concept. A second aspect to consider is the participation of existing structural components in the expression of interior architectural character. Exposed steel plates from previous strengthening work are visible on the bare interior side of the URM front façade. They convey industrial rawness which reinforces the coherency of the concept. The third set of systems to take into account is the non-structural components including plumbing, ventilation duct fans and electric systems. Through their expression they further contribute to the expression of an industrial vocabulary.

Like Building \#1, Building \#3 possesses a full interior refurbishment, a refined front façade, and an exposed shotcrete shear wall. An identical concept based on the contrast between the existing layer of architecture and the new could therefore be potentially generated. However, the main treatment of the interior refurbishment with white plastered walls means that no particular architectural character is identifiable. Only the bar possesses a distinct raw and industrial architectural character thanks to an unrefined exposed concrete shear wall, an exposed eccentric braced frame, and three steel posts helping the URM front façade resist out-of-plane forces. Despite these seismic elements expressing a common technical vocabulary and contrasting with the main façade, at the scale of the overall building, any new concept is unidentifiable.

The other shear walls in Buildings \#2 and \#4 also fail in expressing a new architectural concept due to their very small dimensions making them trivial components. Secondly, in Building \#4, the internal shear walls are located in secondary spaces which possess low architectural interest. Finally, always in Building \#4, the external walls are designed to visually merge with the façades which do not take part in any concept.

\section{$\circ$ Category 7 - Conservation and preservation principles}

\section{- 7.1: Minimum intervention}

\begin{tabular}{|c|c|c|c|c|c|c|}
\hline $\begin{array}{c}\text { BUILDING \#1 } \\
\text { Internal Shear } \\
\text { Wall } \\
\begin{array}{c}\text { - Longitudinal } \\
\text { Direction }\end{array}\end{array}$ & $\begin{array}{c}\text { BUILDING \#2 } \\
\text { Internal Shear } \\
\text { Wall } \\
\text { - Transverse } \\
\text { Direction }\end{array}$ & $\begin{array}{c}\text { BUILDING \#3 } \\
\text { Internal Shear } \\
\text { Wall } \\
\text { (Bar/restaurant) } \\
\text { - Longitudinal } \\
\text { Direction }\end{array}$ & $\begin{array}{c}\text { BUILDING \#3 } \\
\text { Internal Shear } \\
\text { Wall } \\
\text { - Transverse } \\
\text { Direction }\end{array}$ & $\begin{array}{c}\text { BUILDING \#4 } \\
\text { Internal Shear } \\
\text { Wall } \\
\text { - Transverse } \\
\text { Direction }\end{array}$ & $\begin{array}{c}\text { BUILDING \#4 } \\
\text { External Shear } \\
\text { Wall } \\
\text { - Transverse } \\
\text { Direction }\end{array}$ & $\begin{array}{c}\text { BUILDING \#4 } \\
\text { External Shear } \\
\text { Wall } \\
- \text { Longitudinal } \\
\text { Direction }\end{array}$ \\
\hline ENHANCE & ENHANCE & ENHANCE & ENHANCE & NEUTRAL & NEUTRAL \\
\hline
\end{tabular}

The review of the buildings' key architectural and historic features prior to the seismic retrofit designs was unable to be undertaken. The analysis of this particular sub-category has been conducted giving the designers the benefit of the doubt. For example, the existing URM walls are assumed to be, prior to the seismic retrofit, plain and simply plastered. 
The external shear walls of Building \#4 are considered as having a neutral impact. This means that modification or removal of key architectural and historic features was kept to a minimum. Two reasons justify such a view. First, the shear walls are cast against a fraction of the transverse and longitudinal walls therefore preserving the major parts of the existing façades. Secondly, despite covering existing ornamental features, the latter are not lost but reinstalled on the outside of the shear walls.

The other shear walls systems are considered as positively complying with the minimum intervention principle. The reason comes from the shear walls being installed internally therefore avoiding any contact with the exterior surfaces of main façades carrying the key architectural or historic features. It is assumed that the existing URM walls, against which the retrofit structure is cast or shotcreted in Buildings \#1, \#2 and \#3, were not previously used for ornamental purposes. The installation of the new concrete shear walls over them does not therefore impact negatively on their final architectural value. This comment is also relevant to the two X-braced frames installed in Building \#4 as part of a previous seismic retrofit and replaced by shear walls. As the former structural elements added little value to the building's architecture their replacements had a minimal impact. Two additional facts further justify the positive review of the shear wall systems. The first is found in Buildings \#2 and \#4 and corresponds to the small dimensions of the interior shear walls compared to the size of the buildings. As a physically barely intrusive element, the shear wall has a negligible impact on the building. Secondly, relating to the location of the retrofit system, the two interior shear walls in Building \#4 are installed in the internal car-park which corresponds to a secondary space with limited architectural and historic value.

- 7.2: Compatibility with existing architectural character

\begin{tabular}{|c|c|c|c|c|c|c|}
\hline $\begin{array}{c}\text { BUILDING \#1 } \\
\text { Internal Shear } \\
\text { Wall } \\
\text { - Longitudinal } \\
\text { Direction }\end{array}$ & $\begin{array}{c}\text { BUILDING \#2 } \\
\text { Internal Shear } \\
\text { Wall } \\
\text { - Transverse } \\
\text { Direction }\end{array}$ & $\begin{array}{c}\text { BUILDING \#3 } \\
\text { Internal Shear } \\
\text { Wall } \\
\text { (Bar/restaurant) } \\
\text { - Longitudinal } \\
\text { Direction }\end{array}$ & $\begin{array}{c}\text { BUILDING \#3 } \\
\text { Internal Shear } \\
\text { Wall } \\
\text { - Transverse } \\
\text { Direction }\end{array}$ & $\begin{array}{c}\text { BUILDING \#4 } \\
\text { Internal Shear } \\
\text { Wall } \\
\text { - Transverse } \\
\text { Direction }\end{array}$ & $\begin{array}{c}\text { BUILDING \#4 } \\
\text { External Shear } \\
\text { Wall } \\
\text { - Transverse } \\
\text { Direction }\end{array}$ & $\begin{array}{c}\text { BUILDING \#4 } \\
\text { External Shear } \\
\text { Wall } \\
\text { - Longitudinal } \\
\text { Direction }\end{array}$ \\
\hline ENHANCE & NEUTRAL & ENHANCE & NEUTRAL & NEUTRAL & DETRACT & DETRACT \\
\hline
\end{tabular}

Neutral and enhanced compatibility with existing architectural character result from a common approach in the retrofit: the retrofit structure has no impact on the main existing architectural or historic layers and therefore preserves their integrity. In fact, the shear walls are located inside the buildings where there are little to no architectural features adding to the building's architectural character. The façades, from which the main architectural character emanates, remain untouched. The distinction between neutral and enhanced compatibility comes from the additional 
architectural character provided by certain shear walls. The raw exposed shear walls in Building \#1 and the single wall in the bar of Building \#3, bring a new architectural character that contrasts with the existing character expressed by the façades. A sense of surprise is created as interior and exterior architectures respond in contrast while not disturbing one another. Such a result is not achieved by the shear wall in Building \#2, those located in most spaces in Building \#3, and the internal walls in Building \#4. The main architectural character of each of those buildings remains unaffected by the presence of the retrofit shear walls.

The external shear walls installed over the façades of Building \#4 are not compatible with the existing architectural character. As already indicated, anchor plates are reinstalled over the shear walls therefore maintaining the existing visual pattern. However, the depth of the retrofit structure impacts on the continuous and linear aspect of the façades without providing a new pattern.

\section{- 7.3: Reversibility}

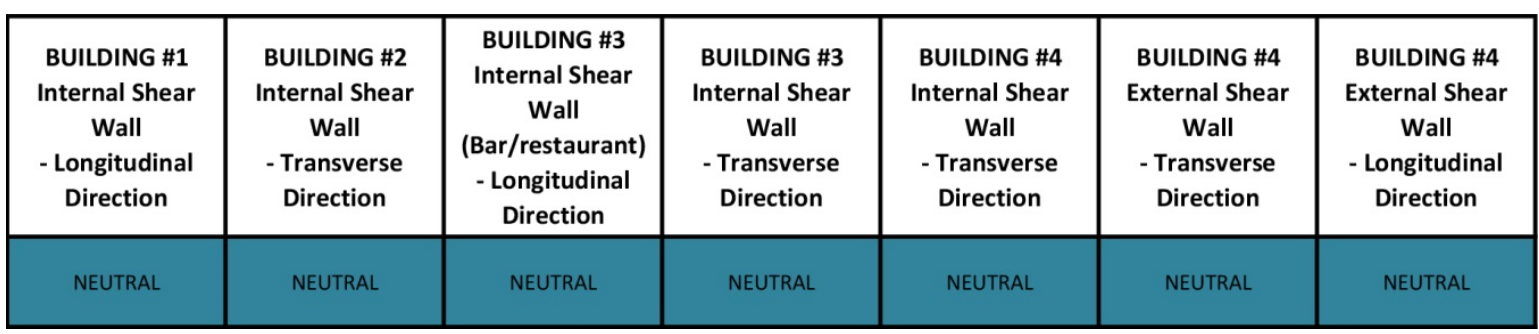

All the shear walls can be considered being removable without affecting key architectural and historic features. In Buildings \#1, \#2 and \#3, the existing interior URM walls against which the shear walls are cast or shotcreted were not used for aesthetic purposes prior to the seismic retrofit work. Although the removal of the shear walls would be damaging, due to the dowelled connections between both structures, the URM walls could be structurally repaired and the existing architectural character untouched. Depending on the size and location of the retrofit structure, its removal might however represent a massive undertaking.

The interior retrofit structure in Building \#4 can also be removed without much consequence on the building's architecture. First, the removal of the shear walls would be easier as they are installed perpendicular to the URM wall. Their physical connections are therefore minimal. Secondly, they are located in a secondary space which is a less sensitive location to work in.

The removal of the external walls of Building \#4 would be particularly difficult to execute due to the façades carrying the building's main architectural character. As the retrofit structure is dowelled into the existing walls, a series of steps including the filling of holes, cover of damaged areas, replaster, repaint of the façades, and finally reinstall existing anchor plates is possible but would 
require a considerable amount of time and particular care. If well undertaken, the visual impact of the removal could however be unnoticed and the existing architectural character preserved.

\section{○ Final comments}

This section presented an analysis of the integration of retrofit shear walls and the architecture of Buildings \#1, \#2, \#3, and \#4. It identified a range of reasons for the different impacts from shear walls. Two main observations can be noticed:

- integration of shear walls and most architectural qualities is neutral,

- integration of external shear walls introduces more negative effects than the integration of internal walls.

Sub-categories 2.1 and 3.1 are worth comparing as they both relate to the relationship between retrofit structure and existing elevations. The first relates to the external façades and the second one to the interior elevations. Where the integration of the external shear walls and the façade is identified as negative, the situation in the interior varies between neutral and enhanced. This difference could be explained by the greater ease of shear walls being incorporated within the building. First of all, shear walls can be located in secondary spaces which limit their impact on the building. Secondly, interior planning is often divided into several spaces therefore allowing new shear walls to be installed over smaller surfaces. These smaller interior spaces allow the retrofit structure to cover existing walls or be used as partition walls. Thirdly, when a shear wall forms a whole side of a space, it can easily be used as an architectural feature. The external location of shear walls is more problematic due to the importance of the façades. The design of the shear wall system is challenged by the large dimensions of façades compared to internal spaces, and by the architectural value they carry whether in terms of openings, ornamentation or rhythm. Two approaches can however allow achieving a neutral or even enhanced quality in terms of relationship between retrofit structure and façades. A design based on either full merging or clear distinction from the existing architectural layer has to be considered. In the first case, the physical replacement of a part of the façade by the new structure might be necessary. In this scenario, materials similar to the ones applied on the rest of the existing façades should be used to facilitate merging. If a distinction between existing and new is preferred or necessary, then the shear walls should at least follow the existing rhythm of the façade or create a new one even if it results in simple symmetry.

Another aspect to mention is the neutral effect of shear walls on the sub-categories 3.3 (Structure and space), 3.4 (Structure and function) and 3.5 (Structure and circulation) in all buildings. The main 
reason comes from the shear walls being commonly installed against existing walls. In replicating the geometry of the URM walls and preserving the interior layout, the retrofit structure maintains the spatial, functional and circulation qualities provided by the existing structure. For new shear walls to enhance these three specific qualities, it is necessary to install them independently from the existing structure.

Looking at sub-category 6.1 (Architectural concept), none of the existing buildings appear to possess what can be called an architectural concept. The closest equivalent to a concept is the overall architectural character embodied by some façades. The enhancement of this category could only be reached by introducing a new concept through the retrofit structure. Only one building achieved it. This concept involved contrasting the interior and exterior of the building - a contrast between the raw and industrial interior design of the retrofit solution and the refined and highly detailed baroque façade. Such an outcome results from the full interior refurbishment of the building which provides greater design opportunities. The raw surface of the shear walls is one of these opportunities. Such a use of the shear walls' materiality allows the retrofit structure to successfully integrate with the concept by contributing to the expression of its architectural message. This integration is reinforced by other structural and non-structural components further expressing the concept.

Regarding sub-categories 7.1 and 7.2, a distinction is noticeable between interior and exterior shear walls. In 7.1, the interior retrofit structure is identified as positive with respect to the minimum intervention where the exterior solution is neutral. The difference is mainly due to the front façades containing the buildings' architectural and historic value as often their interiors have been refurbished, strengthened or adapted to new uses. Sub-category 7.2 covers the compatibility of the retrofit structure with the existing architectural character. For reasons similar to those distinguishing sub-categories 2.1 and 3.1, interior shear walls are better integrated than exterior walls.

Sub-category 7.3 (Reversibility) is the only principle influenced in a similar way both internally and externally. The removal of the shear walls from the existing structures will inevitably require some repairs, but none would have a dramatic impact on the main architectural qualities. The principle of reversibility aims at having removable retrofit structures in order to allow future improved systems to be used. However, shear walls can be approached in a particular way regarding this principle. As most of them are installed over existing walls and with similar dimensions, they maintain the existing space planning. Their removal might therefore not be essential when installing future improved structures. 
Overall, a shear wall appears as a suitable system to integrate with several architectural qualities. Its exposed materiality, often raw and roughened, is used to successfully integrate with interior elevation (3.1), expressiveness (3.2), ornamentation (5.1), architectural concept (6.1), and architectural character (7.2). With qualities related more to physical virtues such as space (3.3), function (3.4), and circulation (3.5), a shear wall can be considered as neutral as it maintains the spatial organisation set by existing walls. Externally, the dimensions and locations of the shear walls combined with the difficulty of properly merging them with the existing façades resulted in poor integration with architectural qualities including elevation (2.1), natural light (4.1), outside views (4.2), and architectural character (7.2). 


\subsubsection{Braced Frame (Buildings \#3, \#4, \#5)}

Table 7. Tables of Analysis representing the influences of the braced frame system on each architectural quality of Buildings \#3, \#4 and \#5

\begin{tabular}{|c|c|c|c|c|c|c|c|}
\hline BUILDING \#3 & $\begin{array}{l}\text { CAT 1. HIDDEN } \\
\text { STRUCTURE }\end{array}$ & $\begin{array}{l}\text { CAT 2. EXPOSED } \\
\text { EXTERIOR STRUCTURE }\end{array}$ & $\begin{array}{l}\text { CAT 3. EXPOSED INTERIOR } \\
\text { STRUCTURE }\end{array}$ & $\begin{array}{l}\text { CAT 4. INTERACTION WITH } \\
\text { EXTERNAL OPENINGS }\end{array}$ & CAT 5. ORNAMENTATION & $\begin{array}{l}\text { CAT 6. EXPRESSION OF } \\
\text { AN ARCHITECTURAL } \\
\text { CONCEPT }\end{array}$ & $\begin{array}{l}\text { CAT 7. CONSERVATION } \\
\text { AND PRESERVATION } \\
\text { PRINCIPLES }\end{array}$ \\
\hline \multirow{5}{*}{$\begin{array}{c}\text { STEEL ECCENTRIC BRACED } \\
\text { FRAME - TRANSVERSE } \\
\text { DIRECTION }\end{array}$} & $\begin{array}{l}1.1 \text { ARCHITECTURAL } \\
\text { REASONS }\end{array}$ & 2.1. ELEVATION & 3.1. ELEVATION & 4.1 MODULATION OF LIGHT & $\begin{array}{l}5.1 \text { USE OF STRUCTURE FOR } \\
\text { ORNAMENTAL PURPOSES }\end{array}$ & $\begin{array}{l}\text { 6.1 EXISTING OR NEW } \\
\text { ARCHITECTURAL CONCEPT }\end{array}$ & $\begin{array}{l}7.1 \text { MINIMUM } \\
\text { INTERVENTION }\end{array}$ \\
\hline & $\begin{array}{l}1.2 \text { THE EFFECT OF THE } \\
\text { HIDING TECHNIQUE UPON } \\
\text { ARCHITECTURE }\end{array}$ & $\begin{array}{l}\text { 2.2 EXPRESSIVE ROLES OF } \\
\text { THE STRUCTURE }\end{array}$ & $\begin{array}{l}\text { 3.2 EXPRESSIVE ROLES OF } \\
\text { THE STRUCTURE }\end{array}$ & $\begin{array}{l}4.2 \text { OUTSIDE } \\
\text { VIEWS/SIGHTUNES }\end{array}$ & & & $\begin{array}{l}\text { 7.2 COMPATIBILTY WITH } \\
\text { EXISTING ARCHITECTURAL } \\
\text { CHARACTER }\end{array}$ \\
\hline & & & 3.3 STRUCTURE AND SPACE & & & & 7.3 REVERSIBILTTY \\
\hline & & & $\begin{array}{l}\text { 3.4 STRUCTURE AND } \\
\text { FUNCTION }\end{array}$ & & & & \\
\hline & & & $\begin{array}{l}\text { 3.5 STRUCTURE AND } \\
\text { CIRCULATION }\end{array}$ & & & & \\
\hline
\end{tabular}

\begin{tabular}{|c|c|c|c|c|c|c|c|}
\hline $\begin{array}{c}\text { BUILDING \#3 } \\
\text { BAR/RESTAURANT }\end{array}$ & $\begin{array}{l}\text { CAT 1. HIDDEN } \\
\text { STRUCTURE }\end{array}$ & $\begin{array}{l}\text { CAT 2. EXPOSED } \\
\text { EXTERIOR STRUCTURE }\end{array}$ & $\begin{array}{l}\text { CAT 3. EXPOSED INTERIOR } \\
\text { STRUCTURE }\end{array}$ & $\begin{array}{l}\text { CAT 4. INTERACTION WITH } \\
\text { EXTERNAL OPENINGS }\end{array}$ & CAT 5. ORNAMENTATION & $\begin{array}{l}\text { CAT 6. EXPRESSION OF } \\
\text { AN ARCHITECTURAL } \\
\text { CONCEPT }\end{array}$ & $\begin{array}{l}\text { CAT 7. CONSERVATION } \\
\text { AND PRESERVATION } \\
\text { PRINCIPLES }\end{array}$ \\
\hline \multirow{5}{*}{$\begin{array}{l}\text { STEEL ECCENTRIC BRACED } \\
\text { FRAME - TRANSVERSE } \\
\text { DIRECTION }\end{array}$} & $\begin{array}{l}1.1 \text { ARCHITECTURAL } \\
\text { REASONS }\end{array}$ & 2.1. ELEVATION & 3.1. ELEVATION & 4.1 MODULATION OF LIGHT & $\begin{array}{l}5.1 \text { USE OF STRUCTURE FOR } \\
\text { ORNAMENTAL PURPOSES }\end{array}$ & $\begin{array}{l}6.1 \text { EXISTING OR NEW } \\
\text { ARCHITECTURAL CONCEPT }\end{array}$ & $\begin{array}{l}7.1 \text { MINIMUM } \\
\text { INTERVENTION }\end{array}$ \\
\hline & $\begin{array}{l}\text { 1.2 THE EFFECT OF THE } \\
\text { HIDING TECHNIQUE UPON } \\
\text { ARCHITECTURE }\end{array}$ & $\begin{array}{l}\text { 2.2 EXPRESSIVE ROLES OF } \\
\text { THE STRUCTURE }\end{array}$ & $\begin{array}{l}\text { 3.2 EXPRESSIVE ROLES OF } \\
\text { THE STRUCTURE }\end{array}$ & \begin{tabular}{|l}
4.2 OUTSIDE \\
VIEWS/SIGHTLINES
\end{tabular} & & & $\begin{array}{l}\text { 7.2 COMPATIBILTY WITH } \\
\text { EXISTING ARCHITECTURAL } \\
\text { CHARACTER }\end{array}$ \\
\hline & & & 3.3 STRUCTURE AND SPACE & & & & 7.3 REVERSIBILITY \\
\hline & & & $\begin{array}{l}3.4 \text { STRUCTURE AND } \\
\text { FUNCTION }\end{array}$ & & & & \\
\hline & & & $\begin{array}{l}3.5 \text { STRUCTURE AND } \\
\text { CIRCULATION }\end{array}$ & & & & \\
\hline
\end{tabular}

\begin{tabular}{|c|c|c|c|c|c|c|c|}
\hline BUILDING \#4 & $\begin{array}{l}\text { CAT 1. HIDDEN } \\
\text { STRUCTURE }\end{array}$ & \begin{tabular}{|l} 
CAT 2. EXPOSED \\
EXTERIOR STRUCTURE
\end{tabular} & $\begin{array}{l}\text { CAT 3. EXPOSED INTERIOR } \\
\text { STRUCTURE }\end{array}$ & $\begin{array}{l}\text { CAT 4. INTERACTION WITH } \\
\text { EXTERNAL OPENINGS }\end{array}$ & CAT 5. ORNAMENTATION & $\begin{array}{l}\text { CAT 6. EXPRESSION OF } \\
\text { AN ARCHITECTURAL } \\
\text { CONCEPT }\end{array}$ & $\begin{array}{l}\text { CAT 7. CONSERVATION } \\
\text { AND PRESERVATION } \\
\text { PRINCIPLES }\end{array}$ \\
\hline \multirow{5}{*}{$\begin{array}{l}\text { STEEL X BRACED FRAME - } \\
\text { TRANSVERSE DIRECTION }\end{array}$} & $\begin{array}{l}\text { 1.1 ARCHITECTURAL } \\
\text { REASONS }\end{array}$ & 2.1. ELEVATION & 3.1. ELEVATION & 4.1 MODULATION OF LIGHT & $\begin{array}{l}\text { 5.1 USE OF STRUCTURE FOR } \\
\text { ORNAMENTAL PURPOSES }\end{array}$ & $\begin{array}{l}6.1 \text { EXISTING OR NEW } \\
\text { ARCHITECTURAL CONCEPT }\end{array}$ & $\begin{array}{l}7.1 \text { MINIMUM } \\
\text { INTERVENTION }\end{array}$ \\
\hline & $\begin{array}{l}1.2 \text { THE EFFECT OF THE } \\
\text { HIDING TECHNIQUE UPON } \\
\text { ARCHITECTURE }\end{array}$ & $\begin{array}{l}\text { 2.2. EXPRESSIVE ROLES OF } \\
\text { THE STRUCTURE }\end{array}$ & $\begin{array}{l}\text { 3.2 EXPRESSIVE ROLES OF } \\
\text { THE STRUCTURE }\end{array}$ & $\begin{array}{l}4.2 \text { OUTSIDE } \\
\text { VIEWS/SIGHTUNES }\end{array}$ & & & $\begin{array}{l}7.2 \text { COMPATIBILTYY WITH } \\
\text { EXISTING ARCHITECTURAL } \\
\text { CHARACTER }\end{array}$ \\
\hline & & & 3.3 STRUCTURE AND SPACE & & & & 7.3 REVERSIBILTTY \\
\hline & & & $\begin{array}{l}3.4 \text { STRUCTURE AND } \\
\text { FUNCTION }\end{array}$ & & & & \\
\hline & & & $\begin{array}{l}3.5 \text { STRUCTURE AND } \\
\text { CIRCULATION }\end{array}$ & & & & \\
\hline
\end{tabular}

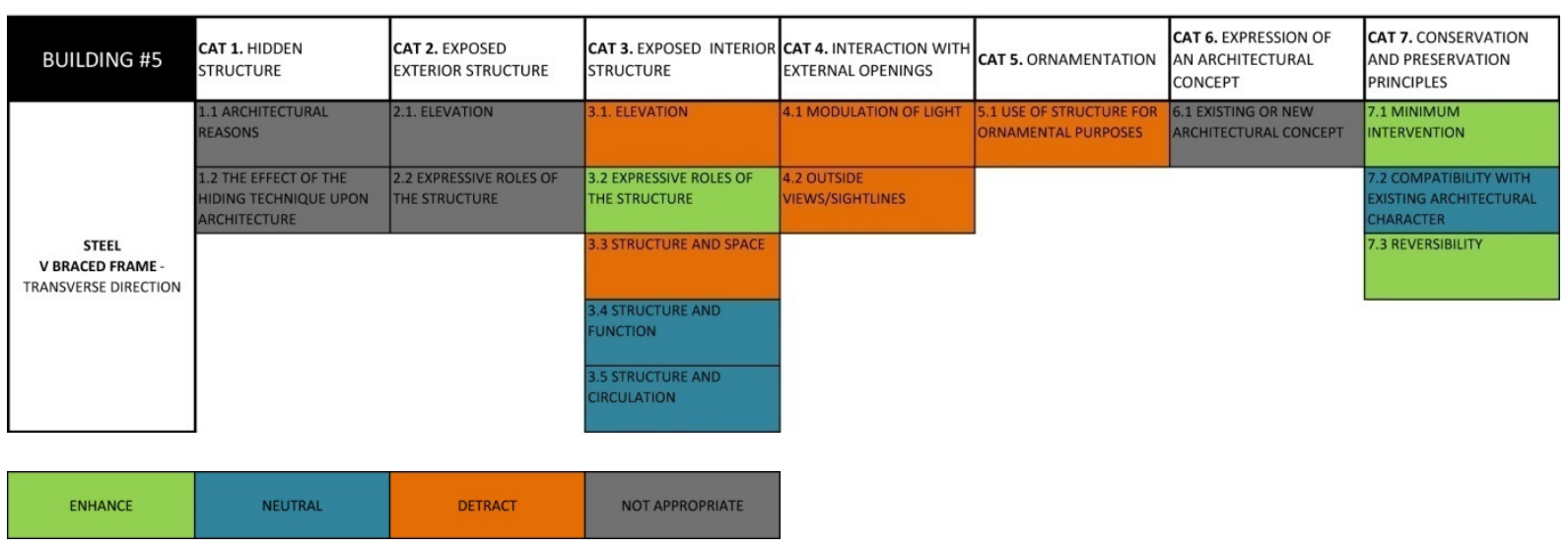




\section{○ Category 1 - Hidden structure}

\section{- 1.1: Architectural reasons}

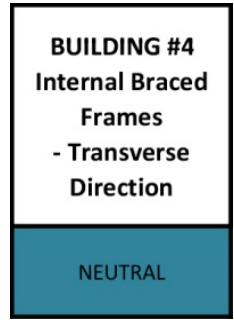

Building \#4 possesses two X-braced frames hidden behind white plasterboard linings (Figure 66). They replace previous X-braced frames from former seismic strengthening which were already hidden in an identical way and with similar materials. As no changes are noticeable, whether visually or in terms of location, the existing functional and aesthetic qualities of the spaces in which the retrofit structure is installed remain identical.

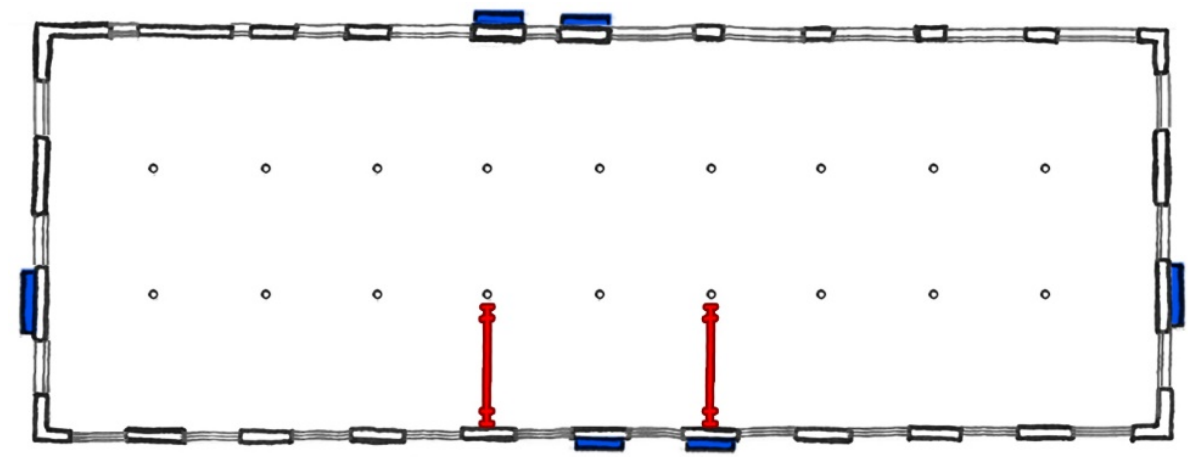

Figure 66. Second-floor plan of Building \#4 with two braced frames (red)

\section{- 1.2: The effect of the hiding technique upon architecture}

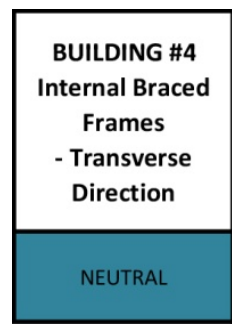

In Building \#4, the screening technique hiding the braced frames structure remains identical before and after the seismic retrofit. It does not contribute to any new architectural quality.

\section{○ Category 2 - Exposed exterior structure}

N/A: all the braced frames are installed inside the buildings. 


\section{○ Category 3 - Exposed interior structure}

\section{- 3.1: Elevation}

\begin{tabular}{|c|c|c|}
\hline $\begin{array}{c}\text { BUILDING \#3 } \\
\text { Internal Braced } \\
\text { Frame } \\
\text { (Bar/restaurant) } \\
\text { - Longitudinal } \\
\text { Direction }\end{array}$ & $\begin{array}{c}\text { BUILDING \#3 } \\
\text { Internal Braced } \\
\text { Frames } \\
\text { - Transverse } \\
\text { Direction }\end{array}$ & $\begin{array}{c}\text { BUILDING \#5 } \\
\text { Internal Braced } \\
\text { Frame } \\
\text { - Longitudinal } \\
\text { Direction }\end{array}$ \\
\hline ENHANCE & DETRACT & DETRACT \\
\hline
\end{tabular}

Three aspects justify the enhancement of the interior elevation by the braced frame in the bar of Building \#3. First, the eccentric braced frame is placed against an existing linear wall over most of its length. It creates a new pattern over the plain surface of the partition wall. Secondly, the pattern is reinforced by the contrast between the white paint of the braced frame and the dark brown colour of the wall. Thirdly, the structure's materiality and its explicit expression reinforces a raw and industrial architectural character initiated by the exposed shotcrete shear wall.

The braced frames in the rest of the spaces in Building \#3 and in Building \#5 disrupt the interior elevations. In Building \#3, the retrofit structures are installed in front of existing URM walls roughly divided by new perpendicular partition walls. As a result, half of a braced frame is located in one space and another half in another space. Each part appears as a residual component, an intruder to the interior elevation in front of which they are installed. In addition, every single eccentric braced frame is located right in front of windows (Figure 67). As a consequence, the particular geometry of the retrofit structure clashes with the rectangular form of the openings.

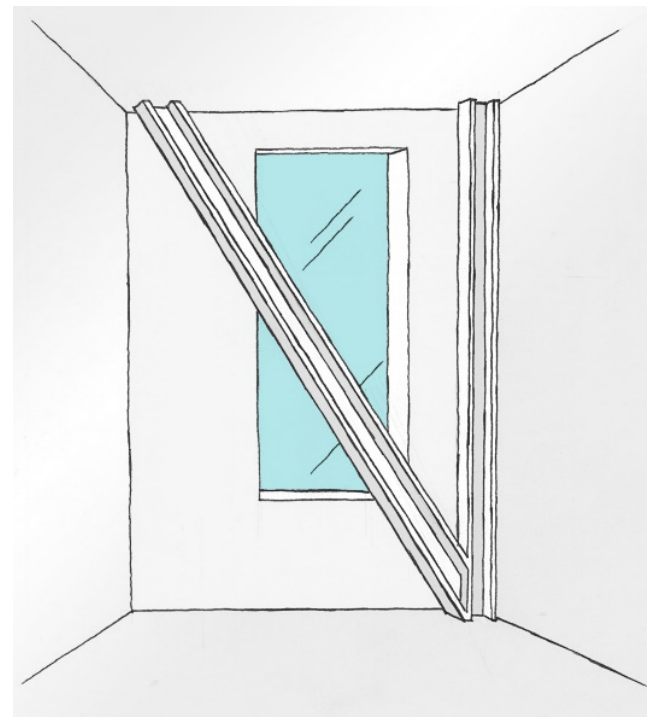

Figure 67. Half of an eccentric braced frame located in a bedroom in Building \#3 
Building \#5 possesses a single two-bay V-braced frame installed in front of a long glazed wall at the bottom of the rear façade (Figure 68). The glazed wall displays a pattern thanks to the combination of its long and wide windows at the bottom and a series of thinner ones above. However, the presence and geometry of the V-braced frame in front of the glazed wall lead to a visual superposition of two distinct patterns. The result is a confusing elevation.

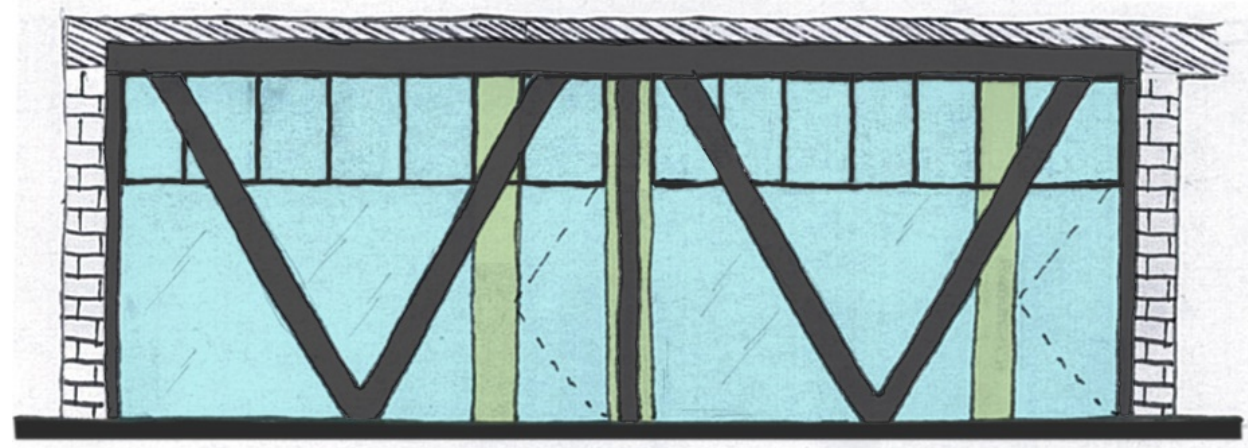

Figure 68. Elevation of the V-braced frame creating a new motif in front of the existing pattern of the glazed wall in Building

\#5

\section{- 3.2: Expressive roles of the structure}

\begin{tabular}{|c|c|c|}
\hline $\begin{array}{c}\text { BUILDING \#3 } \\
\text { Internal Braced } \\
\text { Frame } \\
\text { (Bar/restaurant) } \\
\text { - Longitudinal } \\
\text { Direction }\end{array}$ & $\begin{array}{c}\text { BUILDING \#3 } \\
\text { Internal Braced } \\
\text { Frames } \\
\text { - Transverse } \\
\text { Direction }\end{array}$ & $\begin{array}{l}\text { BUILDING \#5 } \\
\text { Internal Braced } \\
\text { Frame } \\
\text { - Longitudinal } \\
\text { Direction }\end{array}$ \\
\hline ENHANCE & DETRACT & ENHANCE \\
\hline
\end{tabular}

The braced frame is positively expressed in two occasions and through two different approaches. In the bar of Building \#3, the retrofit structure frames a door (Figure 69). The eccentric brace and the door are perfectly aligned. This creates an axial symmetry reinforcing the expressiveness of the retrofit structure and accentuating the presence of the passage in between. In addition, both the retrofit structure and the door are painted white which creates a visual connection between them. This connection is enhanced by the contrast with the dark coloured wall in which the door is located. 


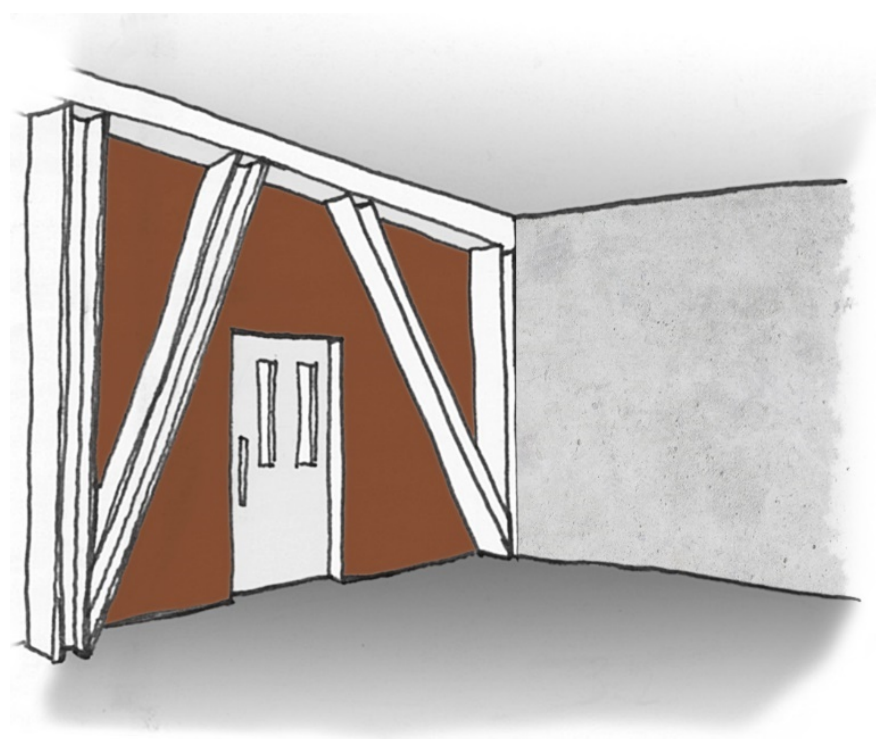

Figure 69. Eccentric braced frame emphasising the passage by framing the door

In Building \#5, the V-braced frame expresses its raw steel materiality and construction technique along its entire length. No interventions are made to soften any reading of the structure. Instead, its detailing ensures that it is clearly identifiable. Such expression refers to previous seismic strengthening work undertaken in the building decades earlier using a series of raw steel moment frames. With the same treatment between the previous and new retrofit structures, visual continuity is ensured between the different spaces at the ground floor. The construction technique is also emphasised by a series of bolts connecting the V-braced frame to the existing beams and columns. The bolts have a raw treatment but possess a light grey colour which contrasts with the irregular dark brown colour of the main structure.

In most spaces in Building \#3, the eccentric braced frames are painted the same colours as the walls they are installed in front of. The aim is to visually merge them to lessen their presence. However, their presence is actually emphasised by their unique geometry and location, always in front of and partially masking windows with natural light highlighting their silhouettes. Consequently, their undeniable presence weakens the plain and simple design of the interior spaces in which they are installed. These aspects are further emphasised by the raw junctions of the retrofit structure with partition walls. They display a lack of cohesion between the structural and non-structural elements. 


\section{- 3.3: Structure and space}

\begin{tabular}{|c|c|c|}
\hline $\begin{array}{c}\text { BUILDING \#3 } \\
\text { Internal Braced } \\
\begin{array}{c}\text { Frame } \\
\text { (Bar/restaurant) } \\
\text { - Longitudinal } \\
\text { Direction }\end{array}\end{array}$ & $\begin{array}{c}\text { BUILDING \#3 } \\
\text { Internal Braced } \\
\text { Frames } \\
\text { - Transverse } \\
\text { Direction }\end{array}$ & $\begin{array}{c}\text { BUILDING \#5 } \\
\text { Internal Braced } \\
\text { Frame } \\
\text { - Longitudinal } \\
\text { Direction }\end{array}$ \\
\hline NEUTRAL & DETRACT & DETRACT \\
\hline
\end{tabular}

In the bar of Building \#3, the retrofit structure remains neutral regarding interior spatial qualities. It is installed against an existing transverse wall which already delineates one of the four sides of the space. The braced frame appears as a feature of the wall but does not strengthen the sense of boundary. The retrofit structure does not contribute to a greater openness or enclosure of the space.

The eccentric braced frames located in front of windows in Building \#3 create a new physical layer, partially reducing the entry of light and accentuating the enclosure of the spaces. The spaces therefore appear smaller without justification from any apparent desire for architectural character or concept.

In Building \#5, the large space in which the V-braced frame is located possesses three opaque sides and the fourth one glazed (Figure 70). Such a configuration orientates views towards the outdoors. The spatial separation between the outside and the inside is reduced thanks to the fully glazed wall. This spatial quality is weakened by the installation of the braced frame in front of the glazed wall as, in combination with the existing window frames, it creates a superposition of layers which visually encloses the space.

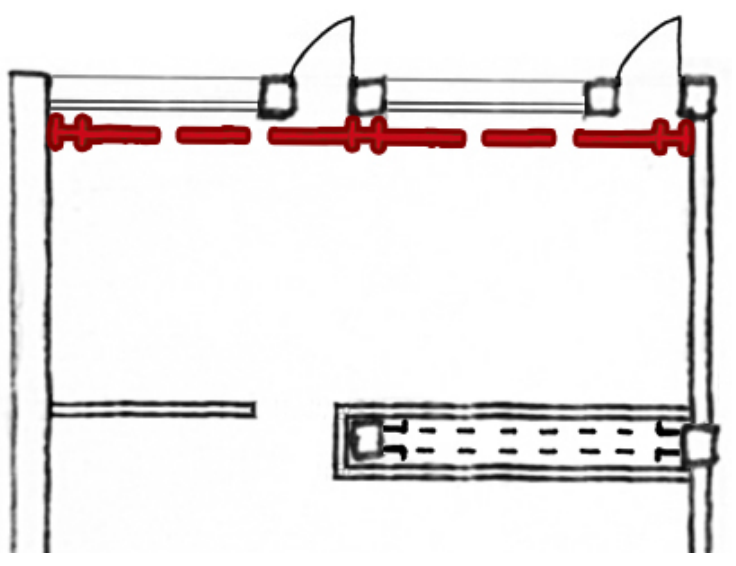

Figure 70. Extract of the ground floor plan of Building \#5 with the $V$-braced frame (red) reinforcing the enclosure of the interior space 
- 3.4: Structure and function

\begin{tabular}{|c|c|c|}
\hline $\begin{array}{c}\text { BUILDING \#3 } \\
\text { Internal Braced } \\
\text { Frame } \\
\text { (Bar/restaurant) } \\
\text { - Longitudinal } \\
\text { Direction }\end{array}$ & $\begin{array}{c}\text { BUILDING \#3 } \\
\text { Internal Braced } \\
\text { Frames } \\
\text { - Transverse } \\
\text { Direction }\end{array}$ & $\begin{array}{l}\text { BUILDING \#5 } \\
\text { Internal Braced } \\
\text { Frame } \\
\text { - Longitudinal } \\
\text { Direction }\end{array}$ \\
\hline NEUTRAL & DETRACT & NEUTRAL \\
\hline
\end{tabular}

In the bar of Building \#3 and in Building \#5, the distance between the braced frames and the perimeter walls is kept to a minimum. In the first building, the retrofit structure touches the existing wall, therefore limiting loss of space. In the second building, the V-braced frame is directly bolted to the existing columns dividing the glazed wall. In both cases, the location of the braced frames against the existing structures and the large dimensions of the spaces lessen the impact on the internal planning and functionality.

In the rest of the spaces in Building \#3, the retrofit structure is installed $100 \mathrm{~mm}$ in front of the perimeter walls (Figure 67 and Figure 71). If such distance is negligible in the rare medium-sized spaces, the impact the retrofit structure's footprint in the numerous smaller spaces is more critical. As most of these spaces are used as bedrooms, the presence of such prominent structure in such small areas highly impacts their usability and flexibility. The interior arrangement of the spaces is thus greatly dependant on the retrofit structure. In addition, as the retrofit structure is located in front of windows, access to them and therefore their use is restricted.

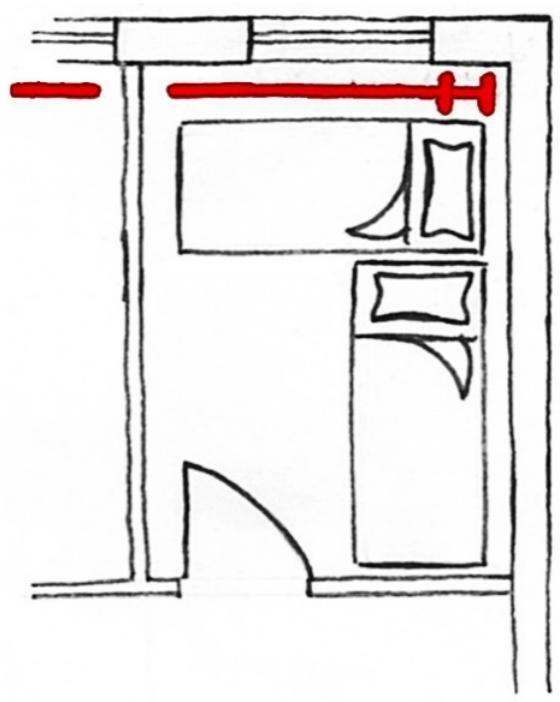

Figure 71. Extract of the first-floor plan of Building \#3 with half of an eccentric braced frame located in a bedroom in Building \#3 
- 3.5: Structure and circulation

\begin{tabular}{|c|c|c|}
\hline $\begin{array}{c}\text { BUILDING \#3 } \\
\text { Internal Braced } \\
\text { Frame } \\
\text { (Bar/restaurant) } \\
\text { - Longitudinal } \\
\text { Direction }\end{array}$ & $\begin{array}{c}\text { BUILDING \#3 } \\
\text { Internal Braced } \\
\text { Frames } \\
\text { - Transverse } \\
\text { Direction }\end{array}$ & $\begin{array}{l}\text { BUILDING \#5 } \\
\text { Internal Braced } \\
\text { Frame } \\
\text { - Longitudinal } \\
\text { Direction }\end{array}$ \\
\hline ENHANCE & DETRACT & NEUTRAL \\
\hline
\end{tabular}

All the braced frames in Buildings \#3 and \#5 are located inside usable spaces therefore they do not impact on any circulation areas. Yet their consequences on circulation in usable areas vary greatly.

In Building \#5, the V-braced frame is installed right in front of the glazed wall all along its length. Thanks to the large dimensions of the space and very close location of the retrofit structure to the glazed wall, the impact of the structural footprint is limited as much as possible and has barely any consequence on interior circulation. In addition, each of the bays of the braced frame surrounds an existing door located between diagonal and vertical members. The dimensions of the structure and the distance between the structural members are large enough to avoid any impact on the passages.

The eccentric braced frame in the bar of Building \#3 is installed against a perimeter wall and has a limited impact due to the large dimensions of the space. In addition, a door is positioned in between the diagonal members of the retrofit structure. However, unlike the doors in Building \#5 located in residual triangular penetrations on one side of each bay, the door in Building \#3 is perfectly aligned with the centre of the braced frame. The way the eccentric braced frames the door enhances the expressiveness of the retrofit structure while stressing the presence of the opening. As a result, the presence of the braced frame highlights and suggests circulation in between two spaces (Figure 69).

The other eccentric braced frames in Building \#3 partially restrict circulation inside the bedrooms due to the size and placement of the retrofit structures with respect to the walls (Figure 71).

\section{○ Category 4 - Interaction with external openings}

\section{- 4.1: Modulation of light}

\begin{tabular}{|c|c|c|c|}
\hline $\begin{array}{c}\text { BUILDING \#3 } \\
\text { Internal Braced } \\
\text { Frame } \\
\text { (Bar/restaurant) } \\
\text { - Longitudinal } \\
\text { Direction }\end{array}$ & $\begin{array}{c}\text { BUILDING \#3 } \\
\text { Internal Braced } \\
\text { Frames } \\
\text { - Transverse } \\
\text { Direction }\end{array}$ & $\begin{array}{c}\text { BUILDING \#4 } \\
\text { Internal Braced } \\
\text { Frames } \\
\text { - Transverse } \\
\text { Direction }\end{array}$ & $\begin{array}{l}\text { BUILDING \#5 } \\
\text { Internal Braced } \\
\text { Frame } \\
\text { - Longitudinal } \\
\text { Direction }\end{array}$ \\
\hline NEUTRAL & DETRACT & NEUTRAL & DETRACT \\
\hline
\end{tabular}


In the bar of Building \#3 and in Building \#4, the retrofit structure has no effect on natural light entering from existing openings. In the first building, the exposed eccentric braced frame is installed deep inside the building, far from the windows located on the opposite side of the space. In the second building, the retrofit structure is hidden behind plasterboard with identical materiality, location and dimensions to the existing ones it has replaced.

The braced frames in the rest of the spaces in Building \#3 and in Building \#5 are installed towards the rear façades, in front of existing openings. Their diagonal members cross various openings, therefore reducing the entry of natural light into the buildings' interiors. As a consequence, the spaces are darker.

- 4.2: Outside views/sightlines

\begin{tabular}{|c|c|c|c|}
\hline $\begin{array}{c}\text { BUILDING \#3 } \\
\text { Internal Braced } \\
\text { Frame } \\
\text { (Bar/restaurant) } \\
\text { - Longitudinal } \\
\text { Direction }\end{array}$ & $\begin{array}{c}\text { BUILDING \#3 } \\
\text { Internal Braced } \\
\text { Frames } \\
\text { - Transverse } \\
\text { Direction }\end{array}$ & $\begin{array}{c}\text { BUILDING \#4 } \\
\text { Internal Braced } \\
\text { Frames } \\
\text { - Transverse } \\
\text { Direction }\end{array}$ & $\begin{array}{l}\text { BUILDING \#5 } \\
\text { Internal Braced } \\
\text { Frame } \\
\text { - Longitudinal } \\
\text { Direction }\end{array}$ \\
\hline NEUTH & DETRACT & NEUTRAL & DETRACT \\
\hline
\end{tabular}

For reasons similar to those mentioned above, the braced fames in the bar of Building \#3 and in Building \#4 have a neutral effect on the views outside. In the first building, the retrofit structure is installed against an existing wall with no external openings. In the second building, the braced frames remain hidden and have no impact on views.

In most spaces in Buildings \#3 and \#5, retrofit structures are installed in front of existing openings with their diagonal members partially reducing the views. Similar to the impact on natural light, the dimensions of the retrofit structural members have a negative impact that varies from moderate to critical.

\section{○ Category 5 - Ornamentation}

\section{- 5.1: Use of structure for ornamental purposes}

\begin{tabular}{|c|c|c|c|}
\hline $\begin{array}{c}\text { BUILDING \#3 } \\
\text { Internal Braced } \\
\text { Frame } \\
\text { (Bar/restaurant) } \\
\text { - Longitudinal } \\
\text { Direction }\end{array}$ & $\begin{array}{c}\text { BUILDING \#3 } \\
\text { Internal Braced } \\
\text { Frames } \\
\text { - Transverse } \\
\text { Direction }\end{array}$ & $\begin{array}{c}\text { BUILDING \#4 } \\
\text { Internal Braced } \\
\text { Frames } \\
\text { - Transverse } \\
\text { Direction }\end{array}$ & $\begin{array}{l}\text { BUILDING \#5 } \\
\text { Internal Braced } \\
\text { Frame } \\
\text { - Longitudinal } \\
\text { Direction }\end{array}$ \\
\hline ENHANCE & NEUTRAL & NEUTRAL & DETRACT \\
\hline
\end{tabular}


In Building \#3, none of the braced frames are considered as ornament because of their rough division by partition walls. The frames appear as residues in each of the spaces. Also, despite their unusual presence in each room and their partial masking of existing windows, creating a clash between new and existing architectural layers, there is no existing ornament for them to affect. However, the retrofit structure in the bar of Building \#3 can be classified as ornament for the reasons previously presented in sub-categories 3.1 and 3.2. In Building \#4 the new plasterboard is strictly identical to that which has been replaced i.e. opaque and white, so no decorative features are displayed.

Like the retrofit structure in the bar of Building \#3, the V-braced in Building \#5 frame can also be considered as ornament (Figure 68). Its raw materiality is fully exposed along the entire length of one side of the space and the frame distinguishes itself from the smoothly plastered walls. It expresses its technical vocabulary and generates a pattern with two symmetrical bays. But, as indicated in sub-category 3.1, the wall behind the retrofit structure is fully glazed. Its combination of long and wide windows at the bottom with thin vertical openings along the top creates a simple yet elegant pattern. However, although the existing wall and the retrofit structure both possess ornamental qualities, the superposition of their two divergent patterns confuses their respective readings and weakens any aesthetic quality their combination could bring to the space.

\section{○ Category 6 - Expression of an architectural concept}

\section{- 6.1: Reinforcement of an existing architectural concept or development of a new one}

There is no obvious existing concept to be identified in any of the buildings. Instead, existing architectural character can be noticed. For each of the three buildings, this corresponds to the front façade which thanks to its characteristics in terms of location, shape and detailing defines in a unique way the building's image. The approach to engage with this current sub-category would be for the retrofit structure of each building to participate in the expression of a new architectural concept. However, none of them succeeds.

The interior hidden braced frames in Building \#4 maintain the characteristics of the spaces prior to the seismic retrofit. In doing so, they do not develop a new concept.

Building \#5 possesses three distinct architectural characters the building which have no relationship to each other. The first architectural character corresponds to front façade with its four curved and ornamented bays divided by extended and ornamented columns. The second one corresponds to 
the refurbished ground floor with dark painted spaces and dim lights, and the third is found at the first floor, with a large open space defined by a series of exposed portal frames supporting the roof. This combination of distinctive architectural characters inhibits the expression of a common architectural message.

The lack of architectural concept in Building \#3 is already explained in sub-category 6.1 of the shear wall section.

\section{$\circ$ Category 7 - Conservation and preservation principles}

\section{- 7.1: Minimum intervention}

\begin{tabular}{|c|c|c|c|}
\hline $\begin{array}{c}\text { BUILDING \#3 } \\
\text { Internal Braced } \\
\text { Frame } \\
\text { (Bar/restaurant) } \\
\text { - Longitudinal } \\
\text { Direction }\end{array}$ & $\begin{array}{c}\text { BUILDING \#3 } \\
\text { Internal Braced } \\
\text { Frames } \\
\text { - Transverse } \\
\text { Direction }\end{array}$ & $\begin{array}{c}\text { BUILDING \#4 } \\
\text { Internal Braced } \\
\text { Frames } \\
\text { - Transverse } \\
\text { Direction }\end{array}$ & $\begin{array}{c}\text { BUILDING \#5 } \\
\text { Internal Braced } \\
\text { Frame } \\
\text { - Longitudinal } \\
\text { Direction }\end{array}$ \\
\hline ENHANCE & ENHANCE & ENHANCE & ENHANCE \\
\hline
\end{tabular}

The installation of braced frames in Buildings \#3, \#4 and \#5 positively contribute to the minimum intervention principle. Two reasons are as follows. The first results from the braced frames being located internally with no affect on the key architectural or historic features of their respective façades. This aspect is further evident in Buildings \#3 and \#5, where retrofit structure is installed near but not on the rear façade which possesses some but less architectural and historic value than the front façade. The second reason is that the braced frames have a very limited physical impact on the existing structures. They do not replace or damage the walls in front of which they are installed. The only exception is the retrofit structure in Building \#4 which takes over two former Xbraced frames. However, as the new braced frames are identical to the former frames with slightly bigger dimensions and are hidden in a similar way with identical materials, the intervention is identified as positive from the perspective of minimum intervention.

\section{- 7.2: Compatibility with existing architectural character}

\begin{tabular}{|c|c|c|c|}
\hline $\begin{array}{c}\text { BUILDING \#3 } \\
\text { Internal Braced } \\
\text { Frame } \\
\text { (Bar/restaurant) } \\
\text { - Longitudinal } \\
\text { Direction }\end{array}$ & $\begin{array}{c}\text { BUILDING \#3 } \\
\text { Internal Braced } \\
\text { Frames } \\
\text { - Transverse } \\
\text { Direction }\end{array}$ & $\begin{array}{l}\text { BUILDING \#4 } \\
\text { Internal Braced } \\
\text { Frames } \\
\text { - Transverse } \\
\text { Direction }\end{array}$ & $\begin{array}{l}\text { BUILDING \#5 } \\
\text { Internal Braced } \\
\text { Frame } \\
\text { - Longitudinal } \\
\text { Direction }\end{array}$ \\
\hline ENHANCE & NEUTRAL & NEUTRAL & NEUTRAL \\
\hline
\end{tabular}


The braced frames in most spaces in Building \#3, as well as in Buildings \#4 and \#5 have a neutral effect on their respective existing architectural characters. The principal and common reason is due to the interior location of their retrofit structures which avoid any impact on the main existing architectural and historic features of their front façades. Looking now at each building's interior, additional reasons further explain the neutral affect of retrofit structure.

In Building \#3, the building's interior refurbishment, with the exception of the bar, consists of plain and simple surfaces with no expressive features. Such a bland treatment does not define new interior architectural character. As a result, and although they negatively affect several architectural qualities, the eccentric braced frames have no architectural character to impact on.

In Building \#4, the retrofit structure replaces two braced frames on two floors. Its slightly larger dimensions and the use of plasterboard identical to the existing ensure no visual difference to the existing interior spaces.

Building \#5 possesses a refurbished ground floor which introduces a new architectural character. It is defined by smoothly plastered URM walls, spaces entirely painted black, minimalist decoration, and dim lights. As a result, the boundaries of the spaces are hardly noticeable. The ground floor also displays a series of steel portal frames from previous seismic retrofit. These structural elements are installed inside the bays of existing frames. Their detailing, combined with their raw materiality, classifies them as structural ornament. Their presence stresses the building's existing structural flaws and the additional work needed to strengthen this weakness. Now, although it possesses a different geometry, the new V-braced frame is very similar to the previous retrofit moment frames. They both expose their steel materiality with identical raw textures and possess exactly the same bolted connections - which result from the replacement of the previous bolts by new and stronger ones. The V-braced frame is considered as being neutral as, despite its contribution to the interior architectural character of the ground floor, does not provide any new architectural layer. Instead it is read as being part of the previous seismic work and therefore does not express the evolution of the building's seismic retrofit history.

The bar of Building \#3 conveys a new raw and industrial architectural character through its refurbishment in contrast with the refined character expressed by the front façade. The eccentric braced frame expresses such interior architectural character thanks to its location, exposure, materiality and geometry. As a result, the interior space gains a new architectural layer that engages with the existing exterior one in a game of contrast. 
- 7.3: Reversibility

\begin{tabular}{|c|c|c|c|}
\hline $\begin{array}{c}\text { BUILDING \#3 } \\
\text { Internal Braced } \\
\begin{array}{c}\text { Frame } \\
\text { (Bar/restaurant) } \\
\text { - Longitudinal } \\
\text { Direction }\end{array}\end{array}$ & $\begin{array}{c}\text { BUILDING \#3 } \\
\text { Internal Braced } \\
\text { Frames } \\
\text { - Transverse } \\
\text { Direction }\end{array}$ & $\begin{array}{c}\text { BUILDING \#4 } \\
\text { Internal Braced } \\
\text { Frames } \\
\text { - Transverse } \\
\text { Direction }\end{array}$ & $\begin{array}{c}\text { BUILDING \#5 } \\
\text { Internal Braced } \\
\text { Frame } \\
\text { - Longitudinal } \\
\text { Direction }\end{array}$ \\
\hline NEUTRAL & NEUTRAL & NEUTRAL & ENHANCE \\
\hline
\end{tabular}

In Buildings \#3, \#4 and \#5, the removal of the braced frames can be undertaken without damaging any key architectural and historic features. However, each braced frame is quite distinctive from the others and only one is particularly easily removable.

The removal of the hidden braced frames in Building \#4 would necessitate the destruction of the plasterboard linings, as well as the removal of the bolted and welded connections to the existing structural components such as I-beams and SHS steel columns. Such work would not impact on any architectural quality as the plasterboard can be replaced by identical material.

In Building \#3, several more significant measures would be required. First, all the braced frames have one of their vertical members dowelled into the existing walls at ground floor level. Their removal would damage the walls but this can be repaired and re-plastered. Secondly, the retrofit structure also possesses bolted connections. The first connections of parallel flange channels to each floor require some work around the diaphragms in order to be removed. The second connections are hidden under a concrete slab at the ground floor. Drilling will be necessary to reach them. The damage to the slab can then be repaired with not much difficulty. Thirdly, most braced frames are roughly divided by partition walls. Each of the partition walls will need to be demolished in order to remove the retrofit structure, and then be replaced. To summarise, although the removal of the braced frames is not difficult and would not irremediably damage the building's architecture, a considerable amount of work in many spaces is required.

The V-braced frame in Building \#5 is particularly easy to remove. The retrofit structure is only installed at the ground floor, unlike that in the other buildings where it is located on several floors. Also, all the bolted connections to the existing columns and beams are exposed and easily accessible. The only challenge would be drilling at the feet of the structure to reach the hidden bolted connections. 


\section{$\circ$ Final comments}

This section focused on the integration of retrofit braced frames and architectural qualities of Buildings \#3, \#4, and \#5. The overall comparison of the Tables of Analysis indicates that:

- most braced frames have a neutral integration with architectural qualities compared to the number of enhanced and negative effects which are almost identical,

- hidden braced frames are almost exclusively considered as neutral unlike the exposed frames which integration with architectural qualities is more variable.

Building \#4 is the only building possessing a hidden retrofit structure which is considered as having a neutral integration with most architectural qualities. Although hiding the retrofit structure visually limits its presence, the neutral effect actually results from several other factors. They correspond to the replacement of the previous structural elements by the new retrofit structure at the same location, comparable dimensions, similar materiality, and identical concealed technique. All these factors preserve the existing architectural qualities and avoid any enhanced effect. For a retrofit structure to contribute to architectural qualities, it does not necessarily need to be exposed, but at least one of the above listed factors needs to be distinct from the characteristics of the replaced structure.

Regarding exposed retrofit structure, the unique and distinctive geometry of a braced frame makes it stand out within a building. This immediate distinction from other structural and non-structural elements is double-edged. On one hand, this unmistakable presence can be used as an advantage to highlight architectural features or qualities. On the other hand, any negative impact on architectural quality is more easily noticeable.

One advantage is the inherent capacity of the structure to engage with an interior elevation and to contribute to ornamental qualities. When fully exposed the retrofit structure generates a pattern which can be more or less developed depending on the number of aligned bays. This capacity needs to be carefully considered in order to neither contradict any existing ornamental feature nor negatively impact on other architectural qualities. As an example, while an X-braced frame may generate a relevant ornamental pattern to a building it would restrain circulation if installed in front of a door. In contrast, an eccentric braced frame would be more suitable for circulation purposes, and if aligned with an opening could even be used for expressive purposes. The large variety of braced frames with their unique geometries implies some predisposition regarding their integration with specific architectural qualities that designers should consider. 
The Tables of Analysis for most spaces of Buildings \#3 and \#5 reveal an almost completely opposite integration outcome from the braced frames. The analysis stresses that the location of braced frames in front of windows has a larger negative impact than solely restricting entry of natural light and views toward the outside. Categories 3 and 5 (Exposed interior structure and Ornamentation) are similarly affected. The reason comes from the external openings being actually related to many architectural qualities. First, a window possesses its own form which may contribute to the aesthetic of the elevation as well as generating an ornamental pattern thanks to the design of its frame or by its combination with other windows. Secondly, its dimensions participate in the interior identity of a space by contributing to its openness or its closeness. Finally, the light passing through a window may influence the perception of a retrofit structure, making it more or less noticeable. Braced frames in front of windows are therefore prejudicial to several architectural qualities dependent on external openings such as modulation of light, outside views, elevation, structure expressiveness, space, and ornamentation.

The dimensions of a space can also have a significant impact on the integration of a braced frame with architectural qualities. Sub-categories 3.4 and 3.5 (Function and Circulation) are highly dependent on the proportion of the space absorbed by the structural footprint, the geometry and dimensions of the braced frame. These three aspects are less relevant in large dimensioned spaces as in the bar of Building \#3 and in Building \#5. In comparison, most small spaces in Building \#3 suffer from the physical presence of retrofit structure as it reduces their usability.

Category 7 (Conservation and preservation approach) is equally neutrally and positively present. In sub-category 7.1 (Minimum intervention), all the braced frames are located internally. Such location ensures the preservation of the front façades which, for most of them, possess heritage value. Over the years, all these buildings have undergone refurbishment leading to the removal of their original interior features. Their façades, however, have mostly remained identical. As they are the element providing heritage value to the building or its surroundings, any work on them is very sensitive. It therefore appears more reasonable to locate braced frames inside and focus on their integration with interior architectural qualities. In sub-category 7.2 (Compatibility of the retrofit structure with existing architectural character), although seismic structure may negatively influence visual qualities such as interior elevations or ornamentation, the architectural character may remain neutral. Such outcome may equally result from two extreme cases. In the first, the retrofit structure, thanks to its shape, materiality or detailing, contributes to architectural character which justifies its presence. In the second case, no structural or non-structural elements whether new or existing participate in the expression of a common architectural character. The retrofit structure does therefore not weaken 
an unidentifiable character. Concerning sub-category 7.3 (Reversibility), the braced frames are often bolted to the existing structure which simplifies their removal. However, the full exposure of their connections greatly facilitates such a procedure.

Overall, braced frame structure appears as a challenging structure to integrate with existing architecture. Its unusual geometry makes it almost the natural focal point of a space. This can be managed by hiding it, leading to a neutral integration as in sub-category 1.1 and 1.2. However, its exposure requires more careful thoughts. The presence of a braced frame in front of external openings commonly results in a poor integration with natural light (4.1) and outside views (4.2). Similar outcome can be noticed with space (3.3) and function (3.4). Braced frame structure has a less straightforward relationship with other architectural qualities. Equally negative or positive influences can be noticed in the case of qualities like interior elevation (3.1), expressiveness (3.2), circulation (3.5), and ornamentation (5.1). The difference between successful and poor integration comes from what appears to be a purposeful architectural decision to use braced frame to add emphasis to certain features of a building in contrast to a disregarded approach (Chapter 4, 'Main relationships between seismic structure and existing architecture', $\mathrm{p}$ 116). 


\subsubsection{Moment Frame (Buildings \#1, \#2, \#5)}

Table 8. Tables of Analysis representing the influences of the moment frame system on each architectural quality of Buildings \#1, \#2, and \#5

\begin{tabular}{|c|c|c|c|c|c|c|c|}
\hline BUILDING \#1 & $\begin{array}{l}\text { CAT 1. HIDDEN } \\
\text { STRUCTURE }\end{array}$ & \begin{tabular}{|l} 
CAT 2. EXPOSED \\
EXTERIOR STRUCTURE
\end{tabular} & $\begin{array}{l}\text { CAT 3. EXPOSED INTERIOR } \\
\text { STRUCTURE }\end{array}$ & \begin{tabular}{|l|} 
CAT 4. INTERACTION WITH \\
EXTERNAL OPENINGS
\end{tabular} & CAT 5. ORNAMENTATION & $\begin{array}{l}\text { CAT 6. EXPRESSION OF } \\
\text { AN ARCHITECTURAL } \\
\text { CONCEPT }\end{array}$ & $\begin{array}{l}\text { CAT 7. CONSERVATION } \\
\text { AND PRESERVATION } \\
\text { PRINCIPLES }\end{array}$ \\
\hline \multirow{5}{*}{$\begin{array}{l}\text { INTERNAL CONCRETE } \\
\text { MOMENT FRAME- } \\
\text { TRANSVERSE DIRECTION }\end{array}$} & $\begin{array}{l}1.1 \text { ARCHITECTURAL } \\
\text { REASONS }\end{array}$ & 2.1. ELEVATION & 3.1. ELEVATION & 4.1 MODULATION OF LIGHT & $\begin{array}{l}5.1 \text { USE OF STRUCTURE FOR } \\
\text { ORNAMENTAL PURPOSES }\end{array}$ & $\begin{array}{l}6.1 \text { EXISTING OR NEW } \\
\text { ARCHITECTURAL CONCEPT }\end{array}$ & $\begin{array}{l}7.1 \text { MINIMUMM } \\
\text { INTERVENTION }\end{array}$ \\
\hline & $\begin{array}{l}1.2 \text { THE EFFECT OF THE } \\
\text { HIDING TECHNIQUE UPON } \\
\text { ARCHITECTURE }\end{array}$ & $\begin{array}{l}\text { 2.2. EXPRESSIVE ROLES OF } \\
\text { THE STRUCTURE }\end{array}$ & $\begin{array}{l}\text { 3.2 EXPRESSIVE ROLES OF } \\
\text { THE STRUCTURE }\end{array}$ & $\begin{array}{l}4.2 \text { OUTSIDE } \\
\text { VIEWS/SIGHTLNES }\end{array}$ & & & $\begin{array}{l}\text { 7.2 COMPATIBILTY WITH } \\
\text { EXISTING ARCHITECTURAL } \\
\text { CHARACTER }\end{array}$ \\
\hline & & & 3.3 STRUCTURE AND SPACE & & & & 7.3 REVERSIBILTYY \\
\hline & & & $\begin{array}{l}3.4 \text { STRUCTURE AND } \\
\text { FUNCTION }\end{array}$ & & & & \\
\hline & & & $\begin{array}{l}3.5 \text { STRUCTURE AND } \\
\text { CIRCULATION }\end{array}$ & & & & \\
\hline
\end{tabular}

\begin{tabular}{|c|c|c|c|c|c|c|c|}
\hline BUILDING \#2 & $\begin{array}{l}\text { CAT 1. HIDDEN } \\
\text { STRUCTURE }\end{array}$ & $\begin{array}{l}\text { CAT 2. EXPOSED } \\
\text { EXTERIOR STRUCTURE }\end{array}$ & $\begin{array}{l}\text { CAT 3. EXPOSED INTERIOR } \\
\text { STRUCTURE }\end{array}$ & $\begin{array}{l}\text { CAT 4. INTERACTION WITH } \\
\text { EXTERNAL OPENINGS }\end{array}$ & CAT 5. ORNAMENTATION & $\begin{array}{l}\text { CAT 6. EXPRESSION OF } \\
\text { AN ARCHITECTURAL } \\
\text { CONCEPT }\end{array}$ & $\begin{array}{l}\text { CAT 7. CONSERVATION } \\
\text { AND PRESERVATION } \\
\text { PRINCIPLES }\end{array}$ \\
\hline \multirow{5}{*}{$\begin{array}{c}\text { EXTERNAL CONCRETE } \\
\text { MOMENT FRAME - } \\
\text { LONGITUDINAL DIRECTION }\end{array}$} & $\begin{array}{l}1.1 \text { ARCHITECTURAL } \\
\text { REASONS }\end{array}$ & 2.1. ELEVATION & 3.1. ELEVATION & 4.1 MODULATION OF LIGHT & $\begin{array}{l}5.1 \text { USE OF STRUCTURE FOR } \\
\text { ORNAMENTAL PURPOSES }\end{array}$ & $\begin{array}{l}\text { 6.1 EXISTING OR NEW } \\
\text { ARCHITECTURAL CONCEPT }\end{array}$ & $\begin{array}{l}7.1 \text { MINIMUM } \\
\text { INTERVENTION }\end{array}$ \\
\hline & $\begin{array}{l}\text { 1.2 THE EFFECT OF THE } \\
\text { HIDING TECHNIQUE UPON } \\
\text { ARCHITECTURE }\end{array}$ & $\begin{array}{l}\text { 2.2 EXPRESSIVE ROLES OF } \\
\text { THE STRUCTURE }\end{array}$ & $\begin{array}{l}\text { 3.2 EXPRESSIVE ROLES OF } \\
\text { THE STRUCTURE }\end{array}$ & $\begin{array}{l}4.2 \text { OUTSIDE } \\
\text { VIEWS/SIGHTUNES }\end{array}$ & & & $\begin{array}{l}\text { 7.2 COMPATIBILTY WITH } \\
\text { EXISTING ARCHITECTURAL } \\
\text { CHARACTER }\end{array}$ \\
\hline & & & 3.3 STRUCTURE AND SPACE & & & & 7.3 REVERSIBILTYY \\
\hline & & & $\begin{array}{l}\text { 3.4 STRUCTURE AND } \\
\text { FUNCTION }\end{array}$ & & & & \\
\hline & & & $\begin{array}{l}3.5 \text { STRUCTURE AND } \\
\text { CIRCULATION }\end{array}$ & & & & \\
\hline
\end{tabular}

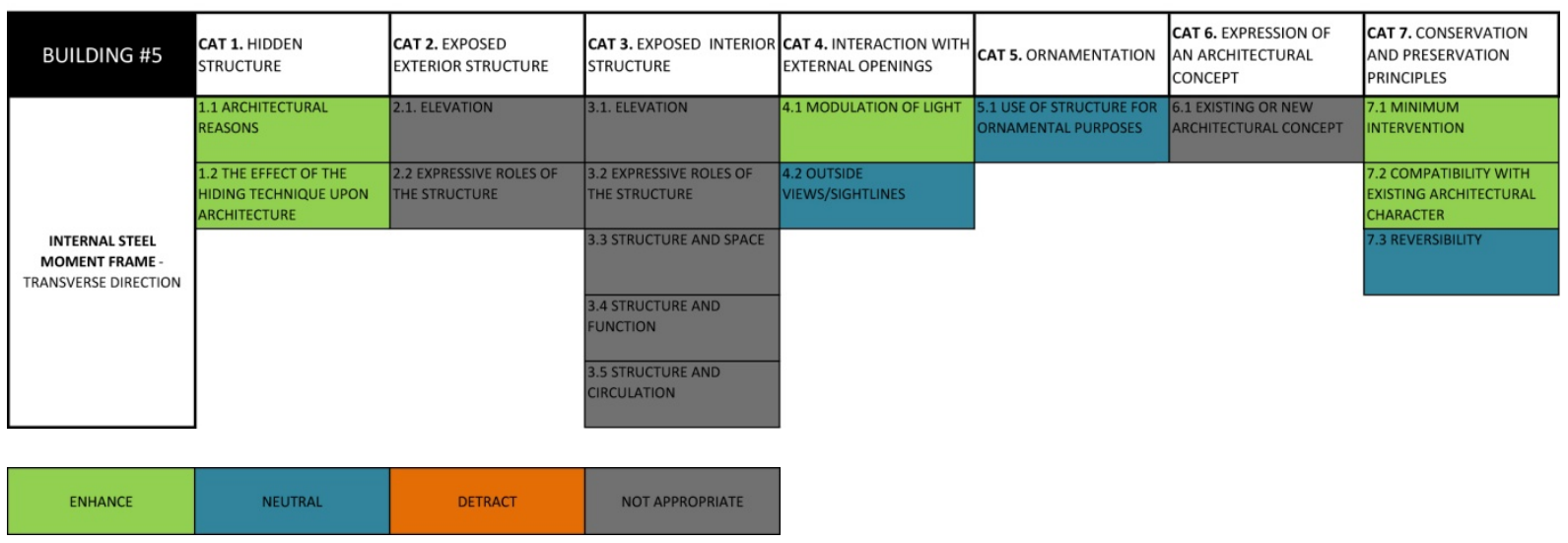

\section{○ Category 1 - Hidden structure}

\section{- 1.1: Architectural reasons}

\begin{tabular}{|c|}
\hline BUILDING \#5 \\
Internal Moment \\
Frames \\
- Transverse \\
Direction \\
\hline ENHANCE \\
\hline
\end{tabular}


As part of the seismic retrofit, the ground floor of Building \#5 has been fully refurbished. A new layout and spatial boundaries are created by three moment frames hidden in between plasterboard linings (Figure 72). This defines internal spaces with specific usages contributing to the new function of the building's ground floor.

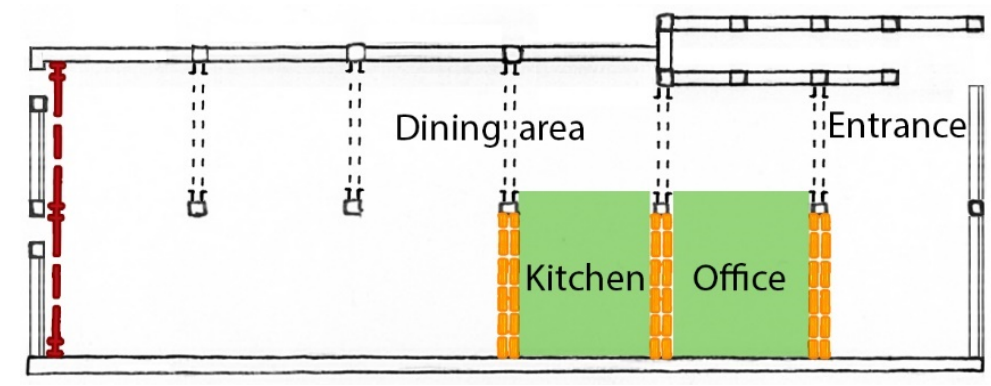

Figure 72. Ground floor plan of Building \#5 with the hidden moment frames (orange) delimiting different areas

- 1.2: The effect of the hiding technique upon architecture

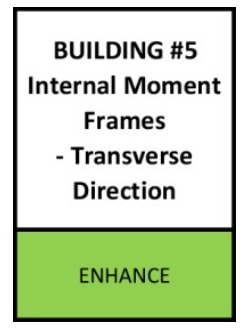

The refurbishment of the ground floor in Building \#5 expresses a cosy and dark architectural character. The surfaces are painted black with minimalist decoration and dim lights, resulting in the spatial boundaries being hardly perceptible. The screening technique being used to hide the retrofit structure contributes to the architectural character as the plasterboard linings are painted black, similar to the existing plastered URM walls.

\section{○ Category 2 - Exposed exterior structure}

- 2.1: Elevation

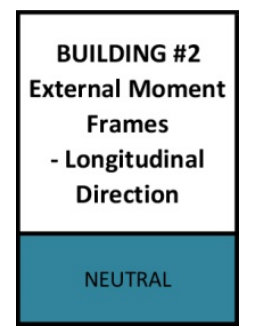

Building \#2 possesses a new three storey five-bay frame located against its main façade and replicating it (Figure 73). The existing geometry, rhythm, pattern, detailing and colour of the façade are thus all visually maintained and expressed by the moment frame. However, two aspects allow 
identifying the moment frame as an added structure. First, the retrofit structure covers five out of the seven existing bays. The untouched bays are located at the extremities of the façade. The depth of the retrofit structure is therefore noticeable on each of its sides. Secondly, the additional layer of retrofit structure increases and accentuates the depth around the windows. Although these two aspects change the existing façade, they are balanced by three other aspects. The first corresponds to the location of the moment frame at the centre of the façade, maintaining the axial symmetry of the external elevation. The second aspect is how the vertical continuity of the retrofit structure runs the full height of the façade and replicates the existing top frieze, minimising the perception of added component. Finally, the existing façade exhibited several layers of depth. These resulted from the different set of components including the pilasters, followed by the main structural frame system behind them, and finally the various openings one step deeper. The addition of the moment frame follows such variation of depths by adding a new physical layer without disrupting the reading of the façade. Overall, the modifications resulting from the moment frame are minor and are sourced from existing characteristics and features of the façade. As a result, the architectural expression of the façade is visually maintained.

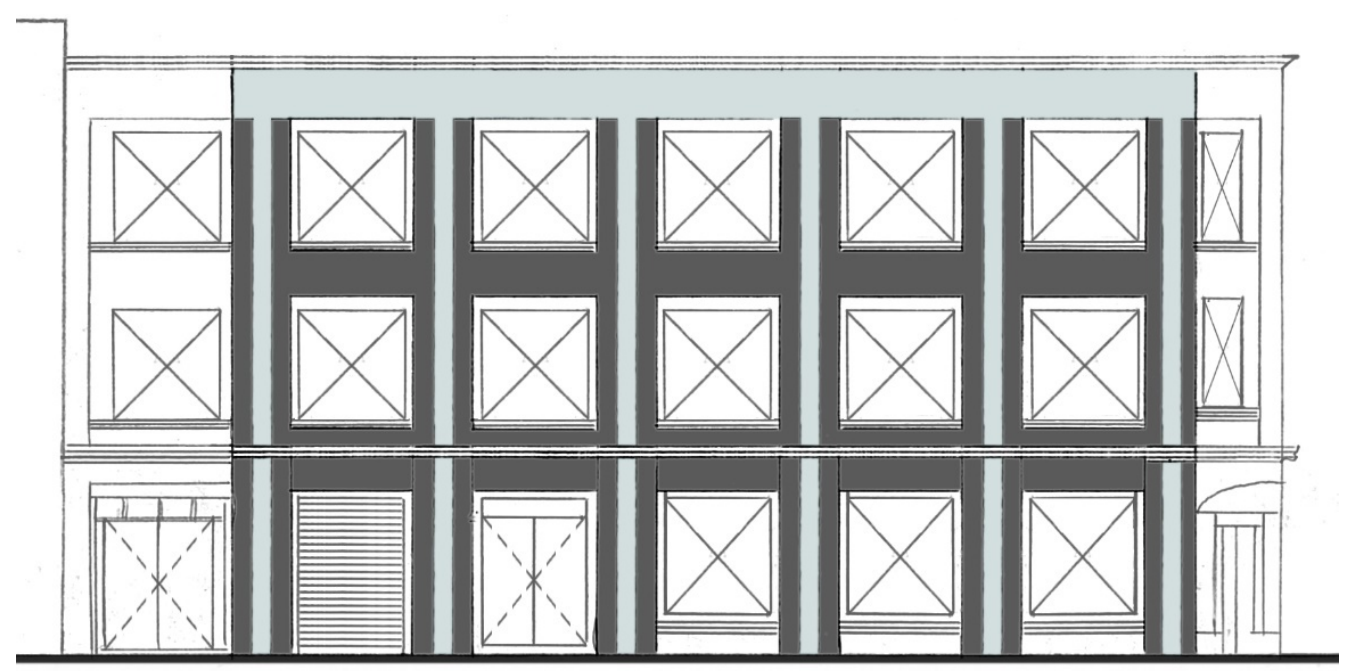

Figure 73. Simplified elevation of the moment frame replicating the existing front façade

\section{- 2.2: Expressive role of the structure}

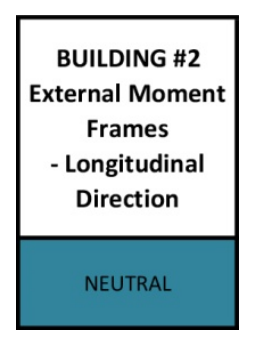

In Building \#2, the detailing of the moment frame emulates the existing façade. Its external features are all replicated including the original division between the bottom floor and the two upper levels. 
In addition, the moment frame is dowelled into the existing façade avoiding any visible connections between them. Such design of the retrofit structure ensures preservation of the existing façade and avoids any potential expressiveness of the moment frame.

\section{O Category 3 - Exposed interior structure}

- 3.1: Elevation

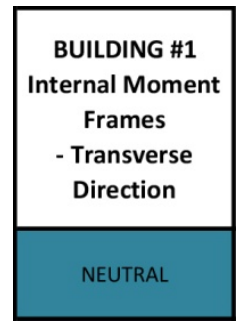

The seismic retrofit of Building \#1 is part of a full internal refurbishment establishing a large open space at each level. The transverse retrofit structure is composed of two three-bay moment frames aligned on a former structural grid. Due to the significant distance between the moment frames and the rear and front façades, no relationships are established between the retrofit structure and the interior transverse elevations. The analysis focuses therefore on other surfaces immediately adjacent to the moment frames, in this case the longitudinal retrofit shear walls. The moment frames meet the shear walls at one end and at $5 \mathrm{~m}$ from the front façade. This disposition and the small number of moment frames barely enliven the longitudinal surfaces. There are therefore no contributions from the transverse retrofit structure to any interior elevations.

\section{- 3.2: Expressive roles of the structure}

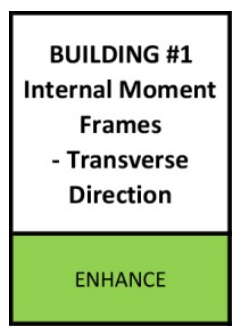

In Building \#1, the middle bay of the moment frame located $5 \mathrm{~m}$ behind the main façade is aligned with the building's main entrance. This relationship was already established by two previous castiron columns which were removed when refurbishing the building. Instead of two thin columns, the much larger dimensions of the retrofit structure, combined with its geometry, literally frames the entrance. In addition, new escalators are installed in between the central bay. The retrofit structure therefore emphasises both the main access to the building and the main interior circulation (Figure 74). 


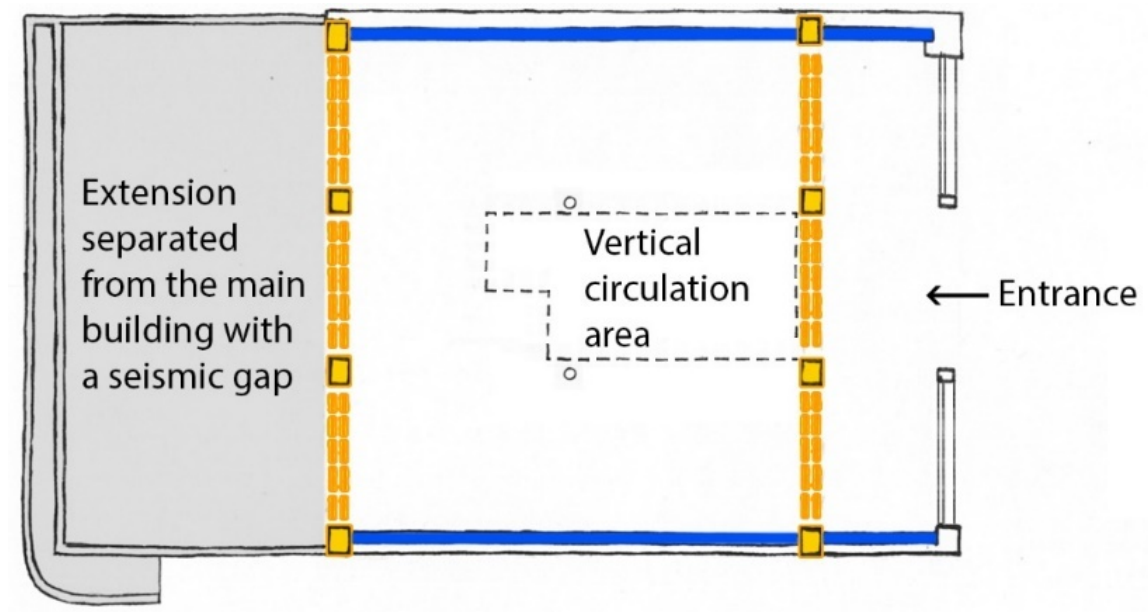

Figure 74. Ground floor plan of Building \#1 with the moment frame (orange) emphasising the building's entrance and interior circulation

The moment frames also express their materiality and construction techniques (Figure 75). Their bare concrete surfaces are exposed, revealing colour changes and marks resulting from the cast-inplace construction technique. Additional features, such as the use of exposed Fibre Reinforced Polymer (FRP) at the junction of the beams and columns of the moment frames, also contribute to the expression of technical vocabulary and emphasise the interior industrial architectural character.

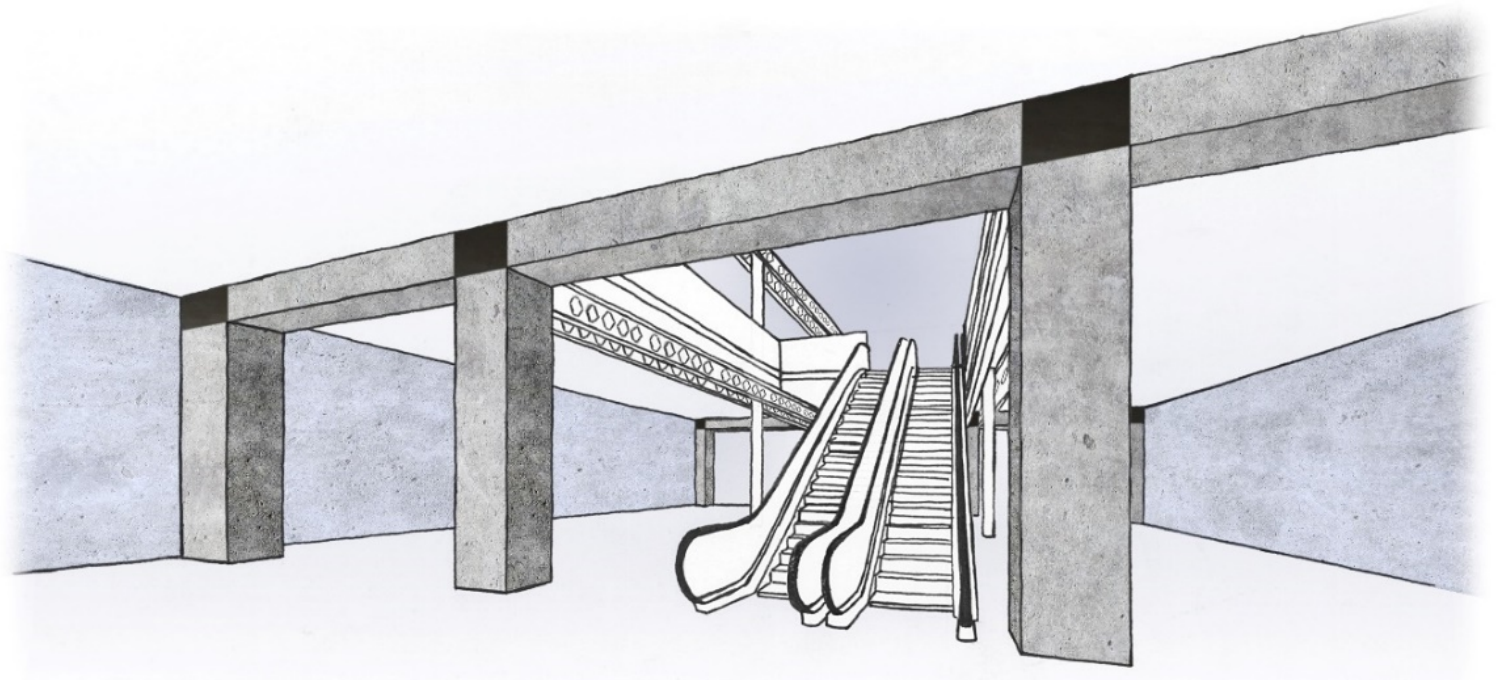

Figure 75. Exposed raw concrete moment frames and shear walls

\section{- 3.3: Structure and space}

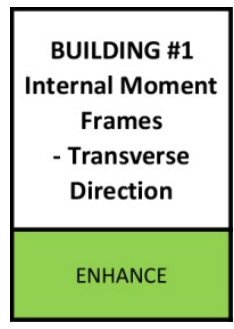


The existing structural grid, on which the two moment frames are aligned, allowed a reading of each floor as a large single volume as well as subdividing it into three smaller spaces: left, central and right. This characteristic is maintained by the three-bay moment frames (Figure 76). As the moment frames are less numerous than the previous columns, they provide greater openness between the three spaces, but also emphasise the spatial boundaries due to their larger dimensions.
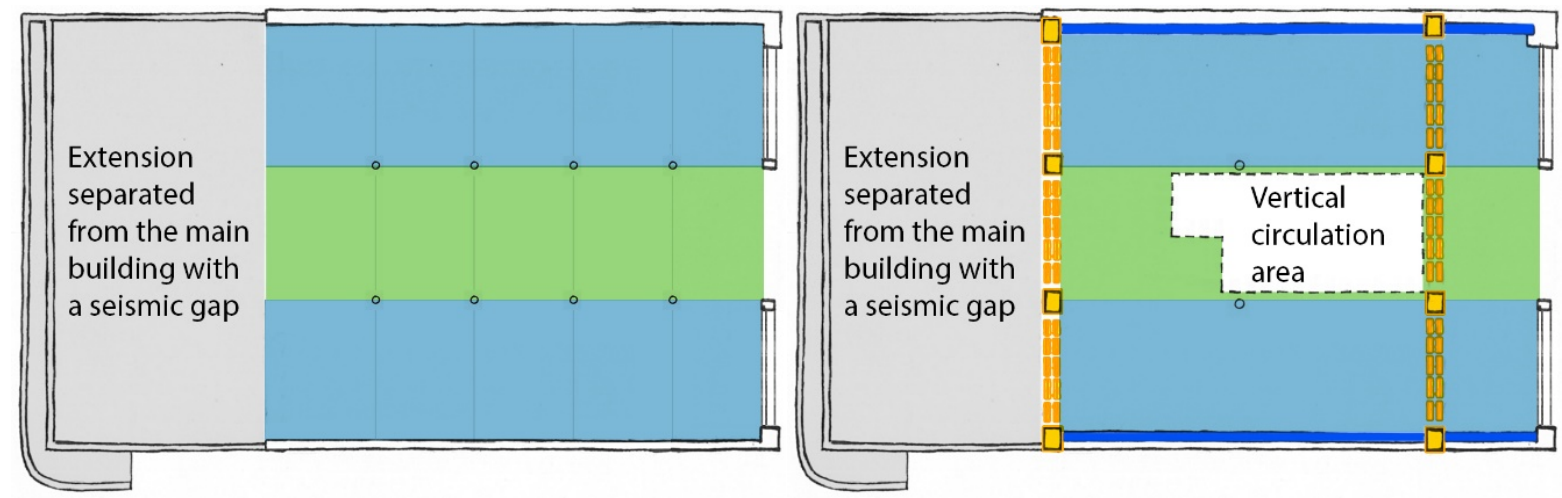

Figure 76. Ground floor plans of Building \#1 before (left) and after (right) the seismic retrofit showing the interior spatial division

In addition, a central opening accommodates the escalators and links together ground and first floor. This horizontal opening generates greater interior spatial openness with a new reading of the existing volumes. The retrofit structure contributes to this spatial reading as it defines, alongside other structural components, the boundaries of the openings. The moment frames also provide, through this opening, visual continuity between the volumes of the ground and first floor.

\section{- 3.4: Structure and function}

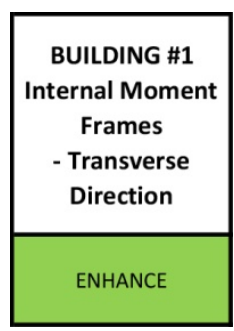

The moment frames, despite their large footprint, maintain the existing usability of the interior large open spaces but also contribute to the definition of new internal functions. As the retrofit structure participates in delimiting the horizontal opening, it helps distinguish the vertical circulation area from the usable spaces located to the sides and facilitates users understanding of how the ground and first floor operate (Figure 76). 
- 3.5: Structure and circulation

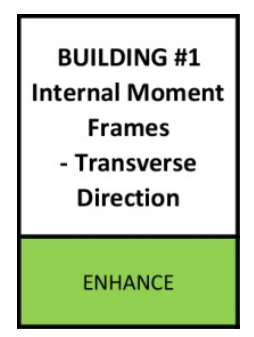

As indicated in sub-categories 3.2 and 3.4 , the moment frames contribute to the quality of circulation by delineating the vertical circulation and framing the escalators.

\section{○ Category 4 - Interaction with external openings}

\section{- 4.1: Modulation of light}

\begin{tabular}{|c|c|c|}
\hline $\begin{array}{c}\text { BUILDING \#1 } \\
\text { Internal Moment } \\
\text { Frames } \\
\text { - Transverse } \\
\text { Direction }\end{array}$ & $\begin{array}{c}\text { BUILDING \#2 } \\
\text { External Moment } \\
\text { Frames } \\
\text { - Longitudinal } \\
\text { Direction }\end{array}$ & $\begin{array}{c}\text { BUILDING \#5 } \\
\text { Internal Moment } \\
\text { Frames } \\
\text { - Transverse } \\
\text { Direction }\end{array}$ \\
\hline NEUTRAL & NEUTRAL & ENHANCE \\
\hline
\end{tabular}

In Building \#1, the first moment frame is installed deep inside the interior of the building, too far to affect the entry of light. The second moment frame is located $5 \mathrm{~m}$ behind the main façade. Its three bays are aligned with the columns of the façade therefore limiting light obstruction. In addition, the skeletal geometry of the retrofit structure allows natural light to freely penetrate the building.

The moment frame in Building \#2 replicates the existing façade. A distance of $200 \mathrm{~mm}$ separates the edges of the moment frames members and the windows openings. Such detailing minimises the impact the new structural depth and the shadows it creates on the entry of natural light.

In Building \#5, the hidden moment frame located a few meters behind one of the façade's large openings has a direct influence on natural light. The plasterboard lining hiding the retrofit structure is painted black and therefore absorbs natural light and avoids its diffusion further inside the building. Such modulation is justified by the ground floor's dark architectural character. 
- 4.2: Outside views/sightlines

\begin{tabular}{|c|c|c|}
\hline $\begin{array}{c}\text { BUILDING \#1 } \\
\text { Internal Moment } \\
\text { Frames } \\
\text { - Transverse } \\
\text { Direction }\end{array}$ & $\begin{array}{c}\text { BUILDING \#2 } \\
\text { External Moment } \\
\text { Frames } \\
\text { - Longitudinal } \\
\text { Direction }\end{array}$ & $\begin{array}{c}\text { BUILDING \#5 } \\
\text { Internal Moment } \\
\text { Frames } \\
\text { - Transverse } \\
\text { Direction }\end{array}$ \\
\hline NEUTRAL & NEUTRAL & NEUTRAL \\
\hline
\end{tabular}

In Building \#1, the location and geometry of the retrofit structure allows direct views toward the outside from any part of the building. In Building \#2, the retrofit structure duplicates the existing main façade, therefore maintaining the original openings. In Building \#5, the hidden retrofit structure modulates natural light but does not influence the view toward the outside. The reason comes from the distance between the hidden moment frame and the façade which forms a usable space. Within this space, the existing outside view is maintained.

\section{○ Category 5 - Ornamentation}

- 5.1: Use of structure for ornamental purposes

\begin{tabular}{|c|c|c|}
\hline $\begin{array}{c}\text { BUILDING \#1 } \\
\text { Internal Moment } \\
\text { Frames } \\
\begin{array}{c}\text { Transverse } \\
\text { Direction }\end{array}\end{array}$ & $\begin{array}{c}\text { BUILDING \#2 } \\
\text { External Moment } \\
\text { Frames } \\
\text { - Longitudinal } \\
\text { Direction }\end{array}$ & $\begin{array}{c}\text { BUILDING \#5 } \\
\text { Internal Moment } \\
\text { Frames } \\
\text { - Transverse } \\
\text { Direction }\end{array}$ \\
\hline NEUTRAL & NEUTRAL & NEUTRAL \\
\hline
\end{tabular}

In Building \#1, the two moment frames have their materiality and geometry exposed. However, neither of these two aspects allows the retrofit structure to be considered as ornament. This is primarily due to the omnipresence of the concrete surfaces of the shear walls and composite decking of each floor weakening the reading of the moment frames as unique ornamental features. The large dimensions of each bay and their simple form are also too plain to classify them as ornaments. In addition, the limited number of two lines of moment frames combined with the significant distance between them prevents the development of any ornamental pattern.

In Building \#2, the external moment frame is detailed to mimic the ornamental features of the façade. The first elements to notice are the pilasters. They are also painted similar to the previous pilasters, with a light grey colour contrasting with the darker tone of the moment frames. Applied to the pilasters, decorative metal plates replace removed ones. Finally, the top of the retrofit structure displays a frieze identical to the one remaining on each extremity of the existing façade. 
In Building \#5, the moment frames do not support any ornamentation. The plasterboard linings hiding them do not possess any decorative features as their aim is not to contribute to ornamental quality. Instead, their presence is purposefully diminished by black painted surfaces in order to fit the intended architectural character.

\section{O Category 6 - Expression of an architectural concept}

- 6.1: Reinforcement of an existing architectural concept or development of a new one

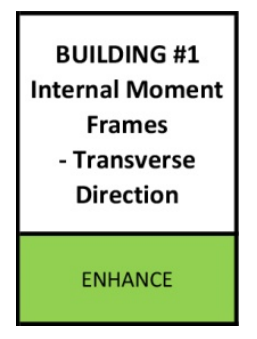

Building \#1 has a new concept developed thanks to the contrast between its interior refurbishment and the front façade. The two massive moment frames express concrete materiality and raw detailing (Figure 75). Combined with new exposed shotcrete shear walls and composite steel and concrete floors, as well as unrefined non-structural elements, they define a raw and industrial architectural character. The result is a stylistic contrast between the gracious Edwardian Baroque main façade and the unrefined building's interior character.

Regarding Buildings \#2 and \#5, none of the retrofit structures contribute to the expression of a new architectural concept. Concerning the first building, the moment frame visually maintains the façade's existing architectural character, therefore not engaging with any concept. As for Building $\# 5$, as stressed in sub-category 6.1 of the braced frames analysis, the three different and unrelated architectural characters hinders the expression of a common architectural concept.

\section{○ Category 7 - Conservation and preservation principles}

\section{- 7.1: Minimum intervention}

\begin{tabular}{|c|c|c|}
\hline $\begin{array}{c}\text { BUILDING \#1 } \\
\text { Internal Moment } \\
\text { Frames } \\
\text { - Transverse } \\
\text { Direction }\end{array}$ & $\begin{array}{c}\text { BUILDING \#2 } \\
\text { External Moment } \\
\text { Frames } \\
\text { - Longitudinal } \\
\text { Direction }\end{array}$ & $\begin{array}{c}\text { BUILDING \#5 } \\
\text { Internal Moment } \\
\text { Frames } \\
\text { - Transverse } \\
\text { Direction }\end{array}$ \\
\hline ENHANCE & NEUTRAL & ENHANCE \\
\hline
\end{tabular}


In Building \#2, the retrofit solution covers almost the entire façade yet visually maintains its architectural features. This is undertaken by careful detailing of the moment frame. The massive intervention on the main façade however prevents the retrofit structure from having a positive influence regarding the minimum intervention principle. The moment frame may therefore be either considered as neutral or negative from that perspective. The answer as to whether or not this is minimum intervention raises the issue of the new retrofit structure's legitimacy to carry the building's cultural heritage value and to be considered as authentic. For Smith (2015, p. 59), professionals see the "heritage value ... to be intrinsic to built fabric rather than to image or superficial resemblance". Although this position can be considered subjective, it is reinforced by key references such as ICOMOS New Zealand Charter (2010) and NZHPT (2007f). They both recommend avoiding if possible the removal or alteration of the fabric. The replacement of ornamental elements and to a larger extent building fabric is tolerated where reasonably justified (ICOMOS, 2010; Look et al., 1997). The justifications however relate to repair and reconstruction reasons. It is therefore difficult to justify the current design decision of replicating the existing façade. On the other hand, each retrofitted project should be treated as a specific case (Smith, 2015) and the conservation and preservation principles are guidelines, not strict rules. A degree of tolerance is therefore accepted.

The influence of the moment frame on Building $\# 2$ is considered as neutral with respect to minimum intervention for two reasons. First, when comparing the original plans of the façade prior to its retrofit, it appears that the building's external appearance has changed over time. Some significant features have been lost or removed such as the existing parapet and the capitals of the pilasters. This leads to a plainer façade with its main architectural character now based on its elevation rhythm, proportions and its varying depth. The design of the moment frame replicates these existing features which are not defined by their materiality or handicraft but by their form, location and dimensions. Secondly, the plaster applied on the existing façade can be considered as its fabric. The plaster itself possessed no decorative treatment and has been painted several times over the decades. The new reinforced concrete moment frame with its surface similarly plastered visually maintains the fabric.

In Buildings \#1 and \#5, the moment frames are identified as positive in the light of the minimum intervention principle. First, the retrofit structure is installed internally in each building which prevents any impact on the front façade. Secondly, the installation of the moment frames has barely any impact on the existing interior structural and non-structural elements. In Building \#1 the moment frames are aligned with the existing structural grid, and in Building \#5 they are installed 
inside the bays of existing frames. In both cases, the retrofit structure greatly limits any damage or loss of existing features.

\section{- 7.2: Compatibility with existing architectural character}

\begin{tabular}{|c|c|c|}
\hline $\begin{array}{c}\text { BUILDING \#1 } \\
\text { Internal Moment } \\
\text { Frames } \\
\text { - Transverse } \\
\text { Direction }\end{array}$ & $\begin{array}{c}\text { BUILDING \#2 } \\
\text { External Moment } \\
\text { Frames } \\
\text { - Longitudinal } \\
\text { Direction }\end{array}$ & $\begin{array}{c}\text { BUILDING \#5 } \\
\text { Internal Moment } \\
\text { Frames } \\
\text { - Transverse } \\
\text { Direction }\end{array}$ \\
\hline ENHANCE & NEUTRAL & ENHANCE \\
\hline
\end{tabular}

In Building \#2, the external moment frame is considered as having a neutral impact on the building façade. The main reason results from the retrofit structure duplicating all the existing features. In doing so, there are no added architectural contributions from the moment frame. Some changes are noticeable but remain negligible and follow existing characteristics such as the axial symmetry and variation of depths.

The moment frames in Buildings \#1 and \#5 do not affect the existing architectural and historic features of their façades. The existing architectural character of each building is thus preserved. In addition, the interior retrofit structure provides a new architectural layer to each building. In Building \#1, the concrete moment frames along with the shear walls and floor slabs express a raw and industrial character inside the building. A contrast is established with the refined front façade which leads to an experience of surprise between the internal and external architectural characters. In Building \#5, the new refurbished ground floor is characterised by extremely dark spaces, dim lights and minimalist decoration. The new moment frames strengthen the interior character thanks to the plasterboard linings installed on each side of them possessing surfaces similar to the smoothly plastered URM walls. This visual continuity is reinforced by the use of black paint on both types of surfaces. As a result, the spatial boundaries are less perceptible, contributing to the interior architectural character.

\section{- 7.3: Reversibility}

\begin{tabular}{|c|c|c|}
\hline $\begin{array}{c}\text { BUILDING \#1 } \\
\text { Internal Moment } \\
\text { Frames } \\
\text { - Transverse } \\
\text { Direction }\end{array}$ & $\begin{array}{c}\text { BUILDING \#2 } \\
\text { External Moment } \\
\text { Frames } \\
\text { - Longitudinal } \\
\text { Direction }\end{array}$ & $\begin{array}{c}\text { BUILDING \#5 } \\
\text { Internal Moment } \\
\text { Frames } \\
\text { - Transverse } \\
\text { Direction }\end{array}$ \\
\hline NEUTRAL & DETRACT & NEUTRAL \\
\hline
\end{tabular}


In Building \#1, the moment frames are deeply connected to several structural elements. The most critical connections are at the junction of the transverse moment frames and the longitudinal URM walls. To accommodate the installation of the new columns inside the existing structure large cuts were made. The removal of the retrofit structure will then require careful repair and restoration of the existing URM walls. The existing architectural character would however remain unaffected as the existing structure was formerly plastered. Another issue relates to the connections of new structural elements with the moment frames. This includes two pairs of long castellated beams connecting the central bays of the two moment frames supporting the composite steel and concrete decking at each floor. Both of these elements are dowelled with the moment frames which further complicates their removal. Damage will be inevitable but would only impact on new retrofit elements, therefore keeping the existing architectural and historic features safe.

The moment frames in Building \#5 are simply bolted to the bays of existing frames which greatly facilitates their removal. However, in order to get access to them, the plasterboard linings hiding them will need to be destroyed. Such work is not detrimental to the building's architectural quality.

The retrofit structure in Building \#2 has not been designed for reversibility. Its installation transfers existing architectural and historic features into the new moment frame. The moment frame is deeply dowelled into the existing façade. The removal of the retrofit structure would be extremely difficult and would significantly damage the original building fabric.

\section{- Final comments}

The above section presented the influences of the retrofit moment frames on various architectural qualities of Buildings \#1, \#2, and \#5. General observations can be made from the Tables of Analysis:

- although the integration of moment frames and architectural qualities has primarily a neutral impact, it also appears that the structure can enhance a large number of these qualities,

- the replication approach integrating the external moment frame in Building \#2 results in a neutral influence on all the architectural qualities, with the exception of reversibility.

Each of the three buildings presents a different approach and use of retrofit moment frame structure. In Building \#1 the retrofit structure is located internally and exposed; in Building \#2 it is installed externally and exposed; and in Building \#5 it is placed internally and hidden. These differences limit the identification of patterns or trends in the Tables of Analysis but do not prevent comparisons. 
A comparison of the Tables of Analysis of Buildings \#2 and \#5 reveals that among the two moment frame solutions, it is the hidden one which engages the most with the architectural qualities. By comparison, the exposed moment frame has a neutral influence on almost all the architectural qualities. A first observation to make is that exposed retrofit structure does not necessarily imply greater enhancement of architectural qualities than hidden retrofit structure. Now looking in more detail, the key distinction between both retrofit solutions results from the new architectural features introduced by the concealed moment frames in Building \#5. Although the retrofit structure is installed inside existing frames, therefore following existing locations and geometry, new linings are used to hide it. These added elements contribute to a positive integration of the moment frames and architectural qualities. This implies that the addition of new elements distinct from existing ones whether in terms of location, form, scale or aspect provides greater opportunities for enhancement of architectural qualities. On the other hand, integrating a structure by identically recreating existing features only maintains the building's architecture.

The design of the external moment frame in Building \#2 represents a particular case in which the retrofit structure replaces the main façade. The effectiveness of the replication is related to the careful detailing and mimicking of the existing architectural features. Another aspect also contributes to the final result. The existing façade consists of an URM wall with a series of aligned openings located over three floors and seven vertical rows. This configuration displays large bays which look very similar to the bays of moment frames. The visual correspondence between the geometry of the façade and the retrofit structure facilitates the reproduction of the architectural features.

In Building \#1, the two moment frames are located on an existing structural grid with their central bays aligned with those of previous columns. This approach could have led to a neutral integration with architectural qualities. However, almost the entire Category 3 (Exposed interior structure) is enhanced by the retrofit structure. This is explained by several factors. As less structural elements are used, the interior space of each floor possesses greater openness. In addition, the large dimensions of the retrofit structure and its detailing reinforce its expressiveness. As a result, a new reading or experiencing of the internal space is defined despite being based on the existing grid. In addition, the retrofit structure frames new architectural features, namely the new escalators and horizontal opening. Their presence is thus emphasised. The retrofit work undertaken inside Building \#1 illustrates that the integration of moment frames, while respectful of existing features and taking reference from them, still provide enhanced architectural qualities. 
In Building \#1, a new concept is expressed by the contrast between the raw and industrial interior character and the refined Edwardian front façade. The success of the concept relies on the interior refurbishment which allows great liberty in terms of design. Equally important is the visual coherence between elements whether structural or non-structural, existing or new. They all convey a common message based on a raw and industrial vocabulary. Without coherence between the moment frames and the other interior elements, the contrast with the façade would have been weakened and possibly unnoticed.

Regarding Category 7 (Conservation and preservation principles), Buildings \#1 and \#5 have similar evaluations despite one retrofit structure being exposed and the other hidden. In sub-category 7.1, it is the interior installation of moment frames and their locations following existing structural alignments that ensure positive integration with minimum intervention. In sub-category 7.2, compatibility with the existing architectural character also relates to the interior location of the retrofit structure and to its visual correspondence with the new architectural character.

Regarding sub-category 7.3, the difficulty removing the new moment frame cuts across reversibility principle in Building \#2. As the new moment frame now represents the new façade and carries the architectural features, its removal should be avoided. This implies that future structural improvements should not be designed based on the removal of the moment frame but on their capacity to accommodate it.

Whether exposed or hidden, a moment frame appears as a particularly suitable seismic structure regarding most architectural qualities. Where the moment frame is exposed, physical qualities such as space (3.3), function (3.4), and circulation (3.5), can be enhanced thanks in great part to its geometry providing flexibility and openness. Moment frames can enhance the expressiveness quality (3.2) in particular where their small number leads to an increase of their dimensions. When justified by the building's function and architectural character, the hiding of the moment frame can be particularly effective in achieving a successful integration. 


\subsubsection{Diaphragms (Buildings \#1, \#2, \#3, \#4)}

Table 9. Tables of Analysis representing the influences of the diaphragm systems on each architectural quality of Buildings \#1, \#2, \#3 and \#4

\begin{tabular}{|c|c|c|c|c|c|c|c|}
\hline BUILDING \#1 & $\begin{array}{l}\text { CAT 1. HIDDEN } \\
\text { STRUCTURE }\end{array}$ & \begin{tabular}{|l} 
CAT 2. EXPOSED \\
EXTERIOR STRUCTURE
\end{tabular} & $\begin{array}{l}\text { CAT 3. EXPOSED INTERIOR } \\
\text { STRUCTURE }\end{array}$ & $\begin{array}{l}\text { CAT 4. INTERACTION WITH } \\
\text { EXTERNAL OPENINGS }\end{array}$ & CAT 5. ORNAMENTATION & $\begin{array}{l}\text { CAT 6. EXPRESSION OF } \\
\text { AN ARCHITECTURAL } \\
\text { CONCEPT }\end{array}$ & $\begin{array}{l}\text { CAT 7. CONSERVATION } \\
\text { AND PRESERVATION } \\
\text { PRINCIPLES }\end{array}$ \\
\hline \multirow{5}{*}{$\begin{array}{l}\text { COMPOSITE STEEL AND } \\
\text { CONCRETE DECKING }\end{array}$} & $\begin{array}{l}1.1 \text { ARCHITECTURAL } \\
\text { REASONS }\end{array}$ & 2.1. ELEVATION & $\begin{array}{l}\text { 3.1. FLOOR AND CEIIING } \\
\text { SURFACE }\end{array}$ & 4.1 MODULATION OF LIGHT & $\begin{array}{l}5.1 \text { USE OF STRUCTURE FOR } \\
\text { ORNAMENTAL PURPOSES }\end{array}$ & $\begin{array}{l}\text { 6.1 EXISTING OR NEW } \\
\text { ARCHITECTURAL CONCEPT }\end{array}$ & $\begin{array}{l}7.1 \text { MINIMUM } \\
\text { INTERVENTION }\end{array}$ \\
\hline & $\begin{array}{l}1.2 \text { THE EFFECT OF THE } \\
\text { HIDING TECHNIQUE UPON } \\
\text { ARCHITECTURE }\end{array}$ & $\begin{array}{l}\text { 2.2 EXPRESSIVE ROLES OF } \\
\text { THE STRUCTURE }\end{array}$ & $\begin{array}{l}\text { 3.2 EXPRESSIVE ROLES OF } \\
\text { THE STRUCTURE }\end{array}$ & $\begin{array}{l}4.2 \text { OUTSIDE } \\
\text { VIEWS/SIGHTLINES }\end{array}$ & & & $\begin{array}{l}7.2 \text { COMPATIBILTYY WITH } \\
\text { EXISTING ARCHITECTURAL } \\
\text { CHARACTER }\end{array}$ \\
\hline & & & 3.3 STRUCTURE AND SPACE & & & & 7.3 REVERSIBILTY \\
\hline & & & $\begin{array}{l}\text { 3.4 STRUCTURE AND } \\
\text { FUNCTION }\end{array}$ & & & & \\
\hline & & & $\begin{array}{l}3.5 \text { STRUCTURE AND } \\
\text { CIRCULATION }\end{array}$ & & & & \\
\hline
\end{tabular}

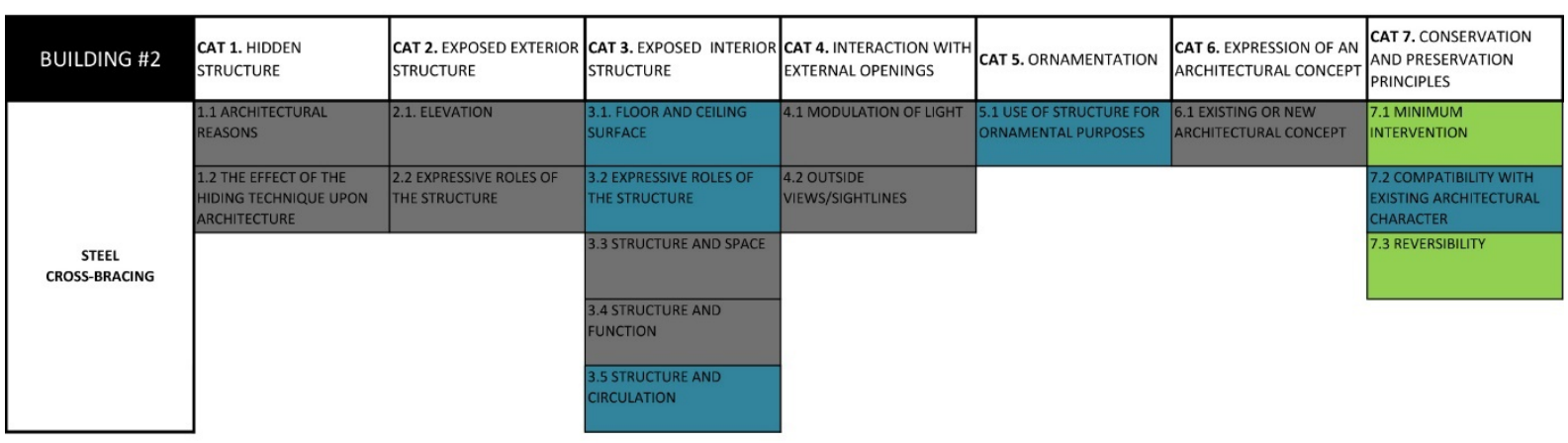

\begin{tabular}{|c|c|c|c|c|c|c|c|}
\hline BUILDING \#2 & $\begin{array}{l}\text { CAT 1. HIDDEN } \\
\text { STRUCTURE }\end{array}$ & $\begin{array}{l}\text { CAT 2. EXPOSED EXTERIOR } \\
\text { STRUCTURE }\end{array}$ & $\begin{array}{l}\text { CAT 3. EXPOSED INTERIOF } \\
\text { STRUCTURE }\end{array}$ & $\begin{array}{l}\text { CAT 4. INTERACTION WITH } \\
\text { EXTERNAL OPENINGS }\end{array}$ & CAT 5. ORNAMENTATION & $\begin{array}{l}\text { CAT 6. EXPRESSION OF AN } \\
\text { ARCHITECTURAL CONCEPT }\end{array}$ & \begin{tabular}{|l} 
CAT 7. CONSERVATION \\
AND PRESERVATION \\
PRINCIPLES
\end{tabular} \\
\hline \multirow{5}{*}{ PLYWOOD PANELS } & $\begin{array}{l}1.1 . \text { ARCHII } \\
\text { REASONS }\end{array}$ & & $\begin{array}{l}\text { 3.1. FLOOF } \\
\text { SURFACE }\end{array}$ & & $\begin{array}{l}\text { 5.1 USE OF STRUCTURE FOR } \\
\text { ORNAMENTAL PURPOSES }\end{array}$ & $\begin{array}{l}\text { 6.1 EXISTING OR NEW } \\
\text { ARCHITECTURAL CONCEPT }\end{array}$ & $\begin{array}{l}7.1 \text { MINIMUMM } \\
\text { INTERVENTION }\end{array}$ \\
\hline & $\begin{array}{l}1.2 \text { THE EFFECT OF THE } \\
\text { HDING TECHNIQUE UPON } \\
\text { ARCHITECTURE }\end{array}$ & $\begin{array}{l}\text { 2.2 EXPRESSIVE ROLES OF } \\
\text { THE STRUCTURE }\end{array}$ & $\begin{array}{l}\text { 3.2 EXPRESSIVE ROLLES OF } \\
\text { THE STRUCTURE }\end{array}$ & $\begin{array}{l}4.2 \text { OUTSIDE } \\
\text { VIEWS/IIGHTLNES }\end{array}$ & & & $\begin{array}{l}\text { 7.2 COMPATBBLITT WITH } \\
\text { EXISTING ARCHTECTURAL } \\
\text { CHARACTER } \\
\end{array}$ \\
\hline & & & |3.3 STRUCTURE AND SPACE & & & & 7.3 REVERSIBILTY \\
\hline & & & $\begin{array}{l}\text { 3.4 STRUCTURE AND } \\
\text { FUNCTION }\end{array}$ & & & & \\
\hline & & & $\begin{array}{l}3.5 \text { STRUCTURE AND } \\
\text { CIRCULATION }\end{array}$ & & & & \\
\hline
\end{tabular}

\begin{tabular}{|c|c|c|c|c|c|c|c|}
\hline BUILDING \#3 & $\begin{array}{l}\text { CAT 1. HIIDDEN } \\
\text { STRUCTURE }\end{array}$ & $\begin{array}{l}\text { CAT 2. EXPOSED EXTERIOF } \\
\text { STRUCTURE }\end{array}$ & $\begin{array}{l}\text { CAT 3. EXPOSED INTERIOR } \\
\text { STRUCTURE }\end{array}$ & $\begin{array}{l}\text { CAT 4. INTERACTION WITH } \\
\text { EXTERNAL OPENINGS }\end{array}$ & CAT 5. ORNAMENTATION & $\begin{array}{l}\text { CAT 6. EXPRESSION OF AN } \\
\text { ARCHITECTURAL CONCEPT }\end{array}$ & $\begin{array}{l}\text { CAT T. CONSERVATION } \\
\text { AND PRESERVATION } \\
\text { PRINCIPLES }\end{array}$ \\
\hline \multirow{5}{*}{$\begin{array}{c}\text { STEEL } \\
\text { CROSS-BRACING }\end{array}$} & $\begin{array}{l}\text { REASONS } \\
\text { Rens }\end{array}$ & & $\begin{array}{l}\text { 3.1. FLOOR AND CELING } \\
\text { SURFACE }\end{array}$ & & $\begin{array}{l}5.1 \text { USE OF STRUCTURE FOR } \\
\text { ORNAMENTAL PURPOSES }\end{array}$ & $\begin{array}{l}6.1 \text { EXISTING OR NEW } \\
\text { ARCHITECTURAL CONCEPT }\end{array}$ & $\begin{array}{l}7.1 \text { MINIMUM } \\
\text { INTERVENTION }\end{array}$ \\
\hline & $\begin{array}{l}1.2 \text { THE EFFECT OF THE } \\
\text { HDING TECHNIQUE UPON } \\
\text { ARCHITECTURE }\end{array}$ & $\begin{array}{l}\text { 2.2 EXPRESSIVE ROLES OF } \\
\text { THE STRUCTURE }\end{array}$ & $\begin{array}{l}\text { 3.2 EXPRESSIVE ROLES OF } \\
\text { THE STRUCTURE }\end{array}$ & \begin{tabular}{|l}
4.2 OUTSIDE \\
VIEWS/SIGHTLINES
\end{tabular} & & & $\begin{array}{l}7.2 \text { COMPATIBILTY WITH } \\
\text { EXISTING ARCHTECTURAL } \\
\text { CHARACTER }\end{array}$ \\
\hline & & & 3.3 STRUCTURE AND SPACE & & & & 7.3 REVERSIBILTY \\
\hline & & & $\begin{array}{l}\text { 3.4 STRUCTURE AND } \\
\text { FUNCTION }\end{array}$ & & & & \\
\hline & & & $\begin{array}{l}3.5 \text { STRUCTURE AND } \\
\text { CIRCULATION }\end{array}$ & & & & \\
\hline
\end{tabular}



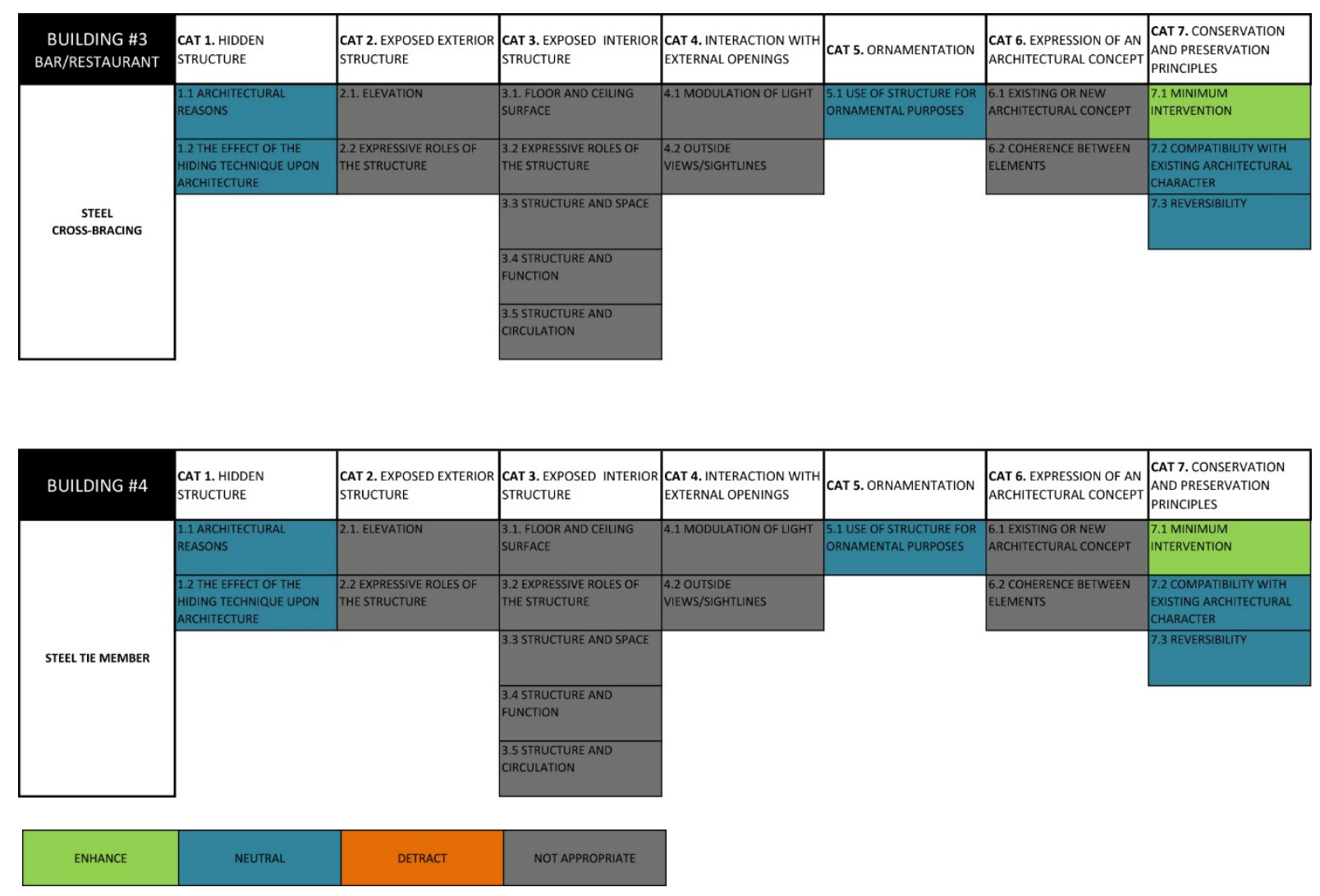

○ Category 1 - Hidden structure

- 1.1: Architectural reasons

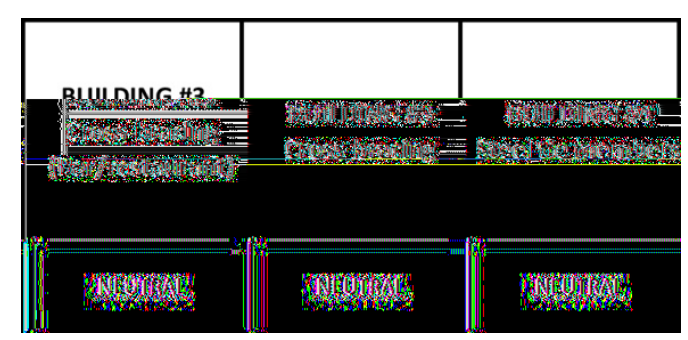

In Building \#3, horizontal cross-bracing is installed under existing timber floors. Most of its connections to other structural components are bolted. These include parallel flange channels (PFC) which are also dowelled into the walls and ensure load transfer between the horizontal and vertical structures. Building \#4 also possesses existing timber floors. Due to former seismic strengthening the retrofit work solely requires stronger wall-to-diaphragm connections. Where the external retrofit shear walls are located, connections are composed of threaded rods between the walls and steel plates welded to existing PFCs. On the solely URM walls, helical ties connect the existing structure to internal timber joists.

Based on the simple and plain design of the internal refurbishment of Building \#3, the horizontal retrofit structure is hidden by plain ceilings with no visual features. This layout conceals the presence 
of the cross-bracing and relates to the lack of interior architectural identity. With no evidence of the retrofit structure's existence, no contributions to visual architectural qualities are noticeable. A similar result is observable in the bar possessing an industrial and raw character. In both cases, the location of cross-bracing at the underside of floors also prevents any physical interaction with users and limits contribution to additional architectural qualities, such as functionality.

Regarding Building \#4, the retrofit structural elements are also accommodated inside the ceilings. The new plasterboard linings maintain the height and visual characteristics of the previous ceilings, thus preserving the existing architectural qualities of the interior spaces.

- 1.2: The effect of the hiding technique upon architecture

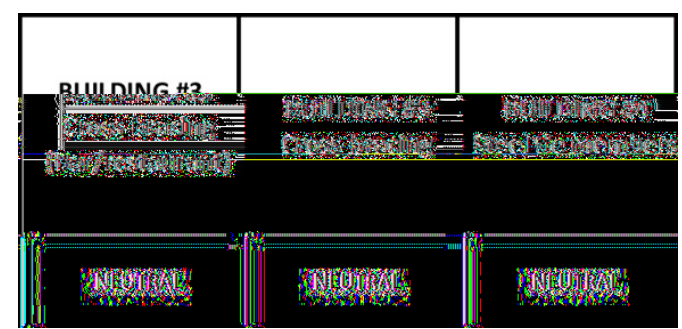

A screening technique is used to hide the horizontal retrofit structures in both buildings. In Building \#3, the plasterboard linings do not express the presence of the cross-bracing and their plain white surface does not introduce any architectural quality. In Building \#4, the use of a similar screening technique prior to and after the seismic retrofit, does not contribute any new architectural quality.

\section{○ Category 2 - Exposed exterior structure}

N/A: all the diaphragms are installed inside the buildings.

\section{○ Category 3 - Exposed interior structure}

\section{- 3.1: Floor and ceiling surface}

\begin{tabular}{|c|c|c|}
\hline $\begin{array}{c}\text { BUILDING \#1 } \\
\text { Composite steel } \\
\text { and concrete } \\
\text { decking }\end{array}$ & $\begin{array}{c}\text { BUILDING \#2 } \\
\text { Cross-bracing }\end{array}$ & $\begin{array}{c}\text { BUILDING \#2 } \\
\text { Plywood panels }\end{array}$ \\
\hline ENHANCE & NEUTRAL & DETRACT \\
\hline
\end{tabular}

Building \#2 possesses two distinct retrofit solutions strengthening the existing floors and influencing differently the surfaces of the diaphragms. At the ground and second floor, cross-bracing is installed 
just under the plasterboard ceilings of the existing timber floors. The other type of retrofit structure corresponds to plywood panels replacing part of the wooden floor-boards at the second floor.

The layout and geometry of the cross-bracing raise two issues. First, the cross-bracing is installed on a portion of an existing structural grid (Figure 77). This configuration creates a shape with no rhythm or overall pattern. Secondly, the diagonal members of half of the cross-braces do not meet at their centres, therefore creating a few different $X$ shapes with no visual continuity. These layout and geometry issues are however greatly mitigated. This first results from the flat shape and small sections of the diagonal members generating barely any additional depth to the ceiling. This characteristic, combined with the use of similar white paint colour on the ceiling and the crossbracing, lessens the presence of the retrofit structure. These two characteristics remarkably soften the lack of consistency of the horizontal retrofit structure.

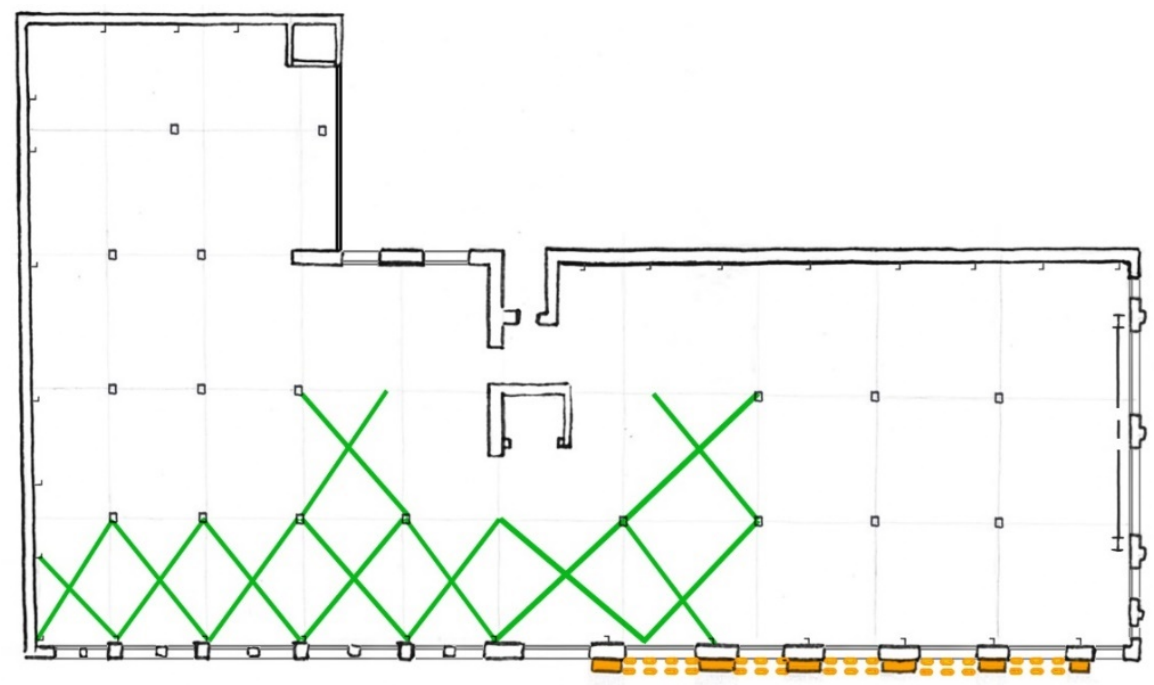

Figure 77. Second-floor ceiling plan of Building \#2 showing the location of the diagonal members of the cross-braces (green)

The plywood panels are also installed based on the existing structural grid (Figure 78). They however replace most of the existing wooden floor-boards just adjacent to the façade. Their negative influence on the existing floor results from the combination of two aspects. First, the presence of two different species of wood creates a contrast of tones. This distinction is reinforced by the raw surface of the plywood in contrast to the varnished floor-boards. In addition, the retrofit ply panels display annular rings as inherent motifs which are different from the rectilinear and longitudinally oriented floor-boards. On its own, the contrast does not detract from the existing flooring. In combination with the layout of the retrofit structure however it affects the relationship between new and existing components. As there is no rhythm or pattern combining both surfaces, the plywood panels appear as intruders. 


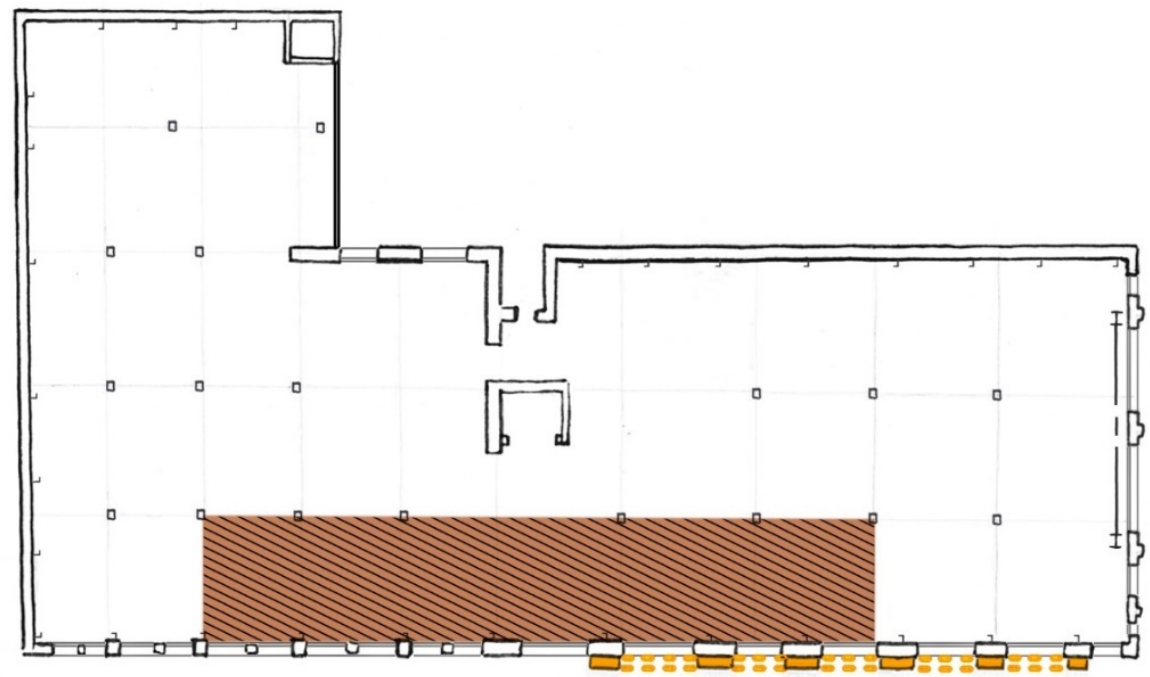

Figure 78. Second-floor plan of Building \#2 showing the location of the plywood panels (brown)

In Building \#1, the internal refurbishment and seismic retrofit result in the replacement of all the original timber floors by composite steel and concrete floors. The top surface of the new diaphragms is a continuous raw concrete. This treatment is different from the bottom of the diaphragms which possesses its own patterns. It is composed of a longitudinally-oriented trapezoidal profiled decking supported by transverse universal beams (UB) (Figure 79). Regarding the ground and first floor, the UBs are themselves supported by two pairs of castellated beams located along the edges of a large horizontal opening in both floors. Finally, a layer of irregularly located services brings fluidity to the strongly geometric structural pattern. This combination of structural and non-structural elements with different geometries and dimensions create a variation of depths which enlivens the bottom surface of the floors. In summary, the retrofit composite floors create new interior surfaces both at the top and the bottom of the floors. These new surfaces contribute the interior industrial character.

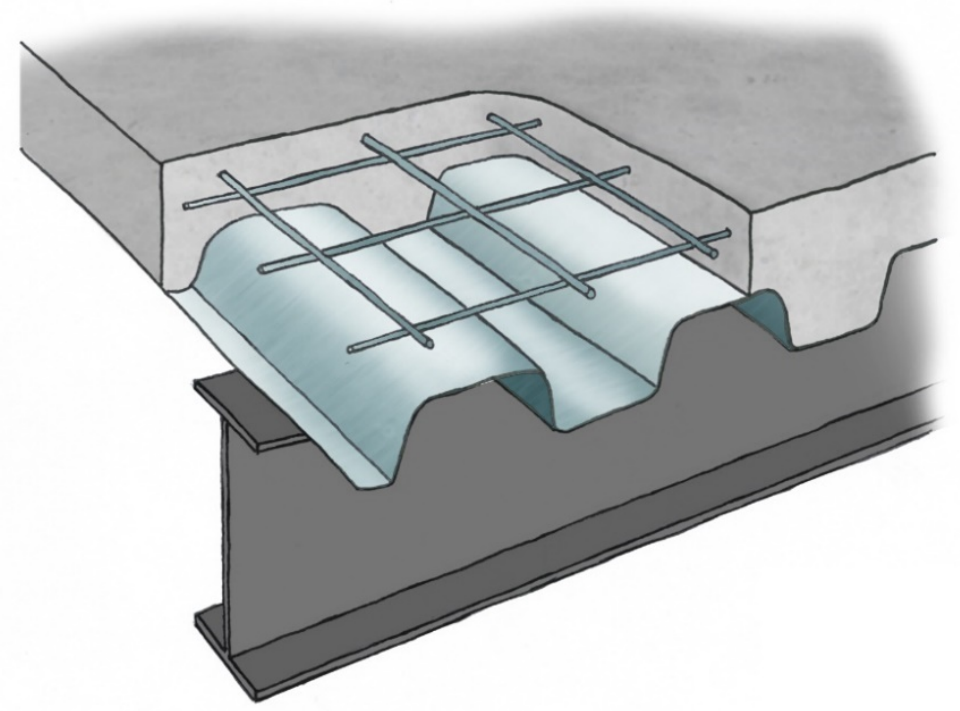

Figure 79. Detailing of the composite diaphragm used in Building \#1 


\section{- 3.2: Expressive roles of the structure}

\begin{tabular}{|c|c|c|}
\hline $\begin{array}{c}\text { BUILDING \#1 } \\
\text { Composite steel } \\
\text { and concrete } \\
\text { decking }\end{array}$ & $\begin{array}{c}\text { BUILDING \#2 } \\
\text { Cross-bracing }\end{array}$ & $\begin{array}{c}\text { BUILDING \#2 } \\
\text { Plywood panels }\end{array}$ \\
\hline ENHANCE & NEUTRAL & DETRACT \\
\hline
\end{tabular}

The presence of the cross-bracing in Building \#2 is diminished due to the flat shape, small sections and white paint of the members. Consequently, the diagonal members lack expressiveness. Their connections with the existing steel posts are however more striking as they express their materiality and construction technique. The detailing is simple but neat: a 90-degree angle steel plate painted red connects one side of an existing steel post to a diagonal member using two pairs of unpainted galvanised bolts. Such treatment of the plates and bolts distinguish them from the white painted cross-bracing and dark grey steel posts. This positive expressive quality is however diminished by the rest of the connections. On a couple of occasions, the cross-braces are not connected to the steel posts but to existing URM walls and to an existing beam. The detailing of the connections then changes with plates of different forms and the use of three and two bolts respectively per diagonal member (Figure 80). In addition, the connections are completely painted white. These variations are partially related to the building being a combination of two previous buildings and not having the steel posts located at identical distances. The lack of consistency in the detailing does not affect the individual technical qualities of the connections but it does limit and reduce their overall expressiveness.
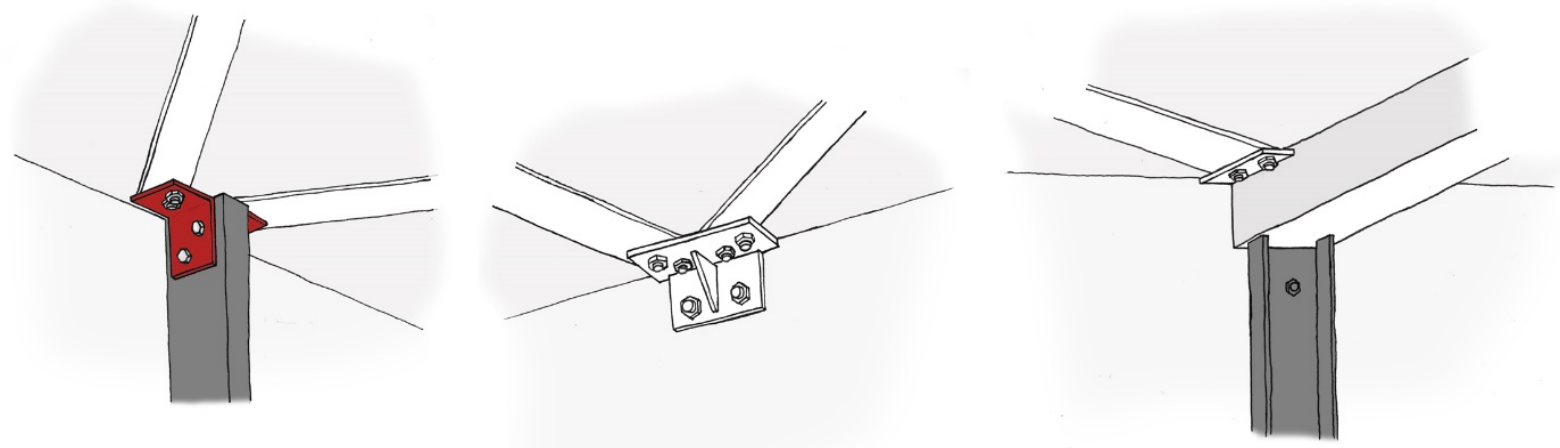

Figure 80. Detailing of the cross-bracing connections in Building \#2

In Building \#1, the composite decking fully expresses its materiality and construction technique. First, the concrete slab on top of the decking is cast-in-situ. The relatively rough surface relates to those of the shear walls and moment frames. Secondly, despite being painted grey, the steel components located under the decking provide a clear reading of the construction technique. Each 
structural layer displays its own characteristics and its connections with other structural components. The steel beams are, for instance, dowelled into the shear walls and moment frames with the use of a plate in between them. As a result, the retrofit structures seem to simply touch one another. The other junctions between the steel beams are more direct and reveal a large number of bolted connections. Such clear expression of the steel technical vocabulary and concrete raw materiality of the composite floors contribute to the interior industrial architectural character.

The plywood panels in Building \#2 are strongly expressive, due to their visual characteristics including their light tone, raw surfaces and annular rings, of their materiality. Their layout and the exposure of the nails fixing them to the existing joists further expresses their construction. Despite similar connections of retrofit panels and existing floor-boards to floor joists, their distinctive timber species and shapes clash and detract from each another. The expressiveness of the retrofit structure is therefore considered negative as it is detrimental to the existing floor-boards.

\section{- 3.3: Structure and space}

N/A: the horizontal orientation of the diaphragms and their locations avoid any interaction with spatial qualities.

\section{- 3.4: Structure and function}

N/A: the horizontal orientation of the diaphragms and their locations avoid any interaction with interior functionality.

\section{- 3.5: Structure and circulation}

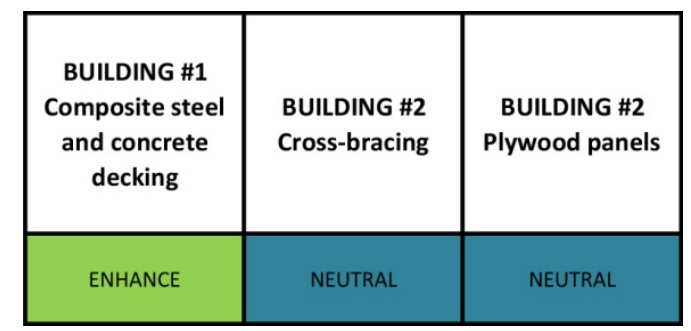

In Building \#2, neither the cross-bracing nor the plywood panels have any physical impact on the interior circulation. The first retrofit structure is located under the ceiling and the second replaces part of the existing floor-boards. Their relevance to the current quality could however be achieved by visually suggesting a circulation route. But such a characteristic is not achieved by the crossbracing as it is barely visible. The plywood panels strongly stand out from the existing floor yet does not define a direction for users to take. 
The interior planning of the ground and first floor of Building \#1 consists of usable spaces on the sides and a circulation area at the centre. This configuration is delimited by the locations of the moment frames. Based on this observation, the new composite floors make two contributions to circulation quality. First, two pairs of castellated beams run in the longitudinal direction and connect the central bays of the front and rear moment frames. The beams possess a unique pattern of hexagonal holes which makes them stand-out from the rest of the horizontal structural components (Figure 81). The layout and the detailing of the beams signal the direction of movement and suggest users move from the entrance to the rear end of the building. Secondly, the castellated beams partially frame the vertical circulation area (Figure 75). Where the moment frames delimit the transverse boundaries of the central horizontal opening, the castellated beams delineate its longitudinal edges. In so doing, the beams contribute to the identification of vertical circulation.

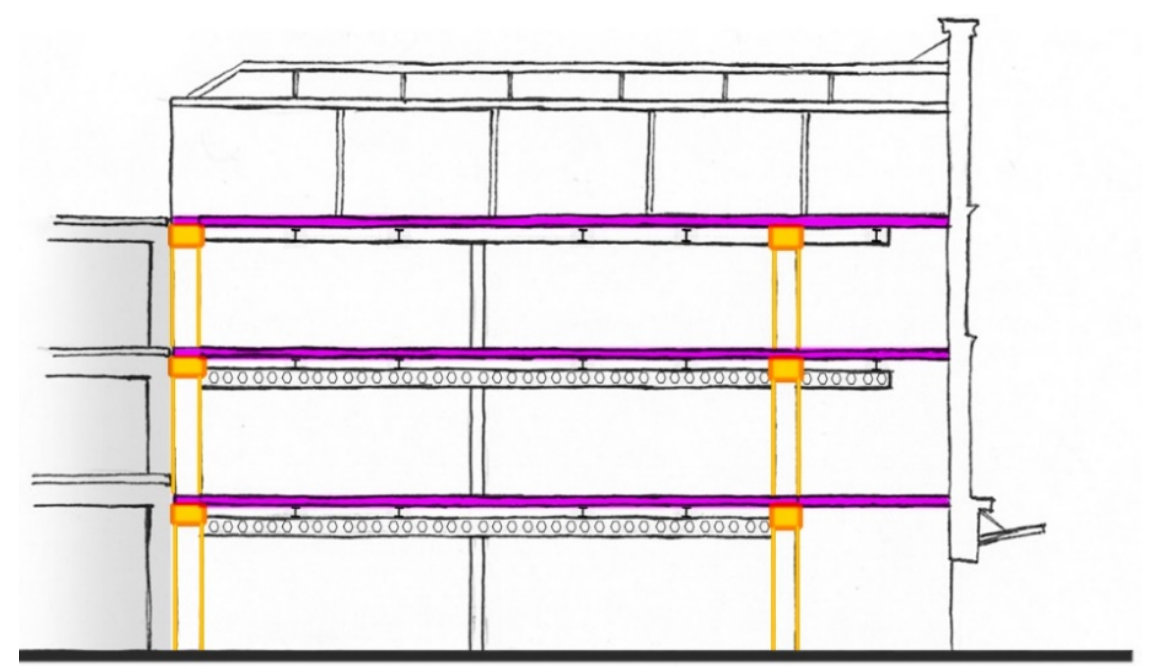

Figure 81. Section of Building \#1 showing the moment frames (orange), diaphragms (purple), and castellated beams located at the ground and first-floor

\section{$\circ$ Category 4 - Interaction with external openings}

N/A: the horizontal orientation of the diaphragms and their locations avoid any modulation of light or interaction with outside views.

\section{○ Category 5 - Ornamentation}

- 5.1: Use of structure for ornamental purposes

\begin{tabular}{|c|c|c|c|c|c|}
\hline $\begin{array}{c}\text { BUILDING \#1 } \\
\begin{array}{c}\text { Composite steel } \\
\text { and concrete } \\
\text { decking }\end{array}\end{array}$ & $\begin{array}{c}\text { BUILDING \#2 } \\
\text { Cross-bracing }\end{array}$ & $\begin{array}{c}\text { BUILDING \#2 } \\
\text { Plywood panels }\end{array}$ & $\begin{array}{c}\text { BUILDING \#3 } \\
\text { Cross-bracing } \\
\text { (Bar/restaurant) }\end{array}$ & $\begin{array}{c}\text { BUILDING \#3 } \\
\text { Cross-bracing }\end{array}$ & $\begin{array}{c}\text { BUILDING \#4 } \\
\text { Steel tie members }\end{array}$ \\
\hline ENHANCE & NEUTRAL & DETRACT & NEUTRAL & NEUTRAL & NEUTRAL \\
\hline
\end{tabular}


In Building \#2, the absence of an overall pattern of the cross-bracing layout and the lack of consistency of their $X$ shapes hinders its contribution to ornamental quality. This is further undermined by the poor visibility of the cross-bracing due to the flat shape of the members and white painting similar to the ceiling. Most of their connections with vertical structure are carefully designed and can be considered as technical ornament. However not all the connections have been treated with the same detailing and therefore lack consistency. As a result, the ornamental quality of the connections is diminished.

In the same building, each plywood panel's annular rings result from its materiality. These inherent motifs provide a possible basis for an ornamental contribution. However, no relationship is developed between the layouts of the retrofit panels and the existing floor-boards. The plywood panels replace part of the former surface, resulting in a clash between the existing and retrofit elements and therefore not developing any ornamental pattern.

In Buildings \#3 and \#4 retrofit structures are hidden in both buildings using white plasterboard linings with smooth surfaces. With no decorative features on the ceilings, or visual relationships with the retrofit structural components, no ornamental quality is introduced.

Among all the structural components of the new composite floors in Building \#1, the castellated beams stand out the most. This results from their central locations, large dimensions, and their location below the composite floors which places them closest to the sight of a building user. This visual prominence, combined with their unique pattern of hexagonal holes along their lengths, justifies classifying labels the castellated beams as ornaments (Figure 75 and Figure 81).

\section{○ Category 6 - Expression of an architectural concept}

\section{- 6.1: Reinforcement of an existing architectural concept or development of a new one}

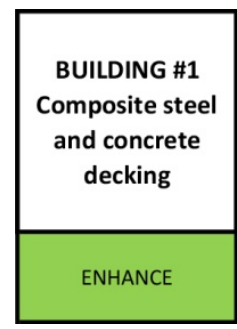

The previous analyses have noted the lack of existing architectural concepts in any of the buildings. Only Building \#1 managed to develop a new concept involving a contrast between its existing front façade and its fully refurbished interior. The new composite floors enrich the interior architectural 
character as explained in sub-categories 3.1 and 3.2 and thus contribute to the architectural concept.

\section{- Category 7 - Conservation and preservation principles}

- 7.1: Minimum intervention

\begin{tabular}{|c|c|c|c|c|c|}
\hline $\begin{array}{c}\text { BUILDING \#1 } \\
\begin{array}{c}\text { Composite steel } \\
\text { and concrete } \\
\text { decking }\end{array}\end{array}$ & $\begin{array}{c}\text { BUILDING \#2 } \\
\text { Cross-bracing }\end{array}$ & $\begin{array}{c}\text { BUILDING \#2 } \\
\text { Plywood panels }\end{array}$ & $\begin{array}{c}\text { BUILDING \#3 } \\
\text { Cross-bracing } \\
\text { (Bar/restaurant) }\end{array}$ & $\begin{array}{c}\text { BUILDING \#3 } \\
\text { Cross-bracing }\end{array}$ & $\begin{array}{c}\text { BUILDING \#4 } \\
\text { Steel tie members }\end{array}$ \\
\hline NEUTRAL & ENHANCE & NEUTRAL & ENHANCE & ENHANCE & ENHANCE \\
\hline
\end{tabular}

The removal and modification of key architectural and historic features are kept to a minimum in Buildings \#1 and \#2. Two reasons can be given. First, as the retrofit structures are solely internal, the heritage façades of both buildings remain unaffected. Secondly, the modification to and loss of interior architectural features are considered moderate, despite different amounts of work in both buildings. In the first building, all the existing floors were replaced by steel and concrete composite systems. With no information on the architectural contribution of the existing floors prior to the seismic retrofit, benefit of the doubt is given to the designers and any loss of possible architectural qualities is disregarded. In Building \#2, the work is less extensive. It focuses on the partial replacement of the surface of one floor. Although affecting the aesthetic of the existing floorboards, the number of plywood panels is limited and the work kept to a minimum.

The other floor diaphragm strengthening systems in Buildings \#2, \#3 and \#4 are positive in regards to the current sub-category. First the systems are located internally, therefore preserving the key architectural and historic features of the existing façades. The second reason relates to the locations of the retrofit structures inside the ceilings as in the case in Buildings \#3 and \#4, or exposed under it in Building \#2. In the first two buildings, the installations of the retrofit structural components avoid any removal or visual modification of the existing floors. In the third building, the ceiling possesses no architectural value that could be affected by the subtle change of surface due to the cross-bracing members. 
- 7.2: Compatibility with existing architectural character

\begin{tabular}{|c|c|c|c|c|c|}
\hline $\begin{array}{c}\text { BUILDING \#1 } \\
\begin{array}{c}\text { Composite steel } \\
\text { and concrete } \\
\text { decking }\end{array}\end{array}$ & $\begin{array}{c}\text { BUILDING \#2 } \\
\text { Cross-bracing }\end{array}$ & $\begin{array}{c}\text { BUILDING \#2 } \\
\text { Plywood panels }\end{array}$ & $\begin{array}{c}\text { BUILDING \#3 } \\
\text { Cross-bracing } \\
\text { (Bar/restaurant) }\end{array}$ & $\begin{array}{c}\text { BUILDING \#3 } \\
\text { Cross-bracing }\end{array}$ & $\begin{array}{c}\text { BUILDING \#4 } \\
\text { Steel tie members }\end{array}$ \\
\hline ENHANCE & NEUTRAL & NEUTRAL & NEUTRAL & NEUTRAL & NEUTRAL \\
\hline
\end{tabular}

Most horizontal retrofit systems have a neutral influence regarding architectural character. The common reason is the absence of interaction between the buildings' façades and the structural components constituting the diaphragms. The architectural characters of the façades are unaffected. Other reasons are specific to each building.

In Building \#2, no specific architectural character is noticeable, but most of the spaces strongly exhibit the materiality of their existing structural components. The interior face of the URM front façade has its bare brick surface exposed, the timber floor-boards are simply varnished, and the steel posts and existing braced frames, although painted grey, display their typical profiles and bolted connections. The retrofit cross-bracing, although related to other steel structural components, is not noticeably expressive. Its contribution to the current sub-category is thus nonexistent. The plywood panels are much more expressive of their wooden materiality. However, they fail to establish a relationship with the existing floor-boards. Considering the scale of the building, the presence and therefore the impact of the plywood panels on the architectural character quality is limited and considered neutral.

In Buildings \#3 and \#4, the hidenness of the retrofit structural components limit any contribution to potential architectural character. As part of the internal refurbishment of Building \#3, the retrofit cross-bracing is hidden inside the new ceilings with no evidence of its presence and the ceilings display no decorative features. The horizontal structure fails to develop a new architectural character in most spaces and to engage with the industrial character of the bar of Building \#3. In Building \#4, plasterboard linings similar to the existing ones cover the strengthening components, therefore maintaining the existing architectural character.

The horizontal retrofit structure in Building $\# 1$ contributes to a contrasting interior character with the front façade. This is achieved by its inherent concrete and steel components. Combined with the shear walls, moment frames, exposed existing structures and exposed services systems, the composite floors create a powerful industrial character. 
- 7.3: Reversibility

\begin{tabular}{|c|c|c|c|c|c|}
\hline $\begin{array}{c}\text { BUILDING \#1 } \\
\begin{array}{c}\text { Composite steel } \\
\text { and concrete } \\
\text { decking }\end{array}\end{array}$ & $\begin{array}{c}\text { BUILDING \#2 } \\
\text { Cross-bracing }\end{array}$ & $\begin{array}{c}\text { BUILDING \#2 } \\
\text { Plywood panels }\end{array}$ & $\begin{array}{c}\text { BUILDING \#3 } \\
\text { Cross-bracing } \\
\text { (Bar/restaurant) }\end{array}$ & $\begin{array}{c}\text { BUILDING \#3 } \\
\text { Cross-bracing }\end{array}$ & $\begin{array}{c}\text { BUILDING \#4 } \\
\text { Steel tie members }\end{array}$ \\
\hline NEUTRAL & ENHANCE & ENHANCE & NEUTRAL & NEUTRAL & NEUTRAL \\
\hline
\end{tabular}

In all four buildings, the removal of the horizontal retrofit systems can be undertaken without affecting key architectural and historic values.

In Building \#1, the composite floors utilise two main types of connections. The most straightforward ones to remove are the bolted connections between the different steel components. More challenging are the dowelled connections between the steel beams and the concrete shear walls, URM walls, and moment frames. Their removal would lead to some damage of the concrete and URM walls and would involve some repairs. Another aspect to take into account is the removal and reinstallation of the all services attached to the composite floors.

The retrofit systems in Buildings \#3 and \#4 are hidden so this would minimise any potential architectural loss during their removal. Their access would however first require the destruction of the ceilings. In Building \#3, the cross-bracing members are bolted to the flange channels which are dowelled into the concrete and URM walls. Once again, the first type of connection is simple to remove, but the dowelled connections would require repairs. In Building \#4, the threaded rods and helical ties connecting the timber floors to the walls would also require reasonable restoration.

The two horizontal retrofit systems in Building \#2 can be easily removed. The cross-bracing members and their bolted connections, are located below the ceiling and effortlessly accessible. Concerning the plywood panels, they are simply nailed to the existing joists, and would barely require any effort to remove them. Their removal would also allow easy access to the threaded rods tying the joists to the URM wall of the front façade. Following that process, reinstatement of floorboards identical to the existing ones would be required.

\section{- Final comments}

This section discussed the different integration outcomes of retrofit diaphragms and architectural qualities in Buildings \#1, \#2, \#3, and \#4. The comparison of the Tables of Analysis leads to three main observations: 
- the influences of the retrofit diaphragms on the architectural qualities are mostly neutral,

- all the architectural qualities in Building \#1 are enhanced by the horizontal retrofit structure, with the exception of minimum intervention and reversibility principles. None of the other buildings has its retrofit structure contributing to any architectural quality,

- the exposed plywood panels in Building \#2 are the only retrofit elements to negatively influence architectural qualities.

Building \#1 clearly stands out from the other buildings. Its composite floors successfully integrate with several architectural qualities. Their inherent steel and concrete materiality relates to other structural components, both existing and new, and to a significant extent contribute to the contrasting architectural concept as noticeable in sub-category 6.1. The detailing of the new floors provides further enhancements to sub-categories 3.1 (Floor and ceiling surface), 3.2 (Expressive role of the structure), 3.5 (Structure and circulation) and 5.1 (Use of structure for ornamental purposes). Such important architectural roles played by the composite floors could compensate for replacing the existing floors. This approach however directly affects sub-categories 7.1 (Minimum intervention) and 7.3 (Reversibility) which, as a consequence, are limited to neutral influences. These influences could further be identified as negative depending on any loss of architectural and historic values during the replacement of the existing floors and the potential destructive removal of the new composite retrofit structures. Careful reflection must be undertaken by the designers, client and any stakeholder related to the building's heritage value in order to evaluate the architectural gain and the loss from such design decision.

In Building \#2, while both horizontal retrofit systems are exposed, their integration with architectural qualities result in different influences. The following observation can be made. Visually limiting the presence of horizontal structure helps maintain a neutral influence on architectural qualities, while a clear distinction can potentially enhance or weaken them. If the retrofit structure is visually expressed regardless of its relationship with the existing surface, the risk of a negative integration with architectural qualities is high. Where no intentional visual relationship can be designed, the preferable option seems to reduce as much as possible the presence of the new retrofit structure and aim for a neutral integration.

Despite three different architectural contexts, Buildings \#3 and \#4 show very similar results. This leads to two observations. First, physical interactions between horizontal systems and interior spaces are barely existent. Indeed, the locations of horizontal retrofit structures under floors limit their potential contributions to solely visual architectural qualities. The selection and design of hiding techniques are therefore paramount for a potential enhancement of architectural qualities 
by horizontal systems. Secondly, despite three distinct architectural environments, the hidden retrofit structures all have neutral influences on architectural qualities. It appears therefore that the influence of hidden retrofit solutions on architectural qualities might be independent of the interior environment.

Sub-category 7.1 (Minimum intervention) is mostly positively influenced by the retrofit structures with the exception of two neutral results. Although the façades carry the key historic values, some floors may possess inherent architectural interest. Any intervention by retrofit structures on them would therefore either neutrally or negatively influence the minimum intervention principle. In subcategory 7.2, with the exception of Building \#1, architectural character is neutrally influenced. Two observations can be made. First, the ceilings of the existing floors are bland with no architectural contribution. They display smooth and continuous surfaces which provide opportunities for the retrofit solutions to use them as blank canvases in order to develop visual architectural qualities. However, the retrofit structures are either hidden or expressed in a limited way. This leads to the second observation. Integrating retrofit structure with architecture by hiding it inside ceilings mitigates possible negative visual issues. In contrast, direct modifications to existing floors are riskier and require careful reflection on their integration. Buildings \#1 and \#2 provide relevant examples. In Building \#1, the massive change greatly contributes to the architectural character. In Building \#2, it weakens it, although moderately. Finally, in sub-category 7.3 (Reversibility), most retrofit structures have similar types of connections. The distinction between positive and neutral assessment of potential structural removal mainly relates to the amount of work required to access the connections prior to removal.

Overall, a diaphragm system potentially integrates with fewer architectural qualities than vertical seismic structures. While its integration with the remaining architectural qualities is largely neutral, a diaphragm system is also capable of positively contributing to them. This difference partially results from the entire replacement of existing floors by new diaphragms in comparison to the addition of structural components to existing floors. The other reason corresponds to the exposure and detailing of the diaphragm. These two characteristics contribute to the expression of the architectural character and are justified by the architectural concept. Finally, while it might be technically sound, partial replacement of existing floors increases the risk of poor integration.

\subsection{Discussion and Summary}

The integration of retrofit structure and architecture was examined through the results of the Tables of Analysis illustrating the various influences of vertical and horizontal seismic systems on 
architectural qualities. The analyses of the results describe and compare the reasons explaining these influences. A notable variety of consequences can occur between a single seismic system and the architectural qualities. Common patterns have been found which suggest inherent limitations or capacity of a seismic system to affect specific architectural qualities.

Although none of the seismic systems can be considered optimal or flawless from an architectural perspective, some appear more suitable than others to integrate with certain architectural qualities. Thus, this section discusses the results of the analyses by comparing the four main seismic structural systems; namely, shear wall, braced frame, moment frame, and diaphragm. It considers whether certain seismic systems are more likely to positively, neutrally or negatively integrate with specific architectural qualities.

\subsubsection{Category 1 - Hidden structure}

Functionality and architectural character are two qualities enhanced by hidden moment frames in Building \#5. However, the geometry of the retrofit structure has no impact on these architectural qualities as no visual relationship is developed between the encased structure and the linings. The plasterboard linings become directly responsible for achieving positive integration with architectural qualities. This implies that the improvement of architectural qualities such as function and architectural character can be independent of the seismic structure being used. From an architectural perspective, hidden braced frame or shear wall systems can also achieve a similar level of integration regarding the above mentioned architectural qualities.

Hiddenness offers an opportunity to integrate any seismic structure while avoiding its identification. This approach can preserve the existing architectural features and image of an existing building, as is the case with hidden braced frames in Building \#4. Regarding heritage buildings, hidenness appears relevant as it might be able to maintain existing architectural and historic features.

Hiding a seismic structure whose integration has not been thought through when designing the retrofit can greatly attenuate its impact on existing architecture. It is more sensible to hide an undesirable element than let its exposure weaken architectural aspects. Hiding structure to limit architectural issues may explain the lack of poor integration and negative impacts in any of the Tables of Analysis. 


\subsubsection{Category 2 - Exposed exterior structure}

Shear wall and moment frames systems are respectively located on the façades of Building \#4 and \#2. Both systems have been designed to visually merge with the existing façades which results in two findings. First, this approach directly reduces the expressiveness of both seismic structures which as a consequence are considered as neutral. Secondly, neither of the seismic structures enhances the exterior elevations. Regarding the moment frame, the merging approach mimics the existing façade, thus resulting in a neutral impact on the elevation. The shear walls however are installed on sections of façades characterised by uniform and continuous elevations. Although the existing ornamental pattern of steel plates is maintained, the locations and depth of the shear walls as well as the loss or reduction of windows weaken the elevations and architectural character of the existing building.

In the end, neither of the two seismic structures appears particularly effective in positively integrating with external qualities. This observation is partially related to the structures' geometries, dimensions and locations. In addition, the large dimensions of the façades with exposed architectural features can further challenge designers. Finally, the visual merging of new and existing structure prevents positive integration.

\subsubsection{Category 3 - Exposed interior structure}

Regarding Category 3, the braced frame is the only seismic structure that integrates poorly with each of the architectural qualities, although not in all buildings. This appears to be a direct consequence of its unique geometry that highlights its presence in a stronger way than shear wall or moment frame structures. However, advantage can be taken of this characteristic to achieve successful integration with various qualities, as is the case in the bar of Building \#3. The braced frame creates a motif on an internal elevation and expresses the location of a door and its passage which thus contributes to the circulation quality. However, the difficulties of integrating this complex geometry with other features of a building are also noticeable. Partition walls dividing braced frames into random structural components in most spaces in Building \#3 illustrates this issue. The superimposition of the seismic structure on the geometry of openings on existing elevations is another example of poor integration. Finally, the location of the structure can also be detrimental to function and circulation as it may restrain movement and usability of spaces. A braced frame thus appears as a powerful building component for integration with interior architectural qualities only with extreme care and attention from the designers. 
Shear walls can achieve positive integration and enliven certain architectural qualities. In Buildings $\# 1$ and \#3, the large dimensions of the shear walls and their raw materiality redefine the internal elevations and contribute to the structures' expressiveness. This is a reminder that a lack of striking geometry of seismic structure can be compensated by appropriate dimensioning and surface treatments.

Moment frame is used for expressive purposes thanks to its raw materiality and detailing in Building \#1. Similarly to the braced frames, the seismic structure also frames a passage, in this case the building's main entrance and the escalators leading to the upper floor. Moment frame is however the only seismic structure positively integrating and engaging with the spatial and functional qualities of interior spaces in Building \#1. Unlike the shear walls and braced frames commonly installed against or in front of existing walls, the two moment frames are used at the centre of interior spaces. Although their locations are based on an existing structural grid, their small number combined with their massive dimensions opens up the interior while strongly emphasising spatial boundaries. Moment frame thus appears as the most effective structure to integrate with physical qualities in Building \#1.

Concerning the exposed diaphragms, their integration with the architectural qualities greatly varies from one building to another. This is mainly due to the variety of diaphragms' designs and the different structural components constituting them. As a result, no generalisation can be made regarding the integration of diaphragm and interior architecture. In Building \#1, the entire replacement of the existing floors gave the designers the opportunity to enhance all the interior visual qualities. In Building \#2, the visual limitation of the steel cross-bracing ensured a neutral integration. In the same building, the lack of a thoughtful relationship between the existing floor surface and plywood panels weakened their integration.

\subsubsection{Category 4 - Interaction with external openings}

Enhanced integration with natural light is found in two examples involving shear walls and hidden moment frames. In the first case, the white and reflective surfaces of the shear walls contribute to the diffusion of natural light inside the interior spaces. In contrast, in the second case, the dark linings hiding the moment frames prevent light from penetrating too far inside the building. The modulations of light, although positive in both examples, are thus different as they actually serve different objectives. Where in the first example the treatment of natural light improves the usability of the spaces, in the second scenario it contributes to a dark architectural character. These examples 
stress that integration of seismic structure and natural light should be justified by architectural intent.

Examples of shear walls and braced frames poorly integrated with natural light and views due to partial or full obstructions of openings are noticeable. Regarding shear walls, the difficulty arises from their relatively large dimensions required to withstand lateral loads. This characteristic becomes problematic when shear walls are installed on external walls with numerous windows. Concerning the negative impact of the braced frames, it arises from their diagonal members passing in front of openings. Integrating both the geometries of windows and braced frames in a satisfactory way has not been achieved in any of the buildings.

\subsubsection{Category 5 - Ornamentation}

Examples of shear wall and braced frame systems positively integrating with ornamental quality can be noticed in Buildings \#3 and \#4. In each, the seismic system appears as a unique element standing out from other features in internal spaces. For the shear walls, their uniqueness results from their construction techniques creating ornamental surfaces. Regarding the braced frame, its fully displayed geometry contrasts with the existing wall behind.

The unique geometry of a braced frame structure is however double-edged as the V-braced frame in Building \#5 demonstrates. Although the seismic structure possesses several characteristics defining it as ornament, its location in front of an existing glazed wall creates a contradiction of visual patterns. As a result, the integration of the braced frame with ornamental quality is considered negative. This example stresses the importance of not simply detailing a seismic structure as ornamental but also ensuring its compatibility with other ornamental features.

The integration of diaphragm and ornamental quality is largely neutral. This results from design approaches reducing their visual presence by hiding them using bland plasterboard ceilings or painting them to avoid any contrast. Enhanced integration appears with exposed diaphragms when fully replacing existing floors. However, partial seismic strengthening of a diaphragm leads to the risk of disrupting an existing ornamental pattern.

\subsubsection{Category 6 - Expression of an architectural concept}

Building \#1 takes advantage of the seismic retrofit to develop and express an architectural concept. The shear walls and moment frames, as well as the diaphragms, define a strong raw and industrial character inside the building. This interior character, in contrast to the external character, leads to 
an unmistakable architectural concept. As stated by Edward White (1975) a concept is reinforced when different components express it. It is therefore the way the three seismic systems convey the same conceptual message that ensures effective integration. Furthermore, these seismic systems are coherent not only between one another but also with all the structural and non-structural components that display a similar technical and industrial vocabulary.

\subsubsection{Category 7 - Conservation and preservation principles}

Out of the three conservation and preservation principles, minimum intervention appears to be the one most evident in all three vertical seismic structures. This is noticeable by the number of seismic systems located internally in all five buildings, thus preserving architectural and historic features of the façades. Each seismic structure possesses unique aspects to limit the impact of its presence and achieve neutral to positive integration. Regarding shear walls, this results in installations against existing walls possessing no architectural features, location in secondary spaces, or small structural dimensions with respect to the building's size. Braced frames rely on limited physical contact and replacement of existing hidden braced frames. Finally, moment frames are aligned on an existing structural grid or installed inside existing bays. It is difficult to state that one seismic structure is more adapted to this particular minimum intervention principle than another, as each approach appears appropriate. The selection of a seismic system and its implementation must be considered in regard to the existing architectural and historic features that its presence might affect.

Concerning diaphragms, despite their variety of designs, no particular retrofit approach contributes to ensure minimum intervention. The achievement of a positive integration regarding this principle mainly results from most existing floors simply lacking architectural interest.

Although not as numerous as the minimum intervention principle, examples of positive integration and compatibility with existing architectural character are observed with each seismic system in Buildings \#1, \#3 and \#5. The four seismic systems actually follow an identical approach. First, they are located internally therefore maintaining the architectural character of the façades. Secondly, they all participate in an internal refurbishment defining a new architectural character. The outcome in all cases is a new architectural layer distinct from yet complementary to the existing architectural character. The only poor integration of seismic structure and architectural character comes from external shear walls in Building \#4. The reasons are identical to the ones indicated in Category 2 of this section. 
Regarding the reversibility principle, it is almost exclusively neutral with the exception of positive influences from two diaphragms and one braced frame, and one negative influence from a moment frame system. Although these systems are exposed and easily accessible, their connections influence their level of integration. The braced frame in Building \#5 is bolted to the existing structure and similar connections apply to the steel cross-bracing of the diaphragm in Building \#2. Other easily removable connections are the nails attaching the plywood panels to the existing joists in Building \#2. However, the moment frame in Building \#2 is dowelled into the existing façade that it covers almost entirely. The loss and damage to architectural and historic features if the seismic systems should be removed are therefore drastically different.

\subsection{Chapter summary}

This chapter gives insight to factors influencing the contribution of seismic systems to architectural qualities. It indicates issues that weaken integration, as well as characteristics of the seismic structures and conditions that enhance the relationship between seismic retrofit and existing architecture and therefore integration. The chapter also stresses that some seismic systems are more effective to integrate with some architectural qualities than others. Chapter 5 thus provides a first series of answers to two objectives of the research: the identification of factors affecting integration, and potential predisposition of seismic structural systems to engage with existing architectural qualities.

To refine and complement these observations and analyses, further insight into the design process via points of view of key designers is required. The following chapter therefore focuses on interviews of both the structural engineer and architect of each of the five URM buildings. The interviews provide a holistic understanding of the factors and decisions affecting integration, as well as identifying a hierarchy of importance of architectural qualities. 
PAGE LEFT INTENTIONALLY BLANK 


\section{CHAPTER 6. INTERVIEWS OF THE ARCHITECT AND STRUCTURAL ENGINEER OF THE FIVE CASE STUDIES}

\subsection{Introduction}

In the previous chapter, the researcher approached the integration of seismic retrofit and architecture from the perspective of how seismic structures influence architectural qualities. Benefits and disadvantages of each structural system have been presented to provide greater understanding and awareness of the interaction between seismic retrofit and architecture. To further deepen the analysis of factors influencing integration, investigation on the development and achievement of integration of retrofit and architecture in the five case studies must be undertaken. To do so, interviews of the architects and structural engineers of each of the URM buildings have been undertaken.

The current chapter discusses the findings of the interviews and is organised in three sections based on the sets of questions asked to the designers. The first section focuses on the designers' definition of integration based on their experiences as practicing architects and structural engineers. The aim is to understand how each type of designer approaches integration.

The second section focuses specifically on integration within each retrofitted building. For each building, its Tables of Analysis of the seismic systems it possesses are presented. This gives an overview of the seismic retrofit integration and allows comparison with the explanations provided by the designers regarding their consideration of each architectural quality.

The third section relates to the design process and decision-making. The designers are questioned on the development of the retrofit solution, as well as on issues such as leadership and constraints to integration.

In a concluding section, the researcher discusses the findings of the interviews. Two categories of findings are presented. First, based on the designers' experience, critical factors influencing integration are indicated. In addition, recommendations to achieve successful integration are suggested. Secondly, the factors affecting the integration of seismic retrofit and architecture in each of the five URM buildings are presented. 
Chapter 6 thus concludes the objectives of the research initiated in Chapter 5. It highlights key factors affecting integration of seismic retrofit and architecture both within and outside the design process, and refines some of the results from the previous chapter by considering the designers' reflection on their own work.

\subsection{Designers' opinions on integration of seismic retrofit and architecture}

\subsubsection{Practicing architects' opinions}

\section{Successful integration as defined by architects}

The five architects revealed three different conditions for integration to be considered successful. The first condition is based on the respondents' unanimous response that seismic structure and existing architecture are linked to one another if only due to their presence within the same building. Successful integration depends on their mutual respect and that they should not negatively affect each other. The seismic design requires a control of the impact seismic structure may have on existing architecture. Architect \#1 stated that "[a successful integration] doesn't ignore how the building already worked both structurally and architecturally". Seismic structure should therefore be sympathetic to both the architecture and existing structure of a building. The respondents also pointed out specific architectural qualities that seismic structure should avoid disrupting. Several architects mentioned functionality which was justified by Architect \#2 because of its direct consequence on the building's rentability. If seismic retrofit reduces a building's usability the risk of failing to let the property rises. The location of seismic structure in front or behind openings was also brought up by Architects \#3 and \#4. Circulation, natural light and outside views were mentioned as architectural qualities necessitating careful consideration. For Architect \#3, consideration should not solely include modifying the seismic structure to fit the openings, but also the possible adaptation of openings to accommodate retrofit work. Integration may thus not be exclusively dependent on the design of the seismic solution but also on the capacity of the existing architecture to be adjusted. The respondents acknowledged that integration might be equally achieved by exposed or hidden seismic structure. Their only concern was the compatibility of the seismic solution with the building's existing aesthetic, and to a larger extent with its architectural character. The integration of seismic components is achieved where no visual contradictions are present.

The second condition for successful integration was mentioned by one architect (\#1). In this case, integration is not exclusively the result of a respectful impact of seismic structure on existing architecture. Instead, seismic retrofit must have a proactive role in enhancing the building's 
architectural value. Retrofit should respond to the existing architectural concept but also enhance it. Retrofit structures should therefore not simply be considered as technical components. As the architect mentioned, "you also have a structural engineer who really pushes the seismic solution to work architecturally". The engineer must have a wider appreciation of the retrofit structure beyond its technical requirements. Admiring exposed seismic work, the architect added "[a building] should celebrate its strengthening rather than trying to hide it. ... [it's] a celebration of the fact that the building is a living thing that keeps changing". Seismic retrofit should be looked at through various perspectives, but always as a positive contribution to a building's architecture and history.

Finally, successful integration was described as the outcome of a carefully undertaken design process with key aspects to consider. First, Architects \#2 and \#3 commented on the importance of being involved from the very start of the project - between the seismic assessment of the structural engineer and the beginning of Concept Design. The aim is to ensure that each designer can express their requirements so a solution acceptable to both parties can start being designed. The second aspect was the importance of coordination between the different stakeholders, including fire and services engineers. Their presence was also recommended during the Concept Design stage and should help refine the intended solution to make it achievable. Any demands or constraints should be discussed. Accessibility and fire legislation were identified by Architects \#1, \#4 and \#5 as recurring constraints yet not directly affecting integration. Another aspect not directly affecting integration yet necessary to the continuity of the project, is the approval of the Building Consent by the City Council. Architect \#4 suggested having an architect with experience on retrofit projects as well as qualified fire engineers to mitigate any design changes or rejection by the Council. A final aspect concerned the issue of cost. The respondents agreed that respecting the client's budget is a fundamental criterion for successful integration. For Architect \#5, designers and client must be aware that the seismic retrofit work might also lead to some degree of refurbishment or architectural adaptation. Another important point made was the economic consequences of a seismic solution on various non-structural features. Architect \#2 warned that the cheapest seismic scheme might not end up being the most cost-effective solution. He indicated that a cheap solution might have great repercussions on aspects such as mechanical or services requirements, increasing the final cost of the seismic retrofit. In contrast, a more expensive solution with fewer modifications might be more cost-effective to the client.

The last advice provided by Architect \#1 was the need to consider the financial consequences of retrofit regarding the current use of a building. An occupied building usually means tenants paying rent. The seismic solution must therefore be designed so the building users do not have to leave 
their spaces. The advice stressed the importance of guidance from the designers to the client regarding the total cost being more than the basic cost of retrofit structure.

\section{Poor integration as defined by architects}

Most architects pointed out the responsibility of the structural engineer for poor seismic integration. While praising the open-mindedness of most engineers in taking into account architectural requirements, some criticisms were also raised. The main criticism concerned the motivations of some engineers in retrofit projects. Examples of projects driven exclusively by the structural engineer and focusing solely on seismic strengthening with no desire for architectural input or debate were mentioned. Architects \#1 and \#2 suggested either a lack of architectural knowledge or arrogance of the engineers. Structural engineers only aiming for the cheapest or fastest solution instead of considering a solution that would satisfy a larger range of stakeholders, including the client, were also severely criticised. Architect \#1 encouraged engineers to design more sophisticated and state-of-the-art seismic solutions, albeit more time consuming and less straight forward, than rushed and simplistic schemes.

Architects \#4 and \#5 were also critical toward the attitudes of some of their peers. They explained that although the primary goal of retrofit is to seismically strengthen a building, architects should be prepared to contest or at least question an engineer's design. Architectural issues must be pointed out to the engineer, and architects should propose adaptations and suggestions. Poor integration may thus result from an architect not daring to push the engineer to refine his or her seismic design in order to achieve architectural goals. The sizes of seismic members, their scale, location and detailing were stressed as issues that commonly affect integration if not confronted by an architectural perspective.

\subsubsection{Practicing structural engineers' views}

\section{Successful integration defined by structural engineers}

Most structural engineers were aware of the strong interaction between seismic structure and architecture. Like the architects, they stated that the seismic solution should have a limited impact on a building's architecture. The respondents believed that respecting two architectural qualities ensured successful integration. The first is functionality. Engineer \#1 considered this a primary quality as a client would usually undertake seismic retrofit so the building could remain usable. Disrupting this aspect would be considered as a failure of the seismic retrofit design. The second quality encompasses terms such as "architectural sensibility of the space" (\#1), "heritage external 
façades" (\#2), "aesthetic" (\#3), "aspects of architectural significance" (\#5). All these terms can be included within the 'architectural character' quality. The engineers expressed the importance of maintaining these aspects virtually unchanged, or at the very least minimising any modifications. Engineers \#1 and \#3 pointed out that to reach such an aim, hiding the seismic structure would be the most appropriate approach. They did not reject the use of exposed structure but recommended a clear distinction between new and existing features.

The importance of an effective design process in achieving integration was also raised. A first aspect is the consideration of initial requirements and agreements framing the seismic retrofit work. Engineer \#2 listed three requirements; namely, the desired percentage of NBS, cost and timeframe. As long as the retrofit remained within these limits set by the clients, the engineer considered the integration successful. Regarding the percentage of NBS, Engineer \#3 pointed out that the higher the percentage the more seismic structure is required. However, he explained that different percentages of NBS do not affect the achievement of good integration of structure and architecture. The issue of integration is not dependent upon the amount of structure installed but rather on the ways its compatibility with the architecture is approached by the designers. Concerning cost, Engineers \#3 and \#5 considered that hidden seismic retrofits were usually more expensive than exposed ones. They pointed out that this fact must be clarified early on with the client in order to remain within the intended cost. For Engineer \#5, an effective integration also required the minimum disruption to occupants, allowing continuous use of the building while seismically retrofitting the building.

Communications between the various stakeholders was considered as highly important. The engineers suggested meetings early in the design process between all the stakeholders to express their requirements. They added that effective dialogue requires listening to the other parties, implying that compromises would most likely have to be made. The engineers also mentioned accessibility and fire legislation issues. Engineer \#4 stated "[the City Council requires] to improve fire rating and accessibility specifically when seismically strengthening a building. Because those are really unknown by the engineer, we don't know what's required. We just focus on the structure, so it really takes an architect specifically to say "So what the council wants is for us to do this and that, such as a fire wall here, that would be great". And then we say "Oh, you want to put a fire wall here, then let's use that as a seismic element"'". Two important observations can be made. First, the engineer acknowledged the limit of his field of knowledge and thus the necessity to rely on other professionals such as the architect. Second, rather than seeing the fire issue as restricting the seismic retrofit design, the engineer approached it as an opportunity to integrate it into his design. 


\section{Poor integration defined by structural engineers}

Several engineers saw poor integration as a consequence of a lack of architectural input in the retrofit design. The responsibilities of specific stakeholders leading to this situation were highlighted. Starting with clients, Engineer \#2 regretted the decision of some clients not to engage an architect in hope of minimising cost. He explained that "when it comes to the strengthening of a structure, the engineer doesn't necessarily have a more important role to play, and at least having an architect every time would make sense". His view was that the achievement of an effective structural result is not an end in itself, and that ensuring that the seismic solution fits architecturally is equally important. Engineer \#3 shared this point of view. He added that although an architect might be part of the design team, their late involvement in the design process would be detrimental to successful integration.

The second group of stakeholders to be mentioned was the architects. Engineer \#2 stressed that the architect should express their requests and not simply let themselves be driven by the engineer's solution. Architects should speak their mind if they thought changes should be made to the engineer's design. Otherwise the risk of poor integration would increase. This situation however does not necessarily result from a lack of will of the architect. Engineers \#1 and \#3 mentioned that some architects lack knowledge of basic principles of seismic strengthening, such as inertia forces acting in all directions. As a consequence, communication with the engineer is affected and compromises are harder to achieve.

The last group of stakeholders was their fellow structural engineers. Engineers \#3 and \#5 believed that some engineers have a lack of interest or knowledge regarding non-structural elements and their interaction with seismic structures. A respondent mentioned the example of junctions between seismic structure and ceilings, and considered them as often poorly designed from an aesthetic point of view. Engineer \#1 lamented the poor seismic retrofit work of some colleagues who did not realise or underestimated the impact of the location and sizes of the structural members on architectural features. The same respondent also criticised some design software and tools as being "quite coarse sometimes". As a result, some options cannot be properly explored and refined.

The poor consideration or achievement of two additional aspects was mentioned by Engineers \#2 and \#4 as reasons for poor integration. One was the failure of meeting initial goals set by owners and tenants, such as cost, timeframe and disturbance to occupants. The second concerned poor communication between stakeholders. 


\subsubsection{Summary of the designers' definitions of integration}

The aim of questioning architects and structural engineers on the issue of integration was to identify the views of each profession on this topic. Comparison of their answers provides some explanation of the effectiveness of integration in some retrofit projects, as well as pointing out reasons for the lack of integration in others.

Both architects and engineers appreciated the importance of integration of architecture and seismic structure. They showed a conservative attitude toward integration. They both approached it from the perspective of the addition of new structure to a building with already established architectural qualities. Seismic retrofit had to provide sound technical solution while minimising impact on existing architecture. Preservation of functionality and architectural character were identified as common goals, although architects pointed out additional architectural qualities to consider. Both groups also revealed similar views concerning the exposure or hiddenness of seismic structure. Both options were considered appropriate for integration; new structure to be unnoticed when hidden, and read distinctively when exposed. The architects acknowledged that integration requires adaptation and flexibility of both seismic structure and existing architecture. One architect however approached seismic retrofit from the different perspective of enhancing the building's architecture in terms of its qualities and its values. Structural retrofit was an opportunity to integrate innovative design and technical excellence while working architecturally.

The design process was considered as an important factor for the success of integration. Both sets of designers agreed on almost all aspects of the process and seemed aware of the requirements needed to achieve what they consider as successful integration. The presence of the architect as part of the design team was considered mandatory, as well as his or her involvement at the beginning of Concept Design stage. Engineers were conscious of architects' input. This included their architectural contribution to the retrofit design, their guidance on accessibility and fire issues, and their broad understanding of potential impacts on other stakeholders and building users. The designers also pointed out that seismic structure needs to work in combination with other systems such as services and fire safety. Early meetings and discussions with the various stakeholders were therefore deemed necessary to avoid issues later in the design process.

The issue of cost was raised by both sets of designers. Respect for the budget was deemed compulsory for a successful retrofit project. However, none of the designers referred to cost as directly restraining or weakening architectural qualities. Cost was only indirectly raised when designers mentioned clients not hiring architects and selecting the cheapest solutions with the sole 
purpose of cost saving. The architects referred to the importance of understanding the total cost of seismic retrofit, not solely based on the technical solution but also on its economic consequences on other systems and features of a building. The importance of mitigation of tenants' disruption was also pointed out by the respondents. In addition, engineers took the project timeframe seriously. They also noted their primary duty was the achievement of a technically sound system that would meet the client's expectations in terms of NBS percentage. All these aspects reinforce the perception of integration as a multi-layered issue resulting from the achievement of each stakeholder's goals.

Regarding collaboration, architects and engineers agreed that combining their skills was necessary for successful integration. The architects aimed to work with engineers who cared about their opinions and were open to suggestions. They were however also aware of some fellow architects avoiding or being unaware of their role to contribute to the integration of a seismic solution. Another aspect to note was the architects' eagerness to engage with engineers who would aim for state-of-the-art retrofit designs reaching both technical and architectural excellence. The engineers wished that architects would gain more structural knowledge to improve effective dialogue. They also expected architects to guide the client when reviewing a proposed retrofit scheme regarding architectural matters and legislation issues such as accessibility and fire rating. Structural engineers were also aware of the lack of interest of some of their peers regarding non-structural elements and the limitations of their design tools. In general terms, each group requested more openness and acceptance from the other while also realising its own limitations.

\subsubsection{Designers' suggestions to improve integration}

Following the definition of successful and poor integration, the respondents were asked for suggestions to enhance current practice in relation to integration. The answers identified five main ideas.

The first suggestion focused on educating the main decision makers; namely, the architect, structural engineer and client. The previous section pointed out the importance of communication and desire to include external points of view in order to achieve successful integration. For Architect $\# 1$, this open-minded attitude of designers, whether architects or structural engineers, results from their knowledge and experience regarding seismic retrofit designs. Whereas the second aspect, experience, is dependent on the number of projects worked on, the first aspect, knowledge, relies on the opportunities these same designers may have had and still have to learn about each other's discipline. Engineers \#1 and \#3 believed that the subject should be taught at university level, 
suggesting more interaction between students and professionals from different fields. The idea is for practicing architects to educate young structural engineers about architecture, and for professional structural engineers to instruct architecture students about seismic resistance.

Following this academic education, Architect \#1 recommended being regularly informed on the latest seismic technologies. This suggestion reflects two objectives. One is to provide to each project a unique and appropriate state-of-the-art seismic solution. The second objective is to help architects talk more intelligently to engineers about their proposed structural schemes and even suggest ideas. Three different approaches were recommended. The first is a six-monthly or annual meeting with structural engineers. This could take the form of conferences such as the New Zealand Society for Earthquake Engineering (NZSEE) Annual Conference. Currently oriented towards technical aspects of seismic design, the NZSEE conference could gain from the inclusion of architects as interdisciplinary issues could be raised. In a similar way, the New Zealand Institute of Architects (NZIA) In:situ Conference could invite structural engineers to present case-studies of up-to-date seismic technologies. The second suggested approach was "a magazine like Architecture NZ [that] would have an article about the latest and high level seismic strategy developments". Periodicals appeared relevant to the respondent as most architectural firms subscribe to them and could be easily informed regarding seismic design. The third approach corresponded to organising social events and networking. Experiences on projects could be shared as well as acquaintances between architects and engineers developed. This interaction could then facilitate future partnerships.

According to Architects \#2 and \#4, the last stakeholder to educate is the client. In this case, the aim is not so much to provide in depth education on architecture or seismic engineering as to explain the ramification of a seismic retrofit project. The two architects recommended the structural engineer widen clients' perception regarding seismic retrofit. The engineer should describe, even briefly, the different works to be undertaken, including architectural repairs, refurbishment or fire upgrade. In doing so, the respondents hope clients will consider seismic retrofit like any other architectural project and not as solely structural work.

The second suggestion followed the last point. Explanations about the wide repercussions of seismic retrofit should lead the engineer to encourage the client to hire other consultants early on in the design process, starting with the architect. Several tasks should be undertaken by the architect at the beginning of the Concept Design stage. First, Architect \#5 suggested that the architect should review both the tangible and intangible architectural and historic values of the building. This is to raise the awareness of the structural engineer and client on the building's existing qualities. Secondly, clarify with the clients and structural engineer the requirements framing the seismic 
retrofit project, including the client's budget, tenant's disruption, and project timeframe. Thirdly, the architect must work in collaboration with the structural engineer in designing at least two retrofit schemes for the client to select the most appropriate solution. Both designers' requirements can thus be taken into account. Fourthly, as recommended by Architect \#3 and Engineer \#1, an architect should provide guidance to the client in selecting an appropriate seismic retrofit design. The engineer confirmed that usually more than one seismic solution exists for each building and a client would commonly compare their costs. The respondent recommended having the architect pointing out to the client the architectural benefits of each proposed scheme. The aim would be for the client to assess seismic retrofit through the perspective of both cost and architecture. Fifthly, several respondents recommended having an architect to guide the design team through legislative requirements including accessibility and fire issues. Finally, the architect is also required to warn and explain the impacts of the seismic retrofit solution on the different stakeholders of a project.

Following the selection of a seismic solution, the third suggestion arose from most respondents who recommended calling a meeting with all stakeholders. Together the different stakeholders would have a full picture of the retrofit project and could provide precise answers to the client's questions. More importantly, Architect \#5 explained that displaying a selected seismic scheme to the other stakeholders would give them the opportunity to comment upon it. Questions and concerns about workmanship, constructability, accessibility and fire legislation can be brought up and adjustments made if necessary. This approach would mitigate integration issues that may appear later during the design process and construction phase. Engineer \#4 mentioned the importance of the contractor attending such a meeting. The respondent encouraged structural engineers and architects to question the contractor on how they should design the seismic solution as many different construction approaches may exist. Issues such as respect for the timeframe, budget and quality of detailing may be resolved in discussion between these three stakeholders. Once the meeting is over, Architect \#2 then requested that the structural engineer take into account the comments made during the meeting and re-design the seismic solution accordingly.

Engineer \#2 gave the fourth and last suggestion. The respondent recommended using two tools that would first, help the client better understand the suggested seismic retrofit and secondly, facilitate communication between the stakeholders.

The first tool was the assessment instrument currently being developed by Pattinson \& Egbelakin (2016) and referred as the Heritage Evaluation Framework (Partington et al., 2017). Presented in the literature review, this HEF aims at comparing a seismic retrofit scheme to the client's requirements. To do so, the client indicates his or her priorities regarding six main criteria; namely, 
"Seismic Engineering, Heritage, Feasibility, Architecture, Services and Fire Protection, and Buildability" (Pattinson \& Egbelakin, 2016, p. 3). The designers then compare their retrofit scheme to the client's expectations and indicate if they managed to achieve them and to what extent. This is presented through the form of a spider-diagram superimposing the client's requirements and the designers' achievements.

The second tool was the Building Information Modelling software (BIM). This compromises a single three-dimensional digital model which any member of a design team can access and contribute to. This unique model captures all the work to be done, including structure, interior fitting, fabric and services. Engineer \#2 that the model could first be built based on the client's brief by the structural engineer. Once this very first model is developed, the engineer and the architect could then work to refine it. The model would evolve throughout the design process, with more and more details added. The use of a same file by all the design team would reduce loss of information and mitigate conflicts that may appear when superimposing plans of the different stakeholders.

\subsubsection{Summary of the designers' solutions for successful integration}

The solutions suggested by the respondents for successful integration spanned across several design stages and were generally complementary. They covered aspects such as education, guidance, dialogue, and tools for enhanced cooperation. The achievement of successful integration requires a degree of knowledge of seismic retrofit that is common to architects, structural engineers and clients. The aim would be to provide awareness on the interdependence of architectural and engineering disciplines in such types of projects. Architects and structural engineers can gain knowledge from academic education, conferences, specialised magazines and inter-disciplinary events. Concerning clients, they can be educated or at least informed about the issue of integration by the structural engineer at the very beginning of the seismic retrofit project.

The presence of the architect and other consultants at the Concept Design stage was also recommended. The architect would contribute alongside the engineer to the design of one or more schemes, and then guide the client in reviewing their advantages and disadvantages. Only after that would the rest of the stakeholders be included, and a meeting held in order to refine the selected scheme based on all stakeholders' skills and requirements.

The use of design tools was also suggested. One helps designers review proposed schemes and facilitate decision-making. Another facilitates coordination between the stakeholders and avoids 
loss of information by using a single model accessible and editable by any member of the design team.

The responses of the architects and structural engineers varied but common themes linked them. In their view, successful integration in retrofit projects relied on the ability to learn, communicate, and use each stakeholder's skills.

\subsection{Designers' reflections on their seismic retrofit projects and their design processes}

The following section explores how the issue of integration in each of the five URM buildings has been approached by the architect and structural engineer. The aim is to identify which stakeholders and what factors influenced the design of each retrofitted solution, and how this affected integration with the existing architecture.

Each building is analysed individually. For each, the Tables of Analysis established in the previous chapter are reorganised per building rather than per seismic structure. This provides a reading of the entire architectural qualities and how the overall seismic retrofit solution influenced them. These results are compared to the responses of the designers for each of the architectural qualities. Similarities and disagreements between the designers and the Tables of Analysis are contrasted and explained. This approach allows the integration of the seismic retrofit structural systems and architectural qualities to not only be reviewed by the researcher but also by the architects and structural engineers for each case study.

The design process for each building is also analysed through three perspectives. First, the different stages of the design process and the time of involvement of the main stakeholders are examined. Secondly, project leadership is discussed to further explore the relationship between the architect and structural engineer and determine how the leadership role might have shaped the seismic solution. The last perspective explores any final constraints that influenced the seismic design and its integration with the building's architecture. 


\subsubsection{Integration in the seismically retrofitted buildings - Building \#1}

\section{Tables of Analysis}

Table 10 shows the contribution of the seismic retrofit design on the building's architecture as reviewed by the researcher in Chapter 5. All architectural qualities have been positively influenced at least once with the exception of three sub-categories: 4.1 (Modulation of light), 4.2 (Outside views/sightlines) and 7.3 (Reversibility).

Table 10. Tables of Analysis representing the influences of the seismic systems of Building \#1 on architectural qualities

\begin{tabular}{|c|c|c|c|c|c|c|c|}
\hline BUILDING \#1 & $\begin{array}{l}\text { CAT 1. HIDDEN } \\
\text { STRUCTURE }\end{array}$ & $\begin{array}{l}\text { CAT 2. EXPOSED } \\
\text { EXTERIOR STRUCTURE }\end{array}$ & $\begin{array}{l}\text { CAT 3. EXPOSED INTERIOR } \\
\text { STRUCTURE }\end{array}$ & $\begin{array}{l}\text { CAT 4. INTERACTION WITh } \\
\text { EXTERNAL OPENINGS }\end{array}$ & CAT 5. ORNAMENTATION & $\begin{array}{l}\text { CAT 6. EXPREESIION OF } \\
\text { AN ARCHITECTURAL } \\
\text { CONCEPT }\end{array}$ & \begin{tabular}{|l|} 
CAT 7. CONSERVATION \\
AND PRESERVATION \\
PRINCIPLES
\end{tabular} \\
\hline \multirow{5}{*}{$\begin{array}{l}\text { INTERNAL CONCRETE } \\
\text { SHEA WAL- } \\
\text { LONGITUDINAL DIRECTION }\end{array}$} & REASONS & 2.1. ElEV & 3.1. ELEVATION & & $\begin{array}{l}\text {.1. USE OF STRUCTURE FOR } \\
\text { JRNAMENTAL PURPOSES }\end{array}$ & $\begin{array}{l}\text { 6.1 EXISTING OR NEW } \\
\text { ARCHITECTURAL CONCEPT }\end{array}$ & $\begin{array}{l}7.1 \text { MINIMUM } \\
\text { INTERVENTION }\end{array}$ \\
\hline & $\begin{array}{l}\text { 1.2 THE EFFECT OF THE } \\
\text { HDING TECHNIQUE UPON } \\
\text { ARCHITECTURE }\end{array}$ & $\begin{array}{l}\text { 2.2 EXPRESSIVE ROLES OF } \\
\text { THE STRUCTURE }\end{array}$ & $\begin{array}{l}\text { 3.2 EXPRESSIVE ROLES OF } \\
\text { THE STRUCTURE }\end{array}$ & $\begin{array}{l}4.2 \text { OUTSIDE } \\
\text { VIEWS/SIGHTUNES }\end{array}$ & & & $\begin{array}{l}\text { 7.2 COMPATIBILITY WITH } \\
\text { EXISTING ARCHITECTURAL } \\
\text { CHARACTER }\end{array}$ \\
\hline & & & 3.3 STRUCTURE AND SPACE & & & & |7.3 REVERSIBLITY \\
\hline & & & $\begin{array}{l}\text { 3.4 STRUCCUR } \\
\text { FUNCTION }\end{array}$ & & & & \\
\hline & & & $\begin{array}{l}3.5 \text { STRUCTURE AND } \\
\text { CIRCULATION }\end{array}$ & & & & \\
\hline
\end{tabular}

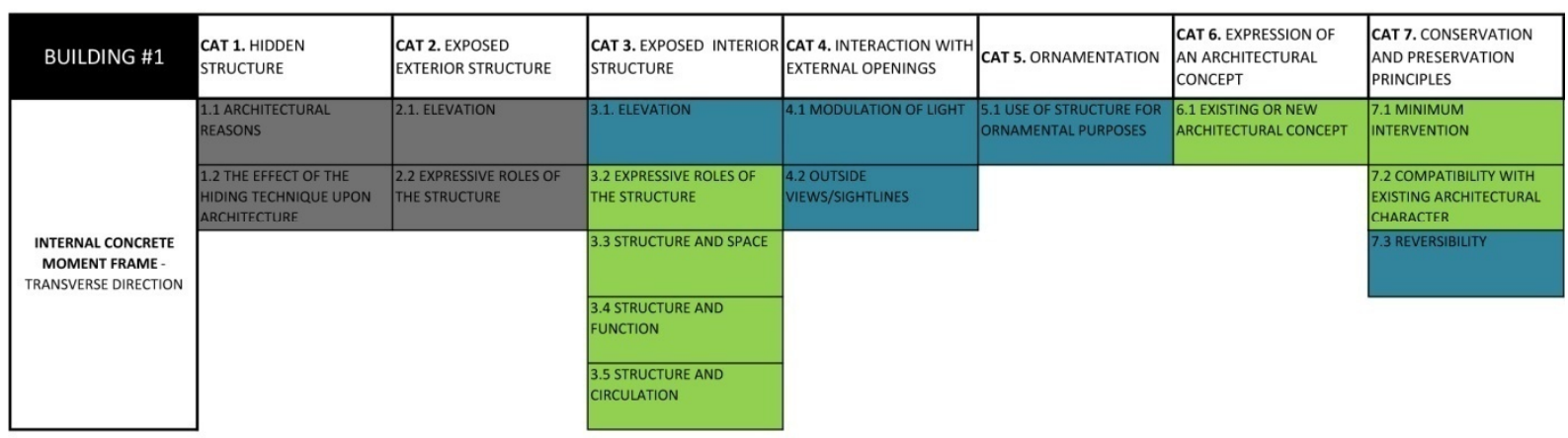

\begin{tabular}{|c|c|c|c|c|c|c|c|}
\hline BUILDING \#1 & $\begin{array}{l}\text { CAT 1. HIDDEN } \\
\text { STRUCTURE }\end{array}$ & $\begin{array}{l}\text { CAT 2. EXPOSED } \\
\text { EXTERIOR STRUCTURE }\end{array}$ & $\begin{array}{l}\text { CAT 3. EXPOSED INTERIOR } \\
\text { STRUCTURE }\end{array}$ & $\begin{array}{l}\text { CAT 4. INTERACTION WITH } \\
\text { EXTERNAL OPENINGS }\end{array}$ & CAT 5. ORNAMENTATION & $\begin{array}{l}\text { CAT 6. EXPRESSION OF } \\
\text { AN ARCHITECTURAL } \\
\text { CONCEPT }\end{array}$ & $\begin{array}{l}\text { CAT 7. CONSERVATION } \\
\text { AND PRESERVATION } \\
\text { PRINCIPLES }\end{array}$ \\
\hline \multirow{5}{*}{$\begin{array}{l}\text { COMPOSITE STEEL AND } \\
\text { CONCRETE DECKING }\end{array}$} & $\begin{array}{l}1.1 \text { ARCHITECTURAL } \\
\text { REASONS }\end{array}$ & 2.1. ELEVATION & $\begin{array}{l}\text { 3.1. FLOOR AND CEILING } \\
\text { SURFACE }\end{array}$ & 4.1 MODULATION OF LIGHT & $\begin{array}{l}5.1 \text { USE OF STRUCTURE FOR } \\
\text { ORNAMENTAL PURPOSES }\end{array}$ & $\begin{array}{l}\text { 6.1 EXISTING OR NEW } \\
\text { ARCHITECTURAL CONCEPT }\end{array}$ & $\begin{array}{l}7.1 \text { MINIMUM } \\
\text { INTERVENTION }\end{array}$ \\
\hline & $\begin{array}{l}\text { 1.2 THE EFFECT OF THE } \\
\text { HIDING TECHNIQUE UPON } \\
\text { ARCHITECTURE }\end{array}$ & $\begin{array}{l}\text { 2.2 EXPRESSIVE ROLES OF } \\
\text { THE STRUCTURE }\end{array}$ & $\begin{array}{l}\text { 3.2 EXPRESSIVE ROLES OF } \\
\text { THE STRUCTURE }\end{array}$ & $\begin{array}{l}4.2 \text { OUTSIDE } \\
\text { VIEWS/SIGHTLINES }\end{array}$ & & & $\begin{array}{l}\text { 7.2 COMPATIBILTY WITH } \\
\text { EXISTING ARCHITECTURAL } \\
\text { CHARACTER }\end{array}$ \\
\hline & & & 3.3 STRUCTURE AND SPACE & & & & 7.3 REVERSBBILTYY \\
\hline & & & $\begin{array}{l}\text { 3.4 STRUCTURE AND } \\
\text { FUNCTION }\end{array}$ & & & & \\
\hline & & & $\begin{array}{l}\text { 3.5 STRUCTURE AND } \\
\text { CIRCULATION }\end{array}$ & & & & \\
\hline
\end{tabular}




\section{Interviews regarding architectural qualities}

\section{○ Category 3 - Exposed interior structure}

\section{- 3.1: Elevation / Floor and ceiling surface}

As seen in the Tables of Analysis, the seismic retrofit contributes to the development of new interior surfaces, in particular through the shear walls and diaphragms. Both designers explained this design as a will to clearly distinguish the retrofit from the existing architecture. The architect stressed a desire to avoid creating faux heritage and allow users to read independently the two periods of history of the building. He added that the shear walls contrasted with the quite beautifully ornate and refined façade, thanks to the "very masculine" and raw treatment of their surfaces. The engineer justified a societal need for people to clearly identify seismic retrofit work following the 2011 Christchurch earthquake. Identification of a seismic design thus appeared as a therapeutic response to the fears and doubts of the public towards the earthquake risk.

\section{- 3.2: Expressive roles of the structure}

The architect justified the strong expressive detailing of the seismic structures and diaphragms as an architectural decision. The aim was for "the building's interior [to have] all its clothes taken off". This added complementary justification for the raw materiality of the seismic structures, and further explained unveiled detailing such as the use of exposed FRP wrapping at the beam-column joints of the moment frames. The designer's desire to fully reveal and emphasise the new seismic work undertaken was part of the contrasting approach taken with the exterior front façade.

Regarding the exposed structural components of the diaphragms, discussions between the architect and the structural and fire engineers were necessary. With the structural engineer, the dialogue aimed at ensuring that the technical vocabulary of the structural components was clear and neat. Regarding the fire engineer, the structural exposure necessitated consideration of the primer and intumescent paint to protect from fire. In both situations, the discussions between architect and the engineers appeared successful as the expressiveness of the composite decking is achieved as described in the diaphragm analysis of the previous chapter.

Both designers pointed out the role of the main tenant in expressing the moment frames. As the tenant required as much space free of columns as possible, the number of moment frames decreased from the initial scheme resulting in increased cross-sectional dimensions. Their size 
contributed to their expressiveness and their limited number were appreciated by the design team. As a solution it saved time, work and cost in comparison to smaller yet more numerous columns.

Finally, the structural engineer emphasised the importance of the contractor achieving the intended quality of detailing. The organisation of construction and the capacity to understand the architectural vision were two qualities required in a contractor. Taking the shear walls and moment frames as examples, the engineer explained that the contractor possessed these two qualities as well as the skills to achieve the desired rendering.

\section{- 3.3: Structure and space}

Both respondents acknowledged the alignment of the moment frames with the existing structural grid as a reference to the building's existing architecture and structure. The architect justified this decision as a way of ensuring a strong relationship between the moment frames and the existing façade, as the later was also aligned on the grid. The engineer wanted to maintain the quality of open space. Both designers added that the fewer number of moment frames compared to the number of previous columns provided greater openness to the interior spaces.

For the architect, the fact that the same tenant occupied both ground and first floor improved the spatial quality. In response to the tenant's programme, a large void was created to join both floors. Supported and delimited by the moment frames and the large castellated beams, the void redefined the reading of the interior spaces. This example stresses the advantage of linking the programme of a building's refurbishment with the seismic retrofit design.

\section{- 3.4: Structure and function}

The main tenant requested the interior spaces to be as open as possible. The reason was to provide as much freedom as possible to the tenant's personal architect when designing the interior fit-outs. From a broader perspective, the owner's architect agreed with this approach of open planning, especially in commercial buildings. He pointed out two advantages. First, it gave greater opportunities when accommodating the tenant's programme. Secondly, it facilitates possible future use by a new occupant with different needs.

The role of the owner's architect regarding the building's functional quality was thus to allocate purposes for the different spaces. Based on the layout of the new moment frames, the architect used the structural bays to distinguish the usable areas on the sides from the vertical circulation zone at the centre of the ground and first floor. 


\section{- 3.5: Structure and circulation}

In sub-category 3.3, the architect revealed his intention of linking the moment frames with the existing façade by having them aligned on the same structural grid. In doing so, the building's main entrance and the central bay of the moment frame right behind it were lined up. Following this logic, the escalators providing vertical circulation were located on the same axis as the entrance and central bay. The front moment frame thus accentuated both the building's entrance as well as its vertical circulation.

Whereas the location of vertical circulation rose from architectural considerations, the contribution of the composite decking to the circulation quality resulted from structural requirements. The architect explained the large void in the first floor required the use of substantial castellated beams for support. As a consequence, the locations of the beams along the longitudinal sides of the void, as well as their dimensions and unique cutting pattern, responded to engineering requirements. The architect agreed that these characteristics led the castellated beams to contribute to circulation quality as explained in sub-category 3.5 of the diaphragm analyses. Overall, the castellated beams were primarily a technical answer to the architectural need of a large void on the first floor, but their necessity then contributed to circulation quality.

\section{○ Category 4 - Interaction with external openings}

The Tables of Analysis point out the neutral influence of the shear walls and moment frames on the qualities of modulation of light and outside views. The designers justified this lack of contribution of the seismic structures by referring to the limitations inherent to the front façade. As the façade carried historic value and was the main feature legitimising the building as heritage, preservation of the existing openings was compulsory. The designers acknowledged that this constraint reduced architectural opportunities. This particular example is the first one to point out a direct restriction on two architecture qualities due to heritage conservation issues.

\section{○ Category 5 - Ornamentation}

\section{- 5.1: Use of structure for ornamental purposes}

For the architect the castellated beams contributed to ornamental quality. As the design approach was based on the exposure and clear reading of the seismic structural components, the technical ornamentation of the beams seamlessly fitted within the interior architectural character. 
The architect justified the lack of other structural ornaments for two reasons. First, limiting ornamentation facilitated incorporation of subsequent retail fit-out designed by the tenant's architect. Secondly, a lack of ornamentation provided greater freedom in terms of re-usability of the spaces. Several fit-outs could be designed over time without risking aesthetic clashes.

Both designers provided a final argument justifying the little ornamentation on the building's interior. By having the concrete shear walls and moment frames unrefined and free of any decorative feature, greater attention was therefore directed toward the existing ornamental components of the historic façade. This argument implies that, although not considered ornamental themselves, seismic structures, based on a specific design concept can highlight the ornamental quality of existing features.

\section{○ Category 6 - Expression of an architectural concept}

\section{- 6.1: Reinforcement of an existing architectural concept or development of a new one}

Early on in the design process, both designers agreed to avoid recreating a faux architectural character inside the building that would reference the existing architecture. Following the selection of one of the proposed seismic retrofit schemes developed by the structural engineer, the architect wanted the seismic work to be read distinctively and independently of the existing architectural layer. He thus ensured the contrast of the simple and raw architectural character of the interior to that of the refined ornamented façade. This resulted in the full exposure of the seismic structures and their unrefined surfaces. However, the architect explained the concept was not solely developed for the treatment of the seismic structure. It had to be considered over the entire building. Therefore, for the contrast to be optimal, the front façade had to be brought back to its original quality. This led parts of façade that were faded, damaged or lost over time, to be restored.

The architect's statement stresses the importance of considering a seismic retrofit project in its entirety - not solely focusing on the structural aspect but also on its relationship with the existing architecture. This implies not only considerations by designers on how a seismic solution can contribute to existing architecture, but also how this architecture may legitimise its presence by responding to the seismic solution. 


\section{○ Category 7 - Conservation and preservation principles}

\section{- 7.1: Minimum intervention}

Considering the minimum intervention principle, the priority for both designers was the preservation of the existing front façade as it was the only protected part of the building. Any changes to it would have been contrary to the preservation principle. This constraint implied undertaking all seismic retrofit work inside the building. The previous internal fit-out had no value to the building and was completely removed. In doing so, the designers had to consider newly revealed features; namely, the two longitudinal URM walls, cast-iron columns and timber floors.

Regarding the URM walls, the architect noted the aesthetic value of exposed bricks, but also referred to the lack of further historic value of these walls. In agreement with the structural engineer and the owner, this led the URM walls to be shotcreted and used as shear walls.

Concerning the cast-iron columns, the designers initial desire was to keep them. However, various reasons justified their removal. From a technical perspective, both respondents indicated the difficulty maintaining the existing columns due to their inability to perform well during an earthquake. Their brittleness and lack of strength would have required major interventions. The architect also mentioned the direct role of the client who found the existing columns "ugly". Finally, the structural engineer recalled the architect's desire for a large floor plate, further justifying the removal of the columns. Their removal thus appears as a collective agreement yet for different reasons.

The existing timber floors also needed to be removed due to their structural inadequacy and their inability to work as proper diaphragms. The difference of appreciation of their value by the designers might further explain the decision to remove them. The architect praised the characteristics of the existing floors, mainly their large dimensions and the amount of wood in them. The engineer however explained that the original floor-boards were replaced in 1980's by plywood which considerably diminished the architectural quality of the floors. This lack of interest in the floors could justify the absence of potential structural solutions to maintain them.

The removal of the cast-iron columns and timber floors was thus not a consequence of the installation of the moment frames and composite decking. Instead it resulted from a combination of personal opinions as well as technical difficulties. However, the architect explained if the existing timber floors and the cast-iron columns had been registered as heritage components, further efforts would have been undertaken to integrate them with the seismic retrofit solution. 


\section{- 7.2: Architectural character}

The consideration of the building's existing architectural character as well as the development of a new interior character contrasting with the façade have already been explained in sub-categories 3.1 and 6.1 .

\section{- 7.3: Reversibility}

Where the designers endorsed the two previous principles, they were less certain about reversibility. The engineer explained that, while agreeing with the principle of being able to remove seismic retrofit work in the future, it was particularly difficult to apply it to URM buildings. She added that the insertion of seismic structures in URM buildings often required sacrificing parts of the existing walls which further complicated future removal. A compromise was therefore almost always necessary between brick walls and reversible seismic structure.

The engineer explained that other issues drove the current seismic solution. First, reversibility was superseded by the principle of future seismic structural components to be added in order to enhance the building's earthquake resistance. The simple retrofit solution based on large lengths of shear walls and few moment frames was, among other reasons, a result of this approach. The second aspect stressed by the engineer was the long-term vision of the client. Rather than strengthening the building step-by-step over time, the client considered the retrofit as an opportunity to enhance the life span of the building for another 100 years. This led the designers to view the seismic structures as legitimate components of the building with which they would age.

This last statement made by the engineer perfectly fitted with the architect's personal thoughts on the retrofit design. The architect did not consider the possibility of removing the seismic structures; quite the opposite. He valued the seismic work as a testimony to our current period. The original architectural layer and the new retrofit work were meant to be distinct, but also to work together as a complementary combination. Like the owner, the architect approached the design as a longterm solution as he clarified "what we've done is not heritage now but I think will be one day. And I think that in 50 years you'll be able to read this building as a series of events, periods and time".

Although the reversibility principle was not adopted, the designers have thought carefully about their seismic solution and its legitimacy inside the building. Rather than approaching the seismic structures as temporary components, they saw them as complementary to the existing architectural layer, both now and in the future. 


\section{- Summary and final comments on architectural qualities}

The designers demonstrated a shared and clear vision driving the seismic retrofit design. They agreed on the role of the seismic structures inside the building and on how to make their presence legitimate from an architectural perspective. Interestingly both designers provided architectural justifications for the design. The fact that both designers were aware of the double role of the structures, as both technical and architectural components, gives an initial explanation for the overall positive influence of the seismic retrofit solution on architectural qualities.

It also appeared that some architectural contributions of seismic structure were fortuitous. The castellated beams were an example of a structural necessity turned into an architectural asset. It appeared that the understanding of the architectural vision by the engineer contributed to ensure that the beams would fit with the interior architectural character.

The difference of architectural and historic importance between the various existing parts of the building was another factor influencing integration by providing more freedom but also additional constraint. The existing façade, the key component of the building, limited any contribution of seismic structure to architectural qualities such as modulation of natural light and outside views. In contrast, the existing cast-iron columns and timber floors were not considered as carrying little value. Their removal allowed for architectural qualities such as space and circulation to be improved. As stressed by Goodwin et al. (2009) a degree of compromise is almost always necessary in heritage listed buildings. The authors therefore suggest identifying the various exciting aspects of a building and defining their importance in order to achieve design to minimise the impact of the retrofit. What could be added to this approach is consideration of the gain for the building. The seismic retrofit would thus not only be considered in terms of potentially weakening existing historic features, but also on how it might bring positive architectural qualities.

The respondents also stressed the influence of stakeholders on the integration issue. Two categories of stakeholders and their related requirements were raised. The first corresponded to the initial demands requested by the tenant and the building's owner. These demands set broad parameters that oriented the design and might be more or less respectful of the existing architecture. The architect and the engineer however remained in charge of accommodating the design with the programme. They could therefore discuss the tenant's and owner's requirements early in the design process if these appeared harmful to the building. They could also consider the potential of the programme to enhance its architecture. The second category corresponded to the fire regulations and construction constraints, the domain of the fire engineer and the contractor respectively. In this 
case, the designers were not exclusively driving the retrofit design but instead had to collaborate with these other two stakeholders. The quality of communication between the four actors was vital. It is necessary to have a fire engineer and a contractor that first, understood of the seismic retrofit design concept; and second possessed the skills and knowledge to provide the best solutions.

The architect approached the integration issue not only in the present but also for the future. Function and ornamentation qualities were thus considered in such a way that the incorporation of future new programmes could be facilitated. The usability of the building throughout its life span appeared therefore as another architectural consideration driving the retrofit solution. It is interesting to note that this approach of the seismic solution does not restrain functionality but rather enhances it. Regarding ornamentation, the neutral influence of shear walls and moment frames could also be explained by this expectation of future accommodation, but is perhaps more relevantly justified by the architectural concept driving the project. The designers justified the lack of deliberate ornamentation of the seismic structures by the concept of interior and exterior contrast. An ornamented treatment of the seismic components would have been contrary to the architectural concept, and would have weakened it. This means that the lack of contribution of a structure to an architectural quality should be put in perspective with the overall treatment of the building. Designers should think about whether or not an architectural quality should be improved upon and evaluate the decision in the light of the intended architectural concept.

The last aspect to notice was the consensus of the owner and architect on the legitimacy of the structure to remain inside the building and become inseparable from it and from its architecture. The architectural contribution of the seismic retrofit was considered so important that the architect predicted it will become part of the building's historic value in the future. This particular attitude raises an interesting thought regarding the reversibility principle. As the Tables of Analysis and the responses of the interviews reveal, the seismic structures have contributed to the enhancement of many architectural qualities. This implies that their removal would affect the architectural qualities dependant on the seismic retrofit. Aspects such as architectural character or concept might be drastically weakened or lost. Based on this argument, the attitude of the owner and architect toward the seismic retrofit solution appears now extremely relevant. This also suggests that the design of new seismic structures in the future, in the place of or in combination with the previous seismic solution, should respect not only the original architectural qualities but also those of previous retrofits. 


\section{$\circ$ Design steps and time of involvement}

Table 11. Table of Design Process: Main stakeholders and their time of involvement in Building \#1

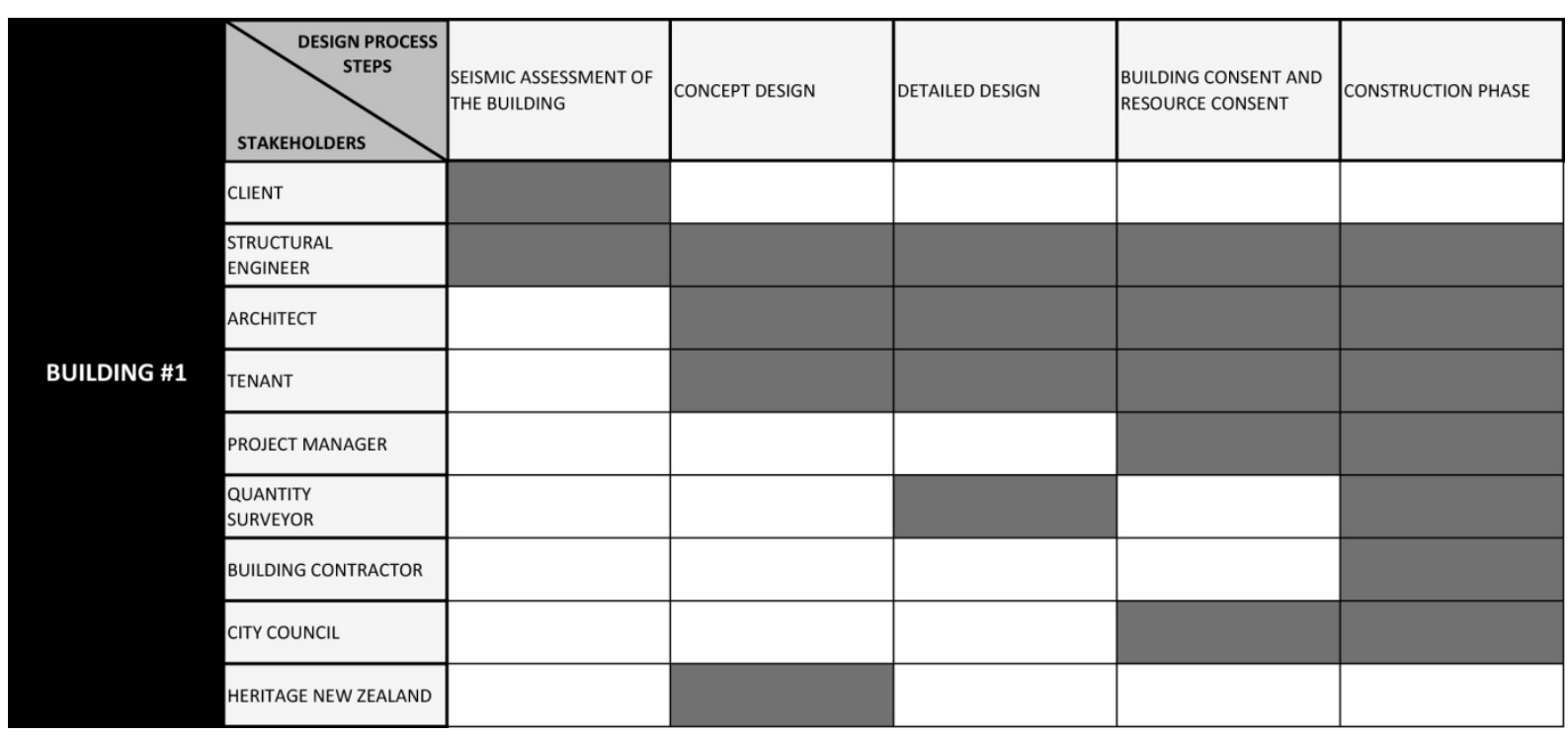

As shown in Table 11, the project started with the client engaging the structural engineer in order to check the earthquake-prone status of the building and target the seismic retrofit to $100 \%$ NBS. At the Concept Design stage, two additional stakeholders got introduced to the project; namely, the architect and the main tenant.

Both designers indicated that the Concept Design was the key stage in the design process and praised the decision of the client to hire both of them early on. They identified such a decision as a key factor in the achievement of a successful integration. The engineer explained that working with the architect at the early stage of the concept allowed him to be involved in the choice of the structural system that would be best for both designers. Although not having much more influence at this stage, the architect could point out the architectural parameters considered of importance. This ensured that the main tenant's needs were also taken into account, in particular the fundamentals of the retailing requirements. As stated by the architect, the retrofit design became integrated "when it felt like we got a scheme that worked structurally, architecturally but also commercially". Both designers further explained that the dialogue between them at such an early stage avoided future issues. The risk of major changes later during the design process was prevented. Based on previous experiences, the architect explained that many clients do not hire an architect early enough in the design process. This is detrimental, first to the engineer's work, as it 
might require some unexpected modifications; and second to integration, due to the lack of proper architectural consideration.

The architect mentioned Detailed Design as the second most important stage. As both designers contributed to it, constant dialogue and clear communication between them was vital. It was also during this stage that the simple and raw aesthetic of the retrofit solution became clearly defined and was designed. As pointed out in the previous section, this aspect was paramount to the successful expression of the concept.

The engineer also explained the roles and contributions of some stakeholders during the design process. She praised the contribution of the contractor during the construction phase as he suggested details that led to the successful achievement of the intended concept. Other stakeholders such as the City Council and Heritage NZ had more minor roles. The first solely checked the proposed seismic retrofit design and had no influence on it. The second had no direct involvement in the design and was only referred to during the Concept Design stage in order to review heritage principles.

\section{○ Leadership}

The structural engineer assumed the role of project leader. The project initially started from the intention of the owner to seismically strengthen the building in order to encourage new tenants. The project was thus mainly approached as structural work.

The architect emphasised the importance of having the leader of the design team with a strong experience in seismic projects and a strong personality. The other stakeholders could rely on the structural engineer when necessary. A particular example given by the architect was the hiring of the engineer by the contractor as structural advisor for temporary works.

The structural engineer provided leadership throughout the entire process, and did not just limit herself to the design and expect the other stakeholders to adapt themselves to her work. According to the architect, she ensured that everything she proposed was "feasible and viable" which involved meeting with the different stakeholders when necessary.

While leading the project, the engineer praised the contribution of the architect during the design process. His experience, as well as their pre-existing relationship on previous projects, contributed to a solid partnership during the retrofit design. They discussed ideas during several design meetings throughout the design process. This avoided any competition between them and ensured that they 
were aiming toward a same goal. The engineer said that these meetings allowed them to ask questions on specific issues rather than making assumptions, clarifying point of views, explaining and justifying design decisions, and reflecting together on design alternatives when necessary. Both designers praised the capacity of the other to communicate and share ideas.

\section{Influences of the project's constraints on integration}

Both designers acknowledged that several constraints drove the retrofit design. The influences of these constraints on the seismic solution and its integration with architecture varied. The engineer mentioned that the first factor that directly influenced the design of the seismic structures was the heritage value of the building. This was mainly characterised by minimising disruption to the façade. This constraint restricted the seismic solution to the interior of the building. The second factor resulted from the tenant's requirement to keep interior spaces as open as possible. This request prevented the use of cross-bracing as initially considered, and led to moment frames with large dimensions. The third constraint pointed out was the site. Due to limited access, many structural components had to be built directly inside the building. The engineer specifically noted that the moment frames and their detailing resulted from the cast-in-place process. Another constraint was the temporary support required while dismantling part of the building and constructing the new structural components simultaneously. The architect explained that such an approach forced the moment frames to be installed in front of the existing cast-iron columns and thus ending up slightly off grid. The comparison of these four constraints with the Tables of Analysis and the answers provided in the previous section reveals that, while these constraints influenced some design decisions, they have not weakened any architectural quality.

Both designers also acknowledged the timeframe and budget as two additional considerations. The short schedule was difficult to achieve, but the budget was not as restraining. None of the designers however mentioned any direct influence of these two aspects on the seismic design.

\section{- Summary of the design process}

The analysis of the design process provided information on factors determining the success of integration in Building \#1. The first factor was the timing of involvement of the architect at the beginning of the Concept Design stage. This allowed architectural input on the structural design very early on in the process. His contribution increased during the Detailed Design stage. The continuous presence of the architect from one stage to the other allowed the architectural concept to be realised in the detailing. The second factor leading to success was the role of the structural engineer 
as the leader of the design team. She was accessible to any stakeholder, provided guidance, encouraged dialogue through meetings, and even took on additional tasks when her expertise was needed. The good relationship between the architect and structural engineer was also beneficial to integration. It allowed the definition of a concept and its maintenance throughout the design process and construction phase, thanks to constant discussions between the designers. Finally, heritage preservation, interior openness, and site constraints have influenced the final design. However, they were considered less as restrictions impacting decisions, but more as legitimate requirements providing opportunities for greater considerations. They forced the designers to think about ways to incorporate them in the design while being relevant to the architectural concept.

\subsubsection{Integration in the seismically retrofitted buildings - Building \#2}

\section{Tables of Analysis}

Table 12 displays mainly neutral influences of the seismic retrofit on the architectural qualities as reviewed by the researcher in Chapter 5 . The only architectural qualities to be positively influenced correspond to minimum intervention (7.1) and reversibility (7.3) and result from internal structural elements. The minimum intervention principle is positively influenced by the small internal shear wall and cross-bracing of the diaphragm. Regarding reversibility, the principle is successfully achieved by the cross-bracing and the plywood panels.

A few negative influences can be noticed. One relates to the main structural component of the seismic solution; namely, the concrete moment frame. This external structure lacks of reversibility (7.3). Most of the negative influences however result from the presence of plywood panels that affect the floor surface (3.1), expressiveness (3.2), and ornamentation quality (5.1). 
Table 12. Tables of Analysis representing the influences of the seismic systems of Building \#2 on architectural qualities

\begin{tabular}{|c|c|c|c|c|c|c|c|}
\hline BUILDING \#2 & $\begin{array}{l}\text { CAT 1. HIDDEN } \\
\text { STRUCTURE }\end{array}$ & $\begin{array}{l}\text { CAT 2. EXPOSED EXTERIOR } \\
\text { STRUCTURE }\end{array}$ & $\begin{array}{l}\text { CAT 3. EXPOSED INTERIOR } \\
\text { STRUCTURE }\end{array}$ & $\begin{array}{l}\text { CAT 4. INTERACTION WITH } \\
\text { EXTERNAL OPENINGS }\end{array}$ & CAT 5. ORNAMENTATION & $\begin{array}{l}\text { CAT 6. EXPRESSION OF AN } \\
\text { ARCHITECTURAL CONCEPT }\end{array}$ & $\begin{array}{l}\text { CAT 7. CONSERVATION } \\
\text { AND PRESERVATION } \\
\text { PRINCIPLES }\end{array}$ \\
\hline \multirow{5}{*}{$\begin{array}{l}\text { INTERNAL CONCRETE } \\
\text { SHEAR WALL - TRANSVERSE } \\
\text { DIRECTION }\end{array}$} & $\begin{array}{l}1.1 \text { ARCHITECTURAL } \\
\text { REASONS }\end{array}$ & 2.1. ELEVATION & 3.1. ELEVATION & 4.1 MODULATION OF LIGHT & $\begin{array}{l}5.1 \text { USE OF STRUCTURE FOR } \\
\text { ORNAMENTAL PURPOSES }\end{array}$ & $\begin{array}{l}6.1 \text { EXISTING OR NEW } \\
\text { ARCHITECTURAL CONCEPT }\end{array}$ & $\begin{array}{l}7.1 \text { MINIMUMM } \\
\text { INTERVENTION }\end{array}$ \\
\hline & $\begin{array}{l}1.2 \text { THE EFFECT OF THE } \\
\text { HIDING TECHNIQUE UPON } \\
\text { ARCHITECTURE }\end{array}$ & $\begin{array}{l}\text { 2.2 EXPRESSIVE ROLES OF } \\
\text { THE STRUCTURE }\end{array}$ & $\begin{array}{l}\text { 3.2 EXPRESSIVE ROLES OF } \\
\text { THE STRUCTURE }\end{array}$ & $\begin{array}{l}4.2 \text { OUTSIDE } \\
\text { VIEWS/SIGHTUNES }\end{array}$ & & & $\begin{array}{l}\text { 7.2 COMPATIBILTYY WITH } \\
\text { EXISTING ARCHITECTURAL } \\
\text { CHARACTER }\end{array}$ \\
\hline & & & 3.3 STRUCTURE AND SPACE & & & & 7.3 REVERSIBILTTY \\
\hline & & & $\begin{array}{l}\text { 3.4 STRUCTURE AND } \\
\text { FUNCTION }\end{array}$ & & & & \\
\hline & & & $\begin{array}{l}\text { 3.5 STRUCTURE AND } \\
\text { CIRCULATION }\end{array}$ & & & & \\
\hline
\end{tabular}
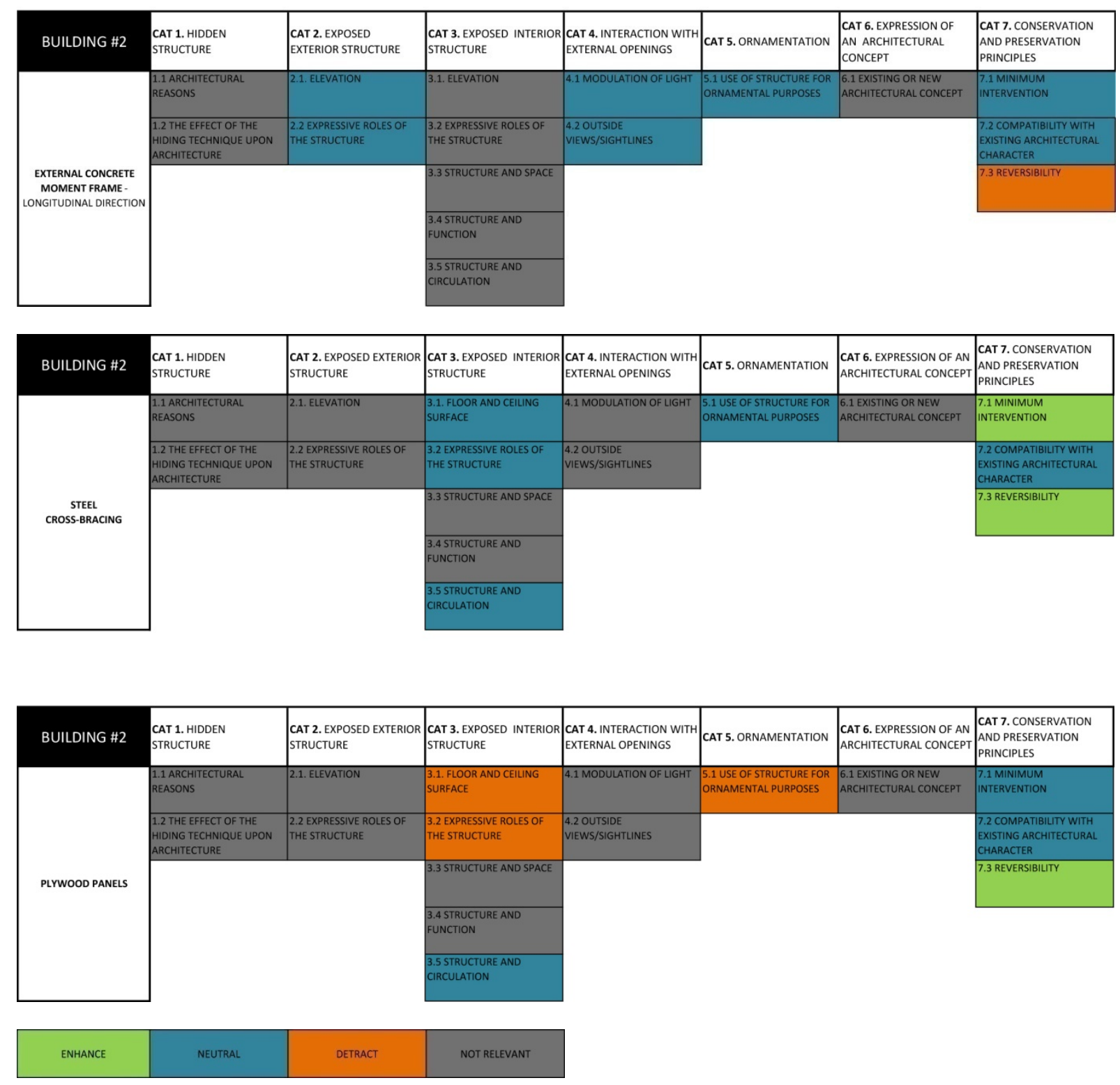


\section{Interviews regarding architectural qualities}

\section{- Category 2 - Exposed exterior structure}

\section{- 2.1: Elevation}

The moment frame replicates the existing front façade and is therefore considered in the Tables of Analysis as having a neutral influence on the external elevation. The architect justified this approach as his personal opinion. While acknowledging the building's heritage value to the area, he explained that the building on its own did not possess a strong architectural character. Instead, he gave more credit to the architectural identity of the surroundings; the sum of buildings possessing similar characteristics. The architect's primary aim was therefore to ensure that the street would retain its visual appearance by avoiding one of its buildings possessing a contrasting elevation.

The architect's approach suited the structural engineer's vision of seismic retrofit. The engineer explained that "when we are [seismically] strengthening a building we are trying to consider that in the final building the strengthening and the existing elements are one. ... So we don't so much differentiate both layers of elements, but we still get strengthening on the existing structure as much as possible". The merging of both new and existing components leading to an almost identical façade prior to and after the seismic retrofit therefore appeared relevant for both designers.

\section{- 2.2: Expressive roles of the structure}

Following the logic of replication and neutral impact, the architect stated that the structural detailing aimed at recreating the existing features of the front façade. The engineer was in charge of designing the moment frame system but explained that the structural detailing was almost exclusively in the hand of the architect. Such work meant adding architectural details onto the structural drawings in order to accommodate the features of the façade to be recreated. Iterations between the designers regarding the depth and dimensions of the columns, as well as the design of their pilasters, had to be undertaken in order to maintain the existing rhythm and visual characteristics. In addition, the architect explained that such work led to recreating non-structural elements such as corbels and decorative steel plates in front of the pilasters.

The engineer added that the City Council influenced the detailing of the façade. To limit the street encroachment, the Council reduced the depth of the moment frame to $350 \mathrm{~mm}$ instead of $400 \mathrm{~mm}$ as formerly designed by the engineer. Although from an architectural point of view this did not affect the detailing of the façade, it made the engineer's work much more difficult when designing 
the reinforcing. It also added further complication to the contractor when the structure was sprayed with concrete.

\section{○ Category 3 - Exposed interior structure}

\section{- 3.1: Elevation / Floor and ceiling surface}

Unlike the façade, the designers did not mention any specific concept when designing the interior. Instead the shear wall and the two diaphragm systems were treated as case-by-case elements depending on their location inside the building.

Located in the hall of the building, the shear wall possesses the same dimensions and plastered rendering as the existing wall against which it was placed. The designers explained wanting to avoid users reading the interior seismic structure as a distinct component. The ease to provide the same plastered and white surface as the previous wall, also encouraged the decision to visually merge the shear wall.

The engineer acknowledged the inconsistent pattern of the cross-braced diaphragm. He justified it as a result of the technical necessity to link the seismic structural elements to the existing vertical steel posts. However, he added that such a visual irregularity was negligible as the cross-bracing was hidden. In fact, it was during the interview that the engineer learned that the braces were actually exposed! This decision was taken by the architect who justified not hiding the structure on the basis of cost. The architect believed that the disruptive pattern of the structure would remain minor due its small dimensions. To further attenuate its presence and therefore its impact on the architecture, he also decided to paint it white like the ceiling.

Concerning the plywood panels, the architect acknowledged that their impact on the existing wooden floor-boards was "unfortunate". He explained that they had the opportunity to save time and avoid disruption of tenants by working on an empty floor. This allowed them to strengthen two storeys at once using the combination of cross-bracing on the ceiling and plywood on the floor. The layout of the panels was left to the technical requirements of the engineer although the architect requested him limit their surface area as much as possible. However, the architect put the impact of the plywood panels in perspective. First, he explained that the existing timber floors were considered secondary elements in comparison with the exterior of the building which had much more value. Secondly, he stated that once occupied, the floor would most likely be carpeted for improved acoustics. 


\section{- 3.2: Expressive roles of the structure}

The designers revealed that they didn't give much consideration to the expressiveness of the seismic structural components. The engineer indicated there was no real interest in highlighting the presence of the shear wall. Its small dimension combined with its location in a narrow hall convinced the designers to visually mitigate its presence.

Concerning the visual presence of the cross-bracing, the architect stated that "it wasn't a conscious choice to express it". He meant that no architectural concept justified the exposure of the braces. That instead resulted from cost concerns. The architect also let the engineer detail the cross-bracing. The architect considered that the interior spaces already possessed an "industrial" steel language due to the exposed steel posts and that the cross-bracing would then complement it. The engineer stressed the difficulties in maintaining a similar structural detailing at the junctions of the steel posts and braces. He was unaware that the diaphragm system would be exposed and so did not consider the lack of consistency.

Finally, the detailing of the plywood panels also resulted from purely technical concerns. Although their strong visual presence was considered by the designers as negatively impacting on the existing floor, the issue was tempered using similar arguments as the ones provided in sub-category 3.1.

\section{- 3.3: Structure and space}

The small dimensions of the hall did not allow for any interaction between the shear wall and the interior space. For the designers, the spatial quality was therefore maintained.

\section{- 3.4: Structure and function}

The shear wall was designed to maintain the function of the hall.

\section{- 3.5: Structure and circulation}

As the hall provides access to the entire building, the designers were careful to maintain this quality. The engineer thought that the $200 \mathrm{~mm}$ added to the existing URM wall in order to strengthen it did not affect access to the building.

The designers did not consider any possible relationship between the layout of the diaphragm systems and circulation. They simply ensured that circulation within the interior spaces would remain unaffected by the presence of the seismic components. 


\section{○ Category 4 - Interaction with external openings}

The preservation of the openings was a logical extension of the design decision to replicate the existing façade. Any modification to outside views or natural light was thus avoided. The architect explained that this achievement was directly related to the geometric correspondence between the existing grid layout of the façade and the moment frame system. Such a match greatly simplified the external design. He added that the structural design maintained an approximate distance of $200 \mathrm{~mm}$ around the openings to reduce the shadows due to the added depth to the façade.

\section{○ Category 5 - Ornamentation}

\section{- 5.1: Use of structure for ornamental purposes}

The architect had to consider both structural and non-structural elements when redesigning the façade as both carried ornamental quality. This meant shaping pilasters in front of the moment frame as well as adding corbels and decorative steel plates identical to the ones removed. The engineer explained the work on the façade required much more architectural expertise than structural knowledge. He also praised the skills of the architect to use the moment frame to achieve architectural objectives without weakening its seismic efficiency. Similarly, the architect appreciated the flexibility provided by the engineer to "alter" the structure in order to achieve an effective replication.

The architect considered the interior structural components as not having much architectural interest and not impacting much on the existing architecture. The designs of the shear wall and diaphragms were therefore almost exclusively structurally driven. The shear wall and braces could easily be painted to reduce their presence and thus their impact. However, the architect acknowledged the weakened ornamental quality of the existing floor-boards by the plywood panels.

\section{○ Category 6 - Expression of an architectural concept}

\section{- 6.1: Reinforcement of an existing architectural concept or development of a new one}

The designers confirmed that the existing building did not possess any former concept but solely an architectural character expressed by its front façade. The idea of developing a new concept using the seismic structure was not considered. The architect stressed the difficulty of implementing a concept as he got involved in the project when the client and engineer had already agreed on a 
seismic solution including an external moment frame. Once brought into the design team, the architect then aimed at facilitating the combination of the external new and existing components. His aim was to maintain the building's visual identity as described in sub-category 2.1.

\section{- Category 7 - Conservation and preservation principles}

\section{- 7.1: Minimum intervention}

Where the minimum intervention principle aims at mitigating modification of existing architectural and historic features (ICOMOS, 2010; Look et al., 1997), the designers explained that they approached it in terms of minimising disruption to the tenants. They however considered that this approach indirectly served the intended goal of the principle. With limited new structural components inside the building, the designers estimated that the interior solution respected the architectural features. The engineer explained that the URM wall against which the shear wall was located did not possess any architectural interest and was located in the entrance hall which did not carry much value either. The presence of the new structural element had therefore no negative impact. Regarding the cross-bracing system, the architect pointed out that it was installed right under a bland ceiling with no particular architectural interest. Finally, the architect said that although the timber floor-boards were valued, they were considered as secondary architectural components. Their removal was thus assumed acceptable. Concerning the external moment frame, the engineer considered the duplication of the existing façade as successfully avoiding any loss of architectural character.

\section{- 7.2: Architectural character}

The issue of the building's architectural character was presented in sub-categories 2.1, 3.1, and 6.1. Overall, the designers preserved the building's architectural character although more consideration was given to the exterior than the interior. This difference was mainly justified by the heritage value of the front façade whereas the interior possessed less interest.

\section{- 7.3: Reversibility}

The respondents admitted not having considered the issue of reversibility. The immediate response given by the architect was "Sounds too engineering for me. I never heard anyone ever mention that". He however admitted to working on buildings needing seismic upgrade and requesting the removal of their former seismic strengthening solutions to implement new ones. While acknowledging that 
such principle made sense, the architect confessed that he never had addressed this principle when designing seismic retrofit.

For the engineer, the principle was not relevant for this particular building as it would have brought too much complexity to the design. He also considered that the seismic work was an integral part of the building, in particular the external moment frame. Removing it would not make much sense in his opinion. However, he pointed out that the previous seismic solution implemented in the '90s could be removed if needed, implying that the former work was not as important to the building as their design.

Based on both designers' statements it appears that the different evaluations of reversibility displayed in the Tables of Analysis were not anticipated by the designers.

\section{- Summary and final comments on architectural qualities}

An assumed dichotomy appeared to have driven the seismic retrofit design. Two main objectives were regularly mentioned: maintaining the existing architectural character by replicating the façade, and keeping the tenants inside the building with limited disruption. These goals defined and set apart the exterior retrofit from the interior work resulting in an absence of interaction between them. Despite being treated separately, both the external and internal seismic structural elements have largely neutral influences on architectural qualities as identified in the Tables of Analysis. The main reasons leading to these outcomes are however radically different. Regarding the façade, the results are related to the decision to replicate as faithfully as possible the existing external architectural character. For the designers, such achievement was considered successful integration. Internally, mitigation of disruption determined the limited presence of structural components; the shear wall being the only vertical structure. Opportunities for the shear wall to engage in any architectural quality were limited due to its small dimensions and lack of architectural interest in the entrance hall. Spending additional time and effort on it was deemed unnecessary, therefore limiting the seismic structure to a neutral presence.

The dichotomy was also noticeable in terms of architectural and historic importance between the façade and the interior first storey receiving the diaphragm systems. The designers acknowledged giving greater care to the exterior elevation as it was the component contributing most to the heritage value of the surrounding area. Less importance was therefore given to interior integration. The largely negative influences of the plywood panels on several architectural qualities were a direct result of such attitude. As the existing timber floor-boards were considered secondary components 
of the building's architecture, the designers deemed acceptable the intrusive presence of the plywood.

Not all decisions regarding integration were taken conjointly. Where the designers agreed on visually merging the moment frame with the façade and working hand-in-hand to achieve the intended result, it was not the case with the cross-bracing. The engineer designed the braces to be hidden by the ceiling. The architect decided to expose them without consulting the engineer which required further action to reduce their visual presence. Although the unusual pattern of the crossbracing was a consequence of technical necessities, the lack of discussion between the two designers prevented any consideration on a geometrical pattern more sympathetic to the aesthetic of the ceiling.

The topic of the cross-bracing also raised the issue of cost and its impact on integration. The architect said that cost saving was made by leaving the diaphragm exposed. However, in order to justify such decision, he explained that the exposure of the braces did not detract from any architectural quality. This attitude reveals a certain balance between cost and integration based on the judgment of the architect. The architect mainly considered the issue of cost but did not want to compromise integration. Unlike the neutral influence of the moment frame which was intended by the designers and considered an optimum solution, the neutral presence of the cross-bracing was instead considered as the outcome of acceptable integration.

The issue of ornamentation quality raised the importance of approaching seismic retrofit as an entire architectural project and not simply as structural strengthening. The case of the front façade provided a relevant example as ornamentation is provided by both the moment frame and nonstructural components including corbels and crafted steel plates. Poor detailing of one of these elements would have negatively impacted on the achievement of an effective replication of the façade. It is thus necessary for seismic structure to work together with other components when both carry the same quality. This observation was understood by the designers, especially the structural engineer who relied on the guidance of the architect to ensure effective integration between the seismic structure and the rest of the façade components. 


\section{$\circ$ Design steps and time of involvement}

Table 13. Table of Design Process: Main stakeholders and their time of involvement in Building \#2

\begin{tabular}{|l|l|l|l|l|l|l|}
\hline & STAKEHOLDERS
\end{tabular}

\section{PARTICIPATION OF THE
STAKEHOLDER}

The seismic retrofit started with the assessment of the building's seismic performance by the structural engineer as shown in Table 13. The client requested structural strengthening to $70 \%$ NBS in order to maintain the current tenants and encourage new tenants.

The Concept Design stage was mentioned by the structural engineer as the most difficult part of the design process. It required balancing the percentage of NBS with the client's budget. This led to a few iterations with the client who further added the constraint of avoiding any disruption to the current tenants. A last scheme was then designed in conjunction with the contractor's project manager and quantity surveyor. The three of them agreed on the idea of an external moment frame as well as working in the vacant first floor in order to reduce cost and facilitate the management of the work. This final scheme was approved by the client toward the end of the Concept Design stage.

Following the selection of the solution, the architect became involved and suggested approaching the moment frame as a duplication of the façade, thus reducing its visual presence. The client did not specify any particular constraints or demands regarding the building's architecture and left the architect fully in charge of his design.

However, the architect explained that his late time of involvement reduced his contribution to the project as the retrofit solution was already chosen. As he stated "we were able to massage the solution but not actually to change it". Although appreciating the final retrofit solution, he wished 
for a more integrative process, in which he would have been involved earlier in order to contribute more intensively to the choice and design of the solution. He also stated that having all the stakeholders involved at the conceptual stage would also have led to enhanced integration. The engineer however considered that the time of involvement of the architect was early enough and did not impact on the quality of the project. He also mentioned the role of the contractor who helped develop the implementation of the structure and its detailing.

As the architect was in charge of accommodating the structure with the architecture of the building, he led discussions with the City Council and Heritage NZ to gain Resource Consent. Such discussions occurred during the Detailed Design stage. The architect had to present the proposed solution to a heritage architect recognised by the City Council. The first heritage architect rejected the solution, advocating for an internal structural solution. A second heritage architect was then contacted and approved the solution. With his support, the architect gained Resource Consent. However, the encroachment license did not get accepted directly. To obtain it, the depth of the moment frame had to be reduced by $50 \mathrm{~mm}$, requiring redesign by the engineer. Apart from that last requirement, none of the respondents mentioned any other difficulties during the design process.

\section{○ Leadership}

The structural engineer stated that he assumed leadership of the design team as the project was primarily structural strengthening. The client solely aimed for seismic retrofit and did not plan any additional refurbishment. Although checking on the adequacy of the overall proposed seismic scheme with the project manager and quantity surveyor, the design of the structural solution was undertaken by the engineer only until the end of the Concept Design stage.

With the arrival of the architect at the beginning of the Detailed Design stage, the leadership started to change. The engineer stated that "once the [seismic] strengthening was finished it was then mostly architectural work. And the fact that you can see this result, which essentially appears like a refurbished existing building and not a strengthened one, comes from the architect's own contribution". The priority was then to accommodate the seismic solution with the architect's requirements in order to replicate the existing architectural character of the façade. As a result, the architect took charge of the façade detailing, asking the engineer for some modifications. This leadership change was accepted by the engineer who explained that the architect's decisions were always compatible with and respected the seismic solution by not compromising structural efficiency. The architect then continued to assume leadership for the application of Building and Resource Consents. The engineer justified this situation as the architect advocated for the 
replicating approach to the City Council and Heritage NZ. Overall, each designer took the lead when his skills were needed at a specific moment in the design process.

\section{Influences of the project's constraints on integration}

The constraints affecting the seismic retrofit design were the tenants' occupancy and the heritage value of the building's façade. Regarding the first constraint, the engineer explained that he initially designed a low cost strengthening solution leaving the façade intact. This design however required a longitudinal shear wall at the rear of the building necessitating the removal of the tenants during the work. The cost of losing the tenants was too high for the client who requested another solution. The moment frame solution, although more expensive than the first scheme, was then proposed and accepted. Following the client's request and the opportunity of having the first storey vacant, the engineer also designed the cross-bracing and plywood panel diaphragm systems. The respondents' answers and Tables of Analysis reveal that the consequences of the constraints vary mainly between neutral and negative influences, the last ones being exclusive to the plywood. The architect admitted that without such a requirement from the client, more options could have been considered, in particular the replacement of the plywood by another set of cross-bracing installed on the ceiling at ground floor.

Regarding the second constraint, the architect pointed out that the preservation of the heritage value of the building's façade by replicating it was not a requirement of the client. Such a decision was made by the architect in agreement with the City Council. A neutral influence of the seismic structure on the architectural qualities of the façade was thus aimed for by the designers. However, the architect said that if the heritage architect had requested a design distinguishing new seismic work from the existing architecture he would have followed the request.

\section{- Summary of the design process}

The factors influencing integration in Building \#2 were diverse and rose from different sources. The aspect that most determined the seismic retrofit solution was the maintenance of the tenants inside the building which implied avoiding internal disruption. This constraint greatly reduced retrofit options. This lack of flexibility led to some structural components negatively impacting on several architectural qualities. Another factor was the time of involvement of the architect at the beginning of the Detailed Design stage. Such late engagement did not allow him to participate in the choice of retrofit solution. Moreover, it greatly limited considerations of integration issues. As a result, the architectural response was a case-by-case design rather than an overall architectural concept. The 
leadership of the design team was shared between the engineer and the architect. The transition from one to another occurred naturally, starting with the engineer in charge of the structural design and followed by the architect adding the architectural detailing. This change in leadership can be considered successful thanks to the mutual confidence the designers had in one another. The City Council and Heritage NZ were also important actors in the project. The first imposed changes on the moment frame encroachment. The second forced the architect to require the involvement of a second heritage architect. While the influence of the two institutions did not reduce the level of integration, it had the potential to impose a completely new design.

\subsubsection{Integration in the seismically retrofitted buildings - Building \#3}

\section{Tables of Analysis}

Based on the reviews undertaken by the researcher in Chapter 5 , three main observations can be made from Table 14. First, the seismic structures have enhanced more architectural qualities in the bar than in the rest of the building. The only exclusive enhanced architectural quality in other spaces is the modulation of natural light (4.1). Secondly, all the vertical seismic structures and cross-bracing system are considered positive in regard to the minimum intervention principle (7.1). Finally, all the eccentric braces, with the exception of that installed in the bar, negatively affect all architectural qualities of Categories 3 (Exposed interior structure) and Category 4 (Interaction with external openings). 
Table 14. Tables of Analysis representing the influences of the seismic systems of Building \#3 on architectural qualities

\begin{tabular}{|c|c|c|c|c|c|c|c|}
\hline BUILDING \#3 & $\begin{array}{l}\text { CAT 1. HIDDEN } \\
\text { STRUCTURE }\end{array}$ & $\begin{array}{l}\text { CAT 2. EXPOSED EXTERIOR } \\
\text { STRUCTURE }\end{array}$ & $\begin{array}{l}\text { CAT 3. EXPOSED INTERIOR } \\
\text { STRUCTURE }\end{array}$ & $\begin{array}{l}\text { CAT 4. INTERACTION WITH } \\
\text { EXTERNAL OPENINGS }\end{array}$ & CAT 5. ORNAMENTATION & $\begin{array}{l}\text { CAT 6. EXPRESSION OF AN } \\
\text { ARCHITECTURAL CONCEPT }\end{array}$ & $\begin{array}{l}\text { CAT 7. CONSERVATION } \\
\text { AND PRESERVATION } \\
\text { PRINCIPLES }\end{array}$ \\
\hline \multirow{5}{*}{$\begin{array}{l}\text { INTERNAL CONCRETE } \\
\text { SHEAR WALL- } \\
\text { LONGITUDINAL DIRECTION }\end{array}$} & $\begin{array}{l}1.1 \text { ARCHITECTURAL } \\
\text { REASONS }\end{array}$ & 2.1. ELEVATION & 3.1. ELEVATION & 4.1 MODULATION OF LIGHT & $\begin{array}{l}5.1 \text { USE OF STRUCTURE FOR } \\
\text { ORNAMENTAL PURPOSES }\end{array}$ & $\begin{array}{l}\text { 6.1 EXISTTING OR NEW } \\
\text { ARCHITECTURAL CONCEPT }\end{array}$ & $\begin{array}{l}7.1 \text { MINIMUMM } \\
\text { INTERVENTION }\end{array}$ \\
\hline & $\begin{array}{l}1.2 \text { THE EFFECT OF THE } \\
\text { HIDING TECHNIQUE UPON } \\
\text { ARCHITECTURE }\end{array}$ & $\begin{array}{l}\text { 2.2 EXPRESSIVE ROLES OF } \\
\text { THE STRUCTURE }\end{array}$ & $\begin{array}{l}\text { 3.2 EXPRESSIVE ROLES OF } \\
\text { THE STRUCTURE }\end{array}$ & \begin{tabular}{|l}
4.2 OUTSIDE \\
VIEWS/SIGHTLINES
\end{tabular} & & & $\begin{array}{l}7.2 \text { COMPATIBILITY WITH } \\
\text { EXISTING ARCHITECTURAL } \\
\text { CHARACTER }\end{array}$ \\
\hline & & & 3.3 STRUCTURE AND SPACE & & & & 7.3 REVERSIBILITY \\
\hline & & & $\begin{array}{l}\text { 3.4 STRUCTURE AND } \\
\text { FUNCTION }\end{array}$ & & & & \\
\hline & & & $\begin{array}{l}3.5 \text { STRUCTURE AND } \\
\text { CIRCULATION }\end{array}$ & & & & \\
\hline
\end{tabular}

\begin{tabular}{|c|c|c|c|c|c|c|c|}
\hline $\begin{array}{c}\text { BUILDING \#3 } \\
\text { BAR/RESTAURANT }\end{array}$ & $\begin{array}{l}\text { CAT 1. HIDDEN } \\
\text { STRUCTURE }\end{array}$ & $\begin{array}{l}\text { CAT 2. EXPOSED EXTERIOR } \\
\text { STRUCTURE }\end{array}$ & $\begin{array}{l}\text { CAT 3. EXPOSED INTERIOR } \\
\text { STRUCTURE }\end{array}$ & $\begin{array}{l}\text { CAT 4. INTERACTION WITH } \\
\text { EXTERNAL OPENINGS }\end{array}$ & CAT 5. ORNAMENTATION & $\begin{array}{l}\text { CAT 6. EXPRESSION OF AN } \\
\text { ARCHITECTURAL CONCEPT }\end{array}$ & $\begin{array}{l}\text { CAT 7. CONSERVATION } \\
\text { AND PRESERVATION } \\
\text { PRINCIPLES }\end{array}$ \\
\hline \multirow{5}{*}{$\begin{array}{l}\text { INTERNAL CONCRETE } \\
\text { SHEAR WALL- } \\
\text { LONGITUDINAL DIRECTION }\end{array}$} & $\begin{array}{l}1.1 \text { ARCHITECTURAL } \\
\text { REASONS }\end{array}$ & 2.1. ELEVATION & 3.1. ELEVATION & 4.1 MODULATION OF LIGHT & $\begin{array}{l}5.1 \text { USE OF STRUCTURE FOR } \\
\text { ORNAMENTAL PURPOSES }\end{array}$ & \begin{tabular}{|l|}
6.1 EXISTING OR NEW \\
ARCHITECTURAL CONCEPT
\end{tabular} & $\begin{array}{l}7.1 \text { MINIMUM } \\
\text { INTERVENTION }\end{array}$ \\
\hline & $\begin{array}{l}\text { 1.2 THE EFFECT OF THE } \\
\text { HIDING TECHNIQUE UPON } \\
\text { ARCHITECTURE }\end{array}$ & $\begin{array}{l}\text { 2.2 EXPRESSIVE ROLES OF } \\
\text { THE STRUCTURE }\end{array}$ & $\begin{array}{l}\text { 3.2 EXPRESSIVE ROLES OF } \\
\text { THE STRUCTURE }\end{array}$ & $\begin{array}{l}4.2 \text { OUTSIDE } \\
\text { VIEWS/SIGHTINES }\end{array}$ & & & $\begin{array}{l}\text { 7.2 COMPATIBILITY WITH } \\
\text { EXISTING ARCHITECTURAL } \\
\text { CHARACTER }\end{array}$ \\
\hline & & & 3.3 STRUCTURE AND SPACE & & & & 7.3 REVERSIBILITY \\
\hline & & & $\begin{array}{l}\text { 3.4 STRUCTURE AND } \\
\text { FUNCTION }\end{array}$ & & & & \\
\hline & & & $\begin{array}{l}\text { 3.5 STRUCTURE AND } \\
\text { CIRCULATION }\end{array}$ & & & & \\
\hline
\end{tabular}

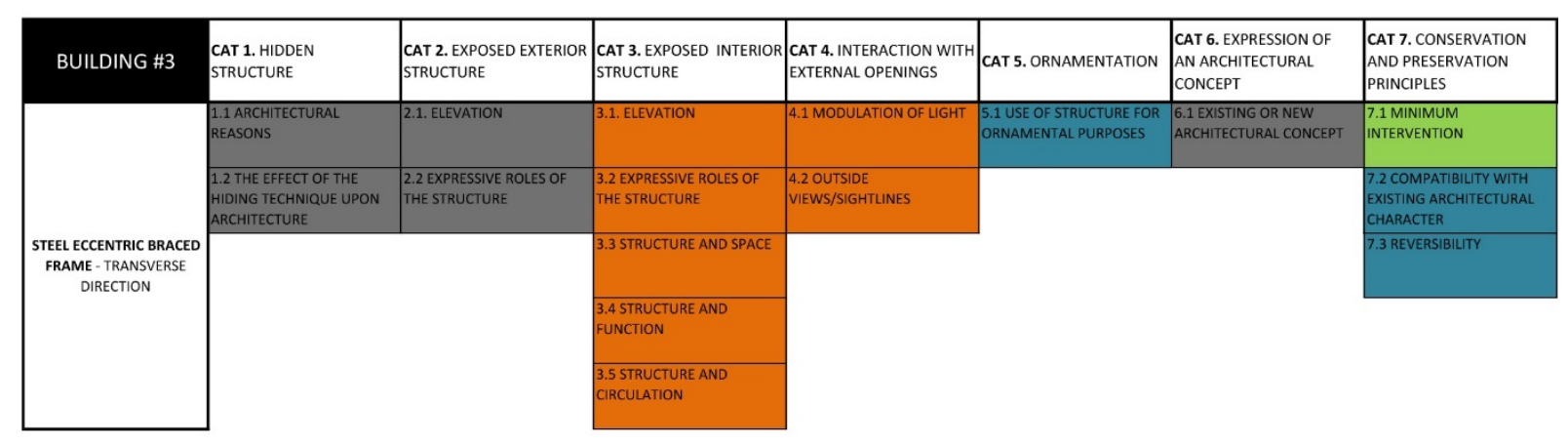

\begin{tabular}{|c|c|c|c|c|c|c|c|}
\hline $\begin{array}{c}\text { BUILDING \#3 } \\
\text { BAR/RESTAURANT }\end{array}$ & $\begin{array}{l}\text { CAT 1. HIDDEN } \\
\text { STRUCTURE }\end{array}$ & $\begin{array}{l}\text { CAT 2. EXPOSED EXTERIOR } \\
\text { STRUCTURE }\end{array}$ & $\begin{array}{l}\text { CAT 3. EXPOSED INTERIOR } \\
\text { STRUCTURE }\end{array}$ & $\begin{array}{l}\text { CAT 4. INTERACTION WITH } \\
\text { EXTERNAL OPENINGS }\end{array}$ & CAT 5. ORNAMENTATION & $\begin{array}{l}\text { CAT 6. EXPRESSION OF } \\
\text { AN ARCHITECTURAL } \\
\text { CONCEPT }\end{array}$ & $\begin{array}{l}\text { CAT 7. CONSERVATION } \\
\text { AND PRESERVATION } \\
\text { PRINCIPLES }\end{array}$ \\
\hline \multirow{5}{*}{$\begin{array}{l}\text { STEEL ECCENTRIC BRACED } \\
\text { FRAME - TRANSVERSE } \\
\text { DIRECTION }\end{array}$} & $\begin{array}{l}\text { 1.1 ARCHITECTURAL } \\
\text { REASONS }\end{array}$ & 2.1. ELEVATION & 3.1. ELEVATION & 4.1 MODULATION OF LIGHT & $\begin{array}{l}5.1 \text { USE OF STRUCTURE FOR } \\
\text { ORNAMENTAL PURPOSES }\end{array}$ & $\begin{array}{l}\text { 6.1 EXISTING OR NEW } \\
\text { ARCHITECTURAL CONCEPT }\end{array}$ & $\begin{array}{l}7.1 \text { MINIMUMM } \\
\text { INTERVENTION }\end{array}$ \\
\hline & $\begin{array}{l}\text { 1.2 THE EFFECT OF THE } \\
\text { HIDING TECHNIQUE UPON } \\
\text { ARCHITECTURE }\end{array}$ & $\begin{array}{l}\text { 2.2 EXPRESSIVE ROLES OF } \\
\text { THE STRUCTURE }\end{array}$ & $\begin{array}{l}\text { 3.2 EXPRESSIVE ROLES OF } \\
\text { THE STRUCTURE }\end{array}$ & $\begin{array}{l}4.2 \text { OUTSIDE } \\
\text { VIEWS/SIGHTLNES }\end{array}$ & & & $\begin{array}{l}\text { 7.2 COMPATIBILTY WITH } \\
\text { EXISTING ARCHITECTURAL } \\
\text { CHARACTER }\end{array}$ \\
\hline & & & 3.3 STRUCTURE AND SPACE & & & & 7.3 REVERSIBILITY \\
\hline & & & $\begin{array}{l}3.4 \text { STRUCTURE AND } \\
\text { FUNCTION }\end{array}$ & & & & \\
\hline & & & $\begin{array}{l}\text { 3.5 STRUCTURE AND } \\
\text { CIRCULATION }\end{array}$ & & & & \\
\hline
\end{tabular}



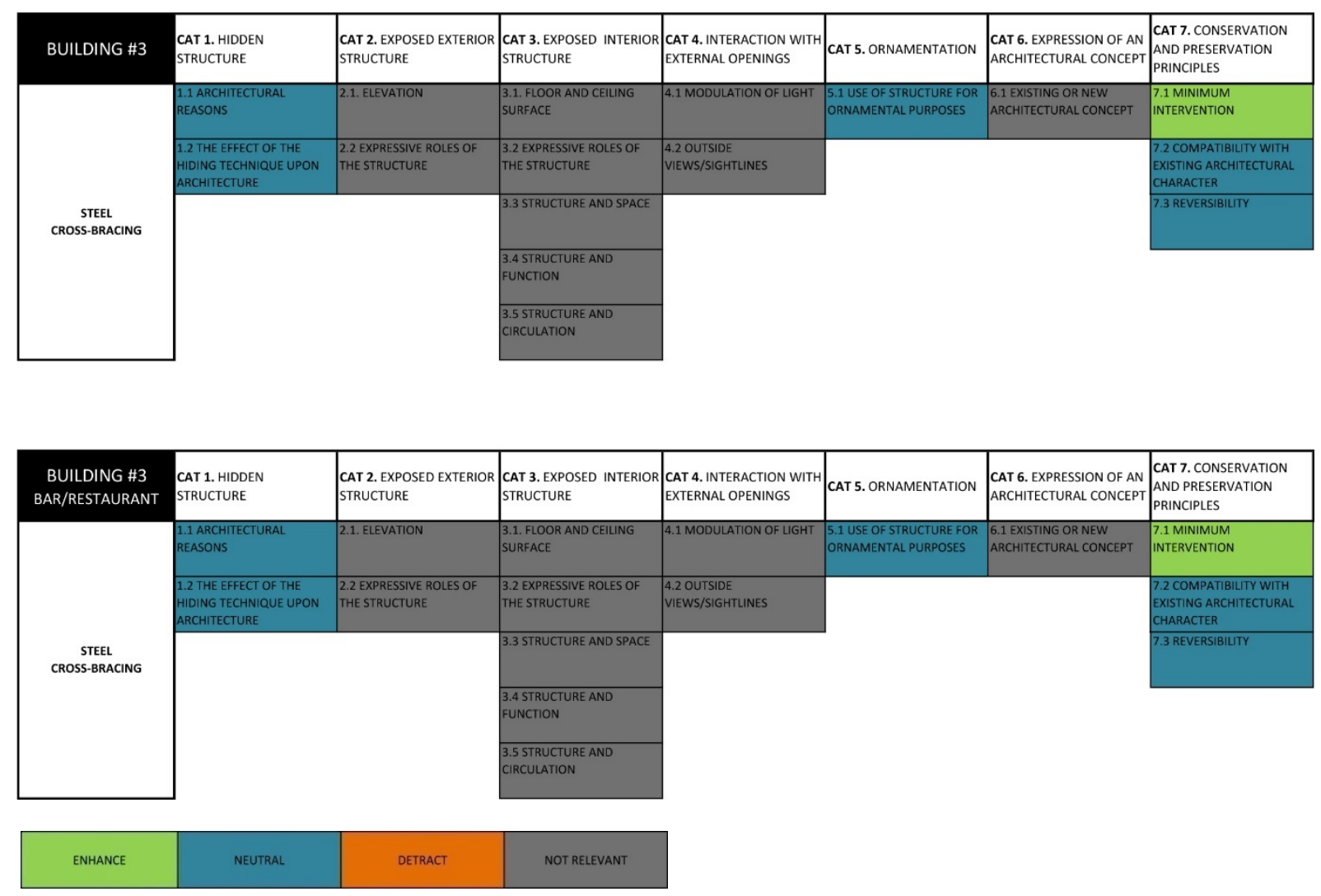

Interviews regarding architectural qualities

\section{○ Category 1 - Hidden structure}

\section{- 1.1: Architectural reasons}

Regarding the hiddenness of the horizontal cross-bracing by plain ceilings, the architect first referred to a desire to avoid unusual appearances in interior spaces. As the diaphragm structural components run under the entire floors, their exposure would have been excessive. The second reason was the fire requirement. Using the ceiling as a fire cell appeared an effective and simple approach.

\section{- 1.2: The effect of the hiding technique upon architecture}

The use of plasterboard lining to hide the cross-bracing was deemed the most practical approach by the designers. The architect explained that the plasterboard was an integral part of the fire system and thus provided the required fire rating. She also justified the plainness of the ceiling by recalling the function of the building, "it's a backpackers' hostel, we don't need a fancy ceiling". 


\section{○ Category 3 - Exposed interior structure}

\section{- 3.1: Elevation}

The Tables of Analysis indicate different influences of similar structures on internal elevations. Eccentric braced frames have either a negative or positive influence; shear walls are found to be neutral in most interior spaces and positive in one situation.

The engineer designed eccentric braced frames internally against the rear walls of the building far from the front façade which contributes to the heritage value of the area. Their locations mainly resulted from functional considerations. Installing them closer to the centre of the building would have affected circulation and usability of spaces. The engineer further justified the exposure of the structure as a way to save money and their interior location to avoid them rusting. The architect added that the eccentric braces were solely technically driven as the architectural and structural plans were developed independently of one another. With no collaboration by the designers, the eccentric braces ended up passing through various partition walls and standing in front of windows. The engineer acknowledged the negative influence of the structure on internal elevations, stating "I think the eccentric braced frames don't work architecturally, they are bloody awful". The architect however tempered the lack of integration by pointing out that the eccentric braces were located at the back of the building, thus not impacting on the "public face of the building".

The architect recognised that, although technically driven, the brace in the bar enriched the existing elevation. She ensured that the structure would be fully readable and contrast with the wall behind it. This approach corresponded to the industrial architectural character she aimed for. The raw shotcrete shear wall in the same space was used for a similar purpose.

The rest of the shear walls however were plain with the same rendering as the plastered URM walls. The architect justified the lack of developed surfaces as a consequence of the client's desire to have a simple interior character.

\section{- 3.2: Expressive roles of the structure}

The engineer confirmed that the technical design of the seismic structures drove their detailing. The architect added that the only influence she could have had on the expressiveness of the structures was to eventually hide them if necessary. Being exclusively technically driven, the structural detailing of the eccentric braced frame and shotcrete shear wall however serve the industrial character of the bar sought by the architect. In the rest of the building, the exposure of the braces 
has an unintentional negative influence on expressive quality regretted by the engineer. However, as justified once more by the architect, the distance between the eccentric braces and the heritage façade puts their impact in perspective.

\section{- 3.3: Structure and space}

For the engineer, the location of the shear walls along the side URM perimeter walls barely had any impact on interior spaces as they follow existing boundaries. The eccentric braces against the rear walls however were acknowledged to affect the rear windows and reduce space. This issue is further amplified by the architectural planning. The architect focused on providing the number of rooms requested by the client regardless of the engineer's design. As a result, many rooms ended up with eccentric braces inside their spaces and in front of their only windows. The architect justified the negative impact on space as a minor issue for the client. The goal was to make the project financially viable in terms of the number of beds for a backpackers' hostel and not be concerned about the spatial quality of their rooms.

\section{- 3.4: Structure and function}

The architect said that the integration of structure and function was considered during the design of the seismic retrofit. She explained that the client's programme was achieved thanks to a completely new interior layout. She relied on the structural engineer to locate and design the seismic structure accordingly. Although some rooms were not fully usable due to the presence of the eccentric braces, the architect again put the negative impact in perspective. She explained that the seismic structure did impact on some spaces but did not put the layout and overall function of the building in jeopardy.

\section{- 3.5: Structure and circulation}

The arguments of the designers regarding the consideration of circulation were similar to those provided in sub-categories 3.1 and 3.4. The first came from the engineer who explained how installing the eccentric braces at the rear of the façade avoided impacting on corridors. The architect acknowledged the reduction of circulation within rooms due to the presence of the eccentric braces but stressed the lack of impact on the rest of the building.

Concerning the eccentric bracing in the bar, the Tables of Analysis point out its positive influence on circulation thanks to how it frames an existing door. The engineer however revealed such contribution to be fortuitous, the location of the structure being solely driven by technical needs. 


\section{- Category 4 - Interaction with external openings}

For the architect, having the eccentric braces largely cover the rear windows was not prejudicial to the natural light and outside views. She explained that despite a small backyard there were no interesting views, not much natural light entering due to the presence of the neighbour's building, and that the interior spaces did not require much light. The negative impact on the existing poor qualities was thus considered reasonable.

The engineer's response put the architect's attitude in perspective as he explained that the rear of the building was not so poor architecturally. He revealed proposing the use of shear walls instead of eccentric bracing which would have resulted in covering the existing openings. The client and the architect refused, arguing to keep natural light inside the building. The qualities of the rear windows were therefore not as negligible as the architect stated previously.

The engineer also explained that ensuring the interior usability of the backpackers' hostel was more important than the impact eccentric braces had on the openings.

One Table of Analysis reflects the positive modulation of natural light by the plastered shear walls along the side boundaries. This quality however was not directly intended by the designers. The architect explained it was a result of the dimension of the shear walls required by the engineer and the simple treatment of their surfaces using white paint to ensure a plain character.

\section{○ Category 5 - Ornamentation}

\section{- 5.1: Use of structure for ornamental purposes}

The engineer did not consider the design of seismic structures for ornamental purposes. The architect however took advantage of them for such a purpose, exclusively in the bar. The architect's attitude confirms the results of the Table of Analysis indicating that the raw shotcrete shear wall and the eccentric braced frame contribute to such a quality. The architect pointed out that her desire for the bar was to highlight each type of structure, whether existing or new, in order to remember the different structural elements comprising the building. 


\section{○ Category 6 - Expression of an architectural concept}

- 6.1: Reinforcement of an existing architectural concept or development of a new one

According to the architect, prior to the retrofit, the interior of the building was in a terrible state and almost entirely stripped out. The only remaining architectural values were the heritage façade and central wooden stairway. Rather than developing an architectural concept, the architect focused on the client's programme and requirement to have a plain aesthetic throughout the building. Only the bar was developed using technical language in order to express an industrial character. The architect explained that the bar was initially not part of the programme and thus did not require the plain treatment the rest of the building got. Based on the presence of the shotcrete shear wall and eccentric braced frame, the architect drew upon them, using the raw surface of the former and exposure of the second, to develop an industrial character.

\section{○ Category 7 - Conservation and preservation principles}

\section{- 7.1: Minimum intervention}

The first aspect the designers took into account regarding minimum intervention was avoiding any unnecessary modifications to the heritage façade and the existing wooden stairway. Yet, since barely any existing features of value remained inside the building, the engineer explained that the minimum intervention principle was mainly approached through cost consideration rather than architectural concerns.

\section{- 7.2: Architectural character}

The issue of the architectural character was considered through two aspects according to the architect. First, the existing features deemed of value and contributing to the building's architectural character were maintained. This implied not applying the eccentric braces to the front façade whether externally or internally, and avoiding modifications to the existing wooden stairway. Secondly, the internal refurbishment allowed for two different aesthetics inside the building: the simple and plain treatment in most spaces, and the raw and industrial character in the bar. The architect explained that she treated the seismic structures accordingly. Regarding the plain aesthetic, the shear walls were plastered and painted white, and the eccentric braces were painted the same colour as the walls behind them. Regarding the industrial character of the bar, the structures were left exposed and unrefined. 


\section{- 7.3: Reversibility}

Both designers said that the issue of reversibility was not considered when designing the seismic retrofit. The architect gave two reasons. First, such an issue was never mentioned as a requirement by any of the stakeholders involved in the project, referring in particular to the City Council and the heritage architect. Secondly, if reversibility was required, it would have been up to the engineer to propose a design suitable for future removal.

The engineer did not see the reversibility of the seismic structures as a necessity. He argued that the location of the structures along the building boundaries do not restrain reconfiguring the interior for future purposes including seismic upgrade. Nevertheless, if the shear walls and eccentric braced frames were required to be removed, their impact would be minimal as they do not affect any of the building's historic or architectural values.

\section{○ Summary and final comments on architectural qualities}

The answers given by the designers concurred with the results of the Tables of Analysis regarding the negative influences of most eccentric braced frames on architectural qualities. Three reasons were identified. The first was the extreme importance given to the client's programme requiring a specific number of rooms, and an effective functionality of the overall layout. These two aspects overshadowed considerations of almost any other architectural qualities. This led to a situation where although the two main requirements were met, some new spaces were negatively affected by the eccentric braced frames. However, the architect justified that most of the negative influences of the eccentric braces were deemed secondary compared to the successful implementation of the client's brief. The second reason related to the lack of collaboration between the architect and engineer regarding the impact of the seismic structures on architectural qualities. Each designer focused on their own design with little interaction with one another. With no unified approach, the consequences of the combination of their designs were, if not neglected, at least overlooked. The third reason corresponded to the difference of value between the heritage front façade and the back of the building. Prioritisation was given to the building's public image and to the maintenance of the main façade. As a consequence, the less valuable rear façade and spaces adjacent to it received the eccentric braced frames and the resulting negative impacts were considered acceptable. This hierarchy of value within the building was used by the architect to put in perspective any poor integration resulting from the presence of the eccentric braced frames. 
Although the seismic structures were neutral, and even problematic in many interior spaces, there is one space in which they positively served the architectural design. Within the bar, the architect took advantage of the seismic structures for architectural purposes. Only in this particular case did she acknowledge the presence of the seismic structures rather than ignoring them. Such an attitude allowed the seismic structures to successfully integrate with several architectural qualities.

Not every architectural contribution from the seismic structures was however intended by the designers. Some were fortuitous, such as the eccentric bracing framing an internal door, or the white plastered shear walls reflecting and diffusing natural light.

While the principles of minimum intervention and existing architectural character were taken into account by the designers, reversibility was disregarded. The relative non-disruptive removal of the seismic structures was fortuitous and largely a consequence of standard technical designs. While their removal is possible, the engineer does not agree that it is the most relevant option if future additional seismic work is required. Instead, he believes that the reversibility principle could be compensated for by providing enough flexibility for internal reorganisation in order to receive and accommodate potential seismic strengthening.

\section{Design process}

\section{- Design steps and time of involvement}

Table 15. Table of Design Process: Main stakeholders and their time of involvement in Building \#3

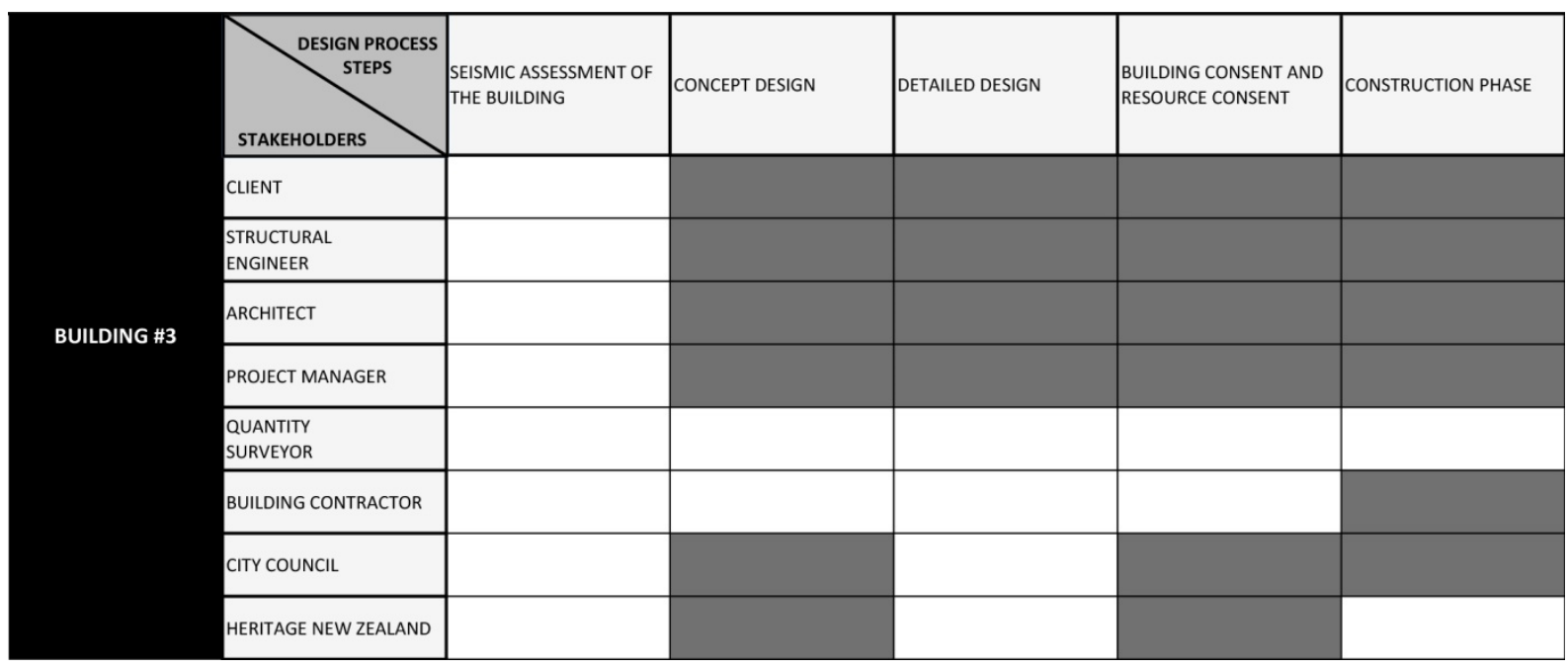


As presented in Table 15, the project did not start from a seismic assessment but from the client's desire to convert the unoccupied building into backpackers' accommodation. Due to the change of use, the City Council required seismic strengthening up to $100 \%$ NBS.

Although both designers were present at the Concept Design stage, their times of involvement differed. Because the project was approached by the client as a fit-out rather than seismic retrofit, the architect got on board first. The architect developed the internal design based on the client's requirements. Once the concept plans were agreed and signed off, the client engaged the structural engineer. The architect was not surprised by the belated engagement of the engineer with the project. She stated that all her projects followed such a process unless the work to be undertaken solely required seismic upgrading. The engineer then also developed the seismic scheme during the Concept Design stage yet with no interaction with the architect.

The two designers brought their plans together at the Detailed Design stage. The architect assumed that, due to the nature of the project and because the architectural design was done first, it was mainly up to the engineer to adapt his structural plans to hers. For the architect, superimposing the two designs at that stage in the design process and letting the structural engineer in charge of merging them was not detrimental to the project. Instead, she justified the poor integration of seismic structure with some architectural qualities due to not properly rechecking the plans following the combining of the designs. The explanations given were the slowness of the engineer in getting the structural design to her, the limited timeframe, and finally the lack of interest from the client in an integrated solution. As a result, and although some discussions through e-mail did occur between the architect and the structural engineer, the design changes accepted by each were minor and did not mitigate integration issues.

The architect also mentioned the role of the project manager and building contractor. She explained that "the project manager was kind of just managing the consultants, the timeframe, and the budget but not the design". While not directly influencing design decisions however, the project manager did affect them. It was him who selected most consultants as they had worked on previous projects together. However, three of them were based in Auckland and were unable to attend any design team meetings. In addition, they were slow at providing information. The architect regretted such a situation as it did not allow enough coordination to accommodate the designs of the mechanical, electrical and fire engineers with the structural and architectural plans. While this was not detrimental to the overall architectural quality, options for enhanced integration could not be considered. Concerning the building contractor, the architect stressed his contribution to the design during the construction phase. While the designers had already defined the internal layout and 
seismic solution, the contractor provided guidance concerning implementation as well as detailing, thus refining some features.

The description of the design process by the designers highlighted the reason behind the aesthetic differences of overall plain interiors and the industrial character of the bar. The architect explained that initially the bar was not part of the architectural design and was meant to be left as an empty shell to provide flexibility for a future use. However, during the construction phase the client decided to use the space as a bar, putting the architect in charge of the fit-out. Taking advantage of the exposed and raw seismic structures, the architect decided to draw upon them to define an industrial character. The two contrasted aesthetics in the building were therefore not an initial thought driving the architectural design but the result of a last-minute request.

\section{○ Leadership}

For the architect, the nature of the project — primarily an interior fit-out for a new function justified her leadership on the project. Beyond any other goals, the achievement of a viable backpackers' hostel was essential and the architect had to ensure such achievement. Due to the building change of use, seismic retrofit was imposed for legislative reasons. As a result, integration between seismic structures and existing architecture was not particularly sought by the designers. As long as the presence of the seismic structural components did not affect the overall usability of the building, their impact was deemed acceptable.

The engineer did not think that the leadership position was held by any of the designers. Each designer worked with great freedom on their own goals. When the designs were combined discussions took place to incorporate the seismic solution. Aspects of the seismic retrofit could be harmonised to please both designers. The eccentric braced frames however remained as such, as according to the engineer they represented the most pragmatic option which led the architect accepting them.

\section{Influences of the project's constraints on integration}

Several constraints affected both architectural and structural designs during the design process. The respondents first mentioned the heritage value of the façade which led the City Council and Heritage NZ to refuse an initial idea suggested by the engineer using a concrete moment frame behind it. The additional thickness was deemed too excessive and this forced the engineer to install eccentric braces instead along the rear walls of the building, far from the heritage façade. 
The designers also mentioned a series of architectural requirements. They explained that the client had a precise idea of the intended project. The plain aesthetic as well as the number and sizes of rooms had to meet the standards of a backpackers' hostel. Following the client's brief, the internal fit-out designed by the architect limited structural options such as locating the eccentric braced frames toward the centre of the building.

The legal requirement to reach $100 \%$ NBS due to the new function of the building was also discussed by the structural engineer and architect. This constraint required achieving a certain level of stiffness which led the engineer to choose shear walls over eccentric braced frames along the side walls although the architect would have preferred the second option. The engineer however clarified that eccentric braces could have been used although they were more difficult to design and there was little time to consider that option.

The architect also addressed the issue of time as the deadline set by the client did not allow for much iteration between her and the structural engineer. The design process barely allowed for any reconfiguration due to the slow progress of the engineer, and to a greater extent, of almost all the stakeholders.

A final constraint was the impossibility of several stakeholders to attend design meetings, and combined with their delay in providing their work forced the architect to accept services, mechanical, and fire safety plans without being able to discuss options.

\section{- Summary of the design process}

Two main factors drove the refurbishment and seismic retrofit of the building and influenced the interaction between the seismic structure and existing architecture. The first factor was the consideration of the nature of the project by the client and architect. Approached through a specific financial model for a backpackers' hostel, the project was considered as an internal refurbishment. The legislative requirement of seismic retrofit was deemed a secondary matter. As a result, the issue of integration of the architectural fit-out and seismic structures was greatly overlooked by the client. The reluctance of the architect to push the design further than simply achieving the client's demands was also detrimental to the project. Only when the architectural design had to be developed after the seismic work, as was the case in the bar, did integration succeed and provided enhanced qualities to the building.

The second factor corresponded to the lack of iterations between the two designers. A tight timeframe and slow production of work from the engineer were indicated by the architect as the 
main reasons causing this issue. However, the architect did not consider the individual development of the architectural and structural designs as well as their lateness during the Detailed Design stage as prejudicial to integration. Yet, it appears reasonable to assume that if the designers would have worked more closely on their respective designs during the Concept Design stage, the combining of their plans would have been more effective. Integration issues could have been raised at a time in the design process where each designer would have had a reasonable flexibility over their plans. However, this would also have required from the architect to accept that adaptation might be necessary from both sides and not solely coming from the engineer.

A long series of constraints were also mentioned. Some had a direct influence on the final solution such as the heritage value and the $100 \%$ NBS requirement forcing the structural engineer to reconsider some options. Others like the physical absence of some stakeholders and a tight timeframe degraded the communication between the members of the design team and affected the organisation of work. Finally, the client's brief set a series of demands solely architecturally oriented such as the plain aesthetic of most internal spaces.

\subsubsection{Integration in the seismically retrofitted buildings - Building \#4}

\section{Tables of Analysis}

Based on the reviews undertaken by the researcher in Chapter 5, the seismic retrofit solution has mainly neutral influences on the architectural qualities as indicated in Table 16. The table reveals that the building's architecture has been preserved, especially in the interior. A few positive contributions from the seismic solution, in particular through the internal shear wall, can be noticed. The internal shear walls, X-braced frames and steel tie members all positively comply with the minimum intervention principle. In addition, the shear walls enhance the expressiveness (3.2) and ornamentation (5.1) qualities of the building. The only negative influences come from the external seismic structure. The longitudinal and transverse shear walls impact similarly on the qualities of elevations (2.1) and architectural character (7.2). The longitudinal walls however have additional negative influences on the natural light (4.1) and outside views (4.2). 
Table 16. Tables of Analysis representing the influences of the seismic systems of Building \#4 on architectural qualities

\begin{tabular}{|c|c|c|c|c|c|c|c|}
\hline BUILDING \#4 & $\begin{array}{l}\text { CAT 1. HIDDEN } \\
\text { STRUCTURE }\end{array}$ & $\begin{array}{l}\text { CAT 2. EXPOSED EXTERIOR } \\
\text { STRUCTURE }\end{array}$ & $\begin{array}{l}\text { CAT 3. EXPOSED INTERIOR } \\
\text { STRUCTURE }\end{array}$ & $\begin{array}{l}\text { CAT 4. INTERACTION WITH } \\
\text { EXTERNAL OPENINGS }\end{array}$ & CAT 5. ORNAMENTATION & $\begin{array}{l}\text { CAT 6. EXPRESSION OF AN } \\
\text { ARCHITECTURAL CONCEPT }\end{array}$ & $\begin{array}{l}\text { CAT 7. CONSERVATION } \\
\text { AND PRESERVATION } \\
\text { PRINCIPLES }\end{array}$ \\
\hline \multirow{5}{*}{$\begin{array}{c}\text { INTERNAL CONCRETE } \\
\text { SHEAR WALL - TRANSVERSE } \\
\text { DIRECTION }\end{array}$} & $\begin{array}{l}\text { 1.1 ARCHITECTURAL } \\
\text { REASONS }\end{array}$ & 2.1. ELEVATION & 3.1. ELEVATION & 4.1 MODULATION OF LGHT & $\begin{array}{l}5.1 \text { USE OF STRUCTURE FOR } \\
\text { ORNAMENTAL PURPOSES }\end{array}$ & $\begin{array}{l}\text { 6.1 EXISTING OR NEW } \\
\text { ARCHITECTURAL CONCEPT }\end{array}$ & $\begin{array}{l}7.1 \text { MINIMUM } \\
\text { INTERVENTION }\end{array}$ \\
\hline & $\begin{array}{l}1.2 \text { THE EFFECT OF THE } \\
\text { HIDING TECHNIQUE UPON } \\
\text { ARCHITECTURE }\end{array}$ & $\begin{array}{l}\text { 2.2 EXPRESSIVE ROLES OF } \\
\text { THE STRUCTURE }\end{array}$ & $\begin{array}{l}\text { 3.2 EXPRESSIVE ROLES OF } \\
\text { THE STRUCTURE }\end{array}$ & $\begin{array}{l}4.2 \text { OUTSIDE } \\
\text { VIEWS/SIGHTINES }\end{array}$ & & & $\begin{array}{l}7.2 \text { COMPATIBILITY WITH } \\
\text { EXISTING ARCHITECTURAL } \\
\text { CHARACTER }\end{array}$ \\
\hline & & & 3.3 STRUCTURE AND SPACE & & & & 7.3 REVERSIBILTY \\
\hline & & & $\begin{array}{l}3.4 \text { STRUCTURE AND } \\
\text { FUNCTION }\end{array}$ & & & & \\
\hline & & & $\begin{array}{l}3.5 \text { STRUCTURE AND } \\
\text { CIRCULATION }\end{array}$ & & & & \\
\hline
\end{tabular}
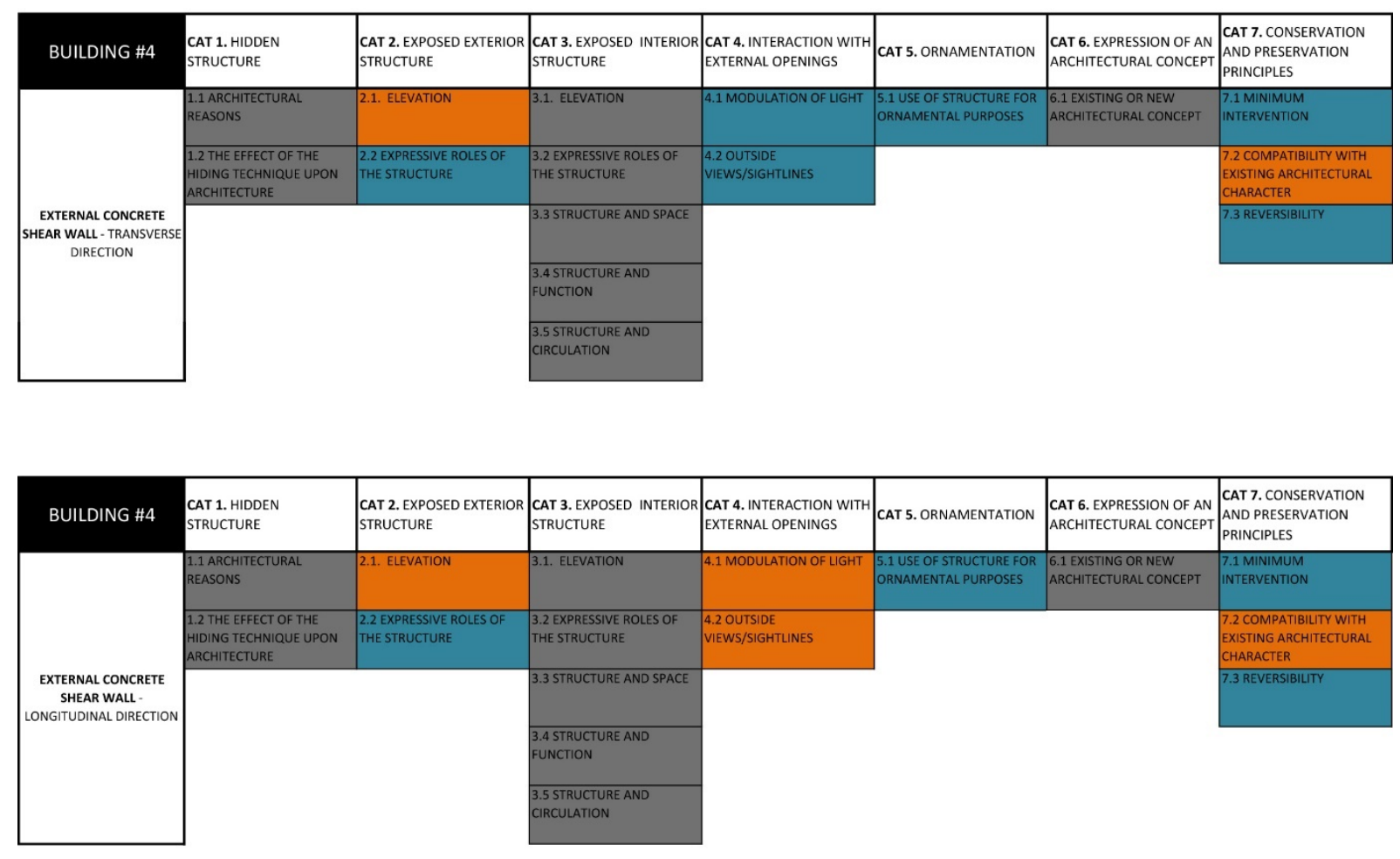

\begin{tabular}{|c|c|c|c|c|c|c|c|}
\hline BUILDING \#4 & $\begin{array}{l}\text { CAT 1. HIDDEN } \\
\text { STRUCTURE }\end{array}$ & \begin{tabular}{|l} 
CAT 2. EXPOSED \\
EXTERIOR STRUCTURE
\end{tabular} & $\begin{array}{l}\text { CAT 3. EXPOSED INTERIOR } \\
\text { STRUCTURE }\end{array}$ & $\begin{array}{l}\text { CAT 4. INTERACTION WITH } \\
\text { EXTERNAL OPENINGS }\end{array}$ & CAT 5. ORNAMENTATION & $\begin{array}{l}\text { CAT 6. EXPRESSION OF } \\
\text { AN ARCHITECTURAL } \\
\text { CONCEPT }\end{array}$ & $\begin{array}{l}\text { CAT 7. CONSERVATION } \\
\text { AND PRESERVATION } \\
\text { PRINCIPLES }\end{array}$ \\
\hline \multirow{5}{*}{$\begin{array}{l}\text { STEEL X BRACED FRAME- } \\
\text { TRANSVERSE DIRECTION }\end{array}$} & $\begin{array}{l}1.1 \text { ARCHITECTURAL } \\
\text { REASONS }\end{array}$ & 2.1. ELEVATION & 3.1. ELEVATION & 4.1 MODULATION OF LIGHT & $\begin{array}{l}.1 \text { USE OF STRUCTURE FOR } \\
\text { ORNAMENTAL PURPOSES }\end{array}$ & $\begin{array}{l}6.1 \text { EXISTING OR NEW } \\
\text { ARCHITECTURAL CONCEPT }\end{array}$ & $\begin{array}{l}7.1 \text { MINIMUM } \\
\text { INTERVENTION }\end{array}$ \\
\hline & $\begin{array}{l}1.2 \text { THE EFFECT OF THE } \\
\text { HIDING TECHNIQUE UPON } \\
\text { ARCHITECTURE }\end{array}$ & $\begin{array}{l}\text { 2.2 EXPRESSIVE ROLES OF } \\
\text { THE STRUCTURE }\end{array}$ & $\begin{array}{l}\text { 3.2 EXPRESSIVE ROLES OF } \\
\text { THE STRUCTURE }\end{array}$ & $\begin{array}{l}4.2 \text { OUTSIDE } \\
\text { VIEWS/SIGHTINES }\end{array}$ & & & $\begin{array}{l}\text { 7.2 COMPATIBILTYY WITH } \\
\text { EXISTING ARCHITECTURAL } \\
\text { CHARACTER }\end{array}$ \\
\hline & & & 3.3 STRUCTURE AND SPACE & & & & 7.3 REVERSIBILITY \\
\hline & & & $\begin{array}{l}\text { 3.4 STRUCTURE AND } \\
\text { FUNCTION }\end{array}$ & & & & \\
\hline & & & $\begin{array}{l}3.5 \text { STRUCTURE AND } \\
\text { CIRCULATION }\end{array}$ & & & & \\
\hline
\end{tabular}



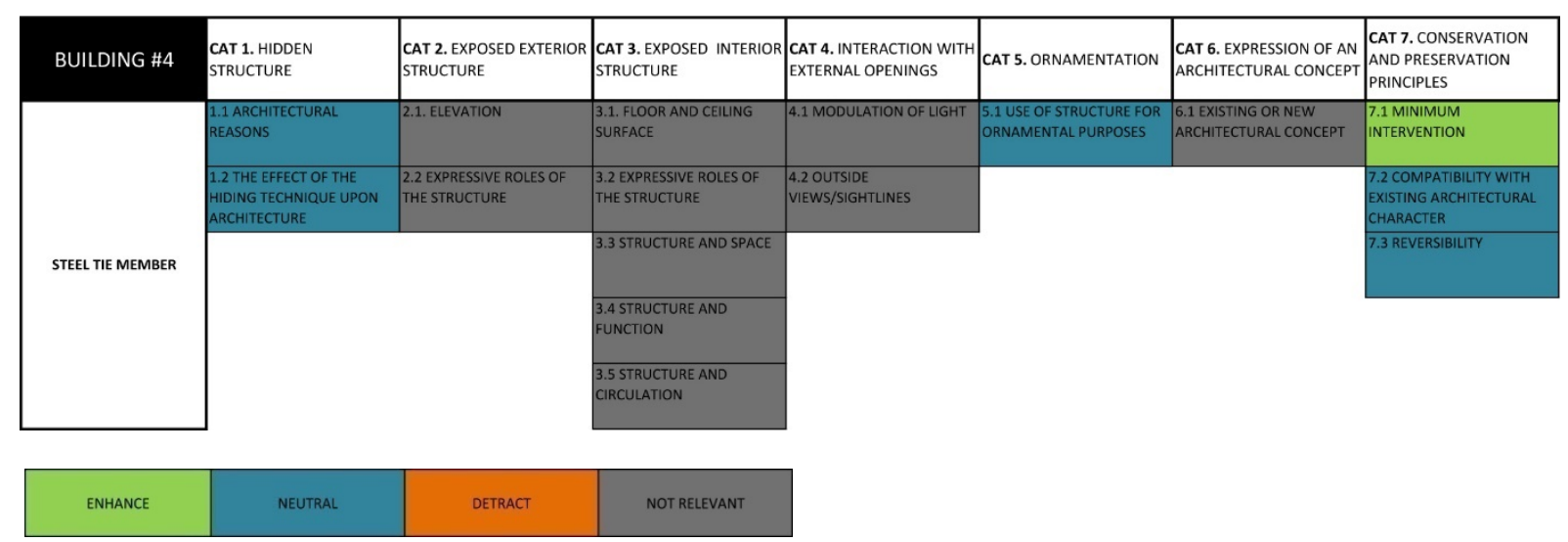

\section{Interviews regarding architectural qualities}

\section{○ Category 1 - Hidden structure}

\section{- 1.1: Architectural reasons}

Both designers justified the concealment of the two new X-braced frames for practical reasons. Existing braces from previous seismic work in 1997 were already concealed in between two partition walls. Their replacement using a similar yet stronger structure and the maintenance of hiddenness of the structure appeared as the less intrusive approach. The architect stressed that this approach preserved the existing internal layout and usability of the spaces.

Concerning the wall-to-diaphragm steel connections, the designers explained that the initial thought was to keep them exposed. The architect stated that their visual presence would have been related to previous seismic work of several exposed steel braced frames. The engineer however explained that due to the existing ceilings being lower than expected, the tie members ended up being re-designed and hidden. Although the end result was not detrimental to the building's architecture the engineer mentioned that this unexpected design change could have been better handled. This implied three things. First, the engineer should not exclusively rely on existing structural plans as was the case in this project. Secondly, the designers should visit internal spaces in order to check the current characteristics of the building. Thirdly, the contractor should be involved earlier in the process in order to jointly review the detailing and any eventual changes to the structural components prior to the construction phase.

\section{- 1.2: The effect of the hiding technique upon architecture}

The plasterboard linings hiding the X-braced frames were identical to the previous ones covering the former braces. Both designers explained their desire to avoid any changes to the interior spaces. 
Where in the previous sub-category the architect justified the indistinguishable design for functional reasons, in this case she pointed out the need to maintain the visual appearance of the spaces.

Concerning the hiddenness of the wall-to-diaphragm steel connections, it simply resulted from the presence of the existing plasterboard ceilings. The designers explained they did not want to spend too much time and work on this aspect in order to minimise disruption to the tenants.

\section{○ Category 2 - Exposed exterior structure}

\section{- 2.1: Elevation}

The presence of the shear walls is identified in the Tables of Analysis as negatively influencing the façades. This is mainly a consequence of the seismic structure disrupting the linearity of the façades without providing any new rhythm to them.

The engineer explained that the design of the shear walls and their locations were solely structurally driven with no consideration for architectural requirements. The only aspect which influenced the engineer's design was the client's requirement to avoid covering any of the tenant's windows. As a result, the shear walls were located in between vertical sets of windows. However, the engineer acknowledged that the shear walls affected external openings of the building car park along the longitudinal façades at the ground level. This resulted in a discontinuity of the horizontal alignment of the windows which he regretted. Overall, while satisfied from a structural point of view, the engineer was critical of the shear walls, admitting that "they just look like a tumour on the building".

Despite being aware of some existing characteristics of the façades being modified and, in some cases, lost, the designers minimised the impact on the façades. First, the engineer explained the client "didn't really care about how the outside would architecturally look". Any impact on the reading of the exterior elevation was thus considered less prejudicial. Secondly, for the architect, the $200 \mathrm{~mm}$ depth of the shear walls over the façades was deemed negligible and not detrimental to their linearity. In addition, the presence of the shear walls was considered sufficiently mitigated thanks to them being plastered and painted similarly to the existing URM walls.

The designers also mentioned other external structural components, in particular the vertical UB columns helping the URM façades to resist out-of-plane forces. The engineer installed them externally on the top floor on the four façades to limit disruption to the tenant's apartments as requested by the client. Their location in between each window created a continuous and strong rhythm on each façade. The architect explained that unlike the shear walls, their geometry and 
materiality did not allow them to be hidden. However, she explained that the UB columns looked unfinished. Although not structurally driven, she then decided to complete their design by connecting the columns using horizontal steel bands at their top and bottom. As a result, the vertical members became squares, leading to the existing windows being framed, and resulting in a new pattern on the façades.

\section{- 2.2: Expressive roles of the structure}

For the architect, expressing the structure just for the sake of highlighting it was not relevant. If the shear walls could have been related to any specific feature of the building, such as the building's entrance, then such option would have been taken into account. She added that with only small existing red anchors providing structural expressiveness to the façade, justifying the expression of the shear walls to the engineer and client would have been difficult. Plastering and painting the shear walls to limit their visual presence therefore appeared to be the best option.

The structural detailing was considered by the engineer as a result of technical requirements and to respond to constructability issues. Only when architectural features were affected by the detailing or expressiveness of structure would discussions with the architect be considered. The UB columns are an example. The architect explained that the addition of steel bands did lead to an architectural contribution to the detailing. However, she actually wanted to soften the vertical geometry of the columns. Such approach was agreed to by the engineer who accepted these additional components to his structure. The architect explained that the addition of steel components did contribute to a greater expressiveness of the structure and also mitigated the negative impact of the UBs on the façades.

\section{○ Category 3 - Exposed interior structure}

\section{- 3.1: Elevation}

The two interior shear walls at the ground floor were considered by both designers as having no impact on the interior elevation of the front façade. Both designers explained that the location of the shear walls, as well as their footprint, were similar to the previous structure and retained the existing rhythm of the elevation. 


\section{- 3.2: Expressive roles of the structure}

The designers' responses were similar to the arguments given in sub-category 2.2. For the architect, the building had no architectural features to justify the expressiveness of the seismic structure. She added that expressing the concrete surfaces of the structures would not have been particularly relevant as the shear walls were located in a secondary space, i.e. the building car park.

The engineer confirmed the lack of architectural consideration given to the detailing of the shear walls. He further noted that the grid pattern of holes on the wall surfaces simply resulted from the cast-in-place technique.

\section{- 3.3: Structure and space}

Based on the client's requirement to minimise internal seismic work, the designers explained that their common goal was to ensure that no internal structure would affect spatial quality. Replacing the X-braces from the previous seismic retrofit work with stronger shear walls was thus preferred to adding extra structural components that could have disrupted the ground floor.

\section{- 3.4: Structure and function}

The engineer indicated that although the ground floor might be a secondary space, its function as a car park was particularly important for the building users. This was another reason for the replacement of the X-braces by shear walls.

\section{- 3.5: Structure and circulation}

Similar arguments to those provided in sub-categories 3.3 and 3.4 explain the neutral influence of the shear walls on circulation.

\section{○ Category 4 - Interaction with external openings}

Both designers believed that the seismic retrofit respected the existing openings of the building. They explained that none of the tenancy windows were affected by the structural components. The architect even pointed out that she and the engineer ensured that a $45^{\circ}$ angle between the shear walls and the edges of the windows was established in order to maintain the amount of natural light entering the building. 
Concerning the shear walls reducing the dimensions of the existing opening on the main façade and completely covering one on the rear façade, the designers considered the negative impact acceptable. The architect recounted asking the engineer at first to maintain all the openings yet she considered that the structural requirement was more important than saving a couple of windows in a secondary space. Similar reflection was made by the engineer. This case illustrates a form of priority of some considerations over others.

\section{○ Category 5 - Ornamentation}

\section{- 5.1: Use of structure for ornamental purposes}

The use of the seismic structures as ornament was not intended by the designers. As for the architect, the plasterboard linings hiding the X-braces and those covering the wall-to-diaphragm steel connections were identical to the existing linings, the external shear walls were visually tempered, and the internal shear walls were left unrefined. Concerning the ornamental pattern displayed by shear walls, the architect and engineer noted that this was not intentional but it did match the rest of the raw and exposed structural components such as the bare URM walls and steel X-braced frames.

The only structural elements both designers considered carrying ornamental quality were the UB columns in combination with the steel bands. The architect explained that such an example stresses the possibility of better integrating structural components into a building by approaching them from an aesthetic point of view.

\section{O Category 6 - Expression of an architectural concept}

\section{- 6.1: Reinforcement of an existing architectural concept or development} of a new one

The architect considered that the existing building did not possess an architectural concept but did possess some features that related to its past function as a warehouse. These included the steel staircase with open risers, the X-braced frames, and the exposed internal URM walls. The engineer had a similar point of view and explained that although the warehouse was converted into an apartment and office building it maintained an "industrial feel".

Concerning any contribution from the seismic solution in developing a new concept, the architect explained trying to express externally the industrial character identified internally. With little 
flexibility around the design of the external shear walls, the architect took instead the opportunity of working with the external steel UB columns to contribute to the architectural character. She said that the additional steel bands reinforce the presence of steel, thus recalling the industrial character and providing a more pleasant aspect to the building exterior.

\section{○ Category 7 - Conservation and preservation principles}

\section{- 7.1: Minimum intervention}

For the engineer, the minimum intervention principle was mainly approached in terms of mitigating the impact of the retrofit solution as requested by the client. This first led to the installation of the biggest seismic components on the external parts of the building in order reduce internal work and limit disruption to interior spaces. The second aspect was to avoid affecting any of the tenancy windows. The last aspect shared by both designers relate to the usability of the building by the tenants. The designers ensured that the solution would not reduce the different means of access. Minimum intervention was thus more oriented toward the wellbeing and satisfaction of the building users than to the preservation of architectural or historic features.

\section{- 7.2: Architectural character}

The architect approached architectural character through two aspects. The first took into account the maintenance of features of architectural and historic interest. One example given was the chimneys, which instead of being demolished were reinforced and filled with concrete so they wouldn't fall off. The second aspect was trying to avoid major changes whether internally or externally. Where changes were necessary the architect decided to blend the structure in, as she attempted with the shear walls, or make them coherent with the industrial character, as was the case with the design of the UB columns. The external shear walls fall into the category of blended structures according to the architect. She explained that their muted presence neither contradicted the existing features of the façades nor reduced the contribution of the UB columns to architectural character.

The example of the UB columns mentioned by the architect relates to the engineer's thoughts on the issue of architectural character. For him, working around the warehouse features of the building was extremely helpful and fortunate as it gave greater flexibility to his design. He explained that this context provided "more rough structural engineering options as opposed to a delicate flowery building that needs to be more carefully done". Although the end result does not show much 
architectural contribution from the variety of structures, such a view reveals how structural engineers can draw upon architectural features to drive their designs.

\section{- 7.3: Reversibility}

None of the designers admitted being aware of the reversibility principle and therefore did not take it into account. The architect noted that a different scheme would have most likely been developed if such principle was considered. She further explained that reversibility would make sense if a client approached seismic retrofit in steps through time. Reversibility would then be relevant as it would facilitate the installation of new seismic structures that might complement and eventually replace some of the previous seismic work.

\section{○ Summary and final comments on architectural qualities}

The first point to notice was that both designers aimed for a seismic solution that would respect and achieve the client's requirements; in particular the mitigation of internal work and disruption to the tenants. The designers worked in a complementary way. The engineer located the main seismic structure externally and the smaller structures in secondary spaces. The architect focused on ways to attenuate their presence by hiding the internal X-braced frames, and plastering and painting the external shear walls.

An architectural contribution from the seismic solution was not intended by the designers who mainly aimed for limited changes. The only exception concerned the external UB columns which, due to their location and materiality, were too obvious to be hidden. This situation forced the architect to detail the UBs to soften their presence and maintain as much as possible the existing architecture. Such an example points out the fact that respecting existing architectural character does not necessarily imply a neutral presence of the seismic solution. Seismic structures can be proactive architecturally.

Another important point raised during the interviews concerned the need for existing architectural references when considering the expressiveness quality of new seismic structure. For the architect, the lack of existing expressive features weakened any justification for using seismic structure to contribute to this quality. As a result, the designers considered the positive influences of the internal shear walls on expressiveness quality (3.2) and to larger extent on ornamentation (5.1) fortuitous.

Some of the negative influences of the external shear walls indicated by the Tables of Analysis were acknowledged by the designers, where others were not. The integration of the structure with the 
natural light (4.1) and outside views (4.2) was considered poor by the designers but acceptable due to the secondary nature of the space being affected. These arguments were similar to those provided in the previous chapter (Chapter 5, shear wall section, sub-categories 4.1 and 4.2). Regarding the external elevations and the architectural character, the architect considered the shear walls to be respectful of both architectural qualities. Such a position was however not supported by the engineer who was critical of the external solution. This situation reveals the difficulty of members of a same design team to share the same opinion on integration. This could be explained by the subjectivity each designer possesses.

The minimum intervention principle was mainly related to the client's requirement to limit disruption to users. The preservation of architectural and historic features, although intrinsic to the minimum intervention principle, was of secondary concern. It seems that the architect did not appreciate the intent of the minimum intervention principle to preserve the building fabric. Concerning the architectural character of the building, the designers tried to maintain it and to some extent express the interior industrial feel externally. In addition, the engineer considered that the existing industrial character allowed greater flexibility in the design of a seismic solution. Drawing upon such character allowed the development of a larger range of retrofit options. Finally, the architect presented a personal view on reversibility. Instead of a seismic solution able to be removed in the future, the architect considered that such a principle would only be relevant if a long-term approach on scalable seismic retrofit was developed between a client and a design team.

\section{Design process}

\section{$\bigcirc$ Design steps and time of involvement}

Table 17. Table of Design Process: Main stakeholders and their time of involvement in Building \#4

\begin{tabular}{|c|c|c|c|c|c|c|}
\hline & $\begin{array}{l}\text { DESIGN PROCESS } \\
\text { STEPS }\end{array}$ & $\begin{array}{l}\text { SEISMIC ASSESSMENT OF } \\
\text { THE BUILDING }\end{array}$ & CONCEPT DESIGN & DETAILED DESIGN & $\begin{array}{l}\text { BUILDING CONSENT AND } \\
\text { RESOURCE CONSENT }\end{array}$ & CONSTRUCTION PHASE \\
\hline & CLIENT & & & & & \\
\hline & $\begin{array}{l}\text { STRUCTURAL } \\
\text { ENGINEER } \\
\end{array}$ & & & & & \\
\hline \multirow[t]{5}{*}{ BUILDING \#4 } & $\begin{array}{l}\text { ARCHITECT/PROJECT } \\
\text { MANAGER }\end{array}$ & & & & & \\
\hline & $\begin{array}{l}\text { QUANTITY } \\
\text { SURVEYOR }\end{array}$ & & & & & \\
\hline & BUILDING CONTRACTOR & & & & & \\
\hline & CITY COUNCIL & & & & & \\
\hline & HERITAGE NEW ZEALAND & & & & & \\
\hline
\end{tabular}


The project started with the client requiring the engineer to strengthen the building beyond $33 \%$ NBS in order to avoid it being listed as earthquake-prone. The engineer convinced the client to raise the percentage of NBS to $45 \%$ as, according to him, the threshold of $33 \%$ might likely move in the future, and because the difference between these two percentages would simply imply slightly bigger structural members.

At the Concept Design stage, the structural engineer, alongside the fire engineer, developed a scheme based on the client's requirements mainly asking for limited internal work. Once approved, the engineer started working on the detailing of the seismic structures and the fire engineer on the fire report.

The architect joined the design team at the beginning of the Detailed Design stage. She explained that the client originally expected her to simply go through the structural engineer's plans and prepare the Building and Resource Consent documents accordingly to the selected seismic solution. However, the selected scheme had to be modified as the engineer had developed the structural design without taking into account the internal layout. This was confirmed by the engineer who had developed the seismic solution based on previous plans. The consequences included X-braced frames passing through the bathrooms and kitchens of tenants, and columns narrowing the main staircase. The architect had therefore to provide actual plans of the building and overlay them on the engineer's plans to reveal all the issues. As a result, the engineering scheme had to be modified with fewer structural components leading to a noticeably different seismic solution.

Such late changes were regretted by both designers. They would have appreciated the architect being involved earlier as this would have avoided the re-design of the first scheme, as well as providing a more streamlined and faster process. The architect suggested being involved right after the seismic assessment and just before the concept. The idea would be to work with the structural engineer and quantity surveyor on the development of a seismic retrofit scheme that would fit their three criteria. For the engineer the Concept Design stage would also have been a good time to work alongside the architect. He suggested the following process: a non-formal talk with the architect about some ideas and suggestions, followed by the development of a couple of schemes by the engineer, which would be finally presented to the architect for a more formal talk on integration.

The inaccuracy of the plans the engineer originally relied on led to several changes to the structural detailing during the construction phase. The height of the ceilings for instance was not considered when detailing the wall-to-diaphragm steel connections and the latter had to be re-designed with the contribution of the contractor on site. These problems made the engineer reflect on the 
presence of the contractor during the Detailed Design stage. He mentioned that they could both develop better structural detailing based on the contractor's expertise so fewer modifications would occur during construction.

A last issue raised by the architect was the site location. The building, although not listed as heritage, is located right next to heritage area in a public space. Any work on the façades had therefore to be carefully considered in relation to the surrounding buildings. The seismic work on the façades had to be described in a Resource Consent which worried the architect due to the UB columns used on the four sides of the building. Thinking that the City Council would consider the columns too dominating and affect the values of the nearby heritage area, the architect decided to add the horizontal bands to soften the reading of the façades. Such a change to the structural design was expected to prevent rejection by the Council.

\section{○ Leadership}

Although involved earlier than the architect and being the one developing the initial retrofit scheme, the structural engineer did not consider himself as the leading stakeholder of the project. He explained that the leadership was divided into two stages and between two different people. From the initial stage to the end of the Concept Design stage, the client provided leadership. The engineer explained that, first, the client contributed to the selection of the percentage of NBS and set the scope of the work by listing his requirements. Secondly, the client approved or rejected the different parts of the seismic retrofit scheme. The engineer therefore considered that the person driving the project was the client, and that he was more responding to the client's demands.

The second stage corresponded to the arrival of the architect at the Detailed Design stage. The engineer had to comply with the changes requested by architect and modify the seismic scheme accordingly. The architectural involvement and leadership in the project were considered crucial. The engineer mentioned how the architect pointed out the negative impact of the initial seismic retrofit scheme on the kitchens, bathrooms and staircase. The architect also explained that engineers have only an eye on the structural side of things but not on the non-structural issues and thus look at cost in terms of seismic structure but neglect the cost of other aspects of a building. She further indicated that the changes she required were never made at the expense of the percentage of NBS. All the changes were always discussed with the engineer to ensure that both would be satisfied with the modifications. 


\section{$\circ$ Influences of the project's constraints on integration}

A first constraint to be mentioned was the percentage of NBS. The engineer explained that raising yet limiting the percentage of NBS to $45 \%$ was actually a constraint they imposed on themselves and the client. Going above this level would have required more structure which would have affected the architecture. Several openings of the façades would have been blocked by the necessary larger dimensions of the shear walls. The selected 45\% NBS was determined as the most appropriate level from a "qualitative sense" according to the engineer.

The second constraint, cost, was also self-imposed, this time by the architect. She assumed that part of her review of the engineer's first scheme was to optimise the seismic solution. This meant not solely looking at the architectural qualities that might have been affected but also avoiding unnecessary costs. Taking the example of the initial columns reducing the access to the staircase, the architect stated "I guess we were trying to limit and minimise the non essential part of the cost. If you have to remove and reinstate the staircase, it's not adding structural value to the building. So we were trying to minimise those".

The building site was referred by the architect as the last constraint yet it encompasses several issues. One was the site boundaries, which following the examination of the survey plan by the architect, was $200 \mathrm{~mm}$ from the building. This forced the initially $250 \mathrm{~mm}$ thick shear walls to be trimmed down by $50 \mathrm{~mm}$. Although not impacting much on their visual presence, this modification was technically challenging for the engineer. Another issue was the presence of an existing brick drain running under the building at the exact location where the shear wall of the front façade was to be built. Although a geotechnical survey was undertaken at the beginning of the design process, the location and dimensions of the drain were not investigated carefully enough. Only during the construction phase did the contractor and engineer have a real understanding of the drain. As a result, although the dimensions of the shear wall were not modified, its foundations had to be redesigned and enlarged.

\section{- Summary of the design process}

The description of the design process by the respondents gave an overall understanding of the critical issues that influenced the seismic retrofit. The first issue was the late involvement of the architect. One consequence was the development during the Concept Design stage of a seismic scheme incompatible with the internal layout. The presence of the architect at the Detailed Design stage allowed rebalancing the scheme and reducing some potential negative impacts, yet also 
limited her flexibility regarding more thoughtful integration. Both designers mentioned the substantial contribution to the design other stakeholders could have brought. For the architect, the presence of a quantity surveyor during Concept Design stage would have helped develop a better solution. According to the engineer, the contribution of the contractor at the Detailed Design stage would have improved the detailing of seismic components.

Another aspect that influenced the seismic design was the location of the building nearby to a heritage area. This forced the architect to consider the building's external appearance on a large scale and in relation to the buildings surrounding it. Subsequently, the architect's design of the UB columns resulted in them contributing positively to the building's architecture.

Information on the leadership on the project revealed the unique position of the engineer. Although in charge of designing the seismic retrofit solution, he did not consider himself being the leader of the project. Instead he was under the client's authority. Similarly, when the architect got involved the engineer continued under her leadership and re-designed the seismic scheme based on new requirements. The engineer's changed leadership position was nevertheless not seen as an issue for integration. However, the engineer's lack of consideration of the existing architectural layout required the modification of the first structural scheme. A greater awareness of non-structural components could have potentially raised the engineer's position to that of the other two stakeholders.

Finally, where some constraints were from the client's requirements, the designers themselves also imposed additional ones. For the engineer, it corresponded to the selection of an appropriate percentage of NBS to avoid spoiling the building's architecture by an overwhelming presence of seismic structure. Concerning the architect, it related to the optimisation of cost. Integration would thus not only mean interaction between seismic structure and architecture, but also focusing the retrofit's influence on architectural features providing the most value to the building.

\subsubsection{Integration in the seismically retrofitted buildings - Building \#5}

\section{Tables of Analysis}

Table 18 below, resulting from the researcher's reviews in the previous chapter, does not indicate any overall pattern of the seismic retrofit on architectural integration. Each seismic structure and its related influences are more easily read separately. The moment frames and their hiddenness positively serve architectural purposes (Category 1), modulate natural light (4.1), contribute to an architectural character (7.2), and comply with the minimum intervention principle (7.1). Regarding 
the V-braced frame, the structure contributes to expressiveness quality (3.2) and adheres with minimum intervention (7.1) and reversibility (7.3) principles. Despite these aspects, the seismic structure negatively impacts several architectural qualities; namely, elevation (3.1), interior space (3.3), modulation of natural light (4.1), outside views (4.2) and ornamentation (5.1).

Table 18. Tables of Analysis representing the influences of the seismic systems of Building \#5 on architectural qualities

\begin{tabular}{|c|c|c|c|c|c|c|c|}
\hline BUILDING \#5 & $\begin{array}{l}\text { CAT 1. HIDDEN } \\
\text { STRUCTURE }\end{array}$ & $\begin{array}{l}\text { CAT 2. EXPOSED } \\
\text { EXTERIOR STRUCTURE }\end{array}$ & $\begin{array}{l}\text { CAT 3. EXPOSED INTERIOR } \\
\text { STRUCTURE }\end{array}$ & $\begin{array}{l}\text { CAT 4. INTERACTION WITH } \\
\text { EXTERNAL OPENINGS }\end{array}$ & CAT 5. ORNAMENTATION & $\begin{array}{l}\text { CAT 6. EXPRESSION OF } \\
\text { AN ARCHITECTURAL } \\
\text { CONCEPT }\end{array}$ & $\begin{array}{l}\text { CAT 7. CONSERVATION } \\
\text { AND PRESERVATION } \\
\text { PRINCIPLES }\end{array}$ \\
\hline \multirow{5}{*}{$\begin{array}{c}\text { STEEL } \\
\text { V BRACED FRAME- } \\
\text { TRANSVERSE DIRECTION }\end{array}$} & $\begin{array}{l}1.1 \text { ARCHITECTURAL } \\
\text { REASONS }\end{array}$ & 2.1. ELEVATION & 3.1. ELEVATION & 4.1 MODULATION OF LIGHT & $\begin{array}{l}\text { 5.1 USE OF STRUCTURE FOR } \\
\text { ORNAMENTAL PURPOSES }\end{array}$ & $\begin{array}{l}\text { 6.1 EXISTING OR NEW } \\
\text { ARCHTECTURAL CONCEPT }\end{array}$ & $\begin{array}{l}7.1 \text { MINIMUM } \\
\text { INTERVENTION }\end{array}$ \\
\hline & $\begin{array}{l}1.2 \text { THE EFFECT OF THE } \\
\text { HIDING TECHNIQUE UPON } \\
\text { ARCHITECTURE }\end{array}$ & $\begin{array}{l}\text { 2.2 EXPRESSIVE ROLES OF } \\
\text { THE STRUCTURE }\end{array}$ & $\begin{array}{l}\text { 3.2 EXPRESSIVE ROLES OF } \\
\text { THE STRUCTURE }\end{array}$ & $\begin{array}{l}4.2 \text { OUTSIDE } \\
\text { VIEWS/SIGHTUNES }\end{array}$ & & & $\begin{array}{l}7.2 \text { COMPATIBILTY WITH } \\
\text { EXISTING ARCHITECTURAL } \\
\text { CHARACTER }\end{array}$ \\
\hline & & & 3.3 STRUCTURE AND SPACE & & & & 7.3 REVERSIBILTY \\
\hline & & & $\begin{array}{l}\text { 3.4 STRUCTURE AND } \\
\text { FUNCTION }\end{array}$ & & & & \\
\hline & & & $\begin{array}{l}\text { 3.5 STRUCTURE AND } \\
\text { CIRCULATION }\end{array}$ & & & & \\
\hline
\end{tabular}

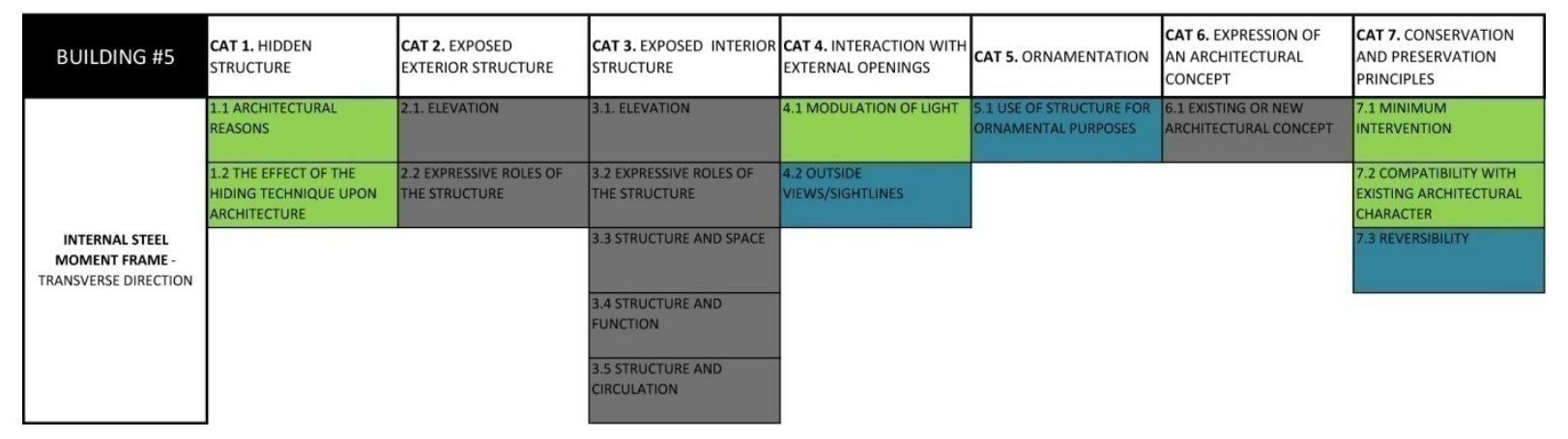

\begin{tabular}{l|l|l|l|} 
ENHANCE & NEUTRAL & DEtract & NOt RELEVANT \\
\hline
\end{tabular}

\section{Interviews regarding architectural qualities}

\section{○ Category 1 - Hidden structure}

\section{- 1.1: Architectural reasons}

When designing the seismic solution, the engineer ensured that the new structures would maintain as much spatial openness as possible to the ground floor. This decision partly justifies the location of the three new steel moment frames inside existing structural bays. Initially intended to be exposed, the moment frames were hidden when a new tenant arrived at the Concept Design stage and planned to refurbish the ground floor to accommodate his restaurant. As a result, the hidden moment frames improved the function of the space. The engineer and architect explained that, the hiddenness of the structure was not their decision but they had to ensure that the seismic retrofit and the interior layout were compatible. 


\section{- 1.2: The effect of the hiding technique upon architecture}

The engineer assumed that the tenant's architect took the decision to use plain plasterboard linings for convenience and cost. In addition, the retrofit architect also pointed out that the linings and the treatment of their surfaces corresponded to the architectural character the tenant wanted for the restaurant.

\section{○ Category 3 - Exposed interior structure}

\section{- 3.1: Elevation}

The engineer explained the moment frames were installed inside existing frames and therefore maintained the original structural grid. Such a decision was driven by two considerations: to use the strength of the existing frames, and to maintain the ground floor space as open as possible to facilitate the new refurbishment. With no direct contact with the interior surfaces, the hidden moment frames did not have any effect on them.

An exposed two-bay V-braced frame was installed on the rear façade, in front of a large glazed wall. The engineer justified this location to avoid functional disruption of the interior space. The impact on the elevation was not considered negative by the engineer as he explained that the vertical members of the braced frame were located in front of existing columns therefore not affecting the glazed wall. Concerning the diagonal members, he considered them negligible. He also pointed out that there was a difference of importance between the front façade contributing to the cultural image of the city and the rather simple rear wall. This difference between the façades justified any negative impact on a secondary element and the area around it. A similar argument was given by the architect who explained that the location of the V-braced framing resulted from a decision to avoid a clash with the front façade. The impact on the elevation of the rear wall was thus considered less prejudicial.

\section{- 3.2: Expressive roles of the structure}

The architect did not intend to use the V-braced frame for any expressive purpose. Instead he explained that what could be considered as structural expressiveness was fortuitous. It resulted from two main factors over which he had no influence; namely, pre-fabrication of structural components due to building accessibility, and their assembly on site. 
The engineer provided a similar argument but added that no existing structure was expressive. With no existing reference, the designers did not want to develop any expressive quality with the new $\mathrm{V}$ braced frame. Such attitude appears quite surprising as the materiality, detailing and connections of the new V-braced frame are almost identical to those of the exposed existing steel moment frames from a previous seismic retrofit. In fact, it seems that the designers did not consider how the technical detailing might contribute to the expressive quality.

\section{- 3.3: Structure and space}

Both designers stated that the impact of the seismic solution on space was carefully considered. The engineer explained that a first aspect was to keep the existing structure and use it to install the moment frames inside. The second aspect corresponded to the installation of the $\mathrm{V}$-braced frame somewhere where it would not intrude upon the space. Locating it in front of the glazed rear wall was deemed by the engineer as the best solution as it avoided reconfiguring the interior space and maintained the existing spatial delimitation. The placement of the seismic structure was thus considered adequate.

None of the designers addressed the more significant enclosure of the space resulting from the Vbraced frame generating a more opaque boundary between the exterior and interior of the building. This can be explained by the engineer reading the space solely in terms of physical boundaries and overlooking the degree of openness.

\section{- 3.4: Structure and function}

The arguments provided by the engineer regarding function were similar to those given in subcategory 3.3. The location of the two seismic systems tried to minimise interior disruption. The architect further confirmed this by adding that a main thought for the retrofit design was to "minimise what degree of intrusion there is and that's purely to do with usable and rentable areas from the tenant's perspective". He added that the design team ensured that the interior of the building was maintained as open as possible in order to accommodate the new fit-out. The seismic solution had therefore no direct influence on functionality but instead ensured maximum flexibility.

\section{- 3.5: Structure and circulation}

The maximum flexibility of the seismic retrofit solution allowed the tenant to configure the ground floor as they wanted to. This was mainly achieved by the tenant's architect who used partition walls to define the interior circulation of the restaurant. 
The engineer and architect also faced the issue of circulation with the V-braced frame. However, as indicated by both designers, the V-braced frame was designed to allow access to the rear outdoors. The spaces between the diagonal and vertical structural members were large enough to maintain passage through the two existing doors of the glazed shear wall.

\section{○ Category 4 - Interaction with external openings}

Both designers said they considered the issue of natural light and views. Concerning the moment frames, the engineer explained he located them toward the centre of the building as the client requested them not to impact on the front windows. This constraint resulted in the closest moment frame being installed one row behind the main façade and thus not affecting views. Concerning the restriction of natural light by the hidden structure, the architect explained that such treatment was decided by the tenant's architect who wanted to design an intimate interior.

Regarding the V-braced frame installed along the rear façade, the engineer explained that the view and natural light coming from the backyard were deemed less important than the maintenance of the outdoor access. He continued by disregarding any quality of the glazed wall and considered the negative impact of the seismic structure as minor.

The architect however acknowledged the negative impact of the structure, yet explained that it was not a result of a careless design. He added that a negative impact may occur when seismically retrofitting a building. The most important thing was however to ensure that such impact was considered by the designers and that other options had been previously ruled out. For the architect, designers should be able to explain and give arguments to the client on why, of all alternatives, one specific solution was selected. In this situation, the architect acknowledged that the main justification for the poor integration of the $V$-braced frame related to the difference of cultural value between the front façade and the rear wall.

\section{○ Category 5 - Ornamentation}

\section{- 5.1: Use of structure for ornamental purposes}

Although acknowledging the possibility of using seismic structure for ornamental purposes, the architect explained that the building possessed no features of interest to take reference from. Secondly, the client would not have wanted the designers to spend time and money on ornamenting the seismic solution and having the tenants reject it. Thirdly, the architect considered that the lack of ornamentation allowed greater reusability of the space if future tenants refurbished it. 
The engineer acknowledged the potential ornamental quality of the steel moment frames and regretted their hiddenness in this regard. The V-braced frame was considered as having the same inherent quality. However, he did not consider its disruption on the pattern of the glazed wall to be substantial.

\section{○ Category 6 - Expression of an architectural concept}

\section{- 6.1: Reinforcement of an existing architectural concept or development} of a new one

None of the designers identified any existing architectural concept of the building. The architect stated that the building was not architecturally relevant and lacked features that could have defined a concept. The only element both designers estimated of value was the existing front façade.

Regarding the development of a new architectural concept using the seismic retrofit, the engineer explained not considering such an aspect during the design. The architect added that the design was to remain simple and low key in order to avoid restraining any present or future internal layout.

\section{- Category 7 - Conservation and preservation principles}

\section{- 7.1: Minimum intervention}

The designers had three different yet complementary views of the minimum intervention principle. For the architect, it implied respecting the existing building by limiting modifications to architectural and historic features. Such an attitude is very similar to the definition of minimum intervention provided by the ICOMOS New Zealand Charter (2010). The architect also explained that to achieve such a principle, the seismic solution and its implementation had to remain simple. Destroying key features to implement a simple seismic solution would not make sense. A last aspect considered by the architect as being part of minimum intervention was flexibility. In limiting the amount of seismic structure, greater freedom was provided to accommodate future fit-outs.

For the engineer, minimum intervention meant utilising the capabilities of the existing structure rather than adding completely new seismic components. Two advantages were stressed: minimum disruption of spaces as the new seismic solution would rely on the existing structure, and a cost saving, as less structure would be required.

Overall, both designers felt that the seismic solution respected the different aspects defining minimum intervention. 


\section{- 7.2: Architectural character}

The designers considered the front façade as the only feature of the building having architectural character. This allowed them to strip out the existing internal layout and refurbish it in accordance with the tenant's demands. The designers explained they respected the existing character as the façade was unaffected and the seismic work restricted to the interior ground floor. The development of additional architectural character was left in charge of the tenant's architect.

\section{- 7.3: Reversibility}

Although the seismic solution could be quite easily removed, the engineer explained that this was not designed for. He considered that the principle of reversibility was irrelevant. He explained that by removing the seismic structure, structural strength is reduced which means more money spent when re-retrofitting the building again.

The architect confirmed that the solution was not designed for reversibility. For him, designers should instead consider the possibility of additional structural components being added at some point in time.

\section{○ Summary and final comments on architectural qualities}

Based on the designers' responses, one specific objective seemed to characterise the seismic retrofit. Whether the influence of a solution ended up being negative, neutral or positive, the designers justified several design decisions by stressing the need to accommodate upcoming and future fit-outs. In this regard, spatial openness, lack of ornamentation, absence of a new architectural concept and a limited amount of seismic structure were all reasons given to support the decision. The designers thus envisioned their seismic retrofit as a long-term solution and were therefore prepared to welcome several fit-outs in the future.

A distinction between the steel moment frames and the V-braced frames appeared throughout the interviews. While both were designed as part of the seismic retrofit, most of the influences the moment frames had on the architectural qualities were enhanced by the refurbishment planned by the tenant's architect. The hiddenness of the moment frames thus led to positive contributions of functionality, architectural character, modulation of light as well as the neutral influences on the outside views and ornamentation. The roles of the engineer and architect although indirect remained important. Indeed, thanks to the location and design of the moment frames great flexibility was provided to the tenant to develop the fit-out. 
Unaffected by the interior refurbishment, the V-braced frame and its influence on the various architectural qualities resulted from the designers' design decisions. They were careful not to affect functionality and circulation as these were considered as the main qualities of the building. Any lack of consideration of these two qualities would have affected the capacity of the ground floor to provide maximum flexibility to interior fit-outs. In this regard, the answers provided by the designers match the neutral influence of the seismic structure on these two sub-categories.

Comparison of the negative influences in the Table of Analysis and the designers' answers raises two issues. First, poor integration between the V-braced frame and elevation, natural light, outdoor views and ornamentation, were considered acceptable by both designers. This mainly relates to the difference of perceived value between the front façade and the rear wall. Indeed, that hierarchy diminishes the appreciation of the qualities the rear façade may possess, resulting in the designers considering them as minor. Secondly, the architectural quality of space raises the issue of interpretation. Where the Table of Analysis considers the negative influence of the V-bracing due to an unnecessary enclosure of the space, the engineer saw it differently. With no modifications on the boundaries of the space, he considered the architectural quality maintained. To a larger extent, this type of disagreement on the definition of an architectural quality could occur between members of the same design team and affect their communication.

Unlike the Table of Analysis, none of the designers considered the V-braced frame as contributing to expressiveness. They explained that using the seismic structure for expressive purposes could only be justified by having existing expressive structural components. They believed that the existing building did not possess such features. A similar attitude was noticeable with ornamentation. The architect considered that, due to a lack of existing ornament in the building, using the seismic structure for ornamental purposes would be irrelevant.

Minimum intervention was highly valued by both designers. The architect mentioned the importance of a seismic solution remaining simple in its installation and maintaining as much flexibility as possible to accommodate new uses and fit-outs. For the engineer, the principle was particularly relevant as it encouraged making the maximum use of the existing structural strength. The ensuing reduced amount of structure also benefited the building's architecture and the client as it mitigated the risks of negative impacts and allowed cost saving.

The two designers also had strong opinions on the reversibility principle. They considered it irrelevant. It was suggested instead that designers should acknowledge the future improvement of their seismic design and not prevent additional structure being installed in the future. 


\section{$\circ$ Design steps and time of involvement}

Table 19. Table of Design Process: Main stakeholders and their time of involvement in Building \#5

\begin{tabular}{|c|c|c|c|c|c|c|}
\hline \multirow{9}{*}{ BUILDING \#5 } & STAKEHOLDERS & $\begin{array}{l}\text { SEISMIC ASSESSMENT OF } \\
\text { THE BUILDING }\end{array}$ & CONCEPT DESIGN & DETAILED DESIGN & $\begin{array}{l}\text { BUILDING CONSENT AND } \\
\text { RESOURCE CONSENT }\end{array}$ & CONSTRUCTION PHASE \\
\hline & CLIENT & & & & & \\
\hline & $\begin{array}{l}\text { STRUCTURAL } \\
\text { ENGINEER }\end{array}$ & & & & & \\
\hline & ARCHITECT & & & & & \\
\hline & NEW TENANT & & & & & \\
\hline & PROJECT MANAGER & & & & & \\
\hline & $\begin{array}{l}\text { QUANTITY } \\
\text { SURVEYOR }\end{array}$ & & & & & \\
\hline & BUILDING CONTRACTOR & & & & & \\
\hline & CITY COUNCIL & & & & & \\
\hline
\end{tabular}

\section{PARTICIPATION OF THE
STAKEHOLDER}

The project started when the City Council undertook an Initial [seismic] Evaluation Procedure (IEP) of the building. Following the IEP assessment, the client decided to seismically retrofit the building. Following a new seismic assessment, indicated in Table 19, the client and engineer, considering the budget, aimed to bring the building up to $70 \%$ NBS.

At the start of the Concept Design stage, the stakeholders involved in the project were the client, structural engineer, quantity surveyor, and a new tenant wanting to install their restaurant on the ground floor. The engineer explained that the beginning of that stage was critical in designing the retrofit scheme as it required a good understanding of the building including its structure and internal spaces. He therefore decided to make the greatest use of the existing structure while confining the seismic structures to the empty ground floor in order to avoid disrupting the tenant already occupying the first floor. As a result, the engineer developed a scheme and got it priced by the quantity surveyor. The engineer considered the proposed scheme as the optimum solution and thus no other options were presented to the client. The solution possessed two key characteristics. First, the existing structure and previous seismic retrofit of the building were maintained thus limiting the amount of new seismic structures and their cost. Secondly, the seismic solution maintained openness to the interior space thus providing flexibility for the new tenant's refurbishment. 
The seismic retrofit scheme was accepted by the client but it did not have any architectural input. Furthermore, the involvement of the architect in between the Detailed Design and Building Consent stages highly limited his contribution to the retrofit.

The architect acknowledged the engineer's solution as appropriate and praised the association of the engineer and quantity surveyor during the Concept Design stage. However, he regretted that his late involvement forced him to comply with the engineer's vision instead of developing a conjoint approach. Several issues could have been considered including existing architectural qualities, building science aspects, accessibility for disabled users, and the fire rating of the building. The architect explained raising such issues early on in the design process would have smoothed the development of the design and facilitated filing the application for the Building Consent.

Finally, the pre-construction collaboration of the contractor with the architect, structural engineer and tenants was mentioned. Although not influencing the design, the agreement from the contractor on a specific sequence and program facilitated the installation of the seismic work and allowed the first floor tenant to maintain their activities during the construction phase.

\section{○ Leadership}

The structural engineer and architect shared a special relationship as they both work within the same firm. This unique situation was however not exploited for this seismic retrofit project. Instead of working together on the solution, the engineer was almost entirely in charge of the seismic retrofit with little contribution from the architect.

The architect explained that such situation was directly related to the owner being constrained to seismically retrofit the building following the IEP from the City Council. The retrofit was therefore solely approached as a structural issue by the client who did not consider an architect relevant during the first stages of the design process. This position was supported by the engineer who thought he did not require the architect's contribution to the seismic scheme. He stated, "In terms of the engineering solution, the idea came from me and everybody else went along with it.... That was the optimum and everyone was happy with it and we moved forward from there. A lot of the jobs are that way".

The architect did not regret the structural engineer's leadership as he found it necessary in regard to the seismic requirements. However, he believed that the poor consideration of his skills resulted in two major issues. First, without the presence of the architect at the Concept Design stage, the engineer's scheme was less challenged and so the chance to develop the most appropriate solution 
was reduced. In contrast, having an architect early on in the process would have allowed the exploration of more options in order to reach a better solution. Secondly, the architect thought that the impact of the implementation process was not considered early enough. He explained that the engineer solely focused on the completed solution. Its achievability and what it would imply in terms of access to the site, to the spaces, and existing services were not addressed. He believed his presence and knowledge could have highlighted such issues at the end of the Concept Design stage. Overall, and unlike the engineer, the architect did not consider the seismic retrofit design to be the best solution.

\section{Influences of the project's constraints on integration}

The constraints raised by the client were considered by the engineer as being reasonable. The first was the budget which was considered less as an issue and more like the scope defining the amount of work to undertake. The second constraint corresponded to the client's demand to avoid installing structure in front of the front windows. For the engineer such a location was never considered anyway as the City Council would have most likely rejected a solution altering the front façade. The last constraint concerned the retention of the openness of the internal space. The engineer indicated that this was actually already taken into account by the previous seismic work undertaken in the 90's. Steel moment frames were installed in between existing structural bays in order to make use of the building's existing strength and limit the loss of space. The engineer explained using the same principle with the new moment frames.

For the architect, the existing building's tenant influenced the design of the seismic solution. Losing or affecting the tenant because of the seismic retrofit was deemed too prejudicial by the client. This led the engineer to install almost all the seismic structures at ground floor. The work at the occupied upper level only involved additional brackets fixed to the existing portal frames. The engineer did not consider such constraint undermining the seismic design. He explained that regardless of the building, his proposed seismic solutions always minimised disruption.

\section{- Summary of the design process}

Three key factors directed and influenced the design process. The first was the almost full control of the engineer over the design of the seismic scheme. Alone, during the Concept and Detailed Design stages, the engineer nevertheless considered several characteristics of the building such as its existing structure, uses and spatial openness of the ground floor. The second factor was the late involvement and limited role of the architect. Although the engineer's solution was considered 
overall as sound, the architect believed that several architectural aspects of the building were not carefully addressed. With little flexibility, the architect could only adjust the seismic design to the building's features instead of approaching them collaboratively. He also addressed the seismic solution not just based on its end result but also on its implementation. The last factor related to the constraints resulting from the client and existing tenant. Budget, preservation of the front façade and interior openness were not considered by the engineer as reducing the effectiveness of the seismic solution. Instead, they appeared as sensible requirements in tune with the current characteristics of the building. Concerning the restriction to locate the seismic structures at the ground floor, the engineer had envisioned a seismic retrofit minimally disruptive to building users.

\subsection{Summary of the interviews}

The interviews of the architects and structural engineers of the five URM buildings provided two categories of information. The first category was the general understanding of integration by the designers. The distinction between successful and poor integration was established. In addition, the architects and engineers suggested ways to improve integration in current practice. The second category focused on each of the five URM buildings and their seismic retrofit. The designers' answers provided an insight into the design process and their achievement of seismic retrofit projects through the perspective of integration. Factors affecting the integration of seismic retrofit and architecture in each of the five URM buildings were identified.

\subsubsection{General factors influencing integration and designers' recommendations for improvement}

Based on their experience, the architects and engineers pointed out several factors influencing the achievement of a successful integration. These factors and the related recommendations ensuring effective integration can be divided in two groups. Some relate to the overall appreciation and understanding of integration, and others to the seismic retrofit practice and more specifically to the design process.

\section{- Factors influencing integration outside the design process}

The architects and engineers explained that integration of seismic structure and architecture was an important issue for both groups of designers. They tried to develop seismic retrofits that would satisfy both technical and architectural requirements. However, two issues affecting integration were identified: 
- the designers' approach seemed conservative as they mainly intended to maintain the existing architecture of the buildings. Consideration of the potential architectural contribution of seismic structure to a building's architecture was marginal.

- both designers acknowledged the resistance among some of their peers in learning from the other's discipline.

To respond to these two issues, the architects and engineers suggested educating their peers, as well as the client, on the issue of integration. This education aims at teaching students and practicing designers about the architectural contribution of seismic retrofit as well as acknowledging external points of view and requirements in order to achieve successful integration.

\section{- Factors influencing integration within the design process}

The architects and engineers also acknowledged the importance of the design process and its organisation in the achievement of a retrofit solution that would successfully integrate with a building's architecture. A series of factors affecting integration in the design process were indicated. They include:

- lack of architectural input in the retrofit design and unsteady collaboration between the architect and structural engineer

- not meeting initial goals set by clients and tenants, including cost, timeframe and disturbance to occupants.

- poor communication between stakeholders.

To responds to these factors affecting integration, the designers considered that an effective design process requires:

- the involvement of the architect at the Concept Design stage, in order to

- review architectural and historic values of the building,

○ determining at the beginning of the design process the initial requirements and agreements framing the seismic retrofitting work. This include:

- respecting the client's budget, including taking into account the cost of seismic structure, and the economic consequences on non-structural components,

- mitigating tenants' disruption, and

- respecting the project timeframe. 
- conjointly develop seismic schemes with the engineer and assure architectural contribution to the schemes in order to aim for state-of-the-art retrofit designs,

- guide the client through the review of the schemes,

- provide guidance on legislative requirements such as accessibility and fire issues, and

- provide awareness on the impacts the seismic solution may have on the stakeholders of a project including building users.

- early meetings and discussions with all the stakeholders involved in the project in order to include their requirements following the approval of a scheme

- use of design tools:

- Heritage Evaluation Framework (HEF) to simplify the review of proposed schemes and facilitate decision-making, and

- Building Information Modelling software (BIM) to allow stakeholders work on a single source containing all the building information.

\subsubsection{Factors influencing integration in the five URM buildings}

The five buildings shared several attributes, that is, brick construction, multi-storey design and commercial activities. In addition, their seismic retrofits included both an architect and a structural engineer, and complied with Building Act 2004. However, as revealed by the designers' answers, the seismic retrofit of each building possessed unique outcomes in regard to integration.

The interviews extracted a variety of factors listed below that influenced the design processes and outcomes of the retrofits. Several of these factors were found in multiple buildings yet the designers' approaches to them varied. As a result, the same factor may have different consequences on the integration of the seismic solutions in different buildings.

\section{- Interior refurbishment}

Buildings \#1, \#3 and \#5 had internal refurbishment alongside their seismic retrofit. The lack of existing fit-outs enabled successful integration between seismic structures and architectural qualities, including those resulting from new refurbishment. This is observed in Building \#1 where the seismic solution served the tenant's requirements and contributed to almost the entire architectural qualities. For Buildings \#3 and \#5 however, the influences of the seismic solutions on the architectural qualities were more nuanced. These differences can be explained by additional factors presented below. 


\section{- A building's new programme}

Although following the client's or tenant's programme is necessary when seismically retrofitting and refurbishing a building, it can also weaken integration. That situation occurred in Building \#3 where the architect strictly focused on meeting a certain economic model of a backpackers' hostel and its functionality. Such a restricted approach, only focusing on one aspect, led to other architectural qualities and their integration with seismic structure being poorly considered.

\section{- Architectural concept}

The development of an architectural concept driving a seismic retrofit appeared to be a very effective approach in the achievement of successful integration. The designers of Building \#1 adopted such approach. It provided common ground for both when making and justifying design decisions. Integration was therefore facilitated when structure and non-structural components were designated to achieve a similar goal.

\section{○ Differences of opinions regarding integration}

Throughout the interviews the architect and structural engineer working on a same building did not always share a similar opinion regarding the extent and quality of integration. Although it is legitimate for each designer to have their own opinion, this becomes problematic when the designer who considers integration as poor would often not challenge it but rather accept it. This lack of questioning and critical debate hinders any opportunity for designers to try to develop an alternative design with an integrated solution pleasing both of them.

\section{- Interpretation of architectural qualities}

Differences of interpretation of architectural qualities between the designers further complicate the achievement of a successful integration. Such an observation mainly resulted from the different interpretation between Engineer \#5 and the review of architectural quality 3.3 (Structure and space) undertaken by the researcher and reported in the previous chapter (Chapter 5, braced frame section, sub-category 3.3). This situation could occur between stakeholders involved in a seismic retrofit project. Not sharing a similar understanding or definition of an architectural quality affects integration. 


\section{- Industrial character}

The term 'industrial' was mentioned in four out of five buildings. It either referred to the existing architectural character or to the development of a new one by the seismic retrofit. It appeared that such a character was valued by both types of designers for different reasons. Architects found in this character an opportunity to develop an architectural concept, as was the case in Building \#1, or to simply justify the presence of exposed seismic structural components as presented in Buildings \#2, \#3 and \#4. Engineer \#4 experienced a greater liberty to explore seismic solutions when the architectural character was more industrial compared to refined.

\section{○ Deliberately aiming for neutrality}

In some cases, the designers sought a neutral influence from seismic structures. Different reasons justified such a decision. Some resulted from avoiding diminishing the streetscape (Building \#2), avoiding spending time and effort on small structures or those located in secondary spaces (Buildings \#3 and \#4), or mitigating undesirable structure when its integration was not considered early enough. On two occasions, Buildings \#4 and \#5, designers justified the lack of expressive and ornamented structures because none of these qualities existed. A neutral influence can also be achieved when justified by the architectural concept, as it was the case in Building \#1. Finally, some neutral qualities in Buildings $\# 1$ and $\# 5$ resulted from the long-term views of the designers to facilitate new fit-outs over time.

\section{○ Fortuitous integration}

Positive instances of integration were sometimes fortuitous. The interviews suggested that such an outcome is neither restricted to a specific seismic structure nor to a particular building. It often resulted from the inherent characteristics of the structural components, as in the case of the interior shear walls of Building \#4. In some cases, it occurred after treatment of the structure's surface that provided an unexpected effect, such as with the shear walls in Building \#3. The interviews pointed out that while some designers were aware of the unexpected contribution of the seismic components, others disregarded them.

\section{○ Multiple hierarchies within a building}

Throughout the interviews, multiple hierarchies influencing seismic retrofit designs and their integration could be noticed. One corresponded to the differences of values of existing features carried by the buildings, such as heritage front façades and secondary rear walls. Another resulted 
from certain architectural qualities having more importance than others. This often resulted from the client's requirements or the designers' judgments. Finally, prioritisation was in some cases given to engineering aspects over architectural qualities or vice-versa.

\section{$\circ$ Conservation and preservation principles}

Although the three conservation and preservation principles respond to architectural and historic concerns, some designers approached minimum intervention and reversibility principles through other perspectives. Minimum intervention implied for some designers mitigating disruption to tenants, minimising seismic structure while utilising the existing strength of the building to reduce cost, or ensuring non-destructive installation of the seismic structure.

Concerning reversibility, many designers did not take it into account or were simply unaware of the principle. For two designers, the seismic structure was designed to become an integral part of the building and its architecture. Its removal was therefore considered not relevant. Others instead suggested designing the seismic retrofit solution with enough flexibility to accommodate future additional structure. Only Architect \#4 acknowledged the value of reversibility, but for the particular scenario of long-term seismic strengthening divided into steps and through time.

\section{Importance of Concept Design stage}

Concept Design appeared to be the most critical stage in the design process for integration. At this stage the seismic scheme is developed, setting the direction of the project. Any further changes would either be limited or imply additional time and cost. To mitigate such an issue and facilitate the development of the rest of the process, some designers stressed the usefulness of the presence of specific stakeholders during the Concept Design stage. The architect was most often mentioned as he or she would not only introduce architectural requirements but also serve as a guide regarding non-structural matters. The presence of the quantity surveyor, project manager, and the contractor were also deemed necessary to address issues early on in the design process.

\section{○ Leadership}

The lead designer varied from one project to another. No scenario appeared to be better than another as the leadership of one designer did not necessarily imply passivity of the other. Effective leadership seemed to be dependent on several factors including solid experience of the lead designer, good communication between the members of the design team, desire to join together both architectural and engineering disciplines, and switching lead when specific skills were required. 


\section{○ Constraints}

The designers mentioned a large number of constraints influencing the seismic design and its architectural integration. The degrees of influence of the constraints however were difficult to determine. Where some designers considered specific constraints to be restrictive, others perceived them as simply setting a framework for their designs. In addition, a constraint did not necessarily negatively affect integration. In some cases, it forced designers to consider other solutions which ultimately enhanced an architectural quality. The constraints fall into four categories. The first related to the site and its building issues, such as boundaries, access, and construction limitations. Another set of constraints arose from legislation rules and entities such as the City Council or Heritage NZ. These encompassed aspects such as the required percentage of NBS when changing building use, as well as the heritage value of the building or its surroundings. The third category involved constraints from clients and tenants. This included the budget, timeframe, mitigation of tenant's disruption, location of the structure, and spatial openness. The last category of constraints came from the designers and stakeholders, including mechanical, electrical and fire engineers, and included cost management, percentage of NBS, speed of design documentation, and stakeholders' presence during design team meetings.

\subsection{Chapter summary}

This chapter focuses on the architects and structural engineers of the five URM buildings and their thoughts about integration. It reveals how the designers define integration and their recommendations to enhance current practice. Their justifications on the treatment of the architectural qualities of the completed buildings and their design processes highlight a large range of factors influencing the integration of seismic retrofit solutions and architecture. Chapter 6 completes the objectives of the research initiated in Chapter 5. It presents key factors affecting integration of seismic retrofit and architecture both within and outside the design process, and refines some of the results from the previous chapter by considering the designers' reflection on their own work.

The following chapter discusses the findings from the entire research presented in this thesis. It provides recommendations to answer the research question of how to achieve successful integration of seismic retrofit and architecture. 
PAGE LEFT INTENTIONALLY BLANK 


\section{CHAPTER 7. DISCUSSION AND CONCLUSIONS}

\subsection{Introduction}

This research has explored factors influencing integration of seismic retrofit and existing architecture in URM buildings. This goal was achieved by conducting qualitative research on five case studies, exploring both the retrofitted buildings and investigating their design processes by interviewing their designers. This combined approach has allowed an analysis of the topic of integration through complementary perspectives, resulting in a comprehensive understanding of each case study.

The research explored integration of structure and architecture in a context that has so far been barely considered by academics and professionals. Indeed, while various authors have demonstrated structure to be capable of contributing architecturally to a building, this aspect has almost exclusively been addressed regarding new projects. Reflection on the architectural role of structure within existing buildings, and more specifically in the context of seismic retrofit is sparse. Furthermore, the design process that influences the integration of seismic structure and architecture in retrofitted buildings has been rarely and only superficially investigated to date.

Throughout this research, analysis of the collected data has identified aspects that reduce integration as well as those capable of enhancing it. These findings not only encourage professionals to reflect on the capacity of their retrofit design to improve an existing building's architecture, but also support them to achieve such goal. Overall, the research has intended to at least highlight or fill a gap in architectural and engineering practice as well as in the discourse about integration.

This concluding chapter starts by summarising the study's main stages and recounting how its complementary methods have addressed and answered the research question. The chapter then continues by discussing the contributions and implications of the findings in regard to building practice and integration discourse. The third part focuses on the limitations of the research. The final section suggests recommendations for future research on the topic of seismic retrofit and architectural integration. 


\subsection{Summary of the research findings}

In contrast to the general passive attitude toward added seismic structure and its interaction with existing architecture, the researcher has explored seismic retrofit through its potential benefits to an existing building's architecture. The study thus explored the limitations and opportunities of integration by addressing the following research question: How can the integration of seismic retrofit and architecture in URM buildings be improved?

To provide a context to answer the question, the literature review in Chapter 2 addressed three main topics: the relationship between structure and architecture, architectural issues in seismic retrofit, and interaction between retrofit structure and architectural quality.

The literature review first identified that structure has the capacity to engage with architecture through its contribution to architectural qualities. Importantly, the achievement of such integration relies on optimal collaboration between architects and engineers during the design process. The chapter then continued by revealing the unbalanced situation regarding different architectural considerations of heritage and non-heritage buildings. Despite the greater interest in the architectural value of heritage buildings, current publications on seismic retrofit simply encourage designers to respect the architecture. The notion of any enhanced structural contribution to existing architecture remains neglected. Based on the previous two sections, the last part proceeded to examine the current literature regarding integration between seismic retrofit and architecture. It was observed that some authors encourage a less passive approach toward seismic retrofit structure. They highlight a desire for structure to interact with the existing architecture. Concerning retrofit practice, some professionals who are concerned about the interaction between structure and architecture use a series of tools to help them evaluate the impact of seismic structure on existing architecture.

Chapter 2 also pointed out a growing interest regarding integration of seismic retrofit and architecture despite little reported progress on this topic. As a result, the potential for improved integration seems achievable, particularly through the capacity of seismic structure to enrich existing architecture.

Chapter 3 primarily outlined the methodology employed in this study to respond to the research question. It described and justified the selected qualitative method and its use of multiple case studies. Several advantages were presented, including the examination of integration within the real-life context, use of multiple sources of information to refine the findings, interpretation of the 
data through the perspective of integration, and comparison of the data with the participants' perception of integration. The use of multiple case studies also allowed comparing information from the various buildings thus identifying differences and similarities of their seismic retrofits and integration with existing architecture. The chapter also presented the various stages of the research design which were established to obtain complementary information. Each stage corresponded to one of the following chapters summarised below.

Using the literature review as its basis, Chapter 4 explored the notion of integration of structure and architecture in greater depth. Drawing upon architectural projects and theories, the chapter investigated the architectural qualities structure influences. It revealed that as structure expresses architectural qualities or concepts, it truly integrates with architecture and enriches it. Integration can thus be seen as the capacity of structure to intensify the qualities and concept of an architectural design.

The following section of Chapter 4 explored integration in the specific context of seismic retrofit. It presented the challenges of working with existing buildings as well as the architectural opportunities seismic structure could bring. Thus, while adding new structure to a completed building raises issues of compatibility and preservation of values, the legitimacy of seismic structure to contribute to existing architecture was established. Based on the findings of the previous sections, the chapter ended by transposing identified architectural qualities to the specific seismic retrofit context. Sixteen architectural qualities that seismic structure can integrate with were then identified and an Observational Checklist (Appendix A) was created.

The research then moved from theory to real life with the following two chapters focused on the analysis of the five case studies. Chapter 5 examined the selected unreinforced masonry buildings (URM) from the perspective of their seismic structures, while Chapter 6 focused on their designers and their views of integration. These chapters presented a comprehensive understanding of integration of seismic retrofit and architecture by looking both at the completed buildings as well as their retrofit design processes.

In Chapter 5, analyses of the five URM buildings allowed correlations to be made between the seismic retrofit systems and their capacity to integrate with architectural qualities. The findings were more varied than initially anticipated since the factors influencing architectural qualities arose not only from the seismic structures but also from other causes as indicated below.

Starting with the seismic structures, the analyses revealed the difficulty of identifying one specific structure as better than another in enhancing architectural qualities. The findings suggested that, 
although some types of structure are pre-disposed to engage with or weaken some architectural qualities, each structural type possesses sufficient flexibility in terms of scale, geometry, materiality, and location to potentially engage with most architectural qualities.

In addition to the characteristics of flexibility noted above, Chapter 5 showed how design decisions affect architectural qualities. For example, the decision to locate retrofit structure inside the buildings avoids affecting important architectural and historic features of the façades. This means seismic retrofit can be viewed positively with respect to the minimum intervention principle. Another example would be undertaking an interior refurbishment alongside a seismic retrofit to provide extra design opportunities to elaborate an architectural concept. As a result, an architectural concept can drive both the refurbishment and the seismic work thus contributing to improved integration between the retrofit and the architecture. A concept provides design justification and coherence between the seismic structure and other components that participate in its expression. However, the case studies also showed that multiple architectural characters within the same building mask any concept.

Chapter 5 highlighted the potential of seismic structure to enhance architectural qualities. However, the analysis revealed that seismic retrofit had a neutral influence on most architectural qualities in the buildings studied. To understand the reasons behind this observation, the next chapter focused on the seismic retrofit designers.

Chapter 6 investigated the designers of the five case studies, focusing on their definition of integration and their consideration of architectural qualities of the seismically retrofitted buildings. The interviews explained the majority of neutral influences from the seismic structures on architectural qualities found in Chapter 5. They revealed that most designers have a conservative approach toward seismic retrofit, designing as neutral as possible to maintain the existing aspects of the building. A possible solution suggested by the architects and structural engineers was the education of their peers and students regarding the issue of integration.

The designers also pointed out that certain conditions and requirements are necessary to achieve an effective design process. This includes the presence of the architect at the Concept Design stage, meetings with the stakeholders early on in the design process to review the seismic strategy, and use of tools to support decision-making and assist enhanced communication and coordination between the stakeholders.

A large number of factors affecting integration in the five URM buildings were also extracted from the interviews. Some positively contributed to effective integration while others negatively 
impacted upon it. However, others are less straightforward, and depending on the approach of the design team, could either achieve successful integration or, in contrast, reduce architectural quality.

Chapter 6 also revealed that minimum intervention and reversibility principles are understood by designers from perspectives other than concerns for heritage value. Minimum intervention was linked to mitigating tenants' disruption and using existing structural strength to reduce cost. The issue of reversibility was however contested by the designers. They prefer a seismic solution that, rather than being removable, accommodates future structure.

The interviews also pointed out that unlike new buildings where the architect is often the design leader, seismic retrofit projects are more ambiguous. The architect or the engineer can lead the design process, as long as he or she has solid experience in seismic retrofit. However, just as importantly, the interviews stressed that any effective leadership requires a high desire from all designers to work together. This goes beyond simple mutual respect and combination of skills; it requires trust between the designers and agreement to achieve a common goal.

Finally, four categories of potential constraints influencing integration were found: site and building issues, legislation, requirements of clients and tenants, and designers' and other stakeholders' concerns and organisations. Most of these constraints can actually be identified early on in the design process, therefore mitigating their impact by appropriate solutions.

The five case study buildings provided insight into the designers' views on integration and to a larger extent into the entire retrofit design process. The variations in how the integration between seismic structure and architectural qualities were treated highlight the complexity of seismic retrofit projects. The achievement of successful integration relies on a combination of very different aspects arising from sources both internal and external to the seismic retrofit project.

The research therefore explored integration between seismic retrofit and architecture from different and complementary perspectives. The result is a comprehensive understanding of the opportunities and issues current designers should be aware of. The findings of the research thus appear to support the hypothesis of the study that integration between seismic retrofit and architecture can be improved. Findings include factors, recommendations and approaches to consider when seismically retrofitting a building. Overall, the achievement of successful integration requires seismic retrofit to be acknowledged as an architectural project with an architectural vision driving its design. 


\subsection{Summary of the main research outcomes}

The research question driving the study was the following: How can the integration of seismic retrofit and architecture in URM buildings be improved? Through this question, the research intended to achieve two aims. First, raise awareness to the architectural opportunities that seismic retrofit can bring to existing URM buildings. Secondly, contribute to improved seismic retrofit practice in regard to integration in URM buildings. With these aims in view, two secondary research questions arose as well as their resulting objectives. The findings of the research are thus summarised and classified based on these questions and objectives.

Secondary question 1: What are the architectural qualities potentially affected by seismic retrofit?

- Objective 1a: Establish a list of architectural qualities against which to review integration of seismic retrofit and architecture.

- Sixteen architectural qualities directly related to seismic retrofit structure were identified. They are divided in seven categories, including Hidden structure, Exposed exterior structure, Exposed interior structure, Interaction with external openings, Ornamentation, Expression of an architectural concept, and Conservation and preservation principles. (Chapter 4, pp. 111-117)

- These sixteen architectural qualities led to the creation of an Observation Checklist - usable by any designer and allowing to review integration of seismic retrofit and architecture. (Chapter 4, pp. 112-116; Appendix A, pp. 288-298)

- Objective 1b: Identify potential predisposition of seismic retrofit structural systems to engage with existing architectural qualities in URM buildings.

While no definitive link between a specific type of seismic structure and its ability to integrate with selected architectural quality could be established, the physical characteristics of some seismic structures predispose them to positively, neutrally, or negatively influencing certain architectural qualities. Designers need to consider these as outlined below:

○ Shear wall: (Chapter 5, pp. 137-139, pp. 184-189)

- suitable for enhanced integration with interior elevation $(3.1)^{1}$, interior expressiveness (3.2), ornamentation (5.1), architectural concept (6.1), minimum intervention (7.1), and interior architectural character (7.2).

\footnotetext{
${ }^{1}$ the numbers in brackets refer to the architectural qualities described in Chapter 4 pp. 110-115
} 
- possible to achieve neutral integration with physical qualities such as space (3.3), function (3.4), and circulation (3.5), as well as with exterior expressiveness (2.2) and reversibility (7.3).

- where located externally, difficult to integrate with elevation (2.1), natural light (4.1), outside views (4.2), and architectural character (7.2).

○ Braced frame: (Chapter 5, pp. 153-155, pp. 184-189)

- appropriate in regard of minimum intervention (7.1), architectural character (7.2) when expressing an industrial vocabulary, and reversibility (7.3).

- due to its geometry, both enhanced and negative integration can occur with interior elevation (3.1), interior expressiveness (3.2), circulation (3.5), and ornamentation (5.1).

- where hidden, like other retrofit structural systems, both the structure and its concealment technique can neutrally integrate with most architectural qualities.

- difficult to integrate with architectural qualities related to physical aspects such as space (3.3) and function (3.4), as well as external openings associated with modulation of natural light (4.1) and outside views (4.2).

- Moment frame: (Chapter 5, pp. 167-169, pp. 184-189)

- where exposed, a moment frame appears suitable for enhanced integration with interior expressiveness (3.2), space (3.3), function (3.4), circulation (3.5), and architectural concept (6.1).

- where the structure is hidden, its concealment technique can positively integrate with functionality and modulation of natural light (4.1).

- whether exposed or hidden, a moment frame can provide enhanced integration with minimum intervention (7.1) and architectural character (7.2).

- allows neutral integration with exterior elevation (2.1), exterior expressiveness (2.2), and outside views (5.1).

- where exposed externally, unlikely to comply with reversibility (7.3).

- Diaphragm: (Chapter 5, pp. 181-183)

- where entirely replacing an existing floor, an exposed diaphragm appears suitable for enhanced integration with most architectural qualities, including floor and ceiling surface (3.1), interior expressiveness (3.2), 
circulation (3.5), ornamentation (5.1), architectural concept (6.1), and architectural character (7.2).

- possible to achieve enhanced integration with minimum intervention (7.1) and reversibility (7.3) when partially seismically strengthening an existing floor.

- where seismically retrofitting the top surface of a floor diaphragm, unlikely to integrate with floor and ceiling surface (3.1), interior expressiveness (3.2), and ornamentation (5.1).

- where hidden, a diaphragm can neutrally integrate with most architectural qualities.

Secondary question 2: What factors and influences affect the integration of seismic retrofit and architecture in URM buildings?

- Objective 2: Examine how designers in New Zealand define and approach integration of seismic retrofit and architecture in order to identify the key factors affecting integration in URM buildings within and outside the design process.

Throughout the research, integration of seismic retrofit and architecture emerged as a complex issue with no standard solution that could be applied to any project. However, a summary of practical recommendations can be extracted from the research. Thus, in order to improve integration in future seismic retrofit projects, the following findings should be considered:

- Recommendation based on key factors affecting integration outside the design process:

- Architects, structural engineers, and clients need to be educated on the issue of integration and its relevance in the context of seismic retrofit. (Chapter 6, pp. 198-201, p. 264). Such an education aims at providing greater consideration for potential architectural contribution of seismic retrofit structure (Chapter 5, p.137, p. 153, p. 167, p. 182; Chapter 6, p. 197, pp. 264-265) and reduce reluctance from some designers to learn from the others' discipline. (Chapter 6, p. 194, p. 196, p.198, p. 264)

- Recommendations based on key factors affecting integration within the design process:

- Commission an architect from the beginning of the Concept Design stage to: 
- review architectural and historic values of the building. (Chapter 6, p. 199, p. 264)

- determine the constraints and requirements set by the client, architect, and structural engineer in order to respect and achieve them throughout the design process. (Chapter 6, pp. 193-195, pp. 200-201, pp. 210-212)

- guide the client and structural engineer through architectural, cost, and legislation issues. (Chapter 6, pp. 198-201, p. 265)

- create effective collaboration with the structural engineer by:

- determining a common goal for the design team to achieve which could be facilitated by adopting an architectural concept. (Chapter 5, pp. 187-188; Chapter 6, p. 207, pp. 210-215, p. 266)

- clarifying potential differences of opinions regarding designers' understanding of integration. (Chapter 6, p. 230, p. 242, p. 266$)$

○ ensuring that all designers share a similar interpretation of each architectural quality. (Chapter 6, p. 259, p. 266)

○ conjointly developing several schemes. (Chapter 6, pp. 199202, p. 265)

- determining which designer would be the most suitable to lead the design process. (Chapter 6, pp. 213-214, pp. 225226, p. 268)

- Improve the effectiveness of the design process by:

- including a range of stakeholders during the Concept Design stage, in particular the contractor, quantity surveyor, fire and services engineers, and project manager. (Chapter 6, p. 200, p. 210, pp. 224225$, p. 249, p. 268$)$

- reviewing proposed schemes in order to select the best. Such a task can be undertaken using an assessment tool. (Chapter 6, pp. 200202, p. 265)

- considering the use of BIM software so the stakeholders can work on a same file. (Chapter 6, pp. 201-202, p. 265) 
- The following circumstances and opportunities favour the achievement of successful integration and should be considered by the designers:

- designing and introducing a new industrial character or drawing upon the existing character. (Chapter 5, pp. 187-188; Chapter 6, p. 237 , p. 248, p. 267)

- using an interior refurbishment to create new architectural qualities integrated with the seismic retrofit structure. (Chapter 5, p. 138 , p. 169 , p. 188 ; Chapter 6 , p. 205 , p. 265 )

- drawing upon a building's new programme to integrate the seismic retrofit structure with the new architectural qualities serving the function of the building. (Chapter 6, p. 205, p. 210, p. 266)

\subsection{Implications of the findings}

This research confirms the views expressed in previous studies (Charleson \& Southcombe, 2014, 2017; Goodwin, 2008; Goodwin et al., 2009; McClean, 2010) that promote a stronger and more thoughtful interaction between seismic retrofit and existing architecture. It intends to encourage academics and professionals to envision seismic retrofit beyond its technical requirements and to consider it as an integral architectural project. The research thus established a series of recommendations outlined in the previous section (Group 1) for designers to consider in order to improve current integration of seismic retrofit and architecture. While all these recommendations have implications for designers, several need to be highlighted.

\subsubsection{Architectural awareness regarding seismic retrofit structure}

The literature review (Chapter 2) and Chapter 4 highlighted the capacity of both structure in general and seismic structure in particular to integrate with the architecture of existing buildings. From there, the research provided in-depth analysis on the relationship between the three most common seismic systems - shear walls, braced frames, and moment frames - and architectural qualities. As a result, strengths and weaknesses of each structure type in regard to architectural qualities have been identified. This raises awareness, in particular to professionals, regarding the advantages of each seismic structure as well as any risks involved. This contribution fills a gap between the guideline documents including the ICOMOS New Zealand Charter (2010) and the Sustainable Management of Historic Heritage Guidance Series (NZHPT, 2007f), and the assessment tools established by Nishizawa (2008), Cattanach et al. (2008), and Pattinson \& Egbelakin (2016). Indeed, the knowledge of the advantages and disadvantages of the seismic structures in regard to 
architectural qualities (Chapter 4) allow designers to compare a selected retrofit system to the principles provided by the guideline documents. Following the design of the scheme the same tools can then be used to review the proposed retrofit solution.

From a more general perspective, the research also provided support for the work of previous authors. Goodwin et al.'s (2009) and McClean's (2010) positions regarding the capacity of seismic retrofit structure to contribute architecturally to a building while respecting the conservation and preservation principles were thus strengthened by the current research's findings.

\subsubsection{Neutral and positive architectural qualities}

The literature review (Chapter 2) and Chapter 4 described and encouraged achievement of successful integration in which seismic structure enhances existing architectural qualities. Chapters 5 and 6 put into perspective the notion that successful integration does not necessarily imply the improvement of all architectural qualities, whether purposefully or fortuitously. In some cases, a deliberate neutrality of architectural qualities is appropriate, such as where a structure has very small dimensions or is located in a secondary space.

A design team needs to reflect upon the existing architectural qualities in order to identify their roles in the overall building and its surroundings. Once this broad perspective is taken, compromises can then be made to keep some architectural qualities neutral without weakening or diminishing the integration of the seismic retrofit and existing architecture.

The need for this broad perspective is also appropriate when an architectural concept drives a retrofit design. As presented in Chapter 5, authors like White (1975) and Jones (1999) encourage expression of the architectural concept through as many different features as possible. In the context of seismic retrofit, this implies using structure to carry the architectural message through its form and detailing, and the various architectural qualities it integrates with. However, the study demonstrated that an architectural concept can be successfully expressed by the seismic retrofit despite not having all architectural qualities improved by it. There are three reasons for this. First, some architectural qualities can better serve a concept when they are not enhanced by the seismic structure. This is the case with the lack of enhanced interior ornamentation in Building \#1, which created a contrast with the refined façade detailing. Secondly, not all architectural qualities are suited to convey the concept as they provide no reinforcement of the intended architectural message. Thirdly, a hierarchy between seismic structures of a same retrofit solution may occur. In this situation, time and effort are better utilised to integrate key structures rather than others 
located in secondary areas or being too small and negligible to contribute to the architectural concept.

The practice of seismic retrofit and its integration with existing architecture is thus not a black and white matter. It must allow for flexibility in design and for nuances in ways to achieve successful integration.

\subsubsection{Reconsideration of conservation and preservation principles}

The research casts a new light on conservation and preservation principles for heritage buildings, especially regarding minimum intervention and reversibility of seismic work. The designers did consider minimum intervention but not reversibility. However, the designers mistakenly attribute to the minimum intervention principle non-heritage benefits such as mitigation of user disruption, and technical and cost advantages. This principle, as far as the designers were concerned, is thus equally appropriate when retrofitting heritage and non-heritage buildings.

In contrast, the reversibility principle is challenged by the designers of both types of buildings. Many interviewees stressed that reversibility cannot be applicable to all retrofit projects. They emphasised the need to reconsider this principle. They understood this principle as designing a seismic solution able to accommodate future seismic structure. Options included locating seismic structure in secondary areas, designing structures that could be easily improved, or be partially or fully removed. Reversibility itself would thus become one option of a larger principle of accommodating future retrofit structure.

The research also supported that of authors like McClean (2010) and Goodwin et al. (2009) who advocate a more engaging and architecturally stimulating interaction between seismic retrofit and existing architecture. The case study analyses revealed that consideration for conservation and preservation principles does not limit successful integration even in heritage buildings.

\subsubsection{The influence of cost on integration}

Interviews of the participants suggested that the budget set by the client does not directly influence integration of seismic retrofit and architecture. A large budget does not necessarily result in a better integration than a smaller one. However, cost remains an important issue in the achievement of a successful seismic retrofit. Throughout the research, cost appeared as a multi-facetted issue that relates to different aspects. Cost is addressed when considering, among others, the: 
- architect's involvement in the design team

- selection of the seismic retrofit structure

- implementation of the seismic retrofit structure which may require some architectural adaptation or refurbishment

- tenants' disruption

- fire upgrading

If these aspects are not considered early enough they can reduce the flexibility of the designers to achieve successful integration. However, the cost issue cannot be perceived simply as the sum of these aspects. It requires the design team to consider the consequences of the interactions between all these aspects. This was highlighted by one participant who stressed that a cheap seismic solution might end up being less-cost effective than one more expensive due to repercussions on nonstructural components.

Cost is therefore a constraint that the design team, and in particular the architect, needs to consider. Understanding issues regarding cost allows the architect to consider options and alternative approaches to achieve the most successful integration. These options include for instance, refining the structure, exposing or hiding it, or minimising the cost of features with little value to the building in favour of more important ones.

\subsection{Limitations of the research}

Like most research, the current study was subject to limitations. They broadly relate to the location of the study, categories of selected buildings, methodology, and presentation.

As presented in section 3.9.2, several advantages justified selecting URM buildings in Wellington to undertake the research. Despite these assets, the decision to focus on one city might be considered as a form of limitation as no comparison of findings were undertaken with URM buildings from another location. However, unlike other studies who can rely on previous works to further develop and compare their findings, the issue of integration of seismic retrofit and architecture has been barely approached and sorely lacks background investigations as noticed in the literature review. As a consequence, a specific research methodology had to be developed to examine this specific topic. This current research and its findings serve as a starting point for future studies using the same methodology and comparing their findings through the model of transferability. Overall, for this qualitative research to be appropriately generalised, a similar methodology should be undertaken by different researchers, several times, and in different contexts. 
The fact that all the potential case studies fitting within the scope of the research were Importance Level 2 buildings can also be considered as a form of limitation. This meant that the research did not include any iconic building. In addition, due to the limited research scope, availability of potential case studies including the availability of the designers, time limitation, and amount of data to investigate, the analysis of all seven typologies of URM buildings (Russell \& Ingham, 2010) was impossible. However, the three typologies presented in the five case studies provided considerable variety in terms of treatment of seismic components, building function, and percentage of NBS to generate rich data collection.

The research relied on five case studies to explore the integration of seismic retrofit and existing architecture. This use of multiple case studies enriched and widened knowledge due to a comparison of various data from building documentation, on-site observations, and interviews. However, this approach reduced the time allocated to each case study. In contrast, research of a single case study would have meant more in-depth exploration. The interviews would not have been limited to the main designers, namely the architect and structural engineer, but would have included other stakeholders such as the client, contractor, and project manager. Their points of view on integration and on the design process of the seismic retrofit would have allowed more understanding of the role and influence of each stakeholder in the design process. While this approach possesses some advantages, it would also have led to drawing conclusions from just one single building.

The architectural qualities analysed in this study were primarily established based on previous research work focusing upon most common uses of structure in architectural projects. This linked structure with architectural qualities. However, some architectural qualities that might be considered as part of architecture were not included. These include building science related qualities listed by Pattinson \& Egbelakin (2016), such as thermal insulation, acoustic performance, and weather-tightness of the building envelope. While these qualities could be affected by seismic retrofit, the review and analysis of their interaction with seismic structure would have widened the research scope too far.

The study drew upon information obtained from building documentation, direct observation, and semi-structured interviews after seismic retrofit of the case study buildings. Therefore the researcher did not follow the development of the seismic retrofit projects. An alternative research approach would have been to attend the design process and construction site meetings from the start to the end of each retrofit project. This would have allowed gathering observational data regarding the interaction between the various stakeholders. Possible additional information on the 
factors influencing integration between seismic retrofit and architectural qualities could have been obtained, thus refining the current findings.

A final limitation concerns the anonymity to the research participants and, to a larger extent, all stakeholders involved in the design and construction of the URM buildings. This has impacted on the presentation of this research as photographs and documentation related to the buildings had to be replaced by simplified sketches. The sketches reinforce the analysis but the required anonymity did not allow establishing a case study database from collected photographs and documentation.

\subsection{Future research recommendations}

The topic of integration of seismic retrofit and existing architecture addressed in this research remains vast and allows for further investigations. Recommendations to expand the study are outlined below.

One avenue for further research would be to investigate how designers from other cities in New Zealand approach the integration of seismic retrofit and architecture. Research similar to the one presented in this thesis could be undertaken in the provinces of Auckland, Canterbury, or Otago and Southland, which possess the three largest URM building stocks of the country (Russell \& Ingham, 2010). This work could also be expanded to URM buildings with typologies and Importance Levels not addressed in this research. The findings could be compared to those obtained in this study, thus strengthening generalisation of findings to New Zealand.

Investigating the topic of integration in seismic retrofit from an international context would also be highly valuable. A large range of earthquake-prone countries could be explored, from those with a long architectural history such as Italy to others with more recent buildings like the USA, but also those in geographical areas with less preparedness measures, as is the case in Nepal or Turkey. These studies would provide insight into the seismic retrofit of existing building from perspectives unique to each nation and enable each to benefit from others.

Integration in the context of seismic retrofit is not constrained to URM buildings. Reinforced concrete, steel, and timber buildings could also be analysed. This would allow exploration of the relationship between the materiality of existing structures and new seismic structure. Possible new concerns specific to each material as well as aspects constant across them would help broaden the concept of integration and enhance its understanding for both professionals and academics. 
The interviews unveiled the roles of other stakeholders, in addition to the architect and structural engineer, in influencing the design of seismic retrofit and affecting the work organisation of the design team. Future research could, therefore, widen the range of stakeholders being interviewed, including the client, contractor, quantity surveyor, and project manager. This approach would provide additional information on factors influencing integration and refine those found in this research.

The continuous presence of the researcher in design team meetings during the design process and construction phase might discover important information on the evolution of a seismic scheme. An in-depth analysis of each design process step, including the time of involvement and tasks of each stakeholder, would extend knowledge on collaboration during a seismic retrofit project. This aspect is particularly interesting as the findings of the research indicated that the notion of integration and the definition of architectural qualities can be interpreted differently by members of the same design team.

The final recommendation concerns the probable constant evolution of seismic technologies and legislation. This will most likely require buildings already retrofitted to have additional seismic work. As a result, previously enhanced architectural qualities might be modified and possibly weakened. Professionals and academics need therefore to reflect on the legitimacy of previously modified qualities that could be affected by new seismic structures. In more simple terms, should integration be considered between the newest retrofit design and the original architecture, the two layers of seismic solutions, or all three aspects? 


\section{REFERENCES}

860-880 Lake Shore Apartments. (n.d.). Retrieved from http://miessociety.org/mies/projects/860880-lake-shore-apartments/

Achilles, R. (2013). The Chicago School of Architecture: Building the Modern City, 1880-1910: Bloomsbury Publishing.

Aguilar, A. (2016). The Seismic Rehabilitation of Historic Buildings, Preservation briefs 41. Washington, USA: National Park Service, U.S. Department of the Interior. Retrieved from http://www.nps.gov/tps/how-to-preserve/briefs/41-seismic-retrofit.htm.

AIA. (2010). The Handbook of Architectural Design Competitions. Washington, USA: The American Institute of Architects.

Al-Kodmany, K., \& Ali, M. (2016). An Overview of Structural \& Aesthetic Developments in Tall Building Using Exterior Bracing \& Diagrid Systems. International Journal of High-Rise Building, 5(4), 271-291.

Alberti, L. B. (1988). On the art of building in ten books. Cambridge, Mass: Mit Press.

Alexander, C. (1977). A pattern language: towns, buildings, construction. New York, USA: Oxford University Press.

Alfoldy, S. (2012). The Allied Arts: Architecture and Craft in Postwar Canada. Montreal, Canada: McGill-Queen's University Press

Ando, T. (n.d.). The Pritzker Architecture Prize. Retrieved from https://www.pritzkerprize.com/laureates/1995

Antonakaki, T. (2007). Lighting and Spatial Structure in Religious Architecture. Paper presented at the 6th International Space Syntax Symposium, Istanbul.

Aplin, G. (2002). Heritage: Identification, Conservation, and Management. South Melbourne: Oxford University Press.

Arnheim, R. (1974). Art and the Visual Perception: A Psychology of the Creative Eye (2nd ed.). Berkeley: University of California Press.

Arnheim, R. (1977). The dynamics of architectural form: Univ of California Press.

Arnold, C. (1996). Architectural aspects of seismic resistant design. Paper presented at the Eleventh World Conference on Earthquake Engineering, Acapulco, Mexico.

Arnold, C. (2001). Architectural Considerations. In F. Naeim (Ed.), The Seismic Design Handbook (2nd ed., pp. 275-326). Boston, MA: Springer.

ASCE. (2007). Seismic Rehabilitation of Existing Buildings (ASCE/SEI 41-06). Reston, Virginia, USA: American Society of Civil Engineers.

Ayuntamiento de Caceres. (n.d.). Guía Turística Casar De Cáceres. Retrieved from http://www.casardecaceres.com/data/sections/262/docs/1442969333.pdf 
Balmond, C. (2002). Informal, the informal in architecture and engineering: Prestel.

Barry, E. M. (1881). Lectures on Architecture delivered at the Royal Academy. London: John Murray.

Baxter, P., \& Jack, S. (2008). Qualitative Case Study Methodology: Study Design and Implementation for Novice Researchers. The Qualitative Report, 13(4), 544-559.

Beeby, T. H. (1977). The Grammar of Ornament, Ornament as Grammar. VIA III, The journal of the Graduate School of Fine Arts.

Benedetti, C., \& Charleson, A. (2000). Exposed architectural timber design: a state-of-the-art summary and resource of contemporary international practice. Paper presented at the World Conference on Timber Engineering, Vancouver, Canada.

Bernabeu Larena, A. (2006). Origin of the Collaboration between Engineers and Architects in Great Britain in the Thirties Paper presented at the Second International Congress on Construction History, Queen's College, University of Cambridge.

Betti, M., \& Galano, L. (2012). Seismic analysis of historic masonry buildings: the vicarious palace in Pescia (Italy). Buildings, 2(2), 63-82.

Beyer, K., \& Lucca, F. (2016). Effect of static and kinematic boundary conditions on the out-of-plane response of brick masonry walls. Paper presented at the Proceedings of the 16th International Brick and Block Masonry Conference (IBMAC). Padova, Italy.

Beyer, K., Penna, A., Vanin, F., Senaldi, I., Godio, M., Guerrini, G., \& Tomassetti, U. (2017). Seismic retrofit of cultural heritage buildings-when less is more. Paper presented at the Proceedings of the 4th Conference on Smart Monitoring, Assessment and Rehabilitation of Civil Structures.

Blaikie, E., \& Spurr, D. D. (1992). Earthquake vulnerability of existing unreinforced masonry buildings: Works Consultancy Services.

Blatter, J. (2008). Case Study. In L. M. Given (Ed.), The Sage Encyclopedia of Qualitative Research Methods (pp. 68-71). Thousand Oaks, USA: Sage Publications.

Bothireddy, H. (2007). Syntactic and Semantic Role of Ornament in Architecture. (M. Arch Thesis), University of Cincinnati. Retrieved from https://www.researchgate.net/publication/34174537 Syntactic and semantic role of or nament in architecture electronic resource

Brainov, M. N. (1980). On aesthetics in structural engineering. IABSE.

BRANZ. (n.d.). Earthquake risk zones. Retrieved from http://www.seismicresilience.org.nz/topics/seismic-science-and-siteinfluences/faults/earthquake-risk-zones/

Breiner, D. M. (1990). Designation List 226 LP-1775 Landmarks Preservation Commission August 14, 1990.

Brophy, V., \& Lewis, J. O. (2011). A green vitruvius: principles and practice of sustainable architectural design (2nd ed.). Hoboken: Routledge. 
Brown, P., Aiken, I. D., \& Jafarzadeh, F. J. (2001). Seismic retrofit of the Wallace F. Bennett Federal Building. Modern steel construction, 41(8), 29-39.

Bruneau, M. (1994). State-of-the-art report on seismic performance of unreinforced masonry buildings. Journal of structural engineering, 120(1), 230-251.

Calatrava, S., Kausel, C. L., \& Julian, A. P. (2002). Santiago Calatrava: Conversations with Students-The MIT Lectures: Princeton Architectural Press.

Calderon, E., Schimek, H., \& Wiltsche, A. (2011). Seeking performative beauty ACADIA 2011: Integration Through Computation: University of Calgary.

Campbell, D. T. (1986). Relabeling internal and external validity for applied social scientists. New Directions for Evaluation, 1986(31), 67-77.

Cattanach, A. G., Alley, G. W., \& Thornton, A. W. (2008). Appropriateness of Seismic Strengthening, Interventions in Heritage Buildings: A Framework for Appraisal. Paper presented at the New Zealand Society for Earthquake Engineering 2008 Conference, Taupo, New Zealand.

CCM Architects. (n.d.). Shed 13. Retrieved from http://www.ccm.co.nz/\#!/projects/heritage/shed$13 /$

Ceroni, F., Pecce, M., Sica, S., \& Garofano, A. (2012). Assessment of seismic vulnerability of a historical masonry building. Buildings, 2(3), 332-358.

Chakraborty, M. (2014). Designing Better Architecture Education: Global Realities and Local Reforms. New Delhi, India: COPAL Publishing Group.

Chalana, M., \& Wiser, J. C. (2013). Integrating preservation and hazard mitigation for unreinforced masonry buildings in Seattle. APT bulletin, 44(2-3), p. 43-51.

Charleson, A. (2008). Seismic Design for Architects - Outwitting the Quake. Oxford, UK: Architectural Press, Elsevier.

Charleson, A. (2014). Structure as Architecture: a sourcebook for architects and structural engineers (2nd ed.). Oxford, UK: Routledge.

Charleson, A., \& Pirie, S. (2009). An investigation of structural engineer-architect collaboration. SESOC Journal (New Zealand), 22(1), 97-104.

Charleson, A., Preston, J., \& Taylor, M. (2001). Architectural expression of seismic strengthening. Earthquake Spectra, 17(3), 417-426.

Charleson, A., \& Southcombe, M. (2014). [Re]Cuba: Renegotiating seismic resilience in Cuba Street Wellington. Wellington, New Zealand: Wellington City Council.

Charleson, A., \& Southcombe, M. (2017). Strategies for the seismic upgrading of pairs of buildings in a historic precinct. New Zealand Society for Earthquake Engineering Bulletin, 50(1), 50-58.

Charleson, A., \& Taylor, M. (2000). Towards and Earthquake Architecture. Paper presented at the 12th World Conference on Earthquake Engineering, Auckland, New Zealand. 
Chernyshov, E. (2008). Light, Dark, and all That's in Between: Revisiting the Role of Light in Architecture. University of Waterloo. Retrieved from https://uwspace.uwaterloo.ca/bitstream/handle/10012/3515/ChernyshovThesisJan22.pdf;j sessionid=5FABA9CB7A8FAB3EE72AF0D88E80755E?sequence $=1$

Ching, F. (2007). Architecture: Form, space, and order (3rd ed.): John Wiley \& Sons.

Ching, F. (2014). Architecture: Form, space, and order (4th ed.). New York, USA: John Wiley \& Sons.

Christianson, J. (1983). State Opera House - Upgrading. NZSEE Quarterly Bulletin, 16(2), 175-178.

CHSC. (2013). California Health and Safety Code. California, USA: Legislative Counsel of California Retrieved from http://law.justia.com/codes/california/2012/hsc/division-13/part3/chapter-2/article-4/section-19162/.

Clark, R. H., \& Pause, M. (2005). Precedents in Architecture: Analytic Diagrams, Formative Ideas, and Partis (3rd ed.). New York, USA: John Wiley \& Sons, Inc.

Collins, P. (1998). Changing Ideals in Modern Architecture 1750-1950. Montreal, Canada: McGillQueen's University Press.

Cook, P. (1996). Primer. London: Academy Editions.

Cooper, M., Carter, R., \& Fenwick, R. (2012a). Final Report Volume 4: Earthquake Prone Buildings. Retrieved from Christchurch, New Zealand:

Cooper, M., Carter, R., \& Fenwick, R. (2012b). Final Report Volume 5: Summary and Recommendations In Volumes 5-7 Christchurch, The City and Approach To This Inquiry. Retrieved from Christchurch, New Zealand:

Cresciani, M., \& Forth, J. (2014). Three resilient megastructures by Pier Luigi Nervi. International Journal of Architectural Heritage, 8(1), 49-73.

Creswell, J. (1994). Research Design: Quantitative and Qualitative Approaches. Thousand Oaks, USA: Sage Publications.

Curtis, N. C. (2011). The secrets of architectural composition: Courier Corporation.

Descottes, H., \& Ramos, C. E. (2011). Architectural lighting: designing with light and space: Princeton Architectural Press.

Donoff, E. (2007). Sculpting with Light: Dynamic lighting redefines the museum-going experience. Retrieved from http://www.archlighting.com/projects/sculpting-with-light o

Egbelakin, T., \& Wilkinson, S. (2008). Factors affecting motivation for improved seismic retrofit implementation. Paper presented at the Australian Earthquake Engineering Conference (AEES), Ballarat, Australia.

Egbelakin, T., Wilkinson, S., Potangaroa, R., \& Ingham, J. (2011). Challenges to successful seismic retrofit implementation: a socio-behavioural perspective. Building Research \& Information, 39(3), 286-300. 
Eguiluz, P. (2015). Hormigón EXPRESIVO en Cáceres. Retrieved from http://www.revistaad.es/arquitectura/articulos/hormigon-expresivo-cacereno/17458

Emmitt, S., Prins, M., \& den Otter, A. (2009). Architectural Management: International research and practice. Chichester, UK: John Wiley \& Sons.

Ercikan, K., \& Roth, W.-M. (2014). Limits of generalizing in education research: Why criteria for research generalization should include population heterogeneity and users of knowledge claims. Teachers College Record, 116(5), 1-28.

Evans, R. (1990). Mies van der Rohe's Paradoxical Symmetries. AA files, 19, 56-68.

Eyre, J. (2002). Architecture or Engineering? Retrieved from http://www.wilkinsoneyre.com/thoughts/essays/architecture-or-engineering

Fay Jones, E. (1999). Outside the Pale: The Architecture of Fay Jones. Fayetteville, USA: University of Arkansas Press.

FEMA. (2006a). Designing for Earthquakes: A Manual for Architects (FEMA 454). Washington, USA: Federal Emergency Management Agency.

FEMA. (2006b). Techniques for the Seismic Rehabilitation of Existing Buildings (FEMA 547). Washington, USA: Federal Emergency Management Agency.

FEMA. (2009). Unreinforced Masonry Buildings and Earthquakes: Developing Successful Risk Reduction Programs: Prepared for Federal Emergency Management Agency. Washington, USA: Federal Emergency Management Agency.

Ferreira Bento, J. (2012). Survey on Architectural Policies in Europe. Amadora, Portugal: Ordem dos Arquitectos.

Firestone, W. A. (1993). Alternative arguments for generalizing from data as applied to qualitative research. Educational researcher, 22(4), 16-23.

Forell/Elsesser Engineers. (n.d.). Seismic Retrofits. Retrieved from http://www.forell.com/seismicretrofits/

Frampton, K. (1985). MODERN ARCHITECTURE, A CRITICAL HISTORY. 4. A+ U-ARCHITECTURE AND URBANISM(175), 31-38.

Gallie, W. B. (1955). Essentially contested concepts. Proceedings of the Aristotelian society, 56(1), 167-198.

Gill, S. S. (2006). A study of the characteristics of natural light in selected buildings designed by Le Corbusier, Louis I. Kahn and Tadao Ando. Texas A \& M University. Retrieved from https://oaktrust.library.tamu.edu/bitstream/handle/1969.1/ETD-TAMU-1727/GILLTHESIS. pdf?sequence $=1 \&$ isAllowed $=y$

Goodwin, C. (2008). Architectural Considerations in the Seismic Retrofit of Unreinforced Masonry Heritage Buildings in New Zealand. (M. Arch Thesis), The University of Auckland, New Zealand. Retrieved from https://www.researchgate.net/publication/41966932 Architectural Considerations in the Seismic Retrofit of Unreinforced Masonry Heritage Buildings in New Zealand 
Goodwin, C., Tonks, G., \& Ingham, J. (2009). Identifying heritage value in URM buildings. SESOC Journal (New Zealand), 22(2), 16-28.

Goodwin, C., Tonks, G., \& Ingham, J. (2011). Retrofit techniques for seismic improvement of URM buildings. SESOC Journal (New Zealand), 24(1), 30-45.

Groat, L., \& Wang, D. (2002). Architectural research methods. New York, USA: John Wiley \& Sons, Inc.

Hanlon, D. (2009). Compositions in architecture. Chichester, UK: John Wiley \& Sons.

Heritage New Zealand. (2014). Information sheet - Applications for entry on the New Zealand Heritage List / Rārangi Kōrero. . Retrieved November 2016, from Heritage New Zealand Pouhere Taonga http://www.heritage.org.nz/the-list/Lmedia/8c1c89c0ef5d48a19821975d1eef68de.ashx

Heritage New Zealand. (n.d.). Conservation Plans. Retrieved from http://www.heritage.org.nz/resources/conservation-plans

Holgate, A. (1986). The Art in Structural Design - An Introduction and Sourcebook. Oxford, UK: Oxford University Press

Holl, S. (2002). Steven Holl: idea and phenomena: Lars Muller Publishers.

ICOMOS. (2010). ICOMOS New Zealand Charter for the Conservation of Places of Cultural Heritage Value. Retrieved from https://www.icomos.org/images/DOCUMENTS/Charters/ICOMOS NZ Charter 2010 FINAL 11 Oct 2010.pdf

Innovations and Influence. (n.d.). Retrieved from http://860880lakeshoredrive.com/innovationsand-influence/

IPENZ, NZAI, SESOC, NZRAB, MBIE, \& NZSEE. (2014). Improving Collaboration Between Architects and Engineers. Retrieved from https://www.nzrab.nz/Editable/Assets/Newslink2015/CollaborationPublication.pdf

Ito, T. (1997). Tarzans in the media forest. In $2 \mathrm{G}$ (Ed.), (Vol. 2, pp. 121-144).

Jaglarz, A. (2011). Perception and illusion in interior design. Paper presented at the International Conference on Universal Access in Human-Computer Interaction.

Jensen, R. M. (2004). The substance of things seen: art, faith, and the Christian community: Wm. B. Eerdmans Publishing.

Jones, O. (2001). The Grammar of Ornament. New York, USA: DK Publishing.

Kahn, L. (1991a). Architecture: Silence and Light, 1970. In A. Latour (Ed.), Louis I. Kahn: Writings, lectures, interviews (pp. 248-257). New York, USA: Rizzoli International Publications.

Kahn, L. (1991b). Form and Design, 1961. In A. Latour (Ed.), Louis I. Kahn: Writings, lectures, interviews (pp. 112-120). New York, USA: Rizzoli International Publications.

Kahn, L. (1991c). Harmony between Man and Architecture, 1974. In A. Latour (Ed.), Louis I. Kahn: Writings, lectures, interviews (pp. 333-343). New York, USA: Rizzoli International Publications. 
Kahn, L. (1991d). How'm I Doing, Corbusier?, 1972. In A. Latour (Ed.), Louis I. Kahn: Writings, lectures, interviews (pp. 297-312). New York, USA: Rizzoli International Publications.

Kahn, L. (1991e). New Frontiers in Architecture, CIAM in Otterlo 1959. In A. Latour (Ed.), Louis I. Kahn: Writings, lectures, interviews (pp. 81-88). New York, USA: Rizzoli International Publications.

Kahn, L. (1991f). Space and Inspirations, 1967. In A. Latour (Ed.), Louis I. Kahn: Writings, lectures, interviews (pp. 224-230). New York, USA: Rizzoli International Publications.

Kazemian, R., \& Rönn, M. (2009). Finnish architectural competitions: structure, criteria and judgement process. Building Research \& Information, 37(2), 176-186.

Kazemian, R., Rönn, M., \& Svensson, C. (2005). Jämförande analys av arkitekttävlingar: erfarenheter från tre nordiska länder (Comparative Analysis of Architectural Competitions) (9171781005). Retrieved from Stockholm, Sweden: https://www.kth.se/polopoly fs/1.110687!/Menu/general/columncontent/attachment/T\%C3\%A4vlingar\%202005.pdf

Kazemian, R., Rönn, M., \& Svensson, C. (2007). Arkitekturtävlingar i finland (Architectural Competitions in Finland). Retrieved from Stockholm, Sweden:

Koliou, M., Lawson, J., Filiatrault, A., \& Kelly, D. (2017). Evaluation of Out-of-Plane Wall Anchorage Force Provisions in Buildings with Rigid Walls and Flexible Roof Diaphragms. Earthquake Spectra, 33(1), 1-23.

Kotsopoulos, S. D. (2008). From design concepts to design descriptions. International Journal of Architectural Computing, 6(3), 335-360.

Krier, R., \& Vorreiter, G. (1988). Architectural composition (Vol. 10): Rizzoli New York.

Kroll, A. (2011). AD Classics: Church of the Light / Tadao Ando Architect \&amp; Associates. Retrieved from https://www.archdaily.com/101260/ad-classics-church-of-the-light-tadao-ando

Kutlu, H. G. (2000). The peculiarities of light as a quality in architecture. İmir Institute of Technology. Retrieved from http://library.iyte.edu.tr/tezler/master/mimarlik/T000106.PDF

L.T. McGuinness. (n.d.). Seismic and Heritage Refurbishment. Retrieved from http://www.ltmcguinness.co.nz/documents/LTM Seismic and Heritage Restoration.pdf

Lagomarsino, S., Abbas, N., Calderini, C., Cattari, S., Rossi, M., Corradini, R. G., . . Piovanello, V. (2011). Classification of cultural heritage assets and seismic damage variables for the identification. WIT Transactions on the Built Environment, 118, 697-708.

Lagomarsino, S., \& Cattari, S. (2015). PERPETUATE guidelines for seismic performance-based assessment of cultural heritage masonry structures. Bulletin of Earthquake Engineering, 13(1), 13-47.

Lagomarsino, S., Cattari, S., \& Calderini, C. (2012). European Guidelines for the seismic preservation of cultural heritage assets. PERPETUATE (EU-FP7 Research Project), Deliverable D, 41, 2012.

Leon, S. (2012). Structure as Architectural Intervention. In H. Kara, A. Georgoulias, \& J. Silvetti (Eds.), Interdisciplinary Design: New Lessons from Architecture and Engineering (pp. 40-54). Barcelona, Spain: Actar Publishers. 
Leung, L. (2015). Validity, reliability, and generalizability in qualitative research. Journal of family medicine and primary care, 4(3), 324.

Lincoln, Y. S., \& Guba, E. G. (1985). Naturalistic inquiry (Vol. 75): Sage.

Llunji, M. (2016). Seismic architecture: The architecture of earthquake resistant structures. Ulcinj, Montenegro: MSPROJECT.

Long, C. (2011). The Looshaus. New Haven and London: Yale University Press.

Look, D. W., Wong, T., \& Augustus, S. R. (1997). The Seismic Retrofit of Historic Buildings: Keeping Preservation in the Forefront, Preservation briefs 41. Washington, USA: National Park Service, U.S. Department of the Interior. Retrieved from http://www.okhistory.org/shpo/presbriefs/41Preserve-Brief-SeismicRetrofit.pdf.

Loos, A., \& Opel, A. (1998). Ornament and crime: selected essays. Riverside, USA: Ariadne Press.

Macdonald, A. (1997). Structural design for architecture. Oxford, UK: Taylor \& Francis.

Macdonald, A. (2001). Structure and architecture (2nd ed.). Oxford, UK: Taylor \& Francis.

Madsen, D. (2012). The Joe and Rika Mansueto Library, University of Chicago. Retrieved from http://www.archlighting.com/projects/the-joe-and-rika-mansueto-library-university-ofchicago 0

Magenes, G., \& Calvi, G. M. (1997). In-plane seismic response of brick masonry walls. Earthquake engineering \& structural dynamics, 26(11), 1091-1112.

Mayring, P. (2007). On generalization in qualitatively oriented research. Paper presented at the Forum Qualitative Sozialforschung/Forum: Qualitative Social Research.

MBIE. (2016). Proposals for Regulations under the Building (Earthquake-prone Buildings) Amendment Act 2016 Retrieved from http://www.mbie.govt.nz/info-services/buildingconstruction/consultations/consultation-earthquake-prone-building-regulations-andmethodology/discussion-document-proposals-for-regulations-under-the-buildingearthquake-prone-buildings-amendment-act-2016.pdf

MBIE. (n.d.-a). How the system for managing earthquake-prone buildings works. Retrieved from https://www.building.govt.nz/managing-buildings/managing-earthquake-pronebuildings/how-the-system-works/\#jumpto-seismic-risk-areas-and-time-frames

MBIE. (n.d.-b). Z-values to determine seismic risk. Retrieved from https://www.building.govt.nz/managing-buildings/managing-earthquake-pronebuildings/how-the-system-works/z-values-seismic-risk/

McClean, R. (2010). Earthquake Strengthening - Improving the Structural Performance of Heritage Buildings. . Sustainable Management of Historic Heritage Guidance Series (draft for consultation). Retrieved from http://www.historic.org.nz/ProtectingOurHeritage/ /media/Corporate/Files/Submissions\% 20and\%20research/DraftGuideEarthquakeStrengthening.ashx

Mcdonald, S. (2008). One Shelley Street, Sydney. Retrieved from http://www.architectureanddesign.com.au/news/bpn/one-shelley-street-sydney 
Mendoza, G. (n.d.). Concreto laminar al extremo.

Retrieved from http://www.imcyc.com/ct2008/oct08/arquitectura.htm

Mezzi, M., Parducci, A., \& Verducci, P. (2004). Architectural and Structural Configurations of Buildings with Innovative Aseismic Systems. Paper presented at the $13^{\text {th }}$ World Conference on Earthquake Engineering, Vancouver, Canada.

Michel, L. (1995). Light: The shape of space: Designing with space and light: John Wiley \& Sons.

Millet, M. S., \& Barrett, C. J. (1996). Light revealing architecture: Van Nostrand Reinhold New York.

Natapov, A., Kuliga, S., Dalton, R. C., \& Hölscher, C. (2015). Building circulation typology and space syntax predictive measures. Paper presented at the Space syntax: Proceedings of the tenth international space syntax symposium.

NEHRP, A. (1997). Commentary on the Guidelines for the Seismic Rehabilitation of Buildings: FEMA.

Nelson, C. (2006). Managing quality in architecture. Oxford, UK: Taylor \& Francis.

Nelson, L. H., \& FAIA. (1988). Architectural character: identifying the visual aspects of historic buildings as an aid to preserving their character, Preservation briefs 17. Washington, USA: National Park Service, U.S. Department of the Interior Retrieved from http://www.nps.gov/history/tps/how-to-preserve/briefs/17-architectural-character.htm.

New Zealand Parliament. (1991). Resource Management Act 1991. New Zealand Retrieved from http://www.legislation.govt.nz/act/public/1991/0069/latest/whole.html.

New Zealand Parliament. (2004). Building Act 2004. New Zealand Retrieved from http://www.legislation.govt.nz/act/public/2004/0072/latest/whole.html.

New Zealand Parliament. (2014). Heritage New Zealand Pouhere Taonga Act 2014. New Zealand Retrieved from http://www.legislation.govt.nz/act/public/2014/0026/26.0/whole.html.

New Zealand Parliament. (2016). Building (Earthquake-prone Buildings) Amendment Act 2016. New Zealand Retrieved from http://www.legislation.govt.nz/act/public/2016/0022/22.0/whole.html.

Newby, F. (1962). Relationship between the architect and the engineer. Builder, 381-384.

Ngo, L. K. (2015). Termitary House / Tropical Space. Retrieved from https://www.archdaily.com/594339/termitary-house-tropical-space

Nicholls, J. (2012). A concrete cathedral for sport - The Crystal Palace Sports Centre. Retrieved from http://www.justinnichollsarchitect.com/2012/10/a-concrete-cathedral-for-sportcrystal.html

Nishizawa, T. (2008). Seismic Isolation Retrofit for Major Tall Building. Paper presented at the $14^{\text {th }}$ World Conference on Earthquake Engineering, Beijing, China.

Nordenson, G. (2003). Tall buildings: The Museum of Modern Art. 
NZCIC. (2004). Design Documentation Guidelines. Retrieved from http://www.acenz.org.nz/uploads/Client/Design\%20Documentation\%20GuidelinesFULL.pdf.

NZHPT. (2007a). Discussion paper $n^{\circ} 1$ - Historic Heritage Principles and Issues. Sustainable Management of Historic Heritage Guidance series, Retrieved from http://www.heritage.org.nz/resources/-/media/c435cc4ced1845ae83ec9a42bec8e6a5.ashx

NZHPT. (2007b). Discussion paper $n^{\circ} 2$ - Assessment of Effects on the Historic Environment. Sustainable Management of Historic Heritage Guidance series, Retrieved from http://www.heritage.org.nz/resources/-

/media/e7892b2e825249d38b24d6500e9af3e2.ashx

NZHPT. (2007c). Guide $n^{\circ} 1$ - Regional policy statements. Sustainable Management of Historic Heritage Guidance series, Retrieved from http://www.heritage.org.nz/resources/Lmedia/8e20dd57d4bf41cbb347be86fae116f4.ashx

NZHPT. (2007d). Guide $n^{\circ} 4$ - Resource Consents. Sustainable Management of Historic Heritage Guidance series, Retrieved from http://www.heritage.org.nz/resources/Lmedia/033ed13f35924f268b80e0b4eda5a62c.ashx

NZHPT. (2007e). Information Sheet $n^{\circ} 12$ - Alterations and additions to historic buildings. Sustainable Management of Historic Heritage Guidance series, Retrieved from http://www.heritage.org.nz/resources//media/a5d7ddee3dc841b9b2c6114e77d35129.ashx

NZHPT. (2007f). Sustainable Management of Historic Heritage Guidance Series. Retrieved from http://www.heritage.org.nz/resources/sustainable-management-guides

NZHPT. (2009). Historic heritage Research Paper $N^{\circ} 1$ - Toward improved national and local action on earthquake-prone heritage buildings (pp. 6-25). Retrieved from http://www.heritage.org.nz/resources/research-and-papers/research

NZSEE. (n.d.). Earthquake Strengthening Awards. Retrieved from http://www.nzsee.org.nz

NZSEE, SESOC, NZGS, MBIE, \& EQC. (2017). The Seismic Assessment of Existing Buildings Vol. Part C, Section 8. Retrieved from http://www.eq-assess.org.nz/assets/2017-07/Section C8Unreinforced Masonry Buildings.pdf

Ogg, A. (1987). Architecture in steel: the Australian context. Melbourne, Australia: Royal Australian Institute of Architects.

Onniboni, L. (2014). Castelvecchio Museum - A masterpiece by Carlo Scarpa. Retrieved from https://archiobjects.org/museo-castelvecchio-verona-italy-carlo-scarpa/

Ostwald, M. J. (2002). Binding Issues and Critical Strengthening. In M. Taylor, J. Preston, \& A. Charleson (Eds.), Moments of resistance (pp. 23-40). Sydney, Australia: Archadia Press.

Owens, M. (1986). Abandoning simplicity: Architectural firm sees a bold, bright pattern in the future. Doylestown, Pennsy/vania Intelligencer, C13.

Oxford English Dictionary. (n.d.). Retrieved from http://www.oed.com 
Özmen, C., \& Ünay, A. İ. (2011). Architect-structural engineer collaboration in sustainable structural system design. Gazi University Journal of Science, 24(4), 919-925.

Parafianowicz, L. (2012). House of Cedar by Suga Atelier. Retrieved from https://www.frameweb.com/news/house-of-cedar-by-suga-atelier

Partington, D., Dizhur, D., Ingham, J., \& Egbelakin, T. (2017). Evaluation designs on existing building using Heritage Evaluation Framework. Paper presented at the New Zealand Society for Earthquake Engineering 2017 Conference, Wellington, New Zealand.

Pascucci, D. (2014). AD Classics: Kubuswoningen / Piet Blom. Retrieved from https://www.archdaily.com/482339/ad-classics-kubuswoningen-piet-blom

Pattinson, M. S., \& Egbelakin, T. (2016). An assessment tool for seismic strengthening of heritage buildings. Paper presented at the New Zealand Society for Earthquake Engineering 2016 Conference, Christchurch, New Zealand.

Pawson, J. (2015). Filtered light. Retrieved from http://www.johnpawson.com/journal/filteredlight/

Peter, J. (1994). The oral history of modern architecture: interviews with the greatest architects of the twentieth century. New York, USA: Abrams.

Phillips, D. (2004). Daylighting: natural light in architecture: Routledge.

Phillips, T. (2002). The Nature of Ornament: A Summary Treatise. Retrieved from http://www.tomphillips.co.uk/publications/item/5311-the-nature-of-ornament-asummary-treatise

Plummer, H. (2009). The architecture of natural light: Thames \& Hudson London.

Polit, D. F., \& Beck, C. T. (2010). Generalization in quantitative and qualitative research: Myths and strategies. International journal of nursing studies, 47(11), 1451-1458.

Pressman, A. (2012). Designing architecture: the elements of process. London, UK: Taylor \& Francis.

Quattrone, A. (2012). Assessment of structural reliability: a dynamic monitoring approach. (Doctoral thesis), Politecnico di Torino.

Rasmussen, S. E. (1964). Experiencing architecture (Vol. 2): MIT press.

Reid Middleton. (2007). Unreinforced Masonry Building Seismic Hazards Study. Seattle, USA.

Robinson, L., \& Bowman, I. (2000). Guidelines for Earthquake Strengthening. Wellington, N.Z.: New Zealand Historic Places Trust.

Rönn, M. (2011a). Architectural quality in competitions, A dialogue based assessment of design proposals. Formakademisk, 4(1), 100-115.

Rönn, M. (2011b). Quality in Architecture-A Disputed Concept. In P. Plowright \& B. Gamper (Eds.), Proceedings of the ARCC Spring Research Conference: Considering Research: Reflecting Upon Current Themes in Architectural Research (pp. 235-244). Detroit, MI: Lawrence Technological University. 
Rothbauer, P. (2008). Triangulation. In L. M. Given (Ed.), The Sage Encyclopedia of Qualitative Research Methods (pp. 892-894). Thousand Oaks, USA: Sage Publications.

Russell, A. P. (2010). Characterisation and Seismic Assessment of Unreinforced Masonry Buildings. (Doctor of Philosophy), The University of Auckland, New Zealand. Retrieved from https://researchspace.auckland.ac.nz/handle/2292/6038

Russell, A. P., \& Ingham, J. (2010). Prevalence of New Zealand's Unreinforced Masonry Buildings. Bulletin of the New Zealand Society for Earthquake Engineering, 43(3), 182-202.

Saint, A. (2008). Architect and engineer: A study in sibling rivalry. New Haven, USA: Yale University Press.

Salvadori, M. G., \& Heller, R. A. (1986). Structure in architecture: the building of buildings (3rd Edition ed.). Englewood Cliffs, USA: Prentice-Hall.

Salvan, G. S. (1999). Architectural Theories of Design: Goodwill Trading Co., Inc.

Sandaker, B. N. (2007). On span and space: exploring structures in architecture: Routledge.

Sandaker, B. N., Eggen, A. P., \& Cruvellier, M. R. (2011). The structural basis of architecture (2nd ed.). London, UK: Taylor \& Francis.

Scarpa, C., Olsberg, R. N., \& Guidi, G. (1999). Carlo Scarpa, architect: intervening with history: Montreal: Canadian Centre for Architecture.

Semper, G. (2011). The Four Elements of Architecture and Other Writings. Cambridge, UK: Cambridge University Press.

Senaldi, I., Magenes, G., \& Ingham, J. (2011). Performance of unreinforced stone masonry buildings during the 2010/2011 Canterbury earthquake swarm and retrofit techniques for their seismic improvement.

Sev, A., \& Özgen, A. (2009). Space efficiency in high-rise office buildings. Metu Jfa, 2.

Sharp, D. (2002). Twentieth century architecture: A visual history: Images Publishing.

Sherman, P. (1962). Louis Sullivan: An Architect in American Thought. Englewood Cliffs, USA: PrenticeHall.

Siem, J., Braaten, B., \& Gilberg, A. (2016). Full scale in four months-Objectives, methods and results. Structures and Architecture: Beyond their Limits, 420-428.

Simitch, A., \& Warke, V. (2014). The language of architecture: 26 principles every architect should know. Gloucester, USA: Rockport Publishers.

Simpson Gumpertz \& Heger Inc. (n.d.). Massachusetts Institute of Technology, Simmons Hall. Retrieved from http://www.sgh.com/projects/massachusetts-institute-technologysimmons-hall

Sinclair, B. R. (2015). Devising Design: Agility, Aptness, Equilibrium, Imperfection. Building Dynamics: Exploring an Architecture of Change; Kolarevic, B., Parlac, V., Eds, 41-58. 
Slak, T., \& Kilar, V. (2008a). Assessment of Earthquake Architecture as a link between architecture and earthquake engineering. Prostor: a scholarly journal of Architecture and urban planning, $16(2(36)), 154-167$.

Slak, T., \& Kilar, V. (2008b). Simplified ranking system for recognition and evaluation of earthquake architecture. Paper presented at the $14^{\text {th }}$ World Conference on Earthquake Engineering, Beijing, China.

Slak, T., \& Kilar, V. (2011). Development of Earthquake Resistance in Architecture from an Intuitive to an Engineering Approach. Prostor: a scholarly journal of Architecture and urban planning, 19(1 (41)), 253-263.

Slak, T., \& Kilar, V. (2012). Parameterization and Evaluation of Seismic Resistance within the Context of Architectural Design. Modern Applied Science, 6(7), 17-35.

Smith, M. (2015). A useful accessory: The use of lightweight replica ornament to manage the cultural heritage values of earthquake-prone buildings. (Master Thesis), Victoria University of Wellington, New Zealand. Retrieved from http://researcharchive.vuw.ac.nz/xmlui/handle/10063/4287

Sokol, D. (2002). City on a Site: Simmons Hall, Massachusetts Institute of Technology by Steven Holl Architects. Retrieved from http://www.archnewsnow.com/features/Feature86.htm

Solberg, C., Rossetto, T., \& Joffe, H. (2010). The social psychology of seismic hazard adjustment: reevaluating the international literature. Natural Hazards and Earth System Sciences, 10(8), 1663-1677.

Spaeth, D. A. (1985). Mies van der Rohe. London, UK: Architectural Press.

Standards New Zealand. (2002). AS/NZS 1170.0:2002, Structural Design Actions Part 0: General Principles. Wellington, New Zealand.

Sullivan, L. H. (2012). Kindergarten chats and other writings. New York, USA: Dover Publications.

Svensson, C. (2009). Speaking of Architecture - A study of the jury's assessment in an invited competition. Nordic Journal of Architectural Research, 21(2/3), 94-107.

Symans, M., Charney, F., Whittaker, A., Constantinou, M., Kircher, C., Johnson, M., \& McNamara, R. (2008). Energy dissipation systems for seismic applications: current practice and recent developments. Journal of structural engineering, 134(1), 3-21.

Tanizaki, J. i. (1977). In praise of shadows: Leete's Island Books.

Taylor, M., Preston, J., \& Charleson, A. (2002). Moments of resistance. Sydney, Australia: Archadia Press.

Thorne, S., \& Darbyshire, P. (2005). Land mines in the field: A modest proposal for improving the craft of qualitative health research. Qualitative Health Research, 15(8), 1105-1113.

Thornton, A. W. (2010). Twenty-five years of strengthening Wellington. Paper presented at the New Zealand Society for Earthquake Engineering 2010 Conference, Wellington, New Zealand. 
Thyer, G. (2011). Crystal Palace National Sports Centre - Arup Associates. Retrieved from https://gareththyer.wordpress.com/2011/07/26/crystal-palace-national-sports-centrearup-associates/

Tomaževič, M. (1999). Earthquake-resistant design of masonry buildings: World Scientific.

Tryggestad, K. (2006). Constructing buildings and ambitions-The Turning Torso case. Paper presented at the Micro-Processes of Managing the Construction of Buildings.

Uihlein, M. S. (2013). Structural Integration: An Undefinable Idea? Proceedings of 1st Annual International Conference on Architecture and Civil Engineering (ACE) (pp. 502-511). Singapore.

Unwin, S. (2013). Analysing architecture: Routledge.

Van der Rohe, M. (1922). Skyscrapers. published in without title in Frühlicht, 1.

Van der Voordt, D., \& Wegen, H. (2005). Architecture in use: an introduction to the programming, design and evaluation of buildings: Routledge.

Venturi, R. (1977). Complexity and contradiction in architecture (Vol. 1): The Museum of modern art.

Vitruvius, P., \& Morgan, M. H. (1960). Vitruvius: the ten books on architecture (M. H. Morgan, Trans.). New-York, USA: Dover Publications.

Volker, L. (2010). Deciding about design quality: value judgements and decision making in the selection of architects by public clients under European tendering regulations. Leiden, Netherlands: Sidestone Press.

Von Meiss, P. (1990). Elements of Architecture: From form to place. London, UK: Taylor \& Francis.

Von Meiss, P. (2013). Elements of Architecture: From Form to Place + Tectonics (2nd ed.): EPFL Press.

Waterloo International Terminal. (1993). n.d. Retrieved from http://www.engineeringtimelines.com/scripts/engineeringltem.asp?id=243

Wellington City Council. (2000). Distric Plan - Volume 1: Objectives, Policies \& Rules. Retrieved from https://wellington.govt.nz/your-council/plans-policies-and-bylaws/district-plan/volume-1objectives-policies-and-rules.

Wellington City Council. (2013). Wellington city council guide: Earthquake Prone Buildings. Retrieved from http://wellington.govt.nz/ /media/services/rates-and-property/earthquake-pronebuildings/files/eq-prone-buildings-guide.pdf.

Wells, M. (2005). Skyscrapers: Structure and design: Laurence King Publishing.

Wenk, T. (2008). Seismic retrofitting of structures: Strategies and collection of examples in Switzerland. Bern, Switzerland: Federal Office for the Environment FOEN.

Weston, R. (2004). Plans, sections and elevations: key buildings of the twentieth century: Laurence King Publishing. 
Weston, R. (2010). Key Buildings of the Twentieth Century: Plans, Sections, and Elevations. New York, USA: WW Norton \& Company.

Whiffen, M., \& Koeper, F. (1983). American Architecture: 1860-1976 (Vol. 2). Cambridge, Mass., USA: Mit Press.

White, E. T. (1975). Concept sourcebook: a vocabulary of architectural forms. Arizona, USA: Architectural Media.

Whitley, B. E., Kite, M. E., \& Adams, H. L. (2013). Principles of research in behavioral science: Routledge.

Wiendahl, H.-P., Reichardt, J., \& Nyhuis, P. (2015). Handbook factory planning and design: Springer.

Wigley, M. (2002). An Interview with Mark Wigley. Architectural Theory Review, 7(1), 89-102.

Witte, R. (2002). Toyo Ito: Sendai Mediatheque (Case Series): Munich-Berlin-London-New York: Prestel Verlag.

Wraber, I. K., Kirkegaard, P. H., \& Fisker, A. M. (2008). A discussion of the need of a new framework for describing architectural quality. Paper presented at the Architectural Inquiries Conference, Göteborg, Sweden. https://www.researchgate.net/publication/237403326 A discussion of the need of a $n$ ew framework for describing architectural quality

Yeomans, D. (2013). Working relationships between architects and structural engineers: World War II to the 1970s. Structures and Architecture: New concepts, applications and challenges, 439.

Yin, R. K. (1984). Case Study Research: Design and Methods (1st ed.). Beverly Hills: Sage Publications.

Yin, R. K. (1994). Case Study Research: Design and Methods (2nd ed.). Thousand Oaks, USA: Sage Publications.

Yin, R. K. (2009). Case Study Research: Design and Methods (4th ed.). Thousand Oaks, USA: Sage Publications.

Yudelson, J., \& Meyer, U. (2013). The world's greenest buildings: Promise versus performance in sustainable design: Routledge.

Zacek, M. (2004). Conception parasismique, Niveau avant-projet. Villefontaine, France: Les Grands Ateliers.

Zumthor, P. (2006). Peter Zumthor: Atmospheres: Birkhäuser. 
PAGE LEFT INTENTIONALLY BLANK 


\section{APPENDICES}

Appendix A: Observation Checklist 


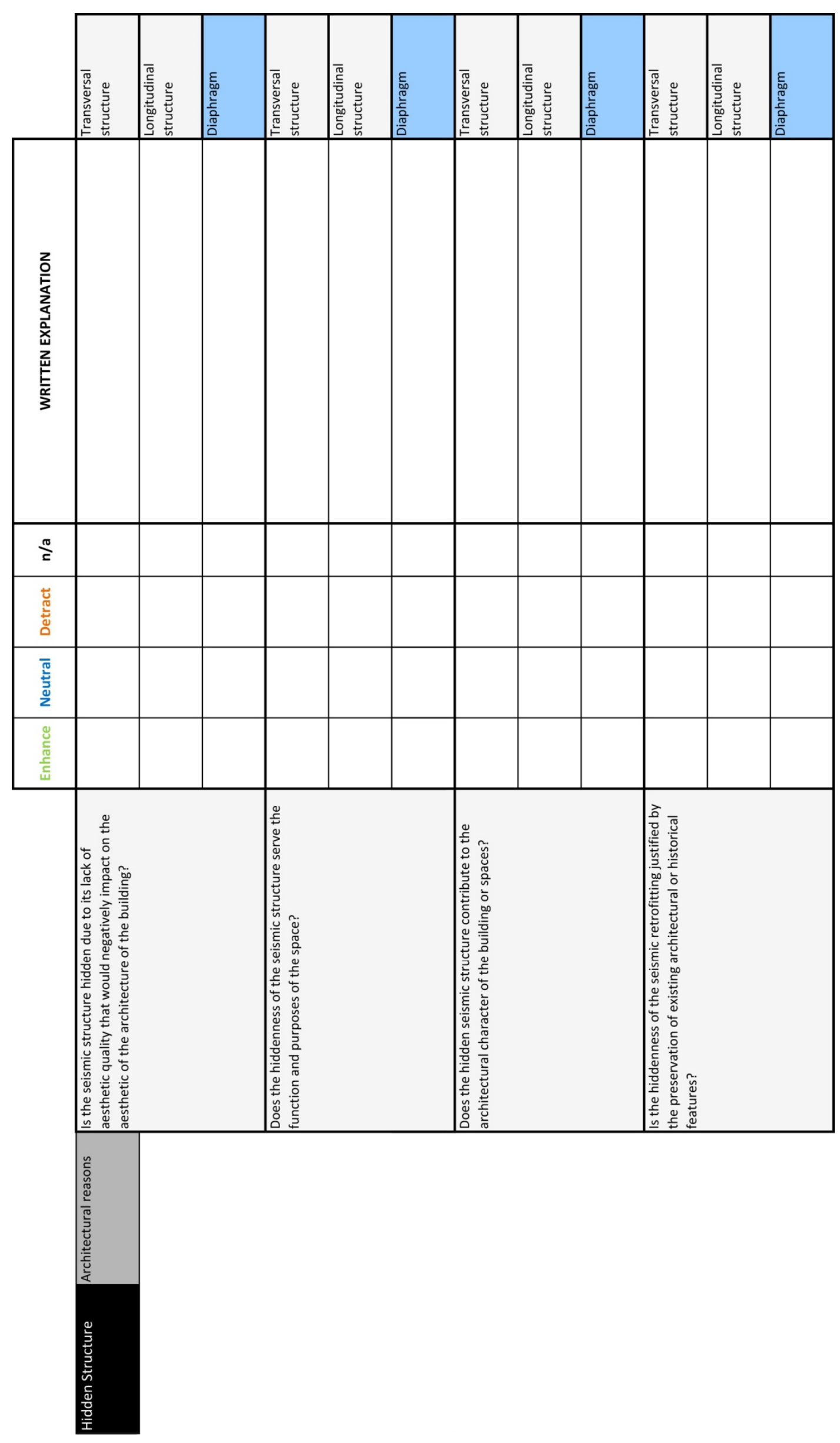




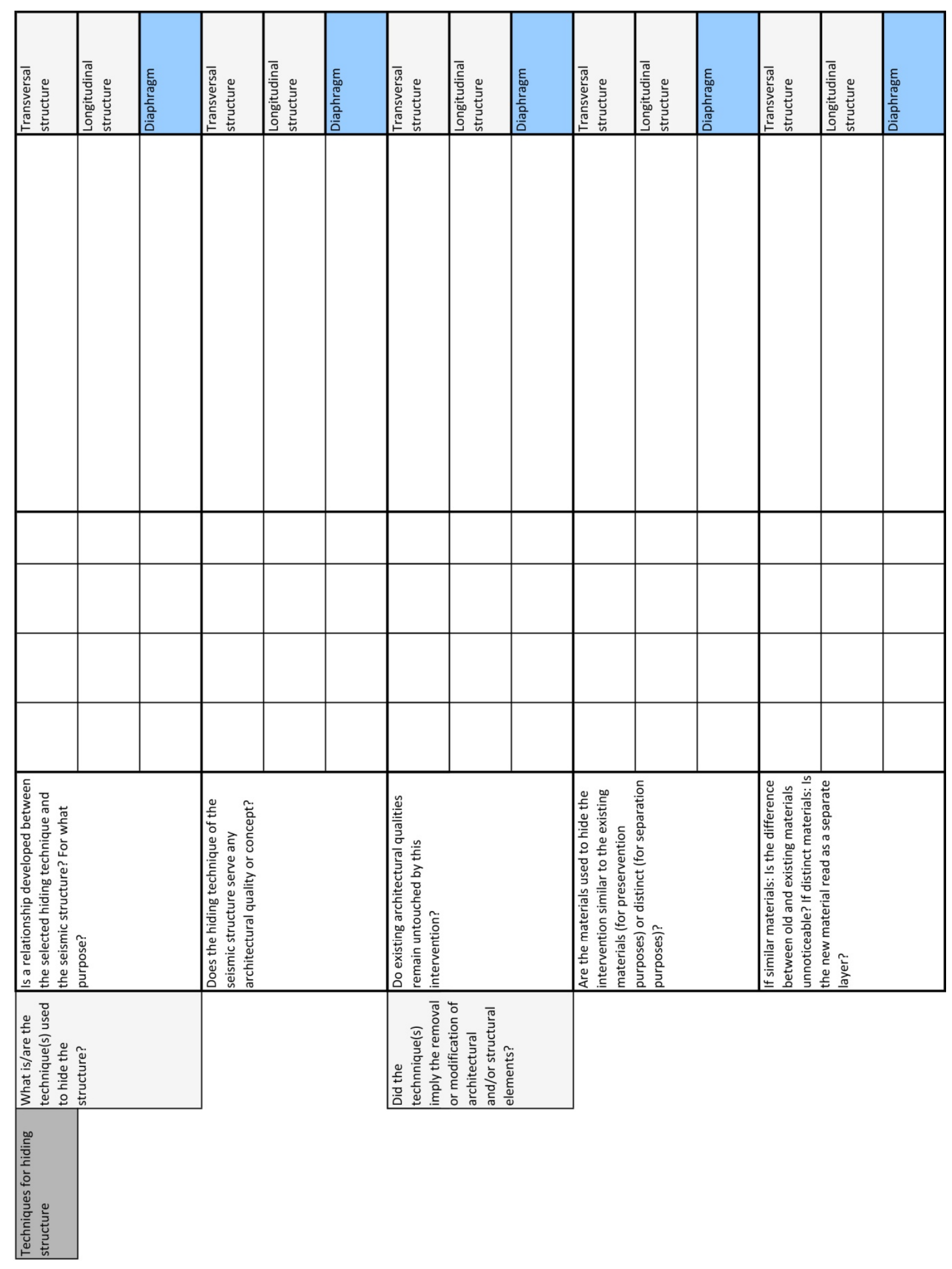



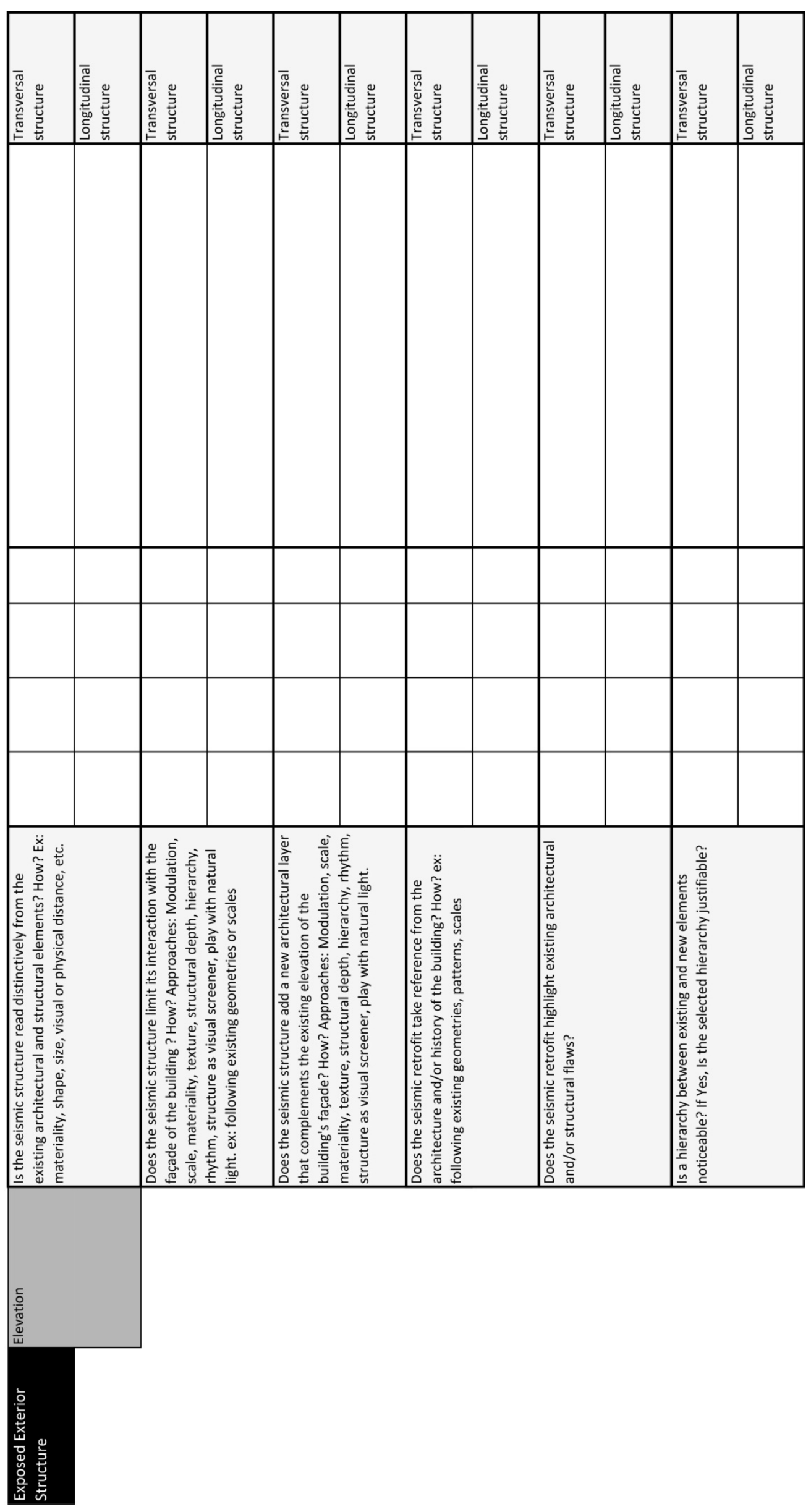


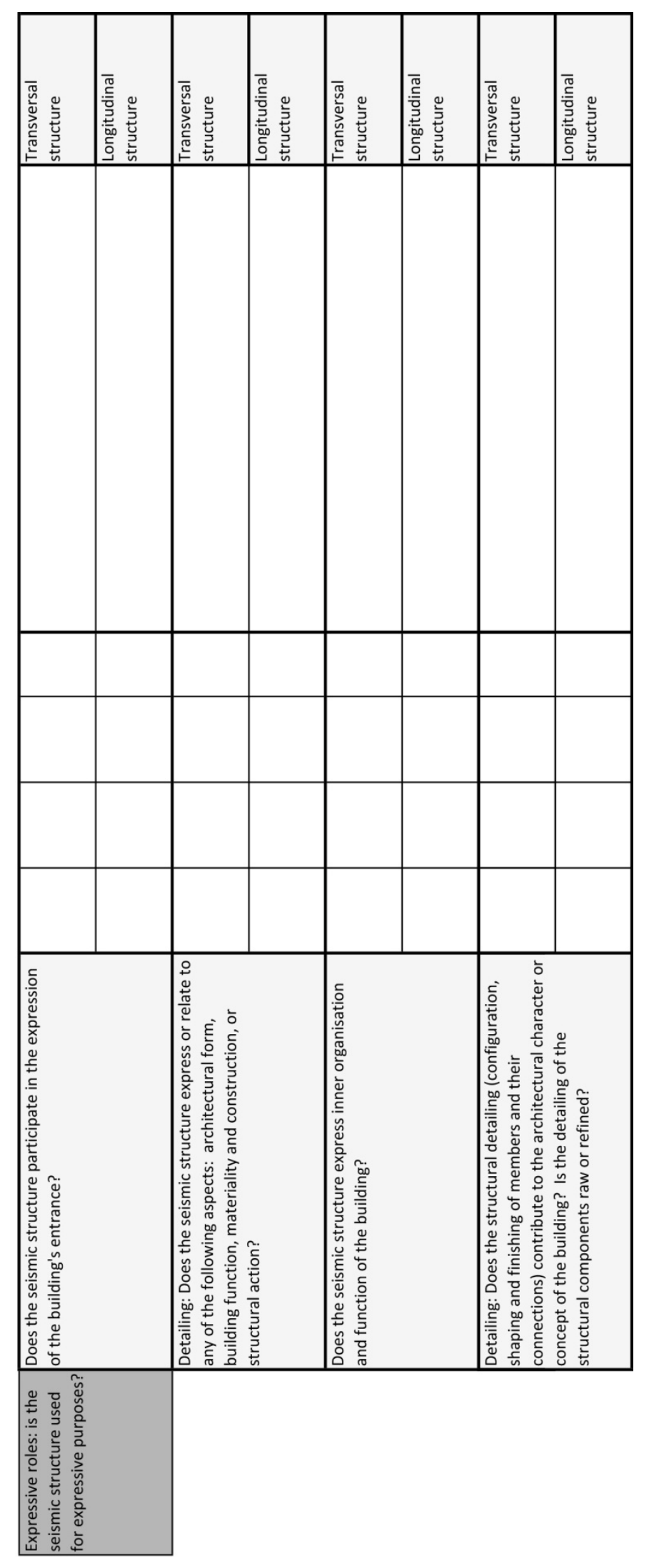




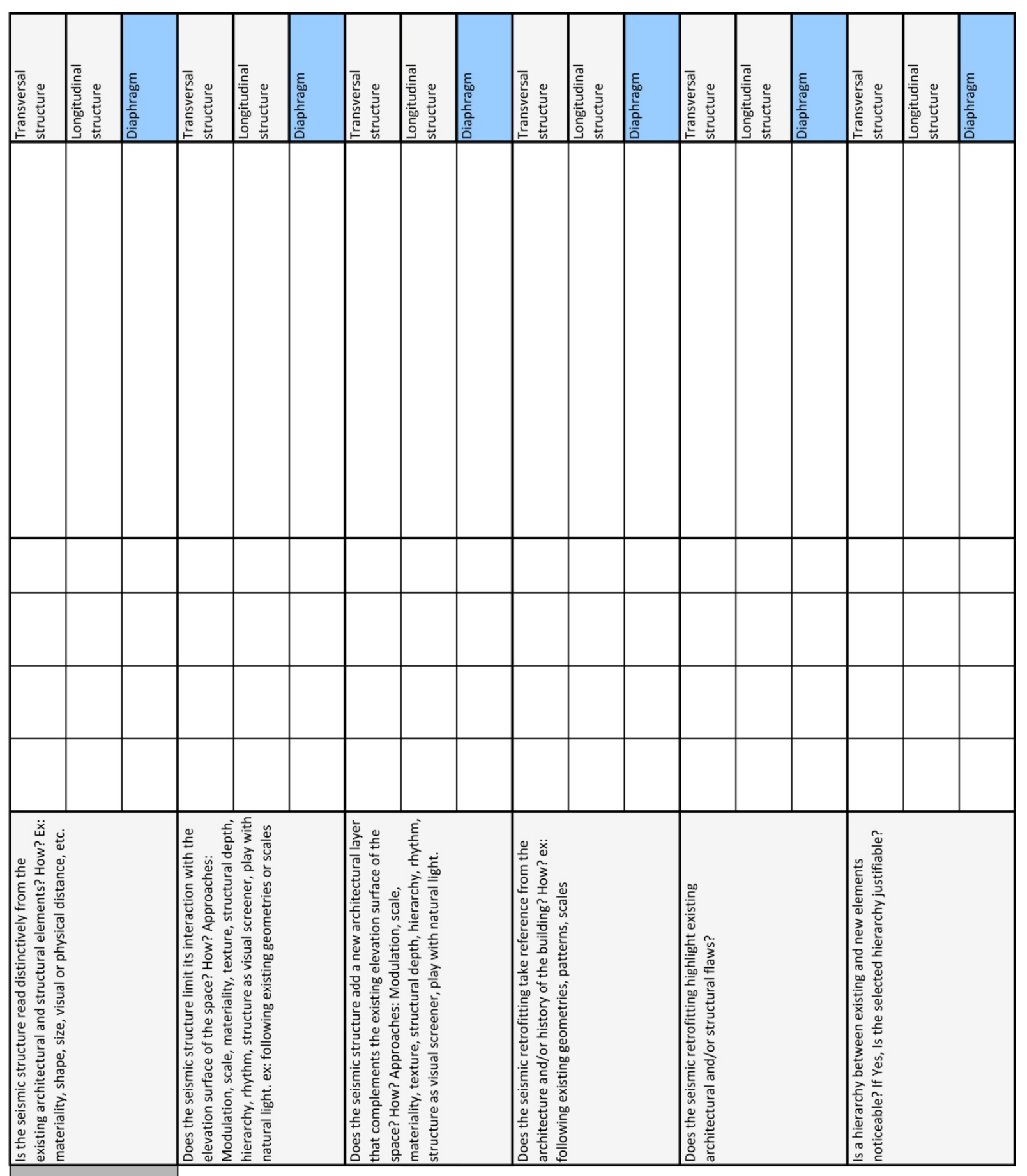

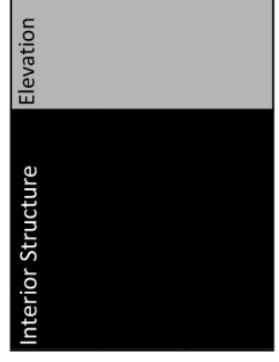



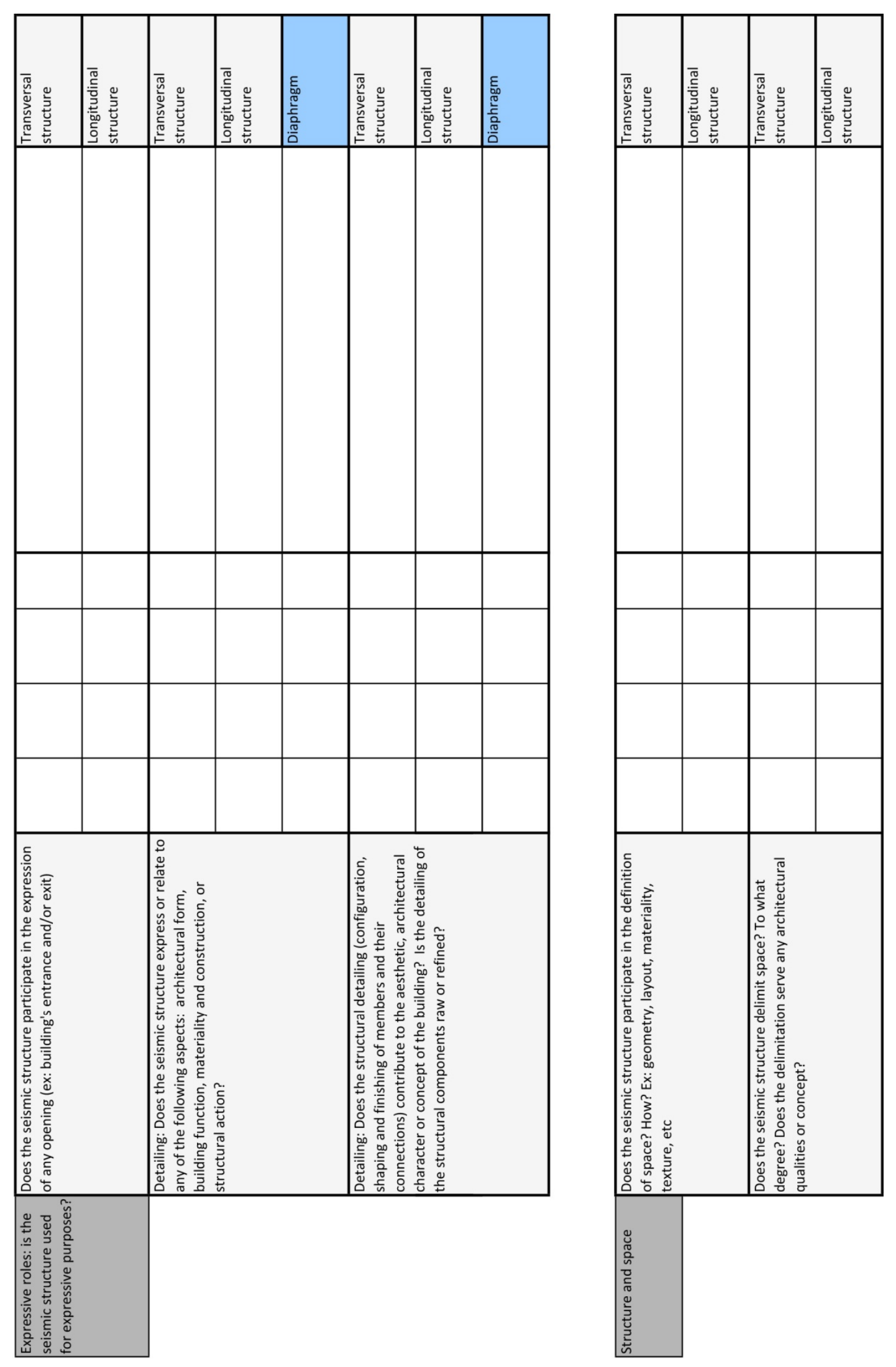


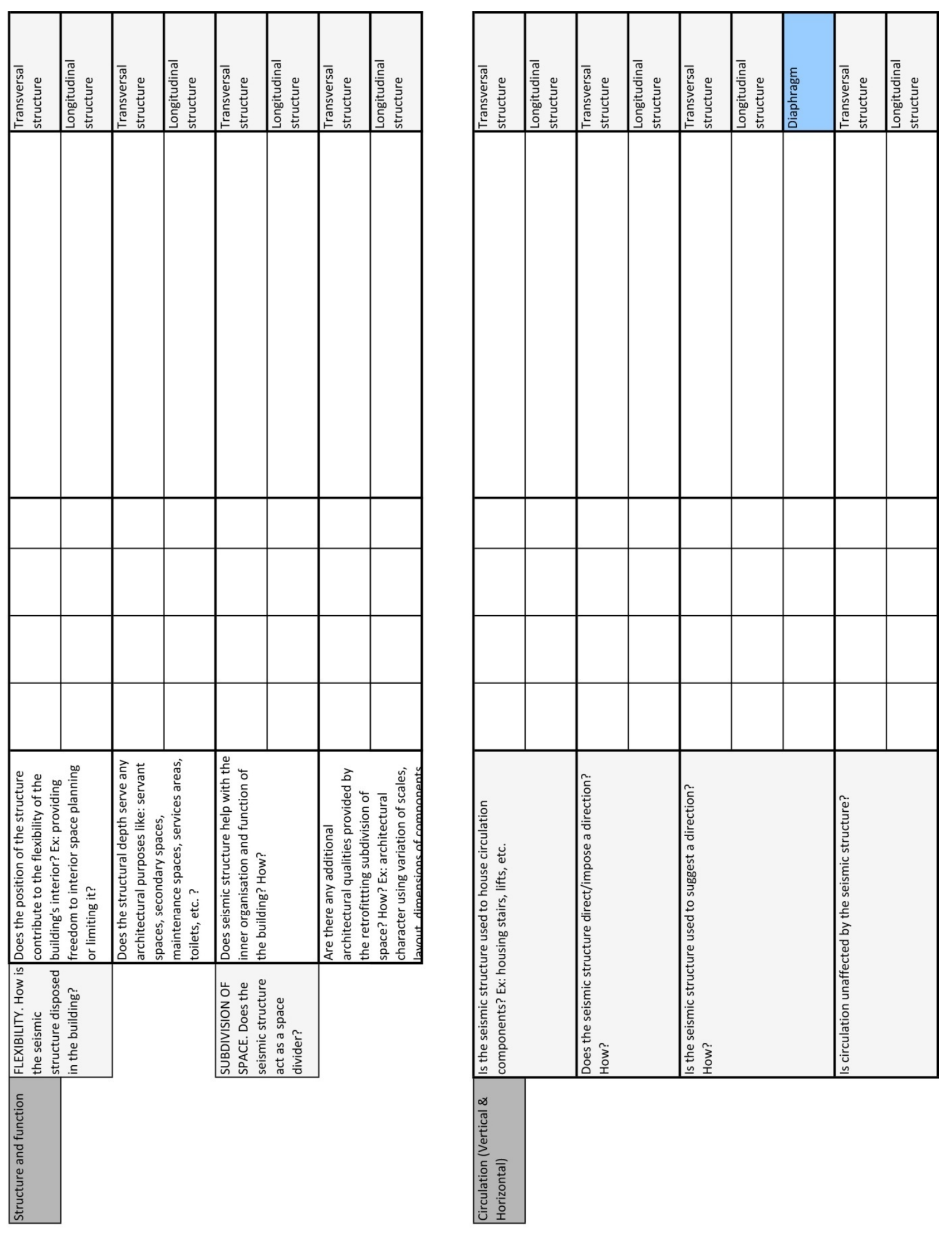




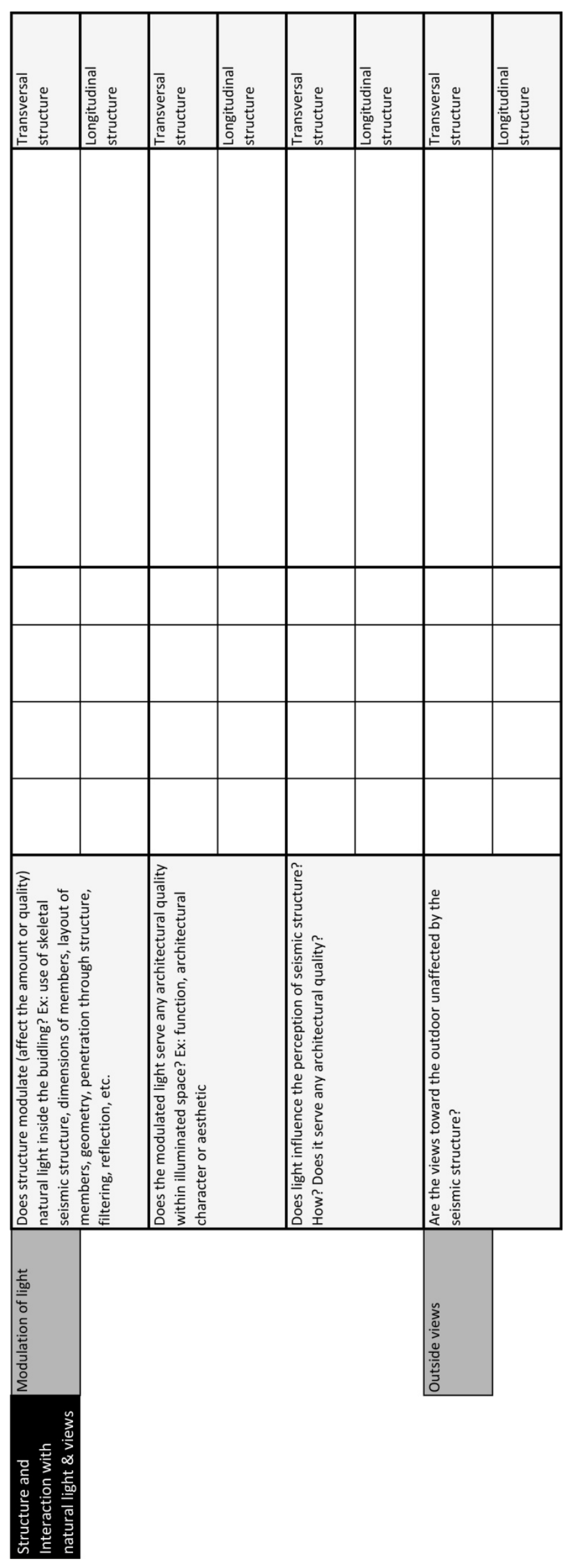




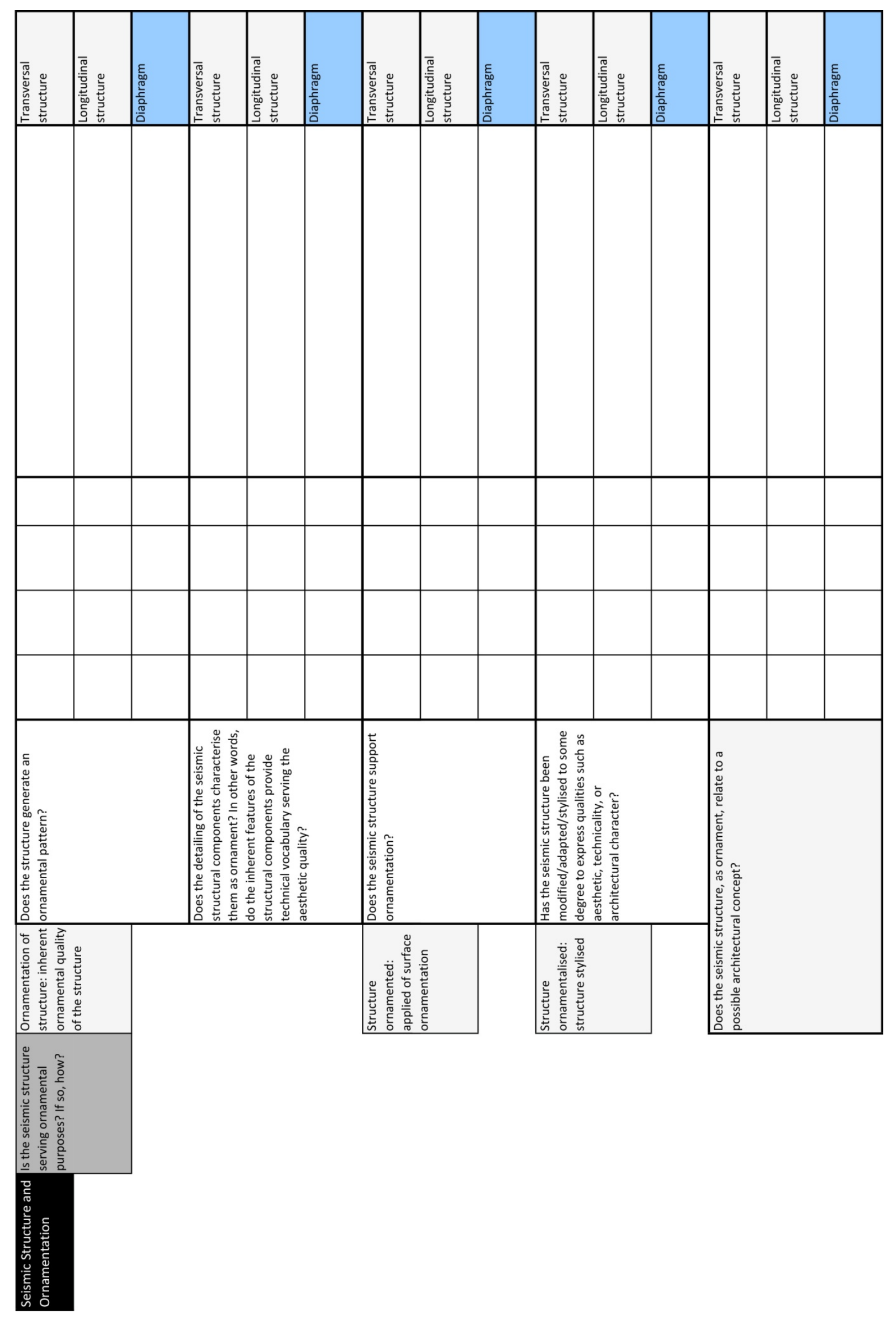




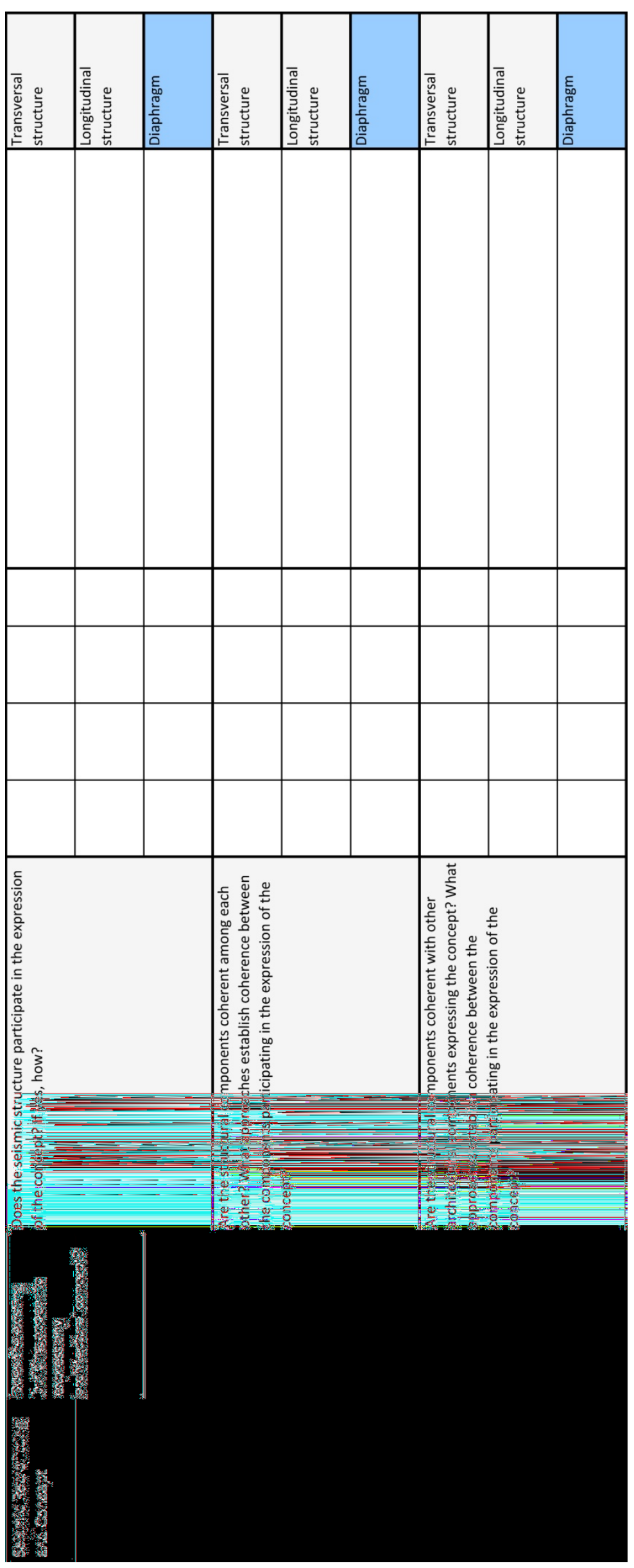




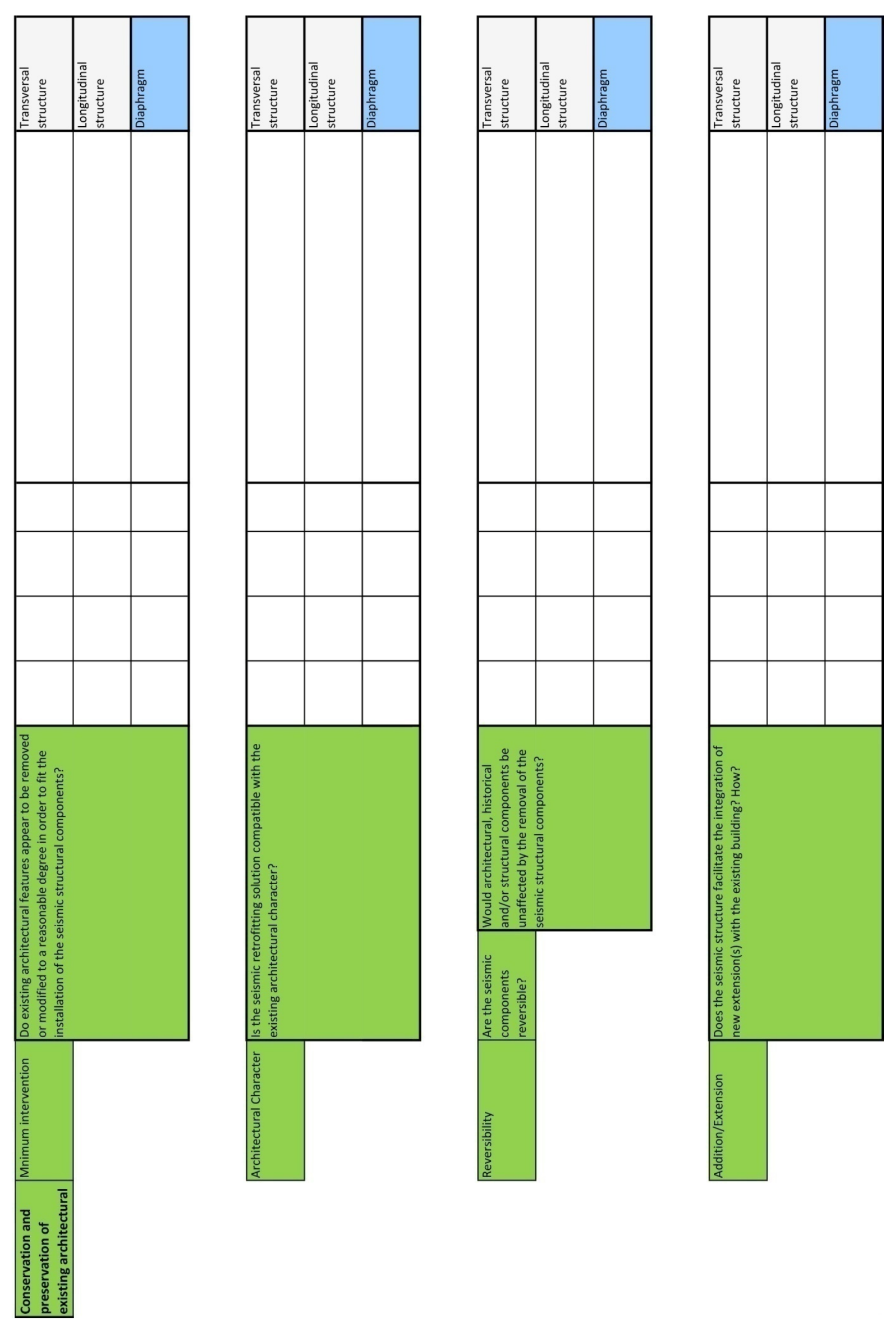




\section{Appendix B: Ethics Approval Memorandum}

TE WHARE WĀNANGA O TE ŨPOKO O TE IKA A MĀUI

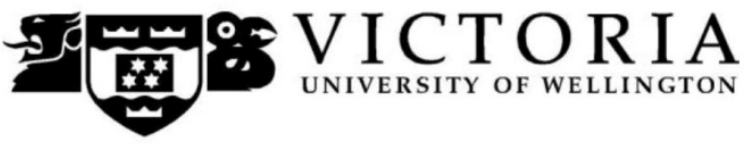

MEMORANDUM

\begin{tabular}{l|l}
\hline TO & Nabil Allaf \\
\hline COPY TO & Andrew Charleson \\
\hline FROM & AProf Susan Corbett, Convener, Human Ethics Committee \\
\hline DATE & 15 December 2015 \\
\hline PAGES & 1 \\
\hline SUBJECT & $\begin{array}{l}\text { Ethics Approval: 22566 } \\
\text { Improving the integration between Seismic Retrofitting and } \\
\text { Architecture }\end{array}$ \\
\hline
\end{tabular}

Thank you for your application for ethical approval, which has now been considered by the Standing Committee of the Human Ethics Committee.

Your application has been approved from the above date and this approval continues until 30 September 2016. If your data collection is not completed by this date you should apply to the Human Ethics Committee for an extension to this approval.

Best wishes with the research.

Kind regards

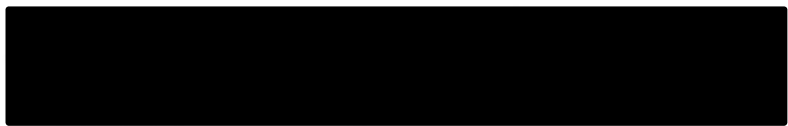

\section{Susan Corbett}

Convener, Victoria University Human Ethics Committee 


\section{Appendix C: Information letter for participants}

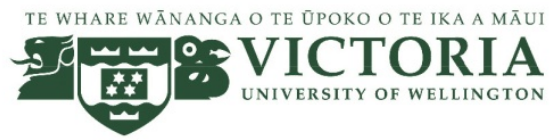

\section{Improving the integration between Seismic Retrofitting and Architecture}

\section{INFORMATION SHEET FOR PARTICIPANTS}

Thank you for your interest in this project. Please read this information before deciding whether or not to take part. If you decide to participate, thank you. If you decide not to take part, thank you for considering my request.

\section{Who am I?}

My name is Nabil Allaf (nabil.allaf@vuw.ac.nz) and I am a Doctoral student in architecture at Victoria University of Wellington, under primary supervision of Associate Professor Andrew Charleson (andrew.charleson@vuw.ac.nz). This research project is work towards my thesis.

\section{What is the aim of the project?}

This project addresses the relationship between the added earthquake-resistant structure and the existing architecture of a building in the context of seismic retrofitting. The aim is to identify current interaction issues between seismic retrofitting and architecture, as well as to reflect on ways to improve their integration. The outcomes of this research can assist architects and structural engineers to design seismic retrofitting projects in which the new seismic structural components engage in more relevant and respectful ways with the existing architecture.

This research has been approved by the Victoria University of Wellington Human Ethics Committee 22566.

\section{How can you help?}

If you agree to take part, I will interview you at your workplace. I will ask you a series of questions divided in three categories: general reflection on the integration issue, reflection on the completed seismically retrofitted building you have designed, and reflection on the design process of the seismically retrofitted building you have designed. The interview should take around $\mathbf{4 5}$ minutes. I will record the interview and write it up later. You can stop the interview at any time, without giving a reason. You can withdraw from the study up to four weeks after the interview. If you withdraw, the information you provided will be destroyed or returned to you.

What will happen to the information you give?

This research is confidential. I will not name you in any reports, and I will not include any information that would identify you or any building you discuss. Only my supervisors and I will 
read the notes or transcript of the interview. The interview transcripts, summaries and any recordings will be kept securely and destroyed 3 years after the research ends.

\section{What will the project produce?}

The information from my research will be used in my PhD thesis. You will not be identified in my report. I may also use the results of my research for conference presentations, and academic reports. I will take care not to identify you in any presentation or report.

\section{If you accept this invitation, what are your rights as a research participant?}

You do not have to accept this invitation if you don't want to. If you do decide to participate, you have the right to:

- choose not to answer any question;

- $\quad$ ask for the recorder to be turned off at any time during the interview;

- withdraw from the study up until four weeks after your interview;

- ask any questions about the study at any time;

- $\quad$ receive a copy of your interview recording (if it is recorded);

- read over and comment on a written summary of your interview;

- $\quad$ agree on another name for me to use rather than your real name;

- be able to read any reports of this research by emailing the researcher to request a copy.

If you have any questions or problems, who can you contact?

If you have any questions, either now or in the future, please feel free to contact either:

\section{Student:}

Name: Nabil Allaf

University email address:

nabil.allaf@vuw.ac.nz

\section{Supervisor:}

Name: Andrew Charleson

Role: Supervisor

School: School of Architecture - Victoria University of Wellington

Phone: +636222

andrew.charleson@vuw.ac.nz

\section{Human Ethics Committee information}

If you have any concerns about the ethical conduct of the research you may contact the Victoria University HEC Convener: Associate Professor Susan Corbett. Email

susan.corbett@vuw.ac.nz or telephone +64-4-463 5480. 


\section{Appendix D: Consent to interview}

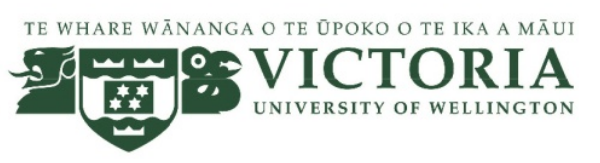

\section{Improving the integration between Seismic Retrofitting and Architecture}

\section{CONSENT TO INTERVIEW}

This consent form will be held for 5 years.

Researcher: Nabil Allaf, School of Architecture, Victoria University of Wellington.

- I have read the Information Sheet and the project has been explained to me. My questions have been answered to my satisfaction. I understand that I can ask further questions at any time.

- I agree to take part in an audio recorded interview.

I understand that:

- I may withdraw from this study up to four weeks after the interview, and any information that I have provided will be returned to me or destroyed.

- The information I have provided will be destroyed 3 years after the research is finished.

- $\quad$ Any information I provide will be kept confidential to the researcher and the supervisor. I understand that the results will be used for a PhD report and a summary of the results may be used in academic reports and/or presented at conferences.

- My name will not be used in reports, nor will any information that would identify me.

- I would like a copy of the transcript of my interview: Yes No

- I would like a summary of my interview: $\quad$ Yes No

- I would like to receive a copy of the final report and have added my Yes No email address below.

Signature of participant:

Name of participant:

Date:

Contact details: 


\section{Appendix E: Questionnaire}

\section{Research Questionnaire \\ Interviewing key designers}

Building \#

Structural engineer \#

Architect \#

\section{Part 1: General reflection on integration}

1. How would you define integration between seismic retrofitting and existing architecture?

a. How would you define a successful integration?

b. How would you define a poor integration?

2. How would you review/assess integration in a seismically retrofitted building? Which criteria would you refer to?

3. Based on your experience, are there any constraints arising from legislation and construction regulations such as seismic engineering publications, planning requirements, building act, site seismic hazards, etc. that directly affect integration either during the design process or the construction phase?

4. Current problems:

a. Question to structural engineers: What do you perceive as being the weakness in architects' approaches or knowledge affecting integration?

b. Question to architects: What do you perceive as being the weakness in structural engineers' approaches or knowledge affecting integration?

5. Do you have any suggestion to enhance current practice in relation to integration?

Part 2: Reflection on the completed seismically retrofitted building

Hidden Seismic Retrofitting:

6. Has the structure been hidden for architectural purposes?

a. If yes, what were the architectural reasons?

b. If not, what where the reasons justifying the hiddenness of the structure?

7. What reasons justified the selected hiding technique?

\section{Expressed Exterior structure:}


8. Has a distinction between the new seismic structure and the existing architecture been sought when designing the seismic solution?

a. If yes, for which reasons?

b. If not, then why?

9. Has a contribution of the seismic solution to the aesthetic or architectural character of the building been sought?

a. If yes, how?

b. If not, why and how did you limit or avoid the potential contribution?

10. Did you reflect on the seismic retrofitting solution as a way to highlight existing architectural and/or structural flaws?

a. If yes, how?

b. If not, why?

11. Did you reference the existing architecture or history of the building when formulating the seismic solution?

a. If yes, which aspects did you refer to and why?

b. If not, why?

12. Did you consider setting up a hierarchy between the existing and new elements?

a. If yes, for which reasons?

b. If not, why?

13. Did you consider using the seismic structure for architecturally expressive purposes?

a. If yes, which ones?

b. If not, why?

14. Did any factor justify the design of the structural detailing?

a. If yes, which ones?

b. If none, why not having considered the detailing of the structural components?

\section{Expressed Interior structure:}

15. Has a distinction between the new seismic structure and the existing architecture been sought when designing the seismic solution?

a. If yes, for which reasons?

b. If not, then why?

16. Has a contribution of the seismic solution to the aesthetic or architectural character of the building been sought?

a. If yes, how?

b. If not, why and how did you limit or avoid the potential contribution?

17. Did you reference the existing architecture or history of the building when formulating the seismic solution?

a. If yes, which aspects did you reference and why?

b. If not, why?

18. Did you consider setting up a hierarchy between the existing and new elements?

a. If yes, for which reasons?

b. If not, why?

19. Did you consider using the seismic structure for expressive purposes?

a. If yes, which ones?

b. If not, why? 
20. Did any factor justify the design of the structural detailing?

a. If yes, which ones?

b. If none, why not having considered the detailing of the structural components?

21. Has the presence of the seismic structure and its impact on space, function, and circulation been considered?

a. If yes, which aspect(s) has/have been considered?

b. If not, why?

\section{Seismic Structure and openings:}

22. Has the interaction between the seismic structure and natural light been considered?

a. If yes, how?

b. If not, why?

23. Has the interaction between the seismic structure and outside views been considered?

a. If yes, how?

b. If not, why?

\section{Seismic structure and ornamentation:}

24. Has the potential of the seismic structure to serve ornamental purposes been considered?

a. If yes, how?

b. If not, why?

\section{Seismic structure and concept:}

25. Did you identify any architectural concept or vision in the building prior to its retrofitting? a. If yes, which one?

i. Does the seismic structure participate in the expression of the existing concept?

1. If yes, how?

2. If not, why?

26. Does the seismic structure participate in the expression of a new architectural concept?

a. If yes, which one and how?

b. If not, why?

27. Has coherence between structural components themselves and the existing structure and architecture being sought during the design of the seismic solution?

a. If yes, which approach has been undertaken to establish coherence?

b. If not, why?

\section{Conservation and preservation:}

28. Has the design of the seismic retrofitting been driven by minimum intervention consideration?

a. If yes, how?

b. If not, why?

29. Has the existing architectural character of the building been considered when designing the seismic solution? 
c. If yes, which approaches have been used to respect the existing architectural character?

d. If not, why?

30. Is the seismic solution reversible?

e. If yes, how?

f. If not, why?

\section{Prioritisation of one architectural quality over another}

31. Does the seismic solution disrupt a specific architectural quality in order to enhance another one?

g. If yes, what justifies this decision?

\section{Personal reflection on the project:}

32. Regarding the finalised project, are there any issues not addressed so far that have influenced the integration of the seismic retrofitting solution and the existing architecture?

33. Regarding the finalised project, are there any aspects of the design that could have been improved in order to enhance the integration between the seismic retrofitting solution and the existing architecture?

\section{Part 3: Design Process}

34. How did the timing of involvement of the architect and structural engineer affect the design of the seismic solution?

35. Which step in the design process appeared to be the most critical in designing the seismic solution and why?

36. Which stakeholder among the design team provided leadership to the project? Did this leadership influence the design of the seismic solution? If yes, how?

37. Did architectural decisions affect the seismic solution, in terms of seismic performance of the building and in terms of budget?

38. Did any specific constraint(s) drive the selected seismic retrofitting design?

39. Which factors affected the design of the seismic retrofitting solution? 